\title{
DEVELOPMENT OF A QUICK DESIGN METHOD FOR COMPOSITE CONCRETE SLAB-OVER STEEL I-GIRDER BRIDGES FOR PROJECT BIDDING
}

\author{
By
}

\section{Ahmed Diab}

B.Eng., Ryerson University, Toronto, Canada, 2016

\author{
A thesis \\ presented to Ryerson University \\ in partial fulfillment of the \\ requirements for the degree of \\ Master of Applied Science \\ in the program of \\ Civil Engineering
}

Toronto, Canada, 2018

(C) Ahmed Diab, 2018 


\section{Author's Declaration}

I hereby declare that I am the sole author of this thesis. This is a true copy of the thesis, including any required final revisions, as accepted by my examiners.

I authorize Ryerson University to lend this thesis to other institutions or individuals for the purpose of scholarly research.

I further authorize Ryerson University to reproduce this thesis by photocopying or by other means, in total or in part, at the request of other institutions or individuals for the purpose of scholarly research.

I understand that my thesis may be made electronically available to the public. 


\title{
DEVELOPMENT OF A QUICK DESIGN METHOD FOR COMPOSITE CONCRETE SLAB-OVER STEEL I-GIRDER BRIDGES FOR PROJECT BIDDING
}

\author{
Ahmed Diab \\ Ryerson University \\ Master of Applied Science \\ Civil Engineering, 2018
}

\begin{abstract}
In bridge analysis, designers calculate maximum bending moment, $\mathrm{M}_{\mathrm{T}}$, and shear force, $\mathrm{V}_{\mathrm{T}}$, of a bridge girder under truck loading, then use available truck fraction, $\mathrm{F}_{\mathrm{T}}$ to generate the longitudinal live load effects. This Thesis presents structural analysis of different girder configurations subjected to CL-W truck loading. Girder geometries include single-, two-, three- and four-span girders. The maximum shear, deflection and moments were plotted and then used to develop equations to represent their values. Furthermore, a software was developed to perform composite steel I-girder design. The software optimizes the I-girder size based on CHBDC design procedure. Using the developed software, a parametric study was conducted to determine the required composite moment of inertia, moment of inertia of the bare steel section and steel web area to satisfy all design requirements. Empirical equations for these three properties were developed to assist bridge designers in estimating steel I-section sizes for contract bidding.
\end{abstract}




\section{Acknowledgements}

The author would like to express his gratitude to his supervisor Dr. Khaled Sennah, for his guidance and support throughout the completion of this research program.

The author would also like to express his sincerest appreciation to his parents for all the support, patience, encouragement, and guidance, throughout every stage of his life including this research.

The author would like to express his sincerely thanks to the Civil Engineering Department, and the technical staff for their assistance and support throughout the execution of this research program.

The author also would like to thank and acknowledge the Canadian Institute of Steel Construction (CISC) for providing this incredible research opportunity and supporting the research program.

The author would also like to acknowledge the support of the Natural Sciences and Engineering Research Council of Canada (NSERC).

Finally, the author is grateful to his family, colleagues, and friends for their support and encouragement throughout this work. 


\section{Table of Contents}

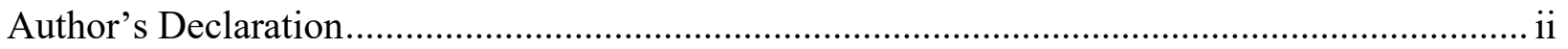

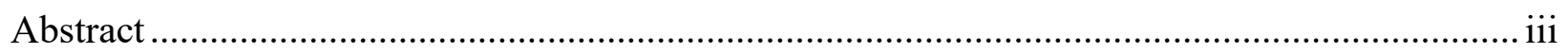

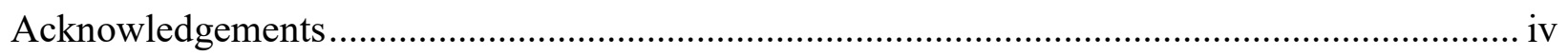

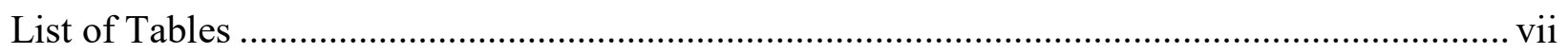

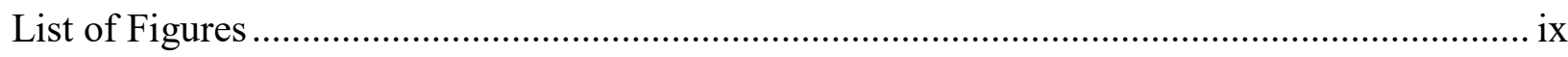

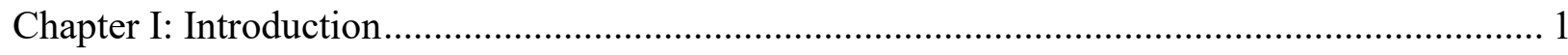

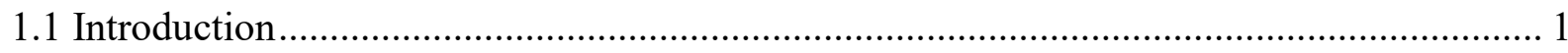

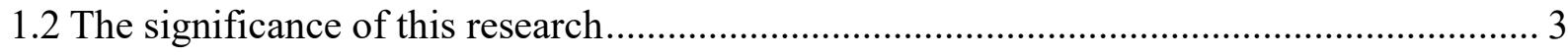

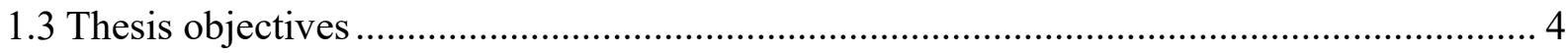

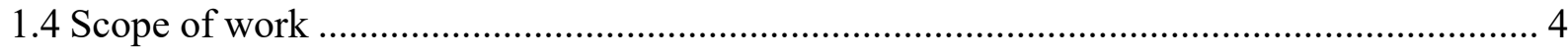

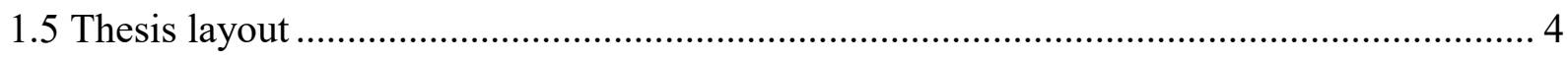

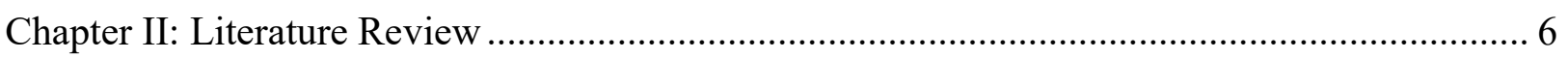

2.1 Application of ready-made design graphs in the concrete bridge industry ...................... 6

2.2 Existing research on simplifying preliminary steel girder design in the bridge industry ..... 8

2.3 Use of programs in bridge analysis and design ..................................................... 14

2.4 Transverse load distribution in bridges .............................................................. 15

2.5 Girder design for superstructure vibration at SLS ................................................ 17

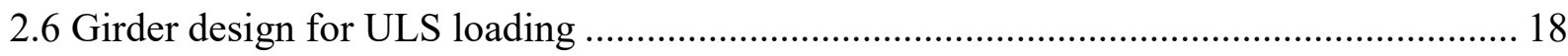

2.7 Girder design for Fatigue Limit State ............................................................... 19

Chapter III: Truck Load Parametric Study .................................................................. 21

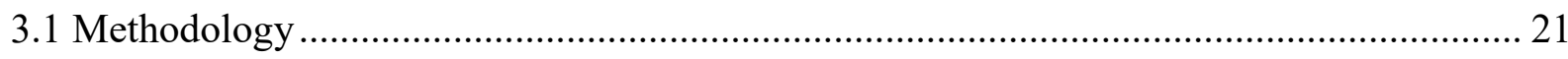

3.2 Sensitivity study: Influence line (IL) vs moving load method .................................... 22

3.3 Results from finite element modelling ................................................................. 25

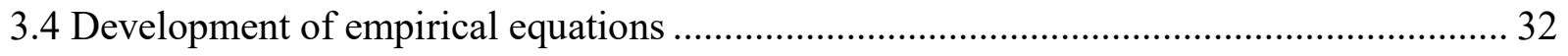




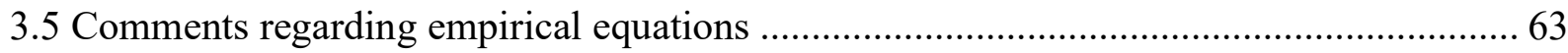

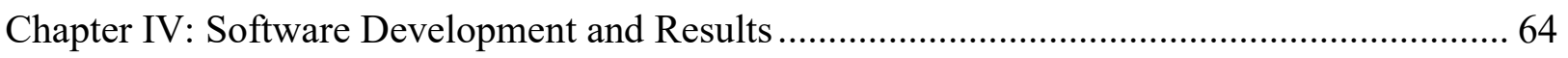

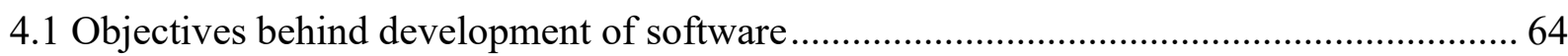

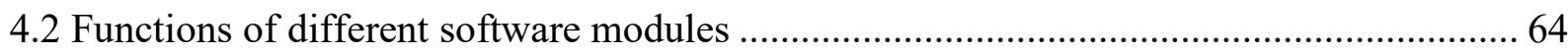

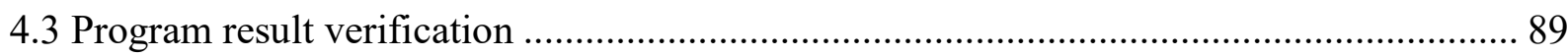

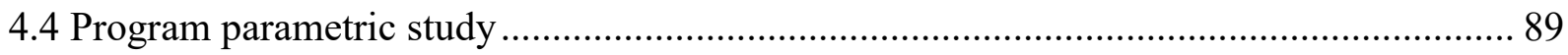

Chapter V: Software Results Analysis and Parametric Study ................................................. 96

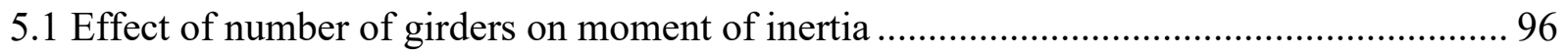

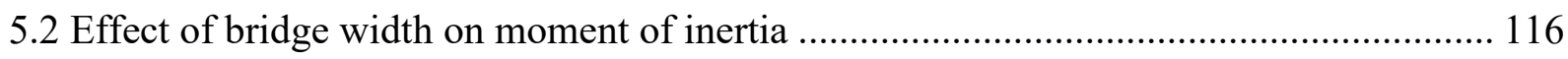

5.3 Effect of number of design lanes on moment of inertia.................................................. 133

5.4 Developed equations for single span bridge configurations ........................................... 141

5.5 Developed equations for two equal span bridge configurations ...................................... 149

5.6 Developed equations for three equal span bridge configurations.................................... 159

5.7 Developed equations for four equal span bridge configurations ..................................... 169

Chapter VI: Conclusion and Recommendations for Future Research ....................................... 179

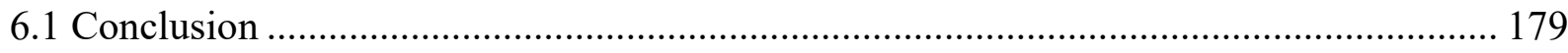

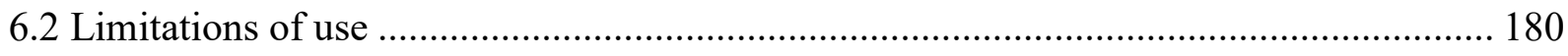

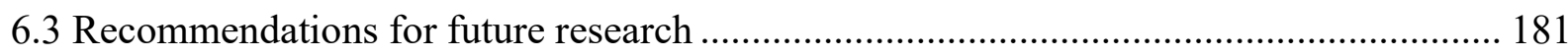

Appendix A: CL-625 truck loading optimization program results..............................................182

Appendix B: CL-800 truck loading optimization program results ............................................233

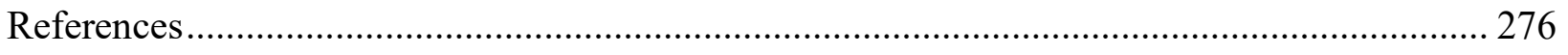




\section{List of Tables}

Table 2.1: Theodor \& Al-Bazi's Bridge Group 1 utilizing WWF shaped steel girders for bridge cases 1 through 12

Table 2.2: Theodor \& Al-Bazi's Bridge Group 2 utilizing W shaped steel girders for bridge cases 13 through 19 .....

Table 2.3: Theodor \& Al-Bazi's Bridge Group 3 utilizing WWF shaped steel girders for bridge cases 20 through 31

Table 2.4: Theodor \& Al-Bazi’s Bridge Group 4 utilizing W shaped steel girders for bridge cases 32 through 38

Table 2.5: Theodor \& Al-Bazi's Bridge Group 5 utilizing WWF shaped steel girders for bridge cases 39 through 50 .

Table 2.6: Theodor \& Al-Bazi's Bridge Group 6 utilizing W shaped steel girders for bridge cases 51 through 57 .....

Table 2.7: Theodor \& Al-Bazi's Bridge Group 7 utilizing WWF shaped steel girders for bridge cases 58 through 69 .

Table 2.8: Nofal's Bridge Group 1 utilizing W shaped steel girders for bridge cases 70 through 77.

Table 2.9: Nofal's Bridge Group 2 utilizing W shaped steel girders for bridge cases 78 through 87.

Table 2.10: Nofal's Bridge Group 1 utilizing W shaped steel girders for bridge cases 88 through 94. 14

Table 3.1: Comparison between moment produced by IL method and moving load method for a three equal span bridge between $25 \mathrm{~m}$ and $50 \mathrm{~m}$ under CL-625 truck loading .... 24

Table 3.3: Maximum live load shear, moment, reaction and deflection generated by one lane of CL-625 truck loading for single span bridge girders obtained SAP2000 software. 25

Table 3.4: Maximum live load shear, moment, reaction and deflection generated by one lane of CL-625-ONT truck loading for single span bridge girders obtained using SAP2000 software ... 26 Table 3.5: Maximum live load shear, moment, reaction and deflection generated by one lane of CL-800 truck loading for single span bridge girders obtained using SAP2000 software. 26

Table 3.6: Maximum live load shear, moments, reactions and deflection generated by one lane of CL-625 truck loading for two equal span bridge girders obtained using SAP2000 software ….. 27 
Table 3.7: Maximum live load shear, moments, reactions and deflection generated by one lane of CL-625-ONT truck loading for two equal span bridge girders obtained using SAP2000 software

Table 3.8: Maximum live load shear, moments, reactions and deflection generated by one lane of CL-800 truck loading for two equal span bridge girders obtained using SAP2000 software ...... 28 Table 3.9: Maximum live load shear, moments, reactions and deflection generated by one lane of CL-625 truck loading for three equal span bridge girders obtained using SAP2000 software .... 29 Table 3.10: Maximum live load shear, moments, reactions and deflection generated by one lane of CL-625-ONT truck loading for three equal span bridge girders obtained using SAP2000 software

Table 3.11: Maximum live load shear, moments, reactions and deflection generated by one lane of CL-800 truck loading for three equal span bridge girders obtained using SAP2000 software 30 Table 3.12: Maximum live load shear, moments, reactions and deflection generated by one lane of CL-625 truck loading for four equal span bridge girders obtained using SAP2000 software . 30 Table 3.13: Maximum live load shear, moments, reactions and deflection generated by one lane of CL-625-ONT truck loading for four equal span bridge girders obtained using SAP2000 software 31

Table 3.14: Maximum live load shear, moments, reactions and deflection generated by one lane of CL-800 truck loading for four equal span bridge girders obtained using SAP2000 software . 31 Table 4.1: Comparison between manual calculation results and program results for a CISC composite concrete slab on straight plate girder bridge design example 89 Table 4.2: Table showing the bridge configuration cases optimized by the program per truck loading per span length 90

Table 4.3: Table showing the optimized results data for $20 \mathrm{~m}$ single span bridge configurations studied under CL-625 truck loading 


\section{List of Figures}

Figure 1.1: Truck configuration for CL-625 truck loading (CSA, 2014) ................................. 2

Figure 1.2: Truck configuration for CL-625-ONT truck loading (CSA, 2014)........................ 2

Figure 1.3: Truck configuration for CL-800 truck loading (Alberta Transportation, 2015) ......... 2

Figure 2.1: Ready-made graph for selection of CPCI girder for single span bridge configurations

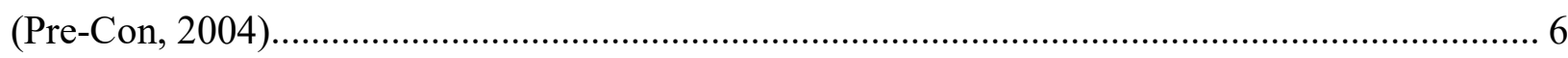

Figure 2.2: Ready-made graph for selection of concrete hollow slab section for single span and multi-span bridge configurations (Pre-Con, 2004) ........................................................ 7

Figure 2.3: Ready-made graph for selection of concrete box girder section for single span and multi-span bridge configurations (Pre-Con, 2004) ............................................................ 8

Figure 2.4: Relationship between span and longitudinal flexural rigidity Dx per unit width ........ 9 Figure 2.5: Variation in distribution parameter with bridge width for three-span bridges: (a) external girder; (b) internal girder (A. Ghani Razaqpur, 2006) .......................................... 16

Figure 2.6: Deflection limits for highway bridge superstructure vibration (CSA, 2014)........... 17 Figure 3.1: Shear and Reaction I.L. Diagram of a 30-m single span bridge and associated CL-W

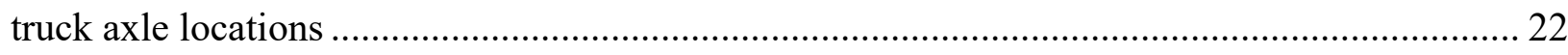
Figure 3.2: Moment I.L. Diagram of a 30-m single span bridge and associated CL-W truck axle locations 22

Figure 3.3: Exterior Reaction and Shear I.L. Diagram of a Two-Span bridge and associated CL-

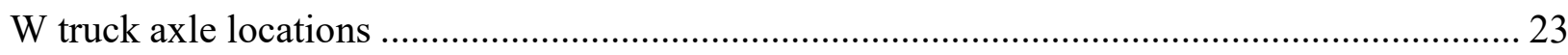
Figure 3.4: Interior Shear I.L. Diagram of a Two-Span bridge and associated CL-W truck axle locations

Figure 3.5: Maximum Positive Moment I.L. Diagram of a Two-Span bridge and associated CLW truck axle locations 23

Figure 3.6: Maximum Negative Moment I.L. Diagram of a Two-Span bridge and associated CL-

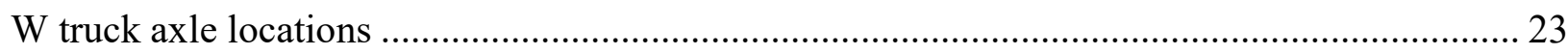

Figure 3.7: Comparison between the developed equations and the results obtained from SAP2000 model for longitudinal moment generated by one lane of CL-W loading in single span bridge configurations 32 
Figure 3.8: Comparison between the developed equations and the results obtained from SAP2000 model for shear and reaction generated by one lane of CL-W loading in single span bridge configuration

Figure 3.9: Comparison between the developed equations and the results obtained from SAP2000 model for deflection generated by one lane of CL-W loading in single span bridge configuration 35

Figure 3.10: Comparison between the developed equations and the results obtained from SAP2000 model for longitudinal positive moment generated by one lane of CL-W loading in two equal spans bridge configurations. 36

Figure 3.11: Comparison between the developed equations and the results obtained from SAP2000 model for longitudinal negative moment generated by one lane of CL-W loading in two equal spans bridge configurations.

Figure 3.12: Comparison between the developed equations and the results obtained from SAP2000 model for exterior shear and reaction generated by one lane of CL-W loading in two equal spans bridge configurations.

Figure 3.13: Comparison between the developed equations and the results obtained from SAP2000 model for interior reaction generated by one lane of CL-W loading in two equal spans bridge configurations 39

Figure 3.14: Comparison between the developed equations and the results obtained from SAP2000 model for interior shear generated by one lane of CL-W loading in two equal spans bridge configurations 40

Figure 3.15: Comparison between the developed equations and the results obtained from SAP2000 model for deflection generated by one lane of CL-W loading in two equal spans bridge configurations 41

Figure 3.16: Comparison between the developed equations and the results obtained from SAP2000 model for longitudinal positive moment in exterior span generated by one lane of CL-

W loading in three equal spans bridge configurations..... 42

Figure 3.17: Comparison between the developed equations and the results obtained from SAP2000 model for longitudinal positive moment in interior span generated by one lane of CLW loading in three equal spans bridge configurations 43 
Figure 3.18: Comparison between the developed equations and the results obtained from SAP2000 model for longitudinal negative moment generated by one lane of CL-W loading in three equal spans bridge configurations

Figure 3.19: Comparison between the developed equations and the results obtained from SAP2000 model for exterior reaction and shear generated by one lane of CL-W loading in three equal spans bridge configurations.

Figure 3.20: Comparison between the developed equations and the results obtained from SAP2000 model for interior reaction generated by one lane of CL-W loading in three equal spans bridge configurations 46

Figure 3.21: Comparison between the developed equations and the results obtained from SAP2000 model for shear left of interior support generated by one lane of CL-W loading in three equal spans bridge configurations.

Figure 3.22: Comparison between the developed equations and the results obtained from SAP2000 model for shear right of interior support generated by one lane of CL-W loading in three equal spans bridge configurations

Figure 3.23: Comparison between the developed equations and the results obtained from SAP2000 model for deflection in exterior span generated by one lane of CL-W loading in three equal spans bridge configurations.

Figure 3.24: Comparison between the developed equations and the results obtained from SAP2000 model for deflection in interior span generated by one lane of CL-W loading in three equal spans bridge configurations.

Figure 3.25: Comparison between the developed equations and the results obtained from SAP2000 model for exterior support reaction and shear generated by one lane of CL-W loading in four equal spans bridge configurations 51

Figure 3.26: Comparison between the developed equations and the results obtained from SAP2000 model for support reaction at first interior support generated by one lane of CL-W loading in four equal spans bridge configurations. 52

Figure 3.27: Comparison between the developed equations and the results obtained from SAP2000 model for longitudinal positive moment in exterior span generated by one lane of CLW loading in four equal spans bridge configurations 53 
Figure 3.28: Comparison between the developed equations and the results obtained from SAP2000 model for deflection in exterior span generated by one lane of CL-W loading in four equal spans bridge configurations.

Figure 3.29: Comparison between the developed equations and the results obtained from SAP2000 model for support reaction at first interior support generated by one lane of CL-W loading in four equal spans bridge configurations. 55

Figure 3.30: Comparison between the developed equations and the results obtained from SAP2000 model for support reaction at centermost interior support generated by one lane of CLW loading in four equal spans bridge configurations 56

Figure 3.31: Comparison between the developed equations and the results obtained from SAP2000 model for shear left of first interior support generated by one lane of CL-W loading in four equal spans bridge configurations

Figure 3.32: Comparison between the developed equations and the results obtained from SAP2000 model for shear right of first interior support generated by one lane of CL-W loading in four equal spans bridge configurations

Figure 3.33: Comparison between the developed equations and the results obtained from SAP2000 model for longitudinal positive moment in interior span generated by one lane of CLW loading in four equal spans bridge configurations 59 Figure 3.34: Comparison between the developed equations and the results obtained from SAP2000 model for longitudinal negative moment at first interior support generated by one lane of CL-W loading in four equal spans bridge configurations 60

Figure 3.35: Comparison between the developed equations and the results obtained from SAP2000 model for longitudinal negative moment at centermost interior support generated by one lane of CL-W loading in four equal spans bridge configurations

Figure 3.36: Comparison between the developed equations and the results obtained from SAP2000 model for deflection in interior span generated by one lane of CL-W loading in four

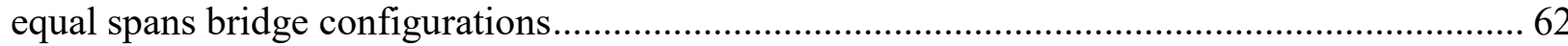

Figure 4.1: Screenshot showing the main menu of the I-girder design software ..... 65

Figure 4.2: Flowchart showing the back-end operations of the dead load module developed as part of the I-girder design software 
Figure 4.3: Screenshot showing the front-end layout of the dead load module developed as part of the I-girder design software

Figure 4.4: Flowchart showing the back-end operations of the live load module developed as part

of the I-girder design software. 68

Figure 4.5: Screenshot showing the front-end layout of the live load module developed as part of the I-girder design software

Figure 4.6: Flowchart showing the back-end operations of the truck factor calculation $\left(\mathrm{F}_{\mathrm{T}}\right)$

module developed as part of the I-girder design software

Figure 4.7: Screenshot showing the front-end layout of the of the truck factor calculation $\left(\mathrm{F}_{\mathrm{T}}\right)$

module developed as part of the I-girder design software

Figure 4.8: Flowchart showing the back-end operations of the permanent deflection at construction stage module developed as part of the I-girder design software.

Figure 4.9: Screenshot showing the front-end layout of the of the permanent deflection at construction stage module developed as part of the I-girder design software. 73

Figure 4.10: Flowchart showing the back-end operations of the superstructure vibration module developed as part of the I-girder design software

Figure 4.11: Screenshot showing the front-end layout of the of the superstructure vibration module developed as part of the I-girder design software

Figure 4.12: Flowchart showing the back-end operations of the construction stage moment module developed as part of the I-girder design software 76

Figure 4.13: Screenshot showing the front-end layout of the of the construction stage moment module developed as part of the I-girder design software

Figure 4.14: Flowchart showing the back-end operations of the ULS adequacy checks module developed as part of the I-girder design software 78 Figure 4.15: Screenshot showing the front-end layout of the of the ULS adequacy checks module developed as part of the I-girder design software..... 79 Figure 4.16: Flowchart showing the back-end operations of the shear stud design at ULS module developed as part of the I-girder design software..... 80

Figure 4.17: Screenshot showing the front-end layout of the of the shear stud design at ULS module developed as part of the I-girder design software 
Figure 4.18: Flowchart showing the back-end operations of the FLS adequacy module developed as part of the I-girder design software 82

Figure 4.19: Screenshot showing the front-end layout of the of the FLS adequacy module developed as part of the I-girder design software..... 83

Figure 4.20: Flowchart showing the back-end operations of the shear studs design at FLS module developed as part of the I-girder design software.....

Figure 4.21: Screenshot showing the front-end layout of the of the shear studs design at FLS module developed as part of the I-girder design software 85

Figure 4.22: Flowchart showing the back-end operations of the girder optimization module developed as part of the I-girder design software.....

Figure 4.23: Screenshot showing the front-end layout of the of the girder optimization module developed as part of the I-girder design software 88

Figure 5.1: Moment of inertia of the steel section per unit width vs span length for a one-lane single span bridge under CL-625 truck loading of $4.5 \mathrm{~m}$ width

Figure 5.2: Moment of inertia of the steel section per unit width vs span length for a one-lane single span bridge under CL-625 truck loading of $6 \mathrm{~m}$ width

Figure 5.3: Moment of inertia of the steel section per unit width vs span length for a one -lane single span bridge under CL-625 truck loading of $7 \mathrm{~m}$ width 98

Figure 5.4: Moment of inertia of the steel section per unit width vs span length for a two-lane single span bridge under CL-625 truck loading of $8 \mathrm{~m}$ width 98

Figure 5.5: Moment of inertia of the steel section per unit width vs span length for a two-lane single span bridge under CL-625 truck loading of $9.5 \mathrm{~m}$ width

Figure 5.6: Moment of inertia of the steel section per unit width vs span length for a two-lane single span bridge under CL-625 truck loading of $11 \mathrm{~m}$ width

Figure 5.7: Moment of inertia of the steel section per unit width vs span length for a two-lane single span bridge under CL-625 truck loading of $11.5 \mathrm{~m}$ width 100 Figure 5.8: Moment of inertia of the steel section per unit width vs span length for a three-lane single span bridge under CL-625 truck loading of $11.5 \mathrm{~m}$ width 100 Figure 5.9: Moment of inertia of the steel section per unit width vs span length for a two-lane single span bridge under CL-625 truck loading of $13 \mathrm{~m}$ width 
Figure 5.10: Moment of inertia of the steel section per unit width vs span length for a three-lane single span bridge under CL-625 truck loading of $13 \mathrm{~m}$ width 101

Figure 5.11: Moment of inertia of the steel section per unit width vs span length for a two-lane single span bridge under CL-625 truck loading of $14.5 \mathrm{~m}$ width 102

Figure 5.12: Moment of inertia of the steel section per unit width vs span length for a three-lane single span bridge under CL-625 truck loading of $14.5 \mathrm{~m}$ width 102

Figure 5.13: Moment of inertia of the steel section per unit width vs span length for a four-lane single span bridge under CL-625 truck loading of $15 \mathrm{~m}$ width 103 Figure 5.14: Moment of inertia of the steel section per unit width vs span length for a four-lane single span bridge under CL-625 truck loading of $16.5 \mathrm{~m}$ width 103

Figure 5.15: Moment of inertia of the steel section per unit width vs span length for a four-lane single span bridge under CL-625 truck loading of $18 \mathrm{~m}$ width 104 Figure 5.16: Moment of inertia of the steel section per unit width vs span length for a five-lane single span bridge under CL-625 truck loading of $18.5 \mathrm{~m}$ width ..... 104

Figure 5.17: Moment of inertia of the steel section per unit width vs span length for a five-lane single span bridge under CL-625 truck loading of $21.5 \mathrm{~m}$ width 105

Figure 5.18: Moment of inertia of the steel section per unit width vs span length for a six-lane single span bridge under CL-625 truck loading of $22 \mathrm{~m}$ width 105

Figure 5.19: Moment of inertia of the steel section per unit width vs span length for a six-lane single span bridge under CL-625 truck loading of $25 \mathrm{~m}$ width 106

Figure 5.20: Moment of inertia of the composite concrete-steel section per unit width vs span length for a one-lane single span bridge under CL-625 truck loading of $4.5 \mathrm{~m}$ width

Figure 5.21: Moment of inertia of the composite concrete-steel section per unit width vs span length for a one-lane single span bridge under CL-625 truck loading of $6 \mathrm{~m}$ width.... 107 Figure 5.22: Moment of inertia of the composite concrete-steel section per unit width vs span length for a one-lane single span bridge under CL-625 truck loading of $7 \mathrm{~m}$ width 108 Figure 5.23: Moment of inertia of the composite concrete-steel section per unit width vs span length for a two-lane single span bridge under CL-625 truck loading of $8 \mathrm{~m}$ width 108 Figure 5.24: Moment of inertia of the composite concrete-steel section per unit width vs span length for a two-lane single span bridge under CL-625 truck loading of $9.5 \mathrm{~m}$ width 109 
Figure 5.25: Moment of inertia of the composite concrete-steel section per unit width vs span length for a two-lane single span bridge under CL-625 truck loading of $11 \mathrm{~m}$ width..... 109 Figure 5.26: Moment of inertia of the composite concrete-steel section per unit width vs span length for a two-lane single span bridge under CL-625 truck loading of $11.5 \mathrm{~m}$ width. 110 Figure 5.27: Moment of inertia of the composite concrete-steel section per unit width vs span length for a three-lane single span bridge under CL-625 truck loading of $11.5 \mathrm{~m}$ width 110 Figure 5.28: Moment of inertia of the composite concrete-steel section per unit width vs span length for a two-lane single span bridge under CL-625 truck loading of $13 \mathrm{~m}$ width.....

Figure 5.29: Moment of inertia of the composite concrete-steel section per unit width vs span length for a three-lane single span bridge under CL-625 truck loading of $13 \mathrm{~m}$ width

Figure 5.30: Moment of inertia of the composite concrete-steel section per unit width vs span length for a two-lane single span bridge under CL-625 truck loading of $14.5 \mathrm{~m}$ width

Figure 5.31: Moment of inertia of the composite concrete-steel section per unit width vs span length for a three-lane single span bridge under CL-625 truck loading of $14.5 \mathrm{~m}$ width 112

Figure 5.32: Moment of inertia of the composite concrete-steel section per unit width vs span length for a four-lane single span bridge under CL-625 truck loading of $15 \mathrm{~m}$ width

Figure 5.33: Moment of inertia of the composite concrete-steel section per unit width vs span length for a four-lane single span bridge under CL-625 truck loading of $16.5 \mathrm{~m}$ width

Figure 5.34: Moment of inertia of the composite concrete-steel section per unit width vs span length for a four-lane single span bridge under CL-625 truck loading of $18 \mathrm{~m}$ width 114

Figure 5.35: Moment of inertia of the composite concrete-steel section per unit width vs span length for a five-lane single span bridge under CL-625 truck loading of $18.5 \mathrm{~m}$ width 114 Figure 5.36: Moment of inertia of the composite concrete-steel section per unit width vs span length for a five-lane single span bridge under CL-625 truck loading of $21.5 \mathrm{~m}$ width 115 Figure 5.37: Moment of inertia of the composite concrete-steel section per unit width vs span length for a six-lane single span bridge under CL-625 truck loading of $22 \mathrm{~m}$ width 115 Figure 5.38: Moment of inertia of the composite concrete-steel section per unit width vs span length for a six-lane single span bridge under CL-625 truck loading of $25 \mathrm{~m}$ width 116 Figure 5.39: Moment of inertia of the steel section per unit width vs span length for a one-lane single span bridge under CL-625 truck loading with three girders 117 
Figure 5.40: Moment of inertia of the steel section per unit width vs span length for a one-lane single span bridge under CL-625 truck loading with four girders

Figure 5.41: Moment of inertia of the steel section per unit width vs span length for a two-lane single span bridge under CL-625 truck loading with three girders 118

Figure 5.42: Moment of inertia of the steel section per unit width vs span length for a two-lane single span bridge under CL-625 truck loading with five girders

Figure 5.43: Moment of inertia of the steel section per unit width vs span length for a two-lane single span bridge under CL-625 truck loading with seven girders

Figure 5.44: Moment of inertia of the steel section per unit width vs span length for a three-lane single span bridge under CL-625 truck loading with four girders

Figure 5.45: Moment of inertia of the steel section per unit width vs span length for a three-lane single span bridge under CL-625 truck loading with seven girders 120 Figure 5.46: Moment of inertia of the steel section per unit width vs span length for a four-lane single span bridge under CL-625 truck loading with five girders 120 Figure 5.47: Moment of inertia of the steel section per unit width vs span length for a four-lane single span bridge under CL-625 truck loading with seven girders

Figure 5.48: Moment of inertia of the steel section per unit width vs span length for a four-lane single span bridge under CL-625 truck loading with nine girders.

Figure 5.49: Moment of inertia of the steel section per unit width vs span length for a five-lane single span bridge under CL-625 truck loading with six girders. 122

Figure 5.50: Moment of inertia of the steel section per unit width vs span length for a five-lane single span bridge under CL-625 truck loading with eight girders

Figure 5.51: Moment of inertia of the steel section per unit width vs span length for a five-lane single span bridge under CL-625 truck loading with ten girders.

Figure 5.52: Moment of inertia of the steel section per unit width vs span length for a six-lane single span bridge under CL-625 truck loading with seven girders

Figure 5.53: Moment of inertia of the steel section per unit width vs span length for a six-lane single span bridge under CL-625 truck loading with ten girders. 124

Figure 5.54: Moment of inertia of the steel section per unit width vs span length for a six-lane single span bridge under CL-625 truck loading with twelve girders 
Figure 5.55: Moment of inertia of the composite concrete-steel section per unit width vs span length for a one-lane single span bridge under CL-625 truck loading with three girders

Figure 5.56: Moment of inertia of the composite concrete-steel section per unit width vs span length for a one-lane single span bridge under CL-625 truck loading with four girders. 126

Figure 5.57: Moment of inertia of the composite concrete-steel section per unit width vs span length for a two-lane single span bridge under CL-625 truck loading with three girders 126

Figure 5.58: Moment of inertia of the composite concrete-steel section per unit width vs span length for a two-lane single span bridge under CL-625 truck loading with five girders

Figure 5.59: Moment of inertia of the composite concrete-steel section per unit width vs span length for a two-lane single span bridge under CL-625 truck loading with seven girders .....

Figure 5.60: Moment of inertia of the composite concrete-steel section per unit width vs span length for a three-lane single span bridge under CL-625 truck loading with four girders 128 Figure 5.61: Moment of inertia of the composite concrete-steel section per unit width vs span length for a three-lane single span bridge under CL-625 truck loading with seven girders ....... 128 Figure 5.62: Moment of inertia of the composite concrete-steel section per unit width vs span length for a four-lane single span bridge under CL-625 truck loading with five girders

Figure 5.63: Moment of inertia of the composite concrete-steel section per unit width vs span length for a four-lane single span bridge under CL-625 truck loading with seven girders

Figure 5.64: Moment of inertia of the composite concrete-steel section per unit width vs span length for a four-lane single span bridge under CL-625 truck loading with nine girders

Figure 5.65: Moment of inertia of the composite concrete-steel section per unit width vs span length for a five-lane single span bridge under CL-625 truck loading with six girders

Figure 5.66: Moment of inertia of the composite concrete-steel section per unit width vs span length for a five-lane single span bridge under CL-625 truck loading with eight girders

Figure 5.67: Moment of inertia of the composite concrete-steel section per unit width vs span length for a five-lane single span bridge under CL-625 truck loading with ten girders

Figure 5.68: Moment of inertia of the composite concrete-steel section per unit width vs span length for a six-lane single span bridge under CL-625 truck loading with seven girders 132 Figure 5.69: Moment of inertia of the composite concrete-steel section per unit width vs span length for a six-lane single span bridge under CL-625 truck loading with ten girders 132 
Figure 5.70: Moment of inertia of the composite concrete-steel section per unit width vs span length for a six-lane single span bridge under CL-625 truck loading with twelve girders.....

Figure 5.71: Envelopes for moment of inertia for the steel and the composite concrete-steel section per unit width vs span length for one-lane single span bridge under CL-625 truck loadings

Figure 5.72: Envelopes for moment of inertia for the steel and the composite concrete-steel section per unit width vs span length for two-lane single span bridge under CL-625 truck loadings

Figure 5.73: Envelopes for moment of inertia for the steel and the composite concrete-steel section per unit width vs span length for three-lane single span bridge under CL-625 truck loading.......

Figure 5.74: Envelopes for moment of inertia for the steel and the composite concrete-steel section per unit width vs span length for four-lane single span bridge under CL-625 truck loadings

Figure 5.75: Envelopes for moment of inertia for the steel and the composite concrete-steel section per unit width vs span length for five-lane single span bridge under CL-625 truck loadings

Figure 5.76: Envelopes for moment of inertia for the steel and the composite concrete-steel section per unit width vs span length for six-lane single span bridge under CL-625 truck loadings

Figure 5.77: Combined envelopes for moment of inertia for the steel and the composite concretesteel section per unit width vs span length.

Figure 5.78: Combined envelopes for moment of inertia for the steel and the composite concretesteel section per unit width vs span length.

Figure 5.79: Combined envelope for moment of inertia for the steel and the composite concretesteel section per unit width vs span length for single span bridge under CL-625 truck loading between three and eleven girders

Figure 5.80: Web area per unit width vs span length for single span bridge under CL-625 truck loading with girder spacing ranging between $1.5 \mathrm{~m}$ and $3.67 \mathrm{~m}$..... 142 Figure 5.81: Web area per unit width vs span length for single span bridge configurations under CL-625 truck loading ranging between three to twelve girders 143 
Figure 5.82: Comparison between program results and developed two-variable equation for web area per unit width vs span length for single span bridge under CL-625 truck loading with girder spacing ranging between $1.5 \mathrm{~m}$ and $3.67 \mathrm{~m}$.

Figure 5.83: Comparison between Dx factor obtained in this research for single span bridge under CL-625 truck loading and the boundary values obtained by Bakht B., and Moses, F (Bakht \& Moses, 1988)

Figure 5.84: Combined envelope for moment of inertia for the steel and the composite concretesteel section per unit width vs span length for single span bridge under CL-800 truck loading between three and eleven girders 146 Figure 5.85: Web area per unit width vs span length for single span bridge under CL-800 truck loading with girder spacing ranging between $1.5 \mathrm{~m}$ and $3.67 \mathrm{~m}$. 147 Figure 5.86: Comparison between program results and developed two-variable equation for web area per unit width vs span length for single span bridge under CL-800 truck loading with girder spacing ranging between $1.5 \mathrm{~m}$ and $3.67 \mathrm{~m}$. 148

Figure 5.87: Comparison between Dx factor obtained in this research for single span bridge under CL-800 truck loading and the boundary values obtained by Bakht B., and Moses, F (Bakht \& Moses, 1988)...

Figure 5.88: Combined envelope for moment of inertia for the steel and the composite concretesteel section per unit width vs span length at support location for two equal span bridge under CL-625 truck loading between three and eleven girders 150 Figure 5.89: Combined envelope for moment of inertia for the steel and the composite concretesteel section per unit width vs span length at midspan location for two equal span bridge under CL-625 truck loading between three and eleven girders 150 Figure 5.90: Web area per unit width vs span length for two equal span bridge under CL-625 truck loading with girder spacing ranging between $1.5 \mathrm{~m}$ and $3.67 \mathrm{~m}$

Figure 5.91: Comparison between program results and developed two-variable equation for web area per unit width vs span length for two equal span bridge under CL-625 truck loading with girder spacing ranging between $1.5 \mathrm{~m}$ and $3.67 \mathrm{~m}$

Figure 5.92: Comparison between Dx factor at support location obtained in this research for two equal span bridge under CL-625 truck loading and the boundary values obtained by Bakht B., and Moses, F (Bakht \& Moses, 1988) 
Figure 5.93: Comparison between Dx factor at midspan location obtained in this research for two equal span bridge under CL-625 truck loading and the boundary values obtained by Bakht B., and Moses, F (Bakht \& Moses, 1988)

Figure 5.94: Combined envelope for moment of inertia for the steel and the composite concretesteel section per unit width vs span length at support location for two equal span bridge under CL-800 truck loading between three and eleven girders

Figure 5.95: Combined envelope for moment of inertia for the steel and the composite concretesteel section per unit width vs span length at midspan location for two equal span bridge under CL-800 truck loading between three and eleven girders

Figure 5.96: Web area per unit width vs span length for two equal span bridge under CL-800 truck loading with girder spacing ranging between $1.5 \mathrm{~m}$ and $3.67 \mathrm{~m}$ 156 Figure 5.97: Comparison between program results and developed two-variable equation for web area per unit width vs span length for two equal span bridge under CL-800 truck loading with girder spacing ranging between $1.5 \mathrm{~m}$ and $3.67 \mathrm{~m}$ 157 Figure 5.98: Comparison between Dx factor at support location obtained in this research for two equal span bridge under CL-800 truck loading and the boundary values obtained by Bakht B., and Moses, F (Bakht \& Moses, 1988) 158 Figure 5.99: Comparison between Dx factor at midspan location obtained in this research for two equal span bridge under CL-800 truck loading and the boundary values obtained by Bakht B., and Moses, F (Bakht \& Moses, 1988) 158 Figure 5.100: Combined envelope for moment of inertia for the steel and the composite concretesteel section per unit width vs span length at support location for three equal span bridge under CL-625 truck loading between three and eleven girders 159 Figure 5.101: Combined envelope for moment of inertia for the steel and the composite concretesteel section per unit width vs span length at midspan location for three equal span bridge under CL-625 truck loading between three and eleven girders 160 Figure 5.102: Web area per unit width vs span length for three equal span bridge under CL-625 truck loading with girder spacing ranging between $1.5 \mathrm{~m}$ and $3.67 \mathrm{~m}$ 161 Figure 5.103: Comparison between program results and developed two-variable equation for web area per unit width vs span length for three equal span bridge under CL-625 truck loading with girder spacing ranging between $1.5 \mathrm{~m}$ and $3.67 \mathrm{~m}$ 162 
Figure 5.104: Comparison between Dx factor at support location obtained in this research for three equal span bridge under CL-625 truck loading and the boundary values obtained by Bakht B., and Moses, F (Bakht \& Moses, 1988) 163

Figure 5.105: Comparison between Dx factor at midspan location obtained in this research for three equal span bridge under CL-625 truck loading and the boundary values obtained by Bakht B., and Moses, F (Bakht \& Moses, 1988) 163

Figure 5.106: Combined envelope for moment of inertia for the steel and the composite concretesteel section per unit width vs span length at support location for three equal span bridge under CL-800 truck loading between three and eleven girders 164

Figure 5.107: Combined envelope for moment of inertia for the steel and the composite concretesteel section per unit width vs span length at midspan location for three equal span bridge under CL-800 truck loading between three and eleven girders 165

Figure 5.108: Web area per unit width vs span length for three equal span bridge under CL-800 truck loading with girder spacing ranging between $1.5 \mathrm{~m}$ and $3.67 \mathrm{~m}$ 166 Figure 5.109: Comparison between program results and developed two-variable equation for web area per unit width vs span length for three equal span bridge under CL-800 truck loading with girder spacing ranging between $1.5 \mathrm{~m}$ and $3.67 \mathrm{~m}$ 167

Figure 5.110: Comparison between Dx factor at support location obtained in this research for three equal span bridge under CL-800 truck loading and the boundary values obtained by Bakht B., and Moses, F (Bakht \& Moses, 1988) 168

Figure 5.111: Comparison between Dx factor at midspan location obtained in this research for three equal span bridge under CL-800 truck loading and the boundary values obtained by Bakht B., and Moses, F (Bakht \& Moses, 1988) 168 Figure 5.112: Combined envelope for moment of inertia for the steel and the composite concretesteel section per unit width vs span length at support location for four equal span bridge under CL-625 truck loading between three and eleven girders 169 Figure 5.113: Combined envelope for moment of inertia for the steel and the composite concretesteel section per unit width vs span length at midspan location for four equal span bridge under CL-625 truck loading between three and eleven girders 170

Figure 5.114: Web area per unit width vs span length for four equal span bridge under CL-625 truck loading with girder spacing ranging between $1.5 \mathrm{~m}$ and $3.67 \mathrm{~m}$ 
Figure 5.115: Comparison between program results and developed two-variable equation for web area per unit width vs span length for four equal span bridge under CL-625 truck loading with girder spacing ranging between $1.5 \mathrm{~m}$ and $3.67 \mathrm{~m}$

Figure 5.116: Comparison between Dx factor at support location obtained in this research for four equal span bridge under CL-625 truck loading and the boundary values obtained by Bakht B., and Moses, F (Bakht \& Moses, 1988)

Figure 5.117: Comparison between Dx factor at midspan location obtained in this research for four equal span bridge under CL-625 truck loading and the boundary values obtained by Bakht B., and Moses, F (Bakht \& Moses, 1988) 173

Figure 5.118: Combined envelope for moment of inertia for the steel and the composite concretesteel section per unit width vs span length at support location for four equal span bridge under CL-800 truck loading between three and eleven girders

Figure 5.119: Combined envelope for moment of inertia for the steel and the composite concretesteel section per unit width vs span length at midspan location for four equal span bridge under CL-800 truck loading between three and eleven girders 175

Figure 5.120: Web area per unit width vs span length for four equal span bridge under CL-800 truck loading with girder spacing ranging between $1.5 \mathrm{~m}$ and $3.67 \mathrm{~m}$ 176 Figure 5.121: Comparison between program results and developed two-variable equation for web area per unit width vs span length for four equal span bridge under CL-800 truck loading with girder spacing ranging between $1.5 \mathrm{~m}$ and $3.67 \mathrm{~m}$

Figure 5.122: Comparison between Dx factor at support location obtained in this research for four equal span bridge under CL-800 truck loading and the boundary values obtained by Bakht B., and Moses, F (Bakht \& Moses, 1988). 178 Figure 5.123: Comparison of Dx factor at midspan location obtained in this research for four equal span bridge under CL-800 truck loading and previous research (Bakht \& Moses, 1988) 178 


\section{Chapter I}

\section{Introduction}

\subsection{Introduction}

As the prices of steel continue to rise, bridge design engineers are moving more towards precast concrete girder superstructures. To add to that, the recent advancements in constructability of precast and prestressed concrete superstructures make concrete girder bridges more of a viable option. As a result, the steel industry must reduce material consumption in order to reduce the overall prices of steel in bridge superstructures. In addition, the steel industry must also increase constructability of steel superstructures by reducing the complexity of designs and making them less time and labour intensive. Currently in the steel industry, there are no ready-to-use information that assist bridge design engineers in selection of appropriate steel sections for bridge superstructures. On the other hand, the precast concrete industry is more advanced in that regard and facilitate ease of section design by having ready-made Tables and graphs for various section shapes and sizes. In many cases, the lack of sufficient information regarding steel section sizes to use leads designers and contractors to select overdesigned steel sections in bidding phases. This leads to an overpriced bid which in many cases leads to the bidder losing the bid. Recently, the Canadian Institute of Steel construction (CISC) created a course titled "Steel Bridges: Design, Fabrication and Construction". This course focuses on providing design steps for I-girder and box-girder bridges as well as assist the students in learning how to interpret the Canadian Highway Bridge Design Code (CHBDC, 2014) chapters 3, 5 and 10 which are related to the design procedure. As useful as it is, it still does not provide project bidders with an accurate easy method of obtaining section sizes which in turn reduces the total material used and bid prices. The research presented in this paper provides a quick and accurate method to calculate the required steel section for slab-on-steel I-girder bridge configurations.

Currently, to arrive at an optimized steel girder size, designers are required to first assume an initial girder size. Following that assumption, the first phase is load analysis phase where designers calculate the applied loading in accordance with the Canadian Highway Bridge Design Code (CHBDC) chapter 5 (CSA, 2014). dead load per girder (DLg). Using the applied dead load, multiple loading cases are tested to compute the most critical factored dead load moment, $\mathrm{M}_{\mathrm{D}}$, shear, $V_{D}$, reaction, $R_{D}$, and deflection, $\Delta_{D}$ for Ultimate Limit State (ULS), Serviceability Limit 
State (SLS), and Fatigue Limit State (FLS) using the amplification and reduction factors specified in the Canadian Highway Bridge Design Code (CHBDC). Following the dead load calculations, designers analyze the effect of live load truck and pedestrian loading either manually using influence line method or by utilizing a Finite Element Modelling (FEM) program such as SAP2000 software. The trucks used in analysis in Canada are (i) CL-625 truck loading used in all Canada's Provinces except Ontario and Alberta, (ii) CL625-ONT truck loading used in Ontario, and (iii) CL-800 truck loading used in Alberta. The truck loadings can be seen in Figure 1.1 through 1.3 .

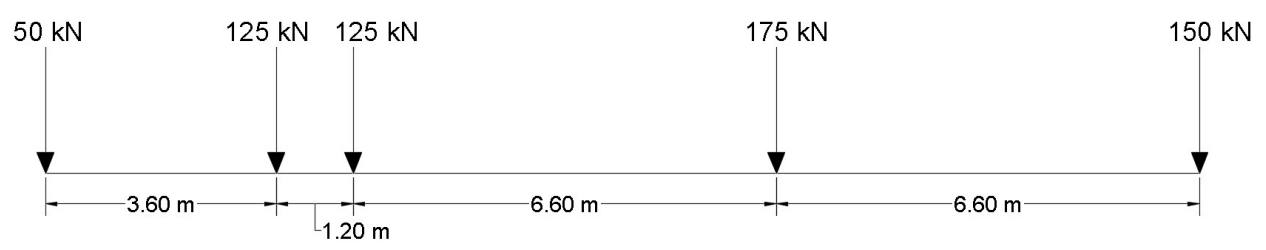

Figure 1.1: Truck configuration for CL-625 truck loading (CSA, 2014)

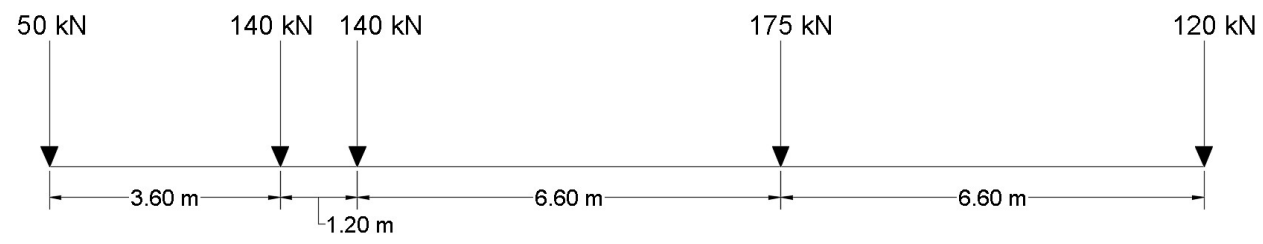

Figure 1.2: Truck configuration for CL-625-ONT truck loading (CSA, 2014)

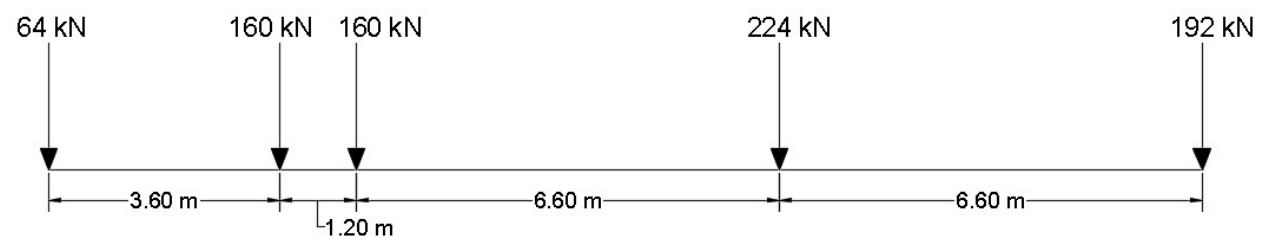

Figure 1.3: Truck configuration for CL-800 truck loading (Alberta Transportation, 2015)

Critical loading conditions are analyzed for moving (lane loading) and congested (truck loading) cases. The final value for applied moment per lane $\left(\mathrm{M}_{\mathrm{T}}\right)$ is calculated as follows:

[1.1] $\mathrm{M}_{\mathrm{T} 1}=\mathrm{M}_{\text {truck }} *(1+\mathrm{DLA})$

[1.2] $\mathrm{M}_{\mathrm{T} 2}=0.8 * \mathrm{M}_{\text {truck }}+\mathrm{M}_{\frac{\text { gkN }}{\mathrm{m}}}$ 
[1.3] $\mathrm{M}_{\mathrm{T}}=\max \left(\begin{array}{l}\mathrm{M}_{\mathrm{T} 1} \\ \mathrm{M}_{\mathrm{T} 2}\end{array}\right)$

Following the calculation of $\mathrm{M}_{\mathrm{T}}$, the value for live load moment per lane $\mathrm{M}_{\mathrm{L}}$ by using the truck fraction factor specified in the CHBDC as follows;

[1.4] $M_{L}=F_{T} M_{T}$ where $F_{T}$ is calculated as follows;

[1.5] $\mathrm{F}_{\mathrm{T}}=\frac{\mathrm{S}}{\mathrm{D}_{\mathrm{T}} \gamma_{\mathrm{C}}(1+\mu \lambda)} \geq 1.05 \frac{\mathrm{nR}_{\mathrm{L}}}{\mathrm{N}}$ for ULS and SLS

[1.6] $\mathrm{F}_{\mathrm{T}}=\frac{\mathrm{S}}{\mathrm{D}_{\mathrm{T}} \gamma_{\mathrm{C}}\left(1+\mu \lambda+\gamma_{\mathrm{e}}\right)} \geq 1.05 \frac{1}{\mathrm{~N}}$ for FLS

The live load factored shear $V_{L}$, reaction $R_{L}$ and deflection $\Delta_{L}$ are calculated in a similar manner. Once the applied loadings are calculated, the desired critical design ULS, SLS, and FLS loading cases are obtained.

Following the load analysis phase, the girder is assessed for adequacy under critical ULS, SLS, and FLS conditions as specified by the CHBDC chapter 10. The girder should be adequate for (1) construction stage permanent deflection SLS check, (2) construction stage applied ULS moment, (3) SLS superstructure vibration, (4) ULS applied moment and shear, (5) Fatigue effect FLS check. If the selected girder size is over-designed or under-designed, the designer would change the section size and repeat the iterative process until an economical section is reached. In this research, this iterative method is replaced by ready-made Tables and equations which can be applied in bidding and preliminary analysis phases in order to obtain an accurate and economic steel section for slab-on-steel I-girder bridge configurations.

\subsection{The significance of this research}

During the preparation of bid documents, bridge design engineers select a bridge geometry which complies with functional requirements of highways. Moreover, bidders have to select between steel and concrete superstructure. However, due to the availability of information regarding precast concrete girders and shortage of time, bidders usually decide to select a concrete superstructure. On the other hand, the steel industry does not provide any means to the project bidders to choose a proper section sizing without spending too much time going through the full design procedure mentioned in section 1.1. Previously, CANBAS software (MTO, 2002) 
was used to quickly analyze and design different bridge dimensions. However, the program has since been withdrawn as it does not comply with the recent versions of the CHBDC. This research aims to provide easy-to-use and quick Tables, equations and graphs that assist in achieving an optimal I-girder section size quickly for biding purposes. This is achieved by means of a parametric study conducted with the help of a VB.Net software developed by the author that optimizes I-girder section sizes in seconds.

\subsection{Thesis objectives}

1- To produce, by means of a parametric study, ready-made equations that calculate applied live load moment $\mathrm{M}_{\mathrm{T}}$, shear $\mathrm{V}_{\mathrm{T}}$, deflection $\Delta_{\mathrm{T}}$ and reaction $\mathrm{R}_{\mathrm{T}}$ for bridges ranging from one to four spans with span length ranging between 12 and $48 \mathrm{~m}$ under the effect of (i) CL-625 truck loading, (ii) CL625-ONT truck loading, and (iii) CL-800 truck loading.

2- To create a VB.Net program that is able to calculate the applied factored loading and perform all the girder adequacy checks given the bridge dimensions for bridges ranging from one to four spans with span length ranging between 12 and $48 \mathrm{~m}$ under the effect of (i) CL-625 truck loading, (ii) CL625-ONT truck loading, and (iii) CL-800 truck loading.

3- To use the VB.Net program in order to conduct a parametric study and create empirical equations for the optimum I-girder moment of inertia $\left(\mathrm{I}_{\mathrm{x}}\right)$, and area of the web $\left(\mathrm{A}_{\mathrm{w}}\right)$.

\subsection{Scope of work}

This research focuses on bridge with one-span, two equal spans, three equal spans and, four equal spans. The span lengths included in this research are between 12 and $48 \mathrm{~m}$ at four meter increments. Bridge widths included in this research are between $4.5 \mathrm{~m}$ and $25 \mathrm{~m}$. Furthermore, This research focuses on bridges without a sidewalk. The research studies bridges that have between three and twelve girders and one to six design lanes. The trucks included in this research are the CL-625 truck loading, CL625-ONT truck loading, and CL-800 truck loading.

\subsection{Thesis layout}

This thesis includes five chapters. Chapter one introduces the reader to the field of work, the research significance and the scope of work. Chapter two discusses the literature review conducted by the author and its significance to the research conducted. Chapter three presents the live load parametric study and the developed live load equations. Chapter four presents the developed software and the methodology of using the software to produce results to be used in 
chapter five. Chapter five discussed the program results and the developed empirical equations for the moment of inertia and area of the web. Chapter six presents the author's conclusions regarding the research and future research recommendations. 


\section{Chapter II}

\section{Literature Review}

\subsection{Application of ready-made design graphs in the concrete bridge industry}

Recent advancements in the concrete industry has made it easier for designers and project bidders to select an optimized section size for preliminary analysis. As discussed previously, this makes the selection of a concrete girder for designing bridge superstructures a much more appealing option. In order to be able to create a similar preliminary design option for slab on steel I-girder bridges, one must study the example of previously conducted research in a similar field. Currently in the "Precast Prestressed Bridge Components Technical Manual" created by Pre-Con for industry use (Pre-Con, 2004), there are multiple different methods available of creating ready-made sections. Visible in Figure 2.1 is a ready-made graph for the CPCI pre-cast girder section in single span. In this figure, there are two different variables that affect the selection of a girder size, girder spacing and girder span. Both the girder span and spacing affect the girder size positively. For instance, at a girder span of $25 \mathrm{~m}$, if a $1.8 \mathrm{~m}$ girder spacing is selected, a CPCI 1200 section would be required. Whereas, for the same girder span a spacing of $2.7 \mathrm{~m}$ is selected, a CPCI 1400 section would be required. A similar graph exists in the same manual for multi-span bridge sections which works in the same way.

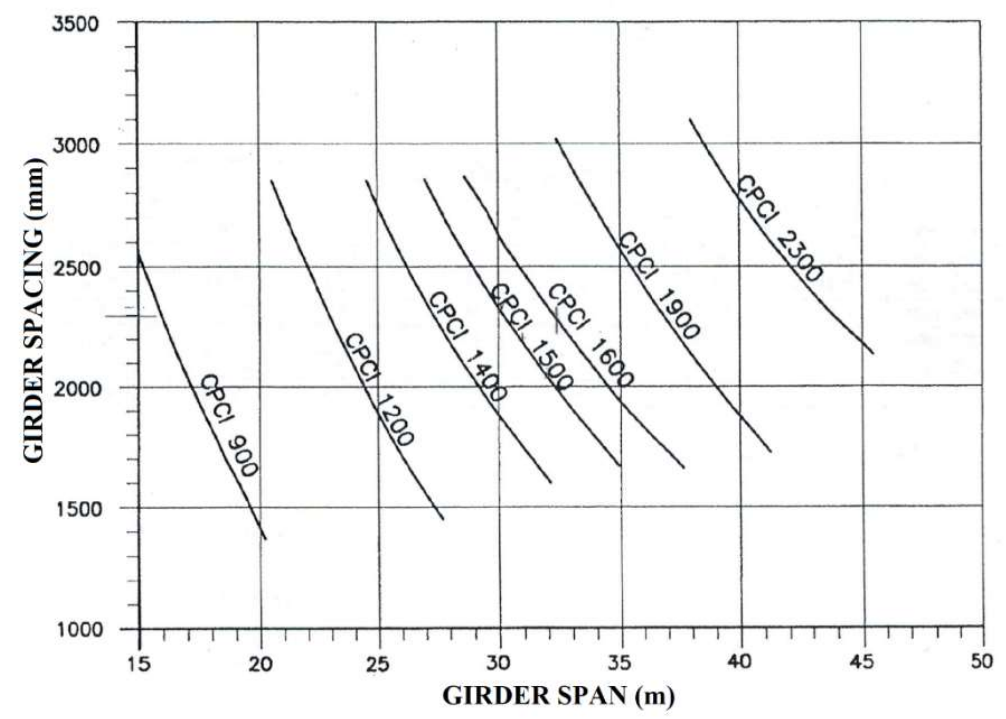

Figure 2.1: Ready-made graph for selection of CPCI girder for single span bridge configurations (Pre-Con, 2004) 
Another example for methods of creating ready-made graphs can be seen in hollow slabs and box girders is shown in Figure 2.2 and 2.3 respectively. In this example, only one factor is taken into account which is the girder span. This is due to the slab being designed based on a onemeter strip method as per the PCI manual (Prestressed Concrete Institute, 1978). This methodology simplifies the preliminary design a great deal and saves the designer or the project bidder precious time in section selection. The author believes that a similar methodology can be applied to steel I-girders by dividing the total moment of inertia of the girder section by the spacing in order to produce a "per unit width" value that can be applied unanimously regardless of spacing.

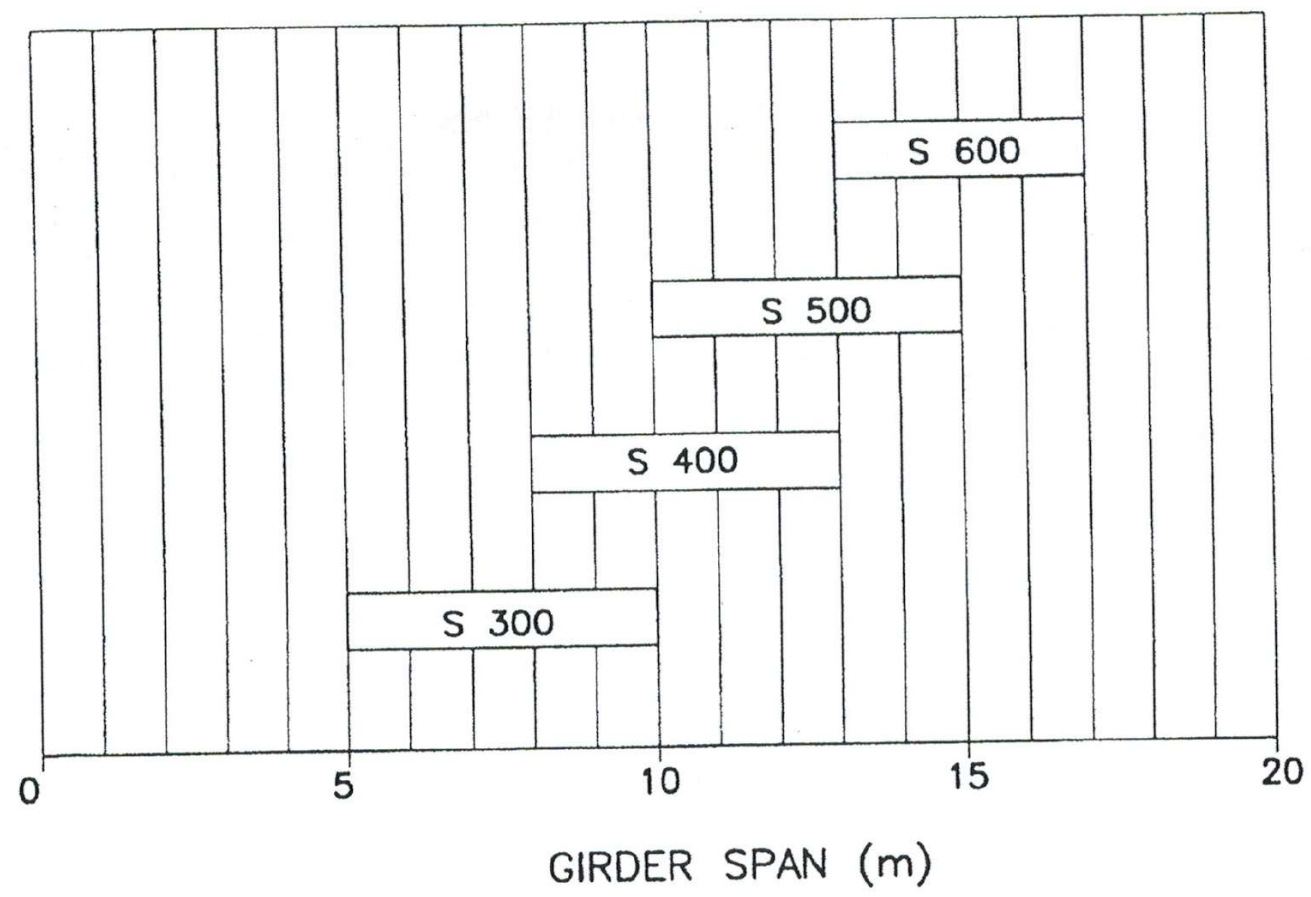

Figure 2.2: Ready-made graph for selection of concrete hollow slab section for single span and multi-span bridge configurations (Pre-Con, 2004) 


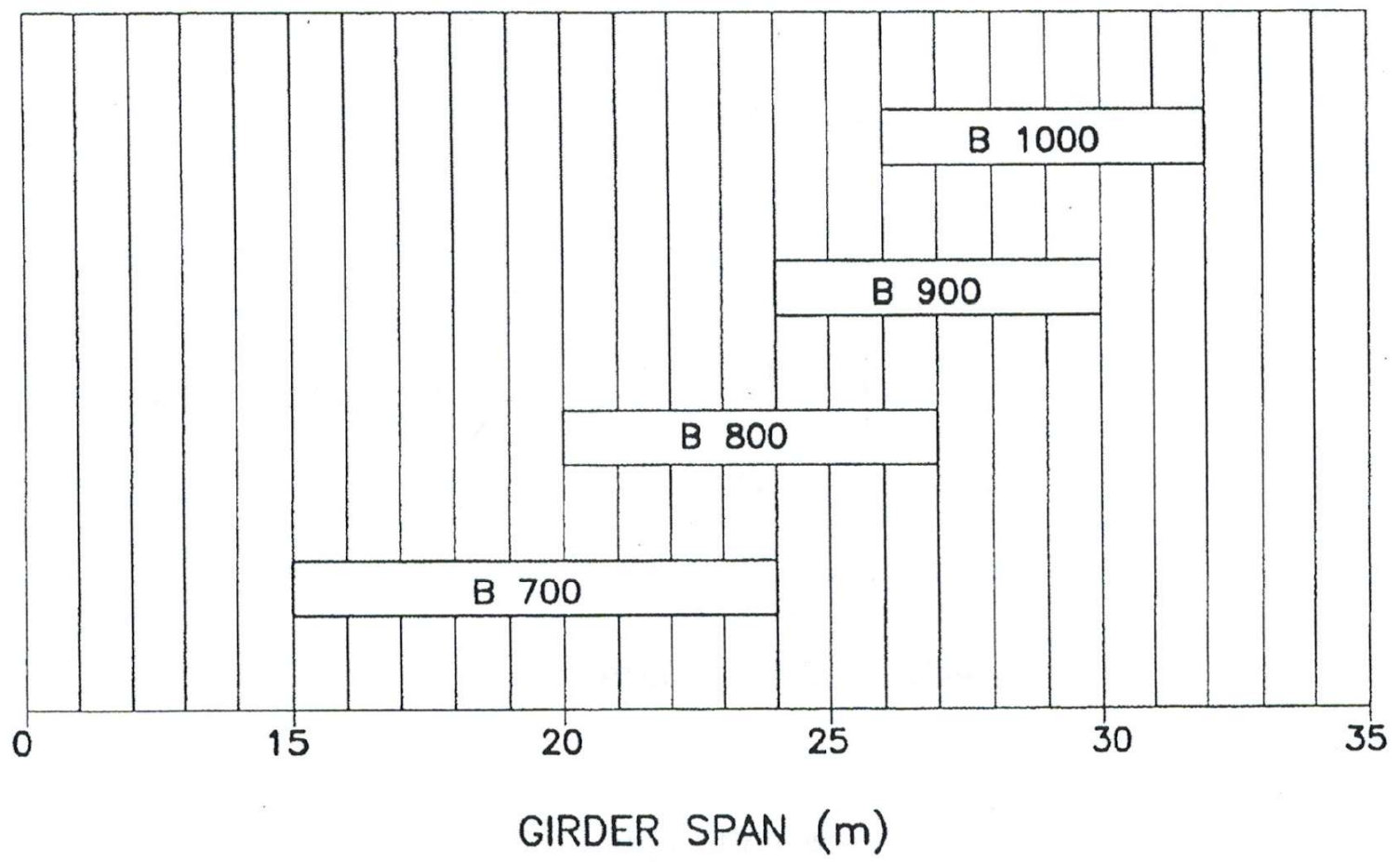

Figure 2.3: Ready-made graph for selection of concrete box girder section for single span and multi-span bridge configurations (Pre-Con, 2004)

2.2 Existing research on simplifying preliminary steel girder design in the bridge industry Upper and lower limits for the longitudinal flexural rigidity (Dx) of single span slab-on-steel girder bridges were established in a publication for the Journal of Structural Engineering in 1988 (Bakht \& Moses, 1988). As can be seen in Figure 2.4, 30 different values for flexural rigidity versus span are plotted and limits are established based on best fit curves. 


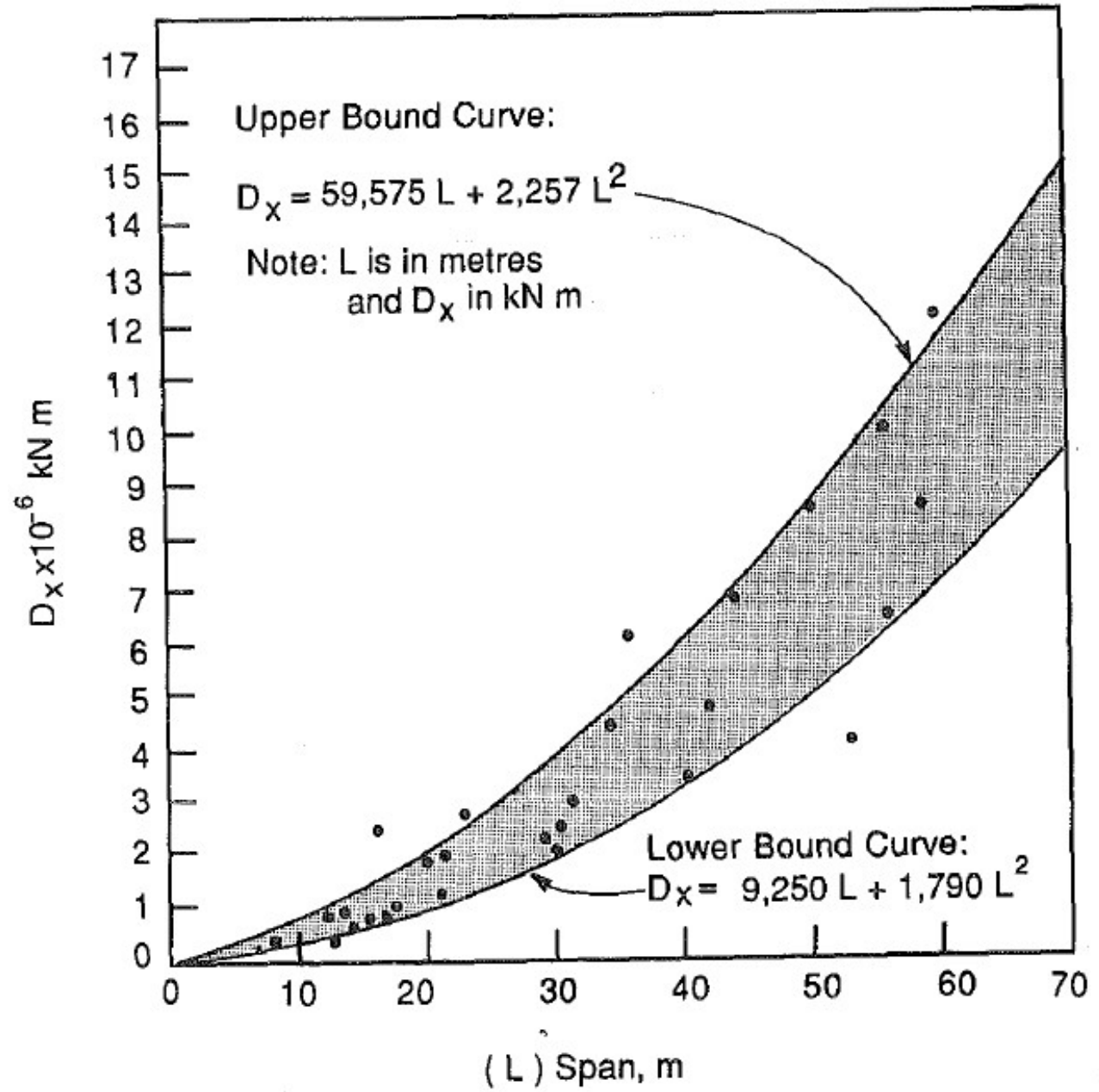

Figure 2.4: Relationship between span and longitudinal flexural rigidity Dx per unit width

The limits established can be seen below;

[2.1] $D_{x}=59,575(L)+2,257\left(L^{2}\right) \mathrm{kN} . \mathrm{m} \quad$ Upper limit for single-span bridges [2.2] $D_{x}=9,250(L)+1,790\left(L^{2}\right) k N . m \quad$ Lower limit for single-span bridges

These results are based on a CL-740 truck loading available in the Ontario Highway Bridge Design Code (OHBDC) (MTO, 1983). It can be seen that out of the 30 samples considered, 5 samples fall out of the predictive model created while the remaining values fall within the model. These equations were then adopted by the OHBDC of 1991 while applying a 25\% increase to the values to become a conservative estimate for Dx of single-span bridge configurations (MTO, 1991). Some parameters in the publication were unclear such as strength of the concrete used 
and, yielding point of the steel which would impact the flexural rigidity. However, it is stated that a slab thickness of $190 \mathrm{~mm}$ was used in their study which was common at the time and can be seen in other load distribution studies (Hays et al., 1987). For such reasons, it is expected that the flexural rigidities obtained in such studies be lower than flexural rigidities that would be obtained in a more recent study with the advancement in material properties, quality control and assurance and increased slab thickness used nowadays.

Another study conducted in 1997 by Theodor \& Al-Bazi shows 69 different bridge configurations with optimized WWF and W shaped steel I-girder sections for slab-on-steel girder single span bridge configurations (Theodor \& Al-Bazi, 1997). In the publication, bridge configurations were divided into 7 groups. Groups 1, 3, 5 and, 7 utilized W shaped sections and short spans between 12 and $24 \mathrm{~m}$. On the other hand, groups 2, 4 and, 6 utilized WWF sections and bridge spans between $18 \mathrm{~m}$ and $40 \mathrm{~m}$. Tables 2.1 through 2.7 show tables for groups 1 through 7 respectively. The sections presented in the manual are based on the CISC Handbook for Steel Construction. Recent changes to the section sizes present in the handbook might render some of the sections discussed in the manual unavailable as per the 2017 version of the handbook (CISC, 2017). It is also worth noting that the sections discussed in the manual do not reach absolute optimization as they are bound by available section sizes in the market in addition to other design parameters. However, the simplicity of these tables makes them a valuable asset for the steel industry and a great example and reference for further research to be done in the area. 
Table 2.1: Theodor \& Al-Bazi's Bridge Group 1 utilizing WWF shaped steel girders for bridge cases 1 through 12

\begin{tabular}{|c|c|c|c|c|c|c|c|c|c|c|c|c|}
\hline Bridge \# & Span (m) & Girder & $A(m)$ & bl (mm) & $d(\mathrm{~mm})$ & b2 (mm) & b4(mm) & h2 (mm) & h4(mm) & hl (mm) & b3 (mm) & h3 (mm) \\
\hline 1 & 18 & WWF $700 \mathrm{X} 152$ & 9.28 & 2500 & 700 & 300 & 300 & 20 & 20 & 225 & 11 & 660 \\
\hline 2 & 20 & WWF $800 \times 161$ & 9.28 & 2500 & 800 & 300 & 300 & 20 & 20 & 225 & 11 & 760 \\
\hline 3 & 22 & WWF 900X169 & 9.28 & 2500 & 900 & 300 & 300 & 20 & 20 & 225 & 11 & 860 \\
\hline 4 & 24 & WWF $1000 \mathrm{X} 223$ & 9.28 & 2500 & 1000 & 300 & 300 & 25 & 25 & 225 & 14 & 950 \\
\hline 5 & 26 & WWF $1100 \times 234$ & 9.28 & 2500 & 1100 & 300 & 300 & 25 & 25 & 225 & 14 & 1050 \\
\hline 6 & 28 & WWF $1200 \mathrm{X} 263$ & 9.28 & 2500 & 1200 & 300 & 300 & 25 & 25 & 225 & 16 & 1150 \\
\hline 7 & 30 & WWF $1200 \times 302$ & 9.28 & 2500 & 1200 & 400 & 400 & 25 & 25 & 225 & 16 & 1150 \\
\hline 8 & 32 & WWF $1200 \times 302$ & 9.28 & 2500 & 1200 & 400 & 400 & 25 & 25 & 225 & 16 & 1150 \\
\hline 9 & 34 & WWF $1400 \times 358$ & 9.28 & 2500 & 1400 & 400 & 400 & 30 & 30 & 225 & 16 & 1340 \\
\hline 10 & 36 & WWF $1400 \times 358$ & 9.28 & 2500 & 1400 & 400 & 400 & 30 & 30 & 225 & 16 & 1340 \\
\hline 11 & 38 & WWF $1600 \mathrm{X} 431$ & $928 \%$ & 2500 & 1600 & 500 & 500 & 30 & 30 & 225 & 16 & 1540 \\
\hline 12 & 40 & WWF1600X431 & 9.28 & 2500 & 1600 & 500 & 500 & 30 & 30 & 225 & 16 & 1540 \\
\hline
\end{tabular}

Table 2.2: Theodor \& Al-Bazi's Bridge Group 2 utilizing W shaped steel girders for bridge cases 13 through 19

\begin{tabular}{|c|c|c|c|c|c|c|c|c|c|c|c|c|}
\hline Bridge \# & $\operatorname{Span}(\mathrm{m})$ & Girder & $A(m)$ & bl (mm) & $d(m m)$ & b2 (nm): & b4 (mur): & h2 (mm) & h4 (mm) & hl (mm) & b3 (mm) & h3 (mm) \\
\hline 13 & 12 & W $610 \times 91$ & 10.46 & 2750 & 598 & 227 & 227 & 12.7 & 12.7 & 225 & 9.7 & 573 \\
\hline 14 & 14 & W $690 \times 125$ & 10.46 & 2750 & 678 & 253 & 253 & 16.3 & 16.3 & 225 & 11.7 & 645 \\
\hline 15 & 16 & W 760X161 & 10.46 & 2750 & 758 & 266 & 266 & 19.3 & 19.3 & 225 & 13.8 & 719 \\
\hline 16 & 18 & W 760X161 & 10.46 & 2750 & 758 & 266 & 266 & 19.3 & 19.3 & 225 & 13.8 & 719 \\
\hline 17 & 20 & W $840 \times 176$ & 10.46 & 2750 & 835 & 292 & 292 & 18.8 & 18.8 & 225 & 14 & 797 \\
\hline 18 & 22 & W 920X201 & 10.46 & 2750 & 903 & 304 & 304 & 20.1 & 20.1 & 225 & 15.2 & 863 \\
\hline 19 & 24 & W $1000 \times 249$ & 10.46 & 2750 & 980 & 300 & 300 & 26 & 26 & 225 & 16.5 & 928 \\
\hline
\end{tabular}

Table 2.3: Theodor \& Al-Bazi's Bridge Group 3 utilizing WWF shaped steel girders for bridge cases 20 through 31

\begin{tabular}{|c|c|c|c|c|c|c|c|c|c|c|c|c|}
\hline Bridge \# & Span (m) & Girder & $A(m)$ & bl (mm) & $d(m m)$ & b2 (mm): & b4 (mm): & h2 (mm) & h4(mm) & hl (mm) & b3 (mm) & h3 (mm) \\
\hline 20 & 18 & WWF $800 \times 161$ & 10.46 & 2750 & 800 & 300 & 300 & 20 & 20 & 225 & 11 & 760 \\
\hline 21 & 20 & WWF 900X169 & 10.46 & 2750 & 900 & 300 & 300 & 20 & 20 & 225 & 11 & 860 \\
\hline 22 & 22 & WWF 900X192 & 10.46 & 2750 & 900 & 300 & 300 & 25 & 25 & 225 & 11 & 850 \\
\hline 23 & 24 & WWF $1000 \times 223$ & 10.46 & 2750 & 1000 & 300 & 300 & 25 & 25 & 225 & 14 & 950 \\
\hline 24 & 26 & WWF $1100 \times 234$ & 10.46 & 2750 & 1100 & 300 & 300 & 25 & 25 & 225 & 14 & 1050 \\
\hline 25 & 28 & WWF $1200 \times 263$ & 10.46 & 2750 & 1200 & 300 & 300 & 25 & 25 & 225 & 16 & 1150 \\
\hline 26 & 30 & WWF $1200 \times 302$ & 10.46 & 2750 & 1200 & 400 & 400 & 25 & 25 & 225 & 16 & 1150 \\
\hline 27 & 32 & WWF $1200 \times 333$ & 10.46 & 2750 & 1200 & 400 & 400 & 30 & 30 & 225 & 16 & 1140 \\
\hline 28 & 34 & WWF $1400 \times 358$ & 10.46 & 2750 & 1400 & 400 & 400 & 30 & 30 & 225 & 16 & 1340 \\
\hline 29 & 36 & WWF $1400 \times 358$ & 10.46 & 2750 & 1400 & 400 & 400 & 30 & 30 & 225 & 16 & 1340 \\
\hline 30 & 38 & WWF $1600 \mathrm{X} 431$ & 10.46 & 2750 & 1600 & 500 & 500 & 30 & 30 & 225 & 16 & 1540 \\
\hline 31 & 40 & WWF1600X431 & 10.46 & 2750 & 1600 & 500 & 500 & 30 & 30 & 225 & 16 & 1540 \\
\hline
\end{tabular}

Table 2.4: Theodor \& Al-Bazi's Bridge Group 4 utilizing W shaped steel girders for bridge cases 32 through 38

\begin{tabular}{|c|c|c|c|c|c|c|c|c|c|c|c|c|}
\hline Bridge \# & $\operatorname{Span}(\mathrm{m})$ & Girder & $A(m)$ & bl (mur) & $d(m m)$ & b2 (mm): & b4 (mm): & h2 (mm) & h4 (mm) & hl (mm) & b3 (mm) & h3 (mm) \\
\hline 32 & 12 & W $610 \mathrm{X} 101$ & 11.46 & 3000 & 603 & 228 & 228 & 14.9 & 14.9 & 225 & 10.5 & 573 \\
\hline 33 & 14 & W $690 \times 125$ & 11.46 & 3000 & 678 & 253 & 253 & 16.3 & 16.3 & 225 & 11.7 & 645 \\
\hline 34 & 16 & W 760X161 & 11.46 & 3000 & 758 & 266 & 266 & 19.3 & 19.3 & 225 & 13.8 & 719 \\
\hline 35 & 18 & W $840 \times 193$ & 11.46 & 3000 & 840 & 292 & 292 & 12.7 & 12.7 & 225 & 14.7 & 797 \\
\hline 36 & 20 & W $840 \times 193$ & 11.46 & 3000 & 840 & 292 & 292 & 12.7 & 12.7 & 225 & 14.7 & 797 \\
\hline 37 & 22 & W $1000 \times 222$ & 11.46 & 3000 & 970 & 300 & 300 & 12.1 & 12.1 & 225 & 16 & 928 \\
\hline 38 & 24 & W 1000x249 & 11.46 & 3000 & 980 & 300 & 300 & 26 & 26 & 225 & 16.5 & 928 \\
\hline
\end{tabular}


Table 2.5: Theodor \& Al-Bazi's Bridge Group 5 utilizing WWF shaped steel girders for bridge cases 39 through 50

\begin{tabular}{|c|c|c|c|c|c|c|c|c|c|c|c|c|}
\hline Bridge \# & $\operatorname{Span}(\mathrm{m})$ & Girder & $A(m)$ & bl (mm) & $d(m m)$ & b2 (mm): & b4 (mm): & h2 (mm) & h4 (mum) & hl (mm) & b3 (mm) & h3 (mm) \\
\hline 39 & 18 & WWF $900 \times 169$ & 11.46 & 3000 & 900 & 300 & 300 & 20 & 20 & 225 & 11 & 860 \\
\hline 40 & 20 & WWF 900X169 & 11.46 & 3000 & 900 & 300 & 300 & 20 & 20 & 225 & 11 & 860 \\
\hline 41 & 22 & WWF $1000 \times 200$ & 11.46 & 3000 & 1000 & 300 & 300 & 20 & 20 & 225 & 14 & 960 \\
\hline 42 & 24 & WWF $1100 \times 234$ & 11.46 & 3000 & 1100 & 300 & 300 & 25 & 25 & 225 & 14 & 1050 \\
\hline 43 & 26 & WWF $1200 \times 263$ & 11.46 & 3000 & 1200 & 300 & 300 & 25 & 25 & 225 & 16 & 1150 \\
\hline 44 & 28 & WWF $1200 \times 302$ & 11.46 & 3000 & 1200 & 400 & 400 & 25 & 25 & 225 & 16 & 1150 \\
\hline 45 & 30 & WWF $1200 \times 302$ & 11.46 & 3000 & 1200 & 400 & 400 & 25 & 25 & 225 & 16 & 1150 \\
\hline 46 & 32 & WWF $1200 \times 333$ & 11.46 & 3000 & 1200 & 400 & 400 & 30 & 30 & 225 & 16 & 1140 \\
\hline 47 & 34 & WWF $1400 \times 358$ & 11.46 & 3000 & 1400 & 400 & 400 & 30 & 30 & 225 & 16 & 1340 \\
\hline 48 & 36 & WWF $1400 \times 358$ & 11.46 & 3000 & 1400 & 400 & 400 & 30 & 30 & 225 & 16 & 1340 \\
\hline 49 & 38 & WWF $1600 \times 431$ & 11.46 & 3000 & 1600 & 500 & 500 & 30 & 30 & 225 & 16 & 1540 \\
\hline 50 & 40 & WWF $1600 \times 431$ & 11.46 & 3000 & 1600 & 500 & 500 & 30 & 30 & 225 & 16 & 1540 \\
\hline
\end{tabular}

Table 2.6: Theodor \& Al-Bazi's Bridge Group 6 utilizing W shaped steel girders for bridge cases 51 through 57

\begin{tabular}{|c|c|c|c|c|c|c|c|c|c|c|c|c|}
\hline Bridge \# & $\operatorname{Span}(\mathrm{m})$ & Girder & $A(m)$ & bl (mm) & $d(m m)$ & b2 (mm): & b4 (mm): & h2 (mm) & h4 (mm) & hl $(\mathrm{mm})$ & b3 (mm) & h3 (mm) \\
\hline 51 & 12 & W 610X101 & 12.46 & 3250 & 603 & 228 & 228 & 14.9 & 14.9 & 225 & 10.5 & 573 \\
\hline 52 & 14 & W $690 \times 125$ & 12.46 & 3250 & 678 & 253 & 253 & 16.3 & 16.3 & 225 & 11.7 & 645 \\
\hline 53 & 16 & W 840X176 & 12.46 & 3250 & 835 & 292 & 292 & 18.8 & 18.8 & 225 & 14 & 797 \\
\hline 54 & 18 & W 840X193 & 12.46 & 3250 & 840 & 292 & 292 & 12.7 & 12.7 & 225 & 14.7 & 797 \\
\hline 55 & 20 & W 840X193 & 12.46 & 3250 & 840 & 292 & 292 & 12.7 & 12.7 & 225 & 14.7 & 797 \\
\hline 56 & 22 & W $1000 \mathrm{X} 222$ & 12.46 & 3250 & 970 & 300 & 300 & 12.1 & 12.1 & 225 & 16 & 928 \\
\hline 57 & 24 & W 1000x249 & 12.46 & 3250 & 980 & 300 & 300 & 26 & 26 & 225 & 16.5 & 928 \\
\hline
\end{tabular}

Table 2.7: Theodor \& Al-Bazi's Bridge Group 7 utilizing WWF shaped steel girders for bridge cases 58 through 69

\begin{tabular}{|c|c|c|c|c|c|c|c|c|c|c|c|c|}
\hline Bridge \# & $\operatorname{Span}(\mathrm{m})$ & Girder & $A(m)$ & bl (mm) & $d(\mathrm{~mm})$ & b2 (mm): & b4 (mm): & h2 (mm) & h4 (mur) & hl (mm) & b3 (mm) & h3(mm) \\
\hline 58 & 18 & WWF 900X169 & 12.46 & 3250 & 900 & 300 & 300 & 20 & 20 & 225 & 11 & 860 \\
\hline 59 & 20 & WWF $900 \times 169$ & 12.46 & 3250 & 900 & 300 & 300 & 20 & 20 & 225 & 11 & 860 \\
\hline 60 & 22 & WWF $1000 \times 200$ & 12.46 & 3250 & 1000 & 300 & 300 & 20 & 20 & 225 & 14 & 960 \\
\hline 61 & 24 & WWF $1100 \times 234$ & 12.46 & 3250 & 1100 & 300 & 300 & 25 & 25 & 225 & 14 & 1050 \\
\hline 62 & 26 & WWF $1200 \times 263$ & 12.46 & 3250 & 1200 & 300 & 300 & 25 & 25 & 225 & 16 & 1150 \\
\hline 63 & 28 & WWF $1200 \times 302$ & 12.46 & 3250 & 1200 & 400 & 400 & 25 & 25 & 225 & 16 & 1150 \\
\hline 64 & 30 & WWF $1200 \times 302$ & 12.46 & 3250 & 1200 & 400 & 400 & 25 & 25 & 225 & 16 & 1150 \\
\hline 65 & 32 & WWF $1400 \times 358$ & 12.46 & 3250 & 1400 & 400 & 400 & 30 & 30 & 225 & 16 & 1340 \\
\hline 66 & 34 & WWF $1400 \times 358$ & 12.46 & 3250 & 1400 & 400 & 400 & 30 & 30 & 225 & 16 & 1340 \\
\hline 67 & 36 & WWF $1400 \times 405$ & 12.46 & 3250 & 1400 & 500 & 500 & 30 & 30 & 225 & 16 & 1340 \\
\hline 68 & 38 & WWF $1600 \mathrm{X} 431$ & 12.46 & 3250 & 1600 & 500 & 500 & 30 & 30 & 225 & 16 & 1540 \\
\hline 69 & 40 & WWF1600X431 & 12.46 & 3250 & 1600 & 500 & 500 & 30 & 30 & 225 & 16 & 1540 \\
\hline
\end{tabular}


In continuation of the work conducted by Theodor and Al-Bazi, 3 more bridge groups were designed by Nofal (Nofal, 1988). Nofal's work focuses on bridges of spans between $12 \mathrm{~m}$ and 20 $\mathrm{m}$ and only considers $\mathrm{W}$ shaped steel girder sections. The research setup is very similar to that discussed above. Tables 2.8 through 2.10 show the 3 additional groups of bridges considered by Nofal summing up to a total of 94 available bridge configurations for short-span single span slab-on-steel girder bridges. Nofal's work showed a focus on girder spacing for bridges with equal span to show the effect of spacing on girder size selection. It can be seen that a decrease of girder spacing causes a decrease in section size selected as it is to be expected.

Table 2.8: Nofal's Bridge Group 1 utilizing W shaped steel girders for bridge cases 70 through 77

\begin{tabular}{|r|r|l|r|r|r|r|r|r|r|r|r|r|}
\hline Bridge \# & Span(m) & Girder & $\mathrm{A}(\mathrm{m})$ & $\mathrm{b} 1(\mathrm{~mm})$ & $\mathrm{d}(\mathrm{mm})$ & $\mathrm{b} 2(\mathrm{~mm})$ & $\mathrm{b} 4(\mathrm{~mm})$ & $\mathrm{h} 2(\mathrm{~mm})$ & $\mathrm{h} 4(\mathrm{~mm})$ & $\mathrm{h} 1(\mathrm{~mm})$ & $\mathrm{b} 3(\mathrm{~mm})$ & $\mathrm{h} 3(\mathrm{~mm})$ \\
\hline 70 & 16 & W 610X125 & 8 & 2750 & 612 & 229 & 229 & 19.6 & 19.6 & 225 & 11.9 & 573 \\
\hline 71 & 16 & W 610X125 & 8 & 2500 & 612 & 229 & 229 & 19.6 & 19.6 & 225 & 11.9 & 573 \\
\hline 72 & 16 & W 610X125 & 8 & 2750 & 612 & 229 & 229 & 19.6 & 19.6 & 225 & 11.9 & 573 \\
\hline 73 & 16 & W 610X125 & 12 & 2750 & 612 & 229 & 229 & 19.6 & 19.6 & 225 & 11.9 & 573 \\
\hline 74 & 16 & W 610X125 & 16 & 2750 & 612 & 229 & 229 & 19.6 & 19.6 & 225 & 11.9 & 573 \\
\hline 75 & 12 & W 610X125 & 8 & 3000 & 612 & 229 & 229 & 19.6 & 19.6 & 225 & 11.9 & 573 \\
\hline 76 & 16 & W 690X170 & 8 & 3000 & 693 & 256 & 256 & 23.6 & 23.6 & 225 & 14.5 & 646 \\
\hline 77 & 20 W 760X161 & 8 & 3000 & 758 & 266 & 266 & 19.3 & 19.3 & 225 & 13.8 & 719 \\
\hline
\end{tabular}

Table 2.9: Nofal's Bridge Group 2 utilizing W shaped steel girders for bridge cases 78 through 87

\begin{tabular}{|r|r|l|r|r|r|r|r|r|r|r|r|r|}
\hline Bridge \# & Span(m) & Girder & A (m) & b1(mm) & d(mm) & b2(mm) & b4(mm) & h $(\mathrm{mm})$ & $\mathrm{h} 4(\mathrm{~mm})$ & $\mathrm{h} 1(\mathrm{~mm})$ & $\mathrm{b} 3(\mathrm{~mm})$ & $\mathrm{h} 3(\mathrm{~mm})$ \\
\hline 78 & 12 & W 610X155 & 8 & 3750 & 611 & 324 & 324 & 19 & 19 & 225 & 12.7 & 573 \\
\hline 79 & 12 & W 610X140 & 8 & 3375 & 617 & 230 & 230 & 22.2 & 22.2 & 225 & 13.1 & 573 \\
\hline 80 & 12 & W 610X125 & 8 & 3000 & 612 & 229 & 229 & 19.6 & 19.6 & 225 & 11.9 & 573 \\
\hline 81 & 12 & W 530X123 & 8 & 2500 & 544 & 212 & 212 & 21.2 & 21.2 & 225 & 13.1 & 502 \\
\hline 82 & 12 & W 530X109 & 8 & 2250 & 539 & 211 & 211 & 18.8 & 18.8 & 225 & 11.6 & 501 \\
\hline 83 & 12 & W 530X101 & 8 & 2000 & 537 & 201 & 201 & 17.4 & 17.4 & 225 & 10.9 & 502 \\
\hline 84 & 16 & W 610X125 & 8 & 2750 & 612 & 229 & 229 & 19.6 & 19.6 & 225 & 11.9 & 573 \\
\hline 85 & 16 & W 610X125 & 8 & 2500 & 612 & 229 & 229 & 19.6 & 19.6 & 225 & 11.9 & 573 \\
\hline 86 & 16 & W 610X125 & 8 & 2750 & 612 & 229 & 229 & 19.6 & 19.6 & 225 & 11.9 & 573 \\
\hline 87 & 16 & W 610X125 & 8 & 2750 & 612 & 229 & 229 & 19.6 & 19.6 & 225 & 11.9 & 573 \\
\hline
\end{tabular}


Table 2.10: Nofal's Bridge Group 1 utilizing W shaped steel girders for bridge cases 88 through 94

\begin{tabular}{|r|r|l|r|r|r|r|r|r|r|r|r|r|}
\hline Bridge \# & Span (m) & Girder & $\mathrm{A}(\mathrm{m})$ & $\mathrm{b} 1(\mathrm{~mm})$ & $\mathrm{d}(\mathrm{mm})$ & $\mathrm{b} 2(\mathrm{~mm})$ & $\mathrm{b} 4(\mathrm{~mm})$ & $\mathrm{h} 2(\mathrm{~mm})$ & $\mathrm{h} 4(\mathrm{~mm})$ & $\mathrm{h} 1(\mathrm{~mm})$ & $\mathrm{b} 3(\mathrm{~mm})$ & $\mathrm{h} 3(\mathrm{~mm})$ \\
\hline 88 & 12 & W $610 X 125$ & 8 & 3000 & 612 & 229 & 229 & 19.6 & 19.6 & 175 & 11.9 & 573 \\
\hline 89 & 12 & W $610 X 125$ & 8 & 3000 & 612 & 229 & 229 & 19.6 & 19.6 & 225 & 11.9 & 573 \\
\hline 90 & 12 & W $610 X 125$ & 8 & 3000 & 612 & 229 & 229 & 19.6 & 19.6 & 275 & 11.9 & 573 \\
\hline 91 & 12 & W 530X123 & 8 & 2500 & 544 & 212 & 212 & 21.2 & 21.2 & 225 & 13.1 & 502 \\
\hline 92 & 12 & W 530X123 & 8 & 2500 & 544 & 212 & 212 & 21.2 & 21.2 & 225 & 13.1 & 502 \\
\hline 93 & 12 & W 530X123 & 8 & 2500 & 544 & 212 & 212 & 21.2 & 21.2 & 225 & 13.1 & 502 \\
\hline 94 & 12 & W 530X123 & 8 & 2500 & 544 & 212 & 212 & 21.2 & 21.2 & 225 & 13.1 & 502 \\
\hline
\end{tabular}

\subsection{Use of programs in bridge analysis and design}

Most recently, Autodesk released a program titled "Structural Bridge Design” (Autodesk Civil Engineering, 2018). This program is available online for purchase and is designed to help engineers perform loading, analysis and code checks as per American standards. This program provides an excellent tool for designers in the final design phase to conduct final checks on the selected girder and bridge dimensions. The program however, does not in itself optimize a girder size or optimize any other sections. It assists with the procedure and makes it much faster. However, it does not provide an alternative to the design iterations in achieving an optimal girder size and thus does not assist in cost reduction for bidding phase purposes.

A very common program in bridge analysis is SAP2000 Finite Element Modelling (FEM) software. This program allows for analysis of point loads, line loads, distributed loads and, moving loads on programmable 1-D, 2-D and 3-D structural members. It is simple enough to be used for a quick analysis of girders modelled as beams and yet it has the capability to model more complex structures very accurately (SAP2000, 2017). SAP2000 software is mainly used for the analysis aspect of the bridge design phase and is not very heavily relied on to perform code checks and find the most appropriate section size. Another FEM software that is more specific to the bridge industry is CSIBridge. It is created by the same creators of SAP2000 but it is designed to assist in modelling, analysis and design of bridge structures (CSI, 2017). It provides more options for design such as bearing members and abutments. It has the ability to perform code checks and update them as the model changes. This provides a great visual tool for bridge designers to finalize their model and optimize it. However, the optimization process is also manual. Moreover, it is very heavily weighed towards the final design phase rather than optimizing the preliminary design phase for bidding purposes. Finally, MIDAS Civil 
Engineering software is another option that is also very heavily weighed towards analysis and design. In additional to FEM analysis, it provides Eurocode checks to the user in order to assist in section selection and optimization (MIDAS Civil, 2014). Even though third party additions are available to the software to incorporate American codes, the software itself does not assist in optimization for preliminary analysis and instead also focuses on final design of bridge sections. For these reasons, the author believes there is a need for a software that is able to provide accurate superstructure section sizing and optimization for preliminary analysis of bridges.

\subsection{Transverse load distribution in bridges}

Existing equations in the CHBDC assist in determining load distribution factors for exterior and interior girders (CSA, 2014). The existing equation is as follows;

[2.3] $\mathrm{F}_{\mathrm{T}}=\frac{\mathrm{S}}{\mathrm{D}_{\mathrm{T}} \gamma_{\mathrm{C}}(1+\mu \lambda)} \geq 1.05 \frac{\mathrm{nR}_{\mathrm{L}}}{\mathrm{N}}$ for ULS and SLS

$[2.4] \mathrm{F}_{\mathrm{T}}=\frac{\mathrm{S}}{\mathrm{D}_{\mathrm{T}} \gamma_{\mathrm{C}}\left(1+\mu \lambda+\gamma_{\mathrm{e}}\right)} \geq 1.05 \frac{1}{\mathrm{~N}}$ for FLS

$\mathrm{S}=$ girder spacing, $\mathrm{m}$,

$\mathrm{n}=$ number of design lanes,

$\mathrm{R}_{\mathrm{L}}=$ multilane reduction factor

$\mathrm{N}=$ number of girders

$\mathrm{D}_{\mathrm{T}}, \gamma_{\mathrm{C}}, \lambda, \gamma_{\mathrm{e}}$ are obtained from tables found in chapter 5 of the CHBDC

$\mu=\frac{\mathrm{We}-3.3}{0.6} \leq 1.0$

$\mathrm{We}=$ design lane width, $\mathrm{m}$

This truck loading distribution factor $\mathrm{F}_{\mathrm{T}}$ is then multiplied by the live load moment obtained from one lane of loading to obtain the loading on the selected girder.

In recent research conducted on the topic of transverse loading, the CHBDC transverse load distribution factor was compared to load distribution factors of AASHTO and load distribution done by means of FEM or manual calculations (Razaqpur \& Esfandiari, 2006). Shown in Figure 2.5 is an example of the results obtained in the study. 

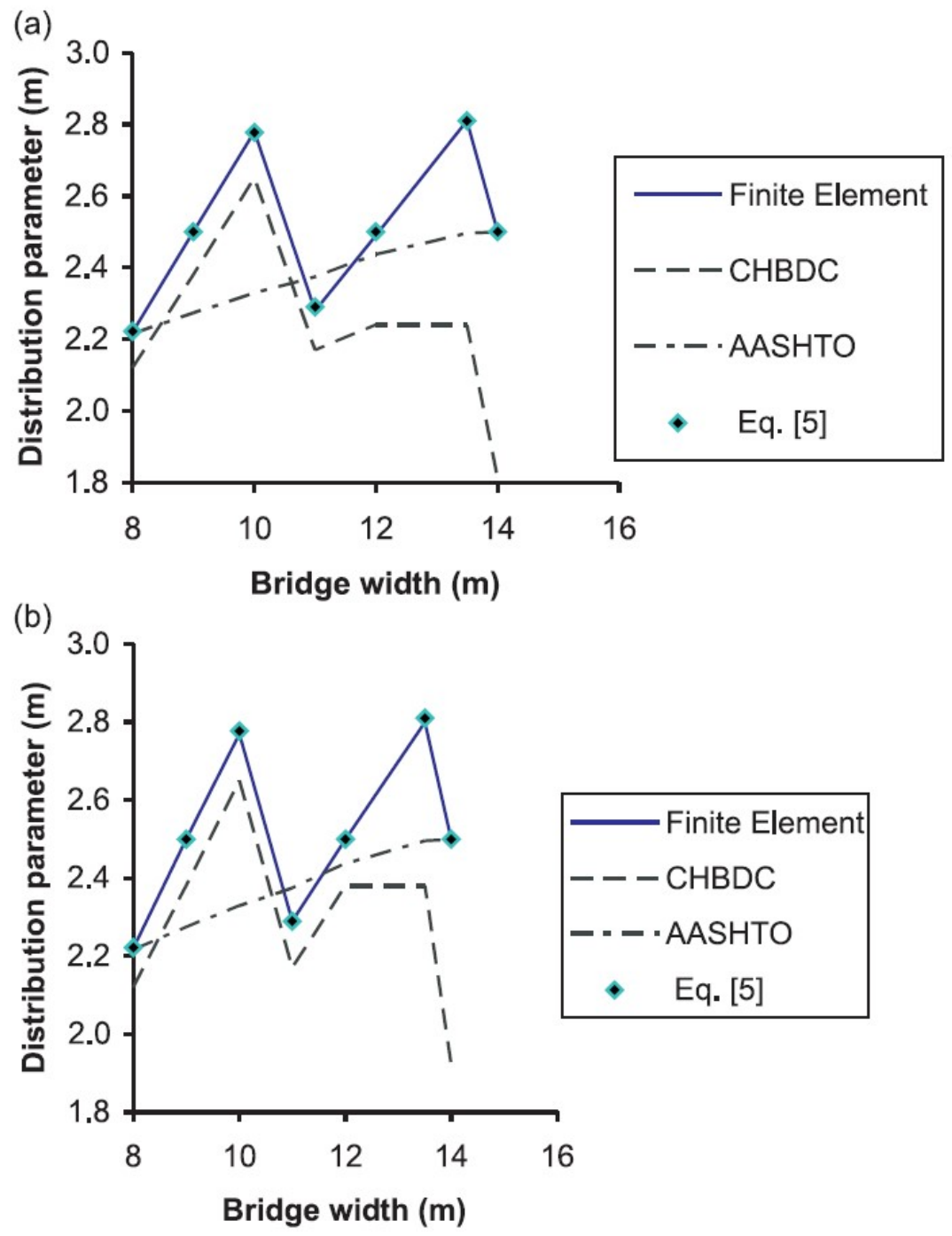

Figure 2.5: Variation in distribution parameter with bridge width for three-span bridges: (a) external girder; (b) internal girder (A. Ghani Razaqpur, 2006)

It was concluded from the study that for bridges with aspect rations between 2.50 and 3.75 (length-to-width ratio), the CHBDC distribution factors provided good results. However, for bridges below this range of aspect ratios, the $\mathrm{CHBDC}$ provides conservative results. It was also found that the load redistribution varies based on state of design which agreed with the methodology of the CHBDC where ULS and SLS are treated differently to FLS design state. It was also concluded in the publication that AASHTO provides very conservative results when compared to CHBDC for transverse load distribution (AASHTO, 2017). 


\subsection{Girder design for superstructure vibration at SLS}

As per the requirements for the CHBDC, the design for bridge superstructure vibration depends on the bridge first flexural frequency, the static deflection due to truck loading magnified by Dynamic Load Allowance (DLA) and, the sidewalk usage frequency (CSA, 2014).

\section{$[2.5] \Delta_{\mathrm{LL}}=\Delta_{\text {truck }} \cdot \mathrm{F}_{\mathrm{T}} \cdot(1+\mathrm{DLA})$}

Once the required parameters are calculated. Figure 2.6 is then used to assess the current girder section for adequacy. If the section is inadequate, a stiffer section should be used instead. Stiffening the section can be in the form of adding stiffeners to the existing girder section or using a larger girder section size, whichever is more feasible.

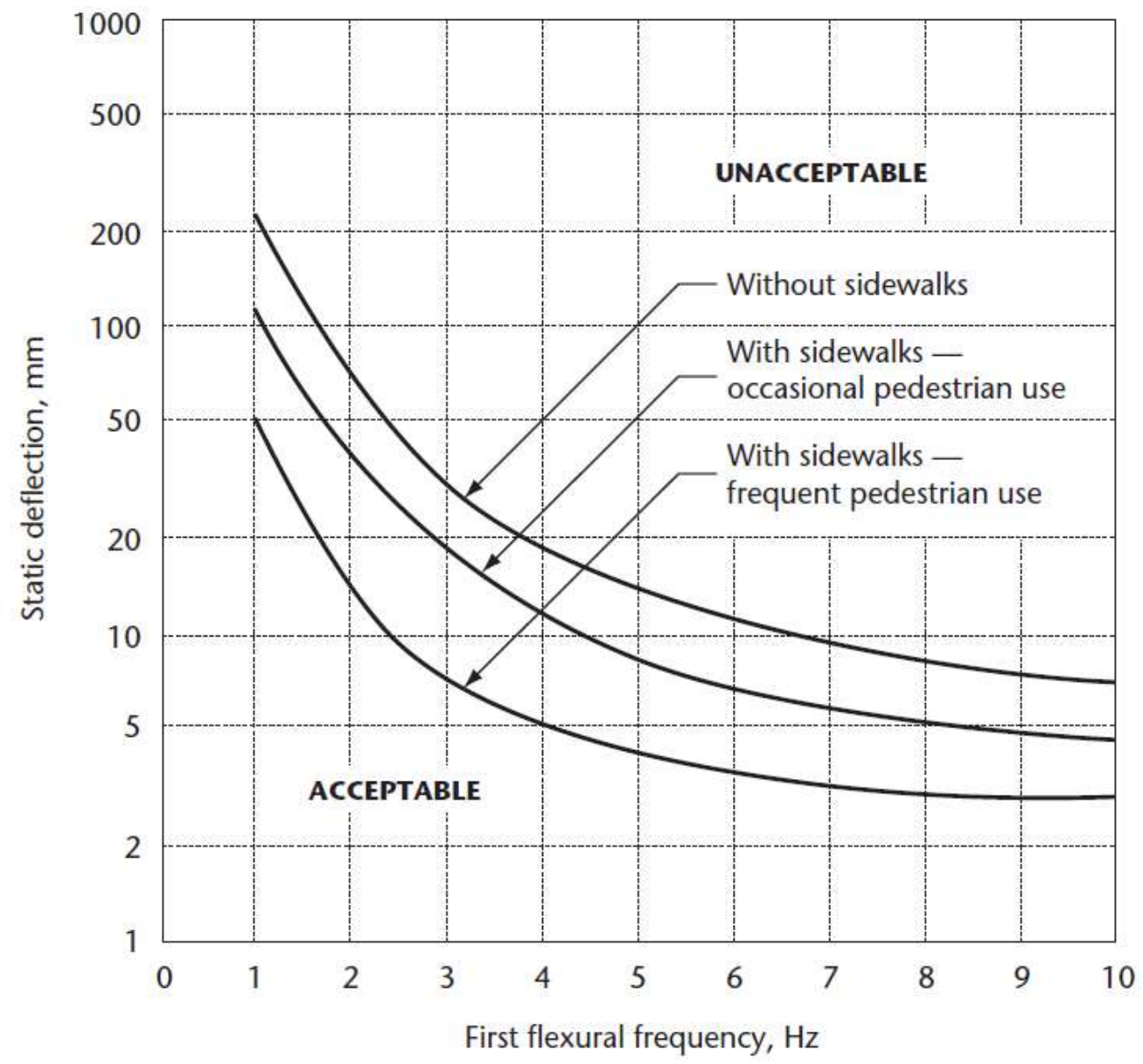

Figure 2.6: Deflection limits for highway bridge superstructure vibration (CSA, 2014) 
It has been shown in a recent study that the aspect ratio of the bridge affects the vibration mode and thus also changes the natural frequency. When aspect ratios re below 4.0, the first mode is dominant while for aspect ratios above 8.0, other modes start becoming more dominant (Duan et al., 2000) Furthermore, it was also shown that maximum vibration occurs when the truck movement duration on the bridge is close to the fundamental period of the bridge (Yang and Lin, 1995). Finally, it was shown that dynamic analysis overestimates the deflection as it overestimates the first flexural frequency of the bridge since it does not take into account the effect of the mass of the truck on the vehicle-bridge system which has a lower first flexural frequency when compared to the bridge system on its own (Yang and Yau, 1997) is unclear whether the CHBDC takes these factors into account in the calculations for superstructure vibration adequacy or not. However, the CHBDC requirements will be used for the purpose of this work nonetheless even if it provides conservative results.

\subsection{Girder design for ULS loading}

According to the CISC Handbook of Steel construction, steel girders are classified into 4 classes. Depending on the girder class specification, the design methodology differs. Classes 1 and 2 are considered to be bulky sections and thus are designed for plastic conditions by using the plastic section modulus $(Z)$. On the other hand, Classes 3 and 4 are slender sections and are thus designed for elastic conditions by using the elastic section modulus, S, (CISC, 2017). The resistance of the girder section is especially important when considering construction stage where the slab is wet and only the girder is acting as a resisting structural member to the construction live loads and the wet concrete and formwork dead loads.

[2.6] $M_{\text {rgirder }} \geq M_{\text {fconstruction }}$

As for the composite design for moment, existing examples shown as part of the CISC course "Steel Bridges Design, Fabrication, Construction" (CISC, 2016) were studied. In the course design examples, the composite section is converted into an equivalent steel section and then the moment resistances of the section are calculated. Under positive moment, the portion of the system above the neutral axis is under compression and thus the concrete is in effect in resisting the loads. However, under negative moment the concrete portion above the neutral axis is considered cracked under tension and only the reinforcement is considered in the load resistance 
calculations. The positive and negative resisting moments are then assessed in comparison with the ultimate applied positive and negative moments (CSA, 2014).

[2.7] $\mathrm{M}_{\mathrm{r}+\text { composite }} \geq \mathrm{M}_{\mathrm{f}+\mathrm{ULS}}$

[2.8] $\mathrm{M}_{\mathrm{r}-\text { composit }} \geq \mathrm{M}_{\mathrm{f}-\mathrm{ULS}}$

Finally, when considering the shear resistance of the girder, it is calculated based on the web area and the considerations in the Handbook of Steel Construction (CISC, 2017).

$[2.9] \mathrm{V}_{\mathrm{r}}=\emptyset_{\mathrm{s}} * \mathrm{~A}_{\mathrm{w}} * \mathrm{~F}_{\mathrm{s}}$

$[2.10] \mathrm{F}_{\mathrm{s}}=\mathrm{F}_{\mathrm{cr}}+\mathrm{F}_{\mathrm{t}}$

$\emptyset_{\mathrm{s}}=$ resistance factor for steel,

$A_{w}=$ area of the I-girder section web, $\mathrm{mm}^{2}$,

$\mathrm{F}_{\mathrm{s}}=\mathrm{ULS}$ shear stress, MPa,

$\mathrm{F}_{\mathrm{cr}}=$ shear buckling stress, $\mathrm{MPa}$,

$\mathrm{F}_{\mathrm{t}}=$ tension field component of post-buckling stress, MPa.

Detailed example of calculation of shear resistance of steel plate I-girder section was found in the CISC course "Steel Bridges Design, Fabrication, Construction" design examples (CISC, 2016). Upon the calculation of shear resistance, it is compared to the factored applied shear to ensure adequacy.

[2.11] $\mathrm{V}_{\mathrm{r}} \geq \mathrm{V}_{\mathrm{fULS}}$

\subsection{Girder design for Fatigue Limit State}

Fatigue stress ranges are calculated based on calculated FLS applied moments. According to the CHBDC, the following design requirement should be achieved (CSA, 2014).

[2.12] $0.52 * \mathrm{C}_{\mathrm{L}} * \mathrm{f}_{\mathrm{sr}}<\mathrm{F}_{\mathrm{sr}}$

$0.52=$ calibration constant to correlate fatigue damage from CL-W truck to that of a real truck, 
$\mathrm{C}_{\mathrm{L}}=$ truck weight factor, 1.0 for CL-625 truck,

$\mathrm{f}_{\mathrm{sr}}=$ calculated stress range due to passage of a CL-W truck, MPa,

$\mathrm{F}_{\mathrm{sr}}=$ calculated stress range resistance of the structural member as per the design detail categories in the CHBDC, MPa. 


\section{Chapter III}

\section{Truck Load Parametric Study}

\subsection{Methodology}

The aim of this portion of the research is to obtain an accurate value for the design live load moment and shear using the three most used trucks in Canada, namely: CL-625, CL-625-ONT and CL-800. CL-625 truck is used for the design of bridges in all provinces and territories except Ontario and Alberta, while CL-625-ONT truck is used for the design of bridges in Ontario (CSA, 2014). CL-800 is identical to CL-625 truck but with gross weight of $800 \mathrm{kN}$ and is used to design bridges in Alberta (Alberta Transportation, 2015). These truck configurations are shown in Figures 1.1 through 1.3.

The CHBDC specifies that the live load moment per girder, $\mathrm{M}_{\mathrm{L}}$, is calculated based equations referenced in chapter 1 .

The longitudinal moment generated by one lane of CL-W loading, $\mathrm{M}_{\mathrm{T}}$, is the maximum moment obtained from a congested and a non-congested state of a truck loading over the bridge. The noncongested state (referred to as truck load), consists of the truck that is being located at the location of maximum moment and is magnified with a dynamic load allowance referred to as DLA as per equation 1.

In the case where the bridge span does not accommodate a full truck, a reduced version of the truck is used where some axles are removed. Few loading cases were considered of which axles to remove to obtain a maximized value for the moment per lane.

The second case to be considered is the congested state where a distributed load of $9 \mathrm{kN} / \mathrm{m}$ is assumed to be acting on the bridge in addition to $80 \%$ of the truck weight. Equation 2 represents the resulting moment for a loaded lane based on this loading case. The $9 \mathrm{kN} / \mathrm{m}$ load is only applied to locations where it would magnify the loading effect when determining the positive moment within the bridge span and the negative moment at the support.

Based on the above-mentioned loading cases, the maximum longitudinal moment generated by one lane of CL-W loading is considered the greatest values of all loading cases considered in girder analysis by equation 3 . 
A similar procedure is used to obtain the maximum longitudinal shear generated by one lane of CL-W loading, $\mathrm{V}_{\mathrm{T}}$, support reaction generated by one lane of CL-W loading, $\mathrm{R}_{\mathrm{T}}$, deflection generated by one lane of CL-W loading, $\Delta_{\mathrm{T}}$. The objective of this portion of the research was to develop finite-element (FE) models, using SAP2000 software (SAP2000, 2017), to obtain $\mathrm{M}_{\mathrm{T}}, \mathrm{V}_{\mathrm{T}}, \mathrm{R}_{\mathrm{T}}$ and, $\Delta_{\mathrm{T}}$ values for single span, two equal span, three equal span and, four equal span bridge configurations with span length between ranging from 12 to $48 \mathrm{~m}$. FE Models of girders were created for three truck types, namely: CL-625, CL-625-ONT and CL-800. The values obtained were tabulated and used to create mathematical models to provide a quick estimate of steel girder sizes at the bidding stage on projects. This falls in line with the ultimate goal of this research which is to create an easy-to-use estimation method to obtain design live load effects without the need to perform detailed calculations and modelling needed for bidding on the project and in the preliminary estimation of girder size in the final design.

\subsection{Sensitivity study: Influence line (IL) vs moving load method}

In order to select a method of analysis between IL and moving load on SAP2000 software, a short sensitivity study was conducted to compare the results from analysis by using both methods. For the case of IL, diagrams were utilized to assist in locating the truck axles over the bridge girder to maximize the moment, shear, reaction and deflection effects. Figures 3.1 through 3.6 show examples of the use of Influence Line diagrams in location CL-W axles in single span and multi-span bridge configurations of $30 \mathrm{~m}$ span length.
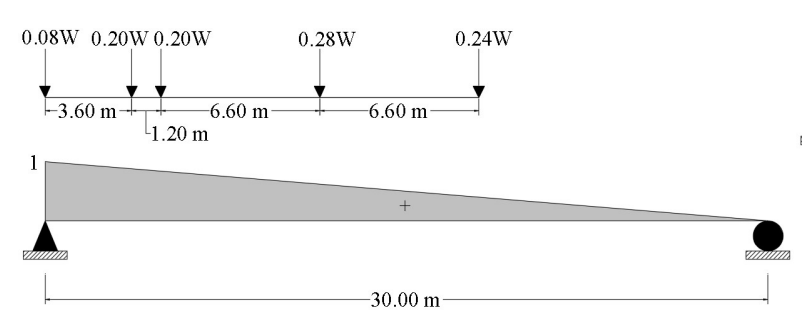

Figure 3.1: Shear and Reaction I.L. Diagram of a $30-\mathrm{m}$ single span bridge and associated CL-W truck axle locations*

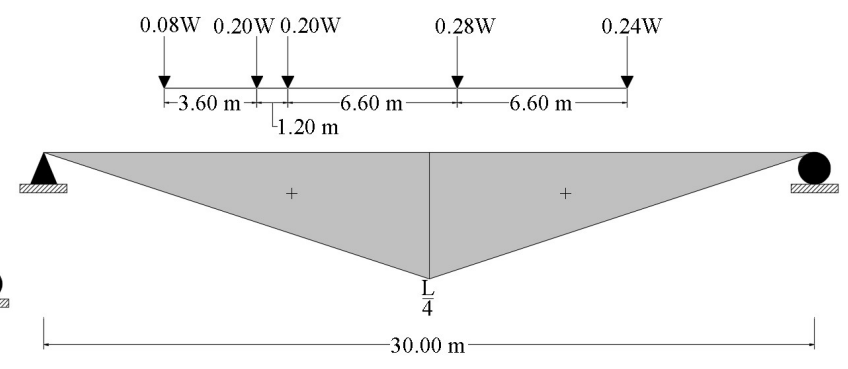

Figure 3.2: Moment I.L. Diagram of a 30-m single span bridge and associated CL-W truck axle locations* 


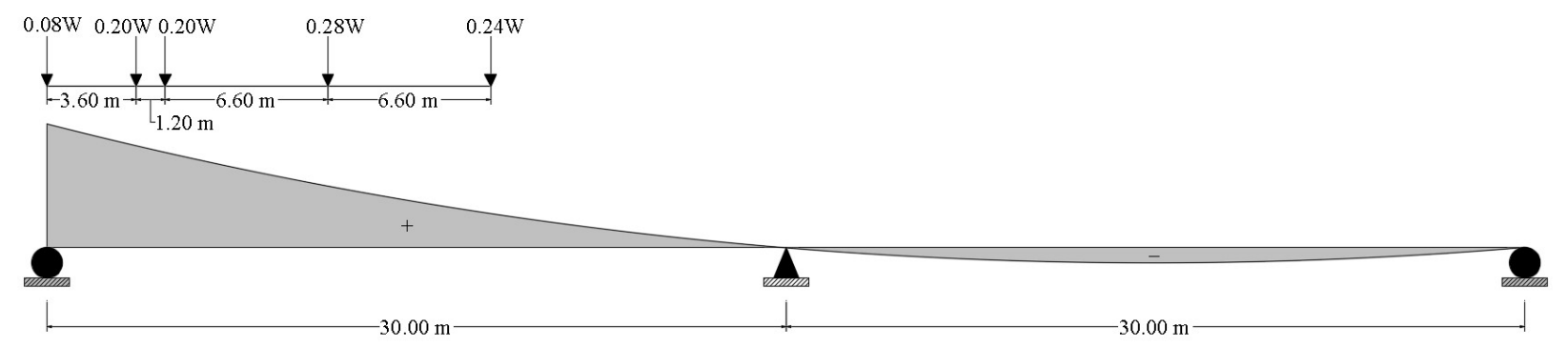

Figure 3.3: Exterior Reaction and Shear I.L. Diagram of a Two-Span bridge and associated CLW truck axle locations*

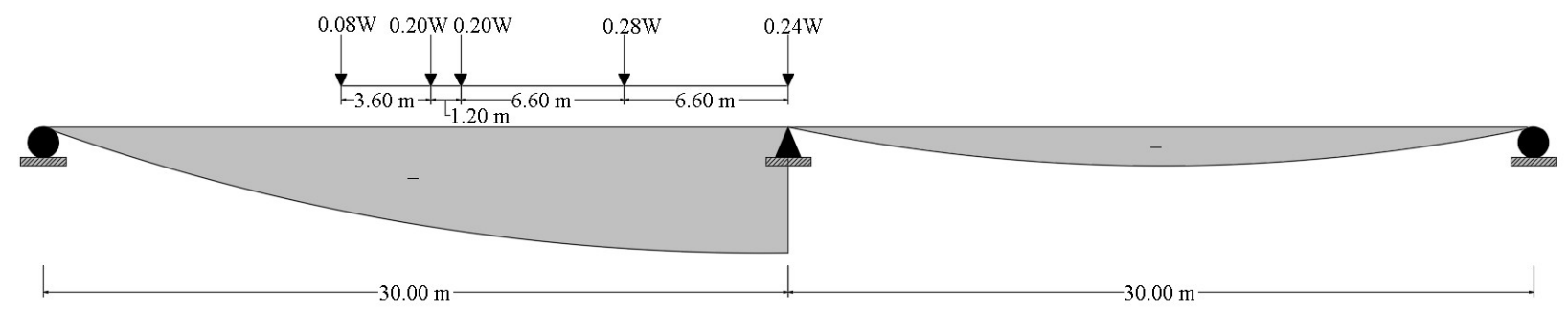

Figure 3.4: Interior Shear I.L. Diagram of a Two-Span bridge and associated CL-W truck axle locations*

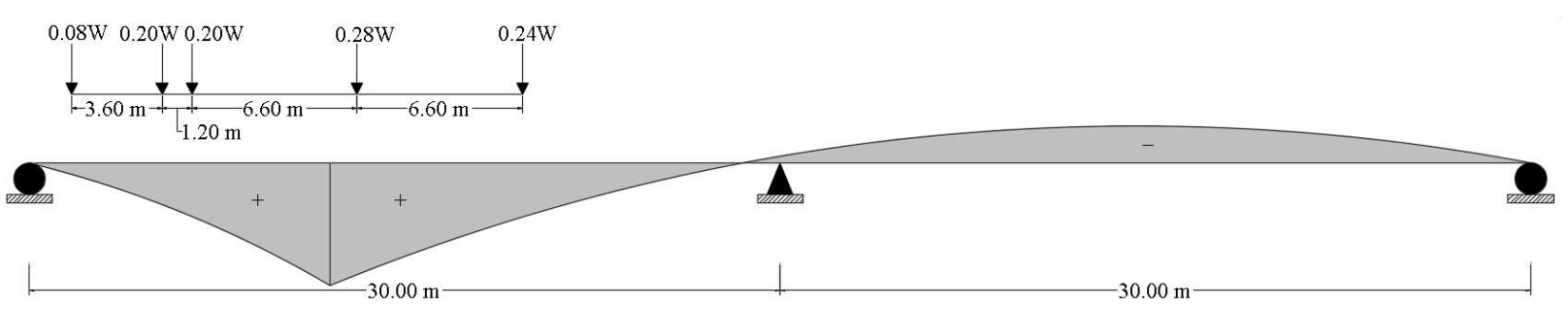

Figure 3.5: Maximum Positive Moment I.L. Diagram of a Two-Span bridge and associated CLW truck axle locations*

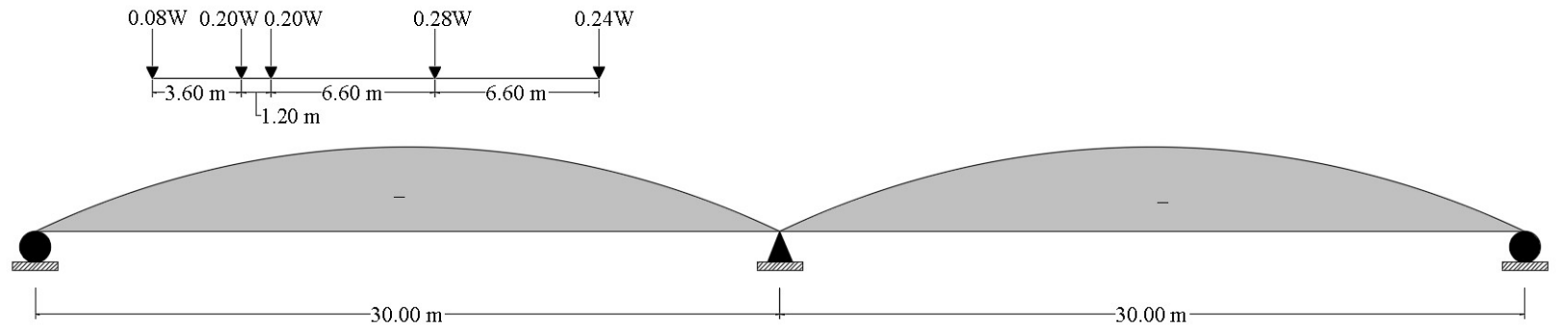

Figure 3.6: Maximum Negative Moment I.L. Diagram of a Two-Span bridge and associated CLW truck axle locations*

*All truck loadings were placed one time facing right side direction of traffic and another time facing left side direction of traffic 
SAP2000 Software was used in conjunction with equations 1 through 4 to obtain accurate results for maximum moment and shear values due to live load per lane. As for the case of moving load, the truck loading was programmed as a moving load into SAP2000 software. A very small increment of movement was selected of $0.1 \mathrm{~m}$. This leads the software to measure the effect of the truck once then move it by $0.1 \mathrm{~m}$ and calculate the results again. This process is repeated throughout the entire lane of loading and an envelope is produced by the software. An example of the comparison of the results due to IL and moving load can be seen in Table 3.1.

Table 3.1: Comparison between moment produced by IL method and moving load method for a three equal span bridge between $25 \mathrm{~m}$ and $50 \mathrm{~m}$ under CL-625 truck loading

\begin{tabular}{|l|l|l|l|}
\hline Span Length (m) & Moment IL (kN.m) & Moment moving load (kN.m) & Difference (\%) \\
\hline 25 & 1885 & 1998 & 5.81 \\
\hline 30 & 2627 & 2724 & 3.60 \\
\hline 35 & 3430 & 3494 & 1.84 \\
\hline 40 & 4278 & 4322 & 1.02 \\
\hline 50 & 6114 & 6139 & 0.41 \\
\hline
\end{tabular}

Upon analyzing the results obtained from the comparison, it was clear that moving load method produces a more critical value due to the fact that the measurement increment is very small. For instance, at $25 \mathrm{~m}$, the moment produced by the moving load method was $5.8 \%$ higher than that produced by IL method. At $50 \mathrm{~m}$, the moment produced by the moving load method was $0.4 \%$ higher than that produced by IL method. In no case was the moment produced by IL method higher than that of moving load method. This is because truck placement using IL method is only an estimate and not very close to the exact solution while in the case of moving load, it approaches the exact solution due to the low increment value of $0.1 \mathrm{~m}$ set by the author. In conclusion, moving load method was selected to conduct the parametric study due to the higher accuracy provided by the low measurement increment. 


\subsection{Results from finite element modelling}

Models were created for the bridge lengths ranging from 12 to $48 \mathrm{~m}$ at 2 meter increments. The results for the CL-625, CL-625-ONT, CL-800 truck loading cases for single span bridge configurations are listed in Tables 3.2 through 3.4 respectively. In these tables, $\mathrm{V}_{\text {truck }}$ and $\mathrm{M}_{\text {truck }}$ are the maximum shear and moment due to truck axle weights without the DLA factor and $\mathrm{V}_{\text {lane }}$ and $\mathrm{M}_{\text {lane }}$ are the values for shear and moment due to uniform loading of $9 \mathrm{kN} / \mathrm{m}$ and $80 \%$ of the truck loading without DLA factor.

Table 3.2: Maximum live load shear, moment, reaction and deflection generated by one lane of CL-625 truck loading for single span bridge girders obtained SAP2000 software

\begin{tabular}{|c|c|c|c|c|c|c|c|}
\hline $\begin{array}{l}\text { Span } \\
\text { length (m) }\end{array}$ & $\begin{array}{l}V_{\text {truck }} \\
(\mathbf{k N})\end{array}$ & $\begin{array}{l}\text { Mtruck } \\
\text { (kN.m) }\end{array}$ & Vlane & $\begin{array}{l}\text { Mlane } \\
\text { (kN.m) }\end{array}$ & $\begin{array}{l}\mathbf{R}_{\mathrm{T}} \& \mathbf{V}_{\mathrm{T}} \\
(\mathbf{k N})\end{array}$ & $\begin{array}{l}\mathbf{M}_{\mathrm{T}} \\
(\mathrm{kN} . \mathrm{m})\end{array}$ & $\begin{array}{l}\Delta \mathrm{T} \times \mathrm{EI} \\
\left(\mathrm{kN} \cdot \mathbf{m}^{3}\right)\end{array}$ \\
\hline 12 & 275 & 738 & 274 & 752 & 344 & 959 & 13135 \\
\hline 14 & 306 & 900 & 308 & 941 & 383 & 1125 & 21743 \\
\hline 16 & 344 & 1125 & 347 & 1188 & 430 & 1406 & 36458 \\
\hline 18 & 369 & 1363 & 376 & 1455 & 461 & 1703 & 56057 \\
\hline 20 & 394 & 1600 & 405 & 1730 & 492 & 2000 & 81153 \\
\hline 22 & 406 & 1838 & 424 & 2015 & 508 & 2297 & 115770 \\
\hline 24 & 419 & 2113 & 443 & 2338 & 523 & 2641 & 161497 \\
\hline 26 & 431 & 2413 & 462 & 2691 & 539 & 3016 & 216860 \\
\hline 28 & 444 & 2713 & 481 & 3052 & 555 & 3391 & 282659 \\
\hline 30 & 450 & 3013 & 495 & 3423 & 563 & 3766 & 359719 \\
\hline 32 & 463 & 3344 & 514 & 3827 & 578 & 4180 & 448772 \\
\hline 34 & 469 & 3631 & 528 & 4206 & 586 & 4539 & 550691 \\
\hline 36 & 475 & 3944 & 542 & 4613 & 594 & 4930 & 666240 \\
\hline 38 & 481 & 4275 & 556 & 5045 & 602 & 5344 & 796248 \\
\hline 40 & 488 & 4569 & 570 & 5455 & 609 & 5711 & 941495 \\
\hline 44 & 500 & 5213 & 598 & 6348 & 625 & 6516 & 1280999 \\
\hline 48 & 513 & 5819 & 626 & 7247 & 641 & 7273 & 1721518 \\
\hline
\end{tabular}


Table 3.3: Maximum live load shear, moment, reaction and deflection generated by one lane of CL-625-ONT truck loading for single span bridge girders obtained using SAP2000 software

\begin{tabular}{|l|l|l|l|}
\hline Span length (m) & $\mathbf{R}_{\mathbf{T}} \boldsymbol{\&} \mathbf{V}_{\mathbf{T}}(\mathbf{k N})$ & $\left.\mathbf{M}_{\mathbf{T}} \mathbf{( k N} \cdot \mathbf{m}\right)$ & $\left.\Delta_{\mathbf{T}} \mathbf{X} \mathbf{E I} \mathbf{~ ( k N . m ~}^{\mathbf{3}}\right)$ \\
\hline 12 & 409 & 1061 & 14547 \\
\hline 14 & 432 & 1275 & 23497 \\
\hline 16 & 464 & 1500 & 36866 \\
\hline 18 & 492 & 1781 & 55501 \\
\hline 20 & 515 & 2062 & 82644 \\
\hline 22 & 533 & 2449 & 119780 \\
\hline 24 & 549 & 2824 & 165964 \\
\hline 26 & 562 & 3199 & 221466 \\
\hline 28 & 573 & 3574 & 287568 \\
\hline 30 & 583 & 3949 & 364608 \\
\hline 32 & 591 & 4364 & 453734 \\
\hline 34 & 599 & 4732 & 556770 \\
\hline 36 & 605 & 5112 & 672634 \\
\hline 38 & 611 & 5523 & 801327 \\
\hline 40 & 617 & 5894 & 948791 \\
\hline 44 & 630 & 6686 & 1287606 \\
\hline 48 & 642 & 7444 & 1699613 \\
\hline
\end{tabular}

Table 3.4: Maximum live load shear, moment, reaction and deflection generated by one lane of CL-800 truck loading for single span bridge girders obtained using SAP2000 software

\begin{tabular}{|l|l|l|l|}
\hline Span length (m) & RT \& VT (kN) & MT (kN.m) & $\Delta$ T x EI (kN.m3) \\
\hline 12 & 478 & 1223 & 16880 \\
\hline 14 & 507 & 1473 & 27683 \\
\hline 16 & 552 & 1805 & 46454 \\
\hline 18 & 593 & 2210 & 71436 \\
\hline 20 & 626 & 2587 & 103576 \\
\hline 22 & 653 & 2965 & 148004 \\
\hline 24 & 675 & 3379 & 206476 \\
\hline 26 & 694 & 3864 & 277237 \\
\hline 28 & 710 & 4355 & 361502 \\
\hline 30 & 724 & 4852 & 460081 \\
\hline 32 & 736 & 5350 & 574055 \\
\hline 34 & 747 & 5847 & 704369 \\
\hline 36 & 757 & 6345 & 852305 \\
\hline 38 & 768 & 6844 & 1018742 \\
\hline 40 & 780 & 7342 & 1204557 \\
\hline 44 & 800 & 8339 & 1638980 \\
\hline 48 & 816 & 9337 & 2163881 \\
\hline
\end{tabular}


Tables 3.5 through 3.7 summarize positive and negative moments, exterior and interior shear forces, deflection and support reactions generated by one lane of loading in two-equal-span girder bridges for CL-625, CL-625-ONT, CL-800 truck loading cases respectively. Similarly, Tables 3.8 through 3.10 summarize positive and negative moments, exterior and interior shear forces, deflection and support reactions generated by one lane of loading in three-equal-span girder bridges for CL-625, CL-625-ONT, CL-800 truck loading cases respectively. Finally, Tables 3.11 through 3.13 summarize positive and negative moments, exterior and interior shear forces, deflection and support reactions generated by one lane of loading in four-equal-span girder bridges for CL-625, CL-625-ONT, CL-800 truck loading cases respectively. Within tables 3.11 through 3.13, $\mathrm{R}_{\text {Text }}, \mathrm{V}_{\text {Text and, }} \mathrm{M}_{\text {Text }}$ represent the reaction, shear and moment at the exteriormost support within a certain bridge span. Similarly, $\mathrm{R}_{\text {Tint }}, \mathrm{V}_{\text {Tint and }}, \mathrm{M}_{\text {Tint }}$ represent the reaction, shear and moment at the interior-most support within a certain bridge span.

Table 3.5: Maximum live load shear, moments, reactions and deflection generated by one lane of CL-625 truck loading for two equal span bridge girders obtained using SAP2000 software

\begin{tabular}{|c|c|c|c|c|c|c|}
\hline $\begin{array}{l}\text { Span length } \\
\text { (m) }\end{array}$ & $\begin{array}{l}R_{T} \& V_{T} \\
\text { exterior } \\
(k N)\end{array}$ & $\begin{array}{l}R_{T} \text { interior } \\
(\mathbf{k N})\end{array}$ & $\begin{array}{l}V_{T} \text { interior } \\
(k N)\end{array}$ & $\begin{array}{l}\mathbf{M}_{\mathrm{T}+} \\
(\mathbf{k N} \cdot \mathbf{m})\end{array}$ & $\begin{array}{l}\mathbf{M}_{\mathrm{T}-} \\
(\mathbf{k N} . \mathbf{m})\end{array}$ & $\begin{array}{l}\Delta_{\mathrm{T}} \mathbf{x} \mathrm{EI} \\
\left(\mathbf{k N} \cdot \mathbf{m}^{3}\right)\end{array}$ \\
\hline 12 & 350 & 542 & 350 & 402 & 770 & 915218 \\
\hline 14 & 372 & 597 & 372 & 431 & 930 & 1518356 \\
\hline 16 & 401 & 636 & 401 & 467 & 1114 & 2526209 \\
\hline 18 & 429 & 663 & 429 & 503 & 1337 & 3877090 \\
\hline 20 & 453 & 684 & 453 & 530 & 1619 & 5657997 \\
\hline 22 & 474 & 700 & 474 & 552 & 1861 & 8123156 \\
\hline 24 & 492 & 725 & 492 & 570 & 2149 & 11258648 \\
\hline 26 & 507 & 754 & 507 & 585 & 2398 & 15170364 \\
\hline 28 & 521 & 781 & 521 & 597 & 2734 & 19820594 \\
\hline 30 & 534 & 808 & 534 & 608 & 3036 & 25225743 \\
\hline 32 & 544 & 834 & 544 & 618 & 3329 & 31634205 \\
\hline 34 & 554 & 859 & 554 & 630 & 3633 & 38823333 \\
\hline 36 & 563 & 884 & 563 & 641 & 3943 & 47025738 \\
\hline 38 & 571 & 909 & 571 & 650 & 4266 & 56413866 \\
\hline 40 & 578 & 933 & 578 & 658 & 4548 & 66680773 \\
\hline 44 & 590 & 981 & 590 & 678 & 5206 & 91062971 \\
\hline 48 & 605 & 1028 & 605 & 707 & 5816 & 121626090 \\
\hline
\end{tabular}


Table 3.6: Maximum live load shear, moments, reactions and deflection generated by one lane of CL-625-ONT truck loading for two equal span bridge girders obtained using SAP2000 software

\begin{tabular}{|l|l|l|l|l|l|l|}
\hline $\begin{array}{l}\text { Span length } \\
(\mathbf{m})\end{array}$ & $\begin{array}{l}\mathbf{R}_{\mathbf{T}} \& \mathbf{V}_{\mathbf{T}} \\
\mathbf{e x t e r i o r} \\
(\mathbf{k N})\end{array}$ & $\begin{array}{l}\mathbf{R}_{\mathbf{T}} \text { interior } \\
(\mathbf{k N})\end{array}$ & $\begin{array}{l}\mathbf{V}_{\mathbf{T}} \text { interior } \\
(\mathbf{k N})\end{array}$ & $\begin{array}{l}\mathbf{M}_{\mathbf{T}+} \\
(\mathbf{k N . m})\end{array}$ & $\begin{array}{l}\mathbf{M}_{\mathbf{T}} \\
(\mathbf{k N . m})\end{array}$ & $\begin{array}{l}\Delta_{\mathbf{T}} \mathbf{X} \text { EI } \\
\left(\mathbf{k N} \cdot \mathbf{m}^{\mathbf{3}}\right)\end{array}$ \\
\hline 12 & 385 & 560 & 385 & 408 & 717 & 10200 \\
\hline 14 & 408 & 611 & 408 & 448 & 860 & 16650 \\
\hline 16 & 435 & 647 & 435 & 498 & 983 & 27548 \\
\hline 18 & 460 & 673 & 460 & 529 & 1071 & 42024 \\
\hline 20 & 482 & 692 & 482 & 553 & 1190 & 61308 \\
\hline 22 & 500 & 707 & 500 & 573 & 1361 & 85750 \\
\hline 24 & 517 & 728 & 517 & 588 & 1533 & 118160 \\
\hline 26 & 531 & 759 & 531 & 601 & 1734 & 157322 \\
\hline 28 & 543 & 784 & 543 & 612 & 1970 & 205139 \\
\hline 30 & 554 & 810 & 554 & 621 & 2209 & 259682 \\
\hline 32 & 564 & 836 & 564 & 629 & 2460 & 323961 \\
\hline 34 & 572 & 861 & 572 & 637 & 2716 & 396883 \\
\hline 36 & 580 & 886 & 580 & 647 & 2979 & 480067 \\
\hline 38 & 587 & 910 & 587 & 655 & 3253 & 574190 \\
\hline 40 & 594 & 934 & 594 & 663 & 3533 & 679251 \\
\hline 44 & 605 & 982 & 605 & 680 & 4119 & 923809 \\
\hline 48 & 614 & 1029 & 614 & 710 & 4738 & 1219816 \\
\hline
\end{tabular}

Table 3.7: Maximum live load shear, moments, reactions and deflection generated by one lane of CL-800 truck loading for two equal span bridge girders obtained using SAP2000 software

\begin{tabular}{|c|c|c|c|c|c|c|}
\hline $\begin{array}{l}\text { Span length } \\
\text { (m) }\end{array}$ & $\begin{array}{l}\mathbf{R}_{\mathrm{T}} \& \mathbf{V}_{\mathrm{T}} \\
\text { exterior } \\
(\mathbf{k N})\end{array}$ & $\begin{array}{l}R_{T} \text { interior } \\
(\mathbf{k N})\end{array}$ & $\begin{array}{l}V_{T} \text { interior } \\
(k N)\end{array}$ & $\begin{array}{l}\mathbf{M}_{\mathbf{T}+} \\
(\mathbf{k N} \cdot \mathbf{m})\end{array}$ & $\begin{array}{l}M_{T-} \\
(k N . m)\end{array}$ & $\begin{array}{l}\Delta_{\mathrm{T}} \mathbf{X} \mathbf{E I} \\
\left(\mathbf{k N} \cdot \mathbf{m}^{3}\right)\end{array}$ \\
\hline 12 & 447 & 696 & 515 & 987 & 920 & 12073 \\
\hline 14 & 476 & 768 & 552 & 1193 & 1118 & 19839 \\
\hline 16 & 513 & 818 & 597 & 1466 & 1280 & 32950 \\
\hline 18 & 548 & 853 & 643 & 1760 & 1414 & 50803 \\
\hline 20 & 579 & 879 & 679 & 2065 & 1527 & 73717 \\
\hline 22 & 606 & 899 & 707 & 2370 & 1637 & 105061 \\
\hline 24 & 629 & 914 & 730 & 2740 & 1775 & 146233 \\
\hline 26 & 649 & 926 & 749 & 3116 & 1995 & 196618 \\
\hline 28 & 667 & 936 & 765 & 3495 & 2262 & 256576 \\
\hline 30 & 683 & 944 & 778 & 3878 & 2536 & 327067 \\
\hline 32 & 697 & 968 & 791 & 4267 & 2818 & 408631 \\
\hline 34 & 709 & 994 & 806 & 4663 & 3106 & 502079 \\
\hline 36 & 720 & 1019 & 820 & 5060 & 3401 & 608285 \\
\hline 38 & 730 & 1044 & 832 & 5457 & 3704 & 727731 \\
\hline 40 & 740 & 1069 & 842 & 5855 & 4015 & 861447 \\
\hline 44 & 755 & 1118 & 860 & 6654 & 4661 & 1173363 \\
\hline 48 & 774 & 1165 & 875 & 7466 & 5339 & 1553095 \\
\hline
\end{tabular}


Table 3.8: Maximum live load shear, moments, reactions and deflection generated by one lane of CL-625 truck loading for three equal span bridge girders obtained using SAP2000 software

\begin{tabular}{|c|c|c|c|c|c|c|c|c|c|}
\hline \multirow{2}{*}{$\begin{array}{l}\text { Span length } \\
\text { (m) }\end{array}$} & \multicolumn{4}{|c|}{ Exterior span } & \multicolumn{5}{|c|}{ Interior span } \\
\hline & $\begin{array}{l}\mathbf{R}_{\mathrm{T}} \\
(\mathrm{kN})\end{array}$ & $\begin{array}{l}\mathbf{V}_{\mathrm{T}} \\
(\mathrm{kN})\end{array}$ & $\begin{array}{l}M_{\mathrm{T}+} \\
(\mathrm{kN} . \mathrm{m})\end{array}$ & $\begin{array}{l}\Delta_{\mathrm{T}} \mathbf{x} \mathbf{E I} \\
\left(\mathbf{k N} \cdot \mathbf{m}^{3}\right)\end{array}$ & $\begin{array}{l}R_{T} \\
(k N)\end{array}$ & $\begin{array}{l}\mathbf{V}_{\mathrm{T}} \\
(\mathrm{kN})\end{array}$ & $\begin{array}{l}M_{\mathrm{T}+} \\
(\mathrm{kN} \cdot \mathrm{m})\end{array}$ & $\begin{array}{l}\text { M }_{\mathrm{T}-} \\
\text { (kN.m) }\end{array}$ & $\begin{array}{l}\Delta_{\mathrm{T}} \times \mathrm{EI} \\
\left(\mathrm{kN} \cdot \mathrm{m}^{3}\right)\end{array}$ \\
\hline 12 & 347 & 403 & 760 & 9252 & 347 & 415 & 632 & 686 & 7141 \\
\hline 14 & 370 & 430 & 919 & 15103 & 370 & 440 & 765 & 833 & 11630 \\
\hline 16 & 398 & 468 & 1131 & 25154 & 398 & 471 & 913 & 961 & 19051 \\
\hline 18 & 426 & 504 & 1358 & 38684 & 426 & 499 & 1097 & 1071 & 29436 \\
\hline 20 & 450 & 533 & 1588 & 56116 & 450 & 523 & 1286 & 1203 & 42870 \\
\hline 22 & 471 & 555 & 1827 & 79883 & 471 & 543 & 1479 & 1354 & 60208 \\
\hline 24 & 489 & 573 & 2108 & 111357 & 489 & 559 & 1673 & 1521 & 84215 \\
\hline 26 & 505 & 587 & 2396 & 149624 & 505 & 574 & 1894 & 1740 & 113559 \\
\hline 28 & 519 & 600 & 2688 & 195284 & 519 & 586 & 2131 & 1975 & 148651 \\
\hline 30 & 531 & 610 & 2986 & 248899 & 531 & 596 & 2373 & 2216 & 189930 \\
\hline 32 & 542 & 621 & 3285 & 310639 & 542 & 605 & 2618 & 2464 & 237831 \\
\hline 34 & 552 & 633 & 3587 & 382269 & 552 & 613 & 2866 & 2719 & 292798 \\
\hline 36 & 561 & 644 & 3892 & 463072 & 561 & 620 & 3117 & 2981 & 355270 \\
\hline 38 & 569 & 653 & 4197 & 554230 & 569 & 626 & 3370 & 3250 & 425822 \\
\hline 40 & 576 & 661 & 4505 & 655918 & 576 & 632 & 3625 & 3527 & 504505 \\
\hline 44 & 589 & 676 & 5123 & 916090 & 589 & 647 & 4145 & 4103 & 689073 \\
\hline 48 & 603 & 706 & 5760 & 1243872 & 603 & 673 & 4673 & 4709 & 916630 \\
\hline
\end{tabular}

Table 3.9: Maximum live load shear, moments, reactions and deflection generated by one lane of CL-625-ONT truck loading for three equal span bridge girders obtained using SAP2000 software

\begin{tabular}{|c|c|c|c|c|c|c|c|c|c|}
\hline \multirow{2}{*}{$\begin{array}{l}\text { Span length } \\
\text { (m) }\end{array}$} & \multicolumn{4}{|c|}{ Exterior span } & \multicolumn{5}{|c|}{ Interior span } \\
\hline & $\begin{array}{l}\mathbf{R}_{\mathrm{T}} \\
(\mathrm{kN})\end{array}$ & $\begin{array}{l}\mathbf{V}_{\mathrm{T}} \\
(\mathrm{kN})\end{array}$ & $\begin{array}{l}\mathbf{M}_{\mathrm{T}+} \\
\text { (kN.m) }\end{array}$ & $\begin{array}{l}\Delta_{\mathrm{T}} \mathbf{x} \mathbf{E I} \\
\left(\mathbf{k N} \cdot \mathbf{m}^{3}\right)\end{array}$ & $\begin{array}{l}R_{T} \\
(k N)\end{array}$ & $\begin{array}{l}\mathbf{V}_{\mathrm{T}} \\
(\mathbf{k N})\end{array}$ & $\begin{array}{l}\mathbf{M}_{\mathbf{T}+} \\
\text { (kN.m) }\end{array}$ & $\begin{array}{l}M_{T-} \\
\text { (kN.m) }\end{array}$ & $\begin{array}{l}\Delta_{\mathrm{T}} \mathbf{x} \mathbf{E I} \\
\left(\mathbf{k N} \cdot \mathrm{m}^{3}\right)\end{array}$ \\
\hline 12 & 384 & 410 & 844 & 10204 & 550 & 415 & 704 & 712 & 7901 \\
\hline 14 & 406 & 449 & 1019 & 16576 & 601 & 440 & 850 & 851 & 12844 \\
\hline 16 & 432 & 500 & 1238 & 27278 & 638 & 471 & 1003 & 968 & 20726 \\
\hline 18 & 457 & 532 & 1480 & 41727 & 665 & 499 & 1200 & 1087 & 31815 \\
\hline 20 & 479 & 556 & 1730 & 60363 & 686 & 523 & 1402 & 1230 & 46146 \\
\hline 22 & 498 & 576 & 1980 & 84265 & 702 & 543 & 1608 & 1377 & 64009 \\
\hline 24 & 514 & 591 & 2265 & 115999 & 716 & 559 & 1816 & 1551 & 87822 \\
\hline 26 & 529 & 604 & 2560 & 154715 & 744 & 574 & 2050 & 1767 & 117485 \\
\hline 28 & 541 & 615 & 2857 & 196888 & 771 & 586 & 2289 & 2001 & 152865 \\
\hline 30 & 552 & 624 & 3156 & 254820 & 797 & 596 & 2535 & 2240 & 194522 \\
\hline 32 & 562 & 631 & 3456 & 317209 & 822 & 605 & 2784 & 2487 & 242802 \\
\hline 34 & 571 & 640 & 3763 & 388915 & 846 & 613 & 3036 & 2740 & 298168 \\
\hline 36 & 578 & 650 & 4072 & 470209 & 870 & 620 & 3290 & 3001 & 360962 \\
\hline 38 & 586 & 659 & 4381 & 561915 & 894 & 626 & 3546 & 3269 & 431723 \\
\hline 40 & 592 & 667 & 4690 & 664262 & 917 & 632 & 3804 & 3544 & 510991 \\
\hline 44 & 603 & 680 & 5309 & 903553 & 964 & 647 & 4324 & 4118 & 696266 \\
\hline 48 & 613 & 708 & 5937 & 1192673 & 1009 & 673 & 4848 & 4724 & 920433 \\
\hline
\end{tabular}


Table 3.10: Maximum live load shear, moments, reactions and deflection generated by one lane of CL-800 truck loading for three equal span bridge girders obtained using SAP2000 software

\begin{tabular}{|c|c|c|c|c|c|c|c|c|c|}
\hline \multirow{2}{*}{$\begin{array}{l}\text { Span } \\
\text { length (m) }\end{array}$} & \multicolumn{4}{|c|}{ Exterior span } & \multicolumn{5}{|c|}{ Interior span } \\
\hline & $\begin{array}{l}\mathbf{R}_{\mathrm{T}} \\
(\mathrm{kN})\end{array}$ & $\begin{array}{l}V_{T} \\
(k N)\end{array}$ & $\begin{array}{l}M_{\mathbf{T}+} \\
\text { (kN.m) }\end{array}$ & $\begin{array}{l}\Delta_{\mathrm{T}} \mathbf{x} \mathrm{EI} \\
\left(\mathrm{kN} \cdot \mathrm{m}^{3}\right)\end{array}$ & $\begin{array}{l}R_{T} \\
(k N)\end{array}$ & $\begin{array}{l}\mathbf{V}_{\mathrm{T}} \\
(\mathrm{kN})\end{array}$ & $\begin{array}{l}\mathbf{M}_{\mathbf{T}+} \\
\text { (kN.m) }\end{array}$ & $\begin{array}{l}M_{\text {T- }} \\
\text { (kN.m) }\end{array}$ & $\begin{array}{l}\Delta_{\mathrm{T}} \mathbf{x} \mathrm{EI} \\
\left(\mathrm{kN} \cdot \mathrm{m}^{3}\right)\end{array}$ \\
\hline 12 & 445 & 445 & 974 & 11775 & 674 & 486 & 810 & 875 & 9115 \\
\hline 14 & 474 & 474 & 1176 & 19324 & 747 & 517 & 979 & 1062 & 14854 \\
\hline 16 & 510 & 510 & 1442 & 32140 & 799 & 559 & 1163 & 1226 & 24361 \\
\hline 18 & 545 & 545 & 1734 & 49438 & 838 & 600 & 1399 & 1367 & 37541 \\
\hline 20 & 576 & 576 & 2034 & 71747 & 866 & 634 & 1641 & 1537 & 54759 \\
\hline 22 & 603 & 603 & 2336 & 102266 & 889 & 663 & 1887 & 1690 & 77013 \\
\hline 24 & 626 & 626 & 2700 & 142329 & 906 & 687 & 2137 & 1830 & 107762 \\
\hline 26 & 646 & 646 & 3068 & 191352 & 920 & 708 & 2424 & 2059 & 145168 \\
\hline 28 & 664 & 664 & 3440 & 249752 & 931 & 726 & 2727 & 2302 & 190136 \\
\hline 30 & 680 & 680 & 3815 & 318289 & 940 & 741 & 3036 & 2570 & 242937 \\
\hline 32 & 694 & 694 & 4203 & 397828 & 952 & 752 & 3349 & 2852 & 304110 \\
\hline 34 & 707 & 707 & 4590 & 488440 & 977 & 767 & 3642 & 3140 & 370415 \\
\hline 36 & 718 & 718 & 4982 & 592285 & 1003 & 776 & 3988 & 3433 & 454410 \\
\hline 38 & 728 & 728 & 5373 & 708756 & 1027 & 785 & 4312 & 3734 & 544481 \\
\hline 40 & 737 & 737 & 5764 & 839004 & 1051 & 798 & 4638 & 4043 & 645356 \\
\hline 44 & 753 & 753 & 6557 & 1144599 & 1099 & 820 & 5306 & 4681 & 881001 \\
\hline 48 & 771 & 771 & 7356 & 1513393 & 1145 & 838 & 5981 & 5349 & 1168096 \\
\hline
\end{tabular}

Table 3.11: Maximum live load shear, moments, reactions and deflection generated by one lane of CL-625 truck loading for four equal span bridge girders obtained using SAP2000 software

\begin{tabular}{|c|c|c|c|c|c|c|c|c|c|c|c|c|}
\hline \multirow[b]{2}{*}{$\begin{array}{l}\text { Span } \\
\text { length } \\
\text { (m) }\end{array}$} & \multicolumn{4}{|c|}{ Exterior span } & \multicolumn{8}{|c|}{ Interior span } \\
\hline & $\begin{array}{l}\mathrm{R}_{\mathrm{T}} \\
(\mathrm{kN})\end{array}$ & $\begin{array}{l}V_{T} \\
(k N)\end{array}$ & $\begin{array}{l}\mathbf{M}_{\mathrm{T}+} \\
(\mathbf{k N} \cdot \mathbf{m})\end{array}$ & $\begin{array}{l}\Delta \mathrm{T} \times \mathbf{x} \text { EI } \\
\left(\mathrm{kN} \cdot \mathrm{m}^{3}\right)\end{array}$ & $\begin{array}{l}\mathbf{R}_{\text {Text }} \\
(\mathbf{k N})\end{array}$ & $\begin{array}{l}R_{\text {Tint }} \\
(\mathbf{k N})\end{array}$ & $\begin{array}{l}V_{\text {Text }} \\
(\mathbf{k N})\end{array}$ & $\begin{array}{l}V_{\text {Tint }} \\
(\mathbf{k N})\end{array}$ & $\begin{array}{l}\mathbf{M}_{\mathbf{T}+} \\
\text { (kN.m) }\end{array}$ & $\begin{array}{l}\text { MT-ext } \\
\text { (kN.m) }\end{array}$ & $\begin{array}{l}\mathbf{M}_{\text {T-int }} \\
\text { (kN.m) }\end{array}$ & $\begin{array}{l}\Delta \mathrm{T} \times \mathbf{E I} \\
\left(\mathrm{kN} \cdot \mathbf{m}^{3}\right.\end{array}$ \\
\hline 12 & 347 & 403 & 760 & 9131 & 526 & 499 & 378 & 380 & 624 & 681 & 630 & 6971 \\
\hline 14 & 370 & 430 & 918 & 15045 & 583 & 558 & 402 & 405 & 755 & 827 & 776 & 11353 \\
\hline 16 & 398 & 468 & 1125 & 24784 & 624 & 601 & 435 & 438 & 895 & 955 & 901 & 18564 \\
\hline 18 & 426 & 504 & 1353 & 38245 & 654 & 633 & 466 & 470 & 1078 & 1070 & 1008 & 28699 \\
\hline 20 & 450 & 533 & 1587 & 55977 & 676 & 658 & 493 & 498 & 1265 & 1203 & 1098 & 41789 \\
\hline 22 & 471 & 555 & 1823 & 79760 & 694 & 677 & 515 & 520 & 1455 & 1371 & 1218 & 58748 \\
\hline 24 & 489 & 573 & 2107 & 110997 & 717 & 692 & 539 & 539 & 1647 & 1541 & 1357 & 82145 \\
\hline 26 & 505 & 588 & 2394 & 149233 & 746 & 718 & 551 & 556 & 1868 & 1766 & 1510 & 110744 \\
\hline 28 & 519 & 600 & 2684 & 194788 & 774 & 745 & 565 & 570 & 2100 & 2005 & 1695 & 144983 \\
\hline 30 & 531 & 610 & 2977 & 248297 & 800 & 770 & 577 & 581 & 2337 & 2252 & 1906 & 185268 \\
\hline 32 & 542 & 621 & 3280 & 310276 & 826 & 795 & 587 & 592 & 2578 & 2505 & 2125 & 232037 \\
\hline 34 & 552 & 634 & 3584 & 381329 & 851 & 819 & 596 & 601 & 2822 & 2765 & 2349 & 284366 \\
\hline 36 & 561 & 644 & 3888 & 461960 & 876 & 843 & 604 & 609 & 3069 & 3032 & 2581 & 346768 \\
\hline 38 & 569 & 653 & 4193 & 549579 & 900 & 866 & 612 & 618 & 3319 & 3307 & 2819 & 415579 \\
\hline 40 & 576 & 662 & 4498 & 654350 & 924 & 889 & 621 & 627 & 3571 & 3589 & 3065 & 492596 \\
\hline 44 & 588 & 678 & 5118 & 906290 & 972 & 934 & 647 & 644 & 4085 & 4178 & 3576 & 688727 \\
\hline 48 & 603 & 707 & 5740 & 1231011 & 1018 & 978 & 678 & 668 & 4614 & 4798 & 4117 & 935892 \\
\hline
\end{tabular}


Table 3.12: Maximum live load shear, moments, reactions and deflection generated by one lane of CL-625-ONT truck loading for four equal span bridge girders obtained using SAP2000 software

\begin{tabular}{|c|c|c|c|c|c|c|c|c|c|c|c|c|}
\hline \multirow[b]{2}{*}{$\begin{array}{l}\text { Span } \\
\text { length } \\
\text { (m) }\end{array}$} & \multicolumn{4}{|c|}{ Exterior span } & \multicolumn{8}{|c|}{ Interior span } \\
\hline & $\begin{array}{l}\mathbf{R}_{\mathrm{T}} \\
(\mathrm{kN})\end{array}$ & $\begin{array}{l}\mathbf{V}_{\mathrm{T}} \\
(\mathrm{kN})\end{array}$ & $\begin{array}{l}\mathbf{M}_{\mathrm{T}+} \\
(\mathbf{k N} \cdot \mathbf{m})\end{array}$ & $\begin{array}{l}\Delta \mathrm{T} \mathbf{x} \text { EI } \\
\left(\mathbf{k N} \cdot \mathbf{m}^{3}\right)\end{array}$ & $\begin{array}{l}\mathbf{R}_{\text {Text }} \\
(\mathbf{k N})\end{array}$ & $\begin{array}{l}\mathbf{R}_{\text {Tint }} \\
(\mathbf{k N})\end{array}$ & $\begin{array}{l}V_{\text {Text }} \\
(\mathbf{k N})\end{array}$ & $\begin{array}{l}\mathbf{V}_{\text {Tint }} \\
(\mathbf{k N})\end{array}$ & $\begin{array}{l}\mathbf{M}_{\mathrm{T}+} \\
(\mathrm{kN} . \mathrm{m})\end{array}$ & $\begin{array}{l}M_{\text {T-ext }} \\
\text { (kN.m) }\end{array}$ & $\begin{array}{l}M_{\text {T-int }} \\
(\mathrm{kN} . \mathrm{m})\end{array}$ & $\begin{array}{l}\Delta \mathrm{T} \times \mathbf{E I} \\
\left(\mathrm{kN} \cdot \mathrm{m}^{3}\right.\end{array}$ \\
\hline 12 & 383 & 410 & 844 & 10186 & 549 & 524 & 414 & 417 & 694 & 710 & 652 & 7727 \\
\hline 14 & 405 & 449 & 1018 & 16529 & 600 & 577 & 439 & 441 & 838 & 849 & 789 & 12561 \\
\hline 16 & 432 & 500 & 1237 & 27238 & 637 & 616 & 469 & 472 & 989 & 966 & 906 & 20253 \\
\hline 18 & 457 & 532 & 1478 & 41652 & 665 & 645 & 497 & 501 & 1183 & 1089 & 1005 & 31059 \\
\hline 20 & 479 & 556 & 1728 & 60282 & 685 & 668 & 520 & 525 & 1382 & 1233 & 1090 & 45063 \\
\hline 22 & 498 & 576 & 1978 & 84130 & 701 & 685 & 540 & 545 & 1585 & 1397 & 1216 & 62524 \\
\hline 24 & 514 & 591 & 2263 & 115864 & 721 & 699 & 557 & 562 & 1791 & 1574 & 1373 & 85885 \\
\hline 26 & 528 & 604 & 2557 & 154486 & 750 & 722 & 572 & 576 & 2019 & 1796 & 1532 & 114784 \\
\hline 28 & 541 & 615 & 2854 & 200399 & 777 & 748 & 584 & 588 & 2257 & 2033 & 1721 & 149354 \\
\hline 30 & 552 & 624 & 3152 & 254280 & 803 & 773 & 594 & 599 & 2499 & 2277 & 1931 & 189866 \\
\hline 32 & 562 & 632 & 3452 & 316669 & 829 & 798 & 604 & 608 & 2744 & 2528 & 2148 & 237130 \\
\hline 34 & 571 & 641 & 3759 & 388240 & 853 & 822 & 612 & 616 & 2993 & 2787 & 2371 & 291146 \\
\hline 36 & 578 & 651 & 4067 & 469399 & 878 & 845 & 619 & 622 & 3243 & 3053 & 2602 & 352589 \\
\hline 38 & 585 & 659 & 4376 & 560821 & 902 & 868 & 625 & 629 & 3496 & 3327 & 2839 & 421865 \\
\hline 40 & 592 & 667 & 4685 & 663046 & 926 & 891 & 630 & 635 & 3750 & 3608 & 3083 & 499243 \\
\hline 44 & 603 & 681 & 5303 & 901932 & 973 & 935 & 651 & 650 & 4263 & 4195 & 3593 & 680332 \\
\hline 48 & 612 & 710 & 5931 & 1190513 & 1019 & 979 & 681 & 671 & 4780 & 4814 & 4132 & 899501 \\
\hline
\end{tabular}

Table 3.13: Maximum live load shear, moments, reactions and deflection generated by one lane of CL-800 truck loading for four equal span bridge girders obtained using SAP2000 software

\begin{tabular}{|c|c|c|c|c|c|c|c|c|c|c|c|c|}
\hline \multirow{2}{*}{$\begin{array}{l}\text { Span } \\
\text { length } \\
\text { (m) }\end{array}$} & \multicolumn{4}{|c|}{ Exterior span } & \multicolumn{8}{|c|}{ Interior span } \\
\hline & $\begin{array}{l}R_{\mathrm{T}} \\
(\mathrm{kN})\end{array}$ & $\begin{array}{l}\mathbf{V}_{\mathrm{T}} \\
(\mathrm{kN})\end{array}$ & $\begin{array}{l}M_{\mathrm{T}+} \\
(\mathrm{kN} . \mathrm{m})\end{array}$ & $\begin{array}{l}\Delta_{\mathrm{T}} \mathbf{x} \text { EI } \\
\left(\mathrm{kN} \cdot \mathrm{m}^{3}\right)\end{array}$ & $\begin{array}{l}R_{\text {Text }} \\
(\mathbf{k N})\end{array}$ & $\begin{array}{l}R_{\text {Tint }} \\
(\mathbf{k N})\end{array}$ & $\begin{array}{l}V_{\text {Tex }} \\
(k N)\end{array}$ & $\begin{array}{l}V_{\text {Tint }} \\
(k N)\end{array}$ & $\begin{array}{l}M_{\mathrm{T}+} \\
(\mathrm{kN} . \mathrm{m})\end{array}$ & $\begin{array}{l}M_{\text {T-ext }} \\
\text { (kN.m) }\end{array}$ & $\begin{array}{l}M_{\text {T-int }} \\
\text { (kN.m) }\end{array}$ & $\begin{array}{l}\Delta_{\mathrm{T}} \mathbf{x} \text { EI } \\
\left(\mathrm{kN} \cdot \mathrm{m}^{3}\right)\end{array}$ \\
\hline 12 & 445 & 516 & 973 & 11750 & 673 & 639 & 484 & 484 & 799 & 871 & 807 & 8919 \\
\hline 14 & 474 & 550 & 1175 & 19311 & 746 & 714 & 515 & 515 & 966 & 1058 & 993 & 14584 \\
\hline 16 & 510 & 599 & 1440 & 32018 & 798 & 770 & 557 & 557 & 1146 & 1223 & 1153 & 23798 \\
\hline 18 & 545 & 646 & 1732 & 49290 & 837 & 811 & 597 & 597 & 1379 & 1369 & 1289 & 36731 \\
\hline 20 & 576 & 682 & 2032 & \begin{tabular}{|l|}
71639 \\
\end{tabular} & 866 & 842 & 631 & 631 & 1619 & 1540 & 1405 & 53476 \\
\hline 22 & 603 & 710 & 2334 & 101955 & 888 & 866 & 660 & 660 & 1862 & 1694 & 1505 & 74947 \\
\hline 24 & 626 & 733 & 2697 & 142062 & 906 & 886 & 684 & 684 & 2108 & 1835 & 1605 & 105061 \\
\hline 26 & 646 & 746 & 3064 & 190690 & 920 & 901 & 705 & 705 & 2391 & 2068 & 1750 & 141657 \\
\hline 28 & 664 & 768 & 3436 & 249284 & 931 & 914 & 723 & 723 & 2688 & 2329 & 1958 & 185545 \\
\hline 30 & 680 & 781 & 3811 & 317749 & 940 & 924 & 738 & 738 & 2991 & 2609 & 2197 & 237130 \\
\hline 32 & 694 & 795 & 4199 & 397018 & 959 & 932 & 752 & 752 & 3299 & 2895 & 2443 & 296953 \\
\hline 34 & 707 & 811 & 4587 & 488035 & 985 & 951 & 763 & 763 & 3612 & 3188 & 2696 & 365688 \\
\hline 36 & 718 & 825 & 4977 & 591070 & 1010 & 975 & 774 & 774 & 3928 & 3488 & 2954 & 443741 \\
\hline 38 & 728 & 836 & 5367 & 707340 & 1035 & 999 & 783 & 783 & 4248 & 3794 & 3219 & 531788 \\
\hline 40 & 737 & 847 & 5758 & \begin{tabular}{|l|}
837788 \\
\end{tabular} & 1060 & 1023 & 795 & 795 & 4571 & 4109 & 3491 & 630367 \\
\hline 44 & 753 & 865 & 6550 & 1142438 & 1108 & 1069 & 817 & 817 & 5229 & 4760 & 4055 & 861015 \\
\hline 48 & 771 & 879 & 7348 & 1510557 & 1155 & 1114 & 835 & 835 & 5896 & 5442 & 4647 & $\begin{array}{l}114594 \\
9\end{array}$ \\
\hline
\end{tabular}




\subsection{Development of empirical equations}

The results obtained from modelling bridge lanes under CL-W loading were plotted and a curve of best fit was created using third degree polynomials. Following that, regression analysis was performed on the results to obtain the correlation factor between the best fit curve and the actual results obtained from SAP2000 software. The following subsections summarize the findings of this data analysis.

\subsubsection{Single span bridge configurations}

Using the results obtained from SAP2000 software, the following equations were developed to obtain the maximum longitudinal moment generated by one lane of CL-W loading as a function of the girder span for the three truck configurations considered in this study. In this particular case, the correlation factor showed the developed equations are $99.95 \%$ representative of the SAP2000 software results. The developed equations ensured that the load effect is at least equal (slightly higher than) those obtained from analysis using SAP2000 software with zero underestimation for safety reasons. Figure 3.7 shows comparison between these developed equations and the data from analysis, showing excellent agreement.

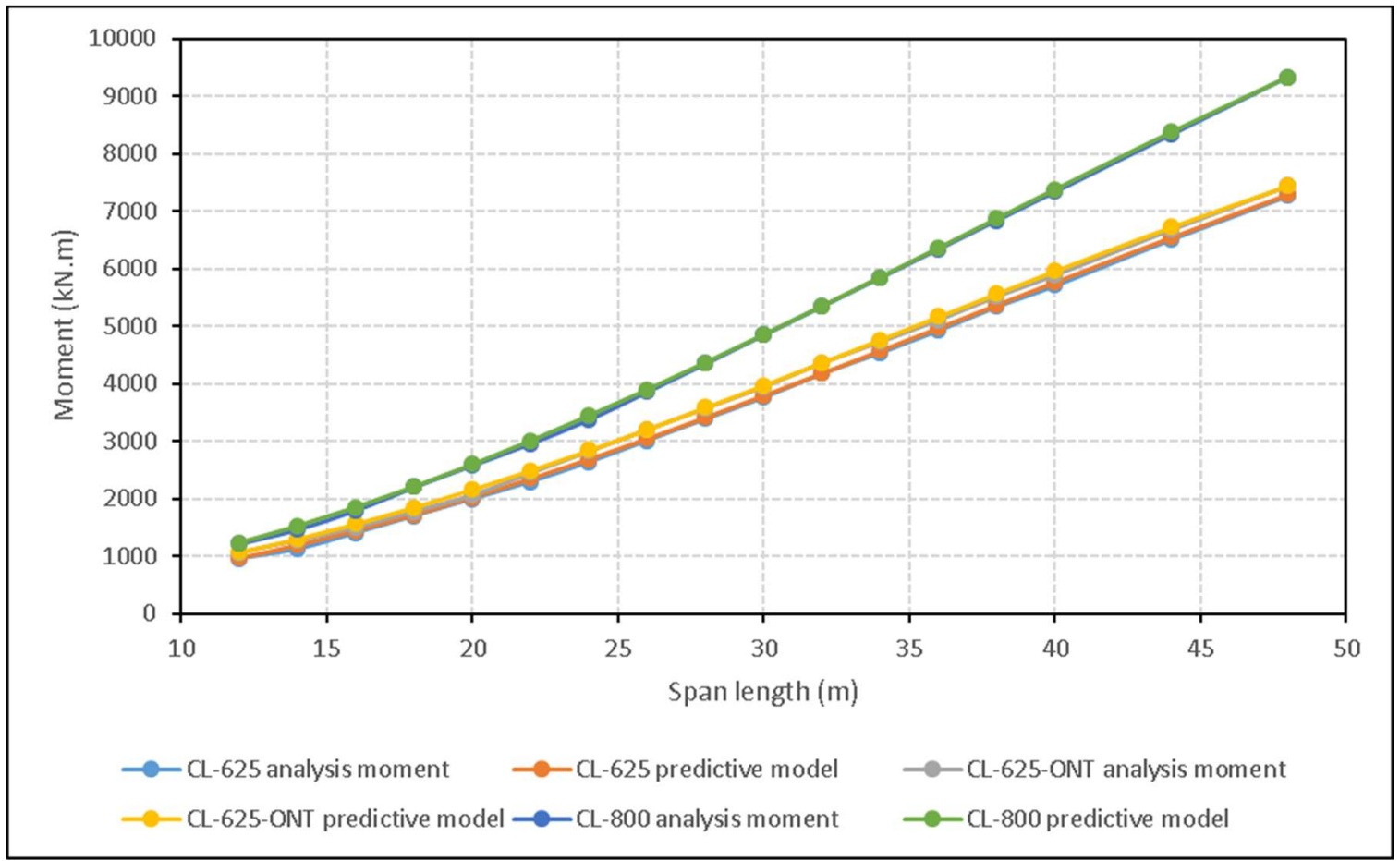

Figure 3.7: Comparison between the developed equations and the results obtained from SAP2000 model for longitudinal moment generated by one lane of CL-W loading in single span bridge configurations 
[3.1] $\mathrm{M}_{\mathrm{T}}=-0.050\left(\mathrm{~L}^{3}\right)+5.6\left(\mathrm{~L}^{2}\right)-6.51(\mathrm{~L})+330 \mathrm{kN} . \mathrm{m}$

[3.2] $\mathrm{M}_{\mathrm{T}}=-0.058\left(\mathrm{~L}^{3}\right)+6.1\left(\mathrm{~L}^{2}\right)-13.6(\mathrm{~L})+460 \mathrm{kN} \cdot \mathrm{m}$

[3.3] $\mathrm{M}_{\mathrm{T}}=-0.063\left(\mathrm{~L}^{3}\right)+7\left(\mathrm{~L}^{2}\right)-4.43(\mathrm{~L})+390 \mathrm{kN} \cdot \mathrm{m}$ for CL-625 Truck

for CL-625-ONT Truck for CL-800 Truck 
In the case of single span shear and reaction generated by one lane of CL-W loading as a function of the girder span for the three truck configurations considered in this study, the following developed equations showed accuracy of the results of $98.5 \%$ on the conservative side. Figure 3.8 shows a comparison between the developed equations and the results obtained from SAP2000 model for shear generated by one lane of CL-W loading in single span bridge girders.

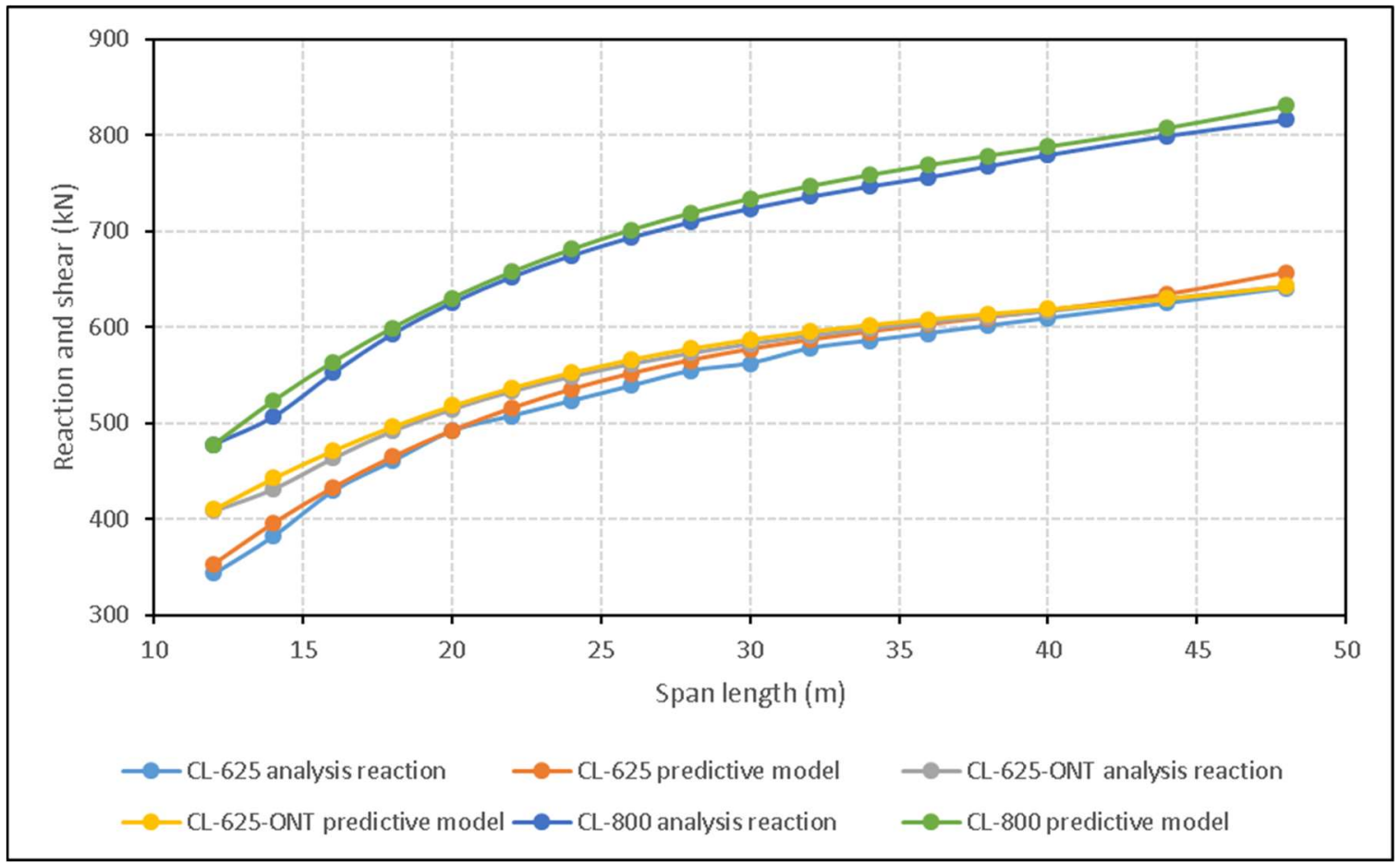

Figure 3.8: Comparison between the developed equations and the results obtained from SAP2000 model for shear and reaction generated by one lane of CL-W loading in single span bridge configuration
[3.4] $\mathrm{R}_{\mathrm{T}}=\mathrm{V}_{\mathrm{T}}=0.0097\left(\mathrm{~L}^{3}\right)-1.1\left(\mathrm{~L}^{2}\right)+44.8(\mathrm{~L})-43 \mathrm{kN}$
for CL-625 Truck
[3.5] $\mathrm{R}_{\mathrm{T}}=\mathrm{V}_{\mathrm{T}}=0.0063\left(\mathrm{~L}^{3}\right)-0.76\left(\mathrm{~L}^{2}\right)+32.7(\mathrm{~L})+116 \mathrm{kN}$
for CL-625-ONT Truck
[3.6] $\mathrm{R}_{\mathrm{T}}=\mathrm{V}_{\mathrm{T}}=0.0086\left(\mathrm{~L}^{3}\right)-1.02\left(\mathrm{~L}^{2}\right)+45(\mathrm{~L})+70 \mathrm{kN}$
for CL-800 Truck 
As for single span deflection generated by one lane of CL-W loading as a function of the girder span for the three truck configurations considered in this study, the models developed showed a correlation factor of $99.99 \%$ to the SAP2000 software results. Figure 3.9 shows comparison between these developed equations and the data from analysis.

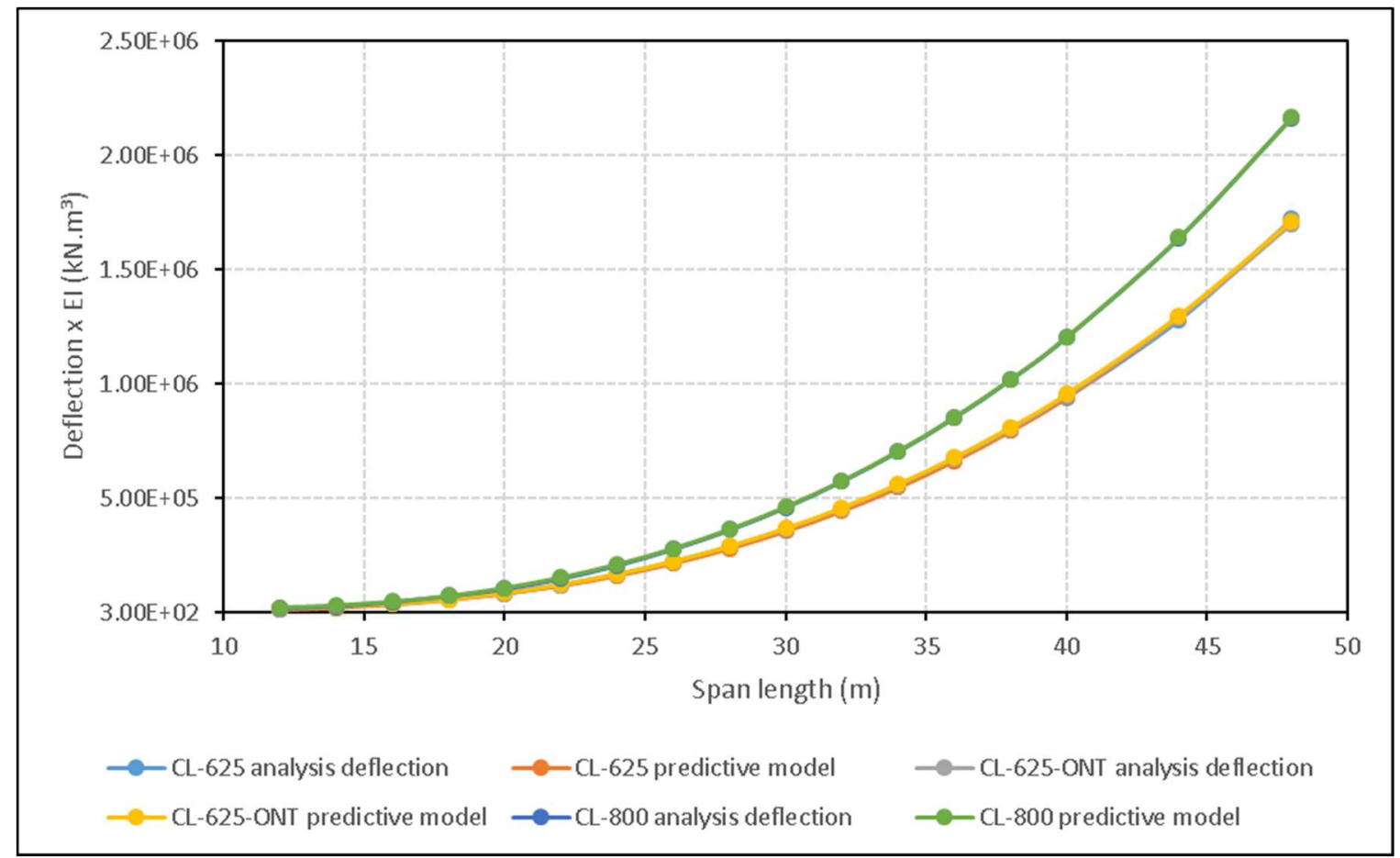

Figure 3.9: Comparison between the developed equations and the results obtained from SAP2000 model for deflection generated by one lane of CL-W loading in single span bridge configuration

$$
\begin{array}{ll}
{[3.7] \Delta_{\mathrm{T}} * \mathrm{EI}=19.3\left(\mathrm{~L}^{3}\right)-176.7\left(\mathrm{~L}^{2}\right)-511.6(\mathrm{~L})+10000 \mathrm{kN} \cdot \mathrm{m}^{3}} & \text { for CL-625 Truck } \\
{[3.8] \Delta_{\mathrm{T}} * \mathrm{EI}=16\left(\mathrm{~L}^{3}\right)+90.5\left(\mathrm{~L}^{2}\right)-6714(\mathrm{~L})+56000 \mathrm{kN} \cdot \mathrm{m}^{3}} & \text { for CL-625-ONT Truck } \\
{[3.9] \Delta_{\mathrm{T}} * \mathrm{EI}=20.4\left(\mathrm{~L}^{3}\right)+110.5\left(\mathrm{~L}^{2}\right)-8817(\mathrm{~L})+75600 \mathrm{kN} \cdot \mathrm{m}^{3}} & \text { for CL-800 Truck }
\end{array}
$$




\subsubsection{Two-equal-span bridge configurations}

The following equations were developed for maximum positive moment, $\mathrm{M}_{\mathrm{T}+}$, generated by one lane of CL-W loading in two-equal-span bridge girders. Figure 3.10 shows comparison between these developed equations and the data from analysis.

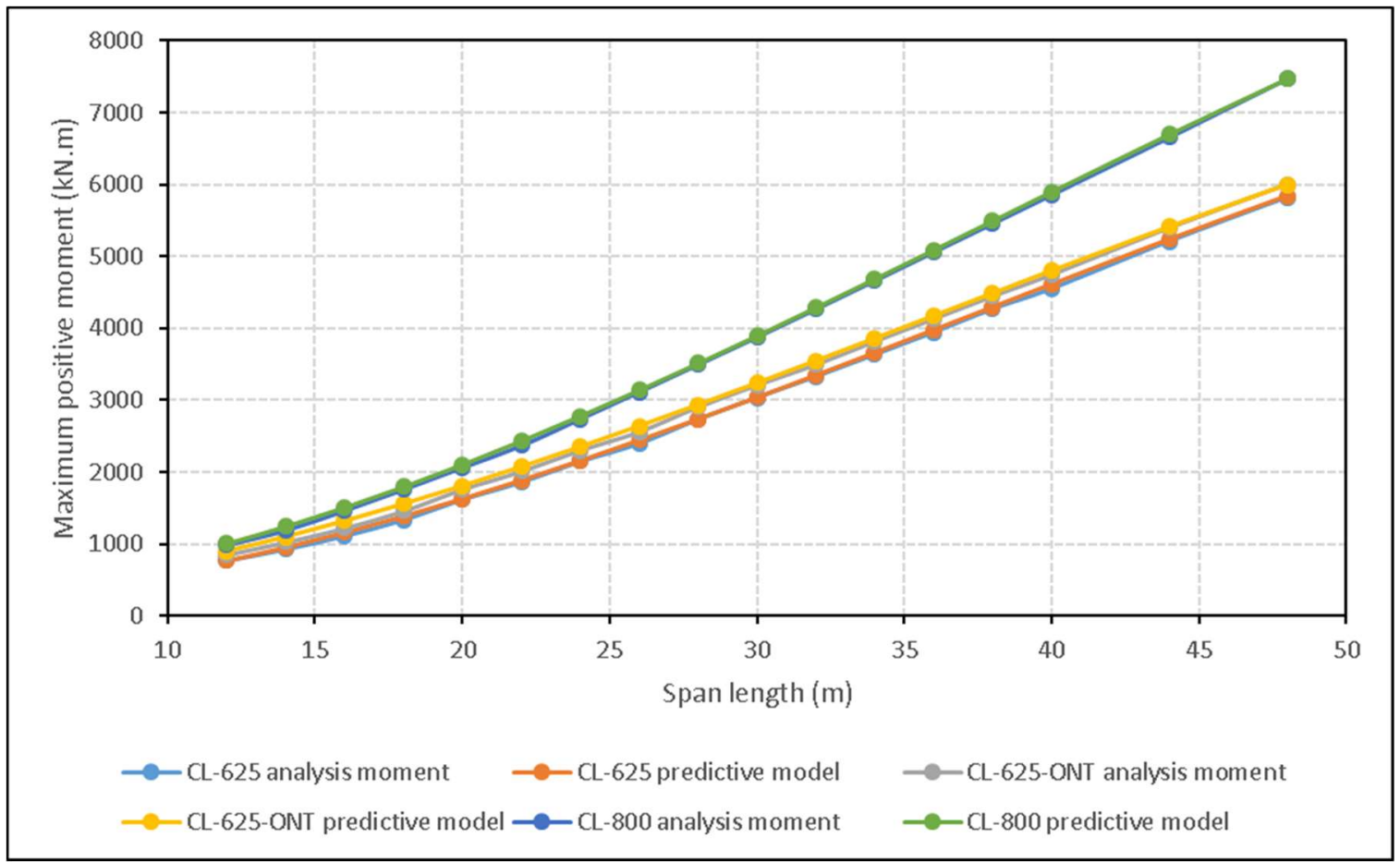

Figure 3.10: Comparison between the developed equations and the results obtained from SAP2000 model for longitudinal positive moment generated by one lane of CL-W loading in two equal spans bridge configurations
$[3.10] \mathrm{M}_{\mathrm{T}+}=-0.037\left(\mathrm{~L}^{3}\right)+4.1\left(\mathrm{~L}^{2}\right)+5.2(\mathrm{~L})+180 \mathrm{kN} \cdot \mathrm{m}$
for CL-625 Truck
$[3.11] \mathrm{M}_{\mathrm{T}+}=-0.035\left(\mathrm{~L}^{3}\right)+3.8\left(\mathrm{~L}^{2}\right)+19.4(\mathrm{~L})+180 \mathrm{kN} . \mathrm{m}$
for CL-625-ONT Truck
[3.12] $\mathrm{M}_{\mathrm{T}^{+}}=-0.045\left(\mathrm{~L}^{3}\right)+5.1\left(\mathrm{~L}^{2}\right)+9.7(\mathrm{~L})+230 \mathrm{kN} \cdot \mathrm{m}$
for CL-800 Truck 
The following equations were developed for maximum negative moment, $\mathrm{M}_{\mathrm{T}-\text {, generated by one }}$ lane of CL-W loading in two-equal-span bridge girders. Figure 3.11 shows comparison between these developed equations and the data from analysis.

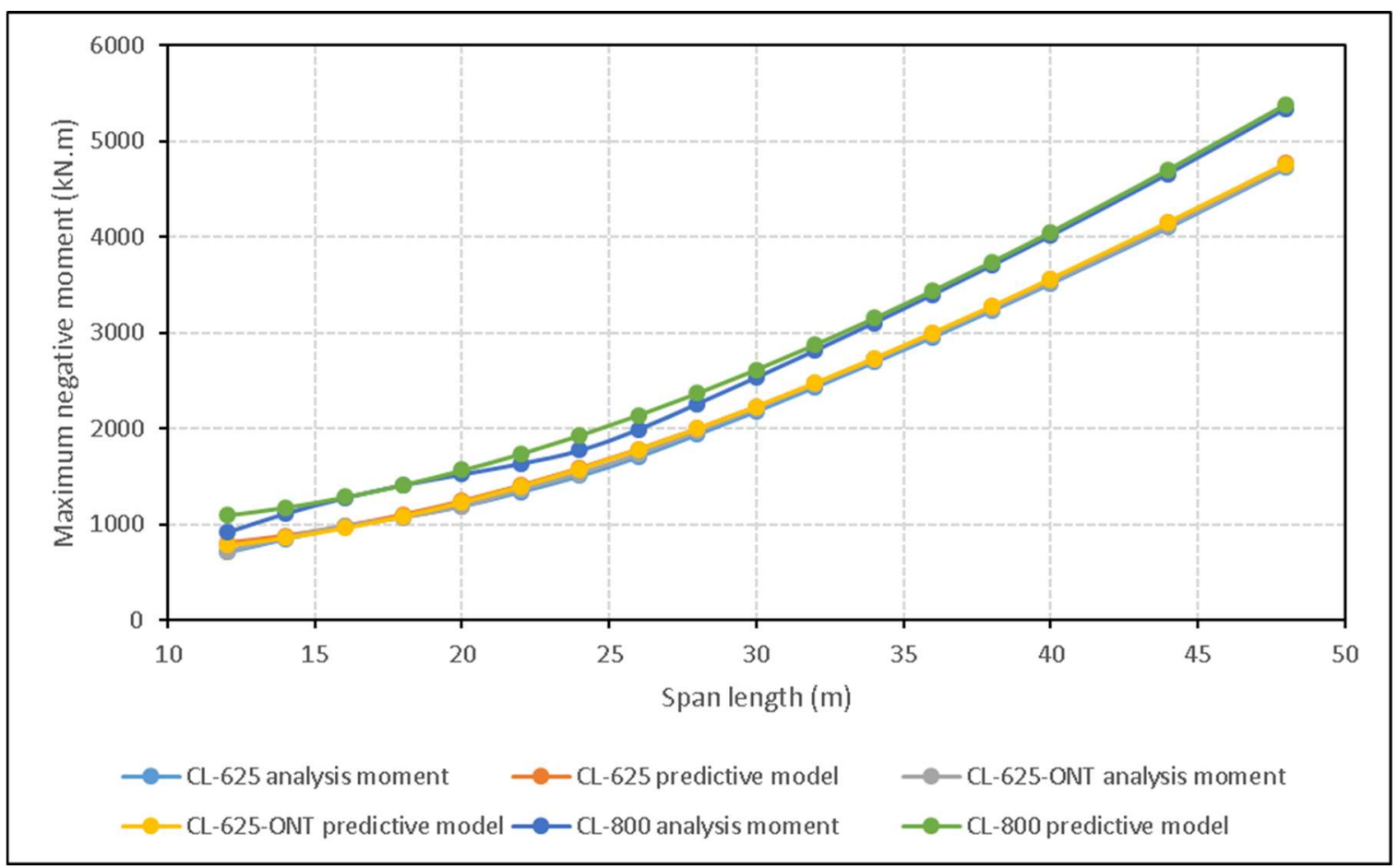

Figure 3.11: Comparison between the developed equations and the results obtained from SAP2000 model for longitudinal negative moment generated by one lane of CL-W loading in two equal spans bridge configurations
[3.13] $\mathrm{M}_{\mathrm{T}-}=-0.0256\left(\mathrm{~L}^{3}\right)+4.03\left(\mathrm{~L}^{2}\right)-54.28(\mathrm{~L})+920 \mathrm{kN} \cdot \mathrm{m}$
for CL-625 Truck
$[3.14] \mathrm{M}_{\mathrm{T}-}=-0.0286\left(\mathrm{~L}^{3}\right)+4.09\left(\mathrm{~L}^{2}\right)-53.71(\mathrm{~L})+885 \mathrm{kN} . \mathrm{m}$ for CL-625-ONT Truck
$[3.15] \mathrm{M}_{\mathrm{T}-}=-0.023\left(\mathrm{~L}^{3}\right)+4\left(\mathrm{~L}^{2}\right)-51.2(\mathrm{~L})+1175 \mathrm{kN} \cdot \mathrm{m}$ for CL-800 Truck 
The following equations were developed for maximum exterior reaction $\mathrm{R}_{\text {Text }}$ and, shear $\mathrm{V}_{\text {Text }}$ generated by one lane of CL-W loading in two-equal-span bridge girders. Figure 3.12 shows comparison between these developed equations and the data from analysis.

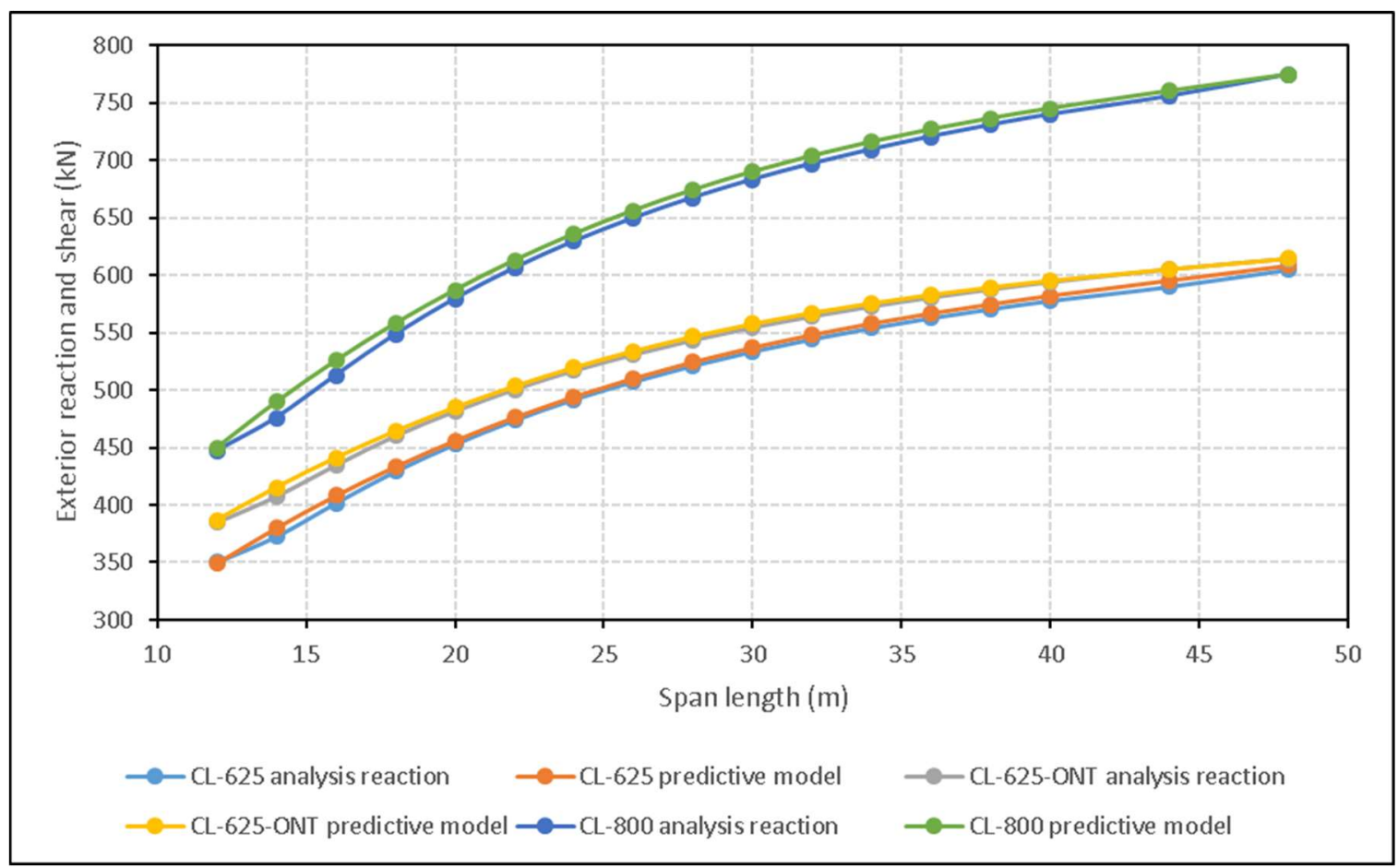

Figure 3.12: Comparison between the developed equations and the results obtained from SAP2000 model for exterior shear and reaction generated by one lane of CL-W loading in two equal spans bridge configurations
$[3.16] \mathrm{V}_{\text {Text }}=0.004\left(\mathrm{~L}^{3}\right)-0.54\left(\mathrm{~L}^{2}\right)+27.5(\mathrm{~L})+90 \mathrm{kN}$
for CL-625 Truck
[3.17] $\mathrm{V}_{\text {Text }}=0.0036\left(\mathrm{~L}^{3}\right)-0.5\left(\mathrm{~L}^{2}\right)+25.4(\mathrm{~L})+147 \mathrm{kN}$
for CL-625-ONT Truck
$[3.18] \mathrm{V}_{\text {Text }}=0.005\left(\mathrm{~L}^{3}\right)-0.69\left(\mathrm{~L}^{2}\right)+35.3(\mathrm{~L})+117 \mathrm{kN}$
for CL-800 Truck 
The following equations were developed for maximum interior support reaction generated by one lane of CL-W loading in two-equal-span bridge girders. Figure 3.13 shows comparison between these developed equations and the data from analysis, showing excellent agreement.

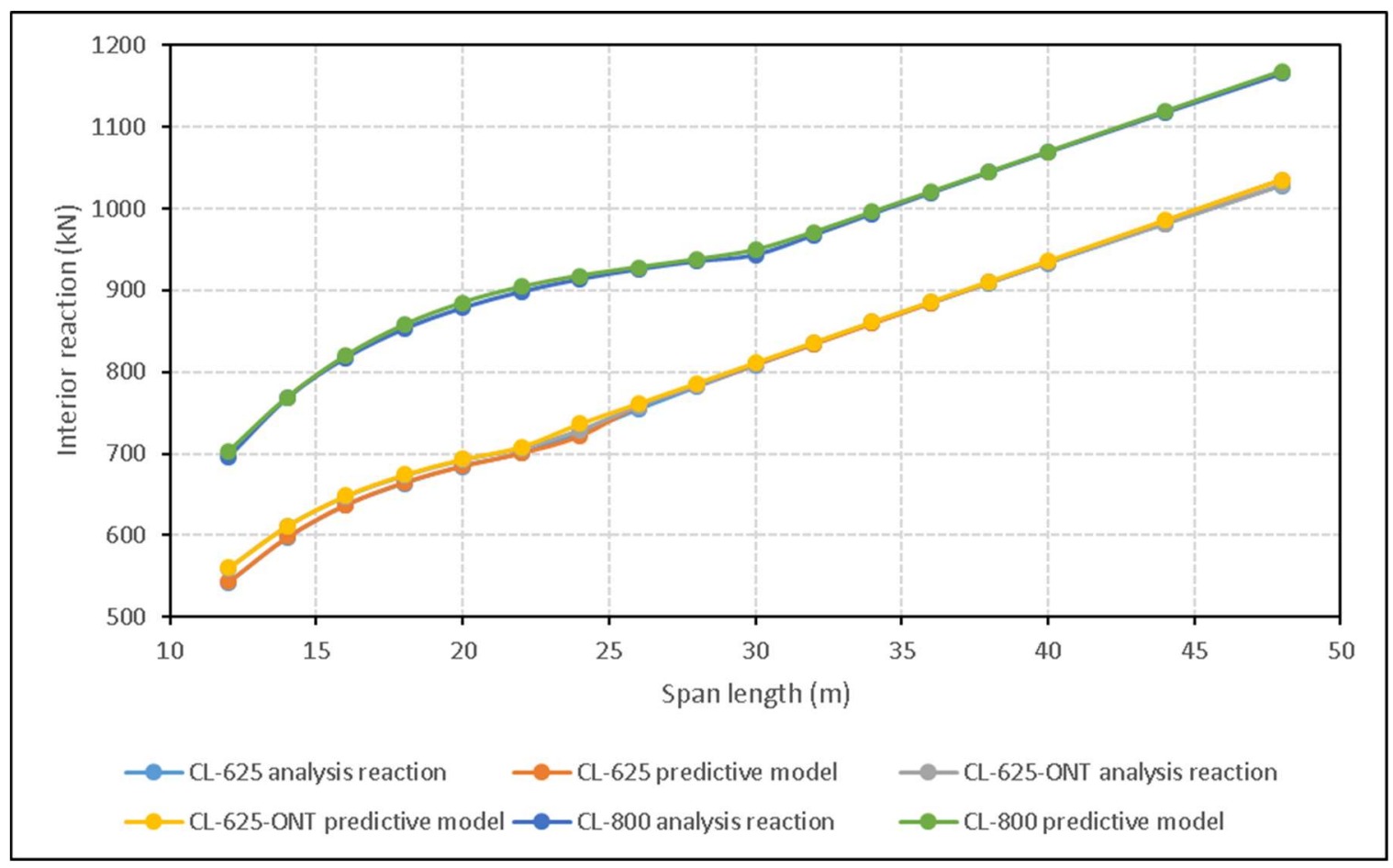

Figure 3.13: Comparison between the developed equations and the results obtained from SAP2000 model for interior reaction generated by one lane of CL-W loading in two equal spans bridge configurations

[3.19] $\mathrm{R}_{\text {Tint }}=0.08\left(\mathrm{~L}^{3}\right)-5.3\left(\mathrm{~L}^{2}\right)+124.6(\mathrm{~L})-327 \mathrm{kN}(12 \mathrm{~m} \leq \mathrm{L} \leq 22 \mathrm{~m})$

$$
\mathrm{R}_{\text {Tint }}=12.57(\mathrm{~L})+420 \mathrm{kN}(22 \mathrm{~m}<\mathrm{L} \leq 48 \mathrm{~m}) \quad \text { for CL-625 Truck }
$$

[3.20] $\mathrm{R}_{\text {Tint }}=0.075\left(\mathrm{~L}^{3}\right)-4.97\left(\mathrm{~L}^{2}\right)+116.5(\mathrm{~L})-252 \mathrm{kN}(12 \mathrm{~m} \leq \mathrm{L} \leq 22 \mathrm{~m})$

$\mathrm{R}_{\text {Tint }}=12.44(\mathrm{~L})+438 \mathrm{kN}(22 \mathrm{~m}<\mathrm{L} \leq 48 \mathrm{~m}) \quad$ for CL-625-ONT Truck

[3.21] $\mathrm{R}_{\text {Tint }}=0.052\left(\mathrm{~L}^{3}\right)-4.1\left(\mathrm{~L}^{2}\right)+113.6(\mathrm{~L})-159 \mathrm{kN}(12 \mathrm{~m} \leq \mathrm{L} \leq 30 \mathrm{~m})$

$\mathrm{R}_{\text {Tint }}=12.32(\mathrm{~L})+577 \mathrm{kN}(30 \mathrm{~m}<\mathrm{L} \leq 48 \mathrm{~m}) \quad$ for CL-800 Truck 
The following equations were developed for maximum interior shear generated by one lane of CL-W loading in two-equal-span bridge girders. Figure 3.14 shows comparison between these developed equations and the data from analysis.

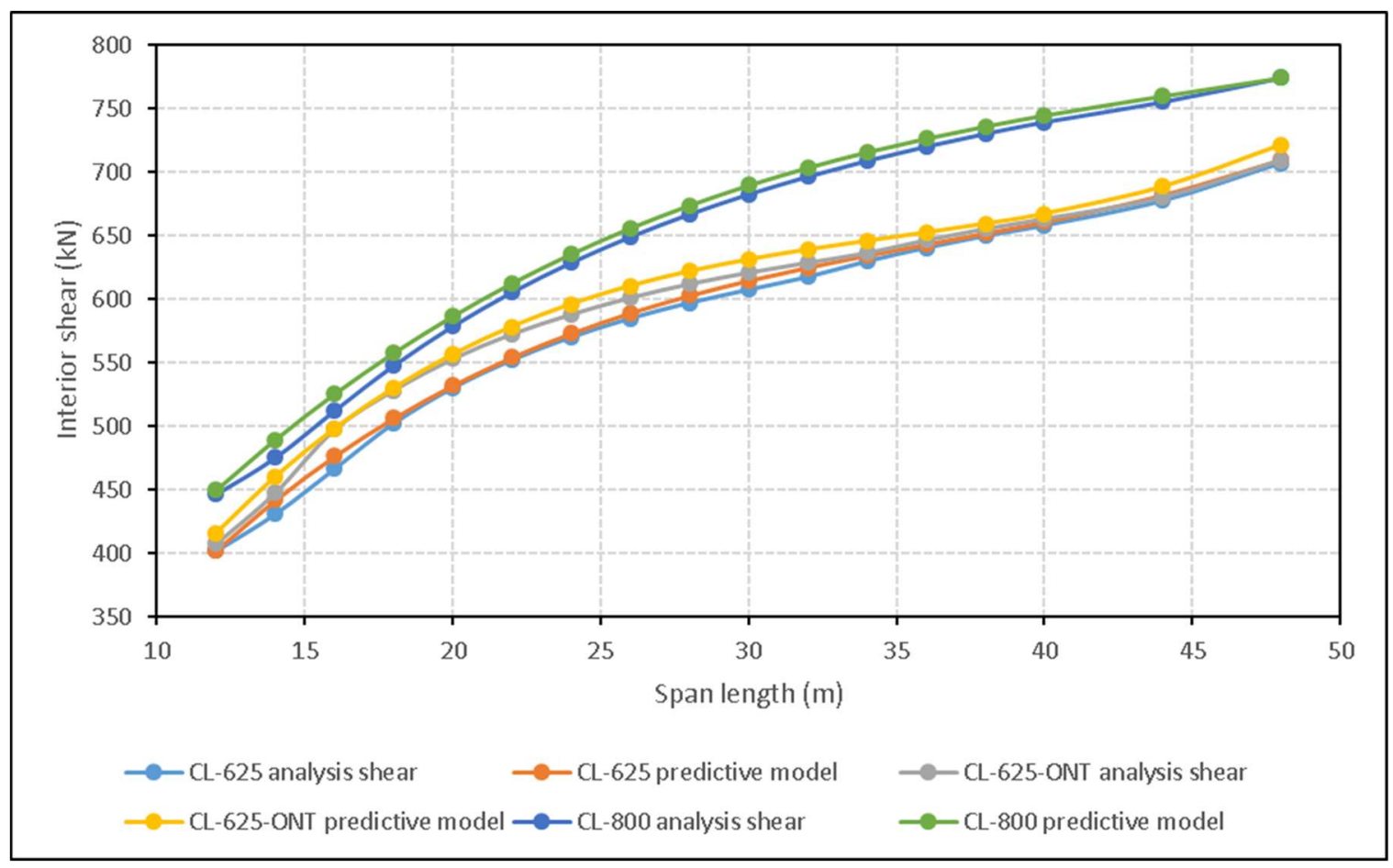

Figure 3.14: Comparison between the developed equations and the results obtained from SAP2000 model for interior shear generated by one lane of CL-W loading in two equal spans bridge configurations

$$
\begin{array}{ll}
{[3.22] \mathrm{V}_{\text {Tint }}=0.0094\left(\mathrm{~L}^{3}\right)-1.027\left(\mathrm{~L}^{2}\right)+41.75(\mathrm{~L})+33 \mathrm{kN}} & \text { for CL-625 Truck } \\
{[3.23] \mathrm{V}_{\text {Tint }}=0.0132\left(\mathrm{~L}^{3}\right)-1.381\left(\mathrm{~L}^{2}\right)+51.43(\mathrm{~L})-25 \mathrm{kN}} & \text { for CL-625-ONT Truck } \\
{[3.24] \mathrm{V}_{\text {Tint }}=0.0088\left(\mathrm{~L}^{3}\right)-1.06\left(\mathrm{~L}^{2}\right)+47.47(\mathrm{~L})+84 \mathrm{kN}} & \text { for CL-800 Truck }
\end{array}
$$


The following equations were developed for maximum deflection generated by one lane of CL$\mathrm{W}$ loading in two-equal-span bridge girders. Figure 3.15 shows comparison between these developed equations and the data from analysis.

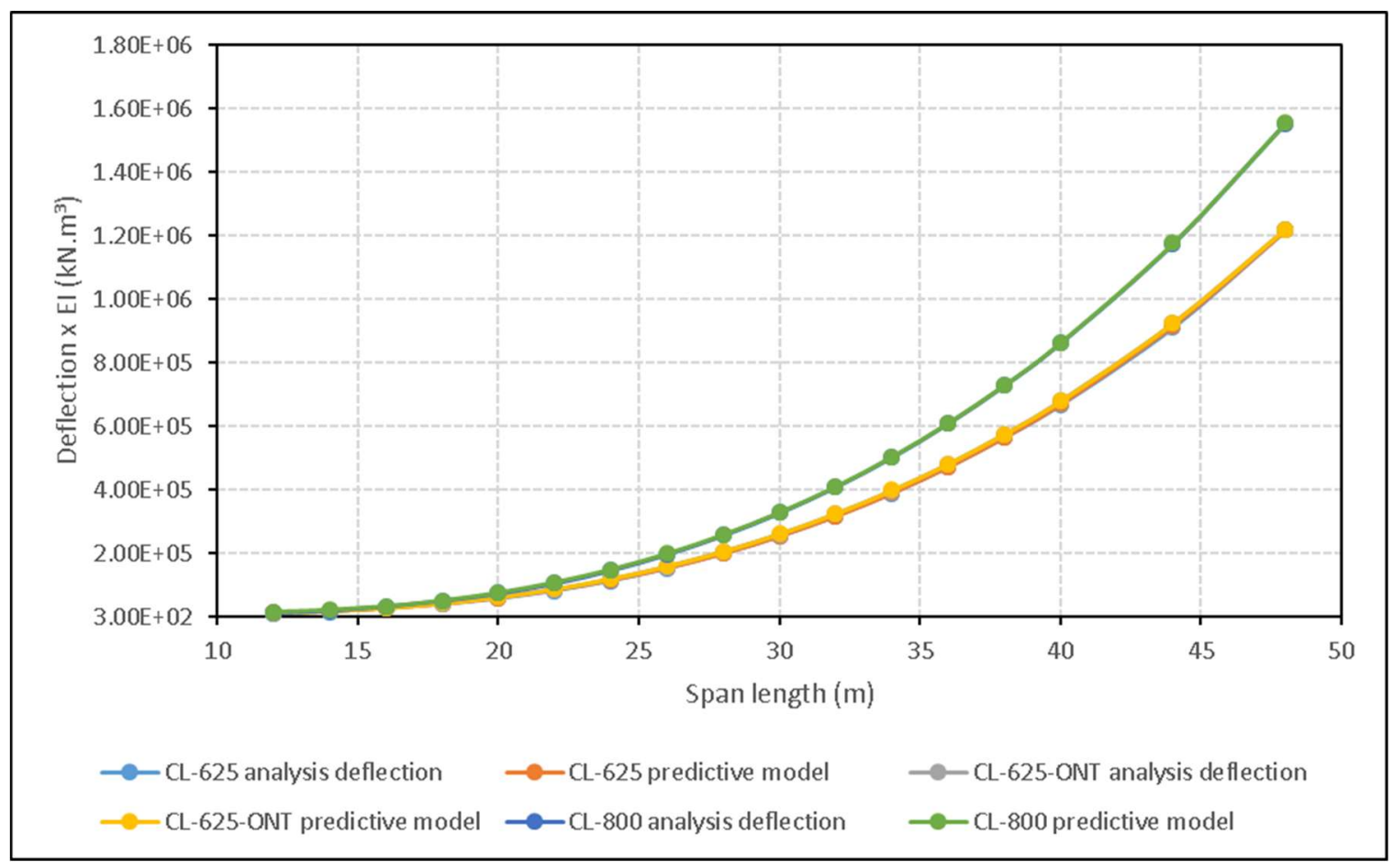

Figure 3.15: Comparison between the developed equations and the results obtained from SAP2000 model for deflection generated by one lane of CL-W loading in two equal spans bridge configurations

$$
\begin{array}{ll}
{[3.25] \Delta_{\mathrm{T}} * \mathrm{EI}=13.2\left(\mathrm{~L}^{3}\right)-74.8\left(\mathrm{~L}^{2}\right)-1870(\mathrm{~L})+21800 \mathrm{kN} \cdot \mathrm{m}^{3}} & \text { for CL-625 Truck } \\
{[3.26] \Delta_{\mathrm{T}} * \mathrm{EI}=16\left(\mathrm{~L}^{3}\right)+90.5\left(\mathrm{~L}^{2}\right)-6714(\mathrm{~L})+56000 \mathrm{kN} \cdot \mathrm{m}^{3}} & \text { for CL-625-ONT Truck } \\
{[3.27] \Delta_{\mathrm{T}} * \mathrm{EI}=20.4\left(\mathrm{~L}^{3}\right)+111\left(\mathrm{~L}^{2}\right)-8817(\mathrm{~L})+75600 \mathrm{kN} \cdot \mathrm{m}^{3}} & \text { for CL-800 Truck }
\end{array}
$$




\subsubsection{Three-equal-span bridge configurations}

The following equations were developed for longitudinal positive moment in exterior span generated by one lane of CL-W loading in three equal spans bridge configurations. Figure 3.16 shows comparison between these developed equations and the data from analysis.

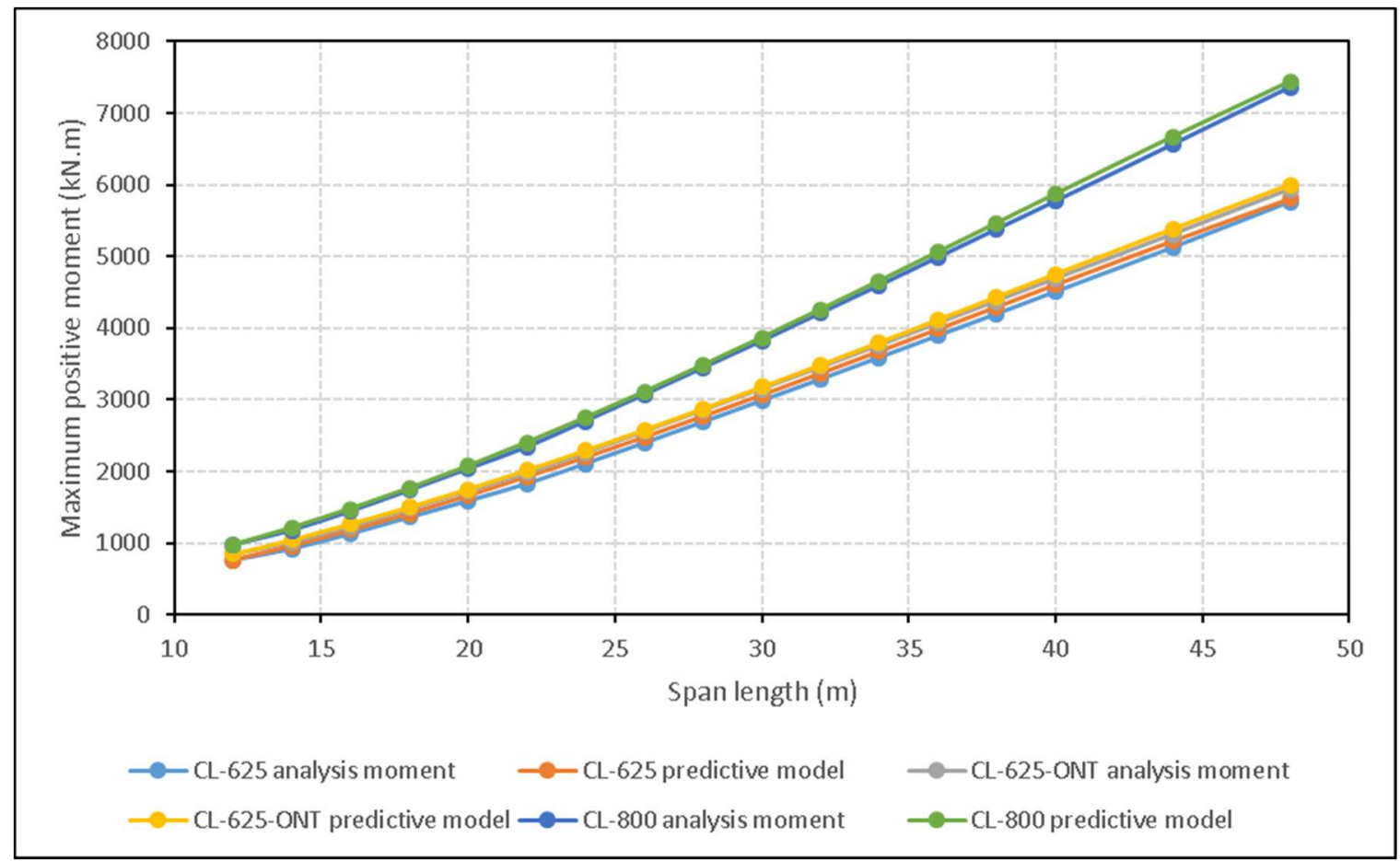

Figure 3.16: Comparison between the developed equations and the results obtained from SAP2000 model for longitudinal positive moment in exterior span generated by one lane of CL$\mathrm{W}$ loading in three equal spans bridge configurations

[3.28] $\mathrm{M}_{\mathrm{T}+\mathrm{ext}}=-0.031\left(\mathrm{~L}^{3}\right)+3.46\left(\mathrm{~L}^{2}\right)+26.35(\mathrm{~L}) \mathrm{kN} . \mathrm{m}$ $[3.29] \mathrm{M}_{\mathrm{T}+\mathrm{ext}}=-0.03\left(\mathrm{~L}^{3}\right)+3.46\left(\mathrm{~L}^{2}\right)+26.35(\mathrm{~L})+82 \mathrm{kN} \cdot \mathrm{m}$ $[3.30] \mathrm{M}_{\mathrm{T}+\mathrm{ext}}=-0.045\left(\mathrm{~L}^{3}\right)+5.1\left(\mathrm{~L}^{2}\right)+9.7(\mathrm{~L})+200 \mathrm{kN} . \mathrm{m}$ for CL-625 Truck for CL-625-ONT Truck

for CL-800 Truck 
The following equations were developed for longitudinal positive moment in interior span generated by one lane of CL-W loading in three equal spans bridge configurations. Figure 3.17 shows comparison between these developed equations and the data from analysis.

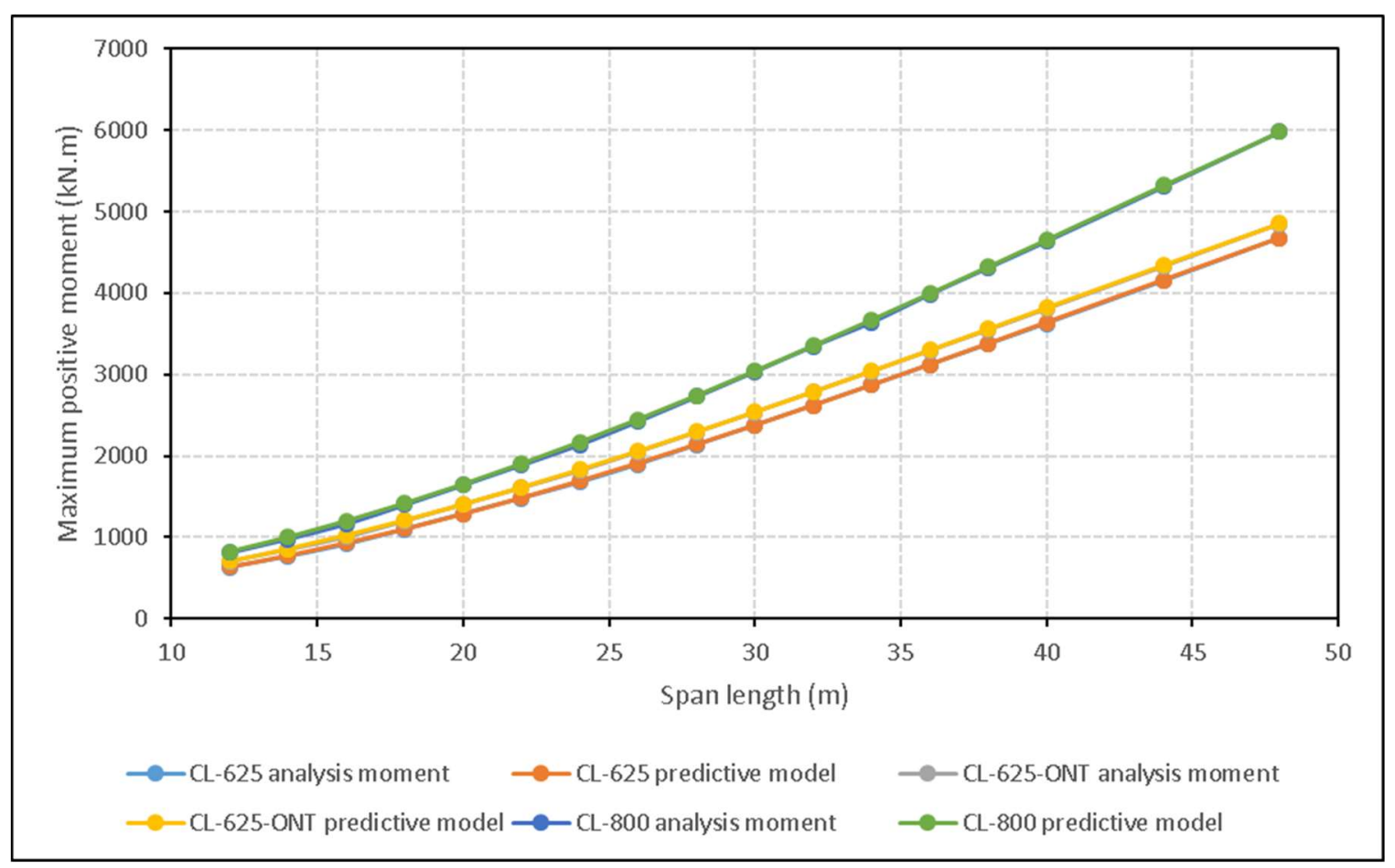

Figure 3.17: Comparison between the developed equations and the results obtained from SAP2000 model for longitudinal positive moment in interior span generated by one lane of CL$\mathrm{W}$ loading in three equal spans bridge configurations
[3.31] $\mathrm{M}_{\mathrm{T}+\text { int }}=-0.024\left(\mathrm{~L}^{3}\right)+3.04\left(\mathrm{~L}^{2}\right)+3(\mathrm{~L})+205 \mathrm{kN} \cdot \mathrm{m}$
for CL-625 Truck
[3.32] $\mathrm{M}_{\mathrm{T} \text { +int }}=-0.024\left(\mathrm{~L}^{3}\right)+2.94\left(\mathrm{~L}^{2}\right)+12.8(\mathrm{~L})+170 \mathrm{kN} \cdot \mathrm{m}$ for CL-625-ONT Truck [3.33] $\mathrm{M}_{\mathrm{T}+\text { int }}=-0.031\left(\mathrm{~L}^{3}\right)+3.9\left(\mathrm{~L}^{2}\right)+3(\mathrm{~L})+280 \mathrm{kN} . \mathrm{m} \quad$ for CL-800 Truck 
The following equations were developed for longitudinal negative moment generated by one lane of CL-W loading in three equal spans bridge configurations. Figure 3.18 shows comparison between these developed equations and the data from analysis.

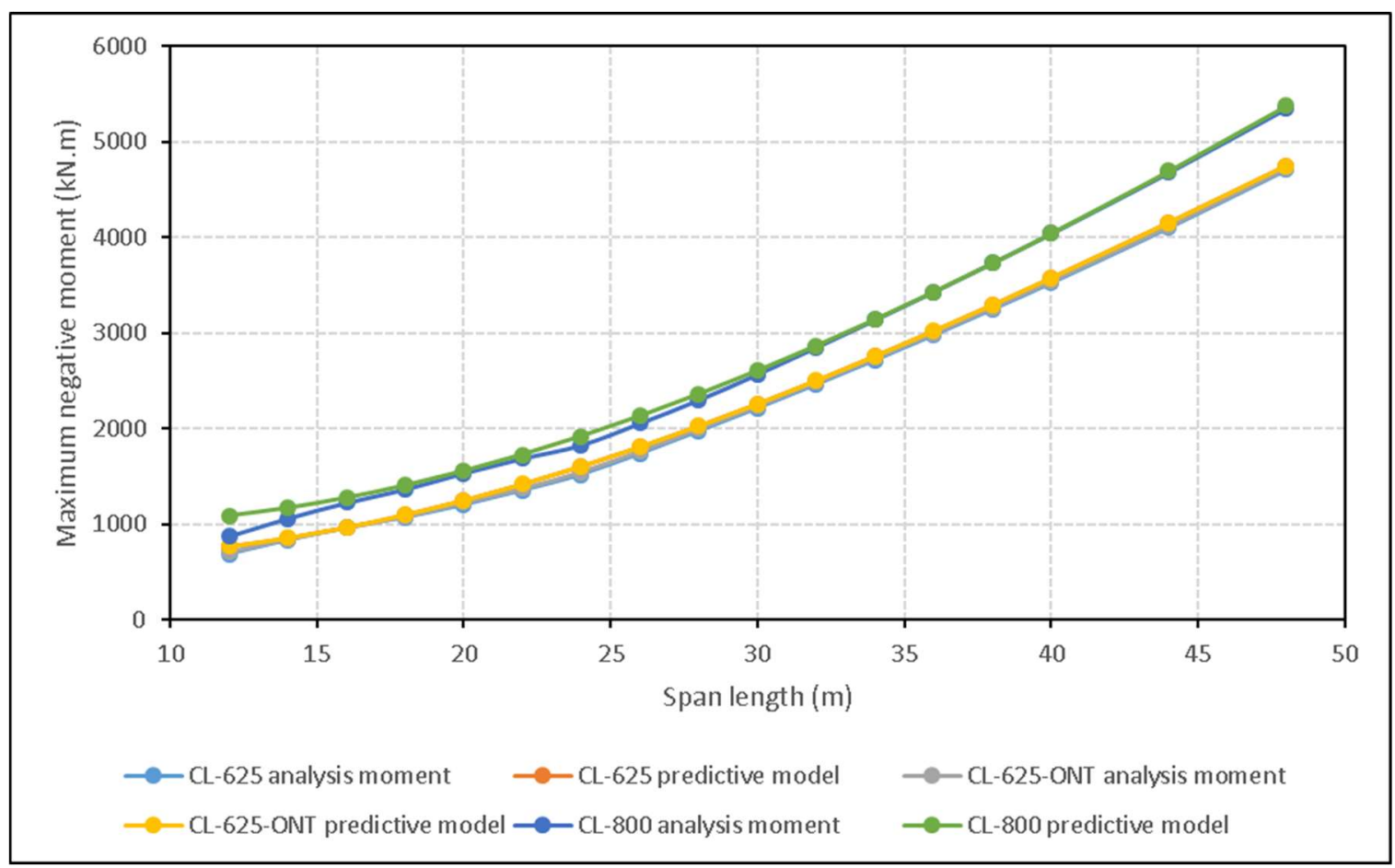

Figure 3.18: Comparison between the developed equations and the results obtained from SAP2000 model for longitudinal negative moment generated by one lane of CL-W loading in three equal spans bridge configurations
[3.34] $\mathrm{M}_{\mathrm{T}_{-}}=-0.0255\left(\mathrm{~L}^{3}\right)+3.84\left(\mathrm{~L}^{2}\right)-42.6(\mathrm{~L})+764 \mathrm{kN} \cdot \mathrm{m}$
for CL-625 Truck
$[3.35] \mathrm{M}_{\mathrm{T}-}=-0.0255\left(\mathrm{~L}^{3}\right)+3.84\left(\mathrm{~L}^{2}\right)-42.6(\mathrm{~L})+770 \mathrm{kN} \cdot \mathrm{m}$ for CL-625-ONT Truck $[3.36] \mathrm{M}_{\mathrm{T}-}=-0.023\left(\mathrm{~L}^{3}\right)+4\left(\mathrm{~L}^{2}\right)-51.2(\mathrm{~L})+1165 \mathrm{kN} \cdot \mathrm{m}$ for CL-800 Truck 
The following equations were developed for exterior reaction and shear generated by one lane of CL-W loading in three equal spans bridge configurations. Figure 3.19 shows comparison between these developed equations and the data from analysis.

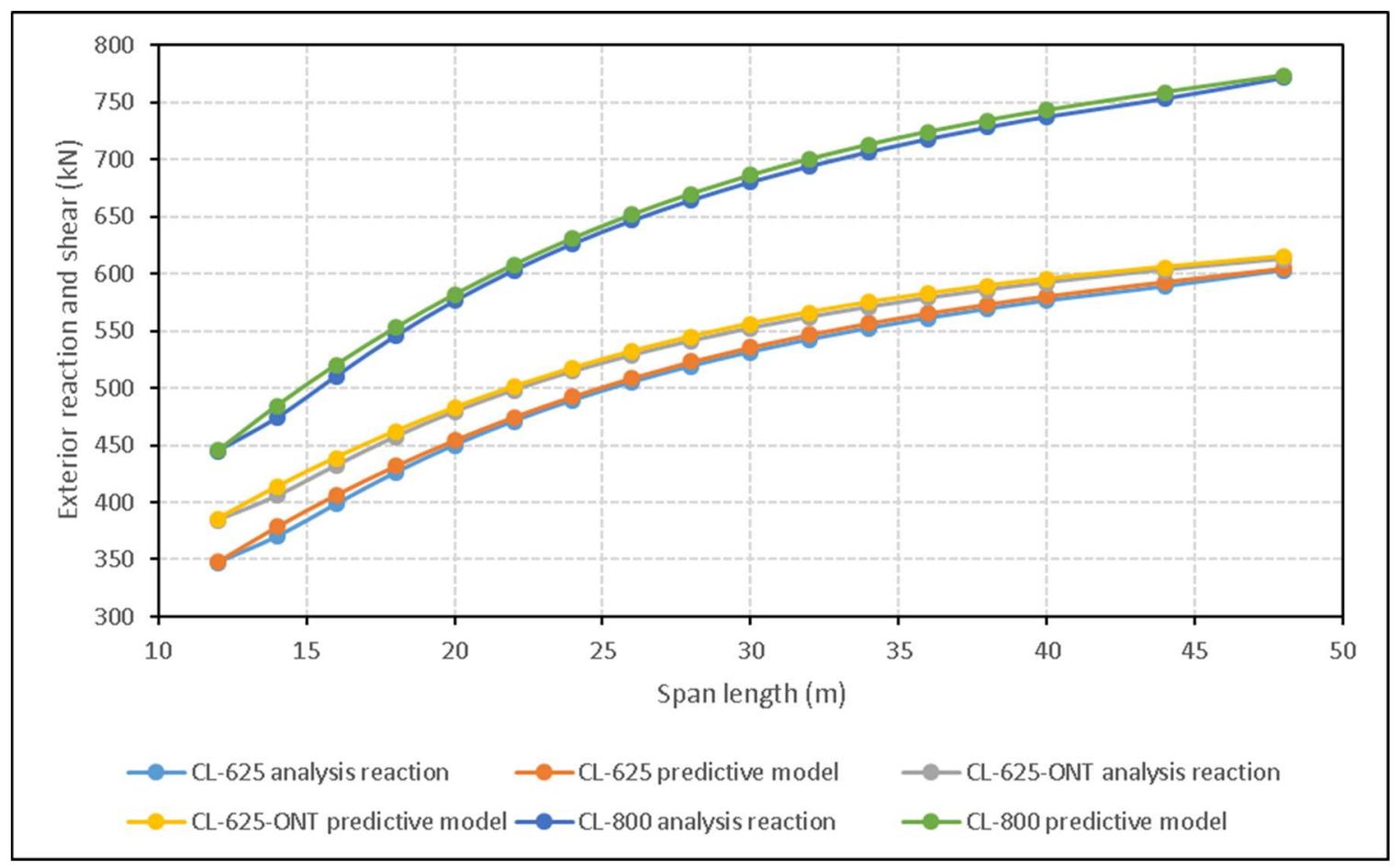

Figure 3.19: Comparison between the developed equations and the results obtained from SAP2000 model for exterior reaction and shear generated by one lane of CL-W loading in three equal spans bridge configurations
$[3.37] \mathrm{V}_{\text {Text }}=0.0037\left(\mathrm{~L}^{3}\right)-0.516\left(\mathrm{~L}^{2}\right)+26.9(\mathrm{~L})+93 \mathrm{kN}$
for CL-625 Truck
$[3.38] \mathrm{V}_{\text {Text }}=0.0033\left(\mathrm{~L}^{3}\right)-0.47\left(\mathrm{~L}^{2}\right)+24.6(\mathrm{~L})+152 \mathrm{kN}$ for CL-625-ONT Truck
$[3.39] \mathrm{V}_{\text {Text }}=0.0047\left(\mathrm{~L}^{3}\right)-0.66\left(\mathrm{~L}^{2}\right)+34.5(\mathrm{~L})+118 \mathrm{kN}$
for CL-800 Truck 
The following equations were developed for interior reaction generated by one lane of CL-W loading in three equal spans bridge configurations. Figure 3.20 shows comparison between these developed equations and the data from analysis.

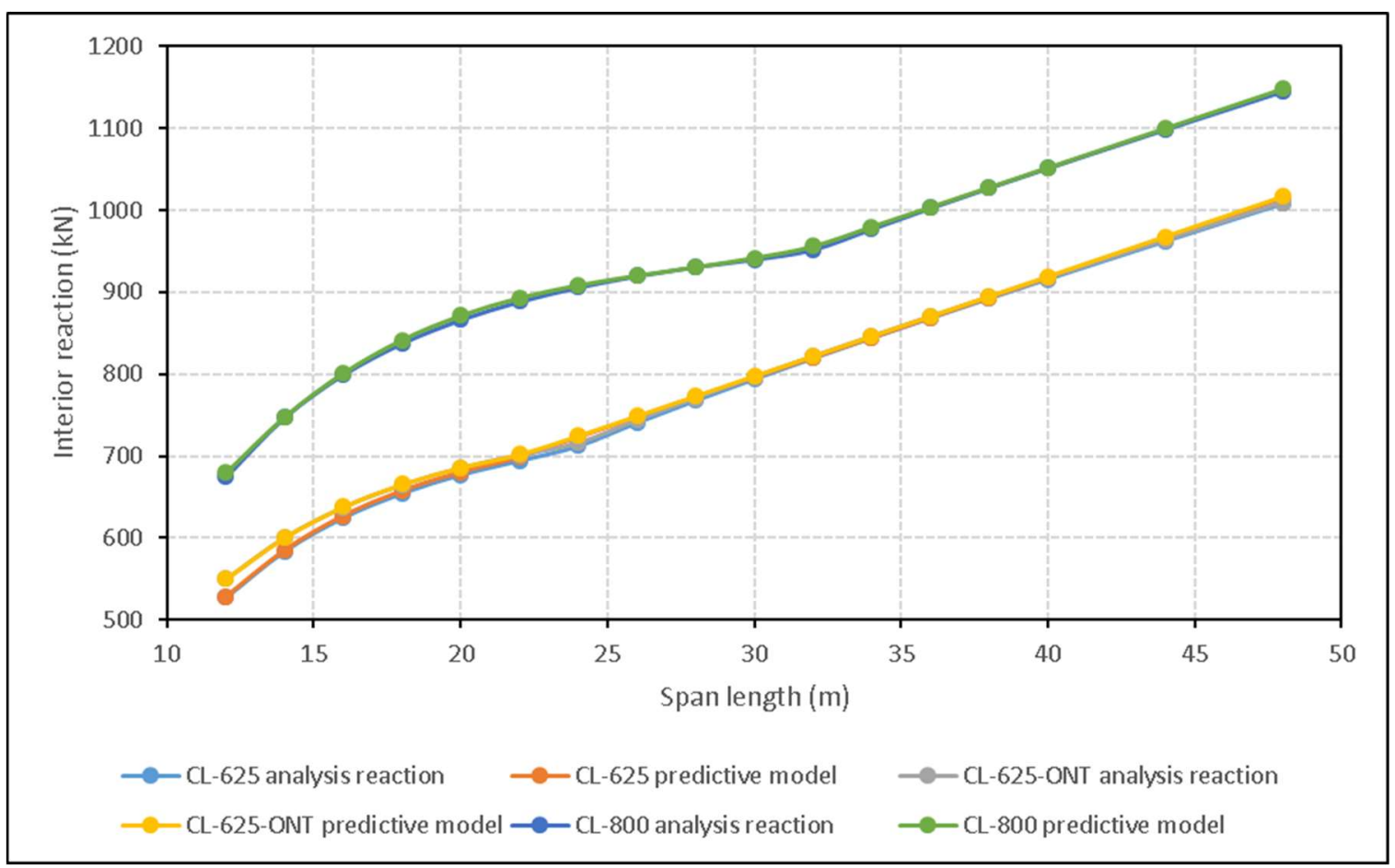

Figure 3.20: Comparison between the developed equations and the results obtained from SAP2000 model for interior reaction generated by one lane of CL-W loading in three equal spans bridge configurations

[3.40] $\mathrm{R}_{\text {Tint }}=0.074\left(\mathrm{~L}^{3}\right)-4.97\left(\mathrm{~L}^{2}\right)+120(\mathrm{~L})-324 \mathrm{kN}(12 \mathrm{~m} \leq \mathrm{L} \leq 22 \mathrm{~m})$ $\mathrm{R}_{\text {Tint }}=12.16(\mathrm{~L})+431 \mathrm{kN}(22 \mathrm{~m}<\mathrm{L} \leq 48 \mathrm{~m}) \quad$ for CL-625 Truck

[3.41] $\mathrm{R}_{\text {Tint }}=0.062\left(\mathrm{~L}^{3}\right)-4.23\left(\mathrm{~L}^{2}\right)+103.7(\mathrm{~L})-192 \mathrm{kN}(12 \mathrm{~m} \leq \mathrm{L} \leq 22 \mathrm{~m})$ $\mathrm{R}_{\text {Tint }}=12.16(\mathrm{~L})+433 \mathrm{kN}(22 \mathrm{~m}<\mathrm{L} \leq 48 \mathrm{~m}) \quad$ for CL-625-ONT Truck

[3.42] $\mathrm{R}_{\text {Tint }}=0.048\left(\mathrm{~L}^{3}\right)-3.9\left(\mathrm{~L}^{2}\right)+111.4(\mathrm{~L})-178 \mathrm{kN}(12 \mathrm{~m} \leq \mathrm{L} \leq 30 \mathrm{~m})$ $\mathrm{R}_{\text {Tint }}=12(\mathrm{~L})+572 \mathrm{kN}(30 \mathrm{~m}<\mathrm{L} \leq 48 \mathrm{~m}) \quad$ for CL-800 Truck 
The following equations were developed for shear left of interior support generated by one lane of CL-W loading in three equal spans bridge configurations. Figure 3.21 shows comparison between these developed equations and the data from analysis.

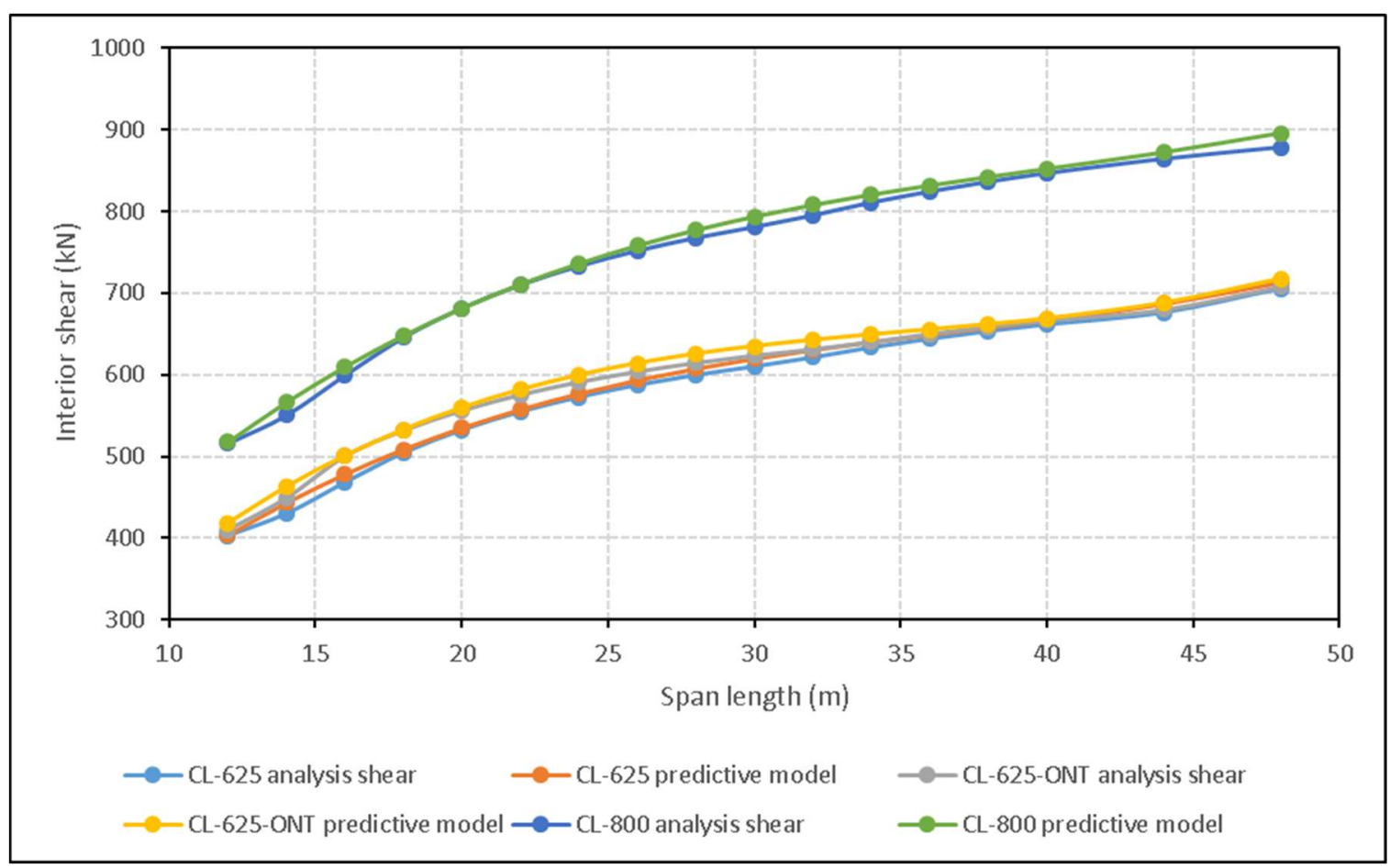

Figure 3.21: Comparison between the developed equations and the results obtained from SAP2000 model for shear left of interior support generated by one lane of CL-W loading in three equal spans bridge configurations

[3.43] $\mathrm{V}_{\text {Tint }}$ left $=0.009\left(\mathrm{~L}^{3}\right)-\mathrm{L}^{2}+41.4(\mathrm{~L})+35 \mathrm{kN}$

for CL-625 Truck

[3.44] $\mathrm{V}_{\text {Tint }}$ left $=0.013\left(\mathrm{~L}^{3}\right)-1.35\left(\mathrm{~L}^{2}\right)+50.9(\mathrm{~L})-20 \mathrm{kN}$

for CL-625-ONT Truck

$[3.45] \mathrm{V}_{\text {Tint }}$ left $=0.009\left(\mathrm{~L}^{3}\right)-1.06\left(\mathrm{~L}^{2}\right)+47.5(\mathrm{~L})+85 \mathrm{kN}$

for CL-800 Truck 
The following equations were developed for shear right of interior support generated by one lane of CL-W loading in three equal spans bridge configurations. Figure 3.22 shows comparison between these developed equations and the data from analysis.

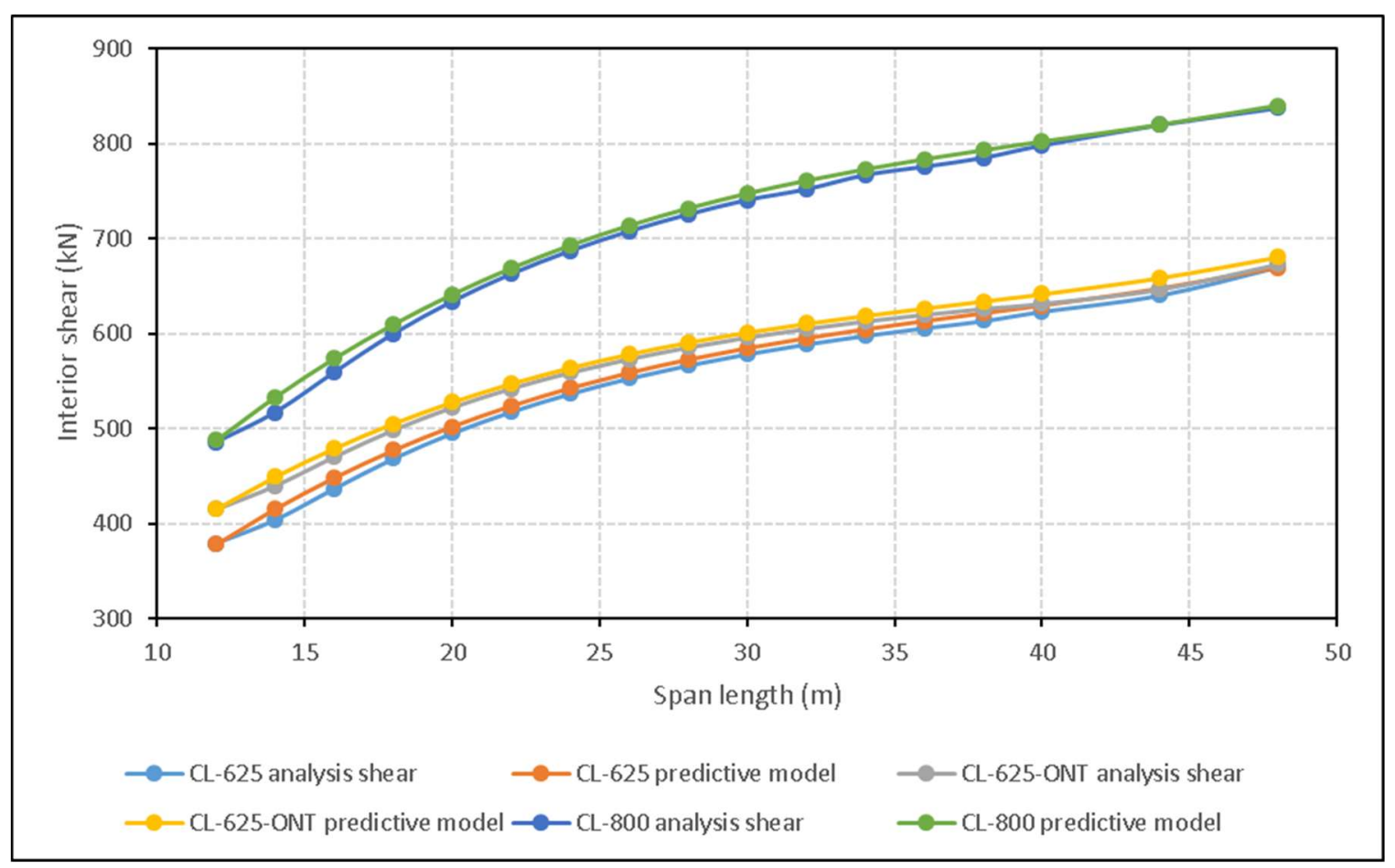

Figure 3.22: Comparison between the developed equations and the results obtained from SAP2000 model for shear right of interior support generated by one lane of CL-W loading in three equal spans bridge configurations

[3.46] $\mathrm{V}_{\text {Tint }}$ right $=0.0077\left(\mathrm{~L}^{3}\right)-0.88\left(\mathrm{~L}^{2}\right)+37.6(\mathrm{~L})+41 \mathrm{kN} \quad$ for CL-625 Truck [3.47] $\mathrm{V}_{\text {Tint }}$ right $=0.0075\left(\mathrm{~L}^{3}\right)-0.84\left(\mathrm{~L}^{2}\right)+35.1(\mathrm{~L})+102 \mathrm{kN}$ for CL-625-ONT Truck $[3.48] \mathrm{V}_{\text {Tint }}$ right $=0.0078\left(\mathrm{~L}^{3}\right)-0.96\left(\mathrm{~L}^{2}\right)+43.8(\mathrm{~L})+87 \mathrm{kN}$ for CL-800 Truck 
The following equations were developed for deflection in exterior span generated by one lane of CL-W loading in three equal spans bridge configurations. Figure 3.23 shows comparison between these developed equations and the data from analysis.

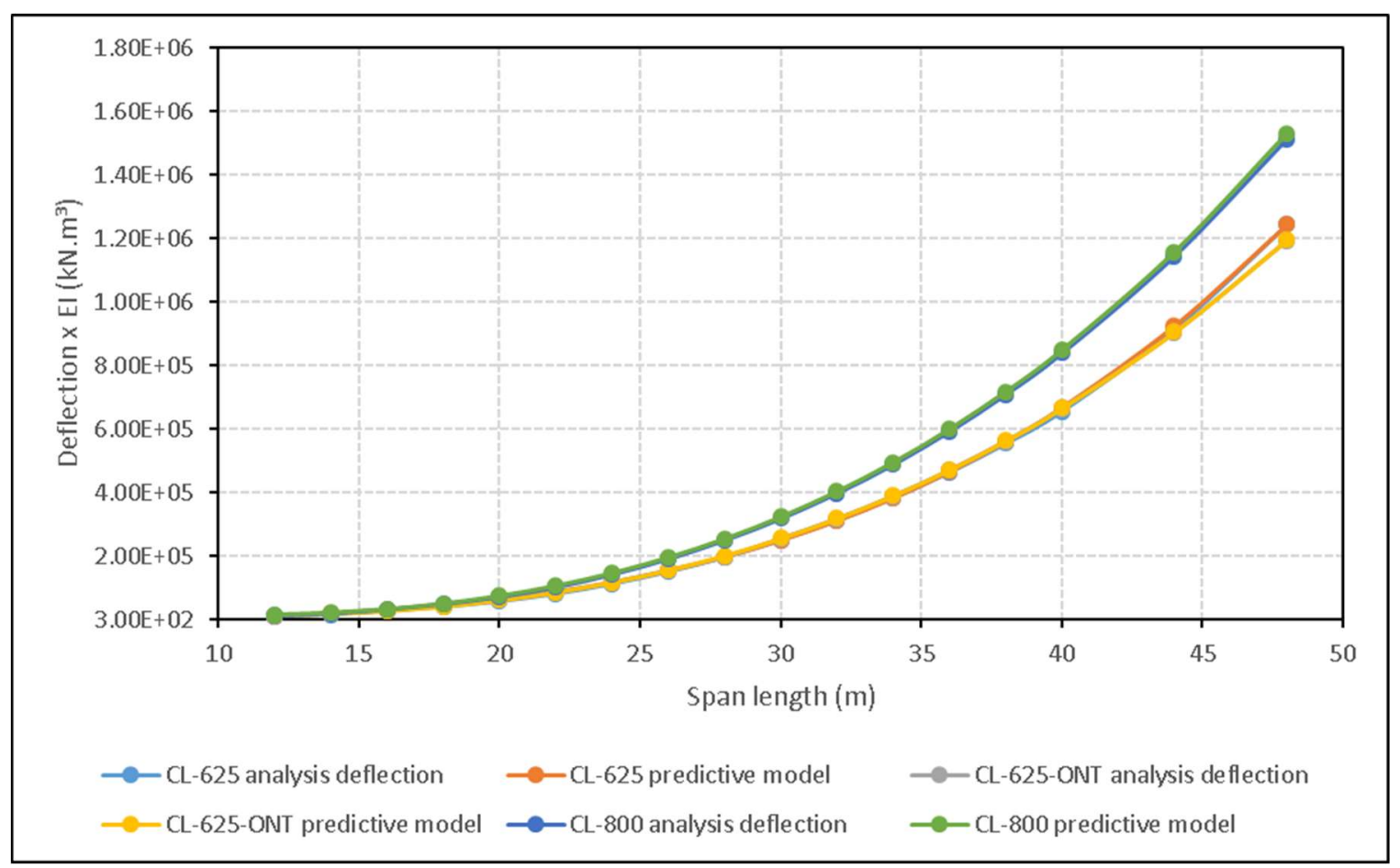

Figure 3.23: Comparison between the developed equations and the results obtained from SAP2000 model for deflection in exterior span generated by one lane of CL-W loading in three equal spans bridge configurations

[3.49] $\Delta_{\text {Text }} * \mathrm{EI}=18.0\left(\mathrm{~L}^{3}\right)-454.6\left(\mathrm{~L}^{2}\right)-7106(\mathrm{~L})-40000 \mathrm{kN} \cdot \mathrm{m}^{3}$ for CL-625 Truck [3.50] $\Delta_{\text {Text }} * \mathrm{EI}=11.7\left(\mathrm{~L}^{3}\right)+25.2\left(\mathrm{~L}^{2}\right)-3900(\mathrm{~L})+36000 \mathrm{kN} \cdot \mathrm{m}^{3}$ for CL-625-ONT Truck [3.51] $\Delta_{\text {Text }} * \mathrm{EI}=15.0\left(\mathrm{~L}^{3}\right)+40\left(\mathrm{~L}^{2}\right)-5630(\mathrm{~L})+50550 \mathrm{kN} \cdot \mathrm{m}^{3}$ for CL-800 Truck 
The following equations were developed for deflection in interior span generated by one lane of CL-W loading in three equal spans bridge configurations. Figure 3.24 shows comparison between these developed equations and the data from analysis.

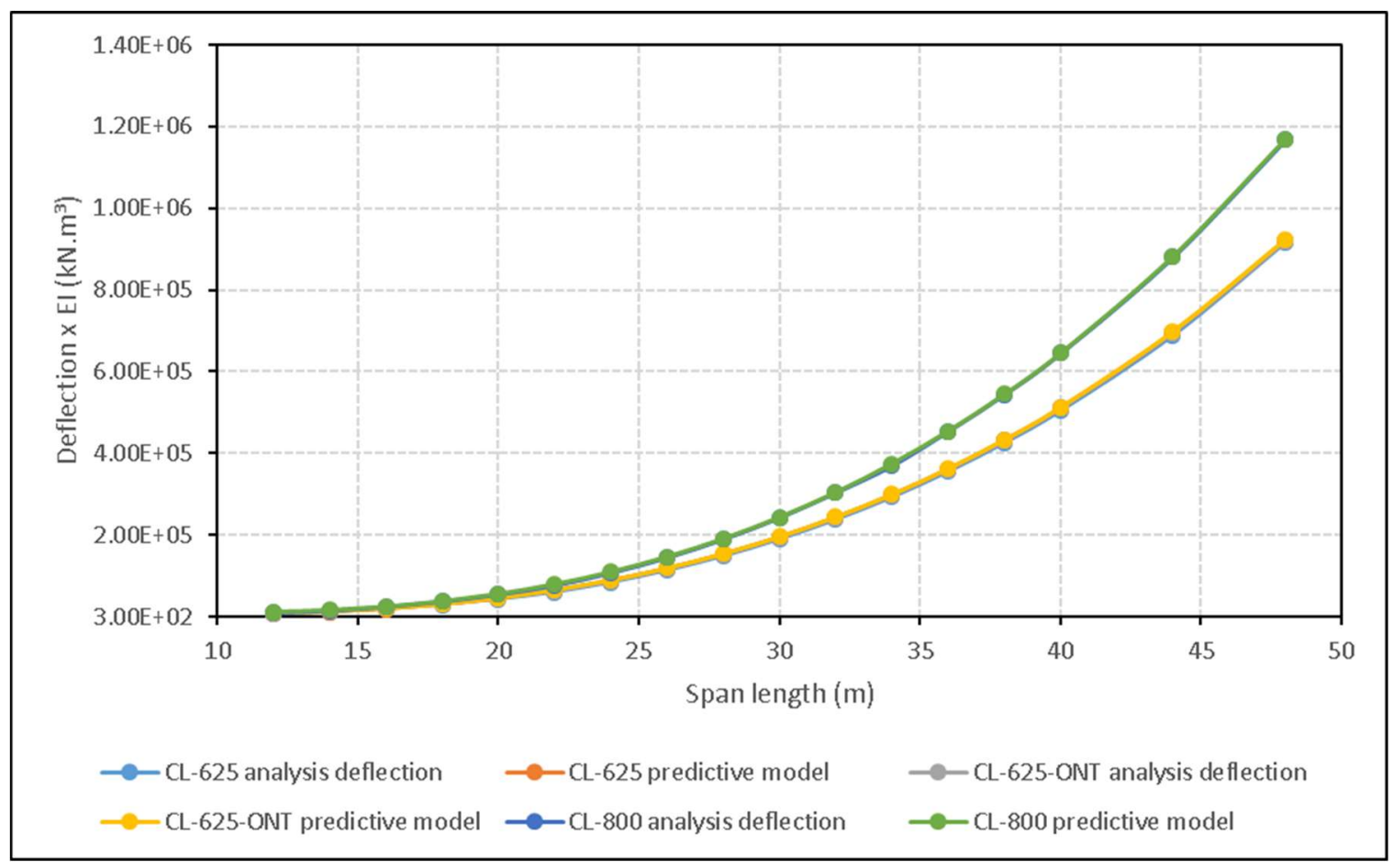

Figure 3.24: Comparison between the developed equations and the results obtained from SAP2000 model for deflection in interior span generated by one lane of CL-W loading in three equal spans bridge configurations

[3.52] $\Delta_{\text {Tint }} * \mathrm{EI}=9.22\left(\mathrm{~L}^{3}\right)+3.43\left(\mathrm{~L}^{2}\right)-2700(\mathrm{~L})+23550 \mathrm{kN} \cdot \mathrm{m}^{3}$ for CL-625 Truck [3.53] $\Delta_{\text {Tint }} * \mathrm{EI}=9.22\left(\mathrm{~L}^{3}\right)+3.43\left(\mathrm{~L}^{2}\right)-2700(\mathrm{~L})+25550 \mathrm{kN} \cdot \mathrm{m}^{3}$ for CL-625-ONT Truck [3.54] $\Delta_{\text {Tint }} * \mathrm{EI}=11.9\left(\mathrm{~L}^{3}\right)-3800(\mathrm{~L})+36700 \mathrm{kN} . \mathrm{m}^{3} \quad$ for CL-800 Truck 


\subsubsection{Four-equal-span bridge configurations}

\subsubsection{Exterior span}

The following equations were developed for exterior support reaction and shear generated by one lane of CL-W loading in four equal spans bridge configurations. Figure 3.25 shows comparison between these developed equations and the data from analysis.

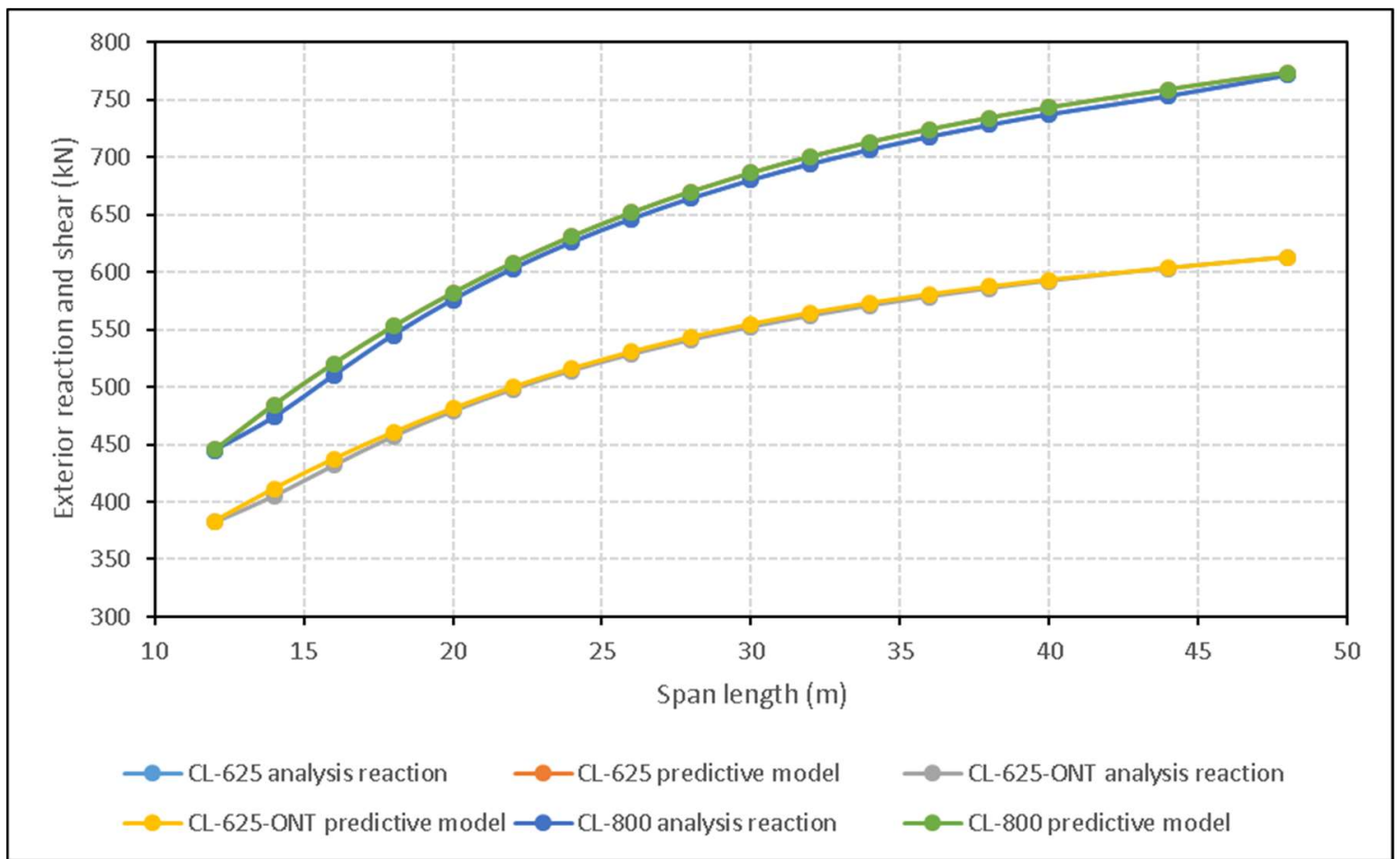

Figure 3.25: Comparison between the developed equations and the results obtained from SAP2000 model for exterior support reaction and shear generated by one lane of CL-W loading in four equal spans bridge configurations

$[3.55] \mathrm{V}_{\text {Text }}=0.0037\left(\mathrm{~L}^{3}\right)-0.516\left(\mathrm{~L}^{2}\right)+26.9(\mathrm{~L})+92 \mathrm{kN}$

for CL-625 Truck

$[3.56] \mathrm{V}_{\text {Text }}=0.0035\left(\mathrm{~L}^{3}\right)-0.49\left(\mathrm{~L}^{2}\right)+25.2(\mathrm{~L})+145 \mathrm{kN}$ for CL-625-ONT Truck

$[3.57] \mathrm{V}_{\text {Text }}=0.0047\left(\mathrm{~L}^{3}\right)-0.66\left(\mathrm{~L}^{2}\right)+34.5(\mathrm{~L})+118 \mathrm{kN}$

for CL-800 Truck 
The following equations were developed for support reaction at first interior support generated by one lane of CL-W loading in four equal spans bridge configurations. Figure 3.26 shows comparison between these developed equations and the data from analysis.

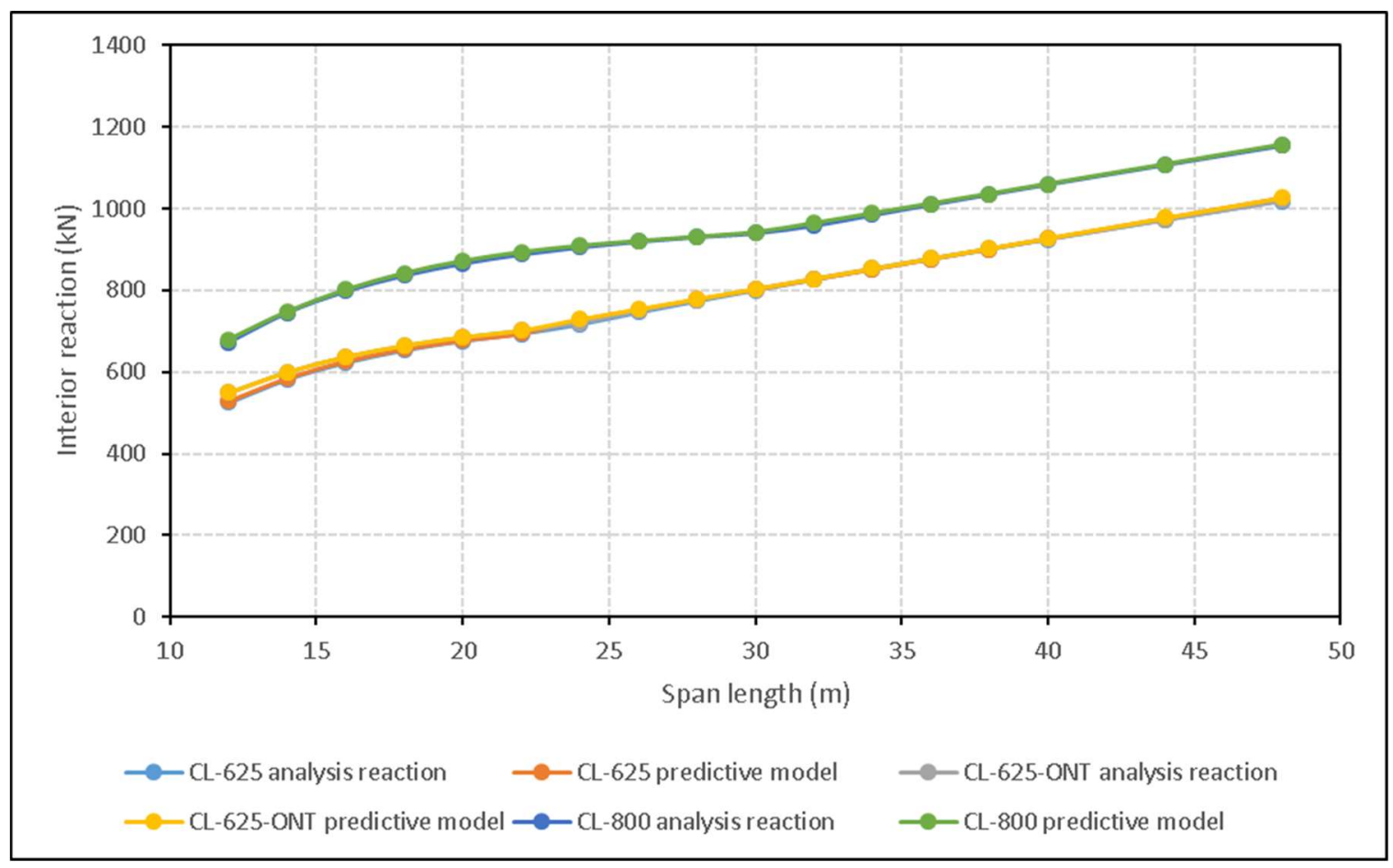

Figure 3.26: Comparison between the developed equations and the results obtained from SAP2000 model for support reaction at first interior support generated by one lane of CL-W loading in four equal spans bridge configurations

$[3.58] \mathrm{V}_{\text {Tint }}=0.009\left(\mathrm{~L}^{3}\right)-\mathrm{L}^{2}+41.6(\mathrm{~L})+33 \mathrm{kN}$

$[3.59] \mathrm{V}_{\text {Tint }}=0.013\left(\mathrm{~L}^{3}\right)-1.36\left(\mathrm{~L}^{2}\right)+51.2(\mathrm{~L})-24 \mathrm{kN}$

$[3.60] \mathrm{V}_{\text {Tint }}=0.009\left(\mathrm{~L}^{3}\right)-1.05\left(\mathrm{~L}^{2}\right)+47.2(\mathrm{~L})+89 \mathrm{kN}$ for CL-625 Truck

for CL-625-ONT Truck

for CL-800 Truck 
The following equations were developed for longitudinal positive moment in exterior span generated by one lane of CL-W loading in four equal spans bridge configurations. Figure 3.27 shows comparison between these developed equations and the data from analysis.

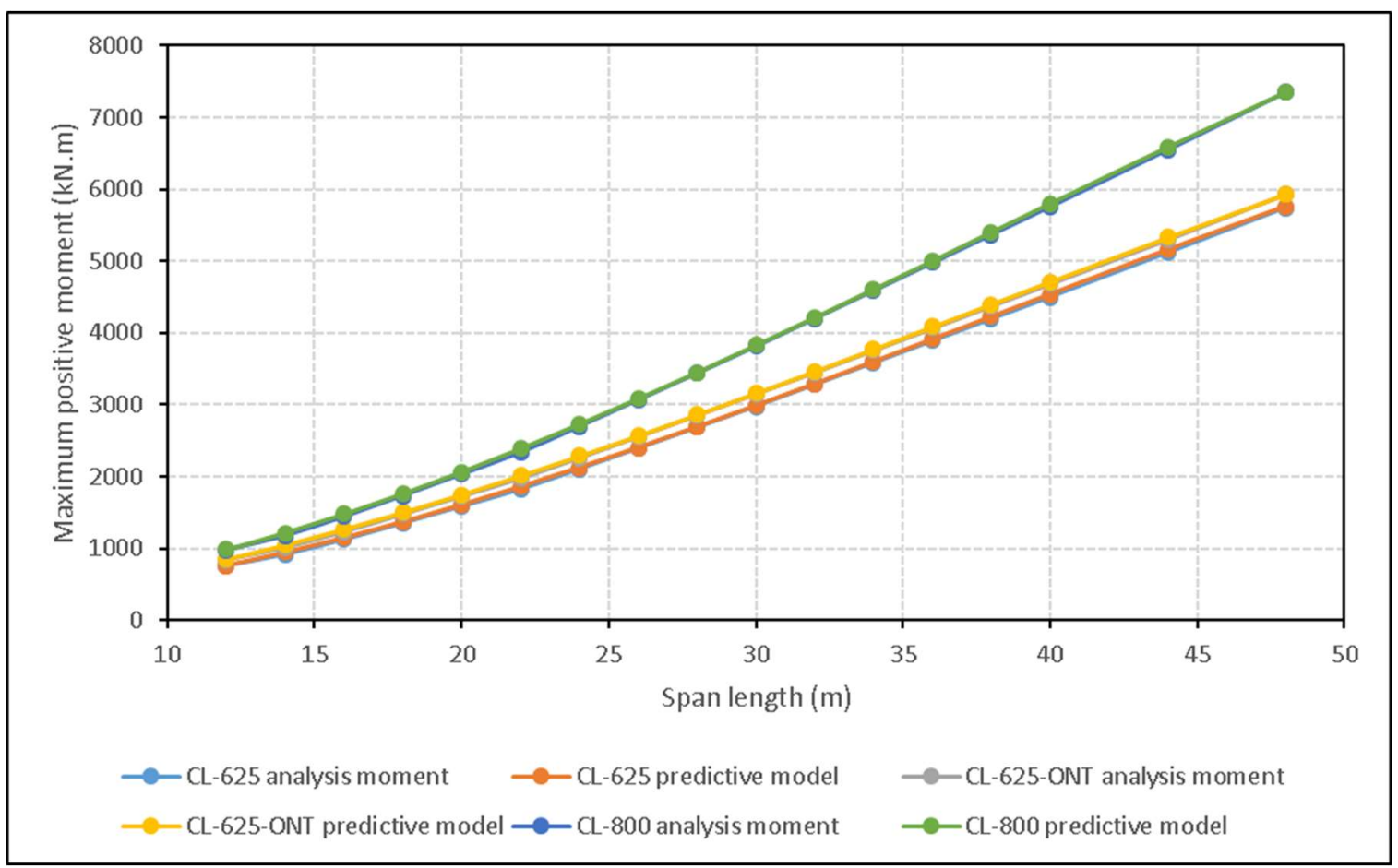

Figure 3.27: Comparison between the developed equations and the results obtained from SAP2000 model for longitudinal positive moment in exterior span generated by one lane of CLW loading in four equal spans bridge configurations

$$
\begin{array}{ll}
{[3.61] \mathrm{M}_{\mathrm{T}+}=-0.034\left(\mathrm{~L}^{3}\right)+3.9\left(\mathrm{~L}^{2}\right)+7.75(\mathrm{~L})+164 \mathrm{kN} . \mathrm{m}} & \text { for CL-625 Truck } \\
{[3.62] \mathrm{M}_{\mathrm{T}+}=-0.031\left(\mathrm{~L}^{3}\right)+3.45\left(\mathrm{~L}^{2}\right)+26.33(\mathrm{~L})+90 \mathrm{kN} . \mathrm{m}} & \text { for CL-625-ONT Truck } \\
{[3.63] \mathrm{M}_{\mathrm{T}+}=-0.044\left(\mathrm{~L}^{3}\right)+5\left(\mathrm{~L}^{2}\right)+9.9(\mathrm{~L})+220 \mathrm{kN} . \mathrm{m}} & \text { for CL-800 Truck }
\end{array}
$$


The following equations were developed for deflection in exterior span generated by one lane of CL-W loading in four equal spans bridge configurations. Figure 3.28 shows comparison between these developed equations and the data from analysis.

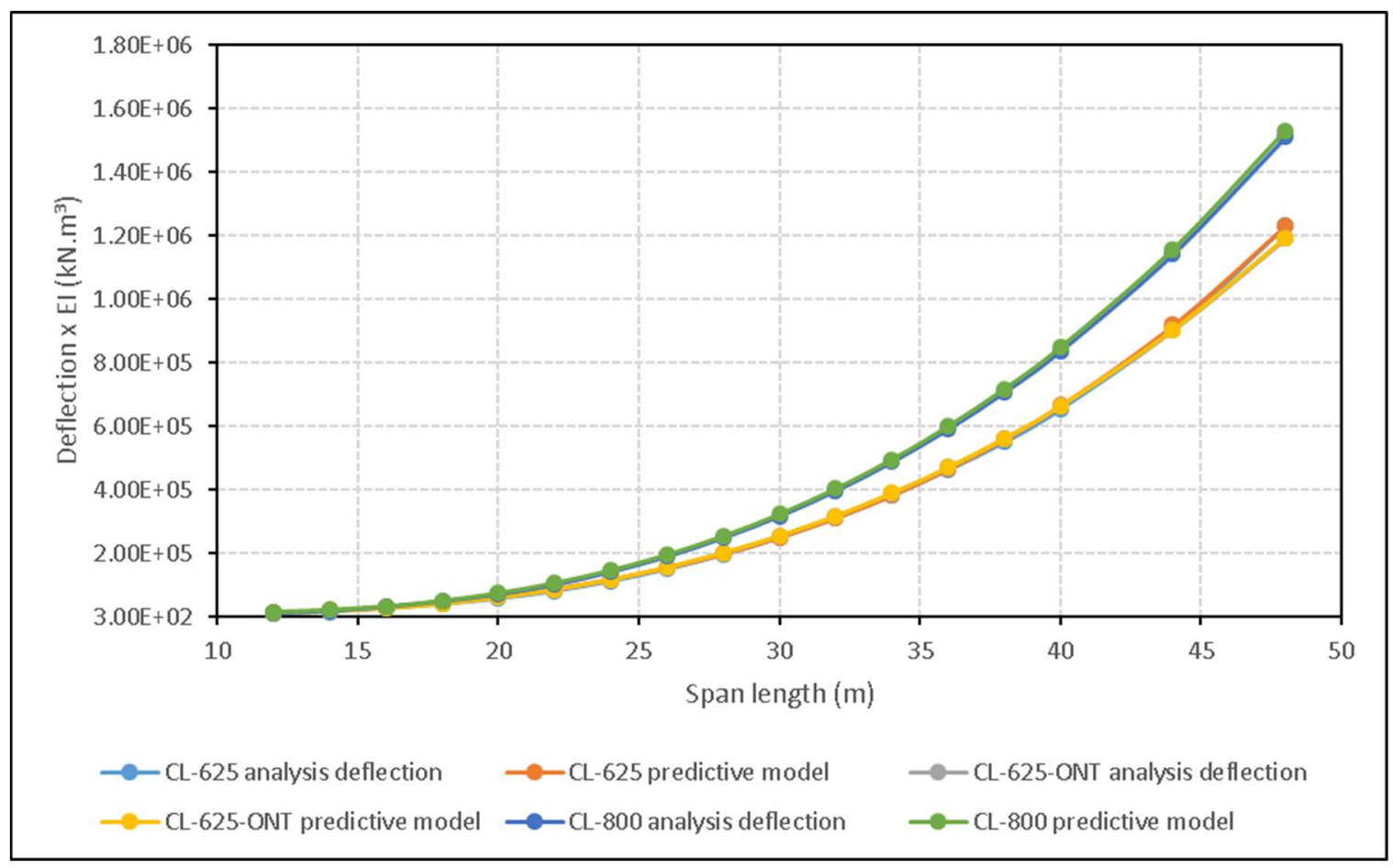

Figure 3.28: Comparison between the developed equations and the results obtained from SAP2000 model for deflection in exterior span generated by one lane of CL-W loading in four equal spans bridge configurations

$$
\begin{array}{ll}
{[3.64] \Delta_{\mathrm{T}} * \mathrm{EI}=17.2\left(\mathrm{~L}^{3}\right)-400\left(\mathrm{~L}^{2}\right)-5944(\mathrm{~L})-31000 \mathrm{kN} \cdot \mathrm{m}^{3}} & \text { for CL-625 Truck } \\
{[3.65] \Delta_{\mathrm{T}} * \mathrm{EI}=11.7\left(\mathrm{~L}^{3}\right)+15\left(\mathrm{~L}^{2}\right)-3560(\mathrm{~L})+32600 \mathrm{kN} \cdot \mathrm{m}^{3}} & \text { for CL-625-ONT Truck } \\
{[3.66] \Delta_{\mathrm{T}} * \mathrm{EI}=15.0\left(\mathrm{~L}^{3}\right)+40\left(\mathrm{~L}^{2}\right)-5630(\mathrm{~L})+50450 \mathrm{kN} \cdot \mathrm{m}^{3}} & \text { for CL-800 Truck }
\end{array}
$$




\subsubsection{Interior span}

The following equations were developed for support reaction at first interior support generated by one lane of CL-W loading in four equal spans bridge configurations. Figure 3.29 shows comparison between these developed equations and the data from analysis.

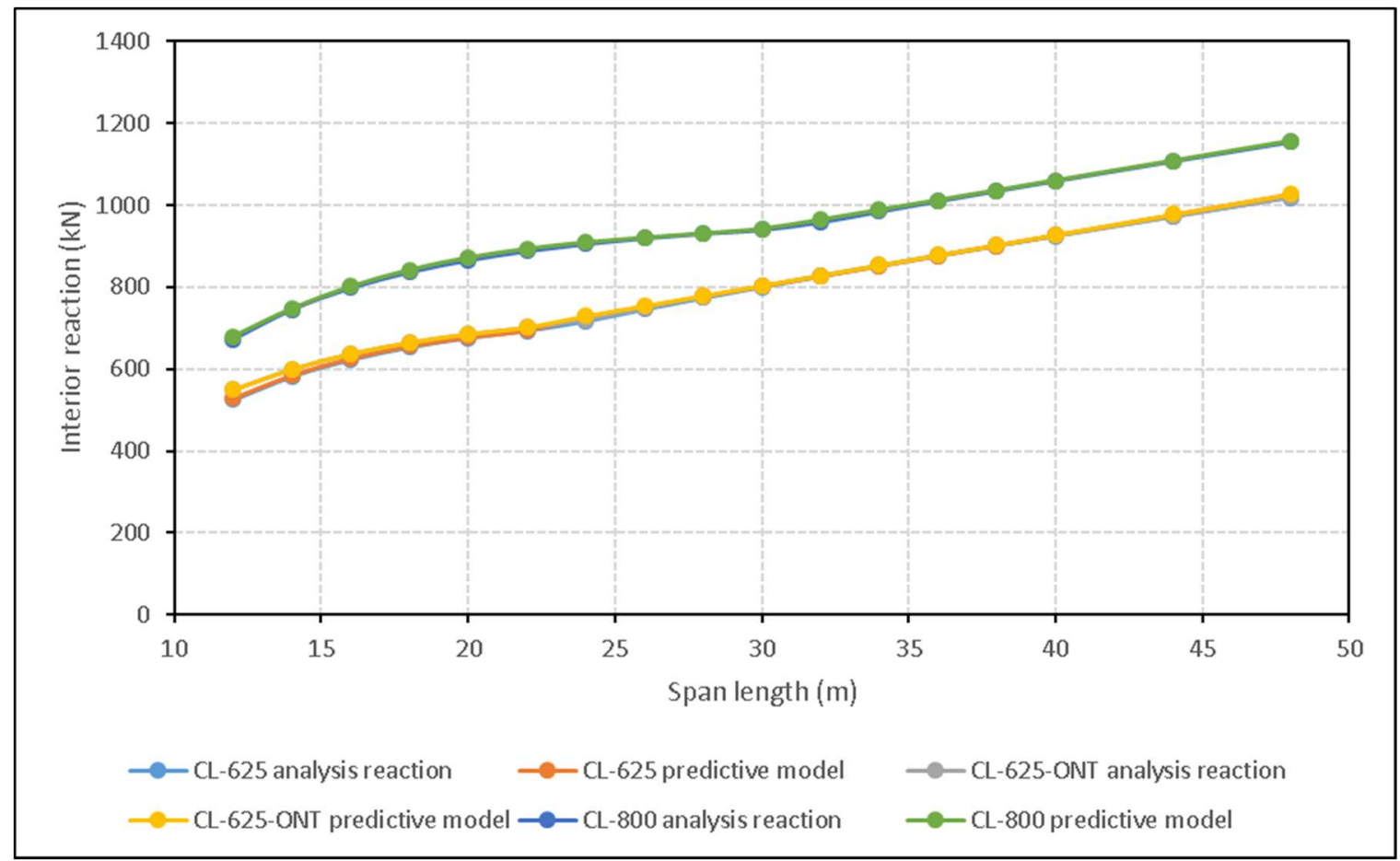

Figure 3.29: Comparison between the developed equations and the results obtained from SAP2000 model for support reaction at first interior support generated by one lane of CL-W loading in four equal spans bridge configurations

$$
\begin{aligned}
& \text { [3.67] } \mathrm{R}_{\text {Text }}=0.073\left(\mathrm{~L}^{3}\right)-4.95\left(\mathrm{~L}^{2}\right)+119.7(\mathrm{~L})-320 \mathrm{kN}(12 \mathrm{~m} \leq \mathrm{L} \leq 22 \mathrm{~m}) \\
& \mathrm{R}_{\text {Text }}=12.4(\mathrm{~L})+430 \mathrm{kN}(22 \mathrm{~m}<\mathrm{L} \leq 48 \mathrm{~m}) \text { for CL-625 Truck } \\
& \text { [3.68] } \mathrm{R}_{\text {Text }}=0.061\left(\mathrm{~L}^{3}\right)-4.18\left(\mathrm{~L}^{2}\right)+103(\mathrm{~L})-190 \mathrm{kN}(12 \mathrm{~m} \leq \mathrm{L} \leq 22 \mathrm{~m}) \\
& \mathrm{R}_{\text {Text }}=12.4(\mathrm{~L})+432 \mathrm{kN}(22 \mathrm{~m}<\mathrm{L} \leq 48 \mathrm{~m}) \text { for CL-625-ONT Truck } \\
& \text { [3.69] } \mathrm{R}_{\text {Text }}=0.048\left(\mathrm{~L}^{3}\right)-3.9\left(\mathrm{~L}^{2}\right)+111.4(\mathrm{~L})-178 \mathrm{kN}(12 \mathrm{~m} \leq \mathrm{L} \leq 30 \mathrm{~m}) \\
& \\
& \mathrm{R}_{\text {Text }}=12(\mathrm{~L})+580 \mathrm{kN}(30 \mathrm{~m}<\mathrm{L} \leq 48 \mathrm{~m}) \text { for CL-800 Truck }
\end{aligned}
$$


The following equations were developed for support reaction at centermost interior support generated by one lane of CL-W loading in four equal spans bridge configurations. Figure 3.30 shows comparison between these developed equations and the data from analysis.

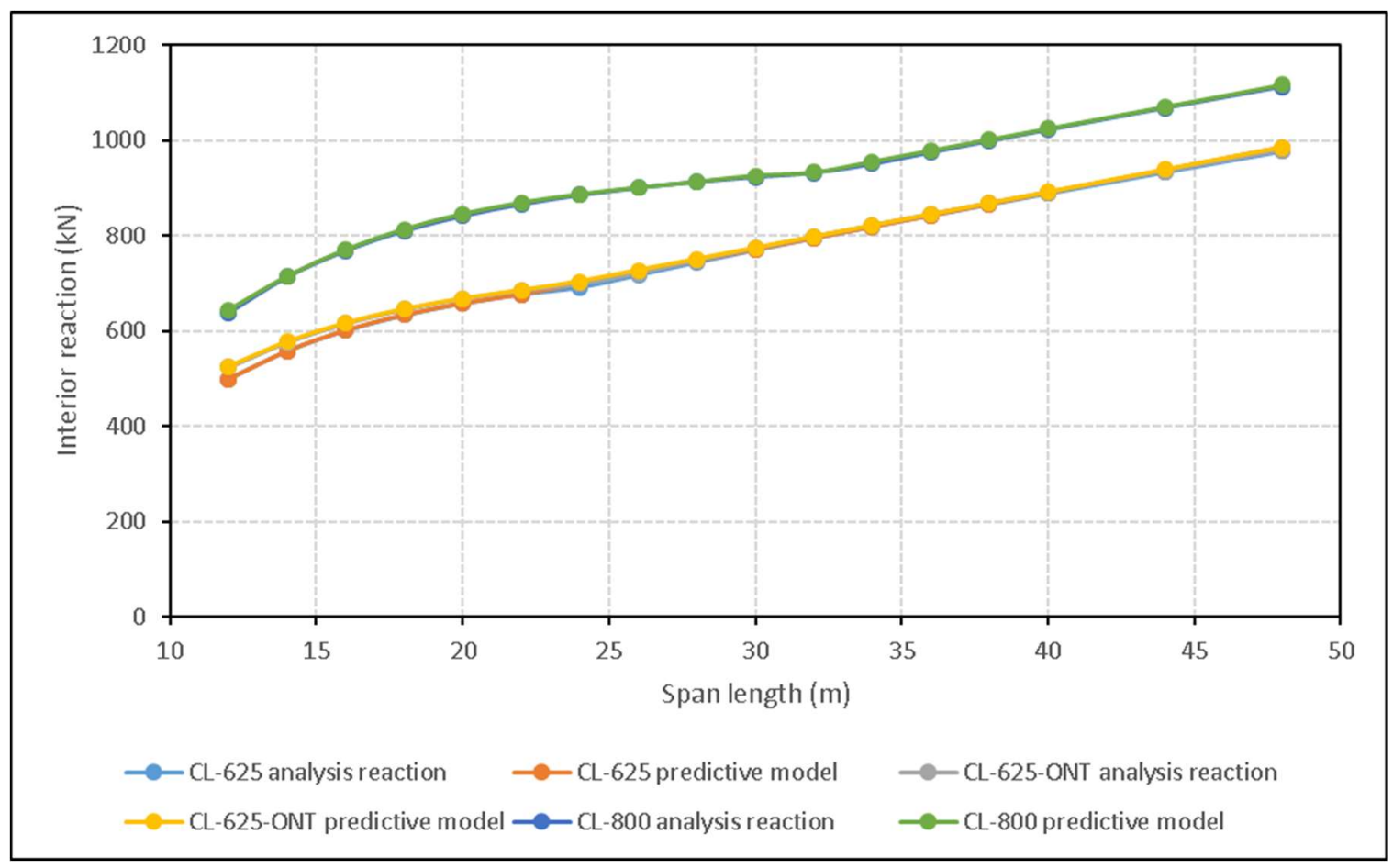

Figure 3.30: Comparison between the developed equations and the results obtained from SAP2000 model for support reaction at centermost interior support generated by one lane of CLW loading in four equal spans bridge configurations

[3.70] $\mathrm{R}_{\text {Tint }}=0.068\left(\mathrm{~L}^{3}\right)-4.7\left(\mathrm{~L}^{2}\right)+116.9(\mathrm{~L})-344 \mathrm{kN}(12 \mathrm{~m} \leq \mathrm{L} \leq 22 \mathrm{~m})$

$$
\mathrm{R}_{\text {Tint }}=11.9(\mathrm{~L})+414 \mathrm{kN}(22 \mathrm{~m}<\mathrm{L} \leq 48 \mathrm{~m}) \quad \text { for CL-625 Truck }
$$

[3.71] $\mathrm{R}_{\text {Tint }}=0.058\left(\mathrm{~L}^{3}\right)-4.06\left(\mathrm{~L}^{2}\right)+102(\mathrm{~L})-215 \mathrm{kN}(12 \mathrm{~m} \leq \mathrm{L} \leq 22 \mathrm{~m})$

$$
\mathrm{R}_{\text {Tint }}=12.4(\mathrm{~L})+432 \mathrm{kN}(22 \mathrm{~m}<\mathrm{L} \leq 48 \mathrm{~m}) \quad \text { for CL-625-ONT Truck }
$$

[3.72] $\mathrm{R}_{\text {Tint }}=0.048\left(\mathrm{~L}^{3}\right)-3.9\left(\mathrm{~L}^{2}\right)+112.8(\mathrm{~L})-230 \mathrm{kN}(12 \mathrm{~m} \leq \mathrm{L} \leq 30 \mathrm{~m})$

$\mathrm{R}_{\text {Tint }}=11.5(\mathrm{~L})+565 \mathrm{kN}(30 \mathrm{~m}<\mathrm{L} \leq 48 \mathrm{~m}) \quad$ for CL-800 Truck

The following equations were developed for shear left of first interior support generated by one lane of CL-W loading in four equal spans bridge configurations. Figure 3.31 shows comparison between these developed equations and the data from analysis. 


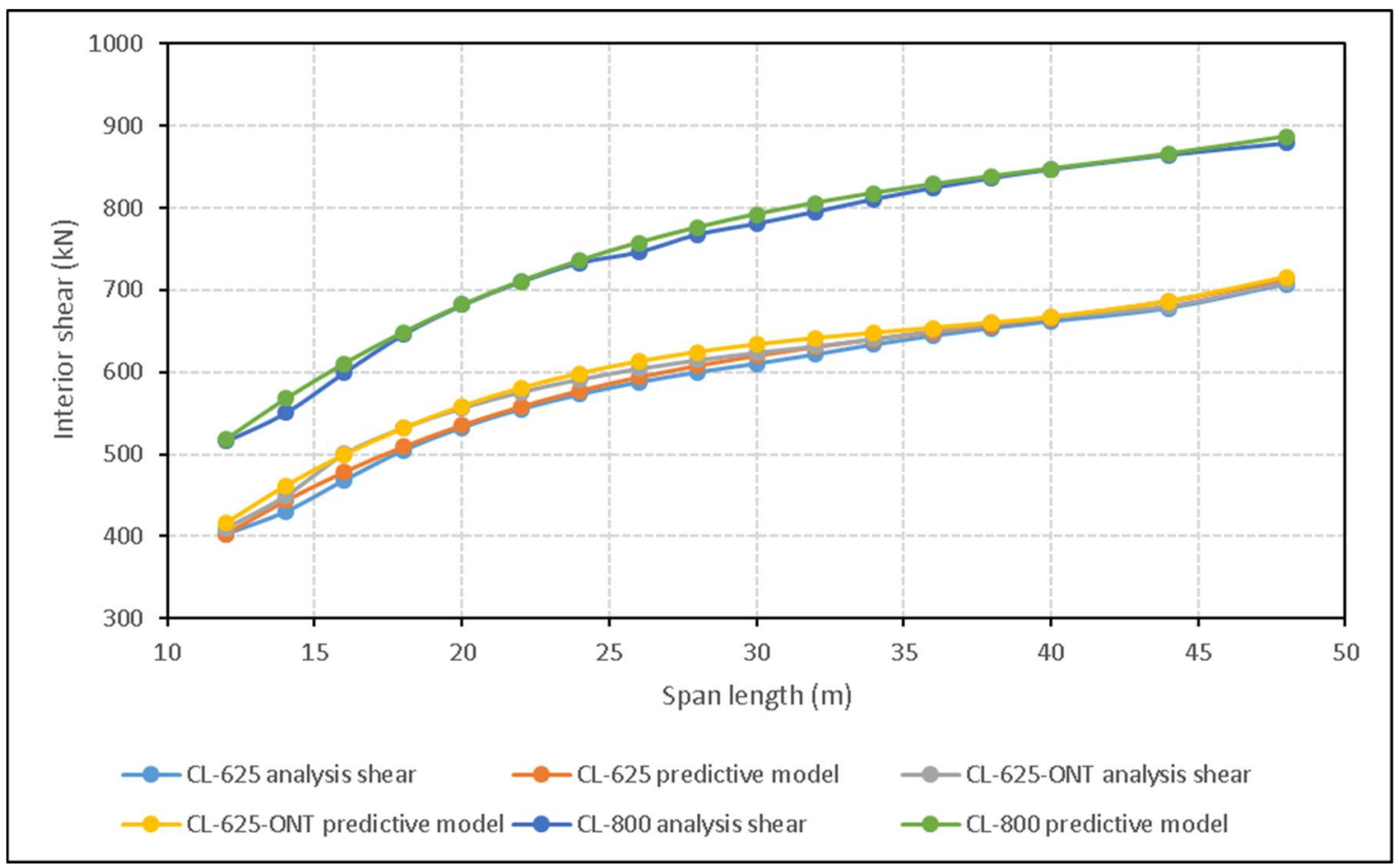

Figure 3.31: Comparison between the developed equations and the results obtained from SAP2000 model for shear left of first interior support generated by one lane of CL-W loading in four equal spans bridge configurations

[3.73] $\mathrm{V}_{\text {Text }}=0.0037\left(\mathrm{~L}^{3}\right)-0.516\left(\mathrm{~L}^{2}\right)+26.9(\mathrm{~L})+92 \mathrm{kN} \quad$ for CL-625 Truck

[3.74] $\mathrm{V}_{\text {Text }}=0.0035\left(\mathrm{~L}^{3}\right)-0.49\left(\mathrm{~L}^{2}\right)+25.2(\mathrm{~L})+145 \mathrm{kN}$ for CL-625-ONT Truck

$[3.75] \mathrm{V}_{\text {Text }}=0.0086\left(\mathrm{~L}^{3}\right)-1.05\left(\mathrm{~L}^{2}\right)+47.2(\mathrm{~L})+89 \mathrm{kN}$ for CL-800 Truck 
The following equations were developed for shear right of first interior support generated by one lane of CL-W loading in four equal spans bridge configurations. Figure 3.32 shows comparison between these developed equations and the data from analysis.

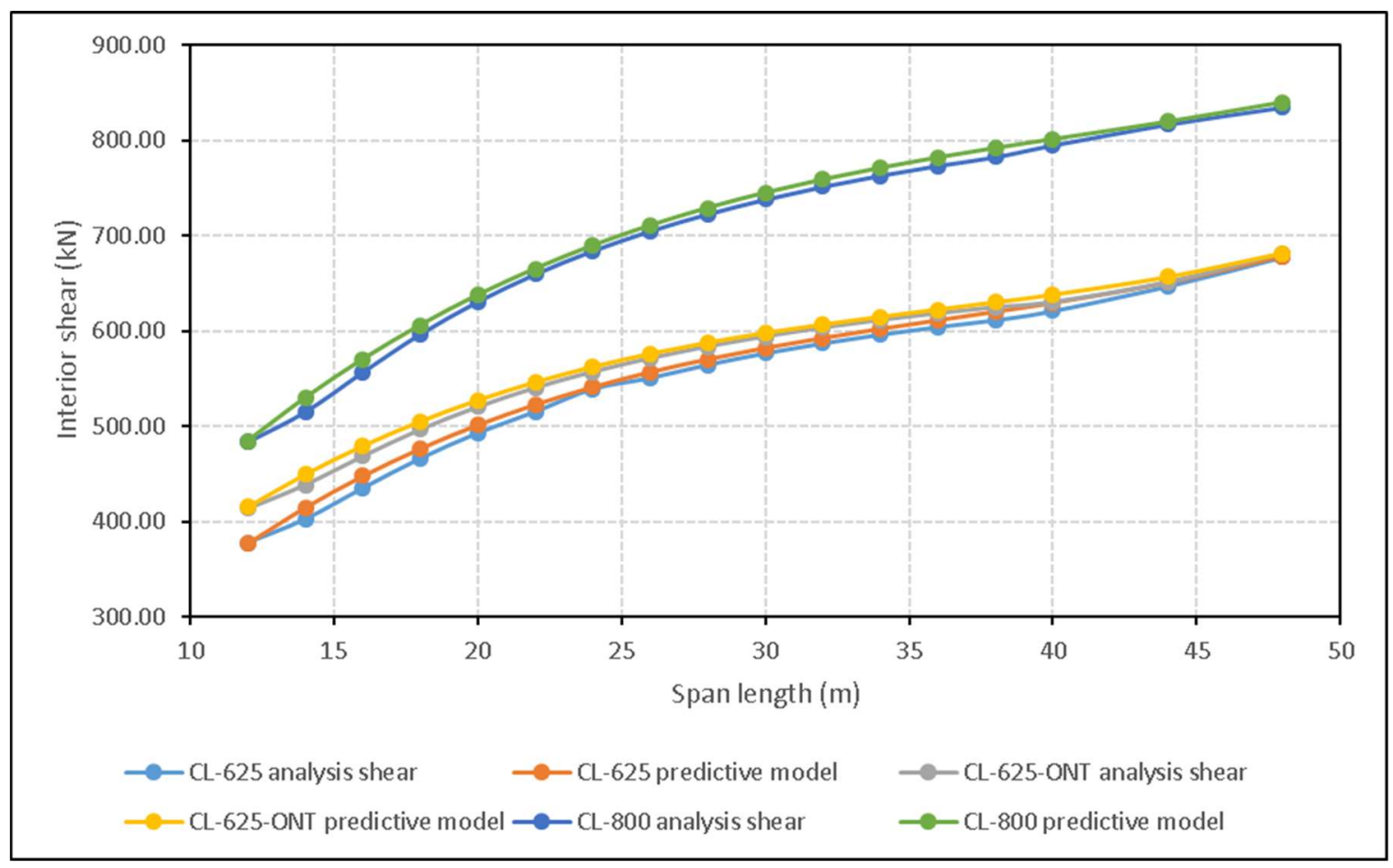

Figure 3.32: Comparison between the developed equations and the results obtained from SAP2000 model for shear right of first interior support generated by one lane of CL-W loading in four equal spans bridge configurations

[3.76] $\mathrm{V}_{\text {Tint }}=0.007\left(\mathrm{~L}^{3}\right)-0.84\left(\mathrm{~L}^{2}\right)+36.7(\mathrm{~L})+48 \mathrm{kN}$ for CL-625 Truck [3.77] $\mathrm{V}_{\text {Tint }}=0.007\left(\mathrm{~L}^{3}\right)-0.81\left(\mathrm{~L}^{2}\right)+34.4(\mathrm{~L})+109 \mathrm{kN}$ for CL-625-ONT Truck $[3.78] \mathrm{V}_{\text {Tint }}=0.008\left(\mathrm{~L}^{3}\right)-0.97\left(\mathrm{~L}^{2}\right)+44.3(\mathrm{~L})+81 \mathrm{kN}$ for CL-800 Truck 
The following equations were developed for longitudinal positive moment in interior span generated by one lane of CL-W loading in four equal spans bridge configurations. Figure 3.33 shows comparison between these developed equations and the data from analysis.

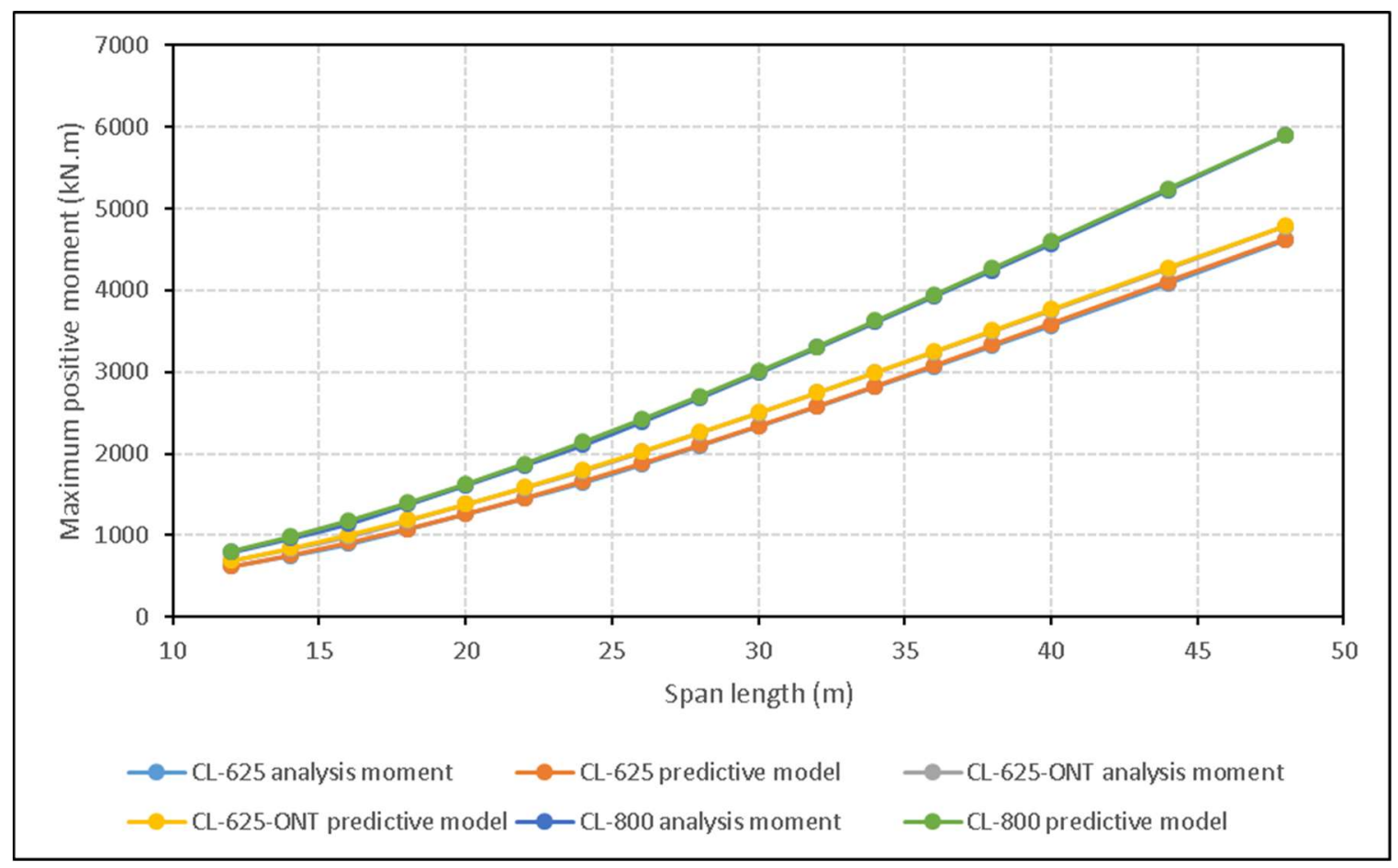

Figure 3.33: Comparison between the developed equations and the results obtained from SAP2000 model for longitudinal positive moment in interior span generated by one lane of CL$\mathrm{W}$ loading in four equal spans bridge configurations

$$
\begin{array}{ll}
\text { [3.79] } \mathrm{M}_{\mathrm{T}+}=-0.023\left(\mathrm{~L}^{3}\right)+2.96\left(\mathrm{~L}^{2}\right)+3.61(\mathrm{~L})+195 \mathrm{kN} . \mathrm{m} & \text { for CL-625 Truck } \\
{[3.80] \mathrm{M}_{\mathrm{T}+}=-0.024\left(\mathrm{~L}^{3}\right)+2.90\left(\mathrm{~L}^{2}\right)+12.6(\mathrm{~L})+167 \mathrm{kN} . \mathrm{m}} & \text { for CL-625-ONT Truck } \\
{[3.81] \mathrm{M}_{\mathrm{T}+}=-0.032\left(\mathrm{~L}^{3}\right)+3.90\left(\mathrm{~L}^{2}\right)+2.6(\mathrm{~L})+269 \mathrm{kN} . \mathrm{m}} & \text { for CL-800 Truck }
\end{array}
$$


The following equations were developed for longitudinal negative moment at first interior support generated by one lane of CL-W loading in four equal spans bridge configurations. Figure 3.34 shows comparison between these developed equations and the data from analysis.

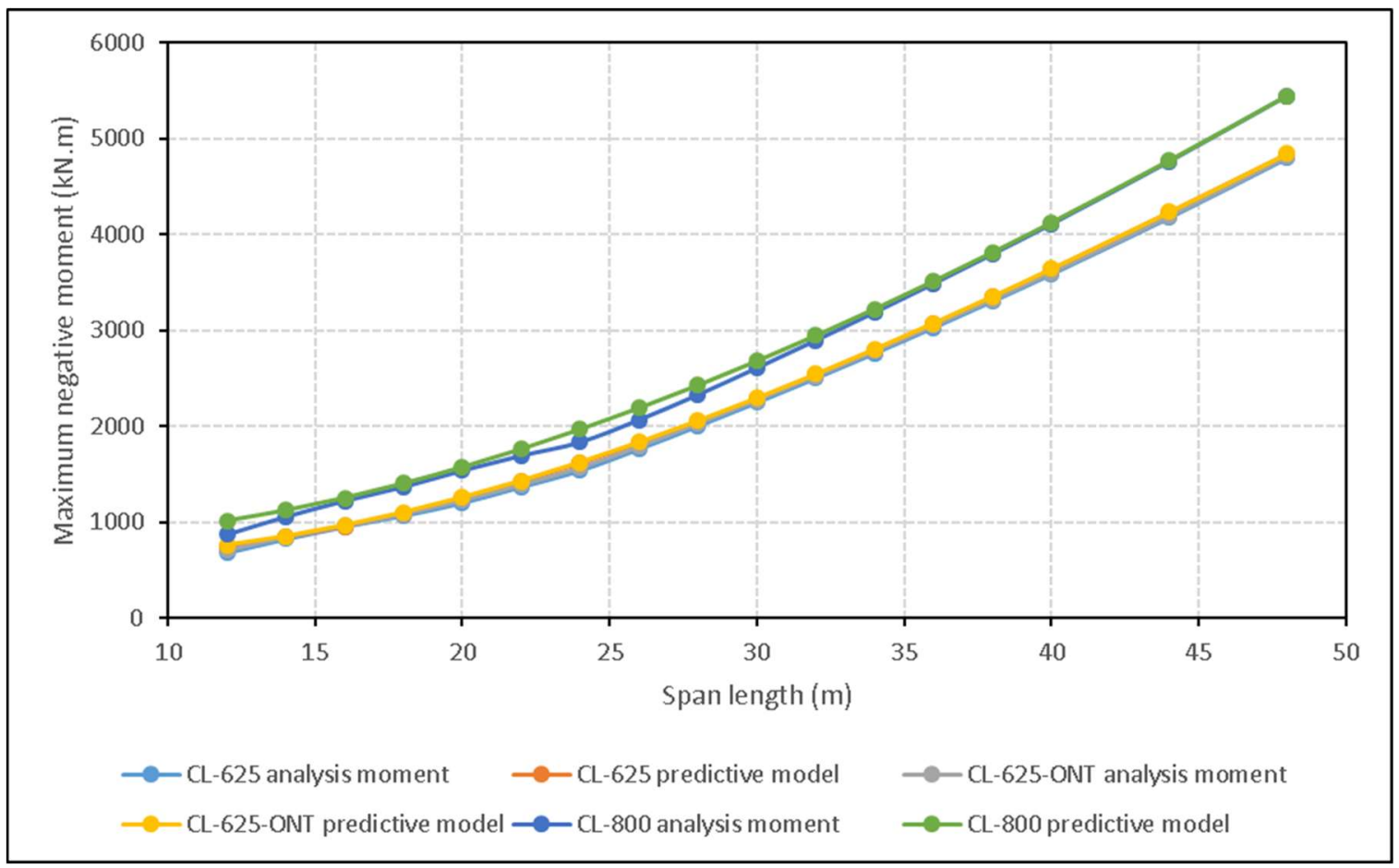

Figure 3.34: Comparison between the developed equations and the results obtained from SAP2000 model for longitudinal negative moment at first interior support generated by one lane of CL-W loading in four equal spans bridge configurations

$$
\begin{array}{ll}
{[3.82] \mathrm{M}_{\text {T-ext }}=-0.026\left(\mathrm{~L}^{3}\right)+3.91\left(\mathrm{~L}^{2}\right)-42.4(\mathrm{~L})+740 \mathrm{kN} . \mathrm{m}} & \text { for CL-625 Truck } \\
{[3.83] \mathrm{M}_{\text {T-ext }}=-0.026\left(\mathrm{~L}^{3}\right)+3.91\left(\mathrm{~L}^{2}\right)-42.4(\mathrm{~L})+750 \mathrm{kN} . \mathrm{m}} & \text { for CL-625-ONT Truck } \\
{[3.84] \mathrm{M}_{\mathrm{T}-\mathrm{ext}}=-0.020\left(\mathrm{~L}^{3}\right)+3.50\left(\mathrm{~L}^{2}\right)-26.5(\mathrm{~L})+865 \mathrm{kN} . \mathrm{m}} & \text { for CL-800 Truck }
\end{array}
$$


The following equations were developed for longitudinal negative moment at centermost interior support generated by one lane of CL-W loading in four equal spans bridge configurations. Figure 3.35 shows comparison between these developed equations and the data from analysis.

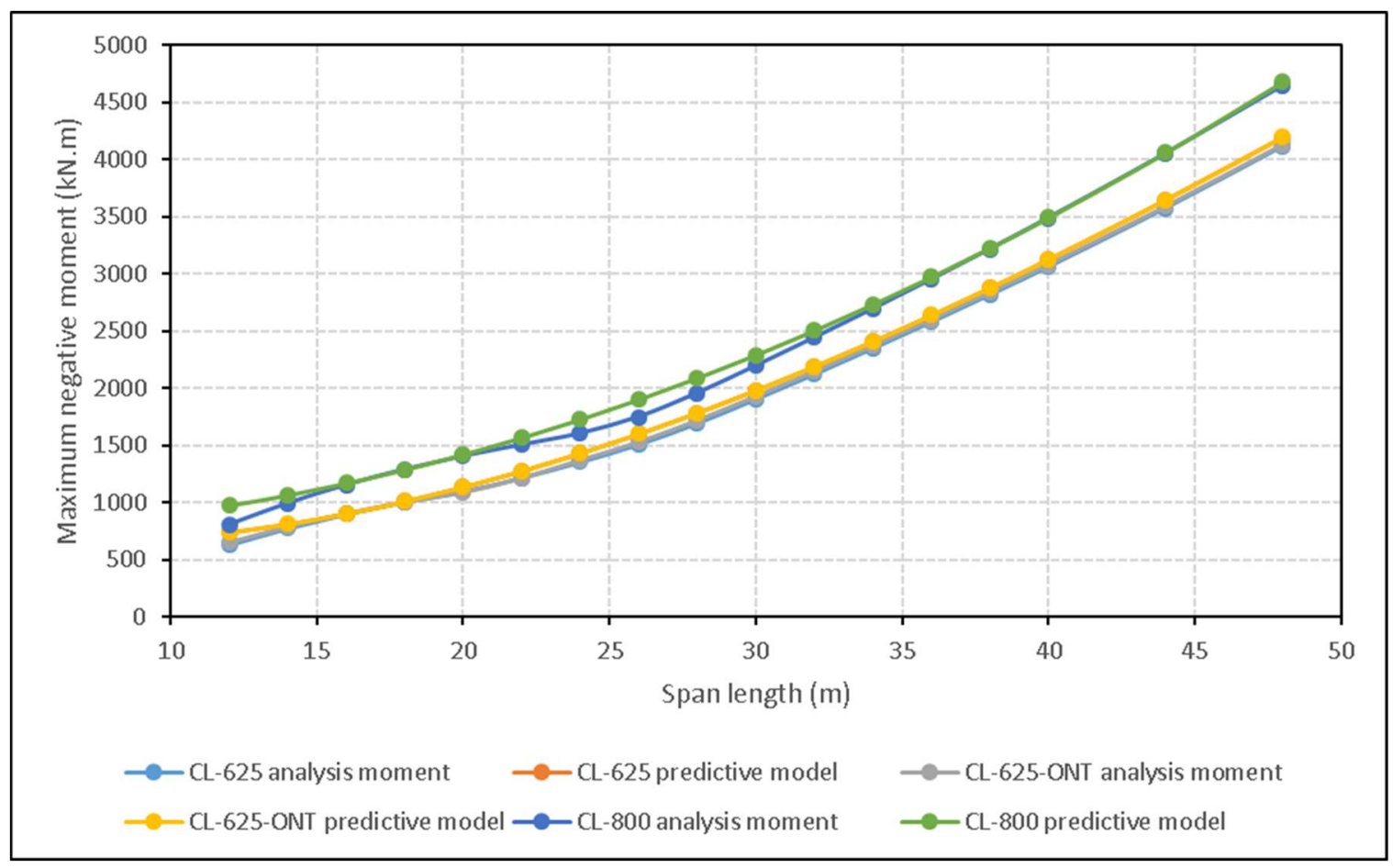

Figure 3.35: Comparison between the developed equations and the results obtained from SAP2000 model for longitudinal negative moment at centermost interior support generated by one lane of CL-W loading in four equal spans bridge configurations

$$
\begin{array}{ll}
{[3.85] \mathrm{M}_{\text {T-int }}=-0.016\left(\mathrm{~L}^{3}\right)+2.96\left(\mathrm{~L}^{2}\right)-32.4(\mathrm{~L})+731 \mathrm{kN} . \mathrm{m}} & \text { for CL-625 Truck } \\
{[3.86] \mathrm{M}_{\text {T-int }}=-0.016\left(\mathrm{~L}^{3}\right)+2.95\left(\mathrm{~L}^{2}\right)-32.4(\mathrm{~L})+735 \mathrm{kN} . \mathrm{m}} & \text { for CL-625-ONT Truck } \\
{[3.87] \mathrm{M}_{\text {T-int }}=-0.0032\left(\mathrm{~L}^{3}\right)+1.94\left(\mathrm{~L}^{2}\right)-3.9(\mathrm{~L})+750 \mathrm{kN} . \mathrm{m}} & \text { for CL-800 Truck }
\end{array}
$$


The following equations were developed for deflection in interior span generated by one lane of CL-W loading in four equal spans bridge configurations. Figure 3.36 shows comparison between these developed equations and the data from analysis.

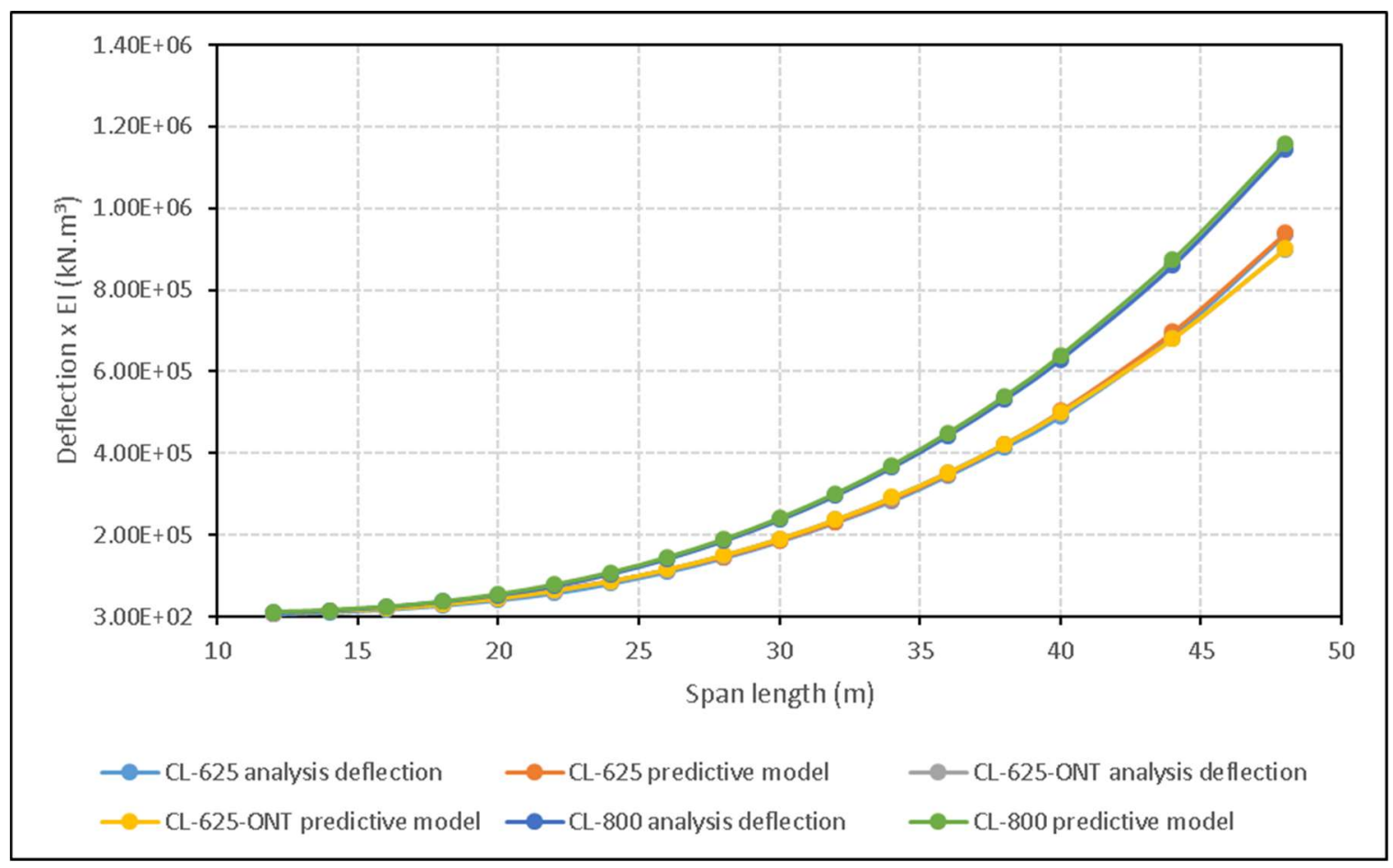

Figure 3.36: Comparison between the developed equations and the results obtained from SAP2000 model for deflection in interior span generated by one lane of CL-W loading in four equal spans bridge configurations

$$
\begin{array}{ll}
{[3.88] \Delta_{\mathrm{T}} * \mathrm{EI}=13.7\left(\mathrm{~L}^{3}\right)-345\left(\mathrm{~L}^{2}\right)-5194(\mathrm{~L})-29000 \mathrm{kN} \cdot \mathrm{m}^{3}} & \text { for CL-625 Truck } \\
{[3.89] \Delta_{\mathrm{T}} * \mathrm{EI}=9.1\left(\mathrm{~L}^{3}\right)+0.78\left(\mathrm{~L}^{2}\right)-2650(\mathrm{~L})+25700 \mathrm{kN} \cdot \mathrm{m}^{3}} & \text { for CL-625-ONT Truck } \\
{[3.90] \Delta_{\mathrm{T}} * \mathrm{EI}=11.8\left(\mathrm{~L}^{3}\right)-3800(\mathrm{~L})+36000 \mathrm{kN} \cdot \mathrm{m}^{3}} & \text { for CL-800 Truck }
\end{array}
$$




\subsection{Comments regarding empirical equations}

In terms of data accuracy, deflection equations proved to be very representative of the data samples with accuracies in the range of $99.99 \%$. Moment equations were also very accurate with accuracy values in the range of $99.95 \%$. Shear and reaction equations were the least accurate with accuracy of $98.5 \%$. All empirical equations were created to slightly overestimate the result by $1-2 \%$. This is to prevent any chance of under-designing the bridge section. Further information and analysis of these results can be found elsewhere (Diab \& Sennah, 2018).

In terms of similarity of results, equations for multi-span bridge configurations seem very similar to one another with only minor variances in the range $5 \%$. Furthermore, there is great similarity between equations produced for the CL-625 and CL-625-ONT truck. As can be seen in Figure 3.37 , moments produced by the CL-625 and CL-625-ONT truck loadings are within 3.5\% of each other overall. 


\section{Chapter IV}

\section{Software Development and Results}

\subsection{Objectives behind development of software}

In order to be able to study the relationships between all the different parameter that affect the selection of a girder section, a quick method of girder design was required to be established. The author elected to design a VB.Net software that needs to be able to:

1) Calculate applied dead load and live load on bridge girders

2) Obtain factored applied moment, shear, deflection and support reactions at ULS, SLS and FLS

3) Asses I-girder section for construction stage permanent (plastic) deflection at SLS

4) Asses section for construction stage applied moment at ULS

5) Asses section for superstructure vibration at SLS

6) Asses section for applied shear, moment and their combined effect at ULS

7) Asses section for fatigue resistance at FLS

\subsection{Functions of different software modules}

The software was designed to meet the objectives stated in section 4.1. The main menu of the software can be seen in Figure 1. The main menu provides the user with an option to input the variables required by the program in the main menu once and then send these values to the other modules so that the modules require no further input from the user. However, if the user only needs to run one module, the option to input the data required by the module into the module itself is also an option. 


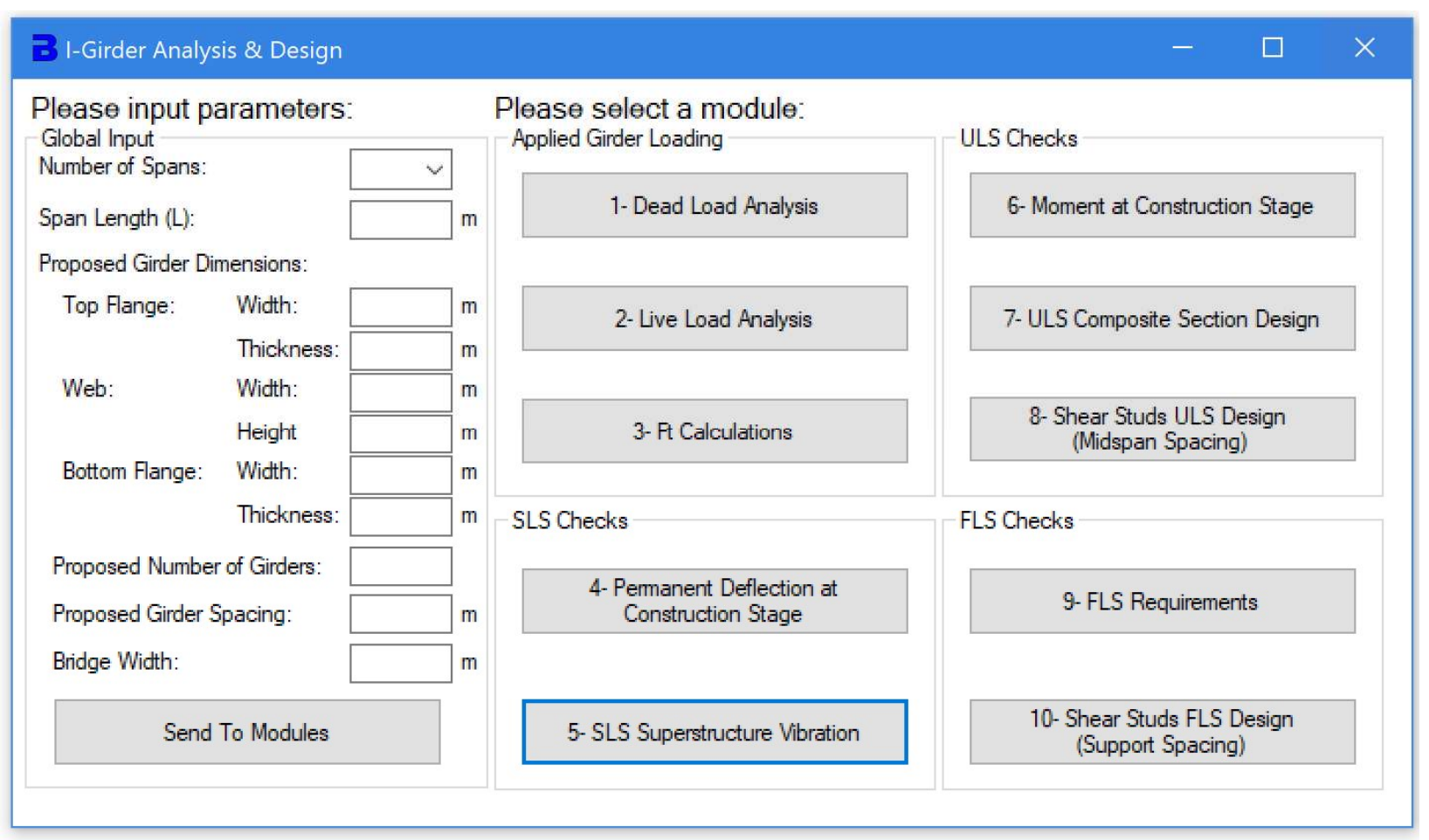

Figure 4.1: Screenshot showing the main menu of the I-girder design software

\subsubsection{Design load values calculation modules}

The first module the in the process of girder analysis is the dead load calculation module. In this module, the program takes the input regarding the bridge dimensions and calculates applied dead load moment, shear, support reactions and deflection. A flowchart showing the operation of the software can be seen in Figure 2. A screenshot showing the front end Graphical User Interface (GUI) can be seen in Figure 3. 


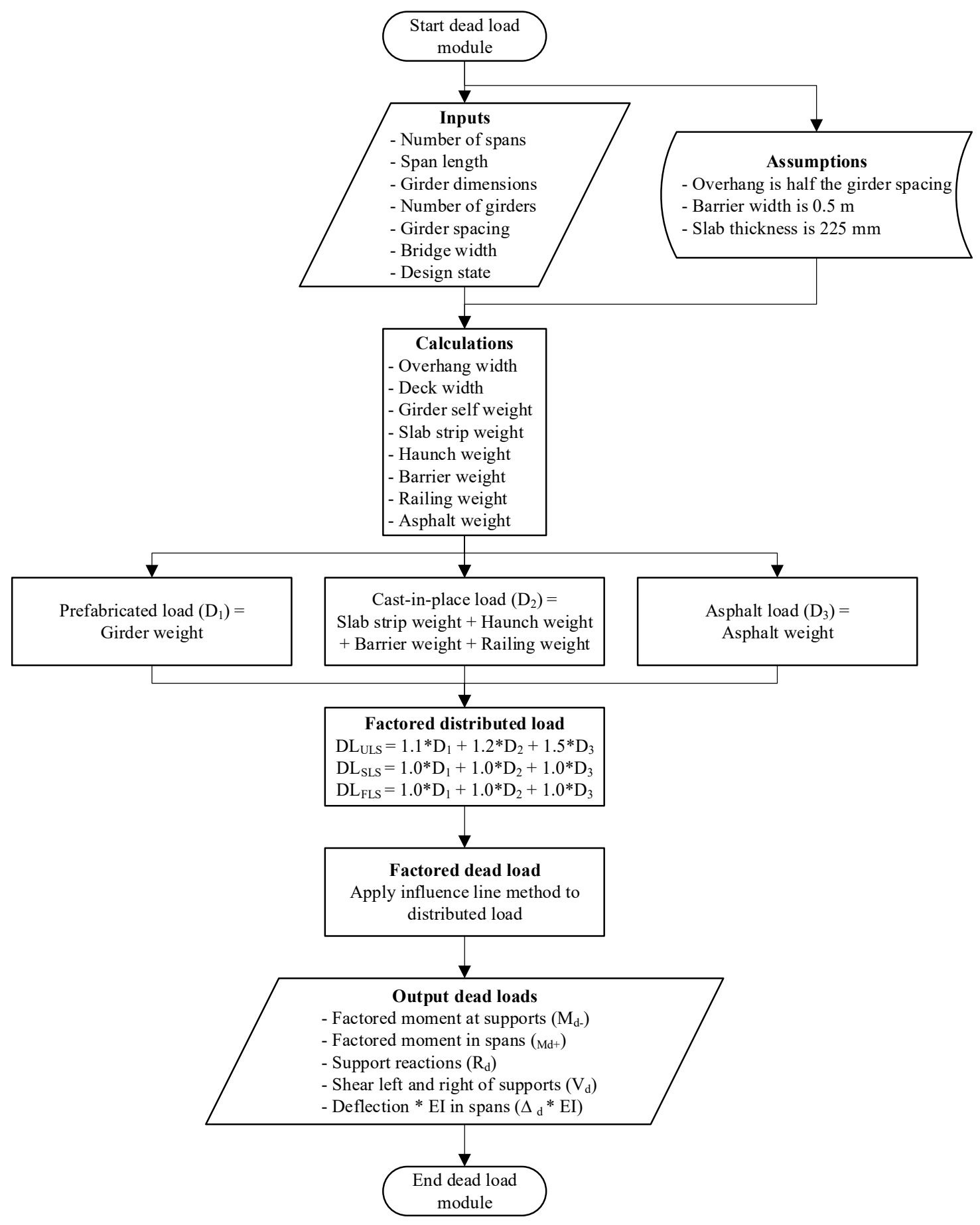

Figure 4.2: Flowchart showing the back-end operations of the dead load module developed as part of the I-girder design software 


\section{Dead Load Module}

- Input

Number of Bridge Spans:

Span Length:

Proposed Girder Dimensions:

Top Flange: Width:

Thickness:

Web:

Width:

Height

Bottom Flange: Width:

Thickness:
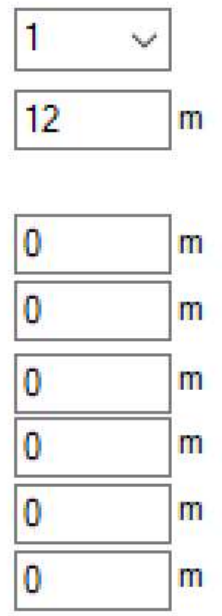

Proposed Number of Girders:

Bridge Width:

Girder Spacing:

Design State:

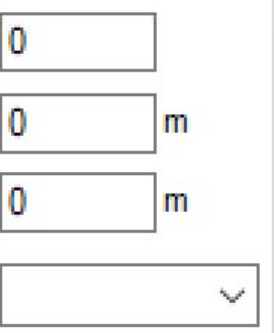

\section{Dead Load Calculations}

Prefabricated:

Cast In Place:

Asphalt Layer:

Total Factored Loading:

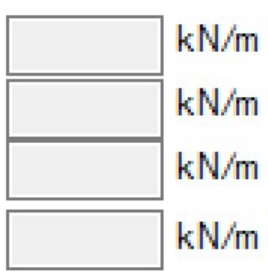

\section{Step 1: Calculate Factored Dead Load}

Dead Load Maximum Reaction

Reaction A:

Reaction B:

Reaction C:

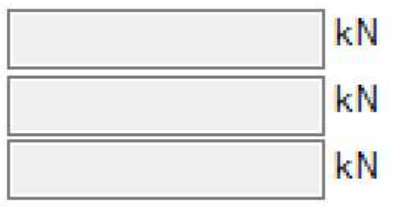

Dead Load Maximum Shear

Shear A:

Shear Right of B:

Shear Left of $\mathrm{B}$ :

Shear Right of $\mathrm{C}$ :

Shear Left of $\mathrm{C}$ :

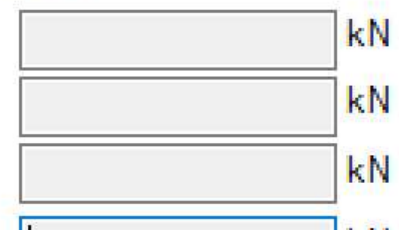

Dead Load Maximum Moment

Moment AB:

Moment B:

Moment BC:

Moment $\mathrm{C}$ :

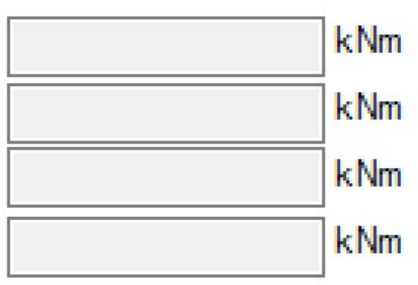

Dead Load Maximum Deflection

Max Deflection: $m^{*} \mathrm{E}$

Step 2: Calculate Dead Load Design Values

Send Values To Other Modules

Figure 4.3: Screenshot showing the front-end layout of the dead load module developed as part of the I-girder design software 
Followed by the dead load calculations module is the live load module. This module depends heavily on the equations developed in chapter 3 of this thesis. This module takes input regarding the number of spans, the span length and the truck loading to be used and produces output that includes maximum longitudinal live load moments at support locations, maximum longitudinal live load moments within spans, support reactions, shear left and right of supports and deflection in spans. A flowchart showing the operation of the module can be seen in Figure 4. The frontend GUI of the module can be seen in Figure 5.

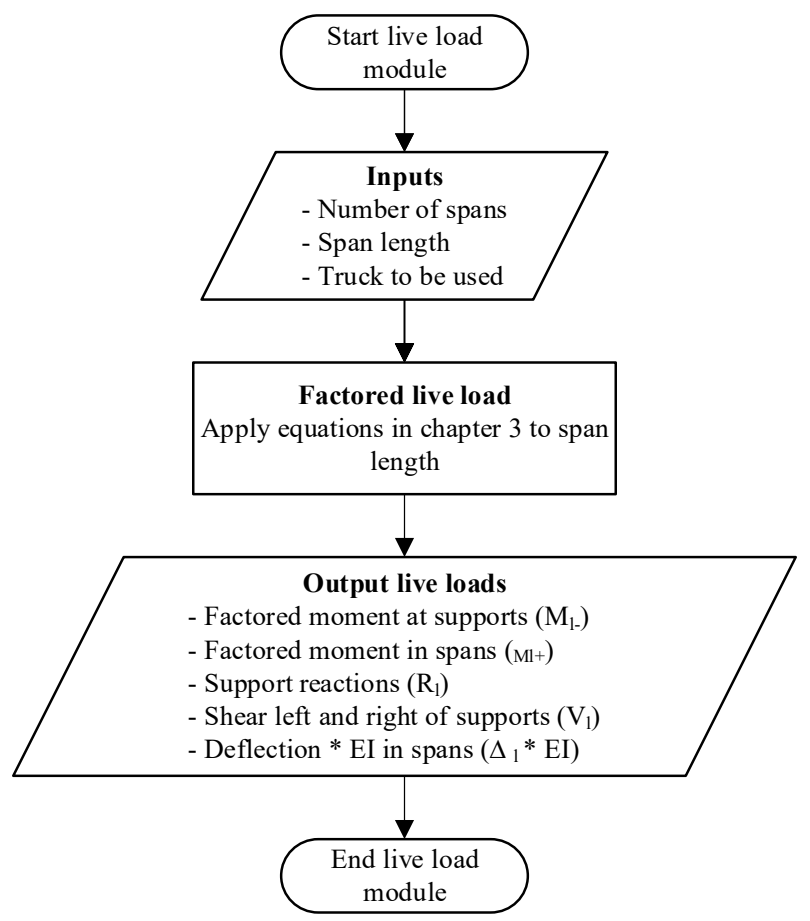

Figure 4.4: Flowchart showing the back-end operations of the live load module developed as part of the I-girder design software 


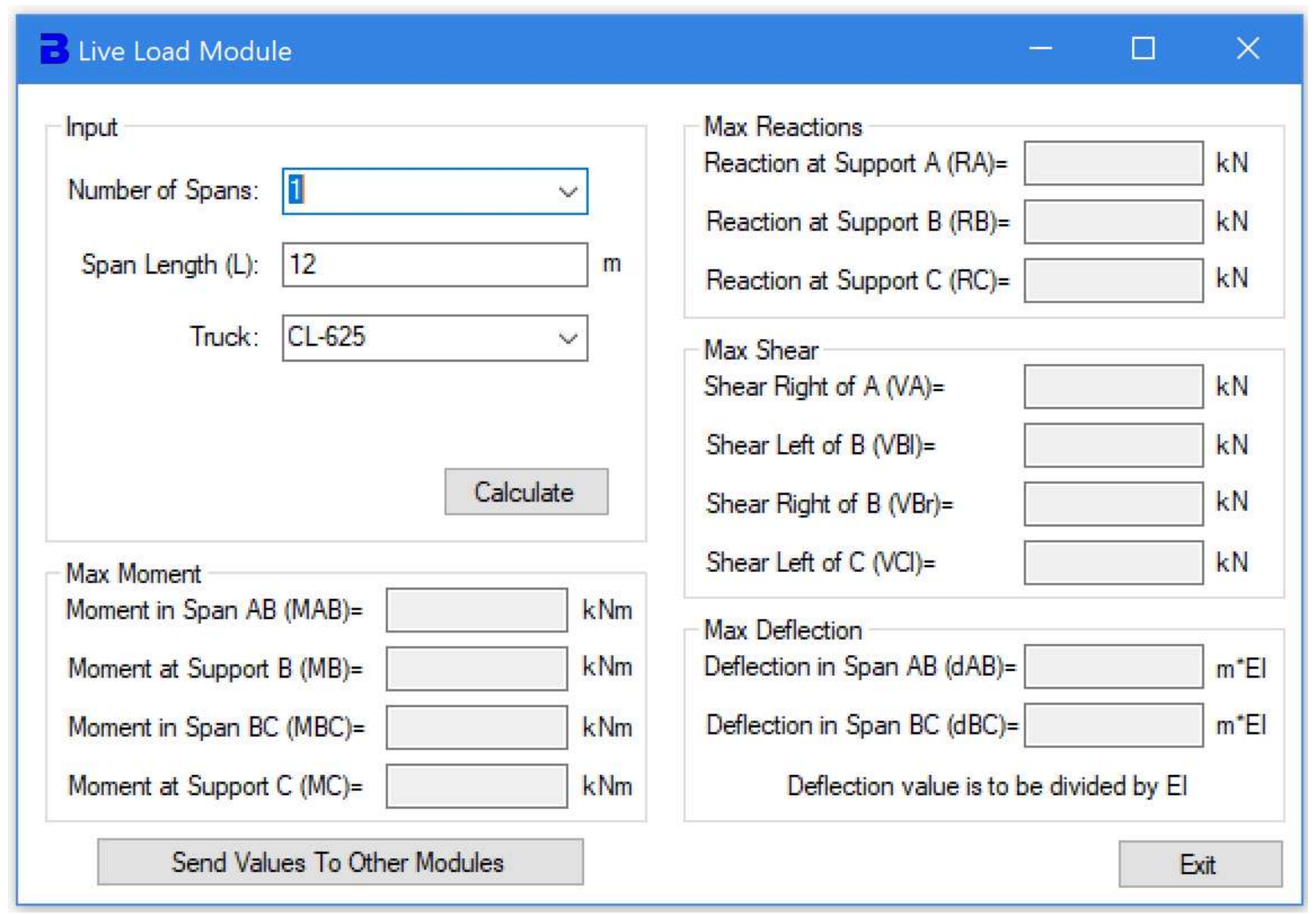

Figure 4.5: Screenshot showing the front-end layout of the live load module developed as part of the I-girder design software

Accompanied by the live load module is the truck factor $\left(\mathrm{F}_{\mathrm{T}}\right)$ module. This module takes input regarding the number of spans, span length, shoulder width, number of girders, girder spacing and, bridge width. This module makes the following assumptions: (i) overhang is half the girder spacing, (ii) barrier width is equal to $0.5 \mathrm{~m}$, (iii) slab thickness is $225 \mathrm{~mm}$, and (iv) the travel lane is $3.5 \mathrm{~m}$. The module conducts the calculations for $\mathrm{F}_{\mathrm{T}}$ according to the CHBDC of 2014 and produces output for $\mathrm{F}_{\mathrm{T}}$ for shear and moment for ULS, SLS and ULS for exterior and interior girders. The back-end operations of the truck factor calculation $\left(\mathrm{F}_{\mathrm{T}}\right)$ module can be seen in Figure 6. The front-end GUI can be seen in Figure 7. 


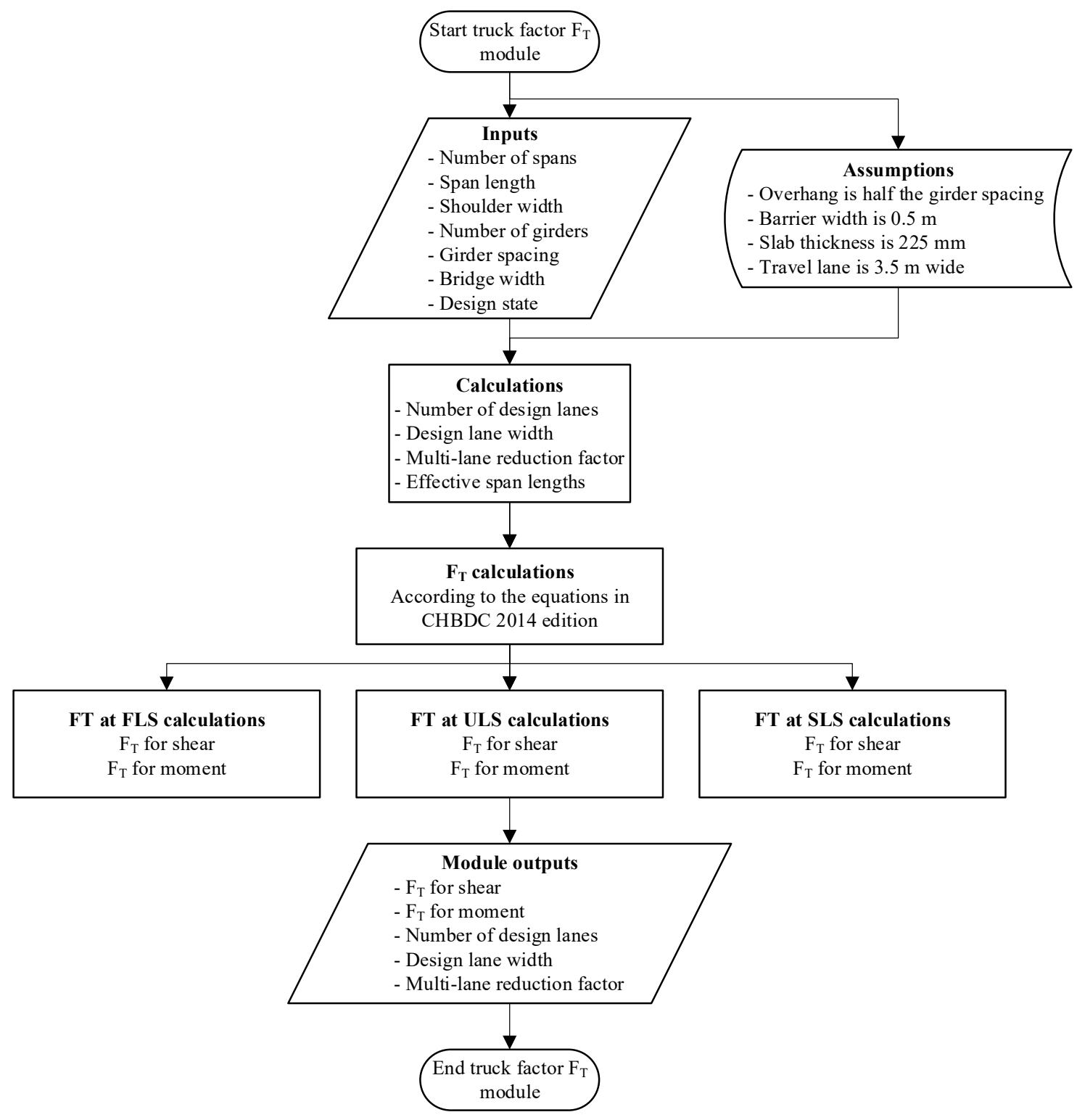

Figure 4.6: Flowchart showing the back-end operations of the truck factor calculation $\left(\mathrm{F}_{\mathrm{T}}\right)$ module developed as part of the I-girder design software 


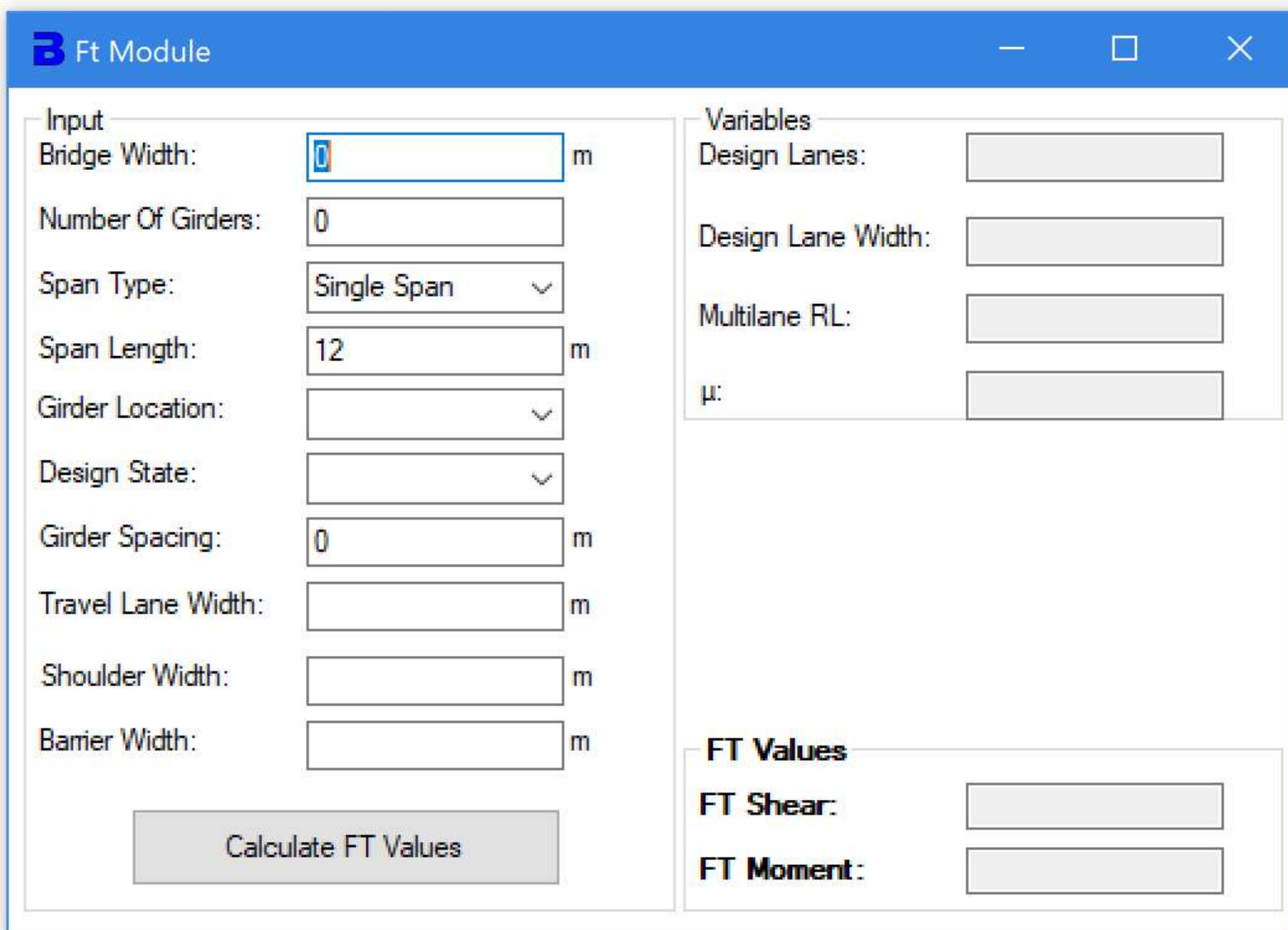

Figure 4.7: Screenshot showing the front-end layout of the of the truck factor calculation $\left(\mathrm{F}_{\mathrm{T}}\right)$ module developed as part of the I-girder design software

\subsubsection{SLS design modules}

The first module in the SLS modules list is permanent deflection at construction stage module which assesses the girder for plastic deflection at SLS during unshored construction. The input for this module includes number of spans, span length, girder dimensions, number of girders, girder spacing, bridge width, and truck loading. This module also obtains data from previously discussed modules. In addition to assumptions previously stated, this module assumes a concrete compressive strength, $\mathrm{f}_{\mathrm{c}}$, of $30 \mathrm{MPa}$. The module conducts the required check and provides the user information on the values of interest regarding the check and whether or not the girder dimensions selected are adequate. The back-end operations of the module can be seen in Figure 8. The front-end GUI can be seen in Figure 9. 


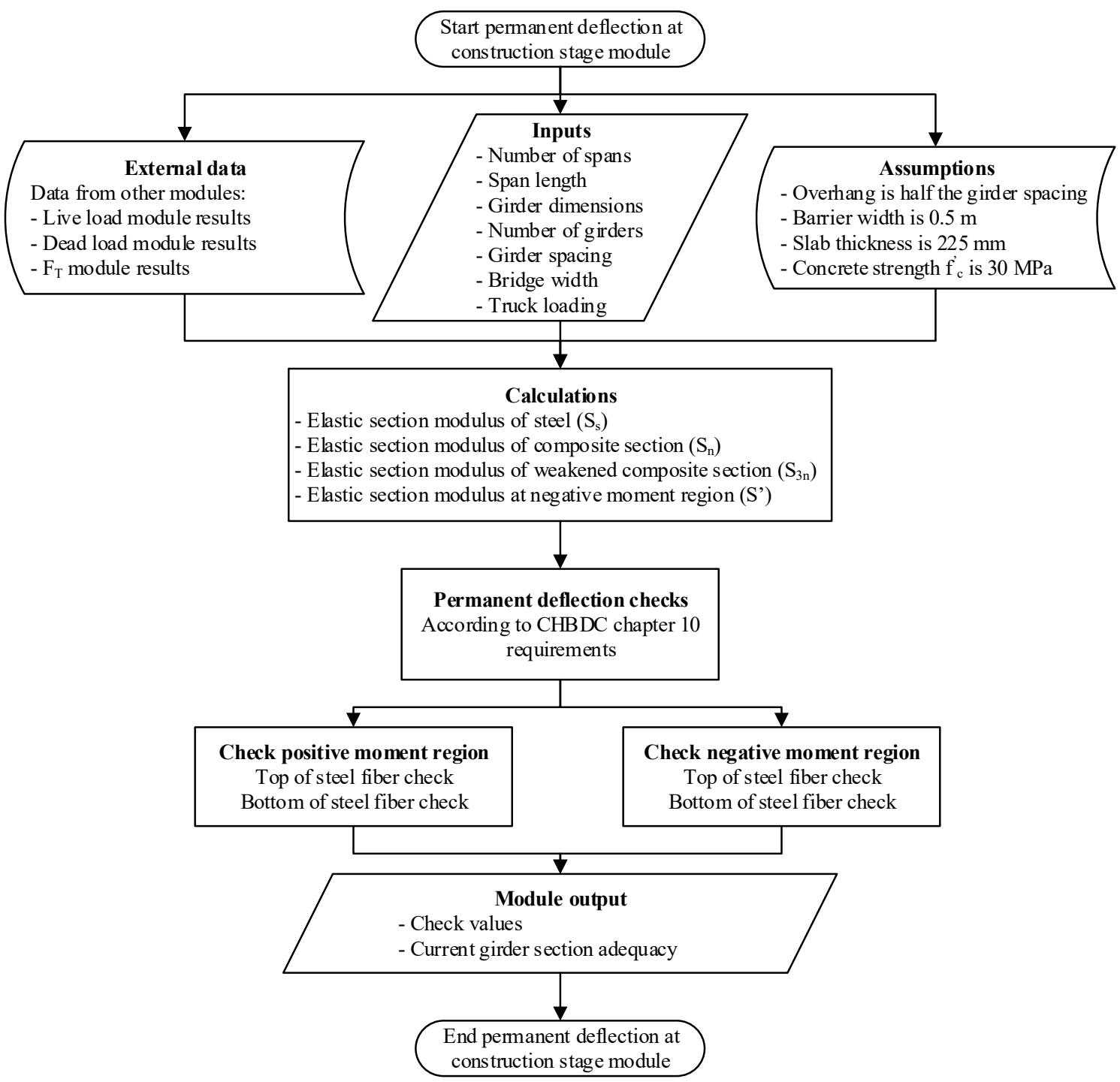

Figure 4.8: Flowchart showing the back-end operations of the permanent deflection at construction stage module developed as part of the I-girder design software 


\section{B Construction Phase Deflection}

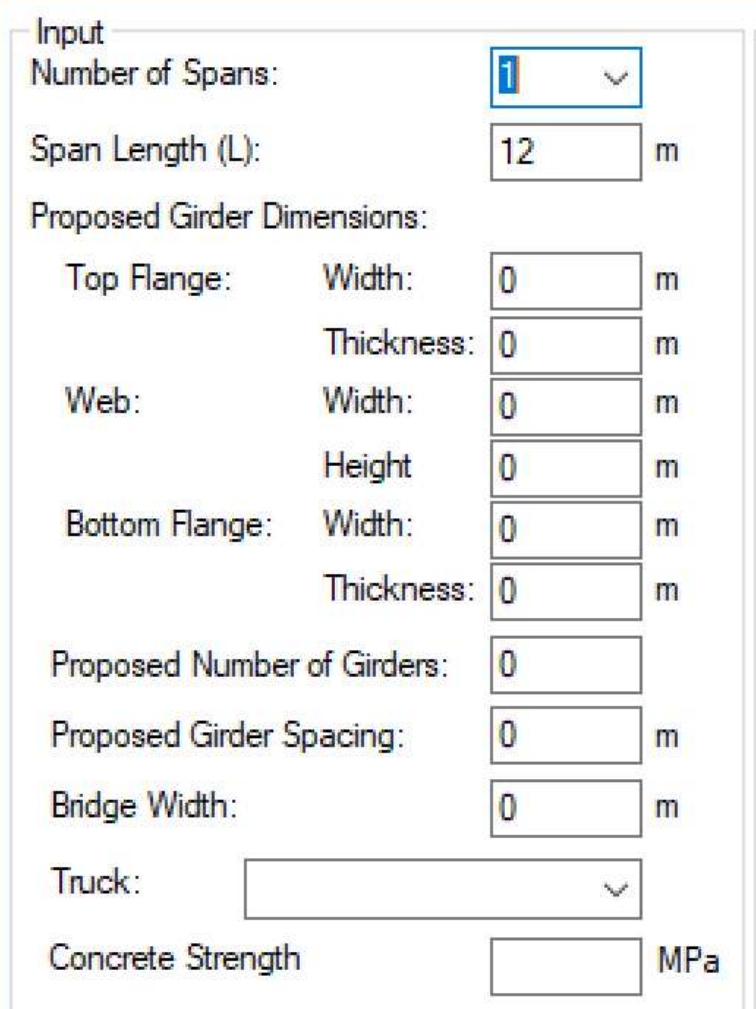

Check Results

Md:

Msd:

Ml:

Stop:

S3ntop:

Sntop:

Stop:

Sbot:

S3nbot:

Snbot:

Sbot:

Positive Region:

Nagative Region:

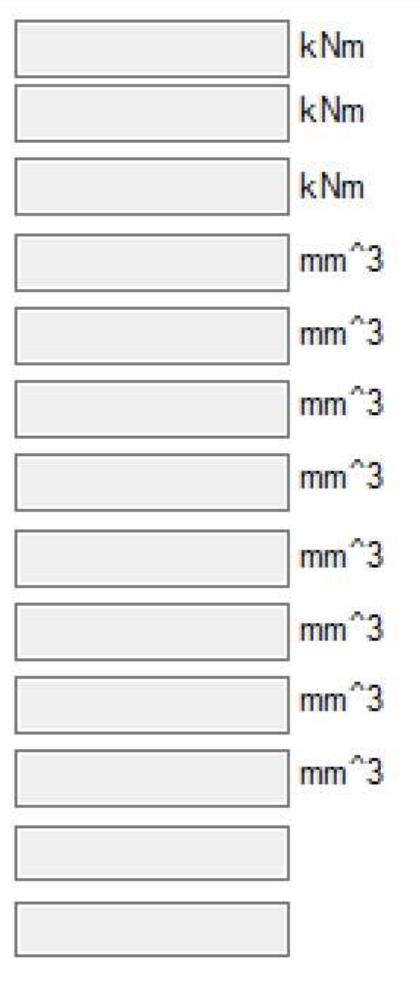

\section{Calculate Deflection Limitations}

Figure 4.9: Screenshot showing the front-end layout of the of the permanent deflection at construction stage module developed as part of the I-girder design software

The second SLS module is the superstructure vibration module. This module obtains input regarding span length, girder dimensions, number of girders, girder spacing and, bridge width. It also obtains data from the live load module and the $\mathrm{F}_{\mathrm{T}}$ module. It assumes a no-sidewalk case by default. However, if the user indicates the existence of a sidewalk, the program automatically takes that into account in the calculations. The program calculates the first flexural frequency of the bridge and the deflection limitation in accordance with the CHBDC and conducts the required checks. The output of this module will include the live load truck deflection at SLS, the deflection limitation of the bridge at the selected sidewalk usage case, and the girder section 
adequacy. The back-end operations of the module can be seen in Figure 10. The front-end GUI can be seen in Figure 11.

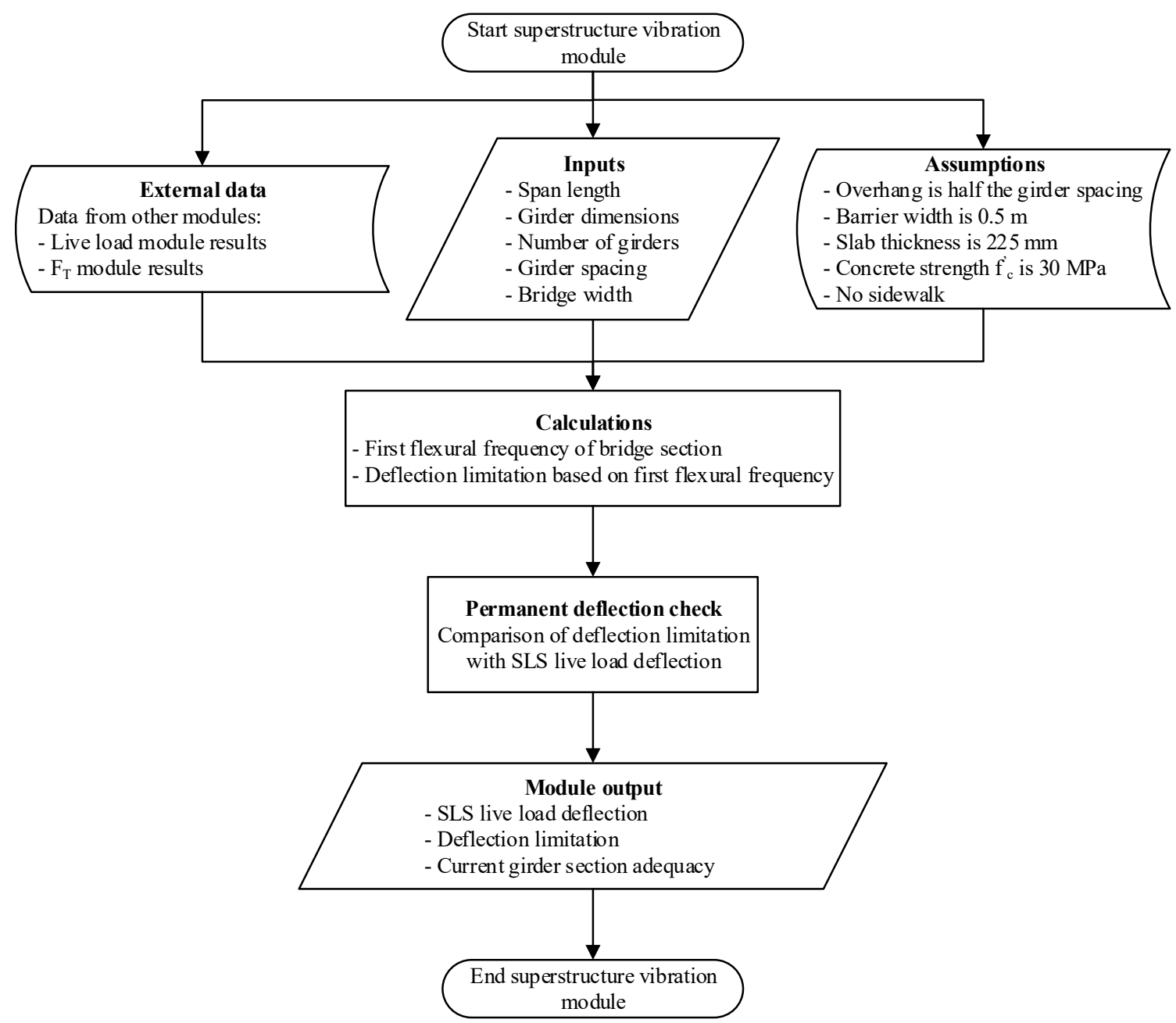

Figure 4.10: Flowchart showing the back-end operations of the superstructure vibration module developed as part of the I-girder design software 


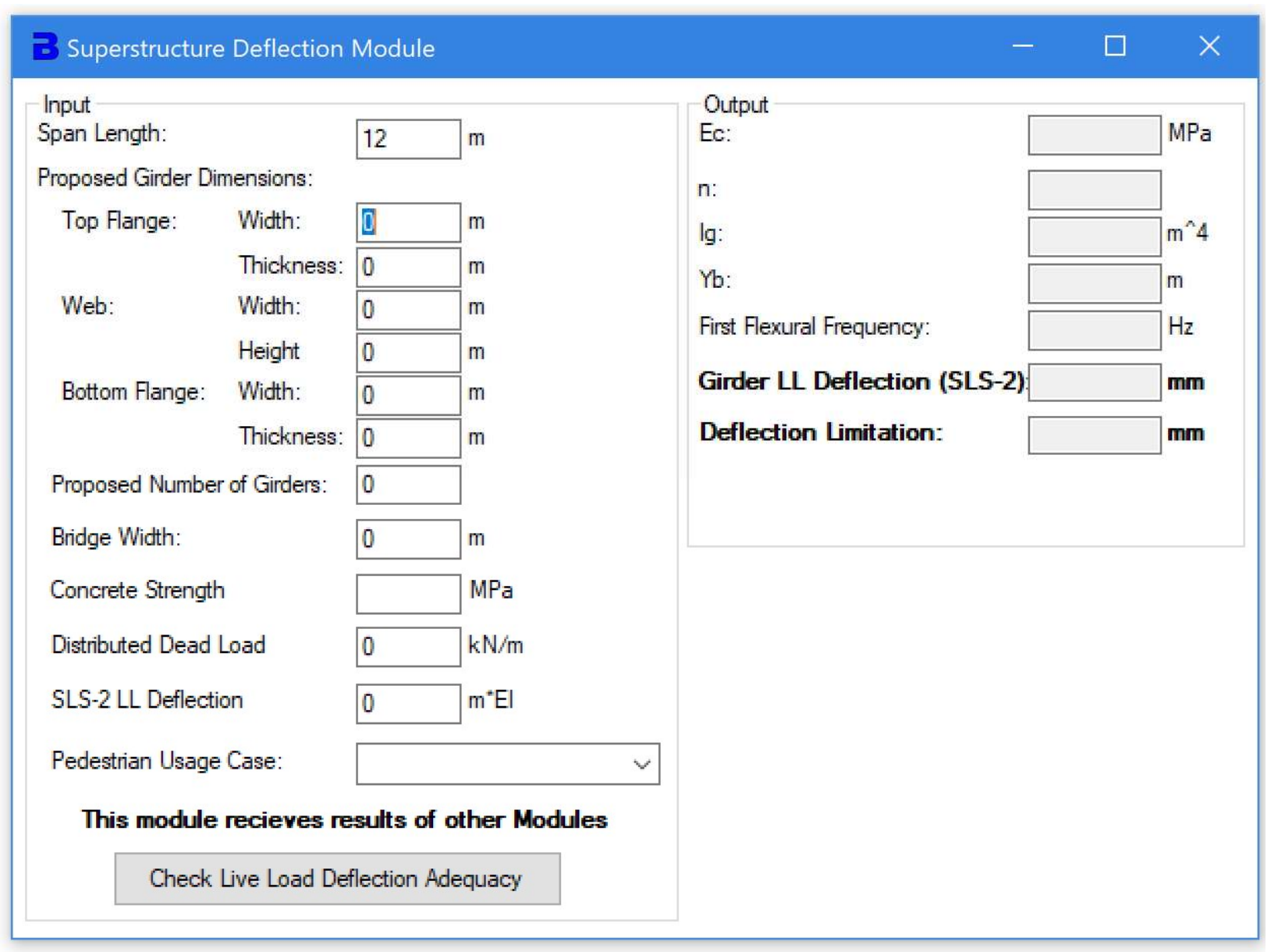

Figure 4.11: Screenshot showing the front-end layout of the of the superstructure vibration module developed as part of the I-girder design software

\subsubsection{ULS design modules}

The first module in the ULS design modules is the construction stage moment module. It obtains data from the design load values calculation modules in addition to user input which includes number of spans, span length, girder dimensions, number of girders, girder spacing and, bridge width. The module outputs the factored applied construction moment, the resisting moment of the steel section and the section adequacy. The back-end operations of the module can be seen in Figure 12. The front-end GUI can be seen in Figure 13. 


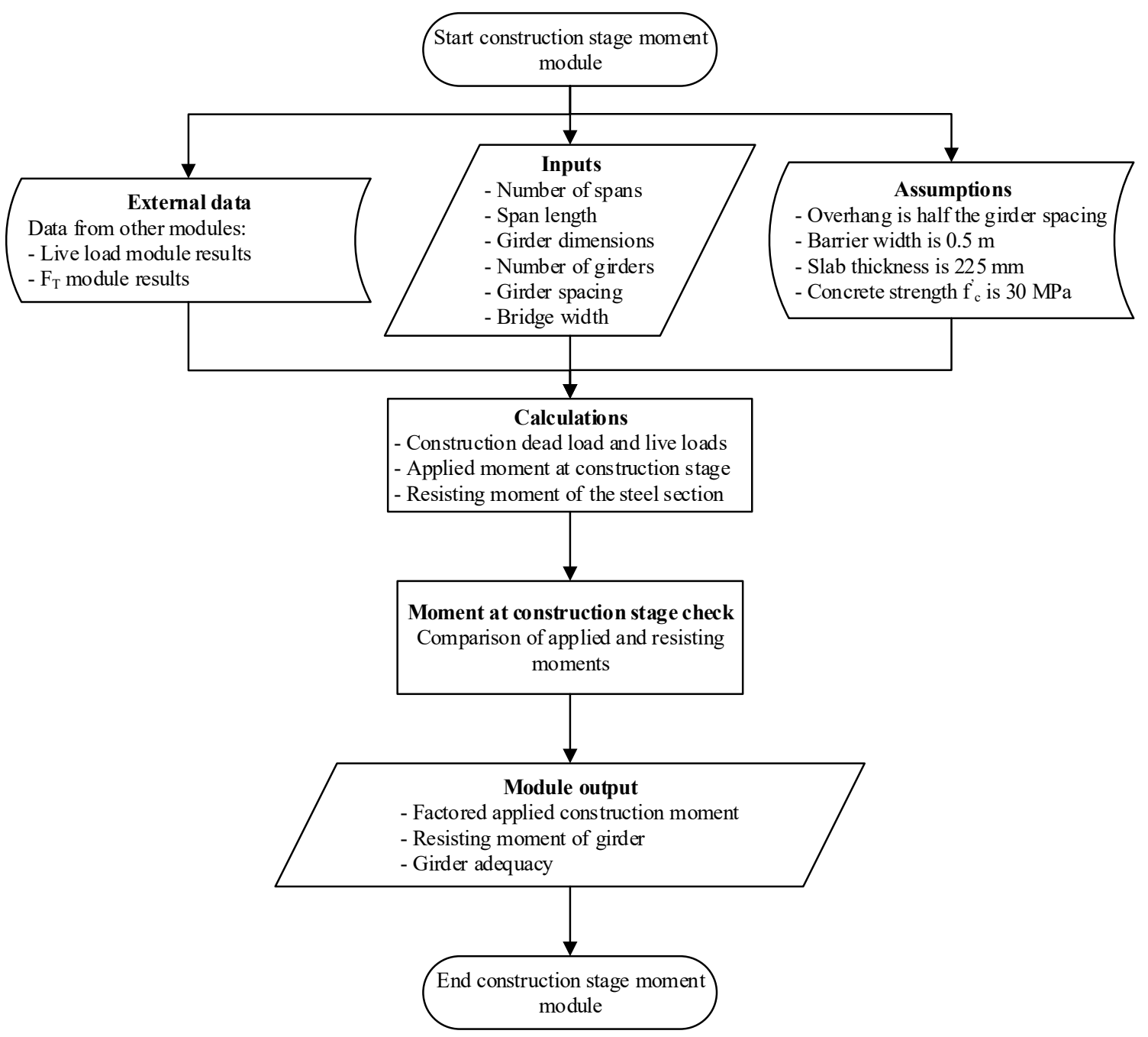

Figure 4.12: Flowchart showing the back-end operations of the construction stage moment module developed as part of the I-girder design software 


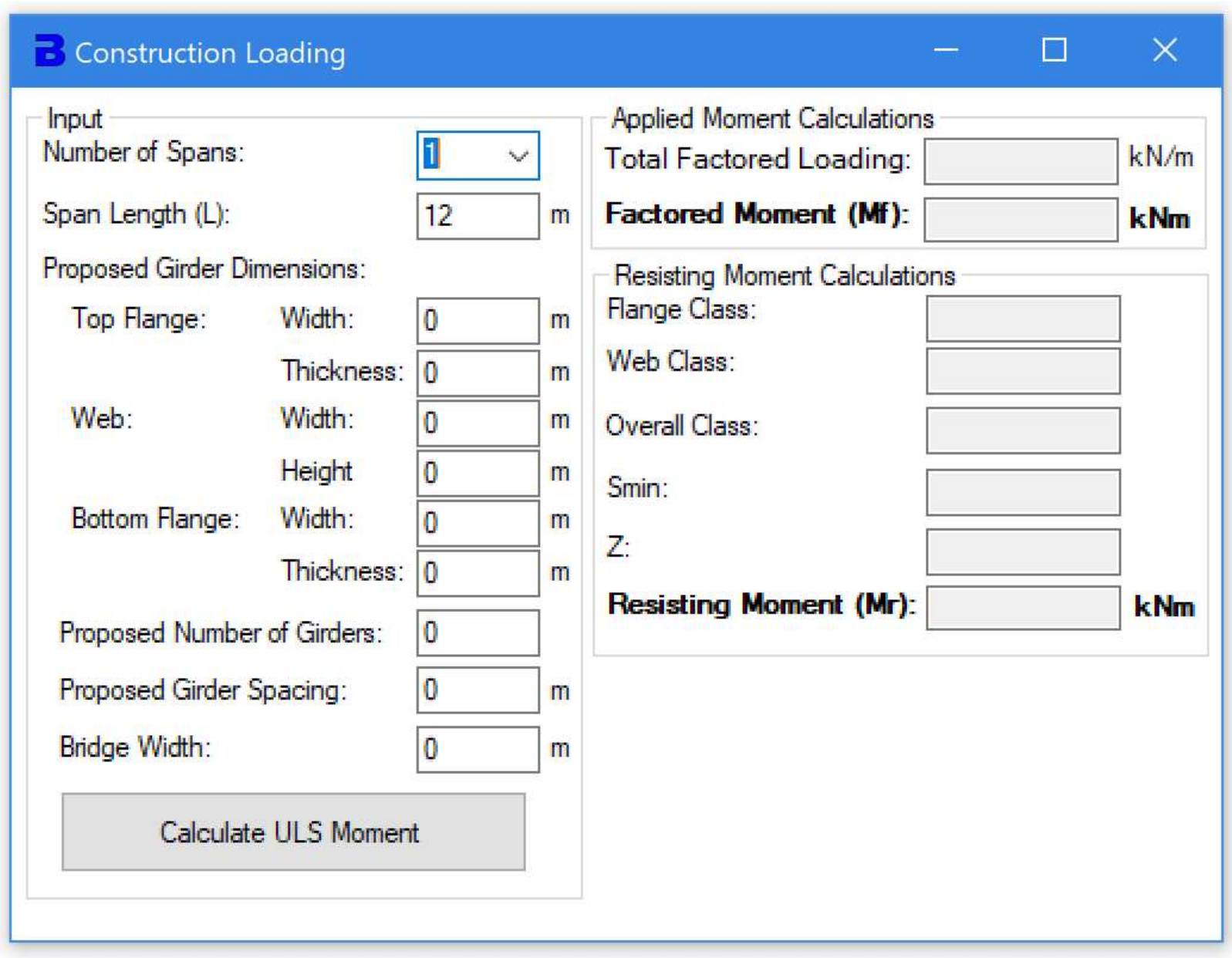

Figure 4.13: Screenshot showing the front-end layout of the of the construction stage moment module developed as part of the I-girder design software

Followed by it is the ULS moment, shear and combined checks module. This module obtains input from the design load values calculation modules in addition to user input regarding number of spans, span length, girder dimensions, number of girders, girder spacing and, bridge width. In addition to the previous assumptions, this module assumes the stiffeners are spaced at the minimum of (i) the maximum allowed stiffener spacing for the bridge geometry as per the CISC "Handbook of Steel Construction" (CISC, 2017) and, (ii) 2 meters. This is due to the fact that in some cases, 2-meter stiffener spacing exceeds the maximum spacing requirement and therefore fails that check. Also, the program assumes 15M bar reinforcement spaced at $300 \mathrm{~mm}$. The output from this module indicates are composite section resisting longitudinal positive moment adequacy, longitudinal negative moment adequacy, shear adequacy, combined checks adequacy, 
and overall section adequacy after conducting all the necessary checks. The back-end operations of the module can be seen in Figure 14. The front-end GUI can be seen in Figure 15.

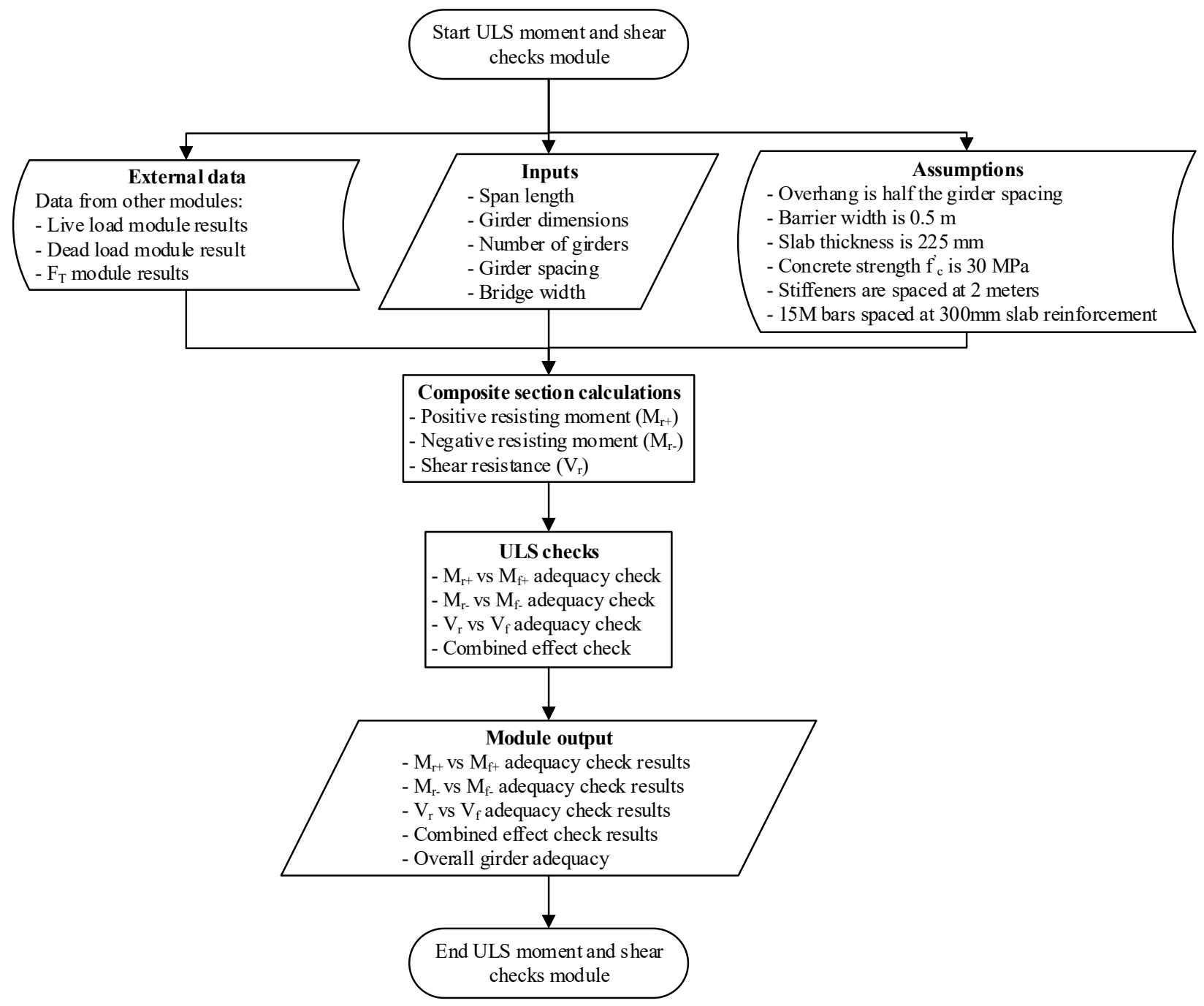

Figure 4.14: Flowchart showing the back-end operations of the ULS adequacy checks module developed as part of the I-girder design software 


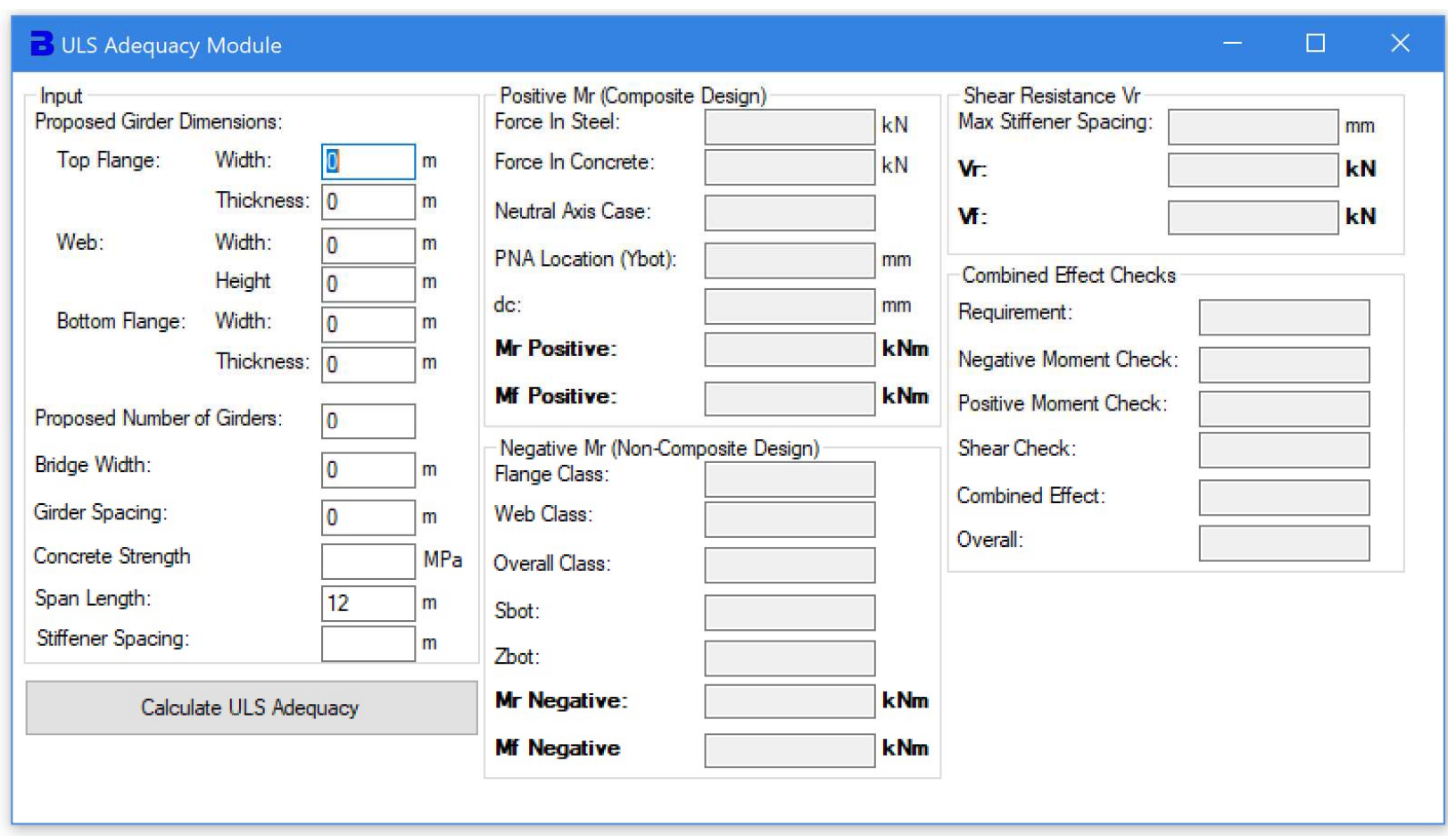

Figure 4.15: Screenshot showing the front-end layout of the of the ULS adequacy checks module developed as part of the I-girder design software

The last module in the ULS modules list is the shear stud ULS module. This module obtains input from the design load values calculation modules in addition to user input regarding number of spans, span length, girder top flange width, number of girders, girder spacing and, bridge width. In addition to the previously stated assumptions, this module assumes a stud diameter of $22 \mathrm{~mm}$. The output from this module includes the total required number of studs, the number of transverse shear stud rows, the number of longitudinal shear stud rows and, the row spacing. The back-end operations of the module can be seen in Figure 16. The front-end GUI can be seen in Figure 17. 


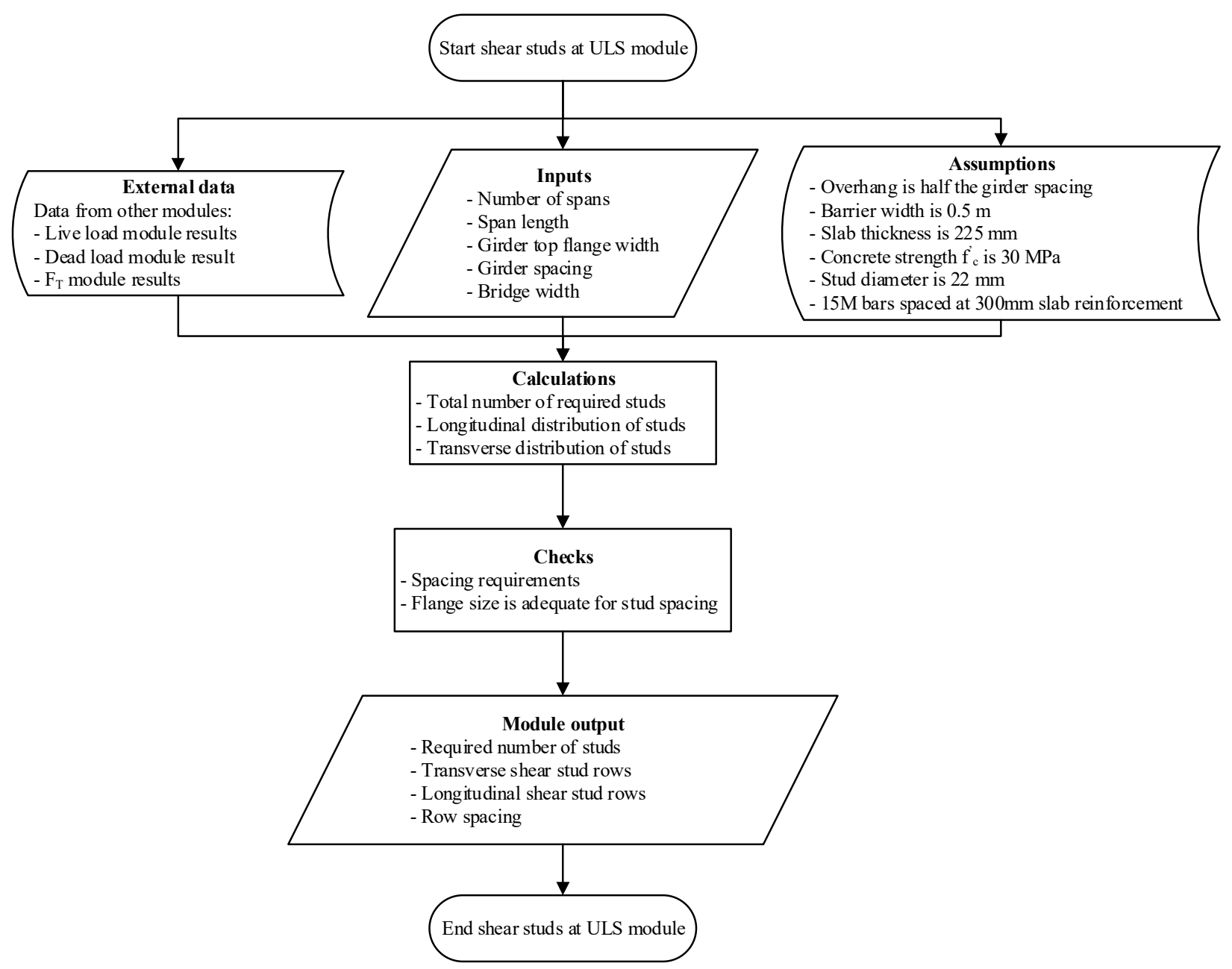

Figure 4.16: Flowchart showing the back-end operations of the shear stud design at ULS module developed as part of the I-girder design software 


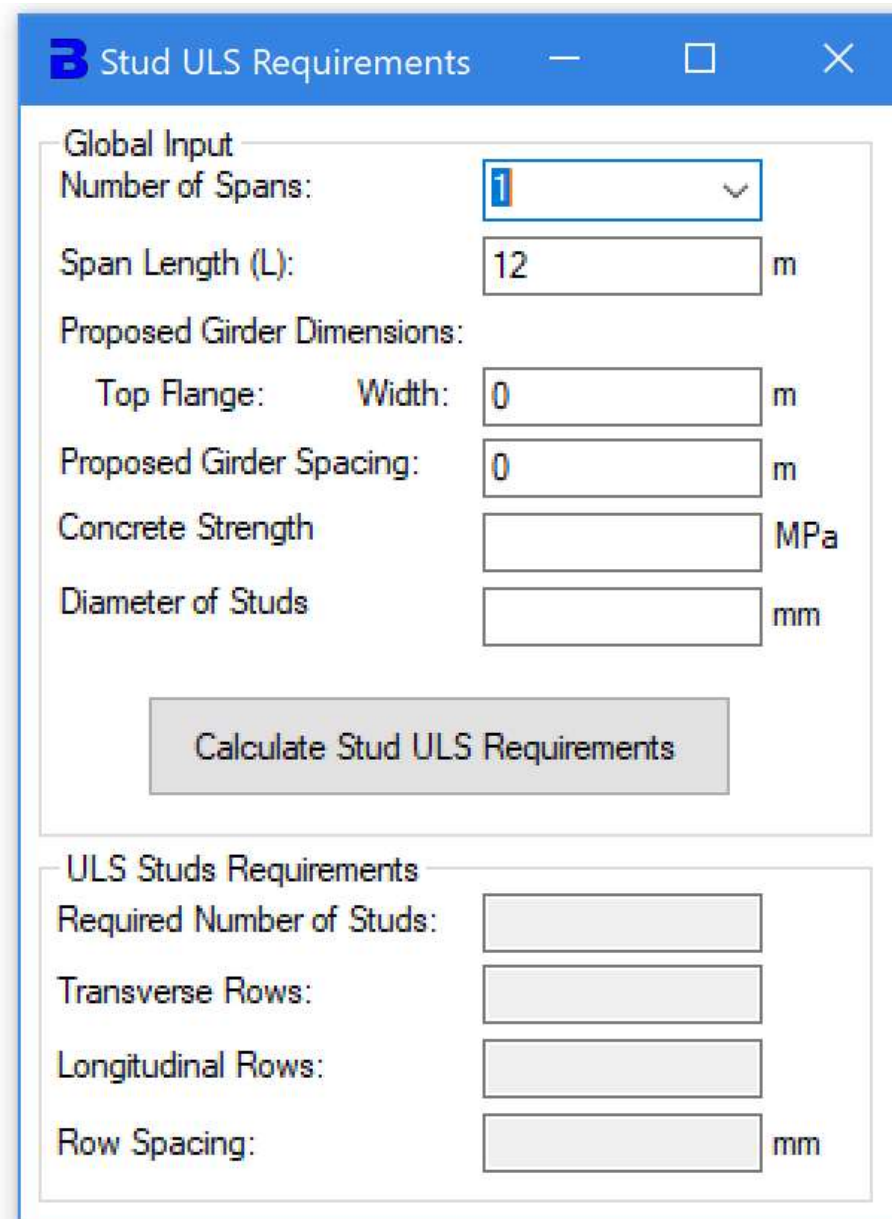

Figure 4.17: Screenshot showing the front-end layout of the of the shear stud design at ULS module developed as part of the I-girder design software

\subsubsection{FLS design modules}

The first module in the FLS design modules is the FLS adequacy module. This module obtains input from the design load values calculation modules in addition to user input regarding number of spans, span length, girder dimensions, number of girders, girder spacing and, bridge width. The module calculates the applied and resisting fatigue stress ratios for an expected bridge life expectancy of 75 years in accordance with the CHBDC. The program then conducts the checks required and provides the user with an output indicating whether or not the girder section is adequate for the applied fatigue stress range and cycles during its lifespan. The back-end operations of the module can be seen in Figure 18. The front-end GUI of the module can be seen in Figure 19. 


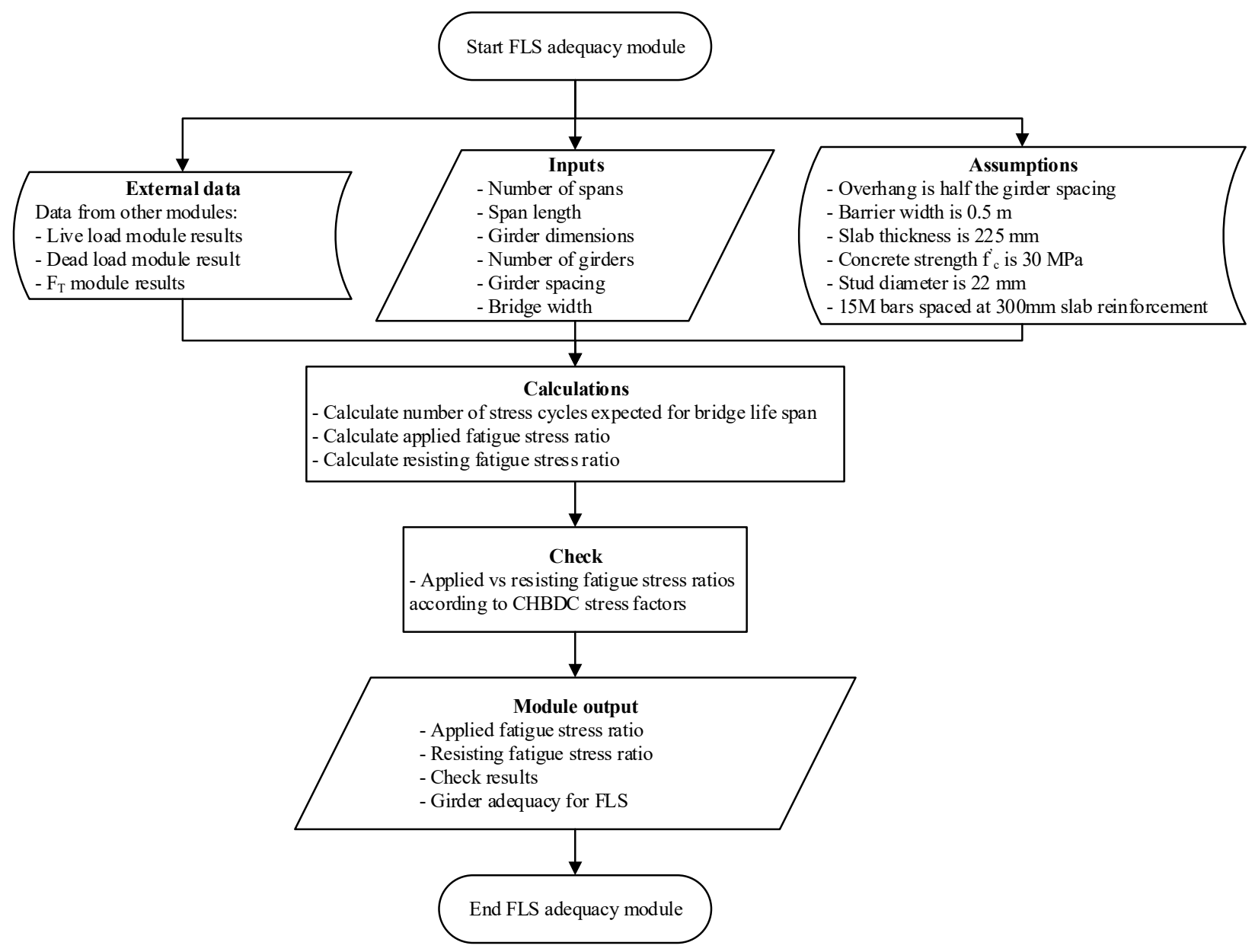

Figure 4.18: Flowchart showing the back-end operations of the FLS adequacy module developed as part of the I-girder design software 


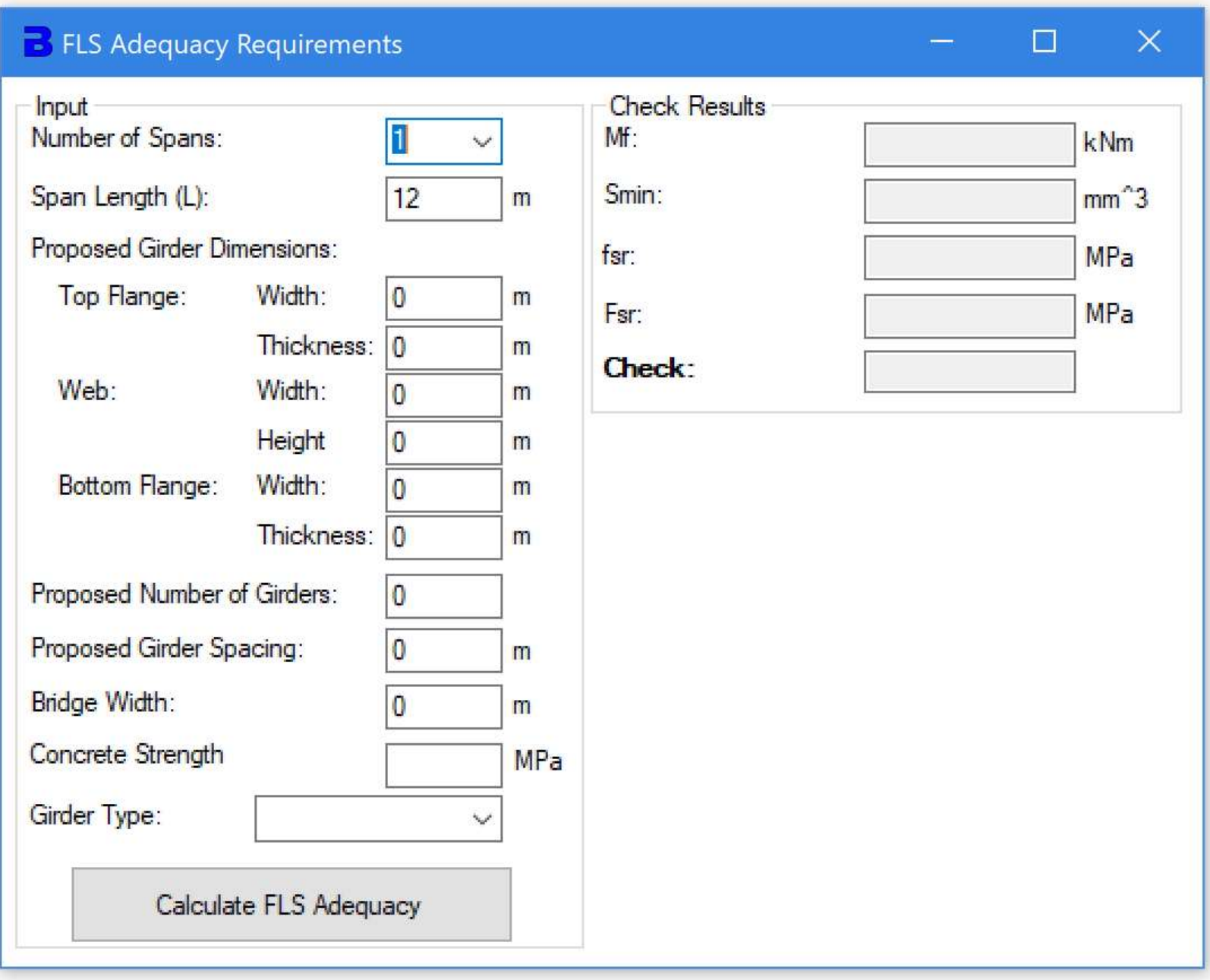

Figure 4.19: Screenshot showing the front-end layout of the of the FLS adequacy module developed as part of the I-girder design software

The last module in the FLS category is the shear stud design at FLS module. This module obtains input from the design load values calculation modules in addition to user input regarding number of spans, span length, girder dimensions, number of girders, girder spacing and, bridge width. It conducts similar calculations to the FLS adequacy module. In addition to the previously stated assumptions, this module assumes a stud diameter of $22 \mathrm{~mm}$. The output from this module includes the total required number of studs, the number of transverse shear stud rows, the number of longitudinal shear stud rows and, the row spacing. The back-end operations of the module can be seen in Figure 20. The front-end GUI of the module can be seen in Figure 21. 


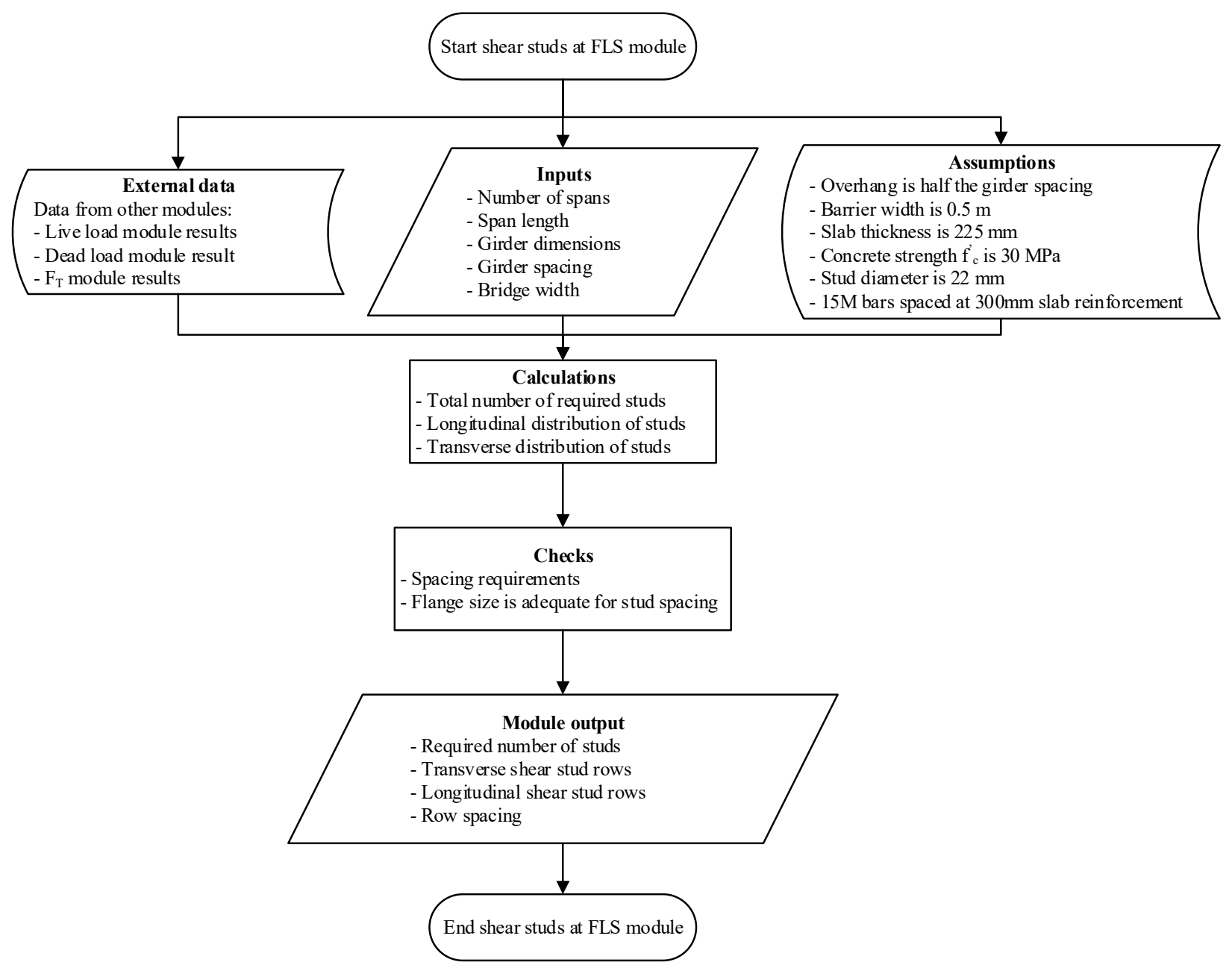

Figure 4.20: Flowchart showing the back-end operations of the shear studs design at FLS module developed as part of the I-girder design software 


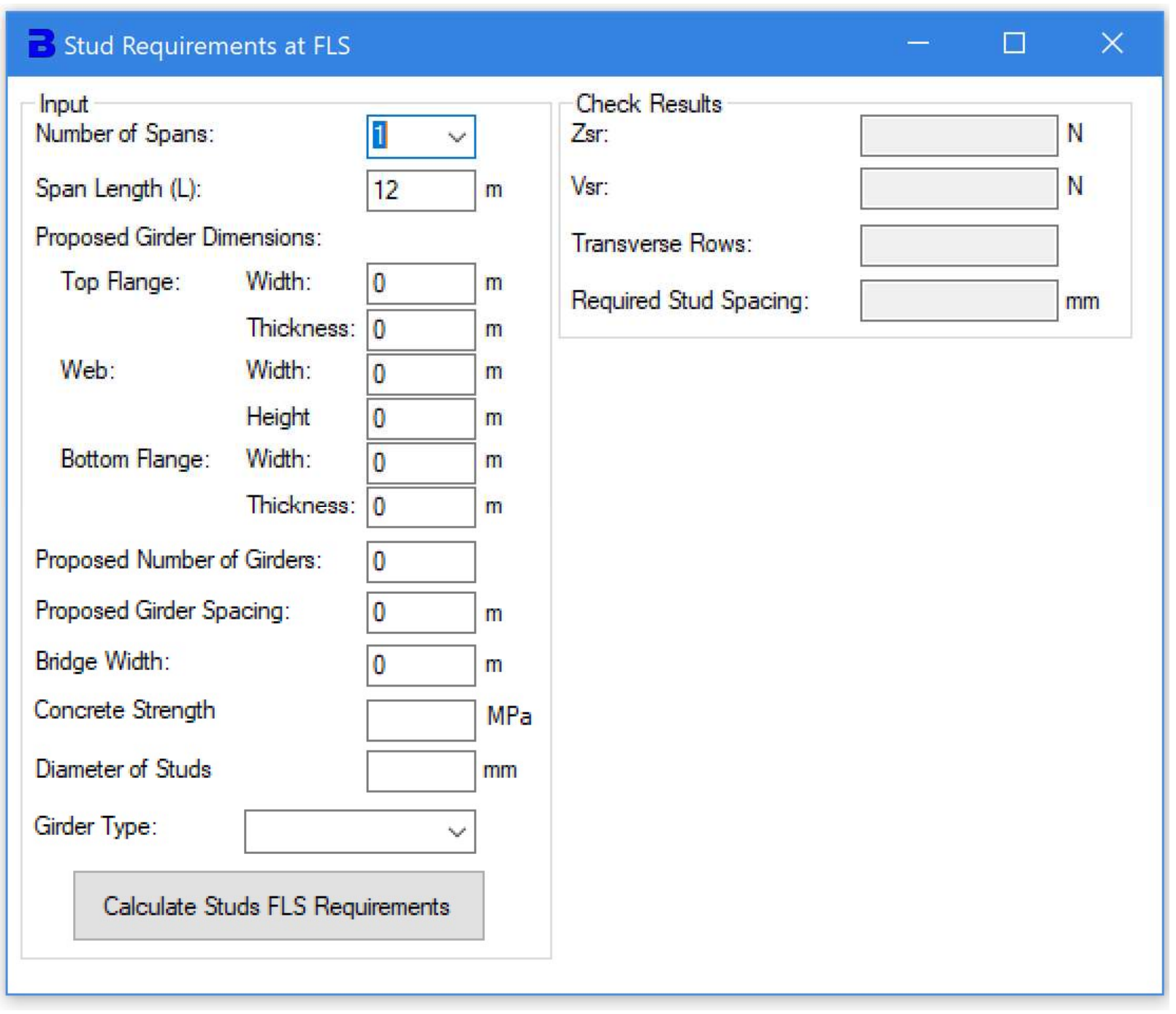

Figure 4.21: Screenshot showing the front-end layout of the of the shear studs design at FLS module developed as part of the I-girder design software

\subsubsection{I-girder size optimization module}

This module combines all the previous modules into one module. This module obtains user input regarding number of spans, span length, number of girders, girder spacing, bridge width, truck loading and shoulder width. It makes the same assumptions as the collective of all the previously discussed modules in addition to a travel lane of $3.5 \mathrm{~m}$. It creates a doubly symmetric I-girder section with a starting flange width (b) of $240 \mathrm{~mm}$, flange and web thickness (w and t) of $12 \mathrm{~mm}$ and, a web height initial value of $\frac{\mathrm{L}}{25} \times 1000 \mathrm{~mm}$. The module calculates the applied design loads, then conducts all the checks conducted by the previously discussed modules and, designs 
the shear studs for midspan and support locations. In case the girder does not meet the check requirements, the program increases its size while maintaining its status as a class 2 section. In contrast, if the section is overdesigned, the program repeats the process in order to obtain a more economical section. The program repeats this process until it reaches the boundary condition where any further decrease in the girder section size makes it inadequate. The program then provides the user with all the check results in addition to the optimized girder section size and shear stud design parameters for midspan and support locations. The back-end operations of the module can be seen in Figure 22. The front-end GUI of the module can be seen in Figure 23. 


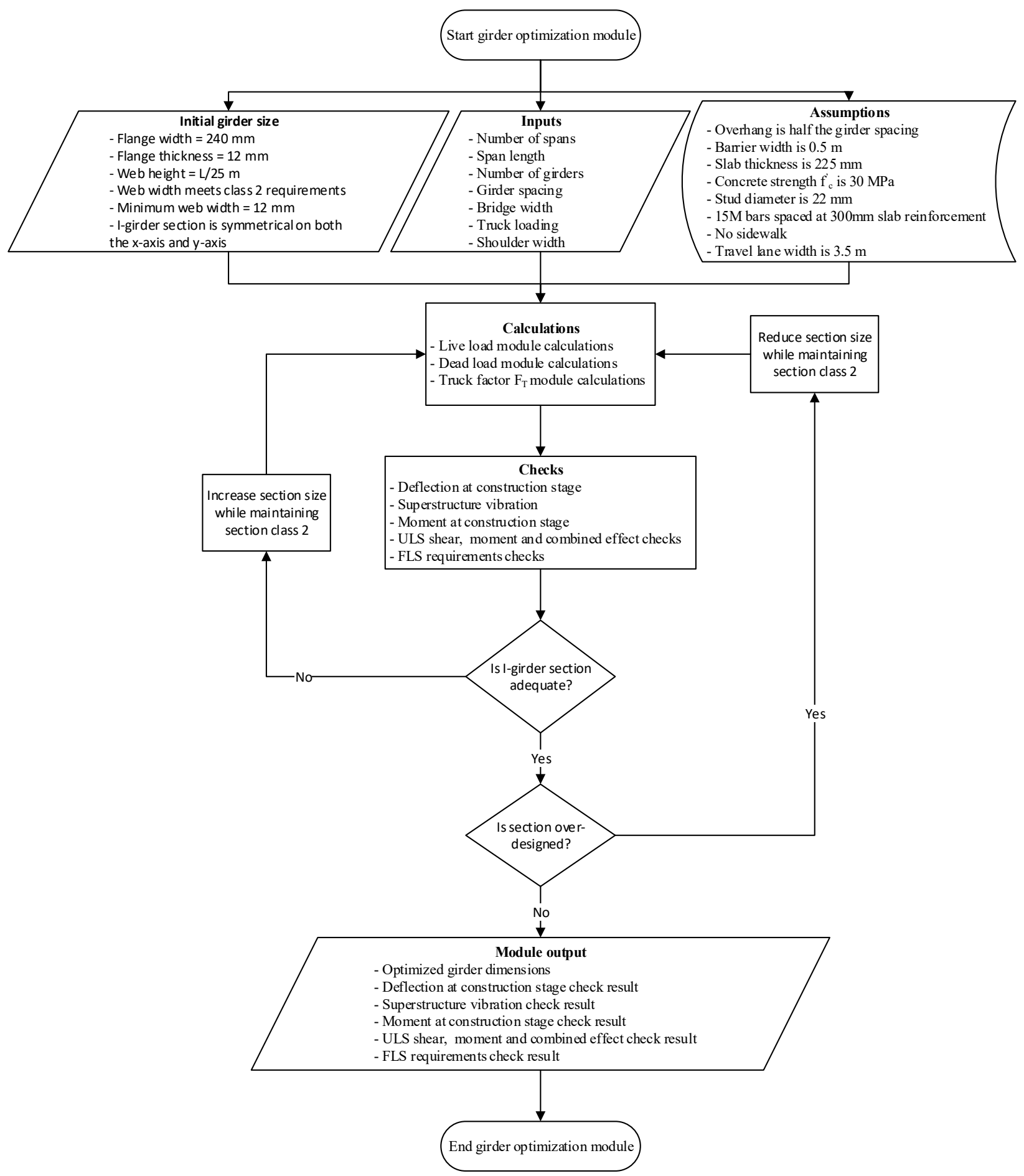

Figure 4.22: Flowchart showing the back-end operations of the girder optimization module developed as part of the I-girder design software 


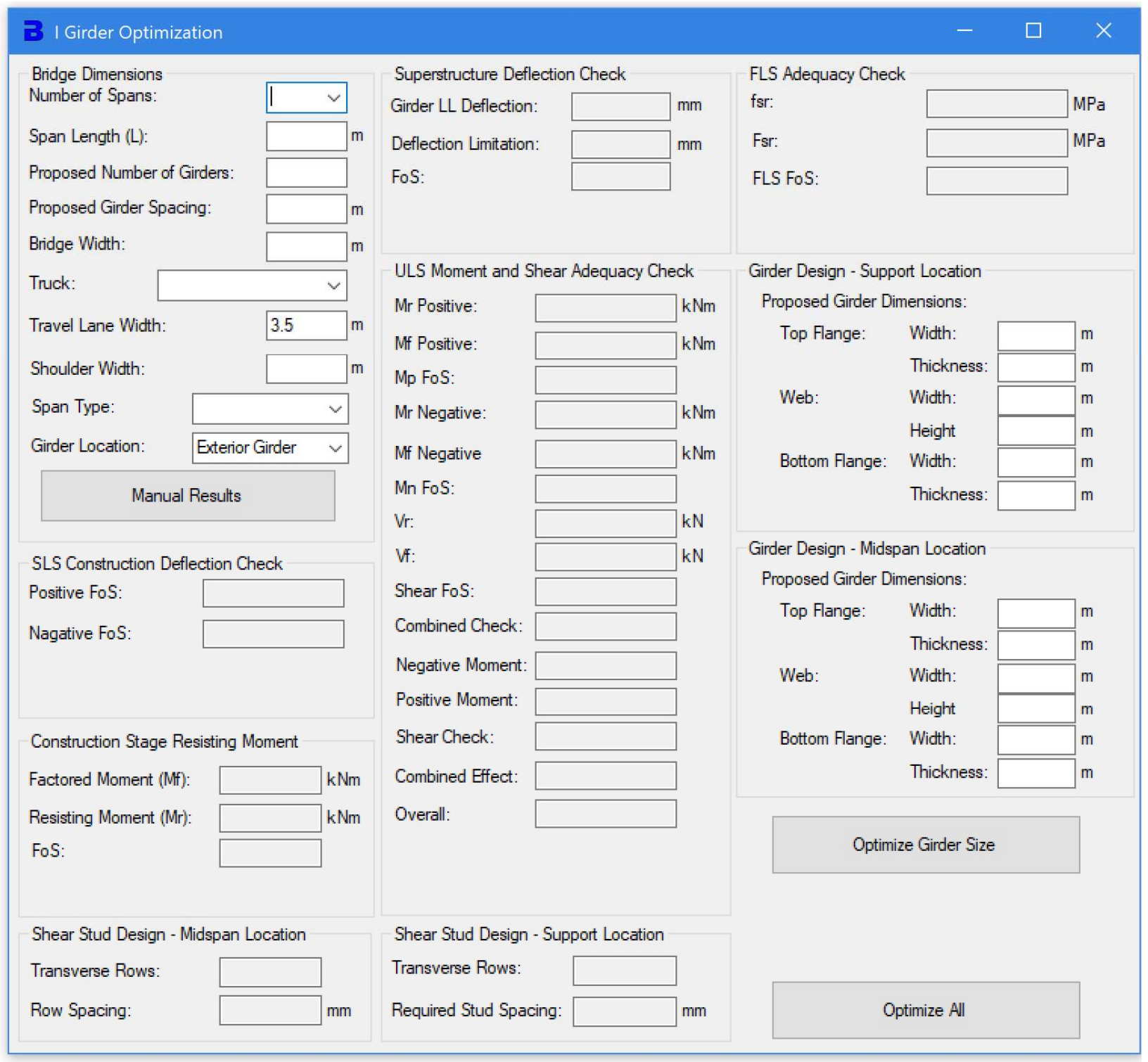

Figure 4.23: Screenshot showing the front-end layout of the of the girder optimization module developed as part of the I-girder design software 


\subsection{Program result verification}

In order to verify the program results, a full design example from the CISC "Steel Bridges, Design, Fabrication, Construction" course design examples book was selected (CISC, 2016). A composite slab on steel plate girder example was selected as it is a straight plate girder bridge which matches the research scope of work. The bridge selected had a span of $45 \mathrm{~m}$ and a lane width of $3.75 \mathrm{~m}$. The girders were spaced at $2.9 \mathrm{~m}$ center to center. The manual results were compared to results from the program. The results can be seen in Table 4.1.

Table 4.1: Comparison between manual calculation results and program results for a CISC composite concrete slab on straight plate girder bridge design example

\begin{tabular}{|l|l|l|}
\hline Value analyzed & Manual results & Program results \\
\hline $\mathrm{M}_{\mathrm{f}}$ at ULS & $17600 \mathrm{kN} \cdot \mathrm{m}$ & $18200 \mathrm{kN} \cdot \mathrm{m}$ \\
\hline $\mathrm{V}_{\mathrm{f}}$ at ULS & $1739 \mathrm{kN}$ & $1740 \mathrm{kN}$ \\
\hline$\Delta_{\mathrm{Limit}}$ at $\mathrm{SLS}$ & $80 \mathrm{~mm}$ & $79 \mathrm{~mm}$ \\
\hline$\Delta_{\mathrm{LL}}$ at SLS & $33 \mathrm{~mm}$ & $33 \mathrm{~mm}$ \\
\hline Construction phase $\mathrm{M}_{\mathrm{f}}$ & $10000 \mathrm{kN} \cdot \mathrm{m}$ & $10200 \mathrm{kN} \cdot \mathrm{m}$ \\
\hline Construction phase $\mathrm{M}_{\mathrm{r}}$ & $11000 \mathrm{kN} \cdot \mathrm{m}$ & $11300 \mathrm{kN} \cdot \mathrm{m}$ \\
\hline Extreme fiber stress & $207 \mathrm{MPa}$ & $245 \mathrm{MPa}$ \\
\hline Composite section $\mathrm{M}_{\mathrm{r}}$ & $25000 \mathrm{kN} \cdot \mathrm{m}$ & $24600 \mathrm{kN} \cdot \mathrm{m}$ \\
\hline Composite section $\mathrm{V}_{\mathrm{r}}$ & $3745 \mathrm{kN}$ & $3250 \mathrm{kN}$ \\
\hline Shear studs at ULS & 3 per row @ $600 \mathrm{~mm}$ & 3 per row @ $600 \mathrm{~mm}$ \\
\hline Shear studs at FLS & 3 per row @ $430 \mathrm{~mm}$ & 3 per row @ $470 \mathrm{~mm}$ \\
\hline
\end{tabular}

As can be observed, the program provides accurate and conservative results when compared to manual calculation. The variation in some data is due to the assumptions made by the program. For instance, the shear resistance heavily depends on the intermediate stiffener spacing. The program assumes stiffener spacing at 2 meters for this case. However, when manually designed, designers can choose to lower the spacing or increase it in order to match the applied factored shear at ULS. As for the remaining values, the program results show excellent representation of manual calculations with a slight overestimation of applied forces and underestimation of resisting forces.

\subsection{Program parametric study}

In order to produce equations that assist designers in obtaining optimized I-girder sizes. The program was used to obtain optimized results for various different bridge configurations between 
1 to 6 design lanes shown in Table 4.2. The parametric study was conducted once for CL-625 truck loading and once for CL-800 truck loading. The CL-625-ONT truck loading case was not considered in this study as it was shown in Figure 3.37 that the variation in results between the CL-625 truck loading and the CL-625-ONT truck loading is within 3\%.

Table 4.2: Table showing the bridge configuration cases optimized by the program per truck loading per span length

\begin{tabular}{|c|c|c|c|c|c|c|c|}
\hline $\begin{array}{l}\text { Number } \\
\text { of design } \\
\text { lanes }\end{array}$ & $\begin{array}{l}\text { Bridge } \\
\text { width, B } \\
\text { (m) }\end{array}$ & $\begin{array}{l}\text { Deck } \\
\text { width, } \\
\text { Wc }(\mathbf{m})\end{array}$ & $\begin{array}{l}\text { Design } \\
\text { lane } \\
\text { width, } \\
\text { We (m) }\end{array}$ & $\begin{array}{l}\text { Number } \\
\text { of girders }\end{array}$ & $\begin{array}{l}\text { Girder } \\
\text { spacing } \\
\text { (m) }\end{array}$ & $\begin{array}{l}\text { Travelling lane } \\
\text { width }(m)\end{array}$ & $\begin{array}{l}\text { Shoulder } \\
\text { width (m) }\end{array}$ \\
\hline 1 & 4.5 & 3.5 & 3.5 & 3 & 1.5 & 3.5 & 0 \\
\hline \multirow[t]{2}{*}{1} & 6.0 & 5.0 & 5.0 & 3 & 2.00 & 3.5 & 0.75 \\
\hline & & & & 4 & 1.50 & 3.3 & 0.75 \\
\hline \multirow[t]{2}{*}{1} & 7.0 & 6.0 & 6.0 & 3 & 2.33 & 3.5 & 1.25 \\
\hline & & & & 4 & 1.75 & 3.5 & 1.25 \\
\hline \multirow[t]{3}{*}{2} & 8 & 7 & 3.5 & 3 & 2.67 & 3.5 & 0 \\
\hline & & & & 4 & 2.00 & 3.5 & 0 \\
\hline & & & & 5 & 1.6 & 3.5 & 0 \\
\hline \multirow[t]{4}{*}{2} & 9.5 & 8.5 & 4.25 & 3 & 3.17 & 3.5 & 0.75 \\
\hline & & & & 4 & 2.375 & 3.5 & 0.75 \\
\hline & & & & 5 & 1.9 & 3.5 & 0.75 \\
\hline & & & & 6 & 1.583 & & \\
\hline \multirow[t]{5}{*}{2} & 11 & 10 & 5 & 3 & 3.67 & 3.5 & 1.5 \\
\hline & & & & 4 & 2.75 & 3.5 & 1.5 \\
\hline & & & & 5 & 2.2 & 3.5 & 1.5 \\
\hline & & & & 6 & 1.833 & 3.5 & 1.5 \\
\hline & & & & 7 & 1.57 & 3.5 & 1.5 \\
\hline \multirow[t]{4}{*}{2} & 11.5 & 10.5 & 5.25 & 4 & 2.875 & 3.5 & 1.75 \\
\hline & & & & 5 & 2.3 & 3.5 & 1.75 \\
\hline & & & & 6 & 1.917 & 3.5 & 1.75 \\
\hline & & & & 7 & 1.643 & 3.5 & 1.75 \\
\hline \multirow[t]{4}{*}{2} & 13 & 12 & 6 & 4 & 3.25 & 3.5 & 2.5 \\
\hline & & & & 5 & 2.6 & 3.5 & 2.5 \\
\hline & & & & 6 & 2.167 & 3.5 & 2.5 \\
\hline & & & & 7 & 1.857 & 3.5 & 2.5 \\
\hline \multirow[t]{4}{*}{2} & 14.5 & 13.5 & 6.75 & 4 & 3.625 & 3.5 & 3.25 \\
\hline & & & & 5 & 2.9 & 3.5 & 3.25 \\
\hline & & & & 6 & 2.417 & 3.5 & 3.25 \\
\hline & & & & 7 & 2.07 & 3.5 & 3.25 \\
\hline \multirow[t]{4}{*}{3} & 11.5 & 10.5 & 3.5 & 4 & 2.875 & 3.5 & 0 \\
\hline & & & & 5 & 2.3 & 3.5 & 0 \\
\hline & & & & 6 & 1.917 & 3.5 & 0 \\
\hline & & & & 7 & 1.643 & 3.5 & 0 \\
\hline \multirow[t]{4}{*}{3} & 13 & 12 & 4 & 4 & 3.25 & 3.5 & 0.75 \\
\hline & & & & 5 & 2.6 & 3.5 & 0.75 \\
\hline & & & & 6 & 2.167 & 3.5 & 0.75 \\
\hline & & & & 7 & 1.857 & 3.5 & 0.75 \\
\hline \multirow[t]{2}{*}{3} & 14.5 & 13.5 & 4.5 & 4 & 3.625 & 3.5 & 1.5 \\
\hline & & & & 5 & 2.9 & 3.5 & 1.5 \\
\hline
\end{tabular}




\begin{tabular}{|c|c|c|c|c|c|c|c|}
\hline $\begin{array}{l}\text { Number } \\
\text { of design } \\
\text { lanes }\end{array}$ & $\begin{array}{l}\text { Bridge } \\
\text { width, B } \\
\text { (m) }\end{array}$ & $\begin{array}{l}\text { Deck } \\
\text { width, } \\
\text { Wc (m) }\end{array}$ & $\begin{array}{l}\text { Design } \\
\text { lane } \\
\text { width, } \\
\text { We (m) }\end{array}$ & $\begin{array}{l}\text { Number } \\
\text { of girders }\end{array}$ & $\begin{array}{l}\text { Girder } \\
\text { spacing } \\
\text { (m) }\end{array}$ & $\begin{array}{l}\text { Travelling lane } \\
\text { width }(m)\end{array}$ & $\begin{array}{l}\text { Shoulder } \\
\text { width (m) }\end{array}$ \\
\hline & & & & 6 & 2.417 & 3.5 & 1.5 \\
\hline & & & & 7 & 2.07 & 3.5 & 1.5 \\
\hline \multirow[t]{5}{*}{4} & 15 & 14 & 3.5 & 5 & 3 & 3.5 & 0 \\
\hline & & & & 6 & 2.5 & 3.5 & 0 \\
\hline & & & & 7 & 2.14 & 3.5 & 0 \\
\hline & & & & 8 & 1.875 & 3.5 & 0 \\
\hline & & & & 9 & 1.67 & 3.5 & 0 \\
\hline \multirow[t]{5}{*}{4} & 16.5 & 15.5 & 3.875 & 5 & 3.3 & 3.5 & 0.75 \\
\hline & & & & 6 & 2.75 & 3.5 & 0.75 \\
\hline & & & & 7 & 2.357 & 3.5 & 0.75 \\
\hline & & & & 8 & 2.06 & 3.5 & 0.75 \\
\hline & & & & 9 & 1.83 & 3.5 & 0.75 \\
\hline \multirow[t]{5}{*}{4} & 18.0 & 17.0 & 4.25 & 5 & 3.6 & 3.5 & 1.5 \\
\hline & & & & 6 & 3 & 3.5 & 1.5 \\
\hline & & & & 7 & 2.57 & 3.5 & 1.5 \\
\hline & & & & 8 & 2.25 & 3.5 & 1.5 \\
\hline & & & & 9 & 2 & 3.5 & 1.5 \\
\hline \multirow[t]{5}{*}{5} & 18.5 & 17.5 & 3.5 & 6 & 3.08 & 3.5 & 0 \\
\hline & & & & 7 & 2.64 & 3.5 & 0 \\
\hline & & & & 8 & 2.32 & 3.5 & 0 \\
\hline & & & & 9 & 2.06 & 3.5 & 0 \\
\hline & & & & 10 & 1.85 & 3.5 & 0 \\
\hline \multirow[t]{5}{*}{5} & 21.5 & 20.5 & 4.1 & 6 & 3.58 & 3.5 & 1.5 \\
\hline & & & & 7 & 3.07 & 3.5 & 1.5 \\
\hline & & & & 8 & 2.69 & 3.5 & 1.5 \\
\hline & & & & 9 & 2.39 & 3.5 & 1.5 \\
\hline & & & & 10 & 2.15 & 3.5 & 1.5 \\
\hline \multirow[t]{6}{*}{6} & 22 & 21 & 3.5 & 7 & 3.14 & 3.5 & 0 \\
\hline & & & & 8 & 2.75 & 3.5 & 0 \\
\hline & & & & 9 & 2.44 & 3.5 & 0 \\
\hline & & & & 10 & 2.2 & 3.5 & 0 \\
\hline & & & & 11 & 2 & 3.5 & 0 \\
\hline & & & & 12 & 1.83 & 3.5 & 0 \\
\hline \multirow[t]{6}{*}{6} & 25 & 24 & 4 & 7 & 3.57 & 3.5 & 1.5 \\
\hline & & & & 8 & 3.125 & 3.5 & 1.5 \\
\hline & & & & 9 & 2.78 & 3.5 & 1.5 \\
\hline & & & & 10 & 2.5 & 3.5 & 1.5 \\
\hline & & & & 11 & 2.27 & 3.5 & 1.5 \\
\hline & & & & 12 & 1.83 & 3.5 & 1.5 \\
\hline
\end{tabular}

The scope of the optimization was as follows:

1- Girder spacing is between $1.5 \mathrm{~m}$ and $3.67 \mathrm{~m}$

2- Slab thickness $=225 \mathrm{~mm}$

3- Travelling lane width $=3.5 \mathrm{~m}$ 
4- Number of design lanes is from 1 to 6

5- Number of steel I-girders is from 3 to 12

6- Span lengths between $12 \mathrm{~m}$ to $48 \mathrm{~m}$ with 4 meter increments

The cases in Table 4.2 were repeated for bridges of span lengths $12 \mathrm{~m}$ to $48 \mathrm{~m}$, for truck loadings of CL-625 and CL-800 and, for single span to four-equal span bridge configurations. The total cases to be optimized were 6240 bridge configuration cases.

The optimized results data for $20 \mathrm{~m}$ single span bridge configurations studied under CL-625 truck loading is shown as an example in Table 4.3. In this table, $\mathrm{N}$ signifies the number of girders, S represents the girder spacing, B represents the bridge width, $\mathrm{n}$ represents the number of design lanes, Aw / S is the total web area per unit width, Is / S represents the steel section moment of inertia per unit width and, Ics / S represents the composite section moment of inertia per unit width. As can be observed in the table, the lowest CTD ratio for any given bridge configuration is 1.00 approximated to 2 decimal places. It can also be observed that multiple cases can govern design. The full results for all 6240 bridge configurations including shear studs design can be found in Appendix A. 
Table 4.3: Table showing the optimized results data for $20 \mathrm{~m}$ single span bridge configurations studied under CL-625 truck loading

\begin{tabular}{|c|c|c|c|c|c|c|c|c|c|c|c|c|c|}
\hline $\mathbf{N}$ & $\mathbf{S}(\mathbf{m})$ & $\begin{array}{l}\text { B } \\
(\mathbf{m})\end{array}$ & $\begin{array}{l}\text { Shoulder } \\
\text { (m) }\end{array}$ & $\mathbf{n}$ & $\begin{array}{l}\text { Construction } \\
\text { stage } \\
\text { permanent } \\
\text { deflection } \\
\text { CTD }\end{array}$ & $\begin{array}{l}\text { Superstructure } \\
\text { Vibration CTD }\end{array}$ & $\begin{array}{l}\text { Construction } \\
\text { Stage } \\
\text { Moment } \\
\text { CTD }\end{array}$ & $\begin{array}{l}\text { ULS } \\
\text { Moment } \\
\text { CTD }\end{array}$ & $\begin{array}{l}\text { ULS } \\
\text { Shear } \\
\text { CTD }\end{array}$ & $\begin{array}{l}\text { FLS } \\
\text { CTD } \\
\text { Ratio }\end{array}$ & $\begin{array}{l}\text { Aw / } \\
\text { S } \\
(\mathbf{m m})\end{array}$ & $\begin{array}{l}\text { Is / S } \\
\left(\mathrm{mm}^{3}\right)\end{array}$ & $\begin{array}{l}\text { Ics / S } \\
\left(\mathbf{m m}^{3}\right)\end{array}$ \\
\hline 3 & 1.5 & 4.5 & 0 & 1 & 1.38 & 1.04 & 1.96 & 1.41 & 1.72 & 1.00 & 6.98 & 1749954 & 4862033 \\
\hline 3 & 2 & 6 & 0.75 & 1 & 1.50 & 1.02 & 1.99 & 1.52 & 1.66 & 1.00 & 5.54 & 1873152 & 5048677 \\
\hline 3 & 2.33 & 7 & 1.25 & 1 & 1.00 & 1.71 & 1.29 & 1.07 & 1.34 & 1.27 & 4.49 & 1110056 & 3375663 \\
\hline 4 & 1.5 & 6 & 0.75 & 1 & 1.36 & 1.04 & 1.88 & 1.40 & 1.73 & 1.00 & 6.94 & 1669964 & 4701923 \\
\hline 4 & 1.75 & 7 & 1.25 & 1 & 1.00 & 1.32 & 1.25 & 1.12 & 1.59 & 1.01 & 5.64 & 1020159 & 3253639 \\
\hline 3 & 2.67 & 8 & 0 & 2 & 1.36 & 1.13 & 1.77 & 1.38 & 1.28 & 1.00 & 4.27 & 1681003 & 4583121 \\
\hline 3 & 3.17 & 9.5 & 0.75 & 2 & 1.05 & 1.39 & 1.29 & 1.10 & 1.06 & 1.00 & 3.49 & 1173820 & 3441331 \\
\hline 3 & 3.67 & 11 & 1.5 & 2 & 1.00 & 2.08 & 1.29 & 1.02 & 1.00 & 1.49 & 3.28 & 1267026 & 3684755 \\
\hline 4 & 2 & 8 & 0 & 2 & 1.33 & 1.10 & 1.68 & 1.40 & 1.59 & 1.00 & 5.35 & 1502718 & 4273776 \\
\hline 4 & 2.375 & 9.5 & 0.75 & 2 & 1.02 & 1.35 & 1.22 & 1.13 & 1.32 & 1.00 & 4.37 & 1041479 & 3214883 \\
\hline 4 & 2.75 & 11 & 1.5 & 2 & 1.00 & 2.04 & 1.27 & 1.05 & 1.18 & 1.52 & 3.90 & 1116488 & 3345400 \\
\hline 4 & 2.875 & 11.5 & 1.75 & 2 & 1.00 & 2.23 & 1.26 & 1.05 & 1.14 & 1.65 & 3.76 & 1111814 & 3325627 \\
\hline 4 & 3.25 & 13 & 2.5 & 2 & 1.00 & 2.20 & 1.23 & 1.05 & 1.03 & 1.59 & 3.39 & 1106606 & 3283265 \\
\hline 4 & 3.625 & 14.5 & 3.25 & 2 & 1.00 & 2.27 & 1.28 & 1.02 & 1.00 & 1.65 & 3.26 & 1230406 & 3589323 \\
\hline 5 & 1.6 & 8 & 0 & 2 & 1.23 & 1.09 & 1.60 & 1.31 & 1.69 & 1.00 & 6.38 & 1372899 & 4059292 \\
\hline 5 & 1.9 & 9.5 & 0.75 & 2 & 1.00 & 1.38 & 1.17 & 1.15 & 1.56 & 1.01 & 5.22 & 952485 & 3076758 \\
\hline 5 & 2.2 & 11 & 1.5 & 2 & 1.00 & 2.06 & 1.24 & 1.09 & 1.41 & 1.55 & 4.67 & 1048103 & 3253580 \\
\hline 5 & 2.3 & 11.5 & 1.75 & 2 & 1.00 & 2.24 & 1.23 & 1.09 & 1.36 & 1.68 & 4.49 & 1040920 & 3221187 \\
\hline 5 & 2.6 & 13 & 2.5 & 2 & 1.00 & 2.21 & 1.20 & 1.08 & 1.23 & 1.61 & 4.05 & 1037364 & 3183385 \\
\hline 5 & 2.9 & 14.5 & 3.25 & 2 & 1.00 & 2.27 & 1.26 & 1.05 & 1.14 & 1.67 & 3.73 & 1115103 & 3329834 \\
\hline 6 & 1.583 & 9.5 & 0.75 & 2 & 1.07 & 1.20 & 1.36 & 1.18 & 1.65 & 1.00 & 6.24 & 1115934 & 3502630 \\
\hline 6 & 1.833 & 11 & 1.5 & 2 & 1.00 & 2.08 & 1.22 & 1.12 & 1.61 & 1.58 & 5.41 & 992503 & 3178103 \\
\hline 6 & 1.917 & 11.5 & 1.75 & 2 & 1.00 & 2.27 & 1.20 & 1.12 & 1.56 & 1.71 & 5.20 & 987679 & 3153777 \\
\hline 6 & 2.167 & 13 & 2.5 & 2 & 1.00 & 2.24 & 1.18 & 1.12 & 1.42 & 1.64 & 4.68 & 982870 & 3107285 \\
\hline 6 & 2.417 & 14.5 & 3.25 & 2 & 1.00 & 2.22 & 1.24 & 1.08 & 1.32 & 1.70 & 4.32 & 1059772 & 3254172 \\
\hline 7 & 1.57 & 11 & 1.5 & 2 & 1.00 & 2.04 & 1.19 & 1.15 & 1.77 & 1.60 & 6.11 & 946352 & 3116427 \\
\hline 7 & 1.643 & 11.5 & 1.75 & 2 & 1.00 & 2.23 & 1.18 & 1.15 & 1.73 & 1.74 & 5.89 & 943135 & 3099381 \\
\hline 7 & 1.857 & 13 & 2.5 & 2 & 1.00 & 2.20 & 1.16 & 1.15 & 1.59 & 1.67 & 5.30 & 938360 & 3048216 \\
\hline 7 & 2.07 & 14.5 & 3.25 & 2 & 1.00 & 2.25 & 1.22 & 1.10 & 1.49 & 1.72 & 4.89 & 1013089 & 3189678 \\
\hline 4 & 2.875 & 11.5 & 0 & 3 & 1.34 & 1.09 & 1.74 & 1.34 & 1.22 & 1.00 & 4.02 & 1679048 & 4564082 \\
\hline 4 & 3.25 & 13 & 0.75 & 3 & 1.05 & 1.35 & 1.30 & 1.09 & 1.05 & 1.00 & 3.43 & 1187020 & 3465965 \\
\hline 4 & 3.625 & 14.5 & 1.5 & 3 & 1.00 & 2.06 & 1.28 & 1.02 & 1.00 & 1.50 & 3.26 & 1230406 & 3589323 \\
\hline
\end{tabular}




\begin{tabular}{|c|c|c|c|c|c|c|c|c|c|c|c|c|c|}
\hline $\mathbf{N}$ & $\mathbf{S}(\mathbf{m})$ & $\begin{array}{l}\text { B } \\
(\mathbf{m})\end{array}$ & $\begin{array}{l}\text { Shoulder } \\
\text { (m) }\end{array}$ & $\mathbf{n}$ & $\begin{array}{l}\text { Construction } \\
\text { stage } \\
\text { permanent } \\
\text { deflection } \\
\text { CTD }\end{array}$ & $\begin{array}{l}\text { Superstructure } \\
\text { Vibration CTD }\end{array}$ & $\begin{array}{l}\text { Construction } \\
\text { Stage } \\
\text { Moment } \\
\text { CTD }\end{array}$ & $\begin{array}{l}\text { ULS } \\
\text { Moment } \\
\text { CTD }\end{array}$ & $\begin{array}{l}\text { ULS } \\
\text { Shear } \\
\text { CTD }\end{array}$ & $\begin{array}{l}\text { FLS } \\
\text { CTD } \\
\text { Ratio }\end{array}$ & $\begin{array}{l}\text { Aw / } \\
\text { S } \\
(\mathbf{m m})\end{array}$ & $\begin{array}{l}\text { Is / S } \\
\left(\mathbf{m m}^{3}\right)\end{array}$ & $\begin{array}{l}\text { Ics / S } \\
\left(\mathbf{m m}^{3}\right)\end{array}$ \\
\hline 5 & 2.3 & 11.5 & 0 & 3 & 1.32 & 1.09 & 1.68 & 1.36 & 1.44 & 1.00 & 4.78 & 1542410 & 4326510 \\
\hline 5 & 2.6 & 13 & 0.75 & 3 & 1.03 & 1.33 & 1.25 & 1.11 & 1.24 & 1.00 & 4.08 & 1083748 & 3289121 \\
\hline 5 & 2.9 & 14.5 & 1.5 & 3 & 1.00 & 2.06 & 1.26 & 1.05 & 1.14 & 1.52 & 3.73 & 1115103 & 3329834 \\
\hline 6 & 1.917 & 11.5 & 0 & 3 & 1.30 & 1.09 & 1.62 & 1.37 & 1.64 & 1.00 & 5.51 & 1434532 & 4142200 \\
\hline 6 & 2.167 & 13 & 0.75 & 3 & 1.01 & 1.32 & 1.20 & 1.13 & 1.43 & 1.00 & 4.69 & 1000568 & 3145459 \\
\hline 6 & 2.417 & 14.5 & 1.5 & 3 & 1.00 & 1.71 & 1.24 & 1.08 & 1.32 & 1.31 & 4.32 & 1059772 & 3254172 \\
\hline 7 & 1.643 & 11.5 & 0 & 3 & 1.28 & 1.09 & 1.57 & 1.38 & 1.80 & 1.00 & 6.21 & 1343712 & 3987498 \\
\hline 7 & 1.857 & 13 & 0.75 & 3 & 1.00 & 1.32 & 1.16 & 1.15 & 1.59 & 1.00 & 5.30 & 938360 & 3048216 \\
\hline 7 & 2.07 & 14.5 & 1.5 & 3 & 1.00 & 1.49 & 1.22 & 1.10 & 1.49 & 1.14 & 4.89 & 1013089 & 3189678 \\
\hline 5 & 3 & 15 & 0 & 4 & 1.36 & 1.11 & 1.76 & 1.34 & 1.18 & 1.00 & 3.89 & 1706902 & 4615071 \\
\hline 5 & 3.3 & 16.5 & 0.75 & 4 & 1.06 & 1.30 & 1.30 & 1.09 & 1.04 & 1.00 & 3.39 & 1190004 & 3468018 \\
\hline 5 & 3.6 & 18 & 1.5 & 4 & 1.00 & 2.03 & 1.27 & 1.02 & 1.00 & 1.49 & 3.25 & 1209014 & 3533277 \\
\hline 6 & 2.5 & 15 & 0 & 4 & 1.34 & 1.06 & 1.71 & 1.36 & 1.36 & 1.00 & 4.48 & 1595642 & 4421218 \\
\hline 6 & 2.75 & 16.5 & 0.75 & 4 & 1.04 & 1.30 & 1.26 & 1.11 & 1.19 & 1.00 & 3.90 & 1106163 & 3324205 \\
\hline 6 & 3 & 18 & 1.5 & 4 & 1.00 & 1.98 & 1.25 & 1.04 & 1.11 & 1.50 & 3.63 & 1116251 & 3323924 \\
\hline 7 & 2.14 & 15 & 0 & 4 & 1.32 & 1.07 & 1.66 & 1.37 & 1.53 & 1.00 & 5.06 & 1504212 & 4262863 \\
\hline 7 & 2.357 & 16.5 & 0.75 & 4 & 1.03 & 1.30 & 1.22 & 1.12 & 1.34 & 1.00 & 4.40 & 1036508 & 3206802 \\
\hline 7 & 2.57 & 18 & 1.5 & 4 & 1.00 & 1.82 & 1.24 & 1.07 & 1.26 & 1.38 & 4.10 & 1067340 & 3252629 \\
\hline 8 & 1.875 & 15 & 0 & 4 & 1.31 & 1.08 & 1.62 & 1.38 & 1.67 & 1.00 & 5.60 & 1420730 & 4116964 \\
\hline 8 & 2.06 & 16.5 & 0.75 & 4 & 1.01 & 1.30 & 1.19 & 1.13 & 1.49 & 1.00 & 4.89 & 979044 & 3112972 \\
\hline 8 & 2.25 & 18 & 1.5 & 4 & 1.00 & 1.56 & 1.22 & 1.09 & 1.39 & 1.22 & 4.56 & 1024532 & 3189834 \\
\hline 9 & 1.67 & 15 & 0 & 4 & 1.26 & 1.09 & 1.58 & 1.35 & 1.70 & 1.00 & 6.13 & 1352714 & 4002331 \\
\hline 9 & 1.83 & 16.5 & 0.75 & 4 & 1.01 & 1.31 & 1.17 & 1.15 & 1.60 & 1.00 & 5.37 & 944517 & 3066832 \\
\hline 9 & 2 & 18 & 1.5 & 4 & 1.00 & 1.42 & 1.20 & 1.11 & 1.53 & 1.10 & 5.02 & 990008 & 3145409 \\
\hline 6 & 3.08 & 18.5 & 0 & 5 & 1.37 & 1.06 & 1.77 & 1.35 & 1.17 & 1.00 & 3.81 & 1725940 & 4649750 \\
\hline 6 & 3.58 & 21.5 & 1.5 & 5 & 1.00 & 2.01 & 1.26 & 1.02 & 1.00 & 1.48 & 3.25 & 1196812 & 3500261 \\
\hline 7 & 2.64 & 18.5 & 0 & 5 & 1.35 & 1.07 & 1.72 & 1.36 & 1.31 & 1.00 & 4.30 & 1631841 & 4484212 \\
\hline 7 & 3.07 & 21.5 & 1.5 & 5 & 1.00 & 1.98 & 1.25 & 1.04 & 1.09 & 1.49 & 3.56 & 1116427 & 3319594 \\
\hline 8 & 2.32 & 18.5 & 0 & 5 & 1.34 & 1.09 & 1.68 & 1.37 & 1.44 & 1.00 & 4.74 & 1546515 & 4331793 \\
\hline 8 & 2.69 & 21.5 & 1.5 & 5 & 1.00 & 1.91 & 1.23 & 1.06 & 1.21 & 1.43 & 3.95 & 1072847 & 3253180 \\
\hline 9 & 2.06 & 18.5 & 0 & 5 & 1.32 & 1.06 & 1.65 & 1.38 & 1.58 & 1.00 & 5.21 & 1476674 & 4213702 \\
\hline 9 & 2.39 & 21.5 & 1.5 & 5 & 1.00 & 1.67 & 1.22 & 1.08 & 1.33 & 1.28 & 4.35 & 1037619 & 3205538 \\
\hline 10 & 1.85 & 18.5 & 0 & 5 & 1.31 & 1.08 & 1.61 & 1.39 & 1.69 & 1.00 & 5.67 & 1415655 & 4112727 \\
\hline 10 & 2.15 & 21.5 & 1.5 & 5 & 1.00 & 1.54 & 1.21 & 1.10 & 1.45 & 1.17 & 4.73 & 1006075 & 3162812 \\
\hline
\end{tabular}




\begin{tabular}{|c|c|c|c|c|c|c|c|c|c|c|c|c|c|}
\hline $\mathbf{N}$ & $\mathbf{S}(\mathbf{m})$ & $\begin{array}{l}\text { B } \\
(\mathbf{m})\end{array}$ & $\begin{array}{l}\text { Shoulder } \\
\text { (m) }\end{array}$ & $\mathbf{n}$ & $\begin{array}{l}\text { Construction } \\
\text { stage } \\
\text { permanent } \\
\text { deflection } \\
\text { CTD } \\
\end{array}$ & $\begin{array}{l}\text { Superstructure } \\
\text { Vibration CTD }\end{array}$ & $\begin{array}{l}\text { Construction } \\
\text { Stage } \\
\text { Moment } \\
\text { CTD }\end{array}$ & $\begin{array}{l}\text { ULS } \\
\text { Moment } \\
\text { CTD }\end{array}$ & $\begin{array}{l}\text { ULS } \\
\text { Shear } \\
\text { CTD }\end{array}$ & $\begin{array}{l}\text { FLS } \\
\text { CTD } \\
\text { Ratio }\end{array}$ & $\begin{array}{l}\text { Aw / } \\
\mathbf{S} \\
(\mathbf{m m})\end{array}$ & $\begin{array}{l}\text { Is / S } \\
\left(\mathrm{mm}^{3}\right)\end{array}$ & $\begin{array}{l}\text { Ics / S } \\
\left(\mathbf{m m}^{3}\right)\end{array}$ \\
\hline 7 & 3.14 & 22 & 0 & 6 & 1.37 & 1.07 & 1.77 & 1.35 & 1.15 & 1.00 & 3.76 & 1739159 & 4674802 \\
\hline 7 & 3.57 & 25 & 1.5 & 6 & 1.00 & 1.99 & 1.26 & 1.02 & 1.00 & 1.47 & 3.24 & 1184009 & 3466187 \\
\hline 8 & 2.75 & 22 & 0 & 6 & 1.36 & 1.08 & 1.73 & 1.36 & 1.27 & 1.00 & 4.16 & 1653892 & 4523036 \\
\hline 8 & 3.125 & 25 & 1.5 & 6 & 1.00 & 1.97 & 1.25 & \begin{tabular}{|l|}
1.04 \\
\end{tabular} & 1.08 & 1.48 & 3.50 & 1114365 & 3308533 \\
\hline 9 & 2.44 & 22 & 0 & 6 & 1.35 & 1.05 & 1.71 & 1.37 & 1.39 & 1.00 & 4.57 & 1588003 & 4409361 \\
\hline 9 & 2.78 & 25 & 1.5 & 6 & 1.00 & 1.90 & 1.23 & 1.05 & 1.18 & 1.47 & 3.85 & 1078727 & 3259109 \\
\hline 10 & 2.2 & 22 & 0 & 6 & 1.34 & 1.07 & 1.67 & 1.38 & 1.51 & 1.00 & 4.95 & 1515263 & 4279550 \\
\hline 10 & 2.5 & 25 & 1.5 & 6 & 1.00 & 1.75 & 1.22 & 1.07 & 1.29 & 1.33 & 4.20 & 1047585 & 3217253 \\
\hline 11 & 2 & 22 & 0 & 6 & 1.33 & 1.05 & 1.64 & 1.39 & 1.62 & 1.00 & 5.33 & 1460673 & 4188564 \\
\hline 11 & 2.27 & 25 & 1.5 & 6 & 1.00 & 1.57 & 1.21 & 1.09 & 1.39 & 1.22 & 4.53 & 1018176 & 3174058 \\
\hline 12 & 1.83 & 22 & 0 & 6 & 1.32 & 1.08 & 1.62 & 1.40 & 1.70 & 1.00 & 5.72 & 1420595 & 4126229 \\
\hline 12 & 1.83 & 25 & 1.5 & 6 & 1.05 & 1.34 & 1.74 & 1.00 & 1.70 & 1.27 & 5.80 & 1558306 & 4417011 \\
\hline
\end{tabular}




\section{Chapter V}

\section{Software Results Analysis and Parametric Study}

\subsection{Effect of number of girders on moment of inertia}

In order to study the effect of the number of girders on the moment of inertia for the steel and the composite sections per unit width (Is/S \& Ics/S), multiple graphs were created where the bridge width (B) and the number of design lanes (n) were set to a constant value while changing the number of girders $(\mathrm{N})$ for single span bridge configurations under CL-625 truck loading.

As can be seen in Figures 5.1 through 5.18, the moment of inertia of the steel section per unit width follows the same pattern regardless of the number of design lanes or bridge width. However, in the case of $\mathrm{N}=12$ for $\mathrm{B}=25 \mathrm{~m}$ seen in Figure 5.19, the moment of inertia does not follow the same pattern exhibited in the other figures. This can be attributed to overdesigning of the bridge configuration due to an excessive amount of steel used to meet the design criteria. To conclude this portion of the study, the moment of inertia per unit width of the steel section show a good relationship with span length regardless of the bridge width or number of design lanes. The exception to this rule is the case of 12 girders used. This exception can be attributed to the use of an excessive amount of steel thus increasing the total moment of inertia and consecutively the moment of inertia per unit width for the steel section. 


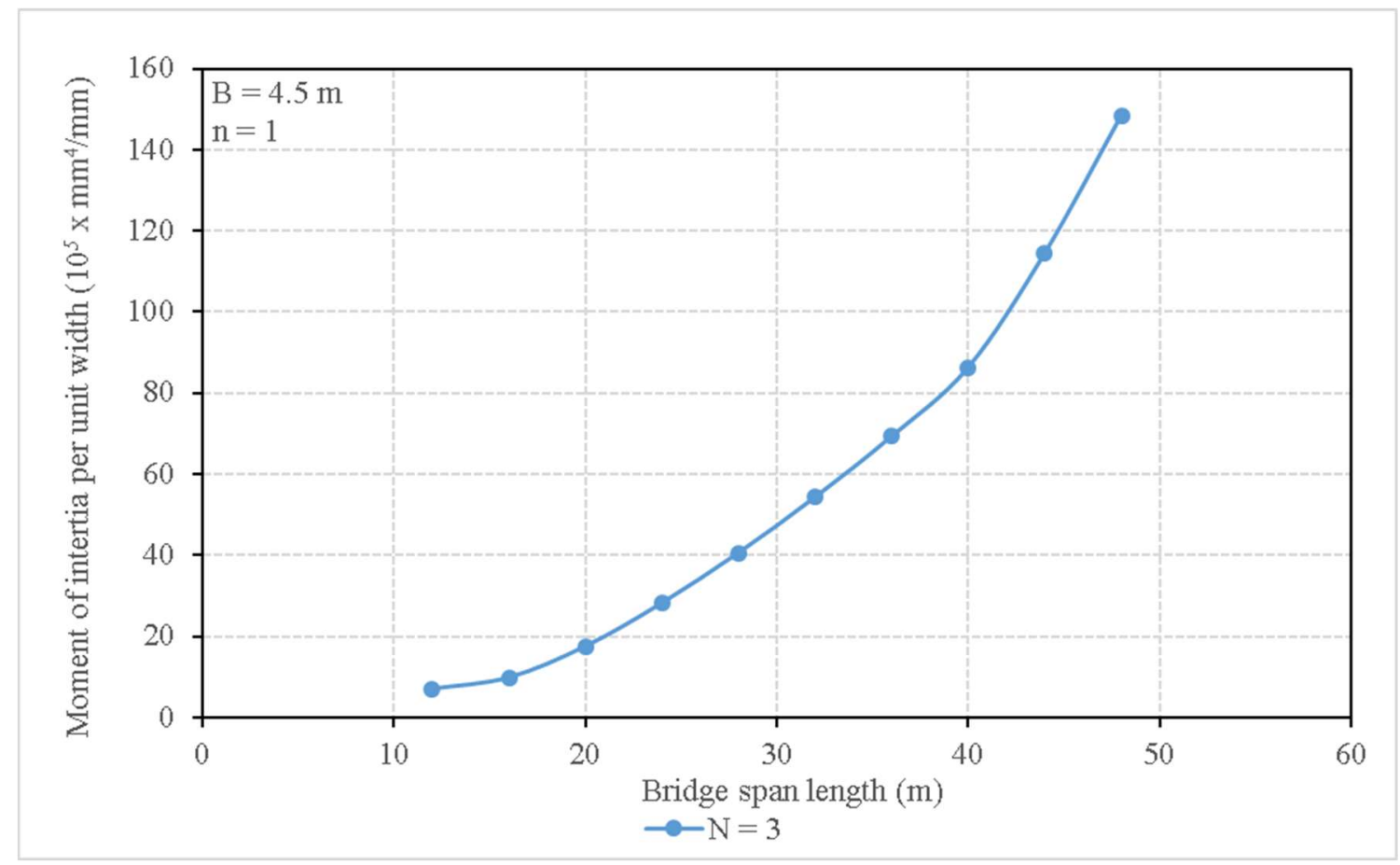

Figure 5.1: Moment of inertia of the steel section per unit width vs span length for a one-lane single span bridge under CL-625 truck loading of $4.5 \mathrm{~m}$ width

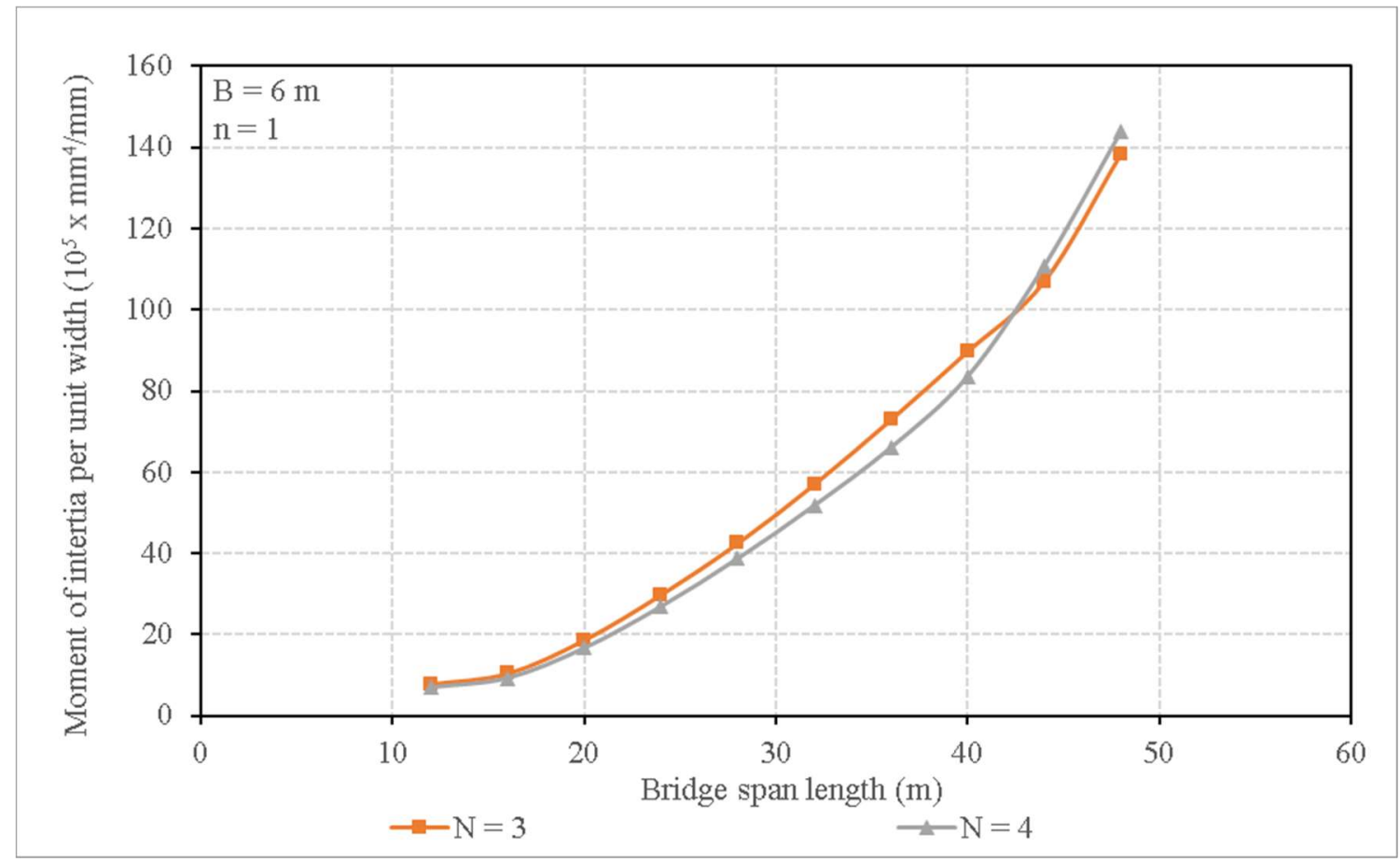

Figure 5.2: Moment of inertia of the steel section per unit width vs span length for a one-lane single span bridge under CL-625 truck loading of $6 \mathrm{~m}$ width 


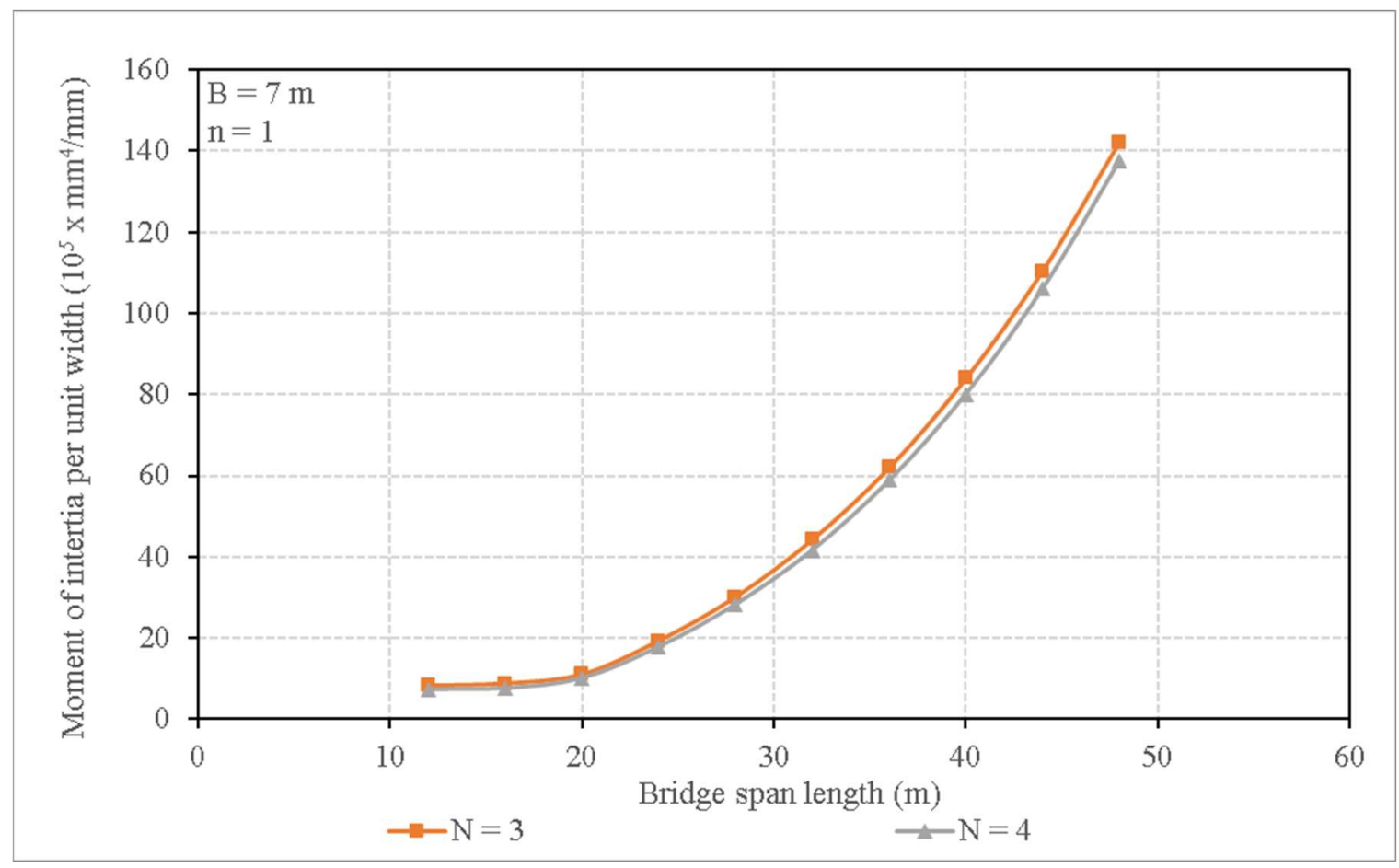

Figure 5.3: Moment of inertia of the steel section per unit width vs span length for a one -lane single span bridge under CL-625 truck loading of $7 \mathrm{~m}$ width

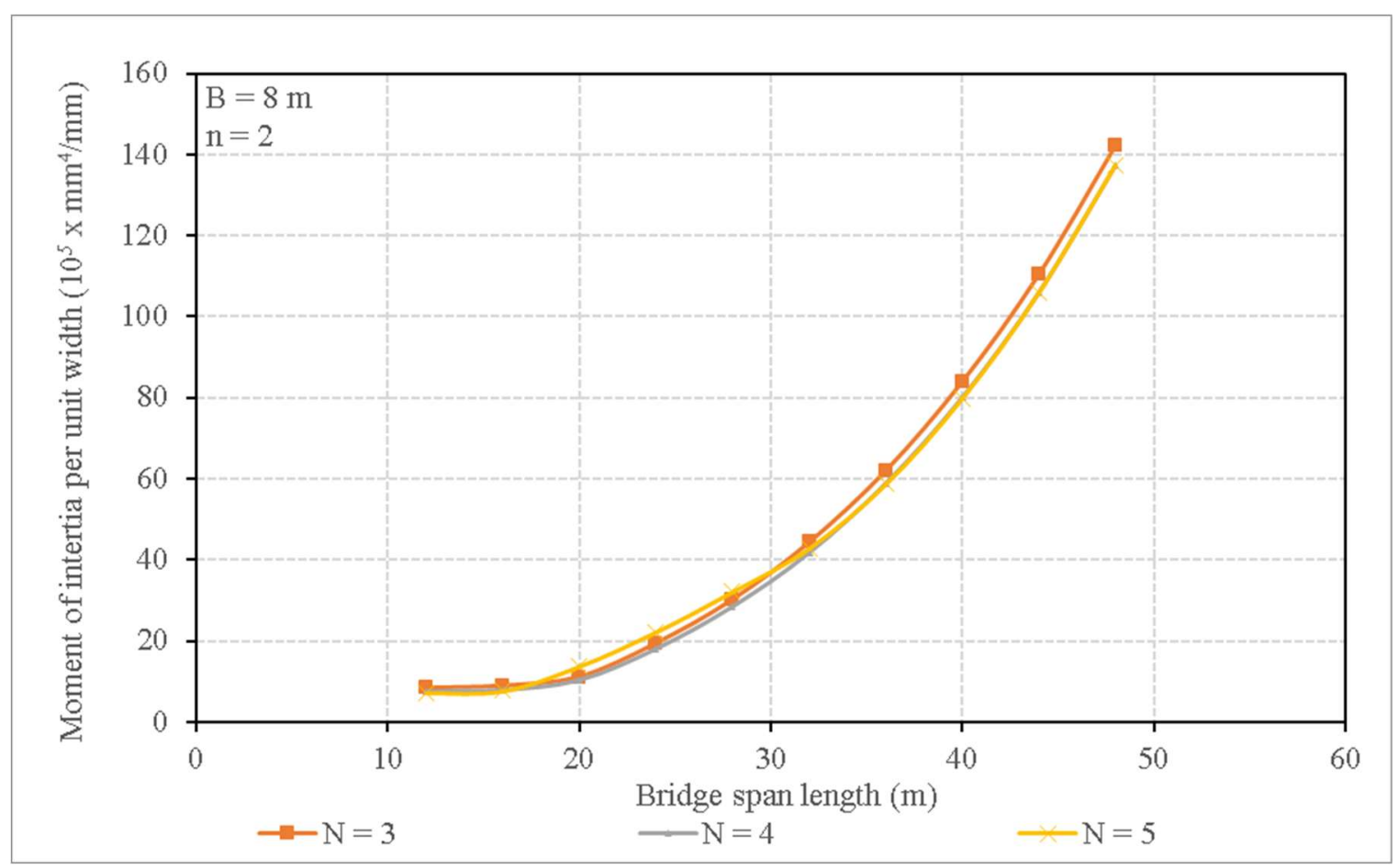

Figure 5.4: Moment of inertia of the steel section per unit width vs span length for a two-lane single span bridge under CL-625 truck loading of $8 \mathrm{~m}$ width 


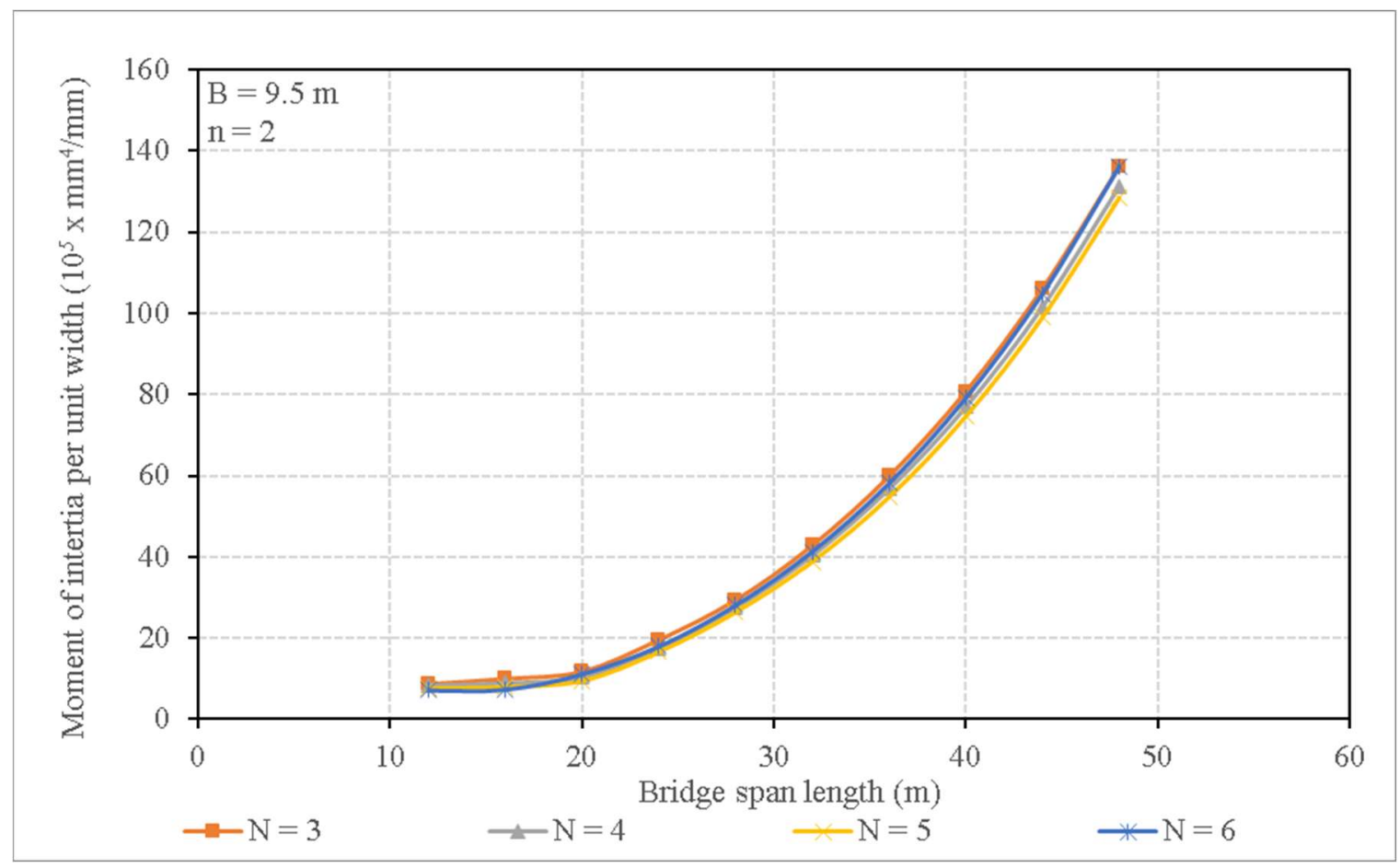

Figure 5.5: Moment of inertia of the steel section per unit width vs span length for a two-lane single span bridge under CL-625 truck loading of $9.5 \mathrm{~m}$ width

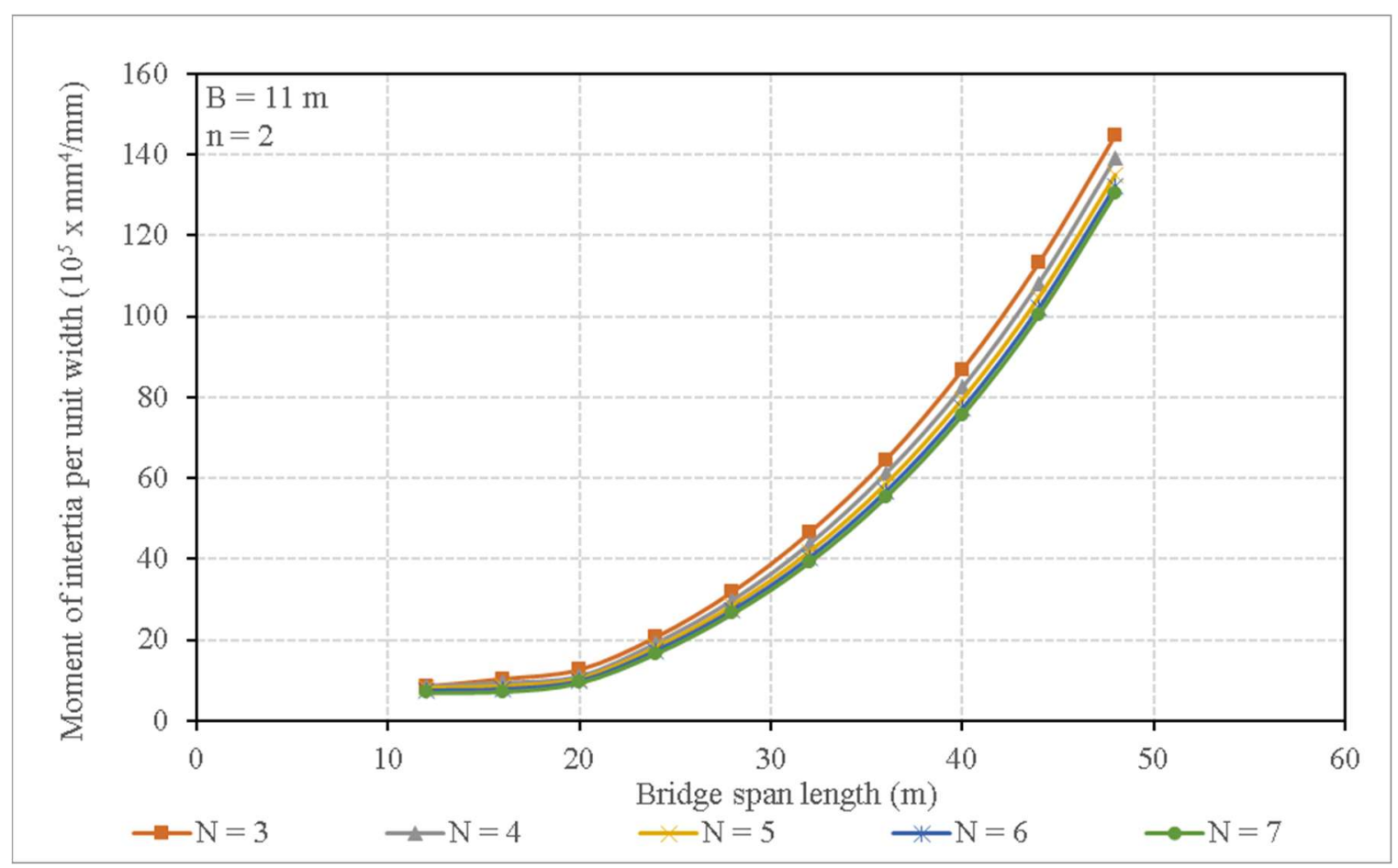

Figure 5.6: Moment of inertia of the steel section per unit width vs span length for a two-lane single span bridge under CL-625 truck loading of $11 \mathrm{~m}$ width 


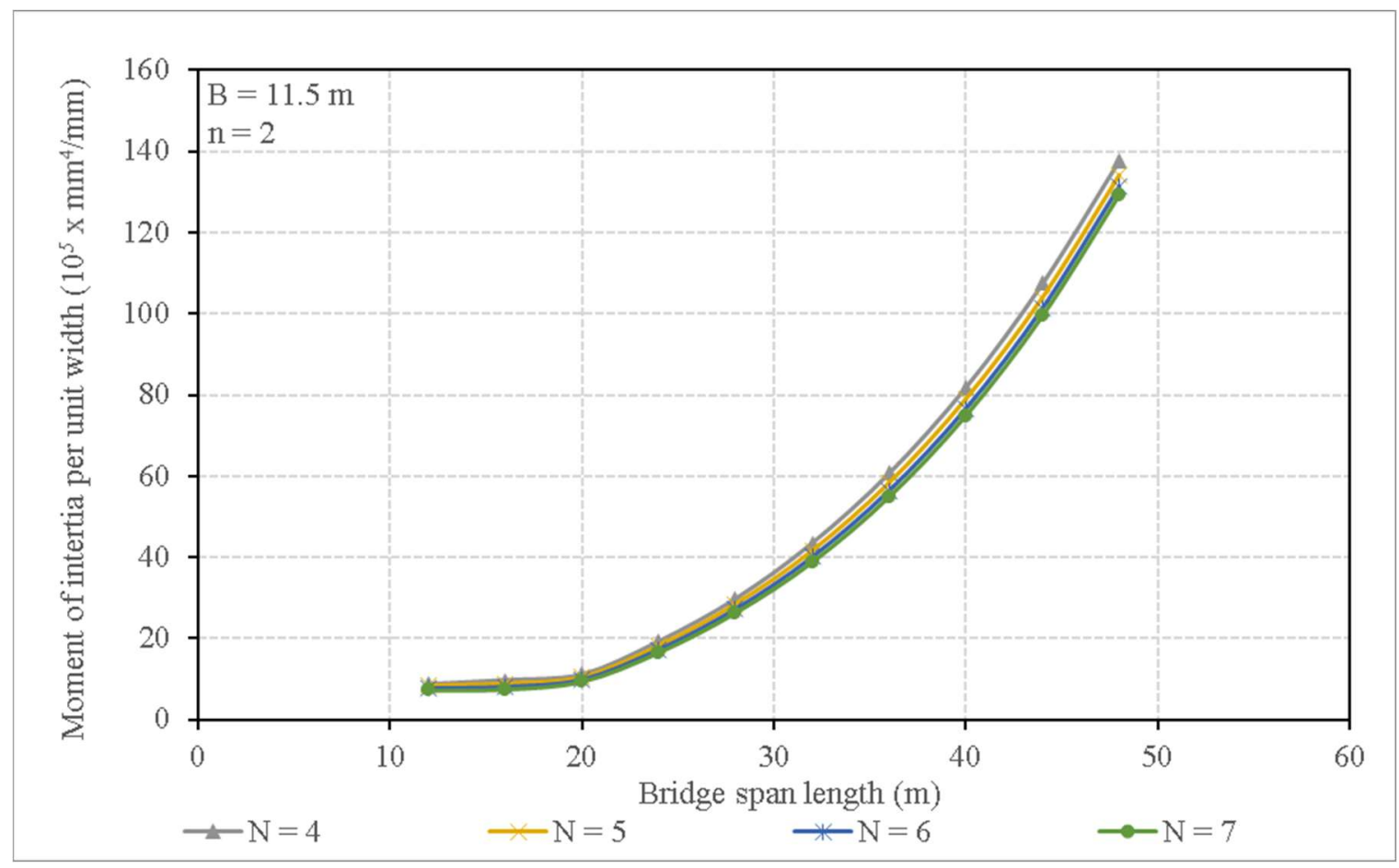

Figure 5.7: Moment of inertia of the steel section per unit width vs span length for a two-lane single span bridge under CL-625 truck loading of $11.5 \mathrm{~m}$ width

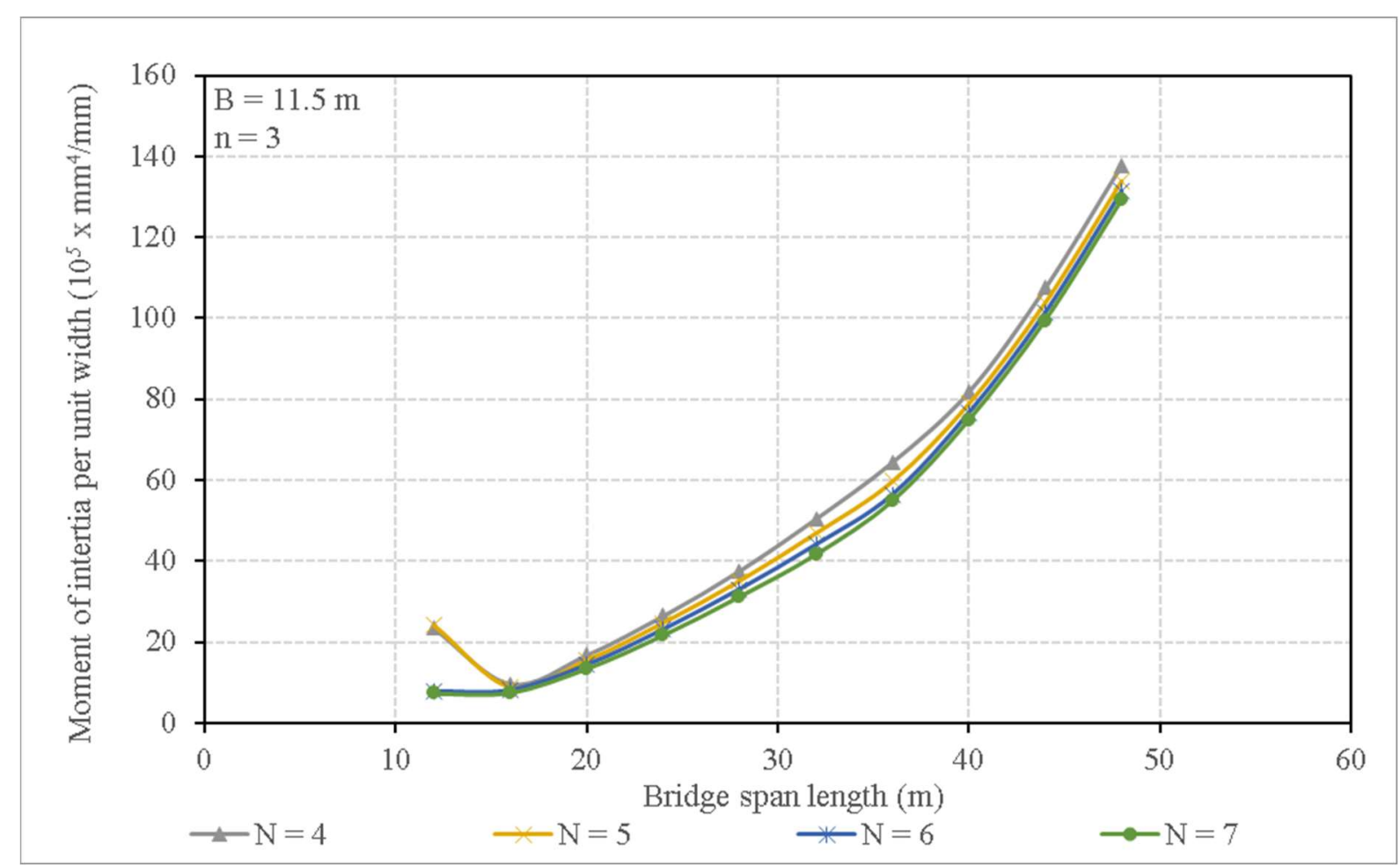

Figure 5.8: Moment of inertia of the steel section per unit width vs span length for a three-lane single span bridge under CL-625 truck loading of $11.5 \mathrm{~m}$ width 


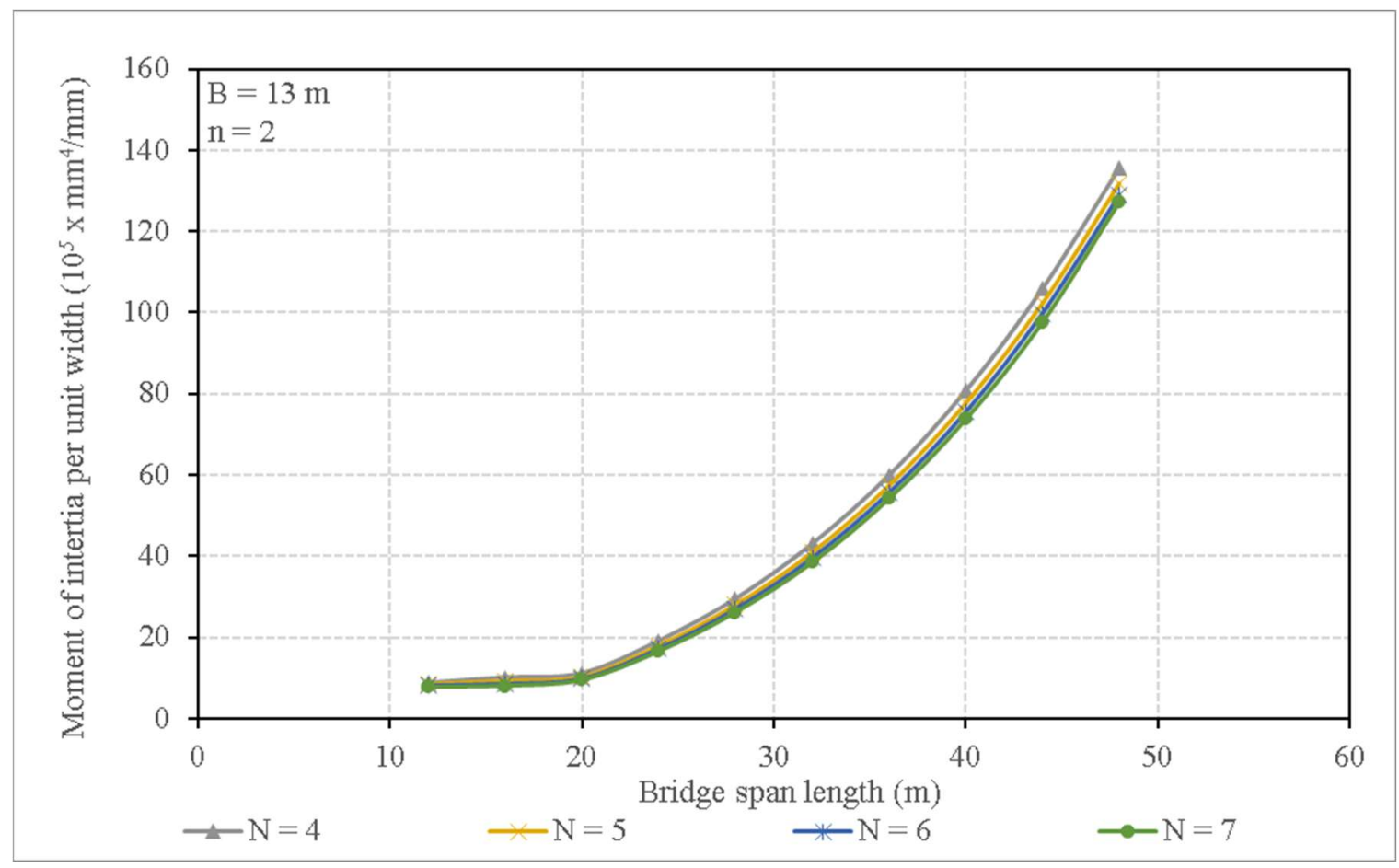

Figure 5.9: Moment of inertia of the steel section per unit width vs span length for a two-lane single span bridge under CL-625 truck loading of $13 \mathrm{~m}$ width

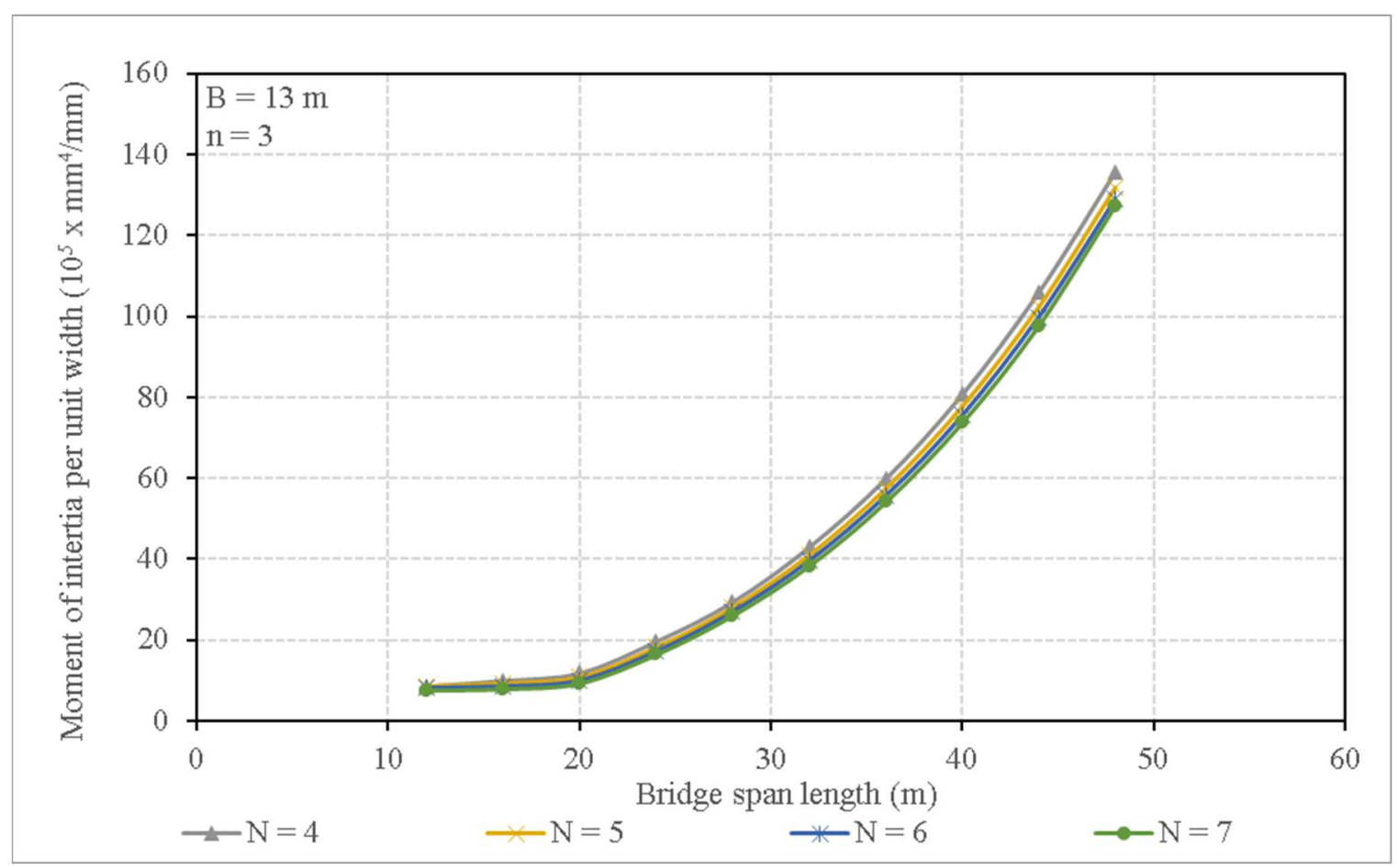

Figure 5.10: Moment of inertia of the steel section per unit width vs span length for a three-lane single span bridge under CL-625 truck loading of $13 \mathrm{~m}$ width 


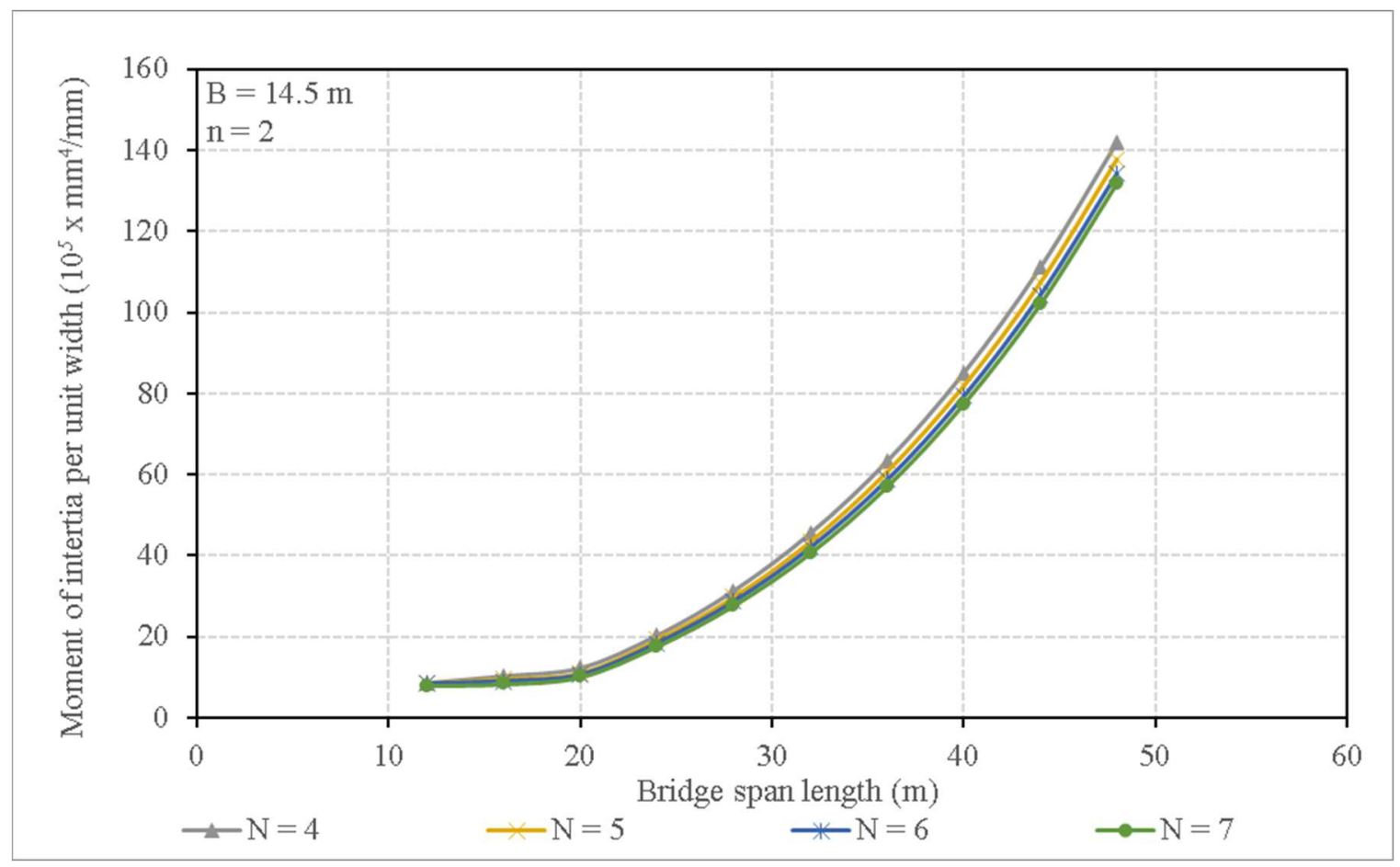

Figure 5.11: Moment of inertia of the steel section per unit width vs span length for a two-lane single span bridge under CL-625 truck loading of $14.5 \mathrm{~m}$ width

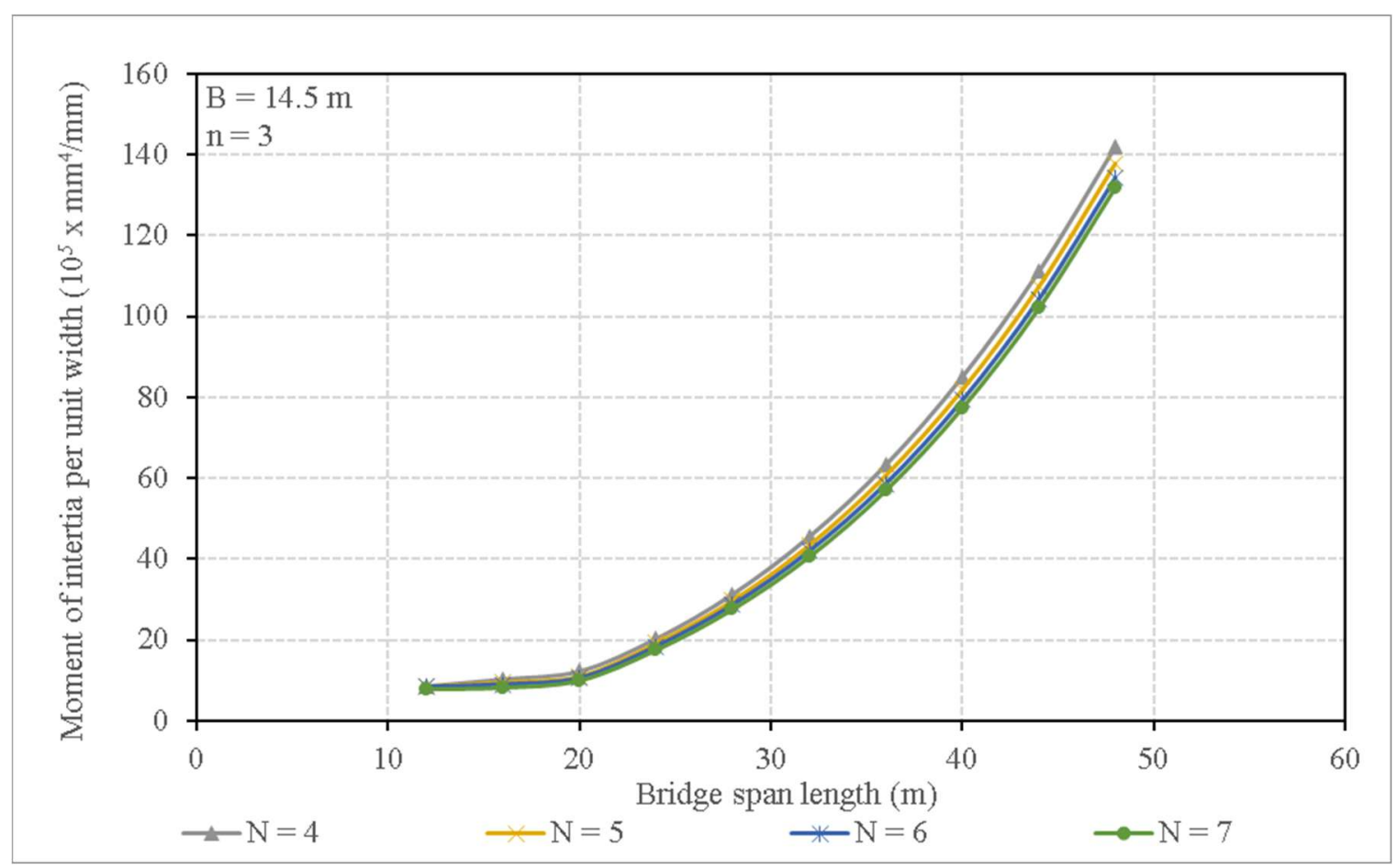

Figure 5.12: Moment of inertia of the steel section per unit width vs span length for a three-lane single span bridge under CL-625 truck loading of $14.5 \mathrm{~m}$ width 


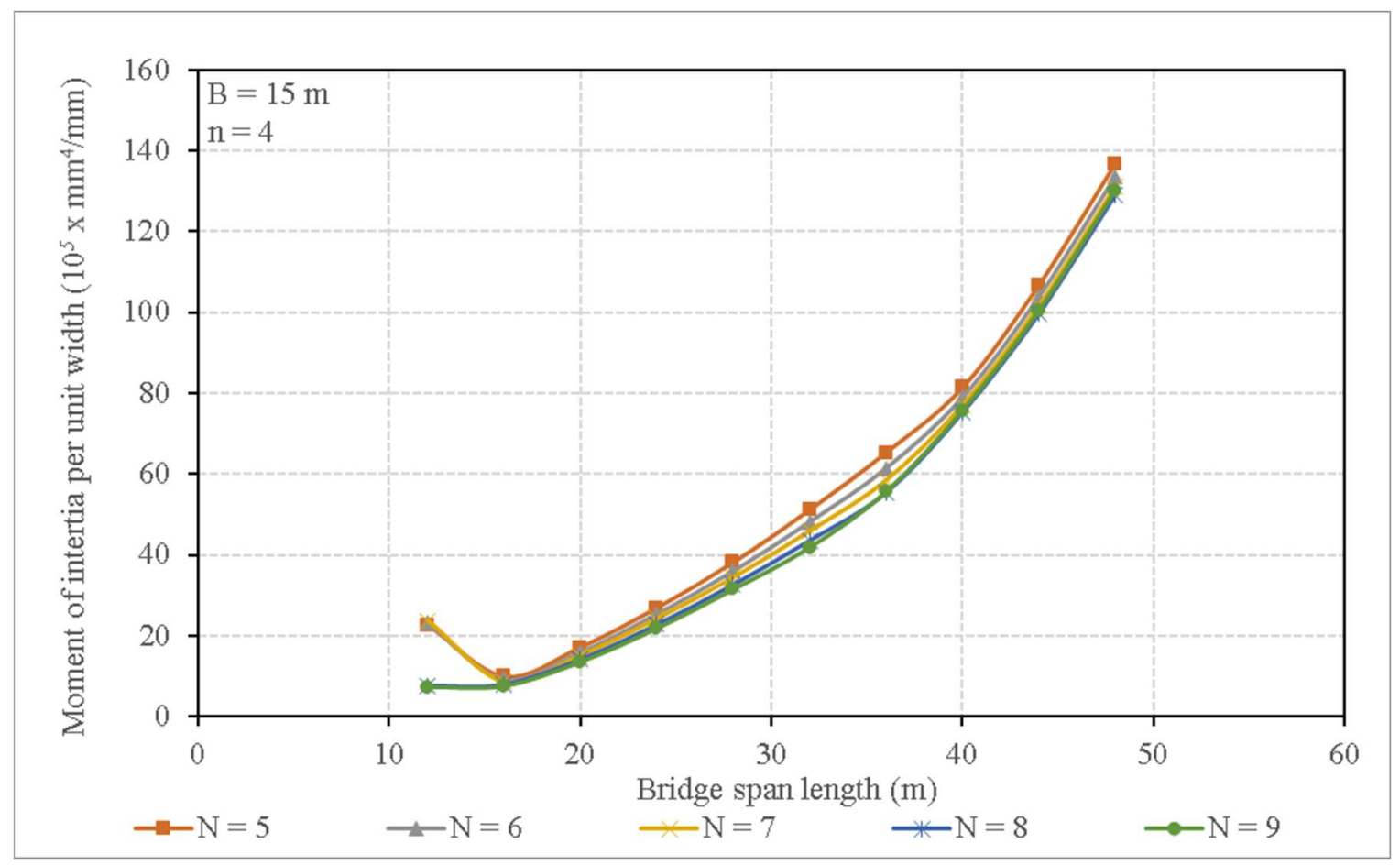

Figure 5.13: Moment of inertia of the steel section per unit width vs span length for a four-lane single span bridge under CL-625 truck loading of $15 \mathrm{~m}$ width

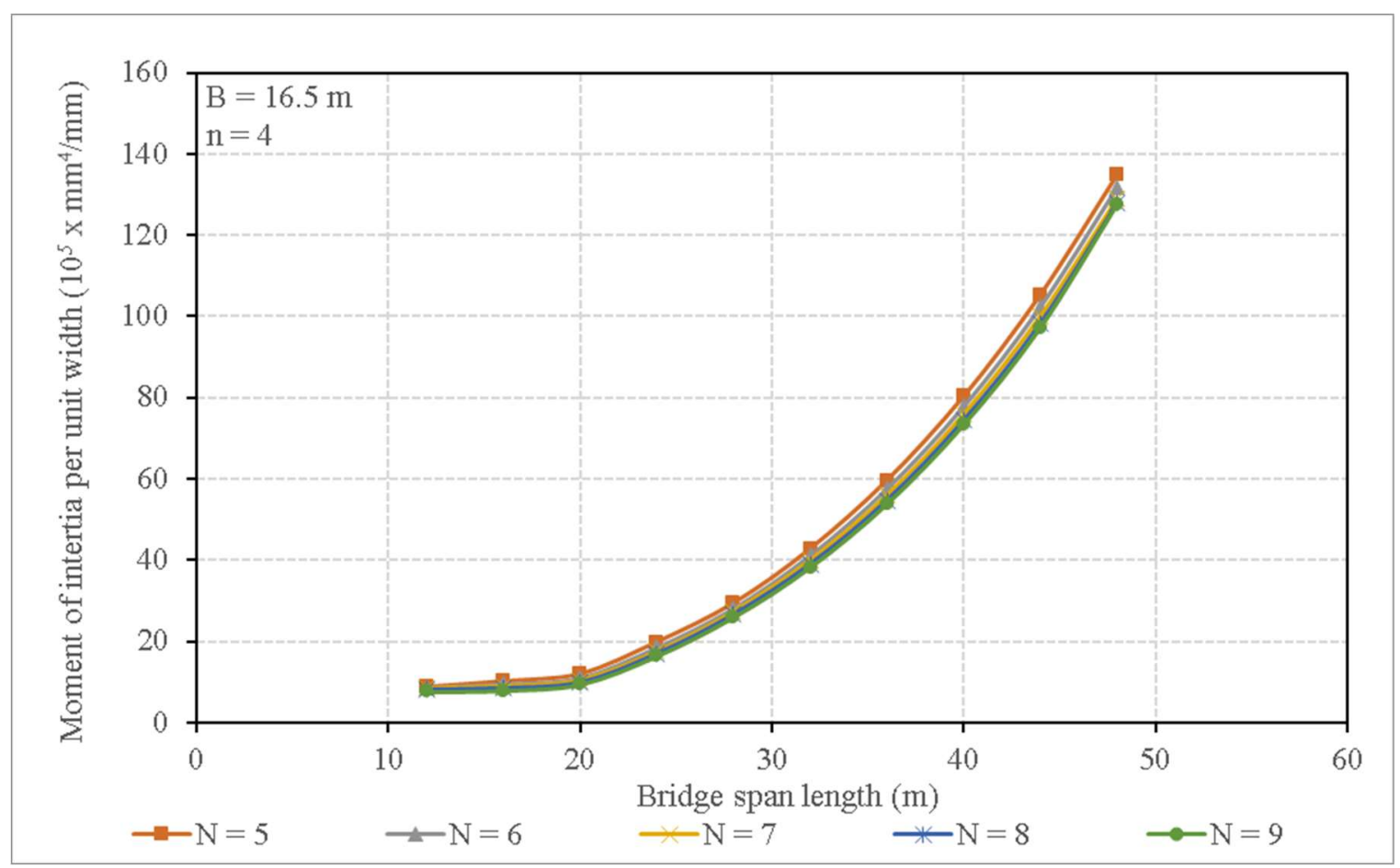

Figure 5.14: Moment of inertia of the steel section per unit width vs span length for a four-lane single span bridge under CL-625 truck loading of $16.5 \mathrm{~m}$ width 


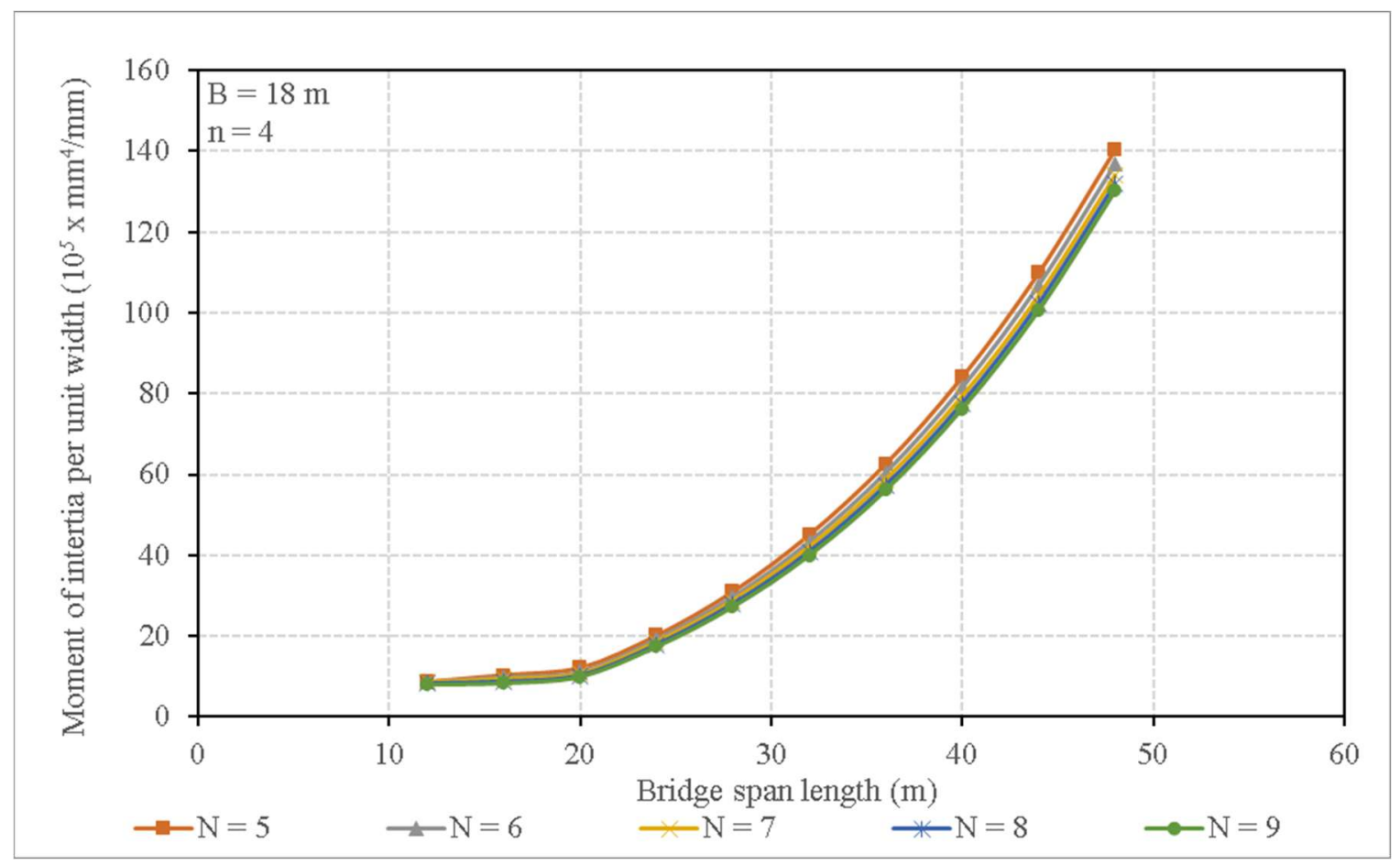

Figure 5.15: Moment of inertia of the steel section per unit width vs span length for a four-lane single span bridge under CL-625 truck loading of $18 \mathrm{~m}$ width

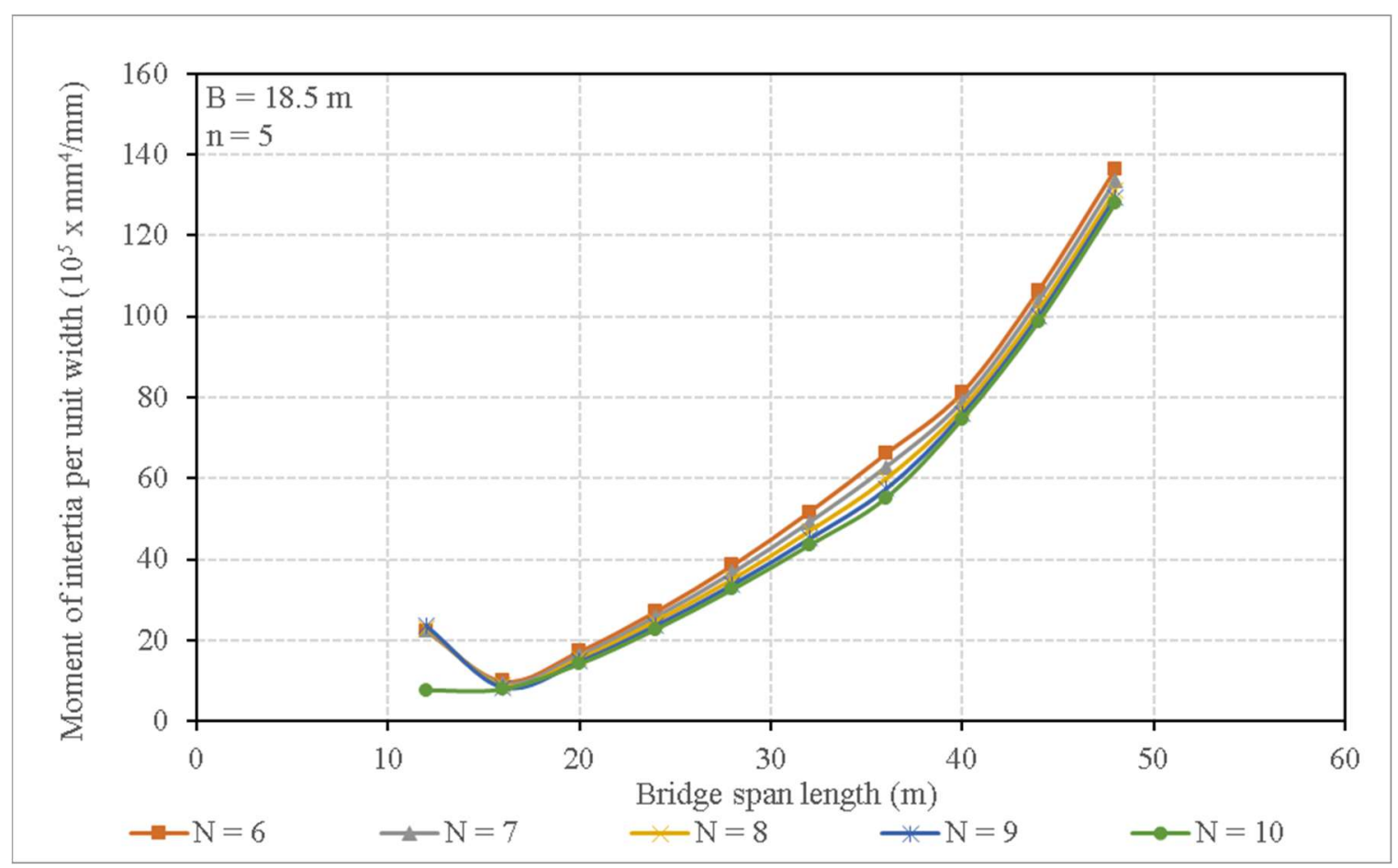

Figure 5.16: Moment of inertia of the steel section per unit width vs span length for a five-lane single span bridge under CL-625 truck loading of $18.5 \mathrm{~m}$ width 


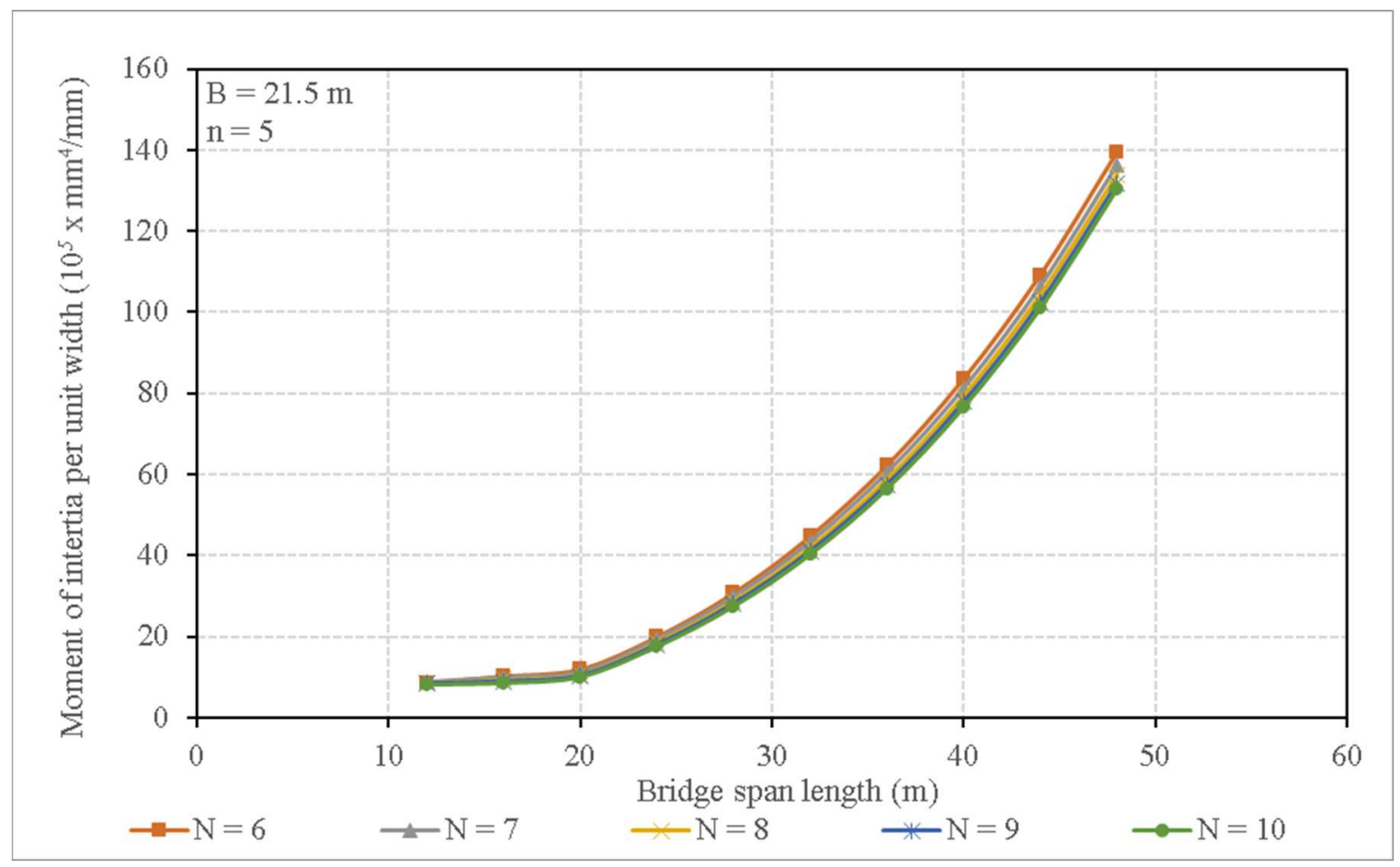

Figure 5.17: Moment of inertia of the steel section per unit width vs span length for a five-lane single span bridge under CL-625 truck loading of $21.5 \mathrm{~m}$ width

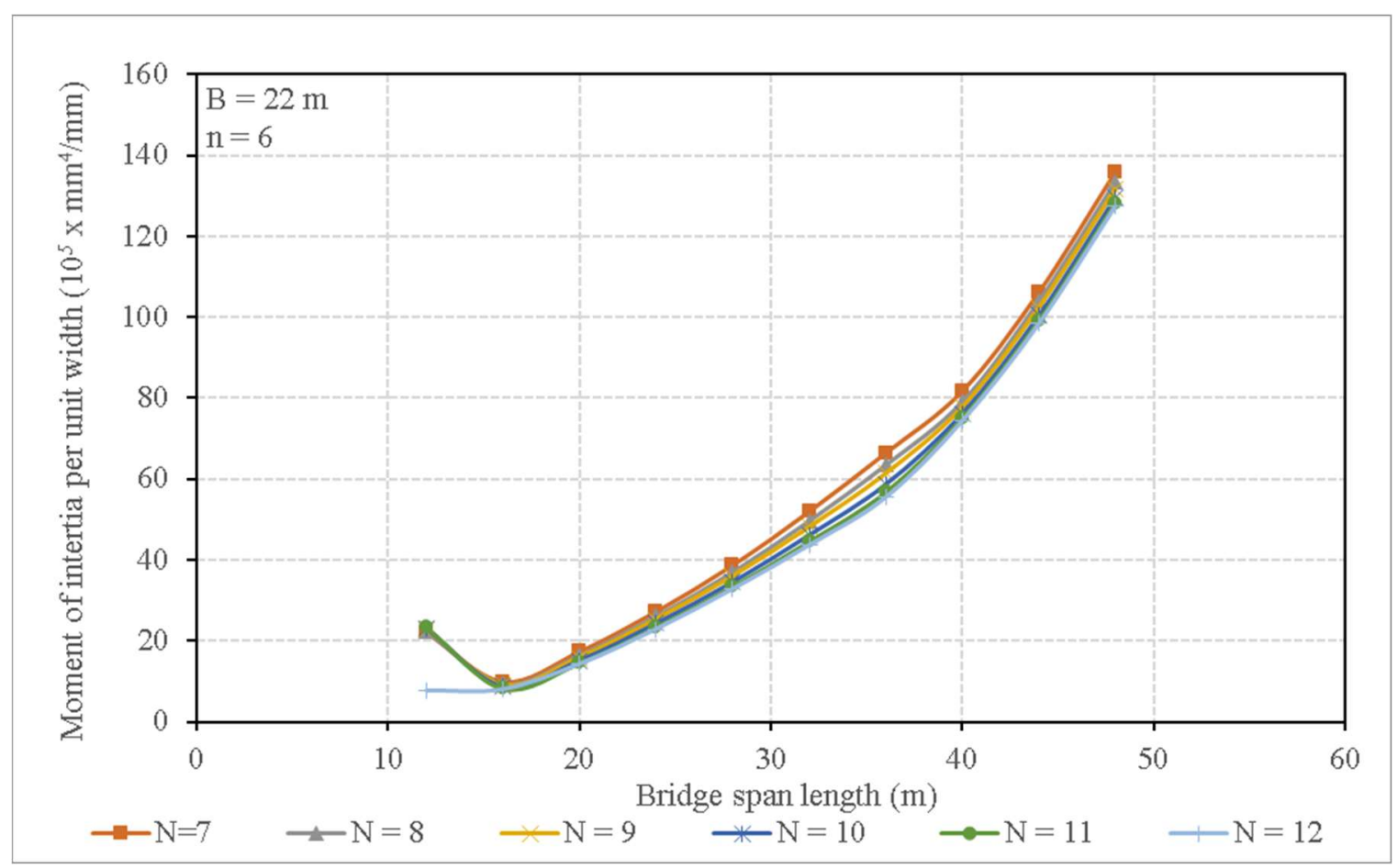

Figure 5.18: Moment of inertia of the steel section per unit width vs span length for a six-lane single span bridge under CL-625 truck loading of $22 \mathrm{~m}$ width 


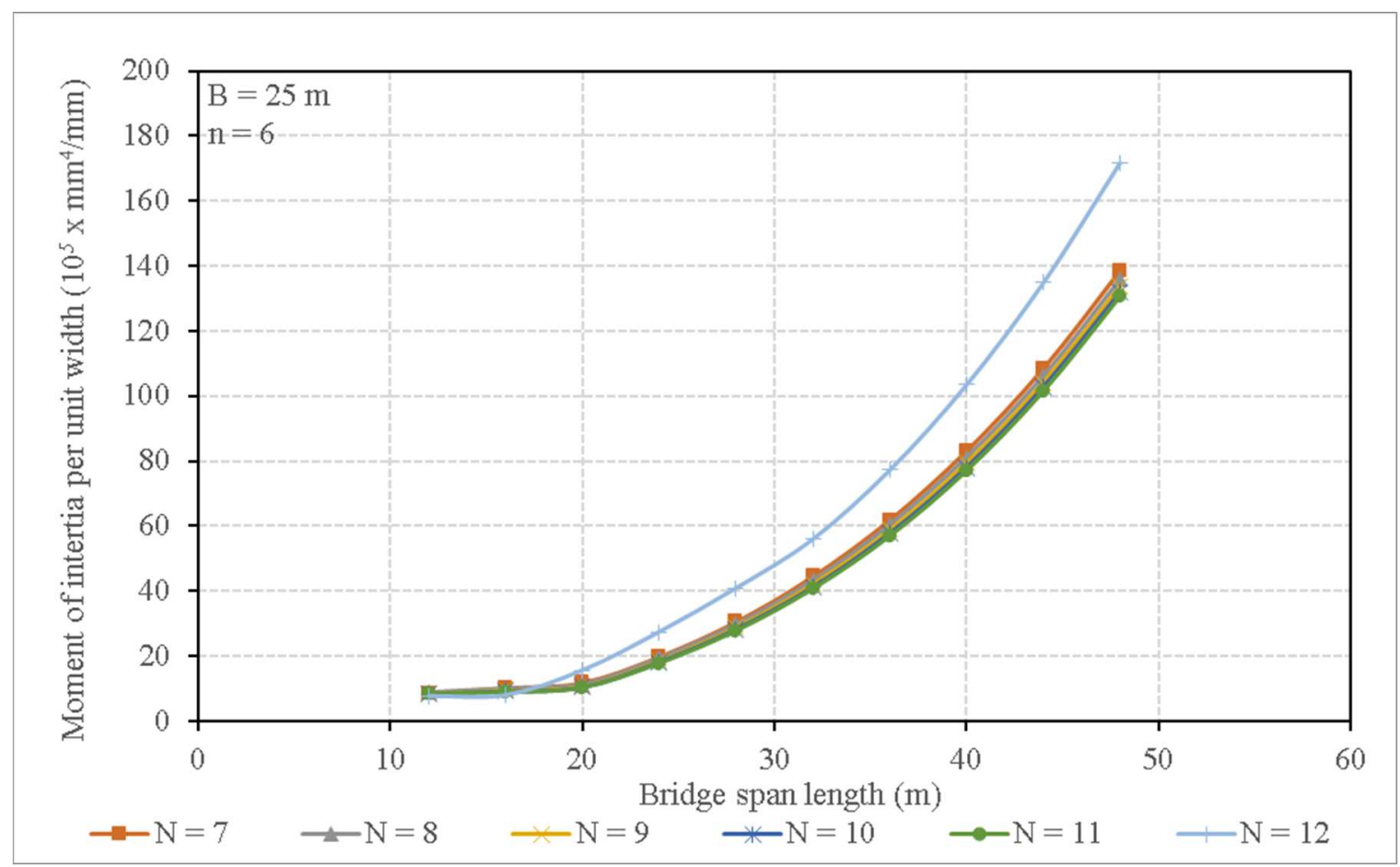

Figure 5.19: Moment of inertia of the steel section per unit width vs span length for a six-lane single span bridge under CL-625 truck loading of $25 \mathrm{~m}$ width

As for the moment of inertia per unit width of the composite section observed in Figures 5.20 through 5.38, the values show a similar pattern to the steel section values. However, in the case of composite section, the values have a much closer packing. This is due to the moment of inertia of the slab per unit width being considered in the calculations which increases the magnitude of the results while reducing the variability. As expected, the case of 12 girders used visible in Figure 5.38 shows the same overdesigned characteristic as in Figure 5.19 for the steel section. This is due to the same reasons previously discussed. As a result, the case of 12 girders was omitted when obtaining parametric equations to represent the results. 


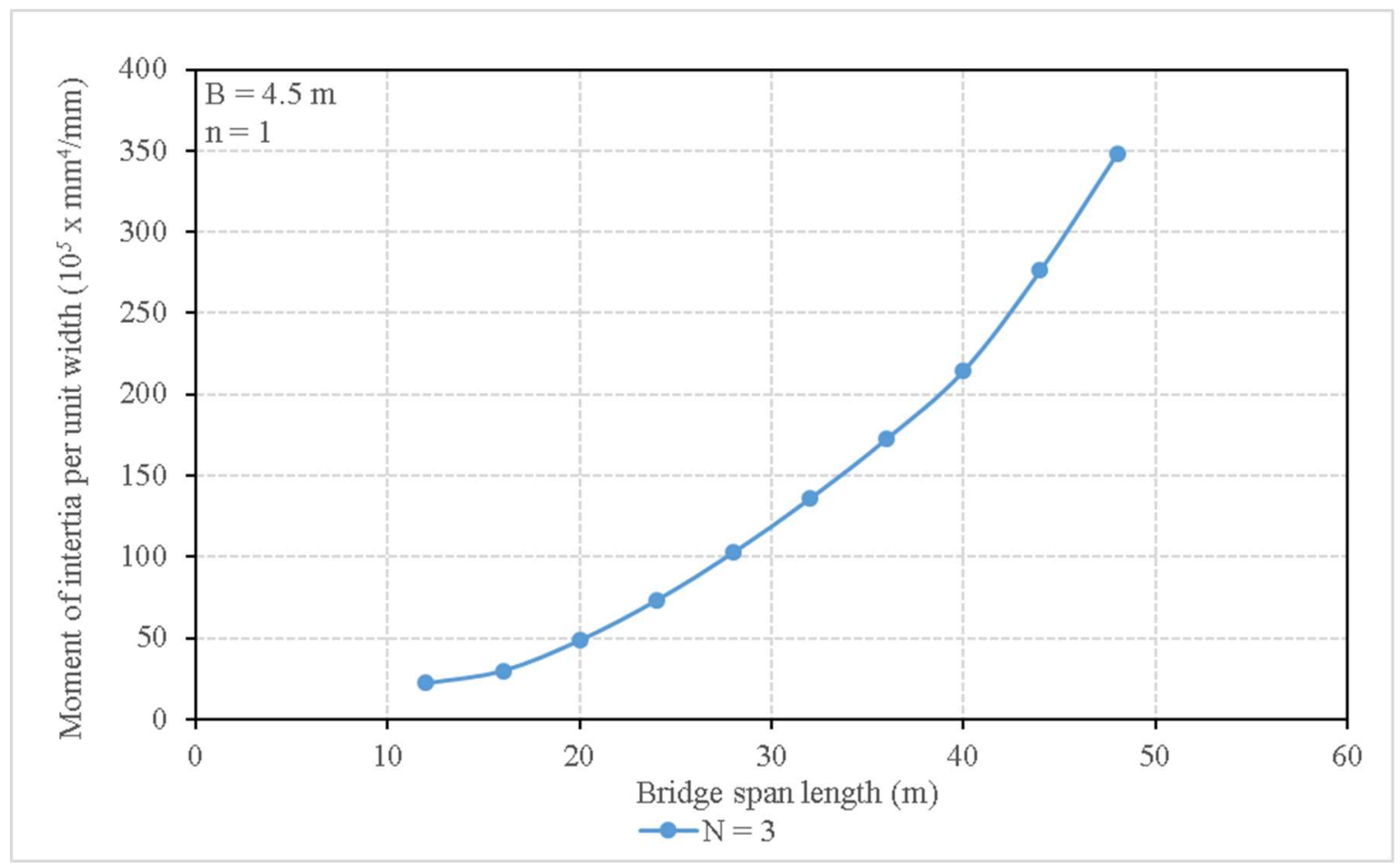

Figure 5.20: Moment of inertia of the composite concrete-steel section per unit width vs span length for a one-lane single span bridge under CL-625 truck loading of $4.5 \mathrm{~m}$ width

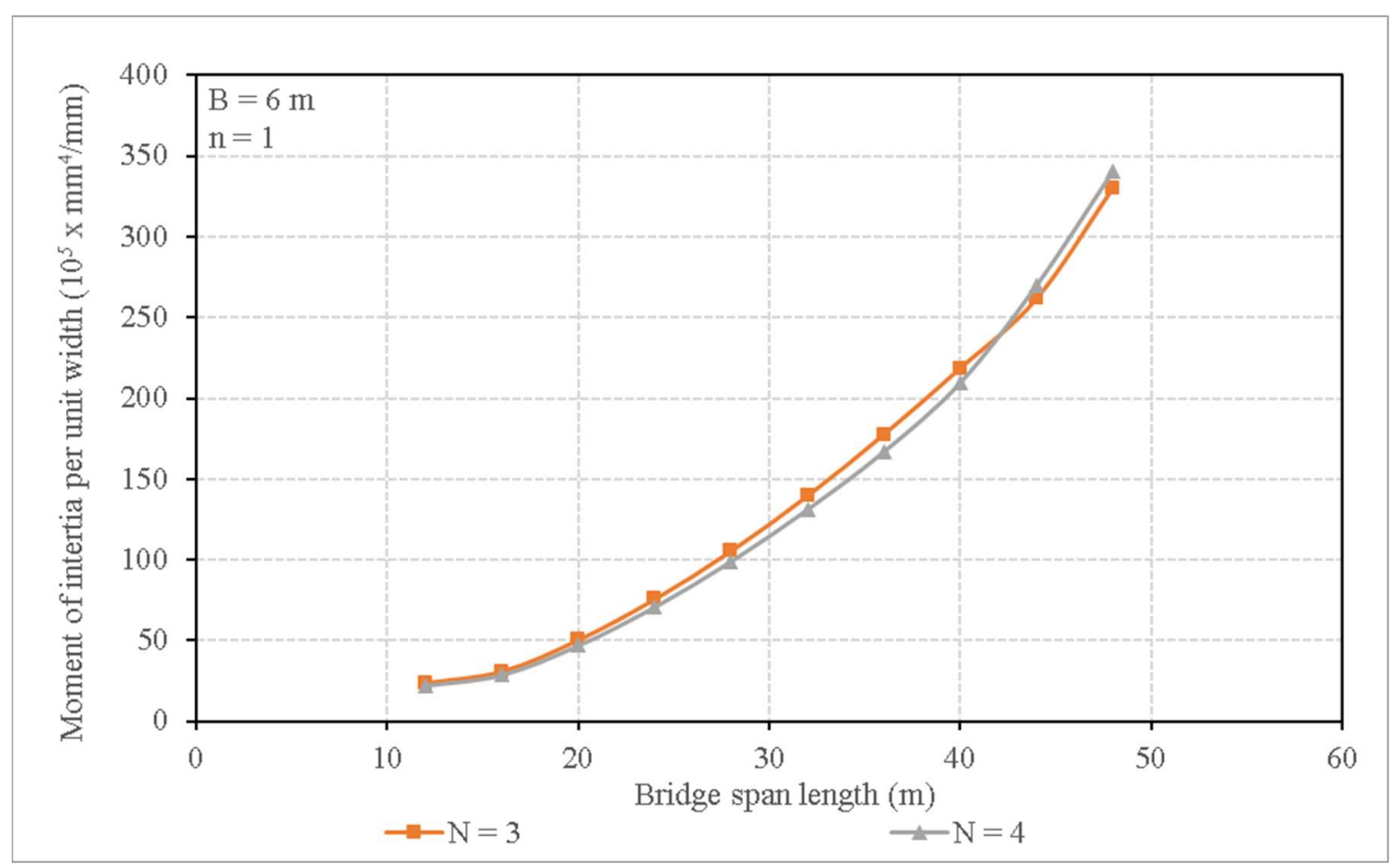

Figure 5.21: Moment of inertia of the composite concrete-steel section per unit width vs span length for a one-lane single span bridge under CL-625 truck loading of $6 \mathrm{~m}$ width 


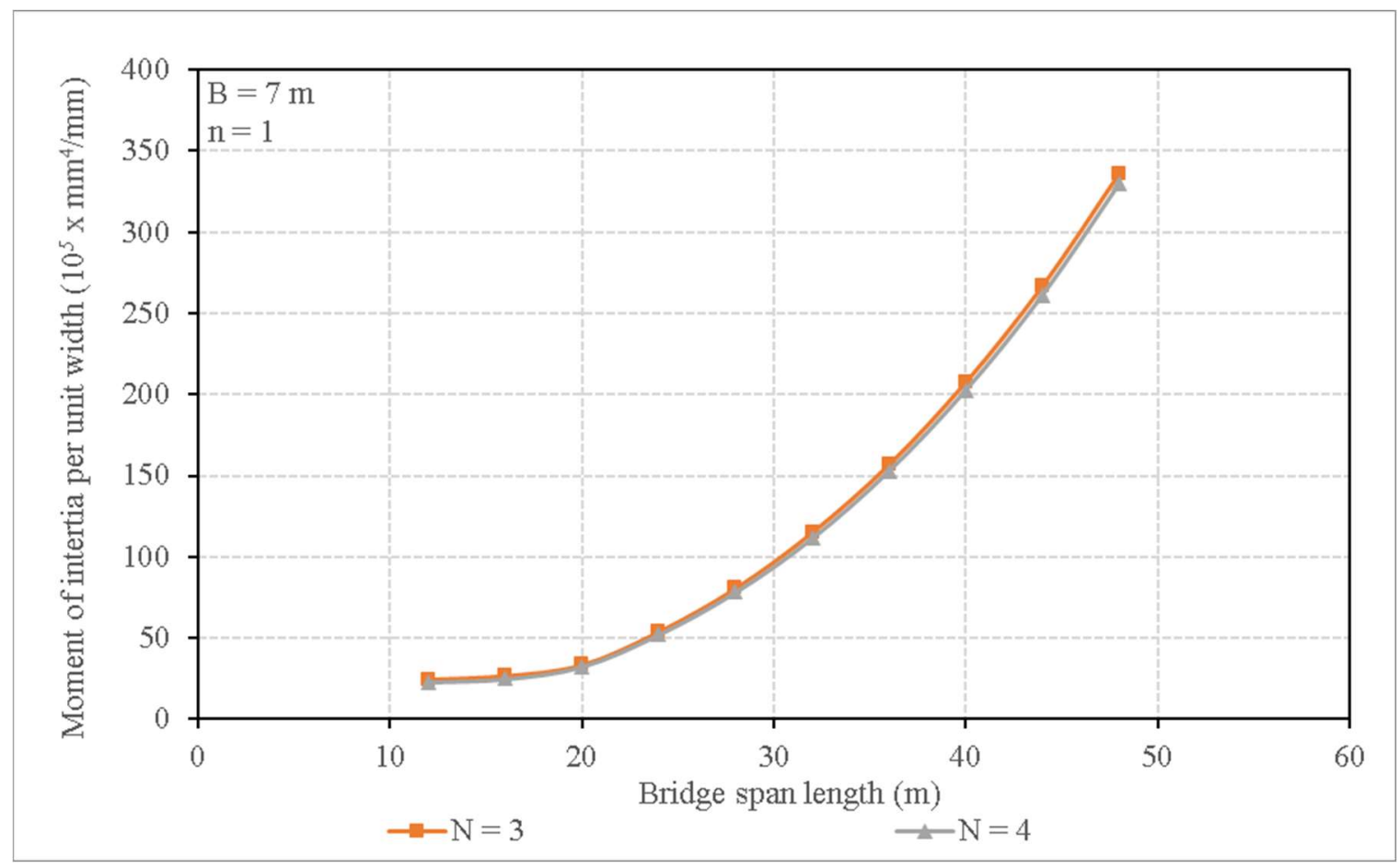

Figure 5.22: Moment of inertia of the composite concrete-steel section per unit width vs span length for a one-lane single span bridge under CL-625 truck loading of $7 \mathrm{~m}$ width

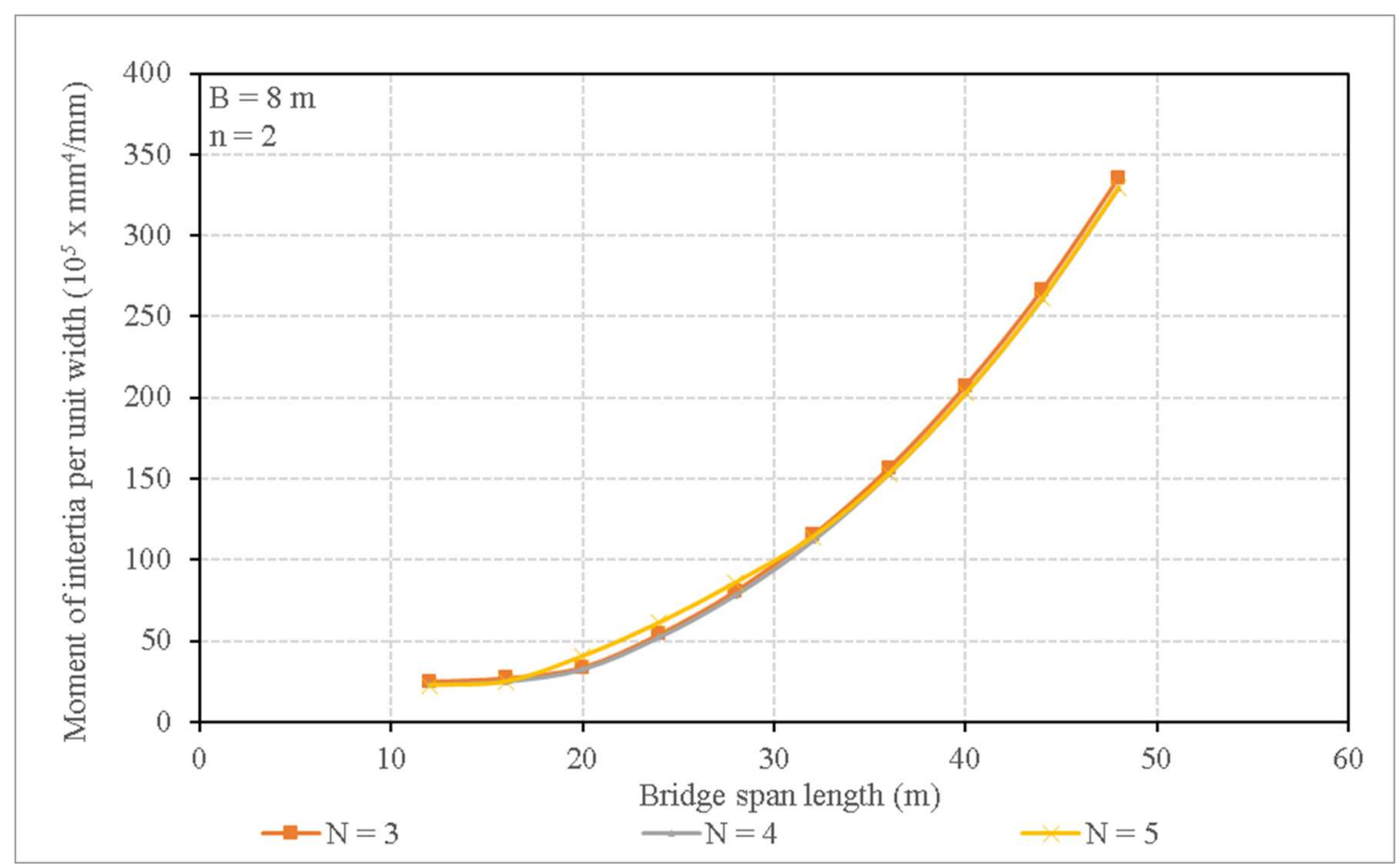

Figure 5.23: Moment of inertia of the composite concrete-steel section per unit width vs span length for a two-lane single span bridge under CL-625 truck loading of $8 \mathrm{~m}$ width 


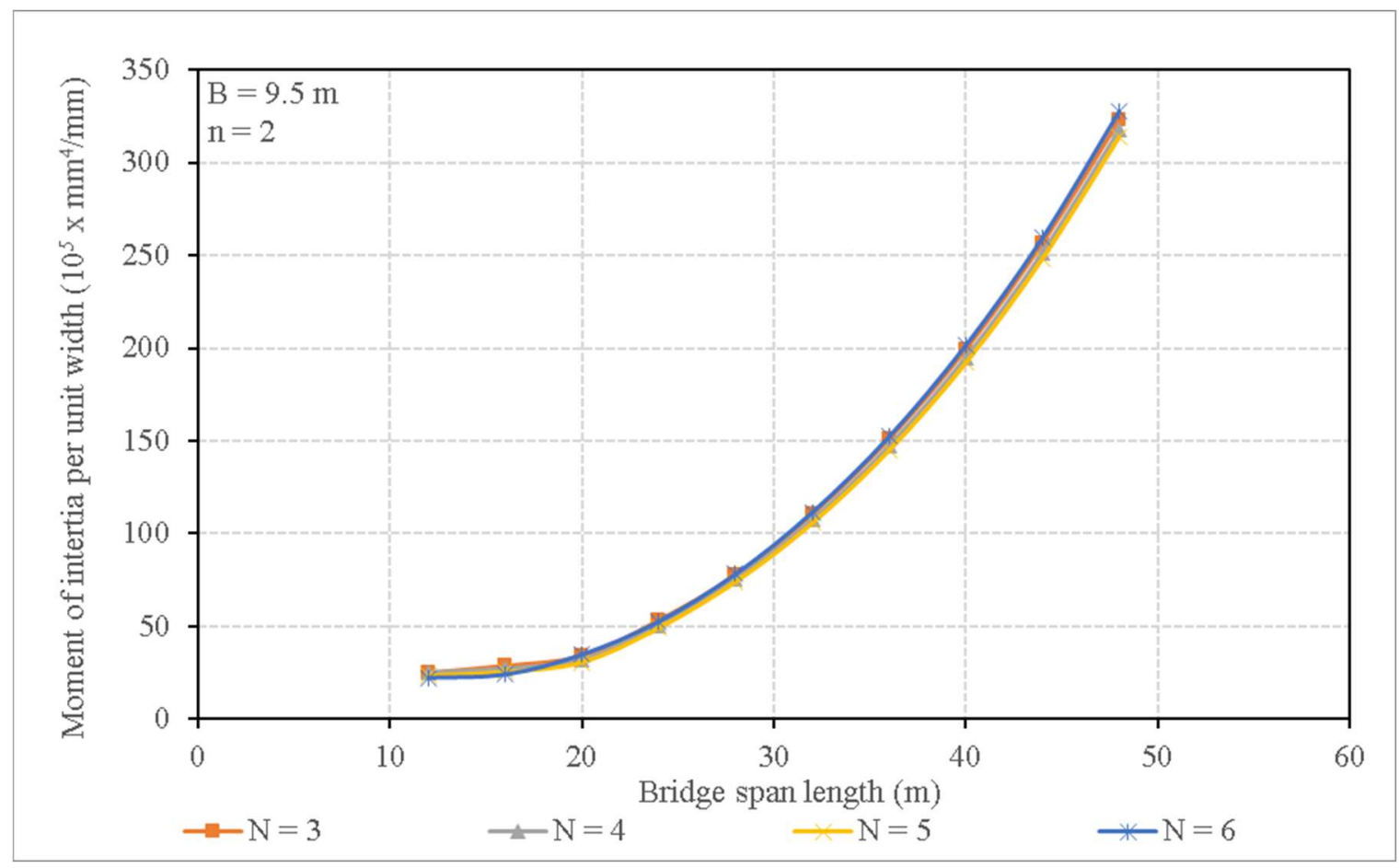

Figure 5.24: Moment of inertia of the composite concrete-steel section per unit width vs span length for a two-lane single span bridge under CL-625 truck loading of $9.5 \mathrm{~m}$ width

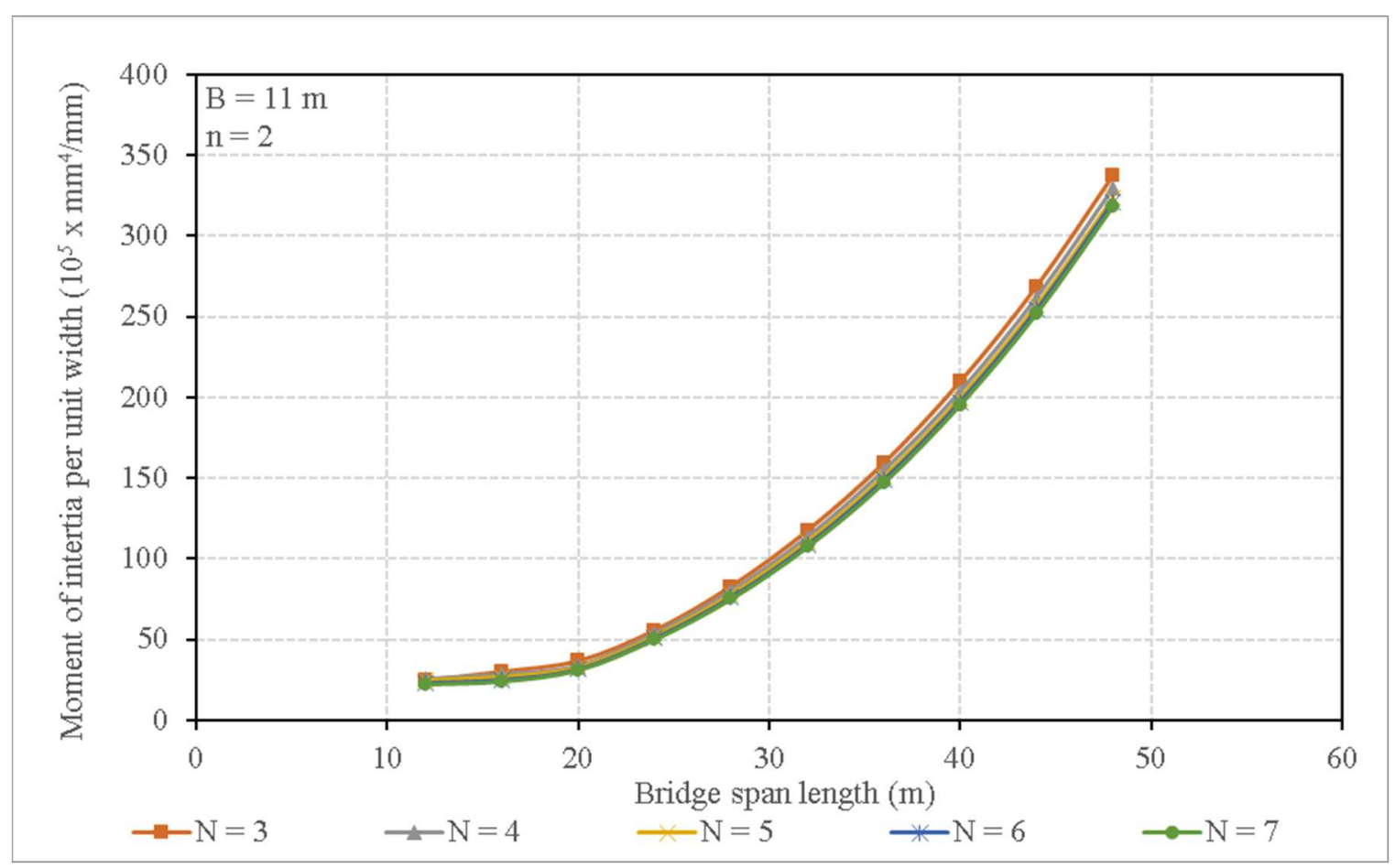

Figure 5.25: Moment of inertia of the composite concrete-steel section per unit width vs span length for a two-lane single span bridge under CL-625 truck loading of $11 \mathrm{~m}$ width 


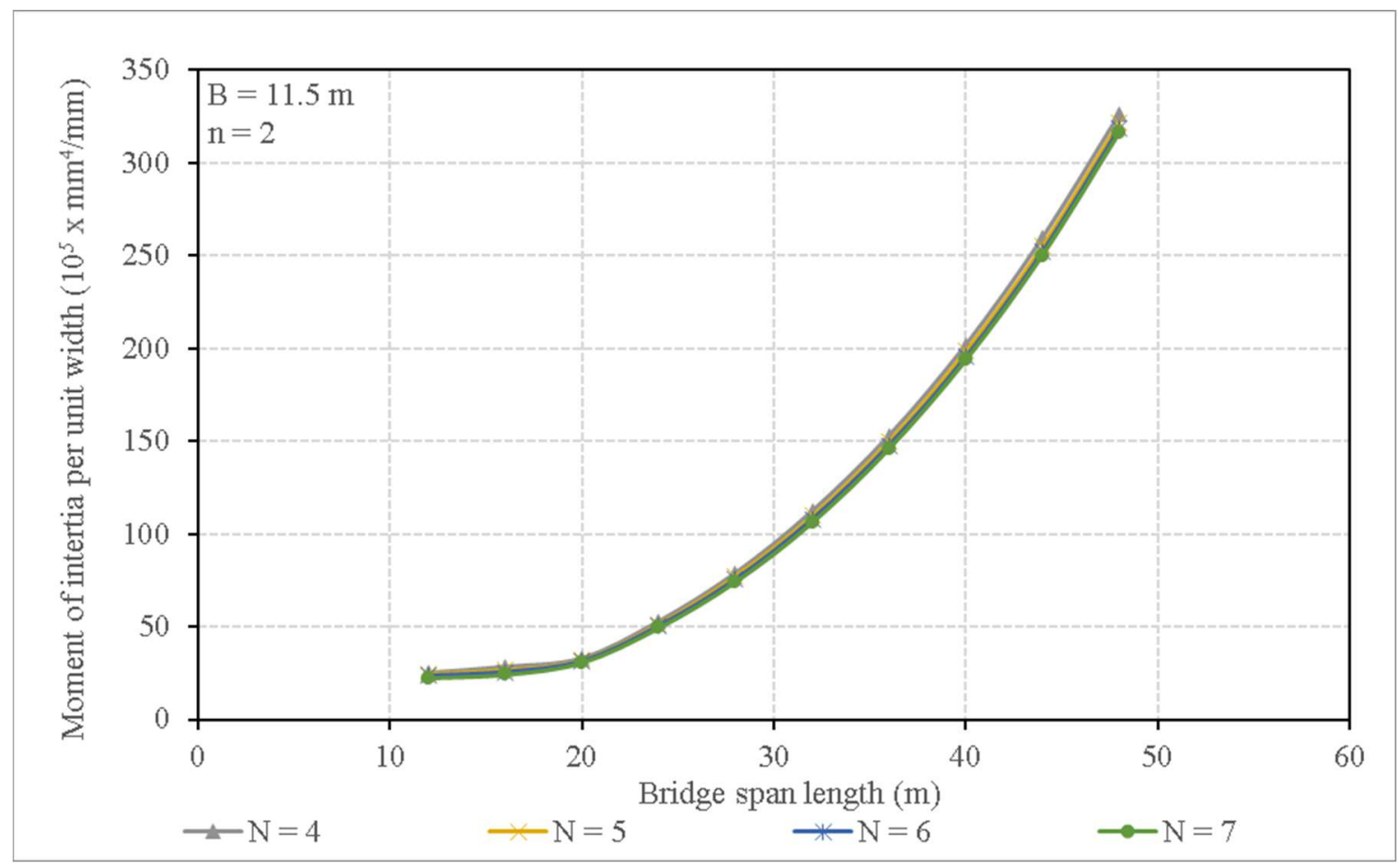

Figure 5.26: Moment of inertia of the composite concrete-steel section per unit width vs span length for a two-lane single span bridge under CL-625 truck loading of $11.5 \mathrm{~m}$ width

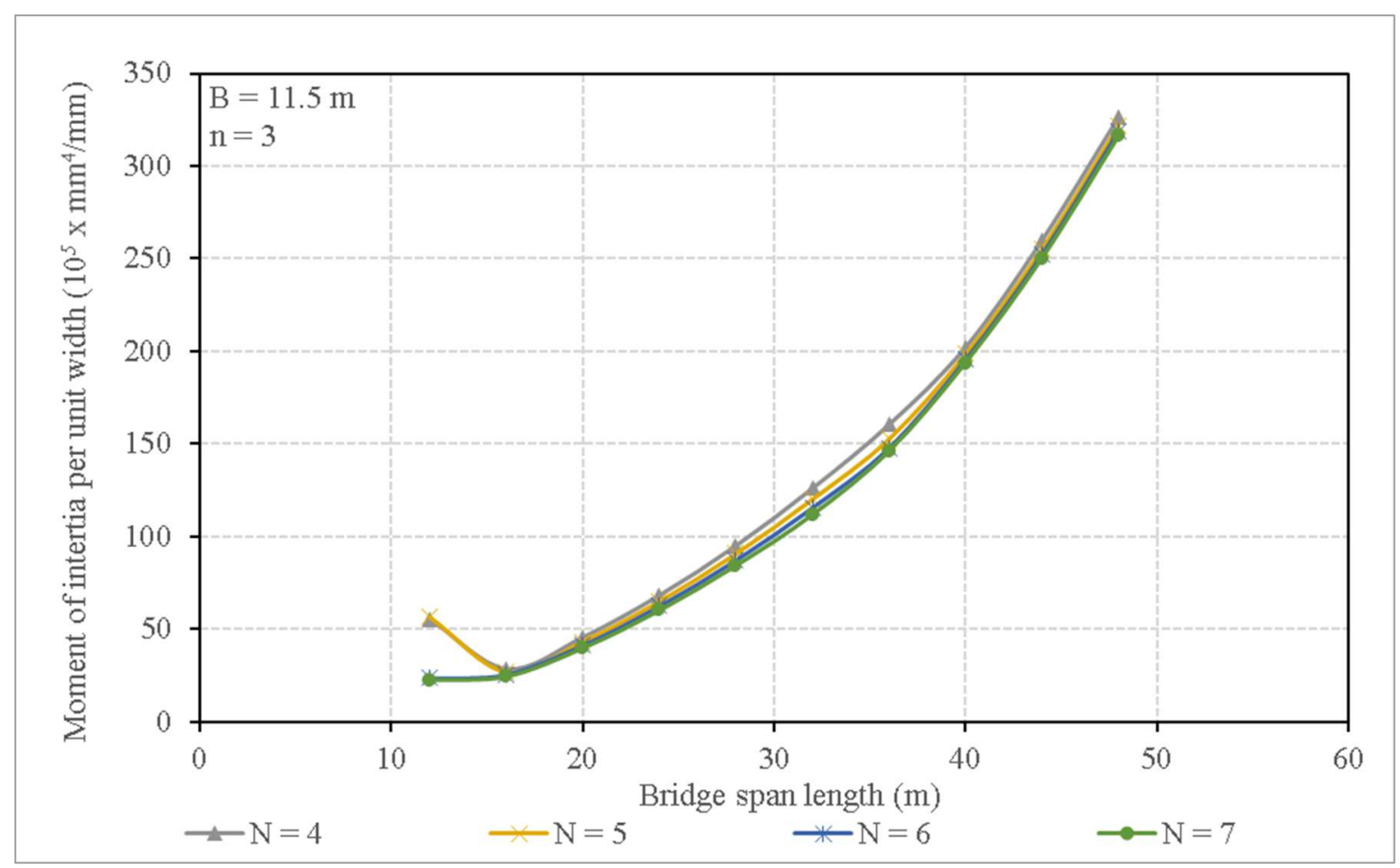

Figure 5.27: Moment of inertia of the composite concrete-steel section per unit width vs span length for a three-lane single span bridge under CL-625 truck loading of $11.5 \mathrm{~m}$ width 


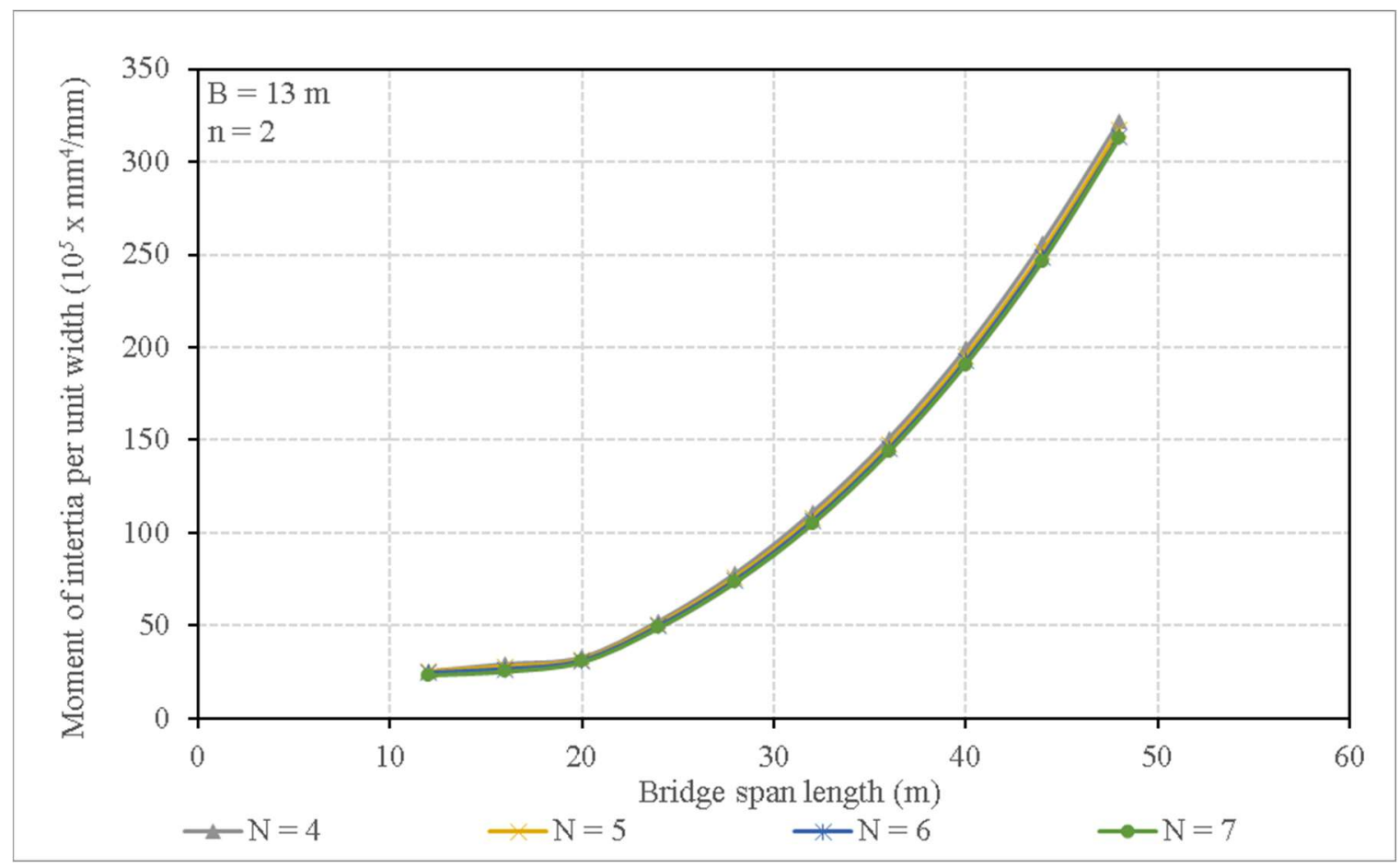

Figure 5.28: Moment of inertia of the composite concrete-steel section per unit width vs span length for a two-lane single span bridge under CL-625 truck loading of $13 \mathrm{~m}$ width

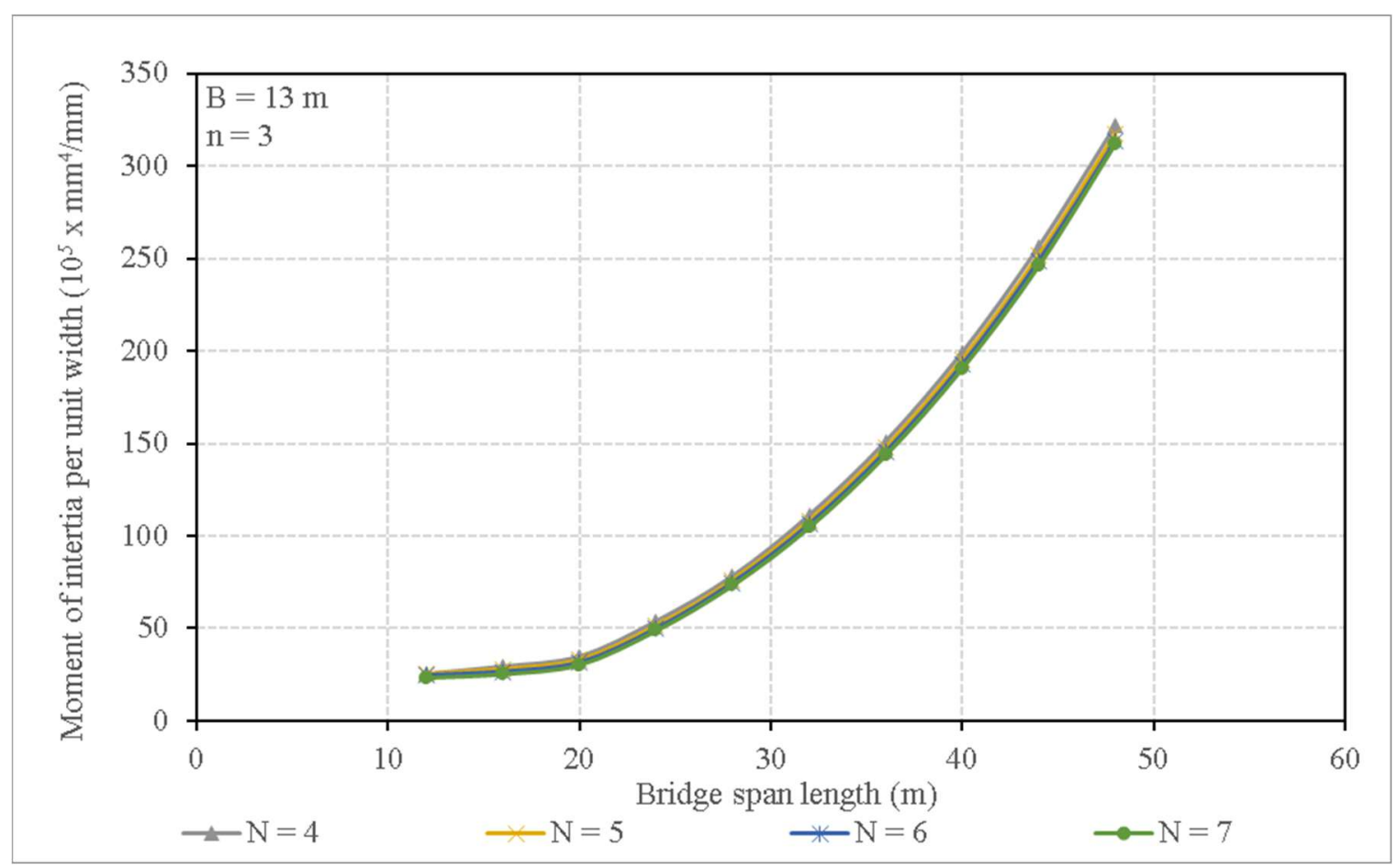

Figure 5.29: Moment of inertia of the composite concrete-steel section per unit width vs span length for a three-lane single span bridge under CL-625 truck loading of 13 m width 


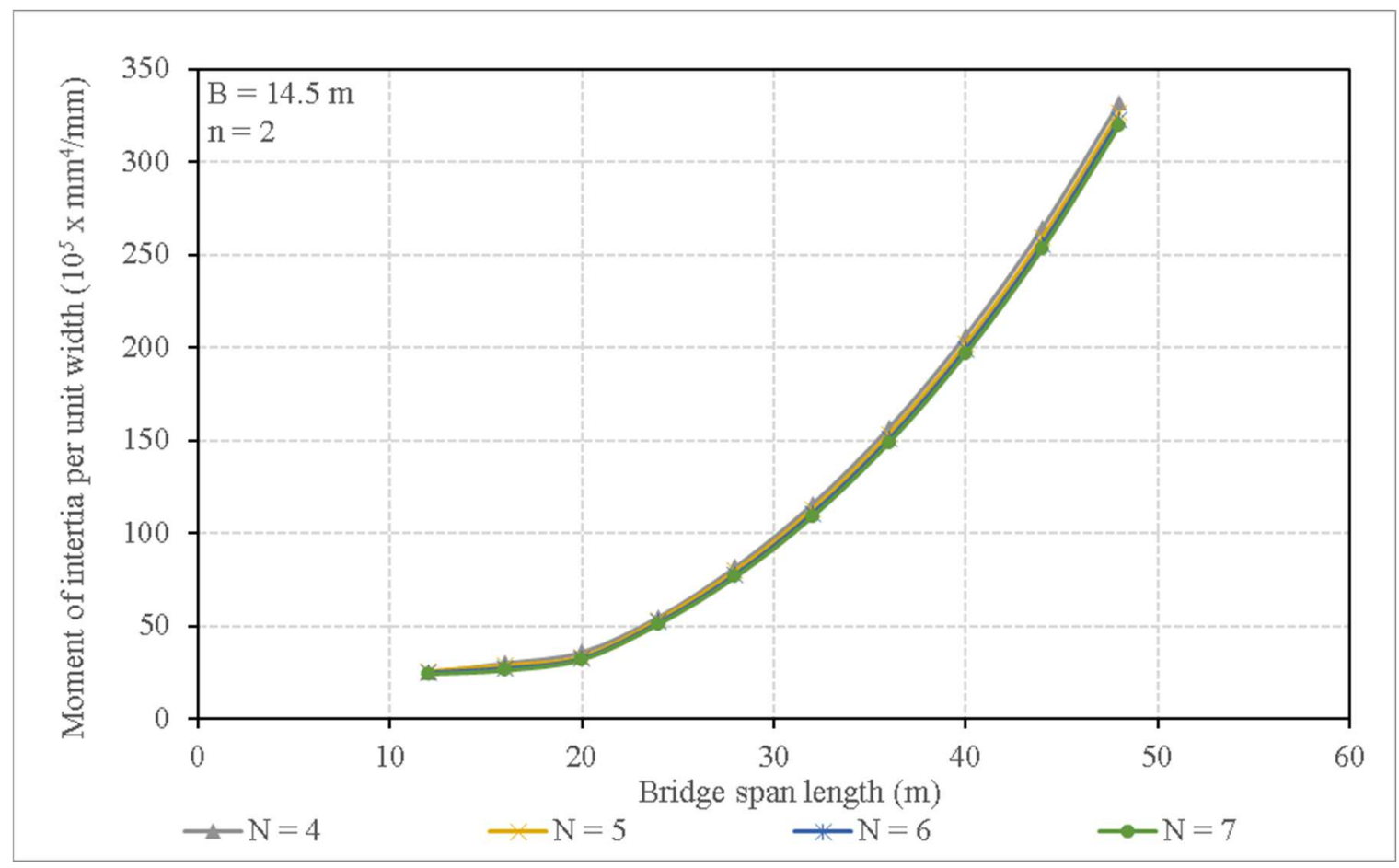

Figure 5.30: Moment of inertia of the composite concrete-steel section per unit width vs span length for a two-lane single span bridge under CL-625 truck loading of $14.5 \mathrm{~m}$ width

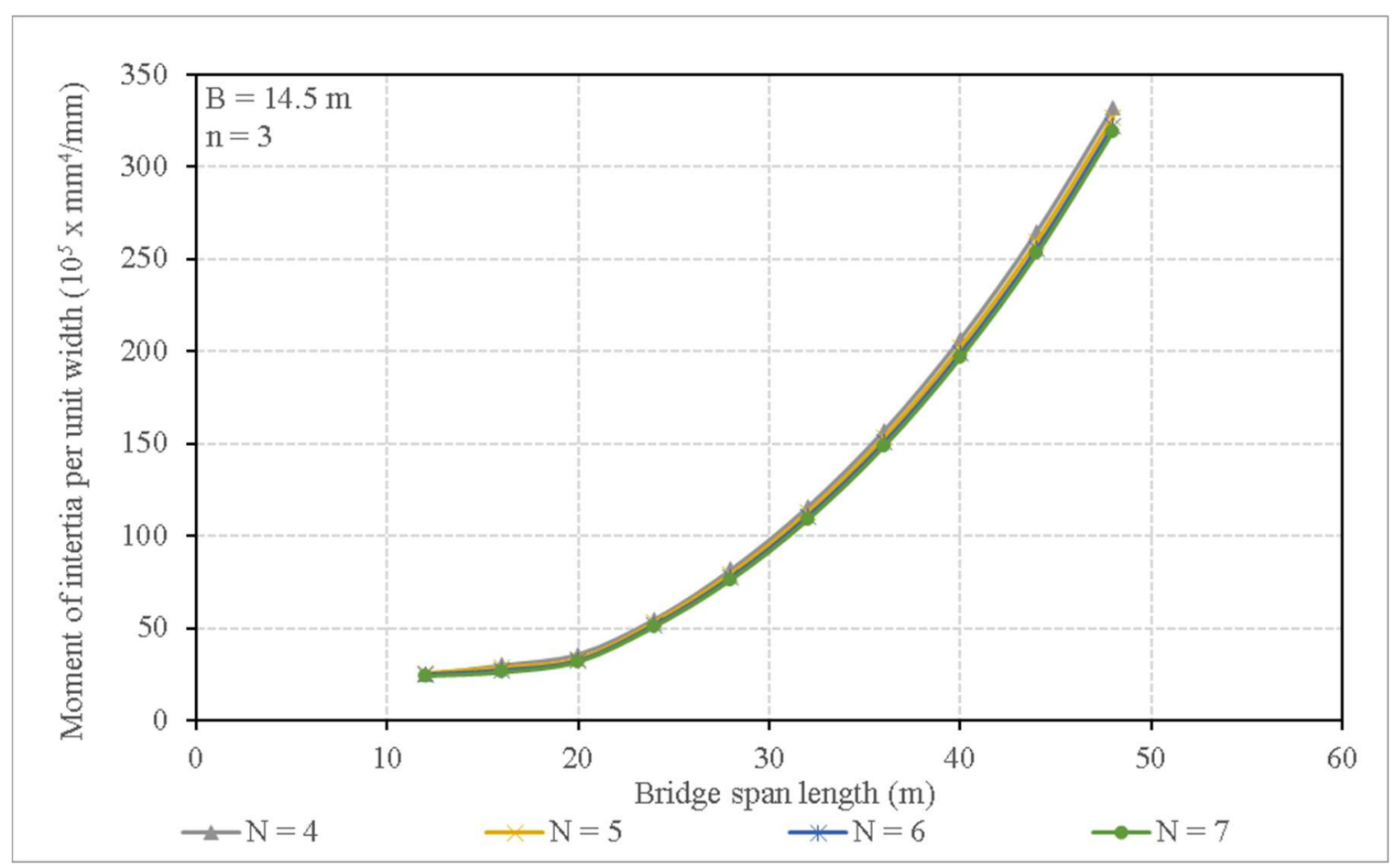

Figure 5.31: Moment of inertia of the composite concrete-steel section per unit width vs span length for a three-lane single span bridge under CL-625 truck loading of $14.5 \mathrm{~m}$ width 


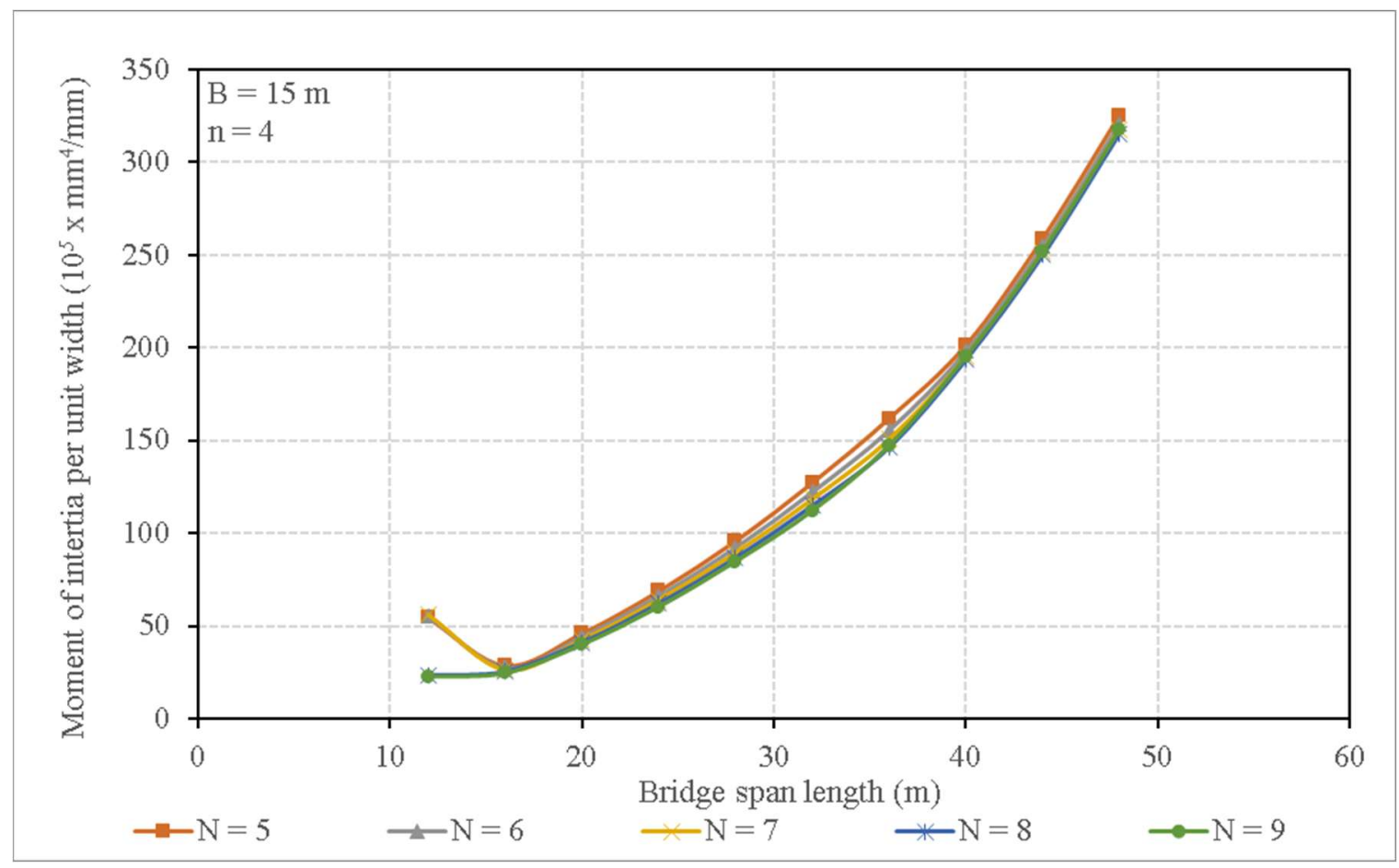

Figure 5.32: Moment of inertia of the composite concrete-steel section per unit width vs span length for a four-lane single span bridge under CL-625 truck loading of $15 \mathrm{~m}$ width

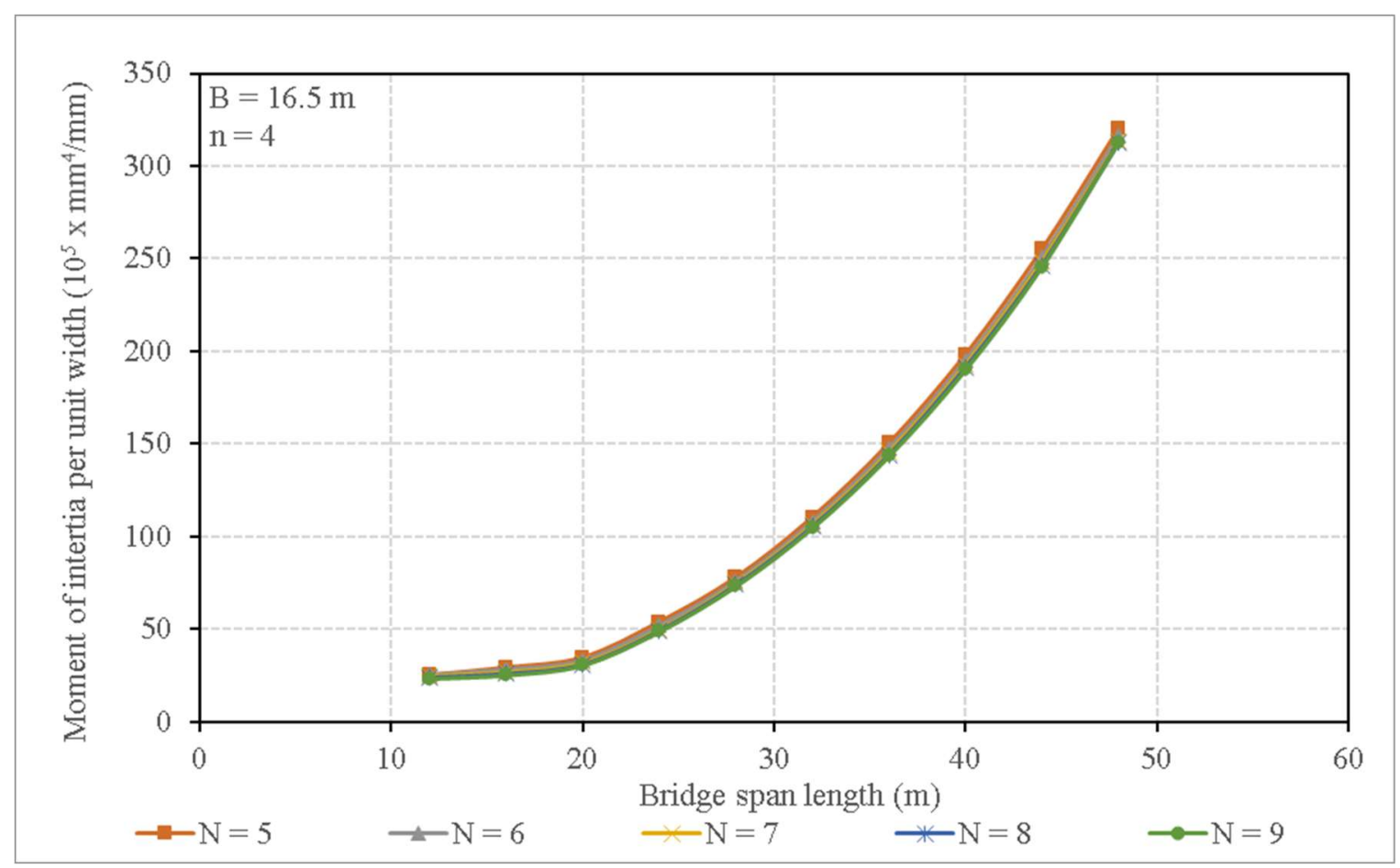

Figure 5.33: Moment of inertia of the composite concrete-steel section per unit width vs span length for a four-lane single span bridge under CL-625 truck loading of $16.5 \mathrm{~m}$ width 


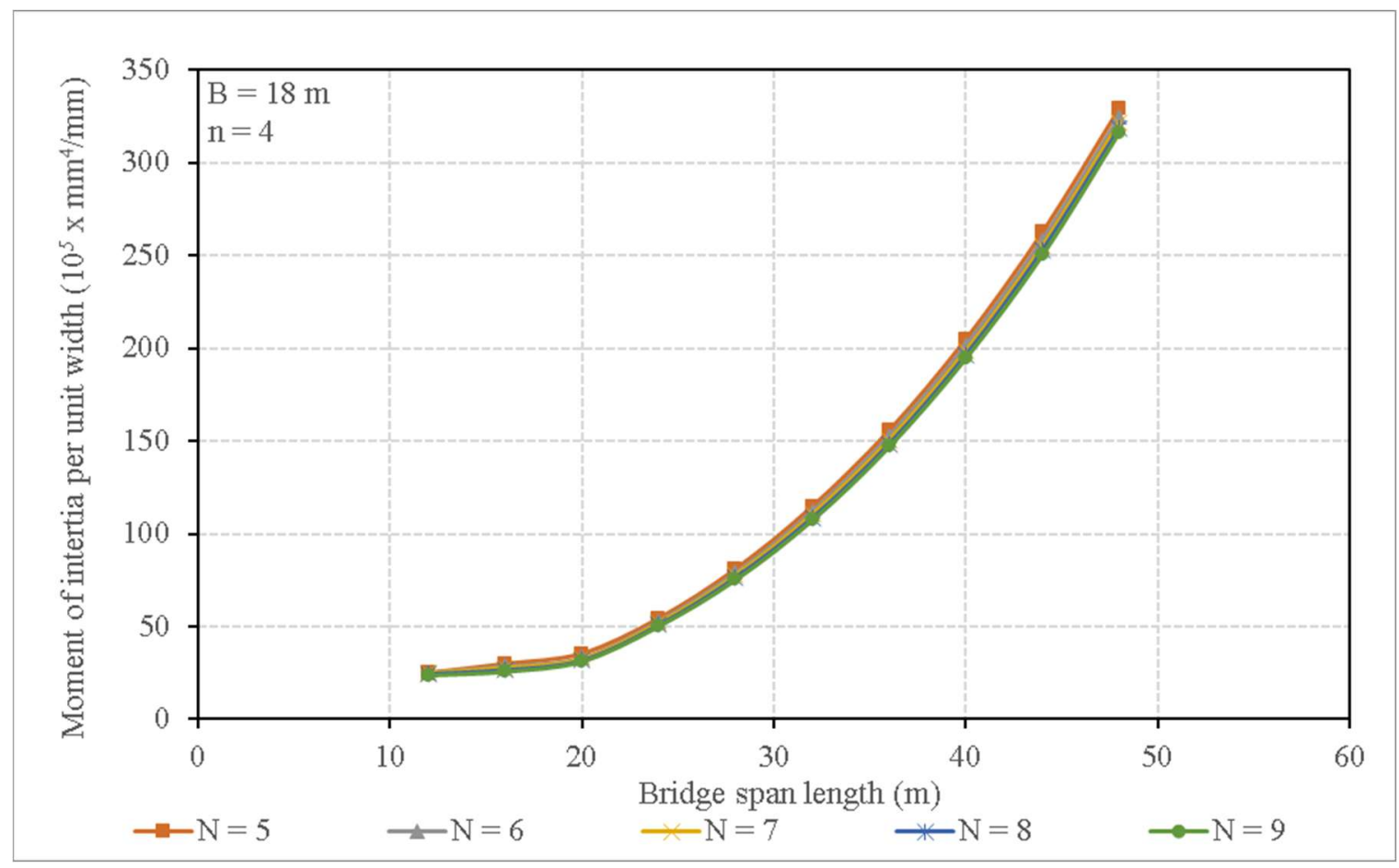

Figure 5.34: Moment of inertia of the composite concrete-steel section per unit width vs span length for a four-lane single span bridge under CL-625 truck loading of $18 \mathrm{~m}$ width

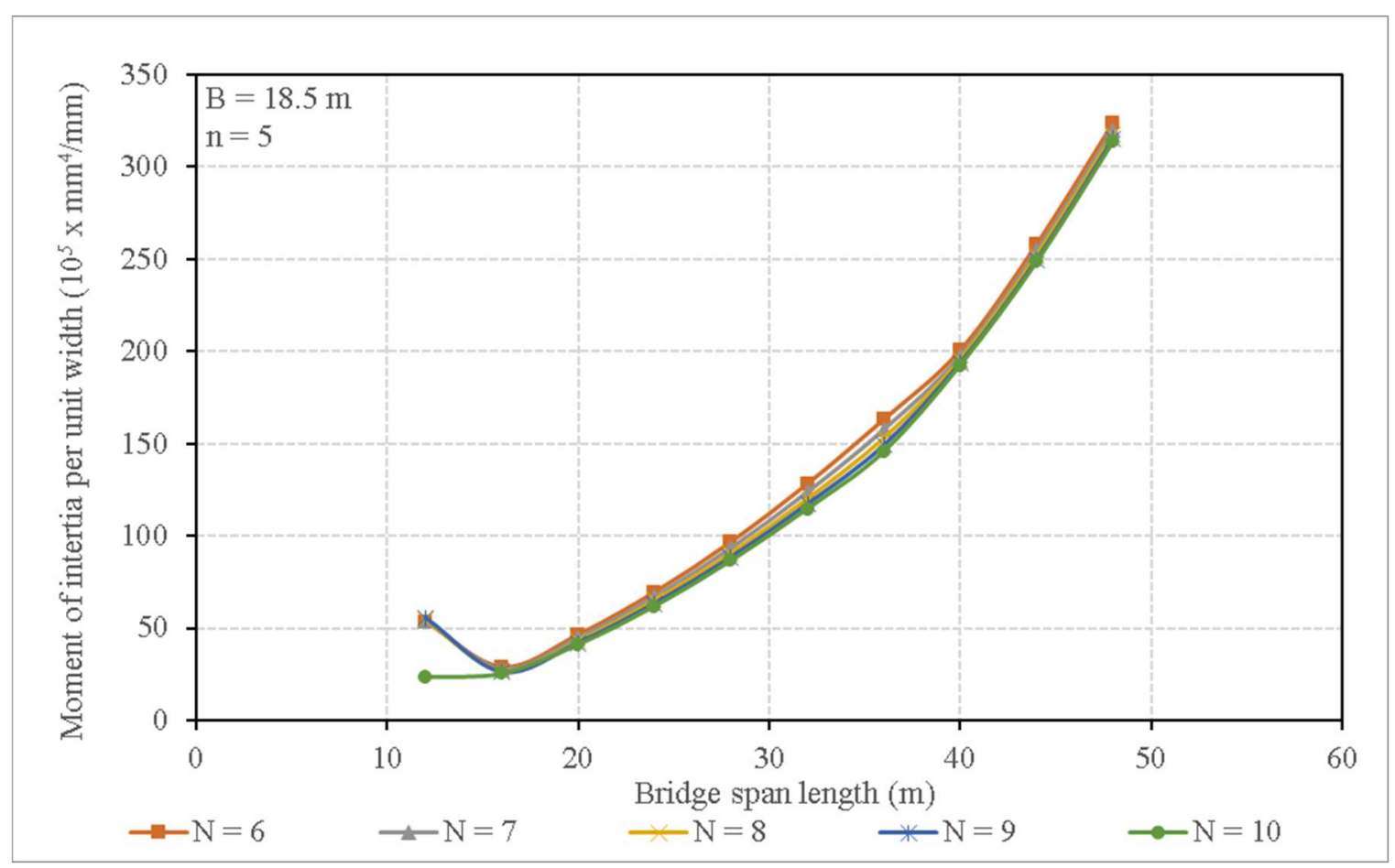

Figure 5.35: Moment of inertia of the composite concrete-steel section per unit width vs span length for a five-lane single span bridge under CL-625 truck loading of $18.5 \mathrm{~m}$ width 


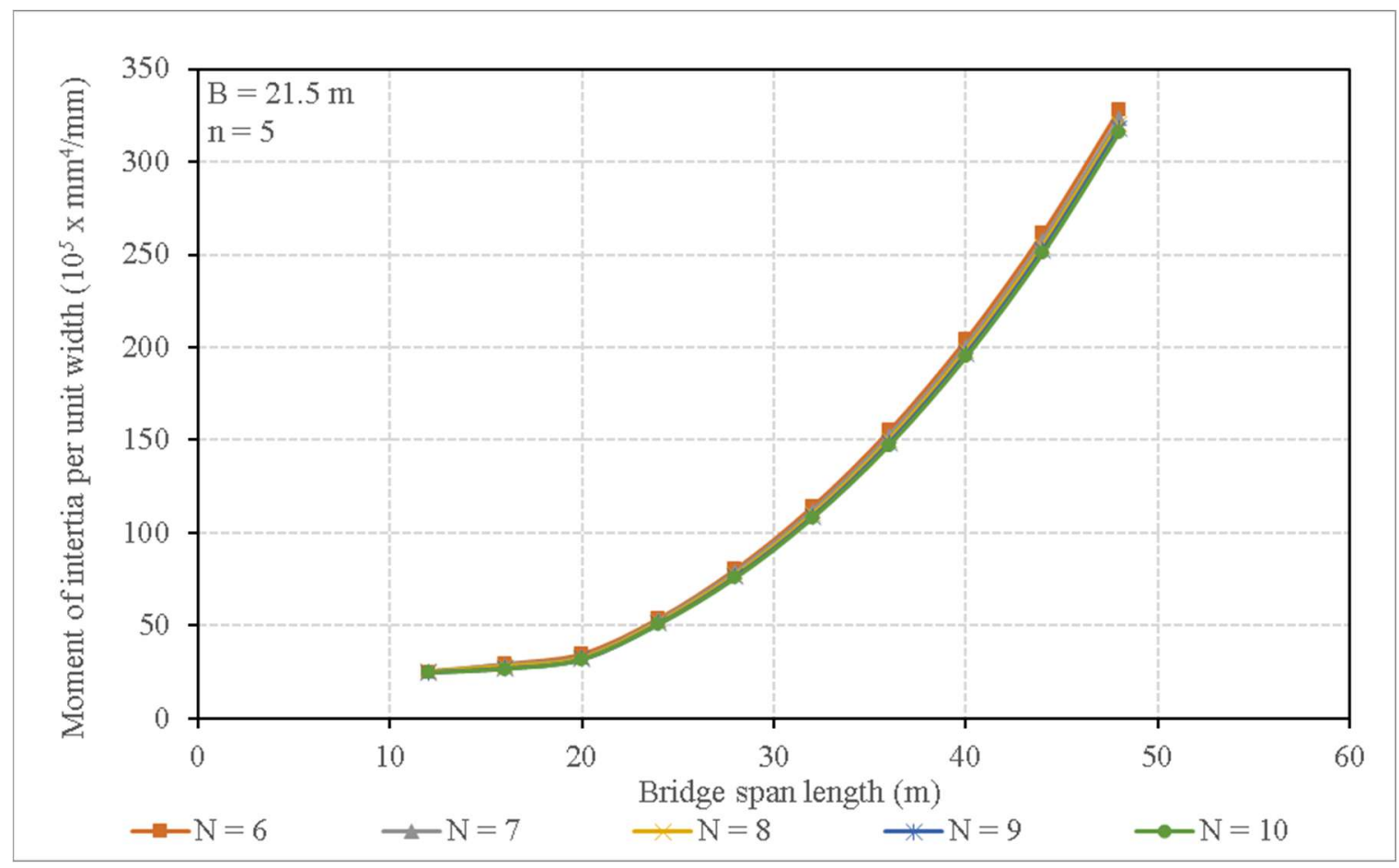

Figure 5.36: Moment of inertia of the composite concrete-steel section per unit width vs span length for a five-lane single span bridge under CL-625 truck loading of $21.5 \mathrm{~m}$ width

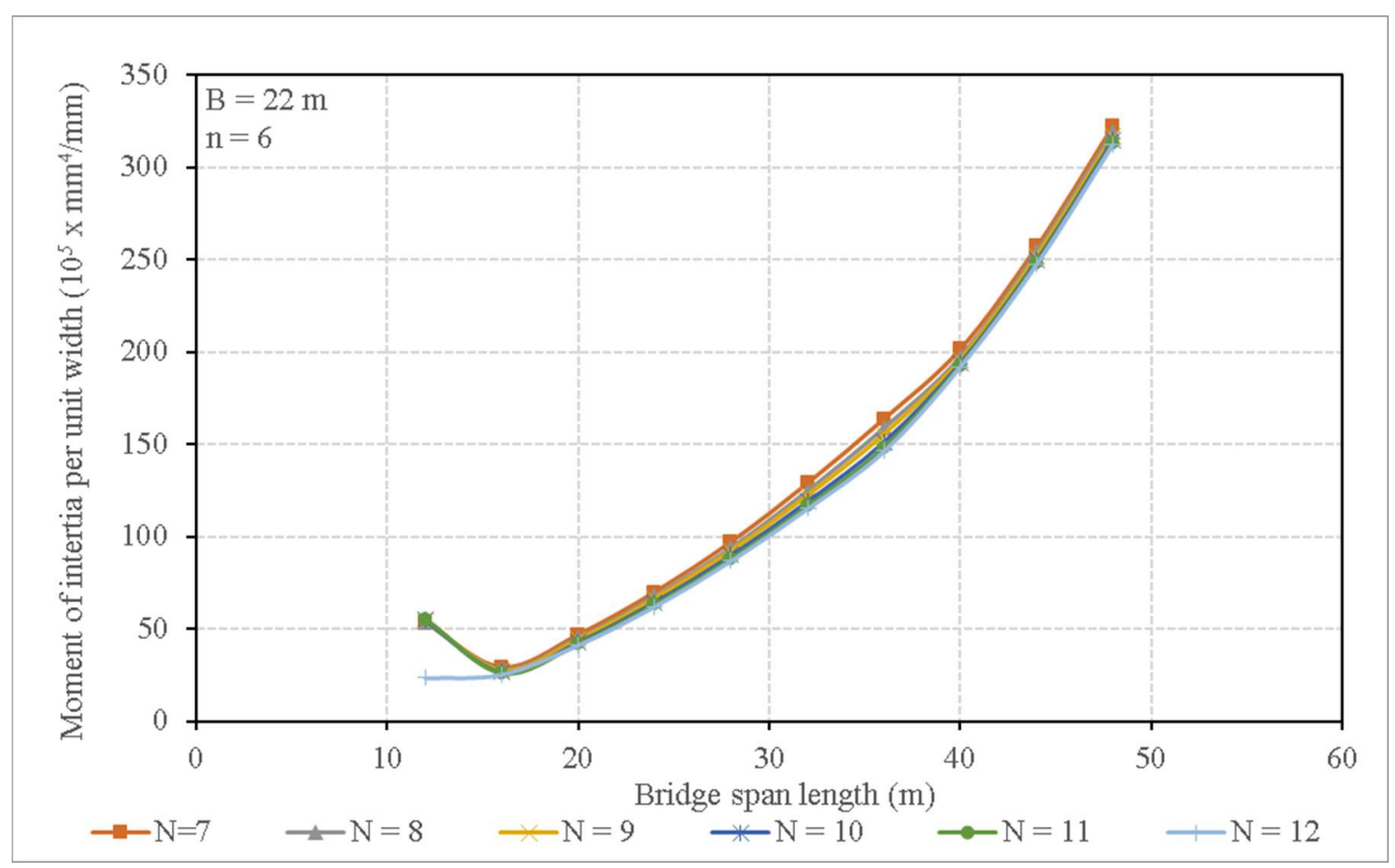

Figure 5.37: Moment of inertia of the composite concrete-steel section per unit width vs span length for a six-lane single span bridge under CL-625 truck loading of $22 \mathrm{~m}$ width 


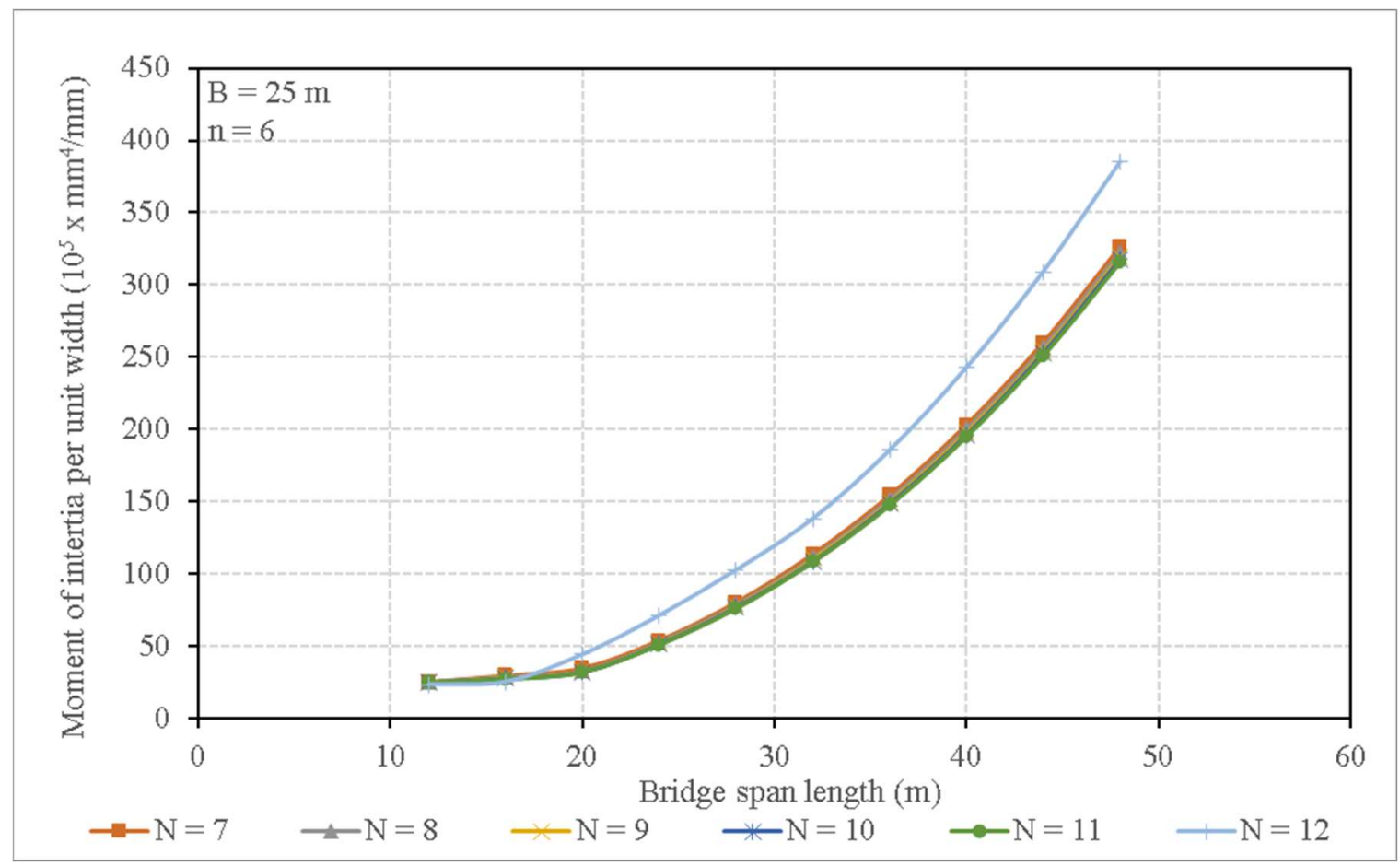

Figure 5.38: Moment of inertia of the composite concrete-steel section per unit width vs span length for a six-lane single span bridge under CL-625 truck loading of $25 \mathrm{~m}$ width

\subsection{Effect of bridge width on moment of inertia}

In order to study the effect of the bridge width (B) on the moment of inertia for the steel and the composite sections per unit width (Is/S \& Ics/S), multiple graphs were created where the number of girders $(\mathrm{N})$ and the number of design lanes (n) were set to a constant value while changing the bridge width (B) for single span bridge configurations under CL-625 truck loading.

As can be seen in Figures 5.39 through 5.54, the moment of inertia of the steel section per unit width does not show any specific relation to the bridge width. This is due to the moment of inertia not being studied as an absolute value but a value per unit width. As was seen before, in the case of $\mathrm{N}=12$ for $\mathrm{B}=25 \mathrm{~m}$ seen in Figure 54, the moment of inertia does not follow the same pattern exhibited in the other figures. As discussed in the previous section, this can be attributed to overdesigning of the bridge configuration due to an excessive amount of steel used to meet the design criteria. To conclude this section, the bridge width (B) does not have an explicit effect on the moment of inertia of the steel section per unit width as the width is already accounted for by dividing the total moment of inertia of the steel section by the spacing. 


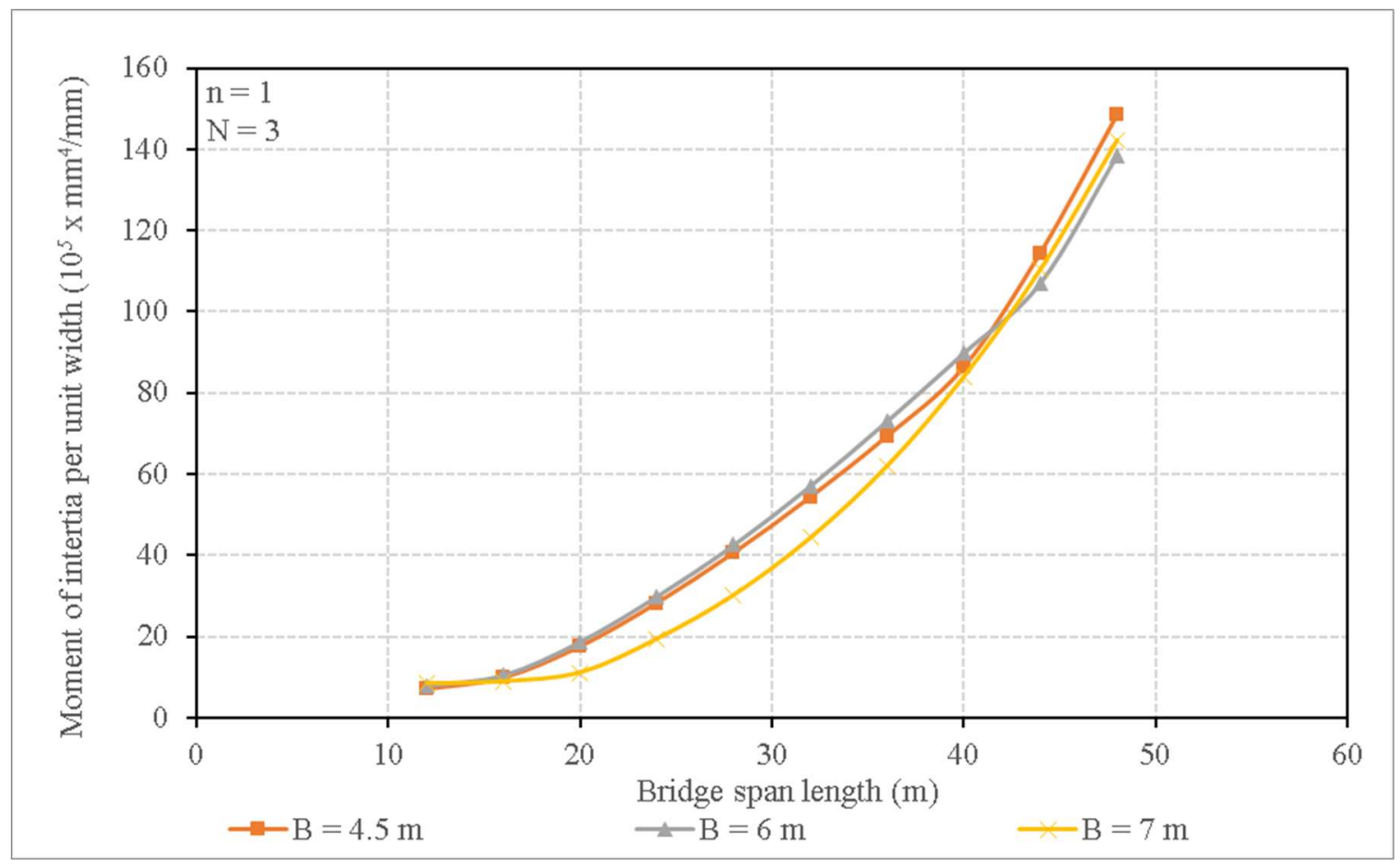

Figure 5.39: Moment of inertia of the steel section per unit width vs span length for a one-lane single span bridge under CL-625 truck loading with three girders

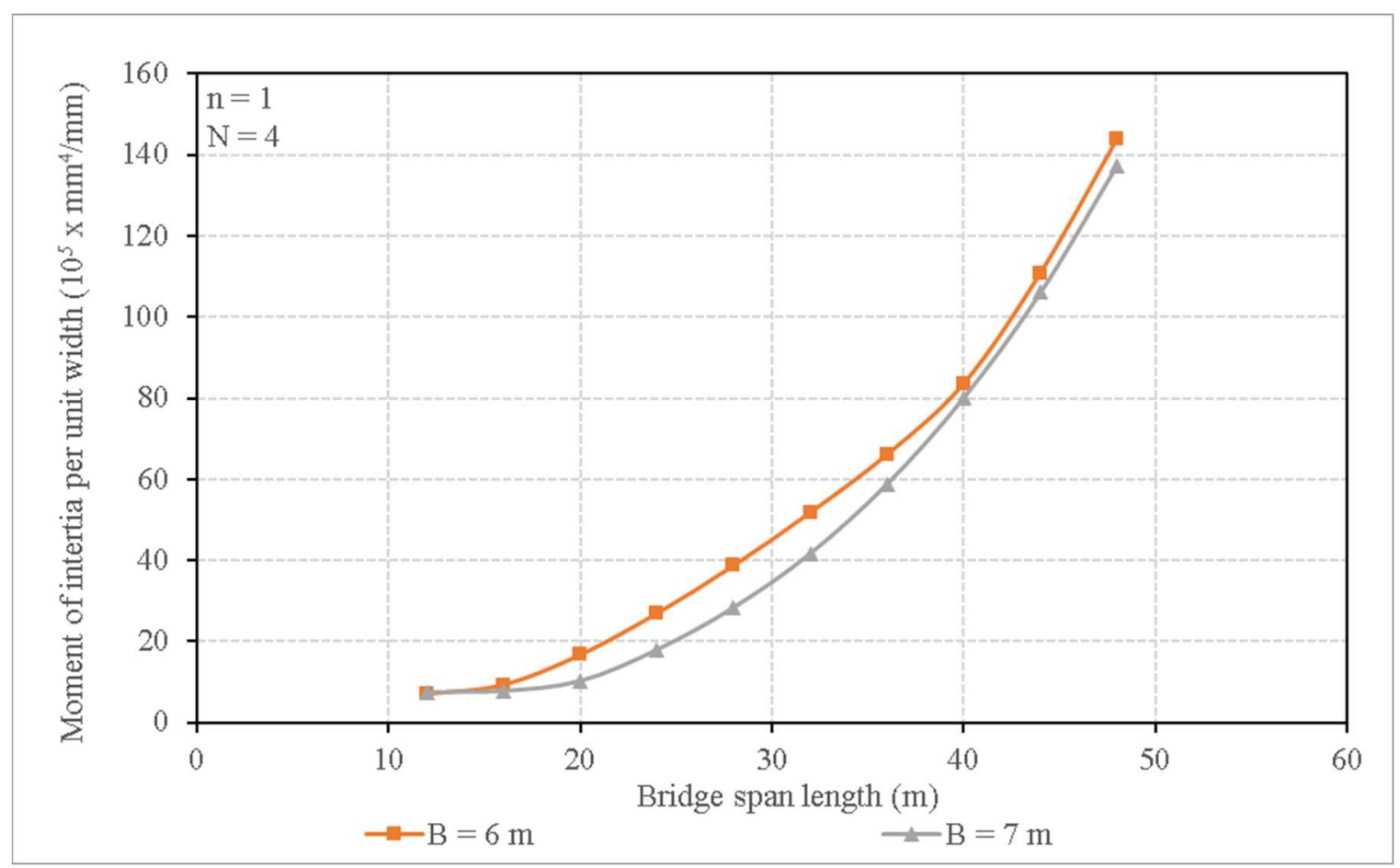

Figure 5.40: Moment of inertia of the steel section per unit width vs span length for a one-lane single span bridge under CL-625 truck loading with four girders 


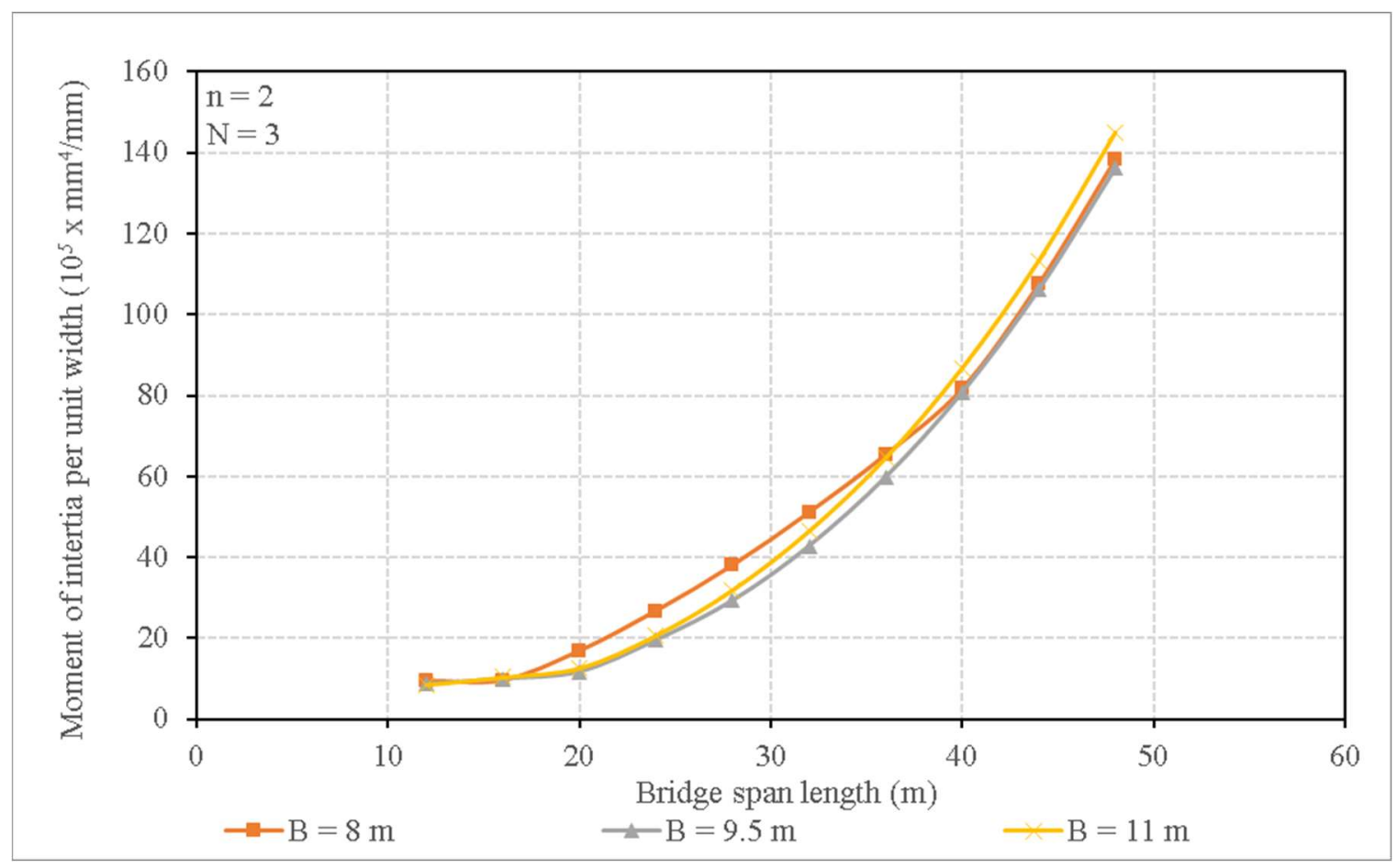

Figure 5.41: Moment of inertia of the steel section per unit width vs span length for a two-lane single span bridge under CL-625 truck loading with three girders

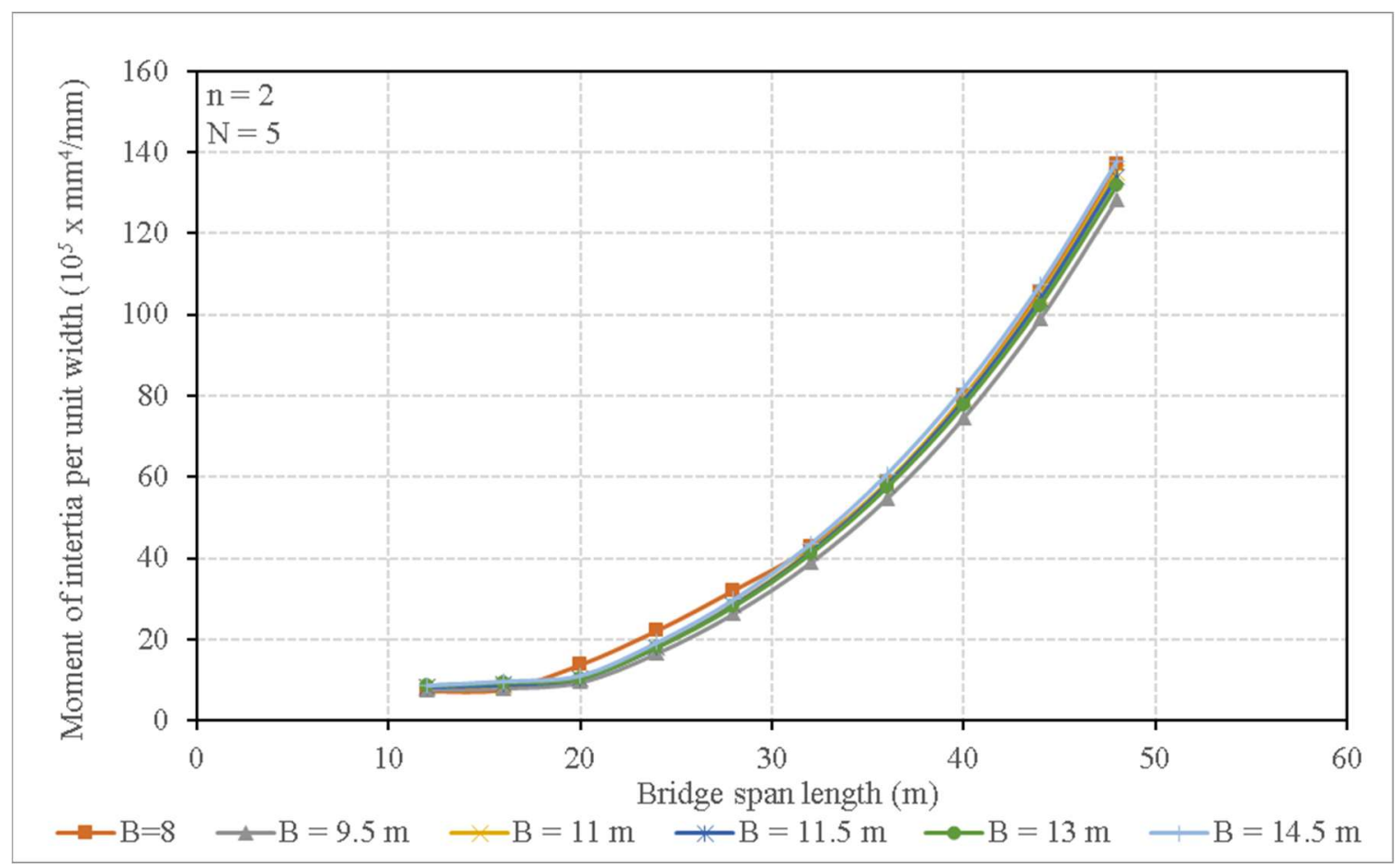

Figure 5.42: Moment of inertia of the steel section per unit width vs span length for a two-lane single span bridge under CL-625 truck loading with five girders 


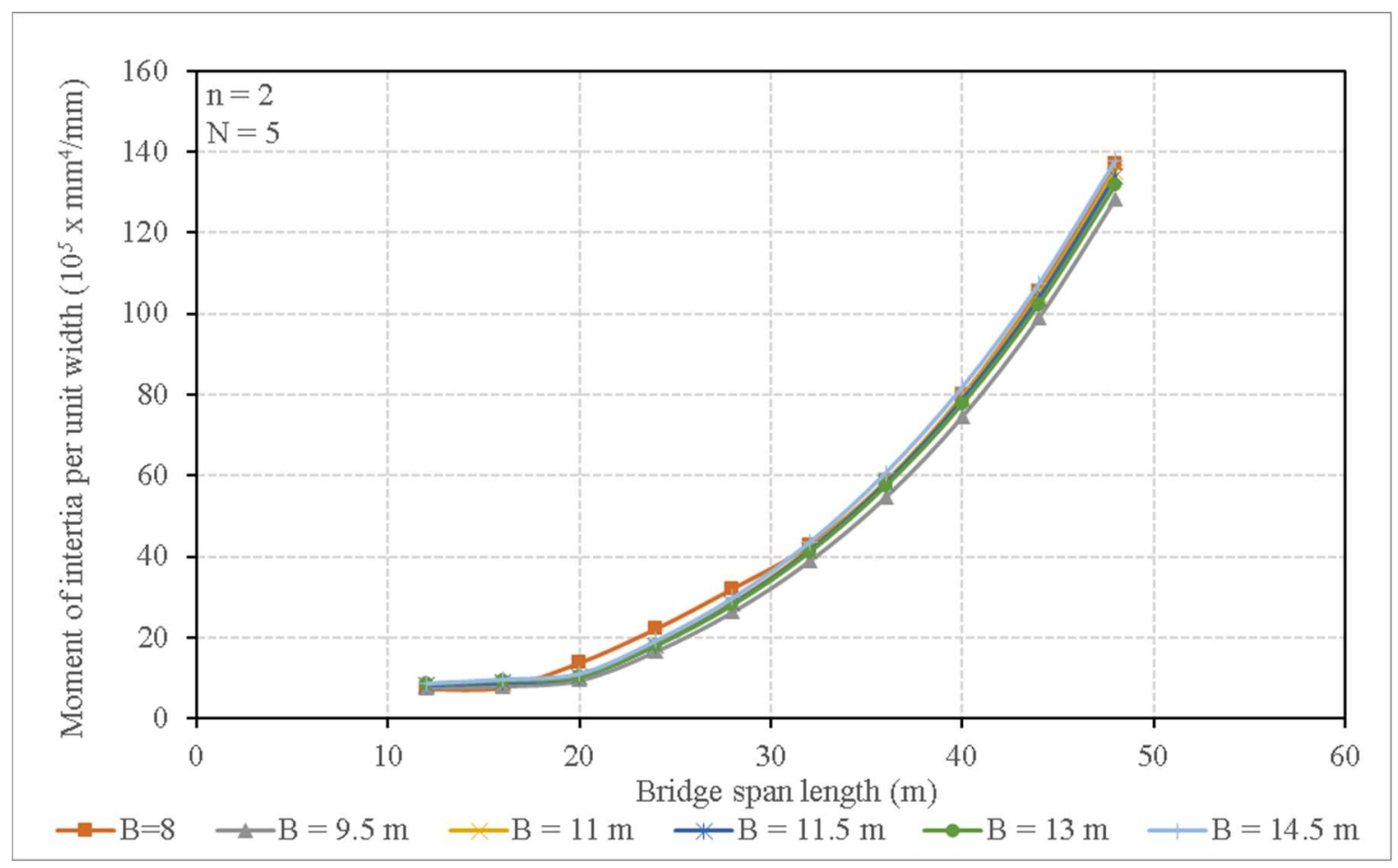

Figure 5.43: Moment of inertia of the steel section per unit width vs span length for a two-lane single span bridge under CL-625 truck loading with seven girders

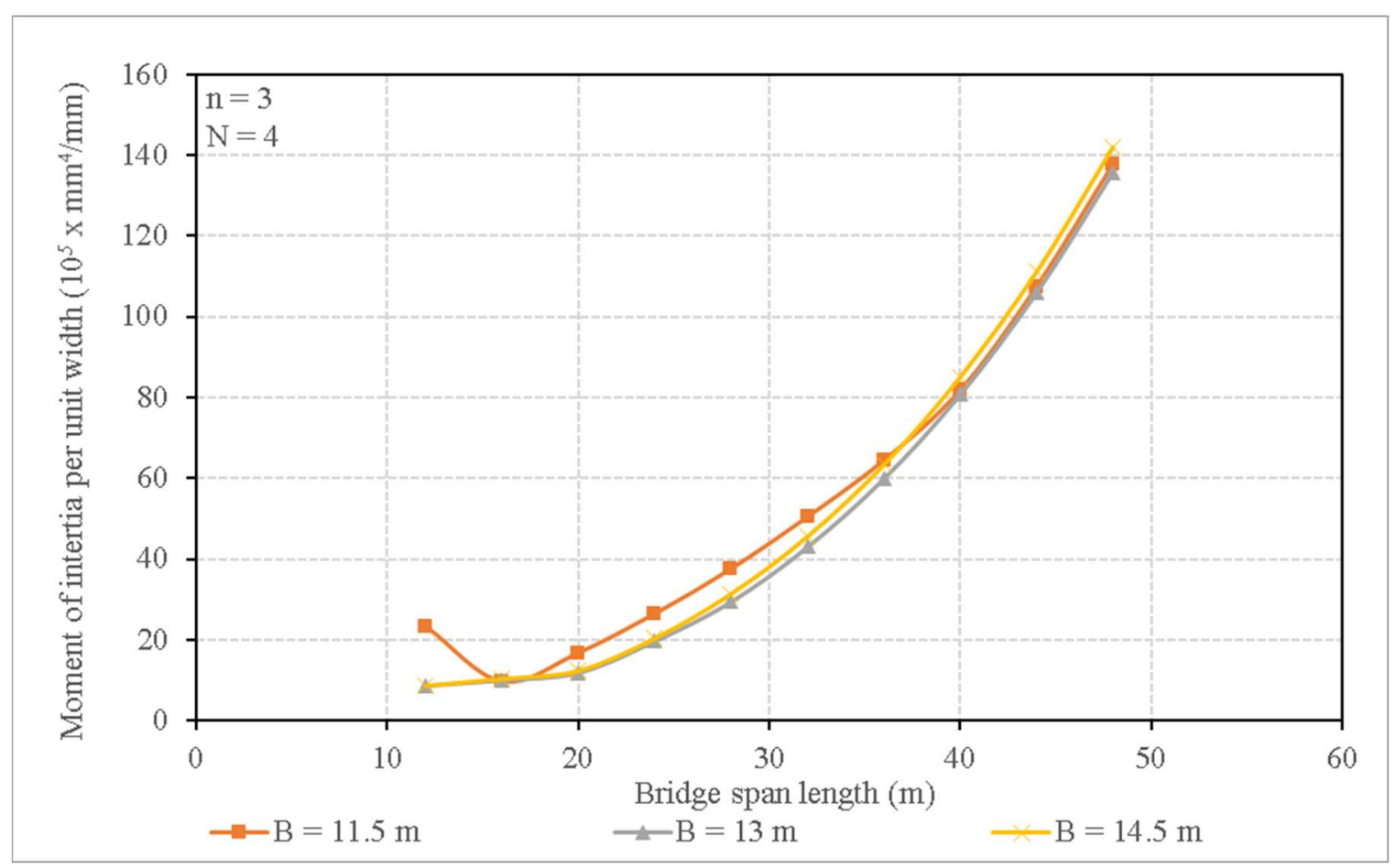

Figure 5.44: Moment of inertia of the steel section per unit width vs span length for a three-lane single span bridge under CL-625 truck loading with four girders 


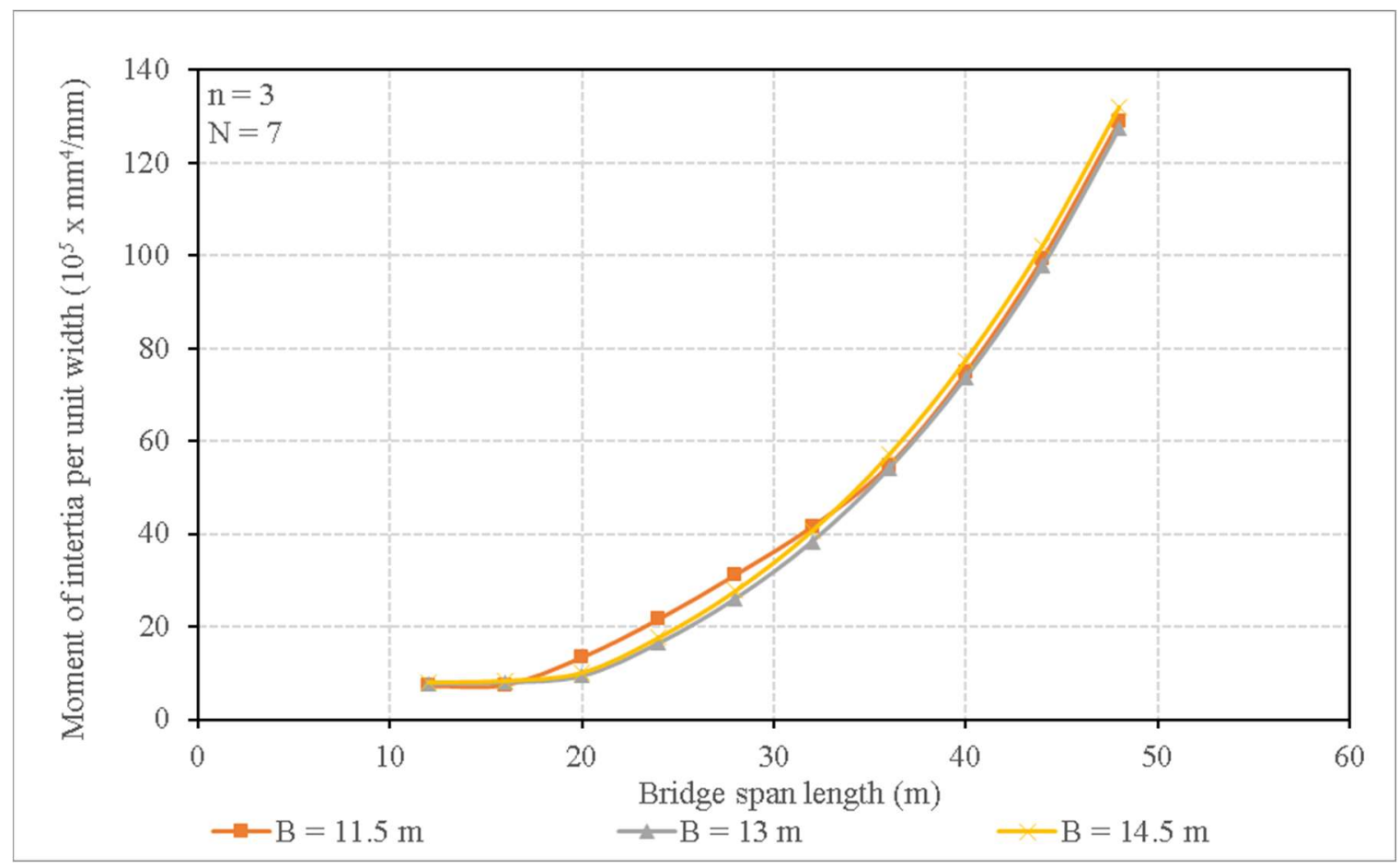

Figure 5.45: Moment of inertia of the steel section per unit width vs span length for a three-lane single span bridge under CL-625 truck loading with seven girders

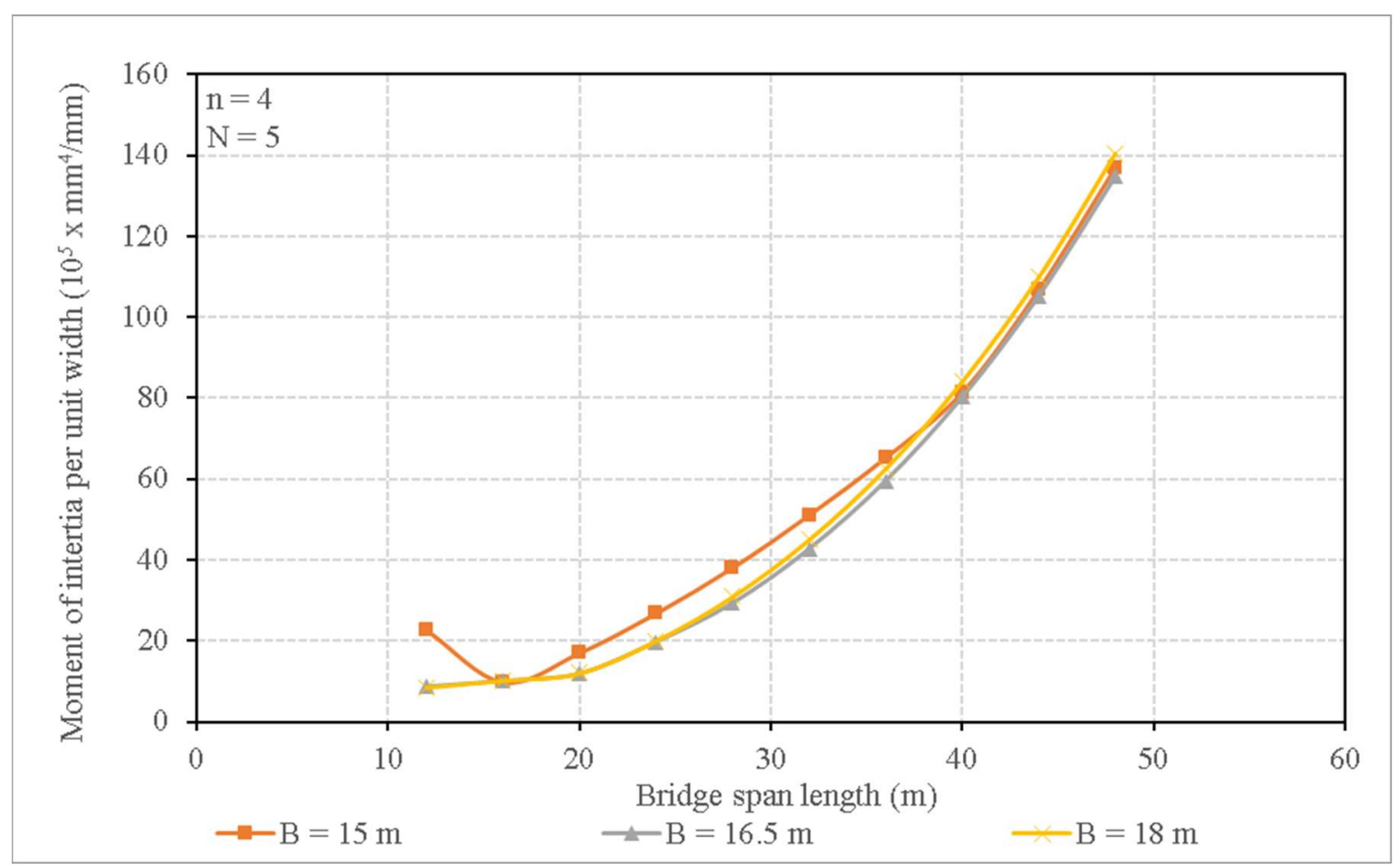

Figure 5.46: Moment of inertia of the steel section per unit width vs span length for a four-lane single span bridge under CL-625 truck loading with five girders 


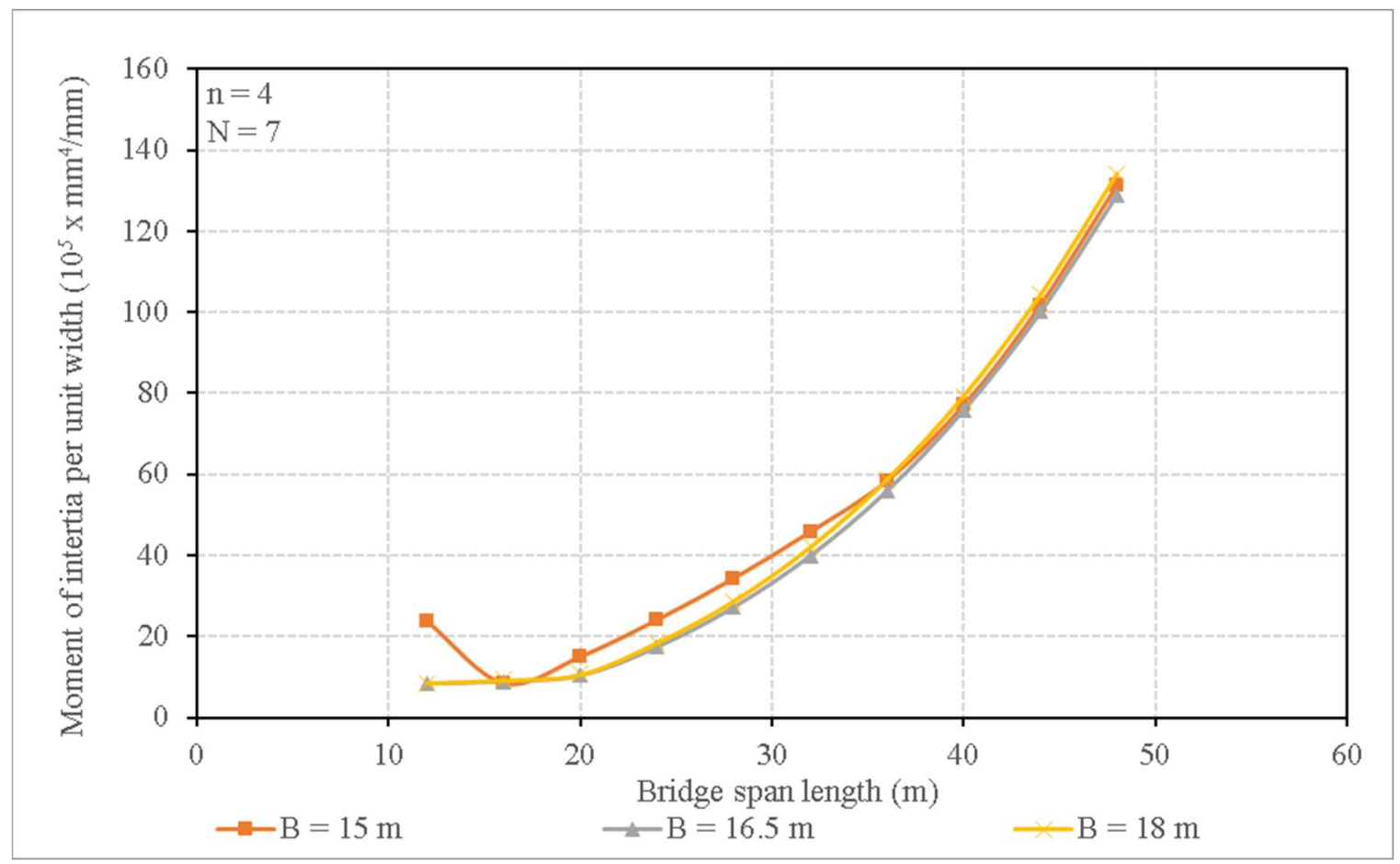

Figure 5.47: Moment of inertia of the steel section per unit width vs span length for a four-lane single span bridge under CL-625 truck loading with seven girders

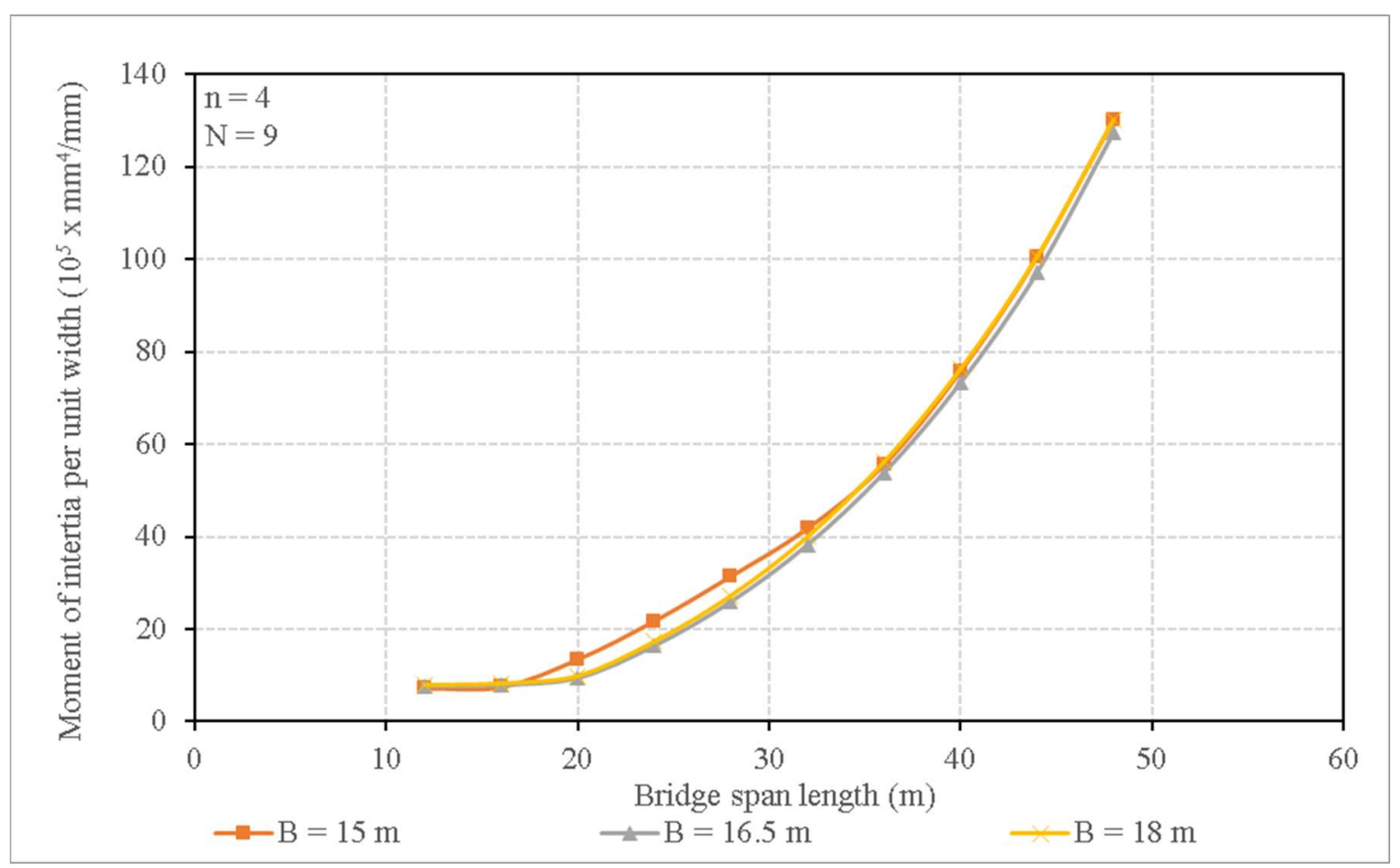

Figure 5.48: Moment of inertia of the steel section per unit width vs span length for a four-lane single span bridge under CL-625 truck loading with nine girders 


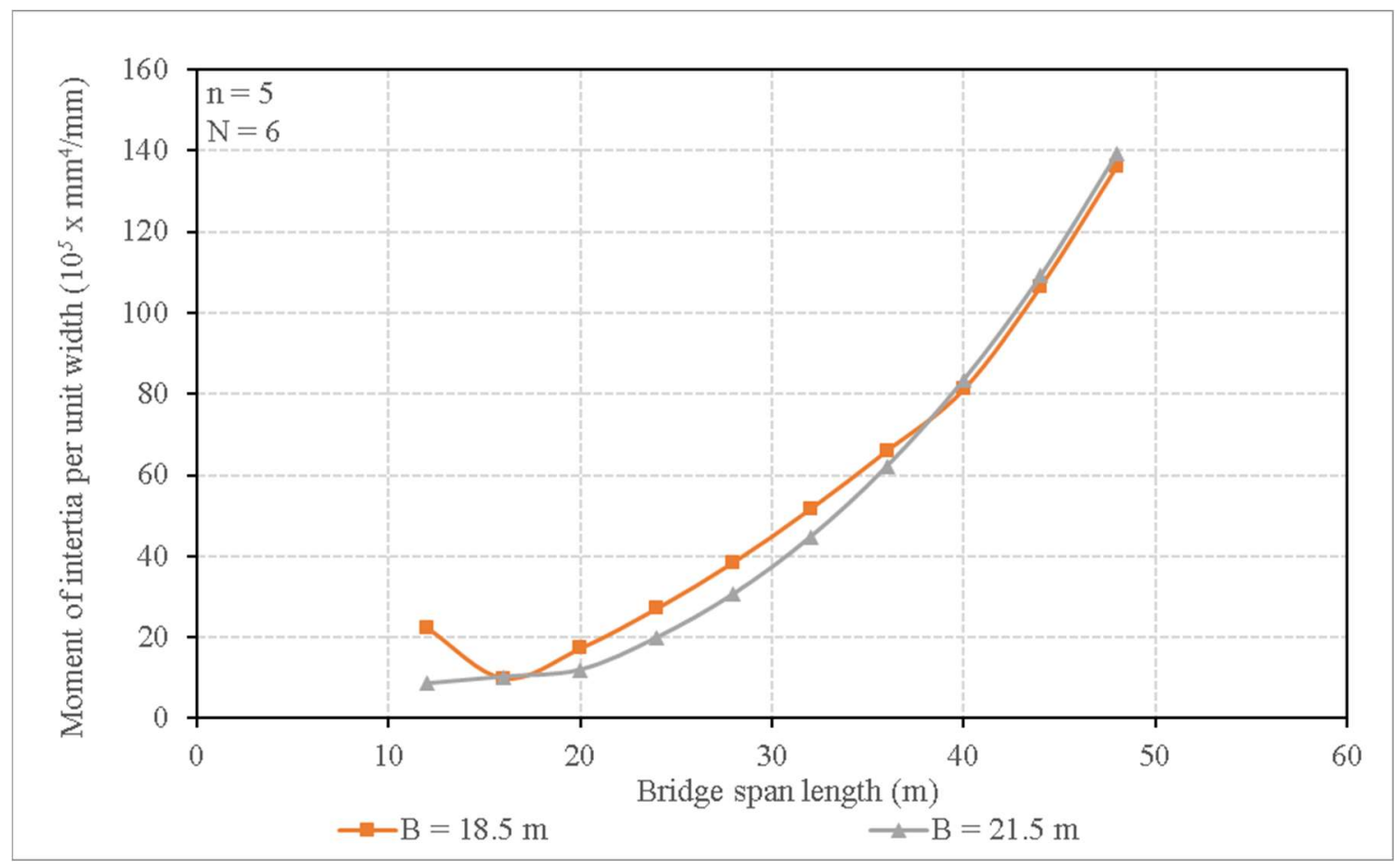

Figure 5.49: Moment of inertia of the steel section per unit width vs span length for a five-lane single span bridge under CL-625 truck loading with six girders

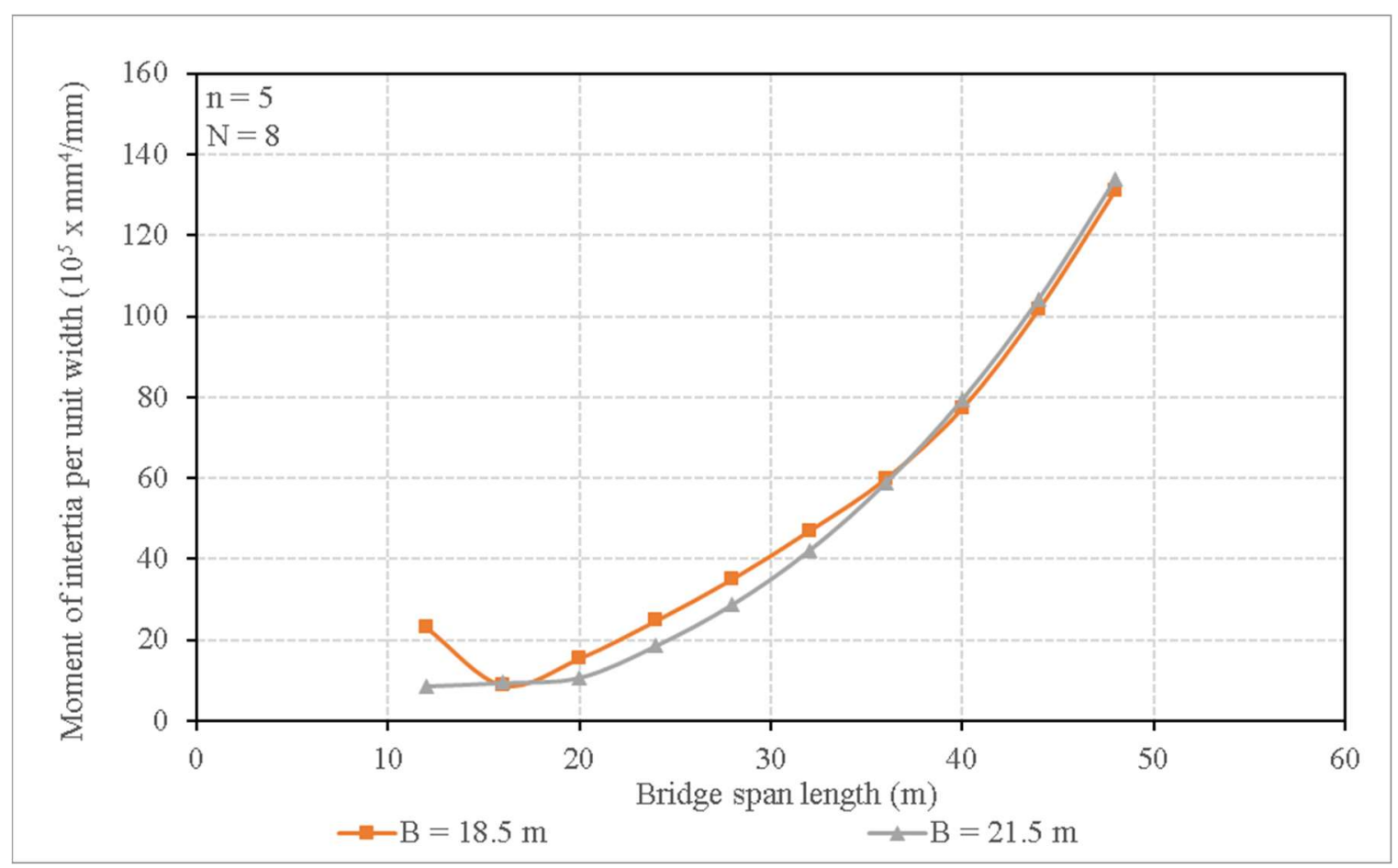

Figure 5.50: Moment of inertia of the steel section per unit width vs span length for a five-lane single span bridge under CL-625 truck loading with eight girders 


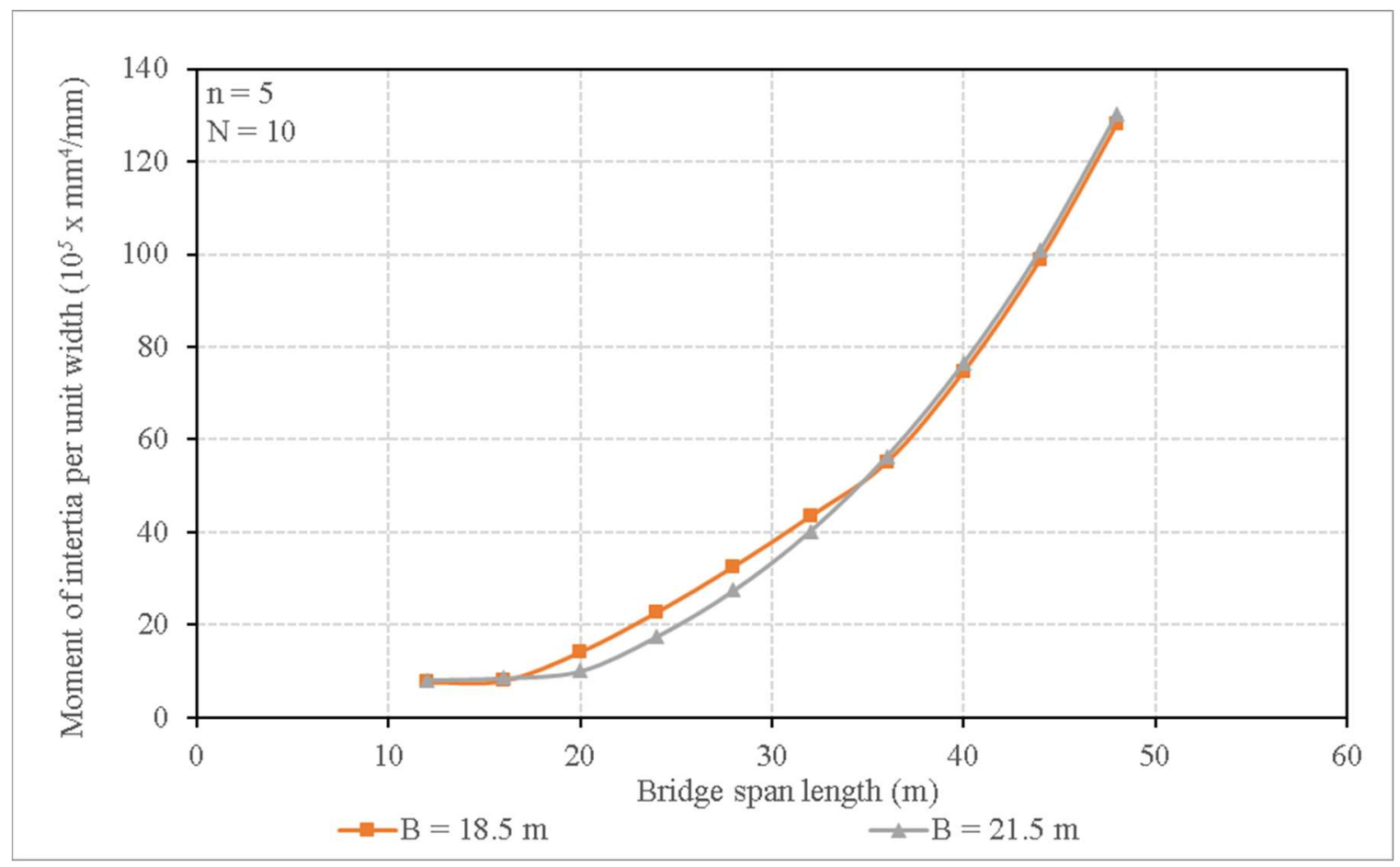

Figure 5.51: Moment of inertia of the steel section per unit width vs span length for a five-lane single span bridge under CL-625 truck loading with ten girders

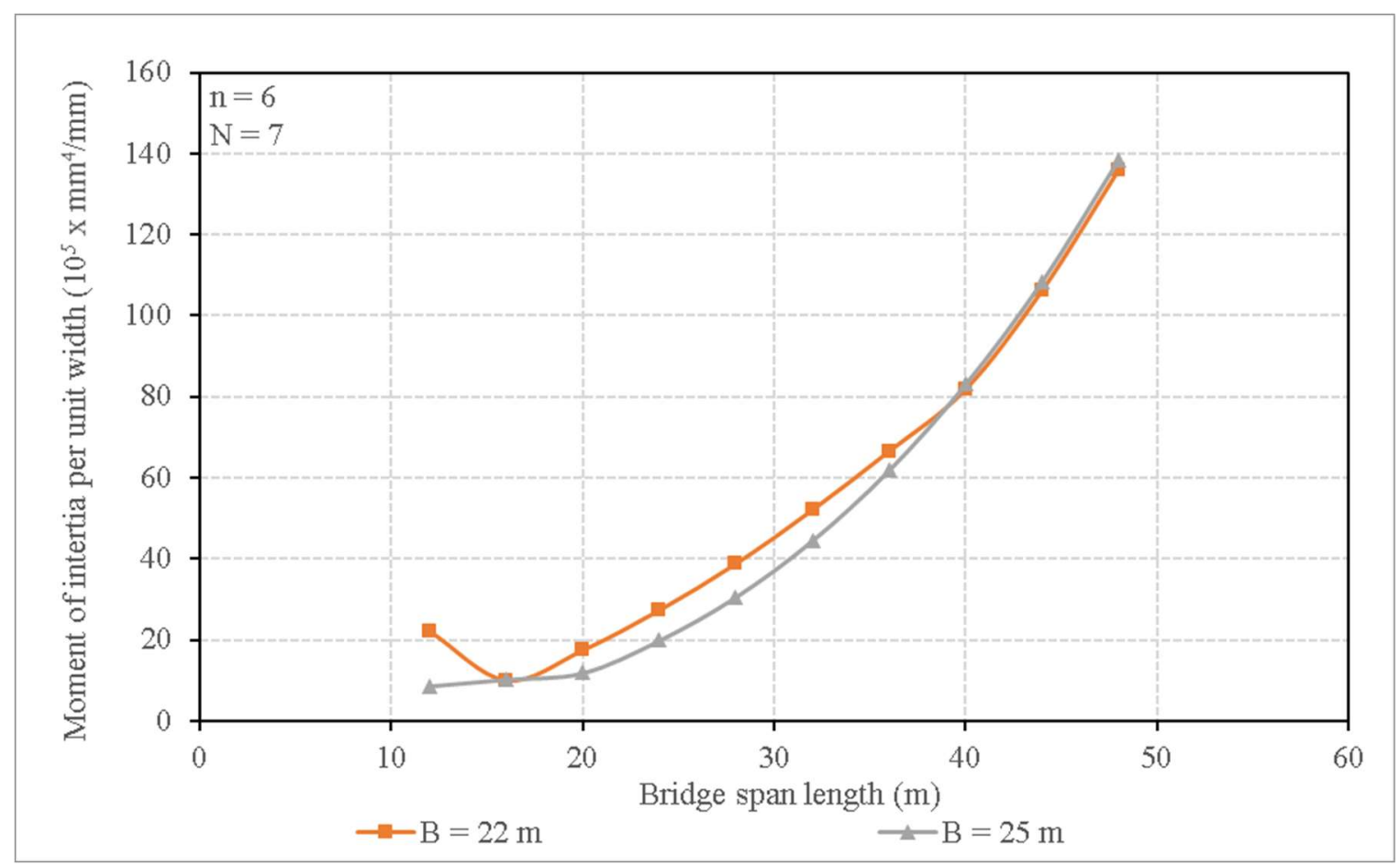

Figure 5.52: Moment of inertia of the steel section per unit width vs span length for a six-lane single span bridge under CL-625 truck loading with seven girders 


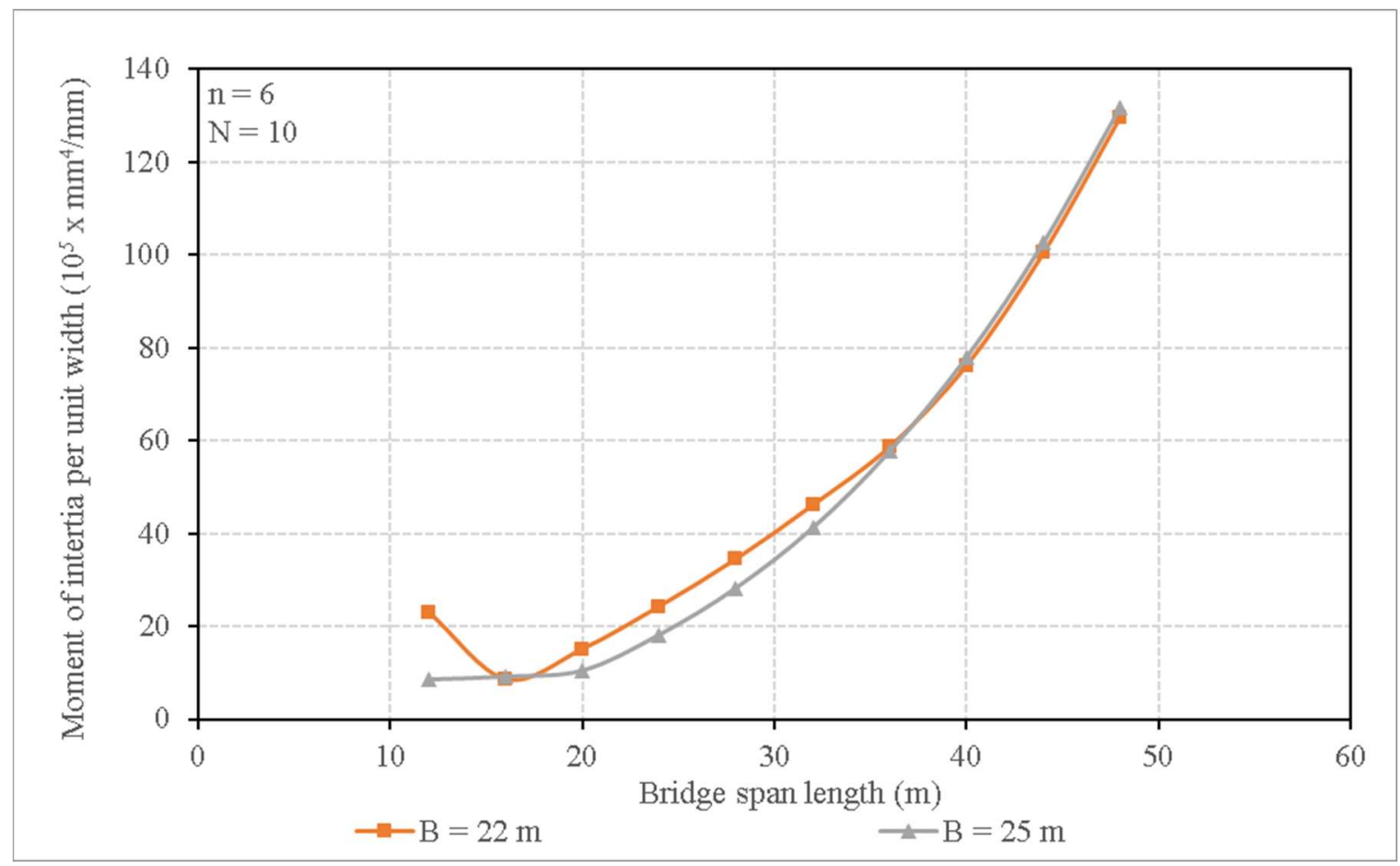

Figure 5.53: Moment of inertia of the steel section per unit width vs span length for a six-lane single span bridge under CL-625 truck loading with ten girders

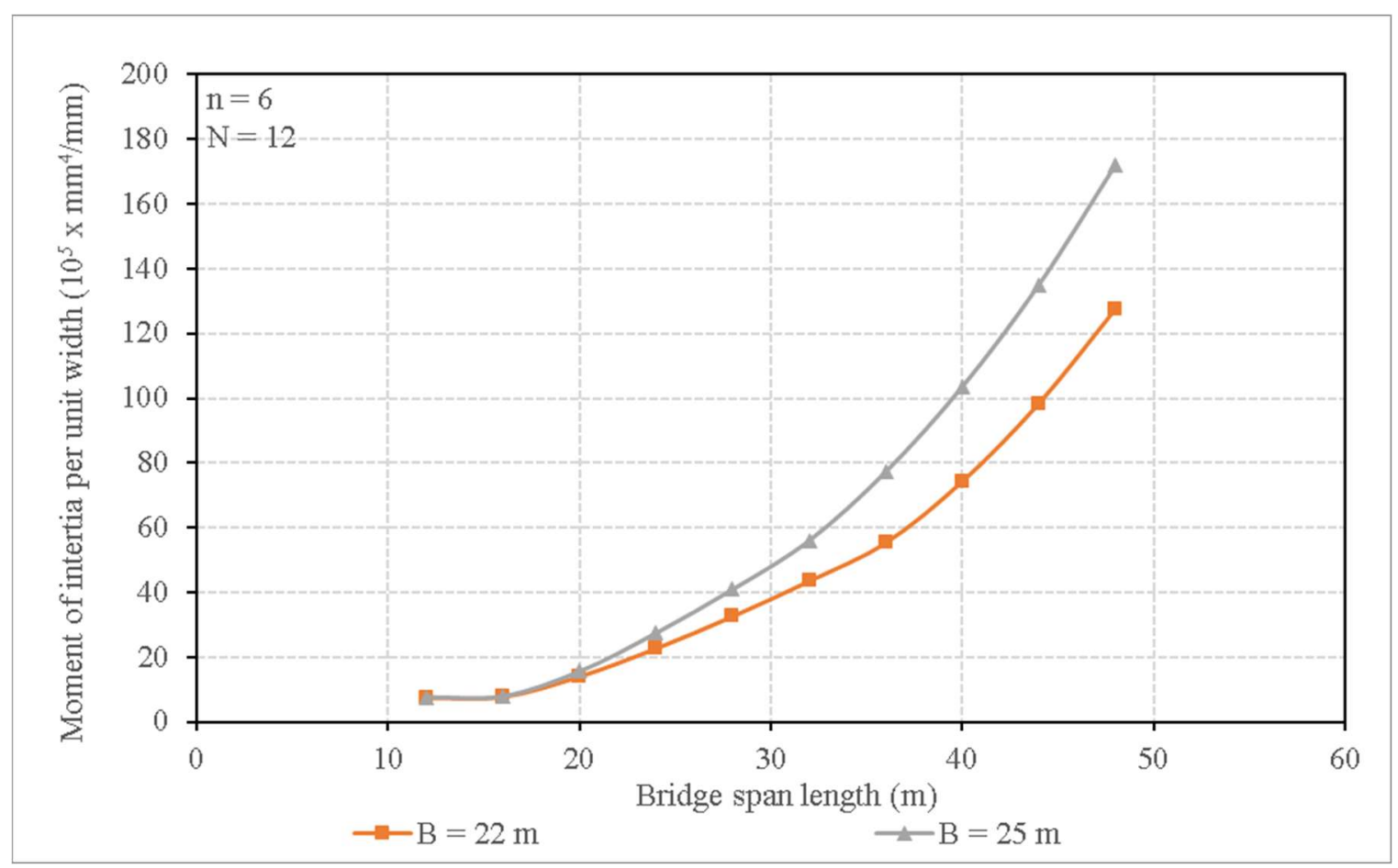

Figure 5.54: Moment of inertia of the steel section per unit width vs span length for a six-lane single span bridge under CL-625 truck loading with twelve girders 
As for the moment of inertia per unit width of the composite section observed in Figures 5.55 through 5.70, the values show a similar pattern to the steel section values. However, in the case of composite section, the values have a much closer packing. This is due to the moment of inertia of the slab per unit width being considered in the calculations which increases the magnitude of the results while reducing the variability as discussed previously. As expected, the case of 12 girders used visible in Figure 5.70 shows the same overdesigned characteristic as in Figure 5.54 for the steel section. This is due to the same reasons mentioned above. As a result, the case of 12 girders was omitted when obtaining parametric equations to represent the results obtained in this section.

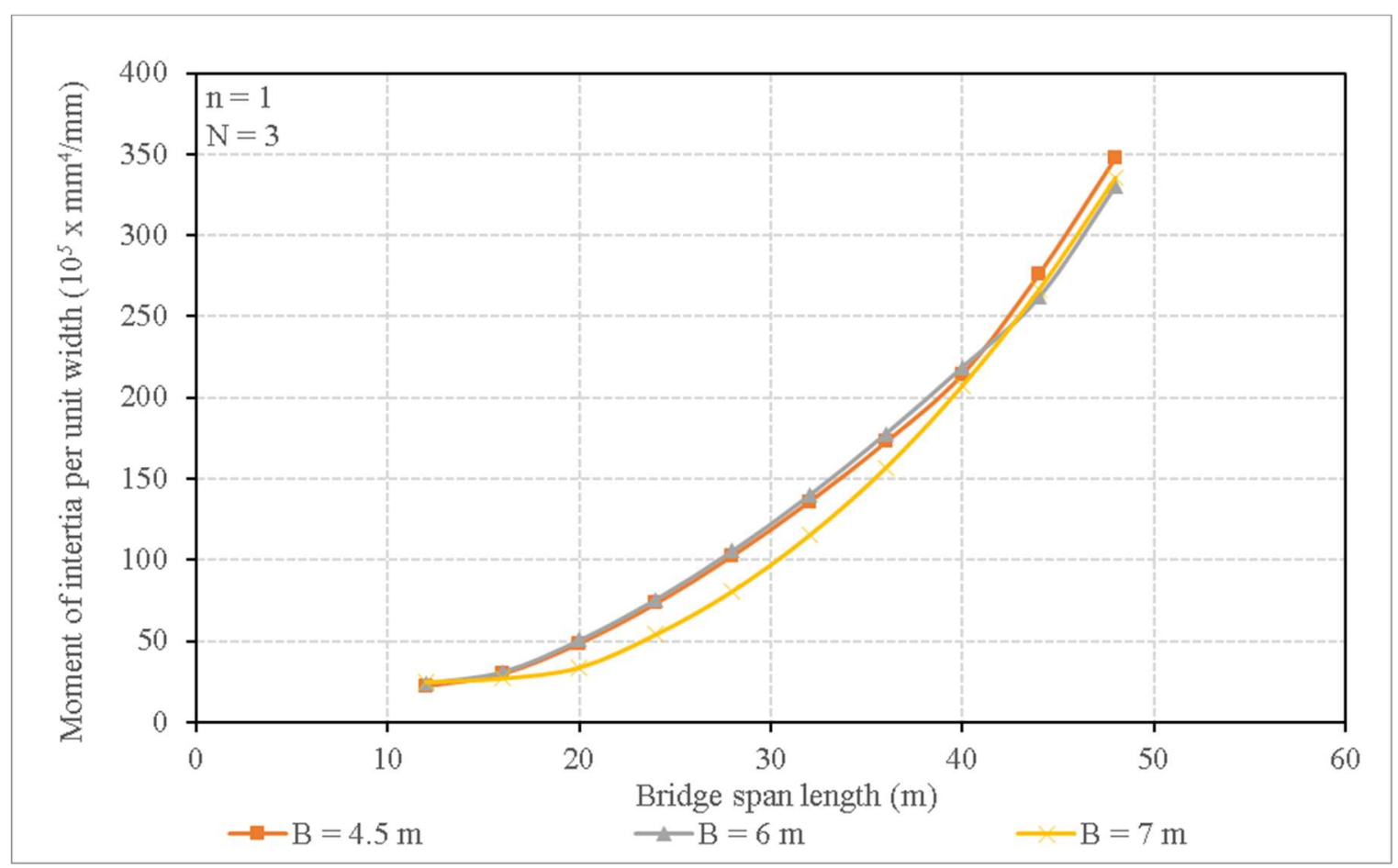

Figure 5.55: Moment of inertia of the composite concrete-steel section per unit width vs span length for a one-lane single span bridge under CL-625 truck loading with three girders 


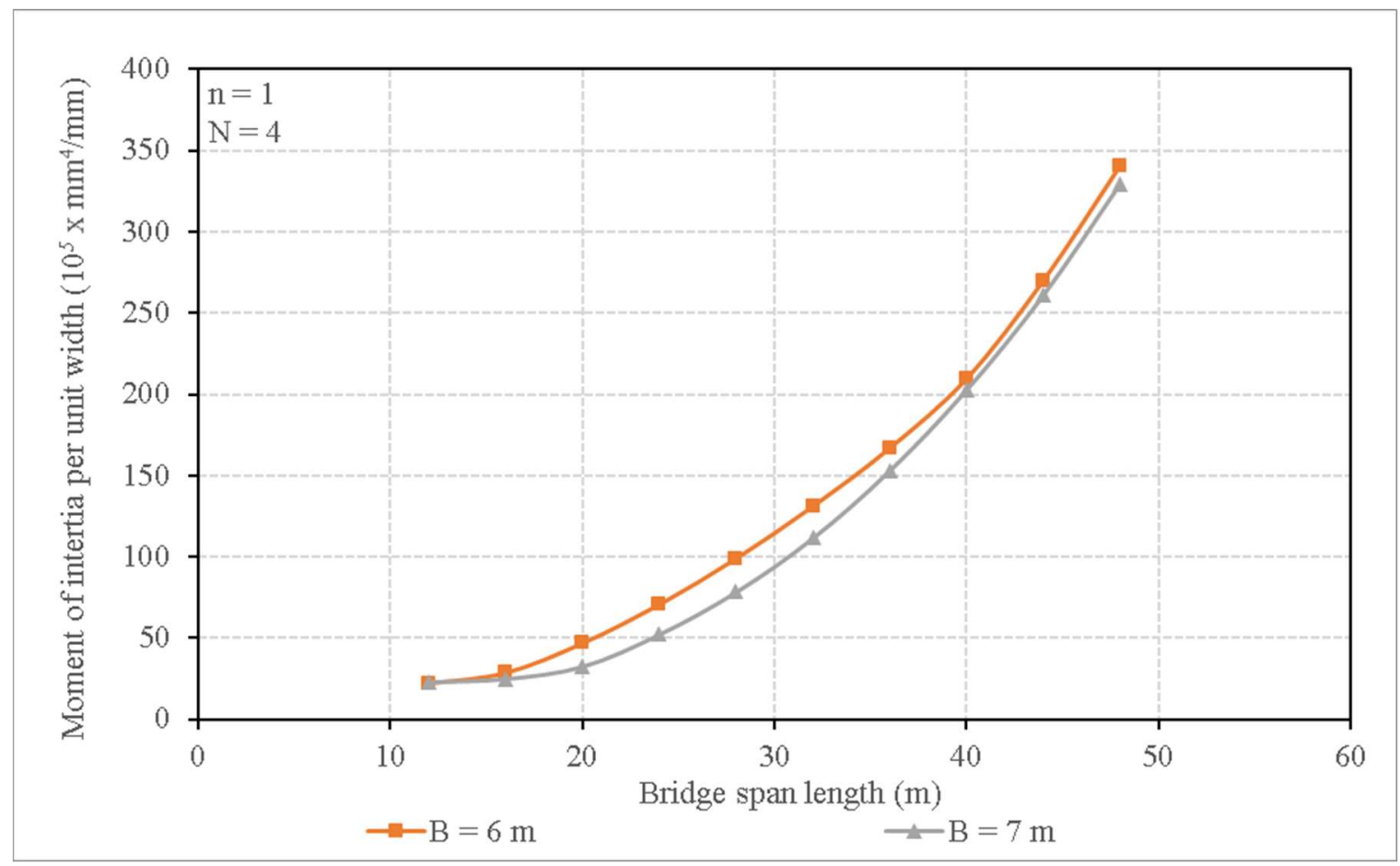

Figure 5.56: Moment of inertia of the composite concrete-steel section per unit width vs span length for a one-lane single span bridge under CL-625 truck loading with four girders

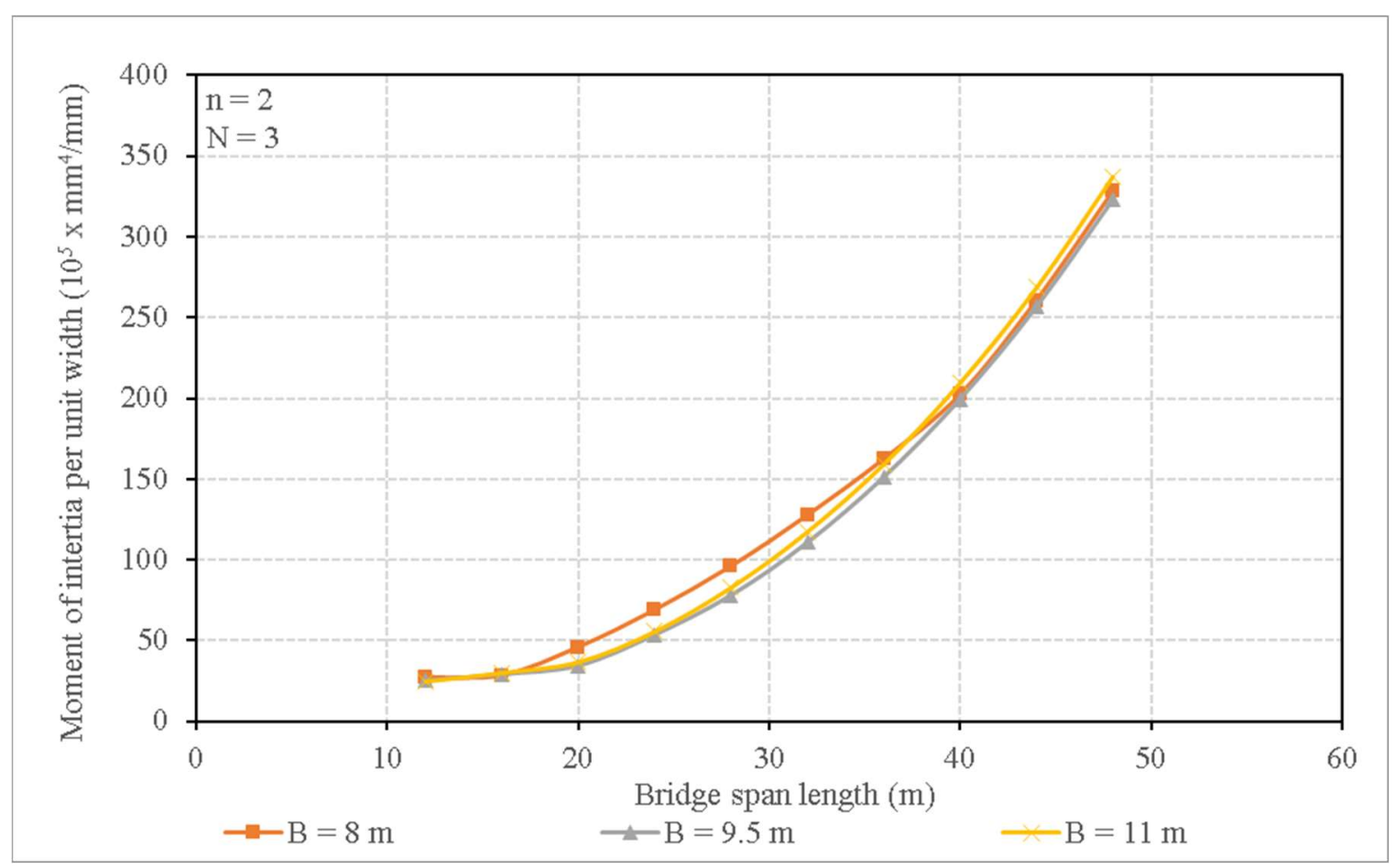

Figure 5.57: Moment of inertia of the composite concrete-steel section per unit width vs span length for a two-lane single span bridge under CL-625 truck loading with three girders 


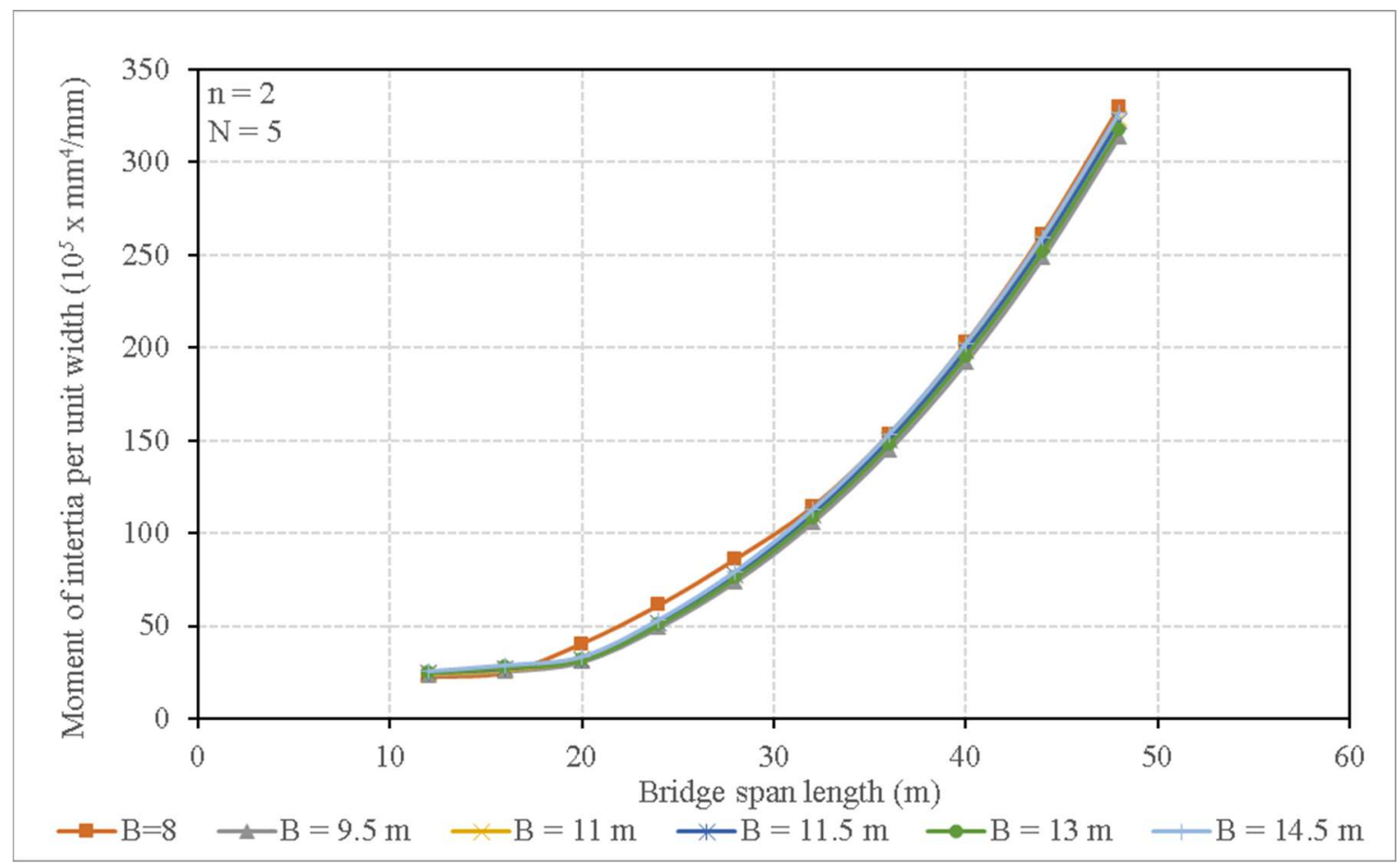

Figure 5.58: Moment of inertia of the composite concrete-steel section per unit width vs span length for a two-lane single span bridge under CL-625 truck loading with five girders

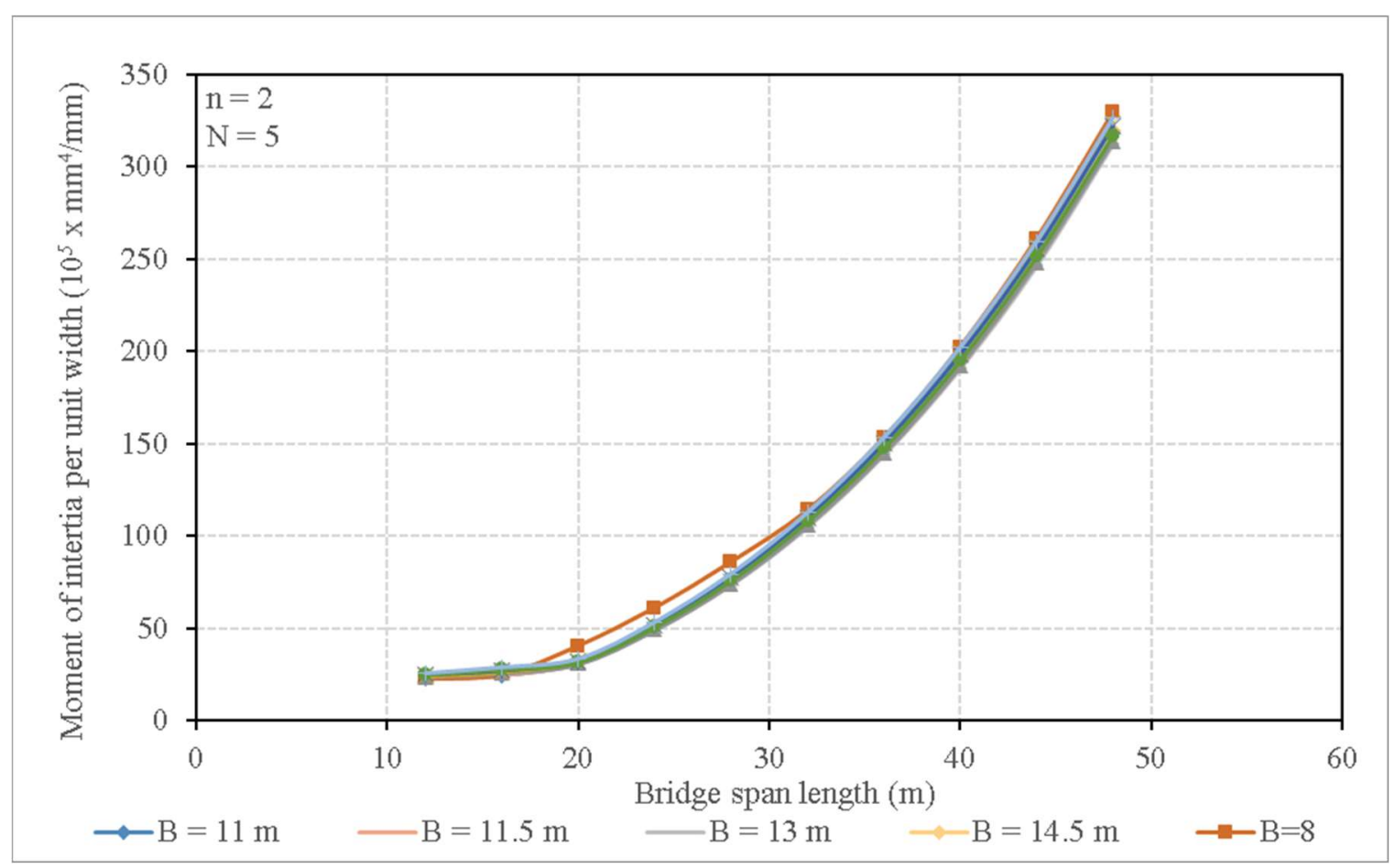

Figure 5.59: Moment of inertia of the composite concrete-steel section per unit width vs span length for a two-lane single span bridge under CL-625 truck loading with seven girders 


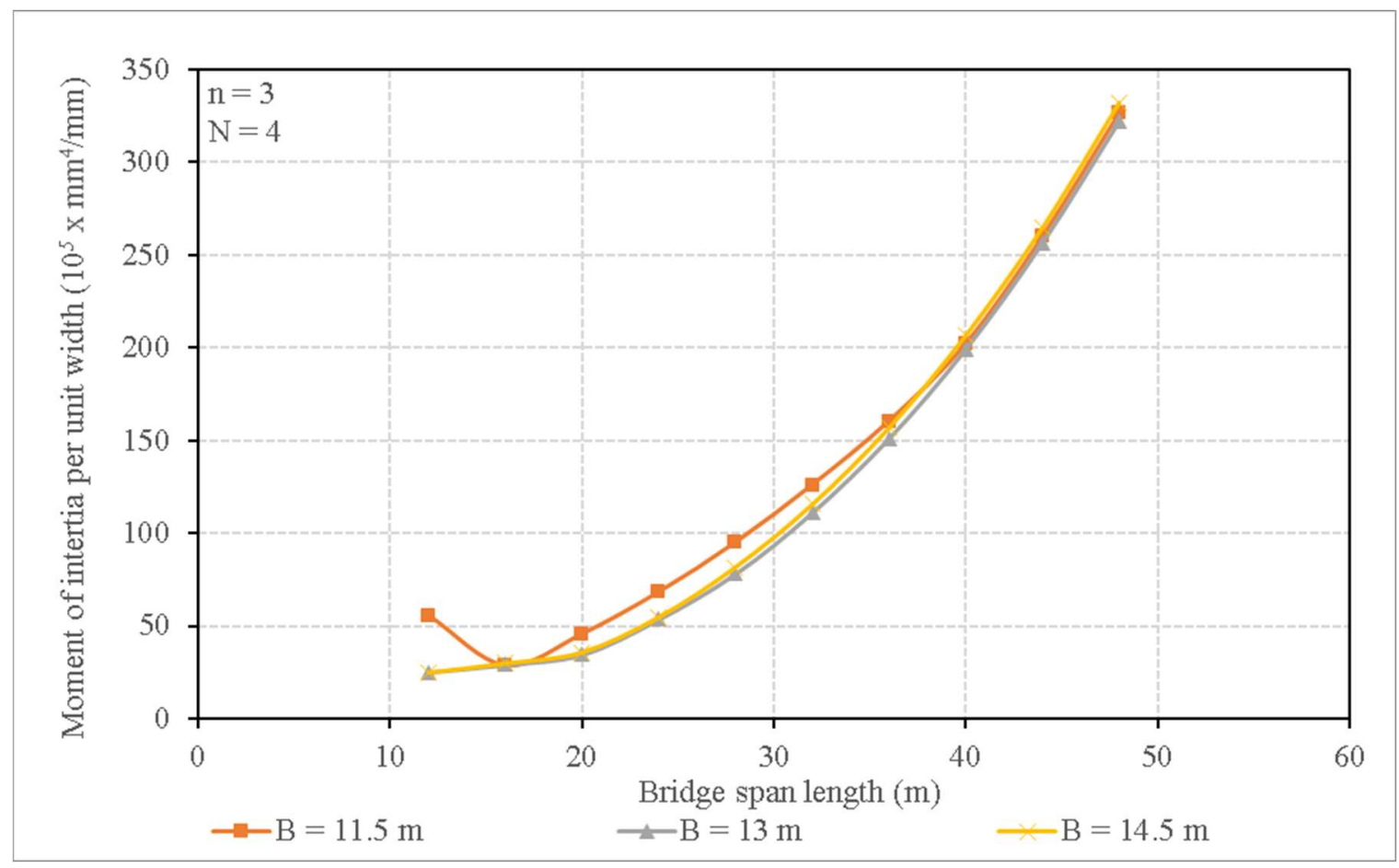

Figure 5.60: Moment of inertia of the composite concrete-steel section per unit width vs span length for a three-lane single span bridge under CL-625 truck loading with four girders

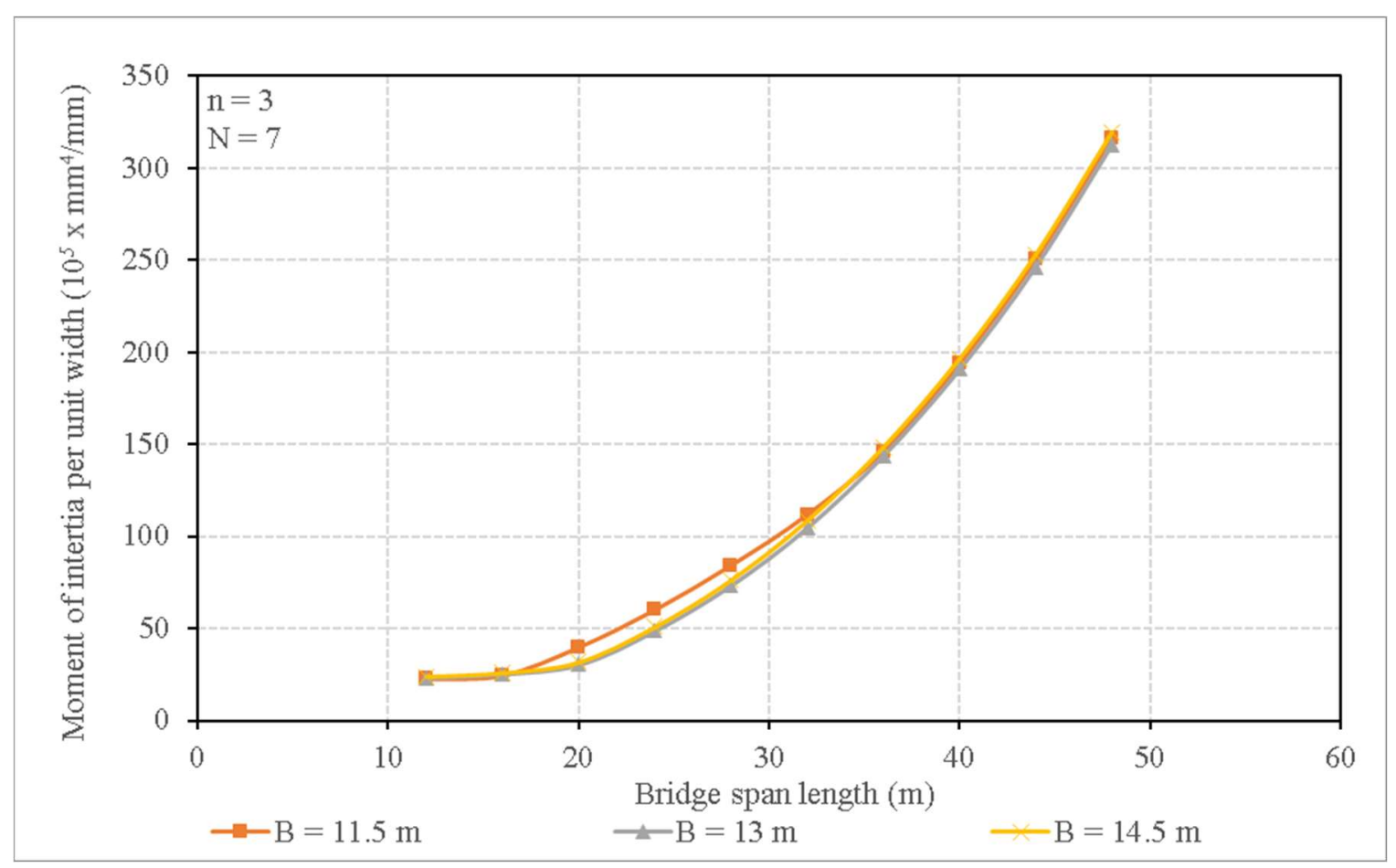

Figure 5.61: Moment of inertia of the composite concrete-steel section per unit width vs span length for a three-lane single span bridge under CL-625 truck loading with seven girders 


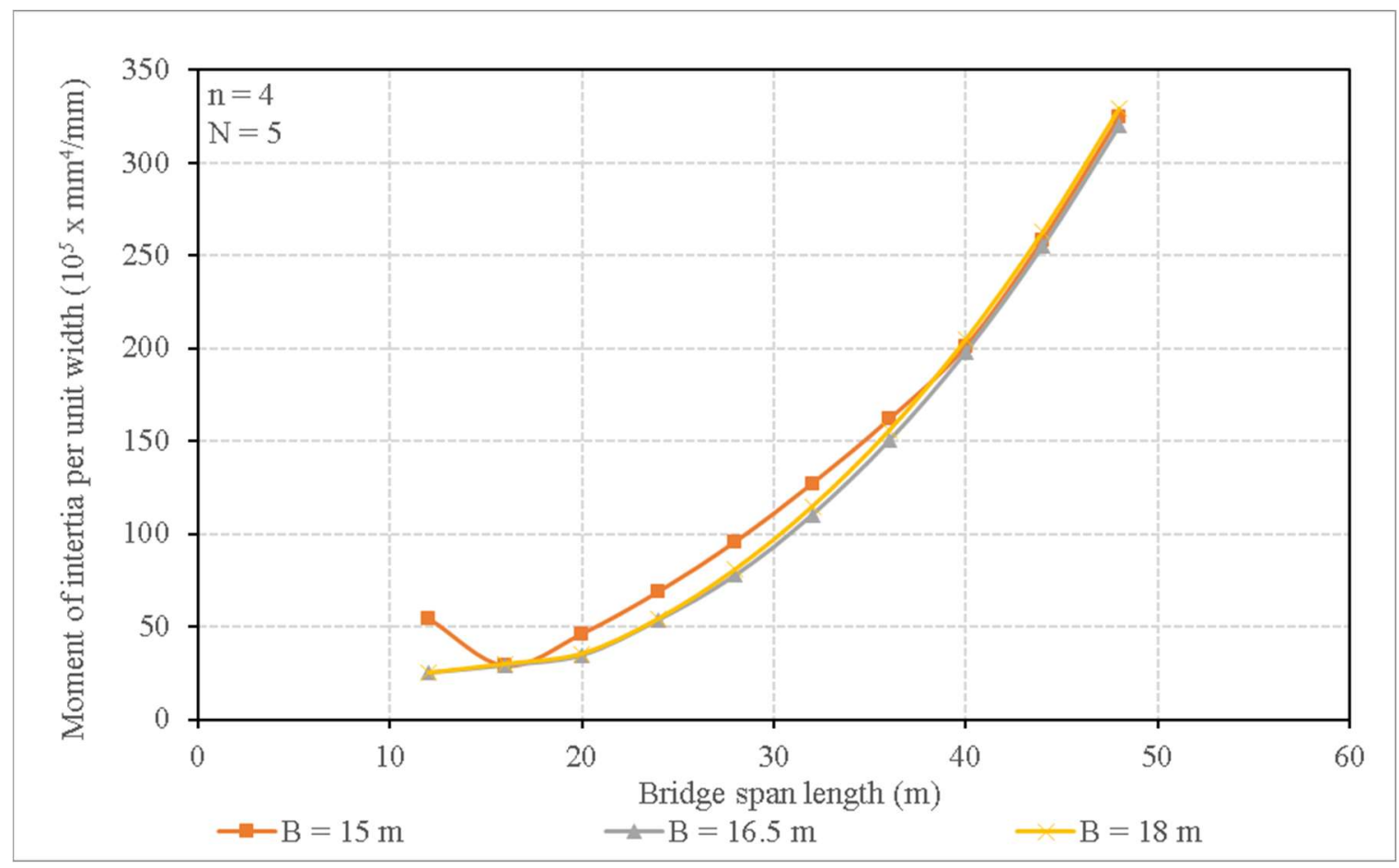

Figure 5.62: Moment of inertia of the composite concrete-steel section per unit width vs span length for a four-lane single span bridge under CL-625 truck loading with five girders

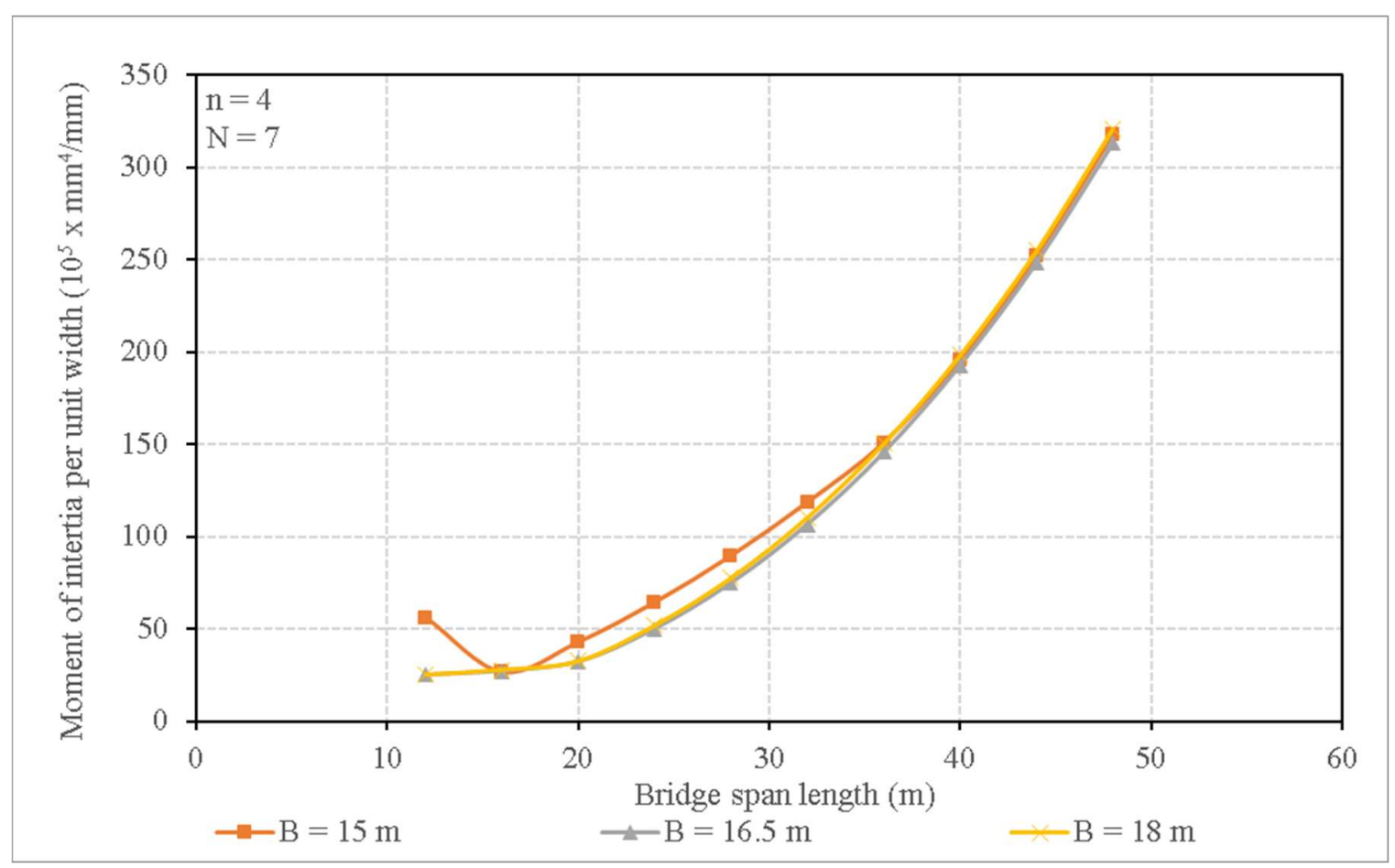

Figure 5.63: Moment of inertia of the composite concrete-steel section per unit width vs span length for a four-lane single span bridge under CL-625 truck loading with seven girders 


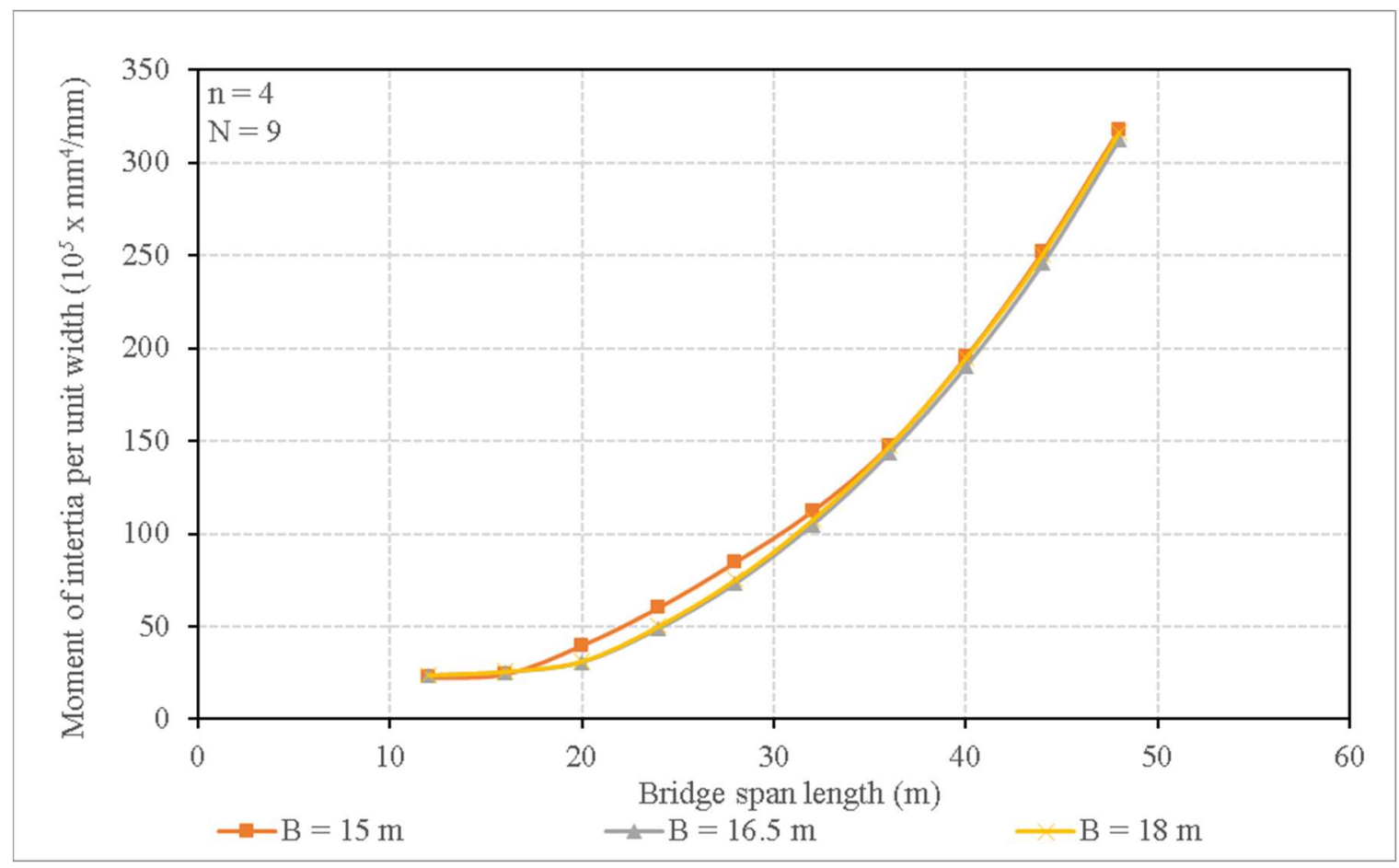

Figure 5.64: Moment of inertia of the composite concrete-steel section per unit width vs span length for a four-lane single span bridge under CL-625 truck loading with nine girders

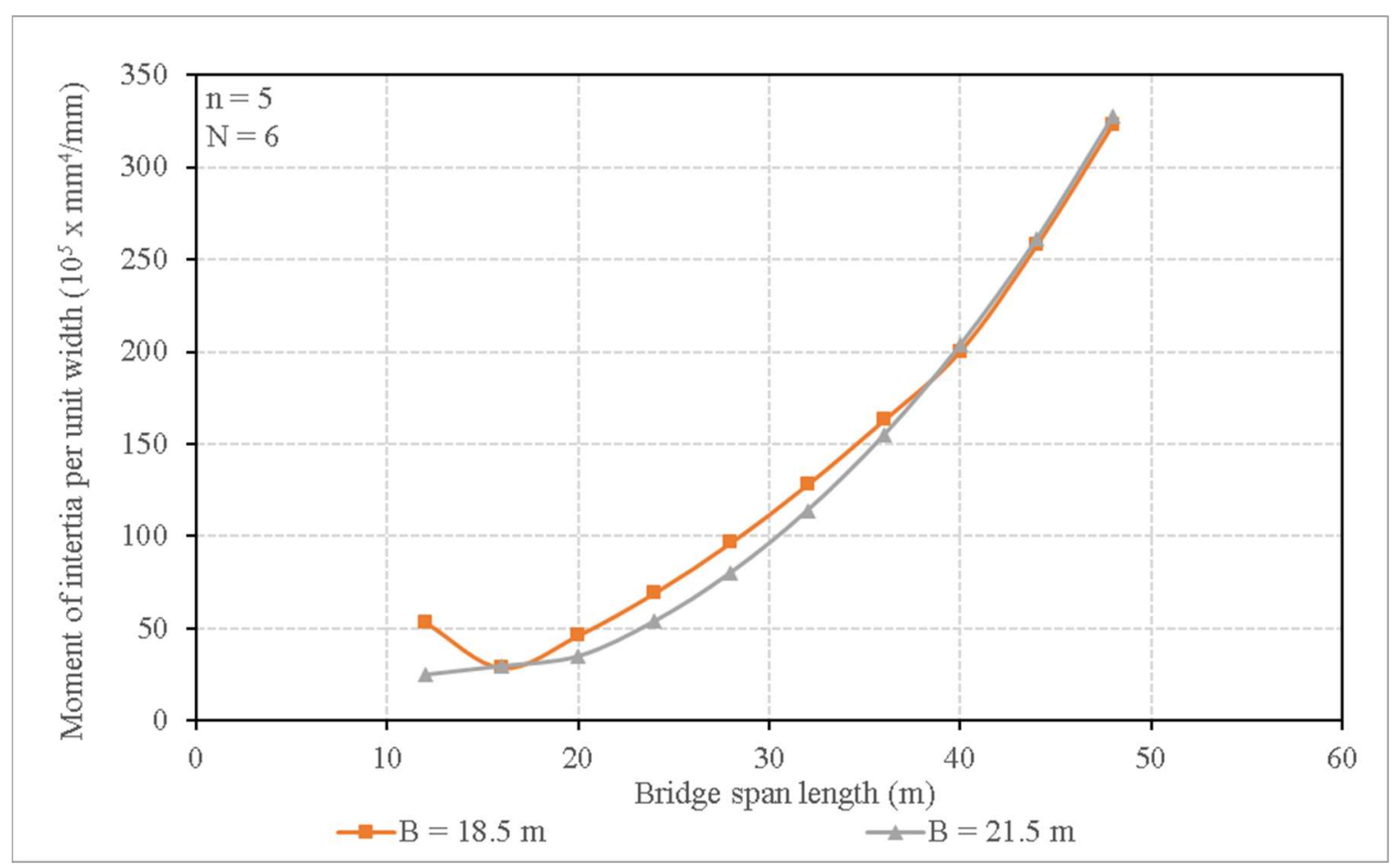

Figure 5.65: Moment of inertia of the composite concrete-steel section per unit width vs span length for a five-lane single span bridge under CL-625 truck loading with six girders 


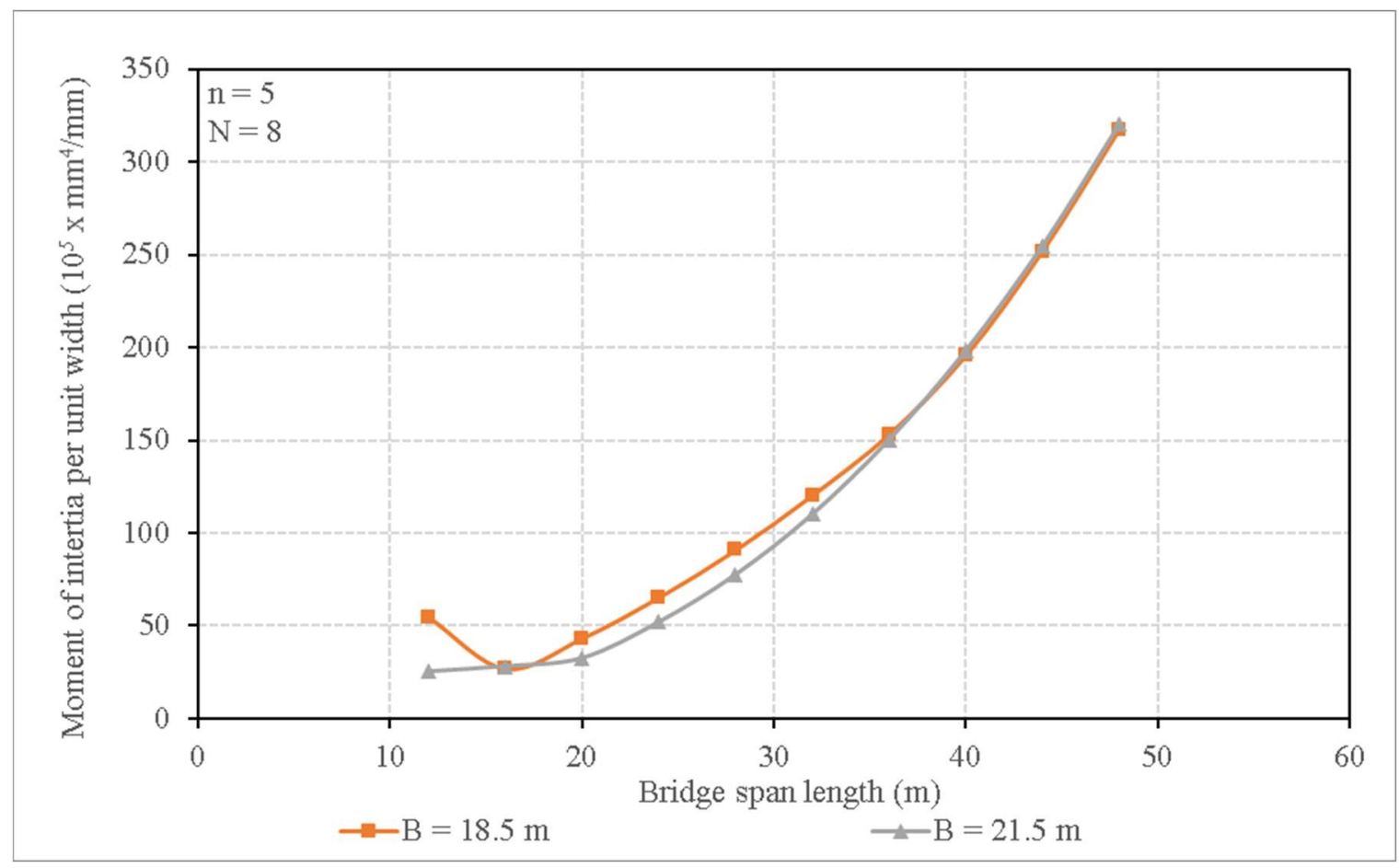

Figure 5.66: Moment of inertia of the composite concrete-steel section per unit width vs span length for a five-lane single span bridge under CL-625 truck loading with eight girders

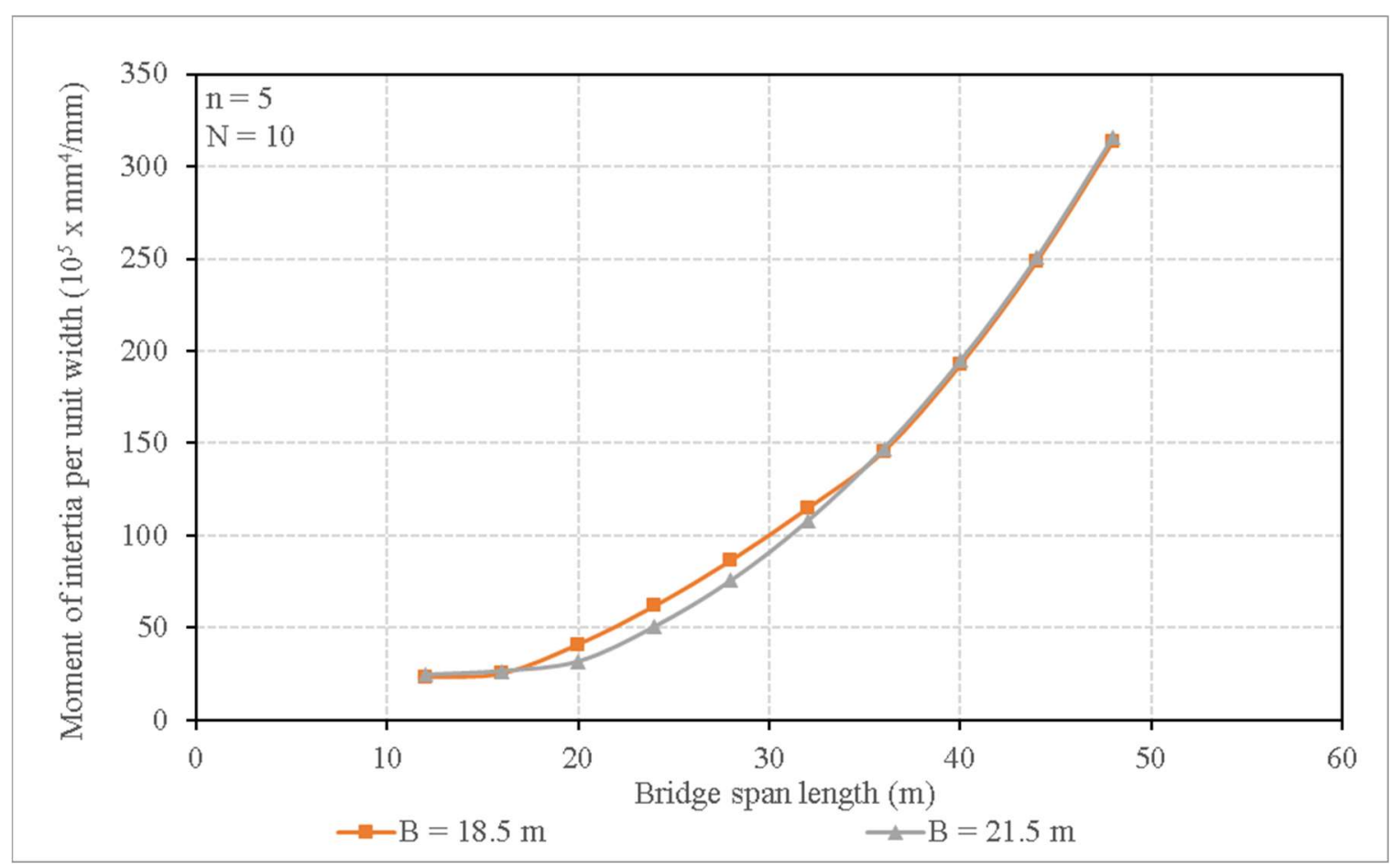

Figure 5.67: Moment of inertia of the composite concrete-steel section per unit width vs span length for a five-lane single span bridge under CL-625 truck loading with ten girders 


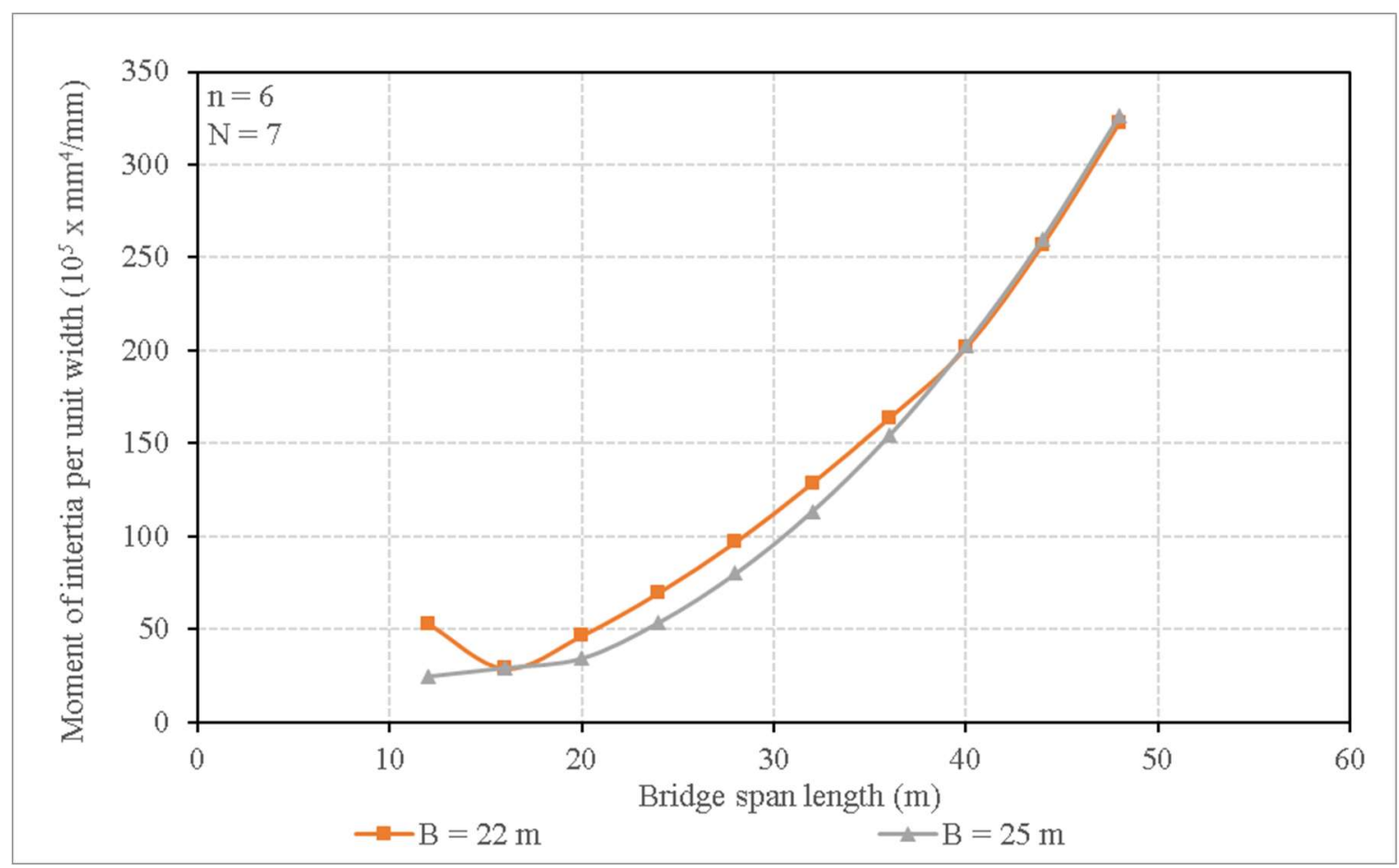

Figure 5.68: Moment of inertia of the composite concrete-steel section per unit width vs span length for a six-lane single span bridge under CL-625 truck loading with seven girders

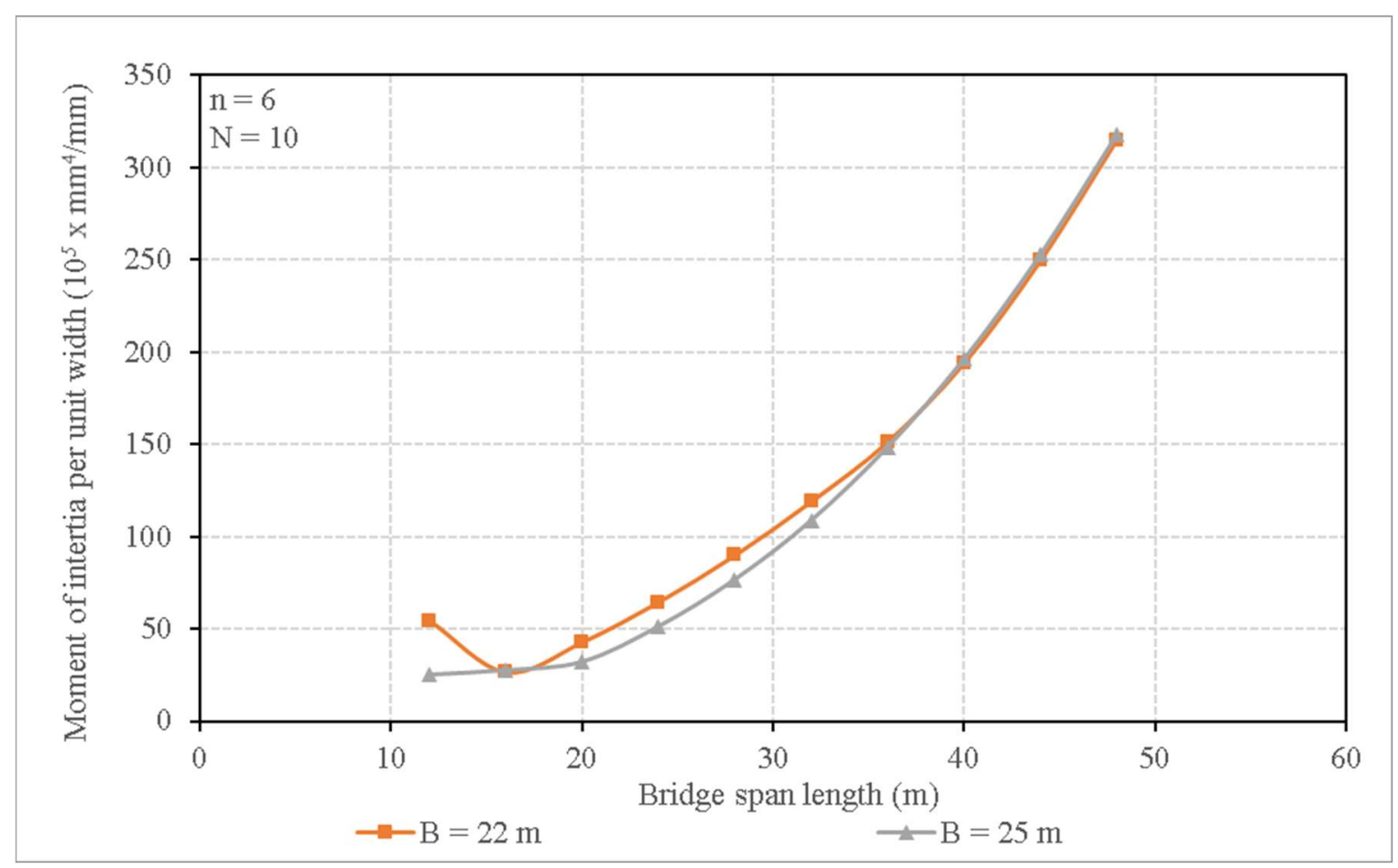

Figure 5.69: Moment of inertia of the composite concrete-steel section per unit width vs span length for a six-lane single span bridge under CL-625 truck loading with ten girders 


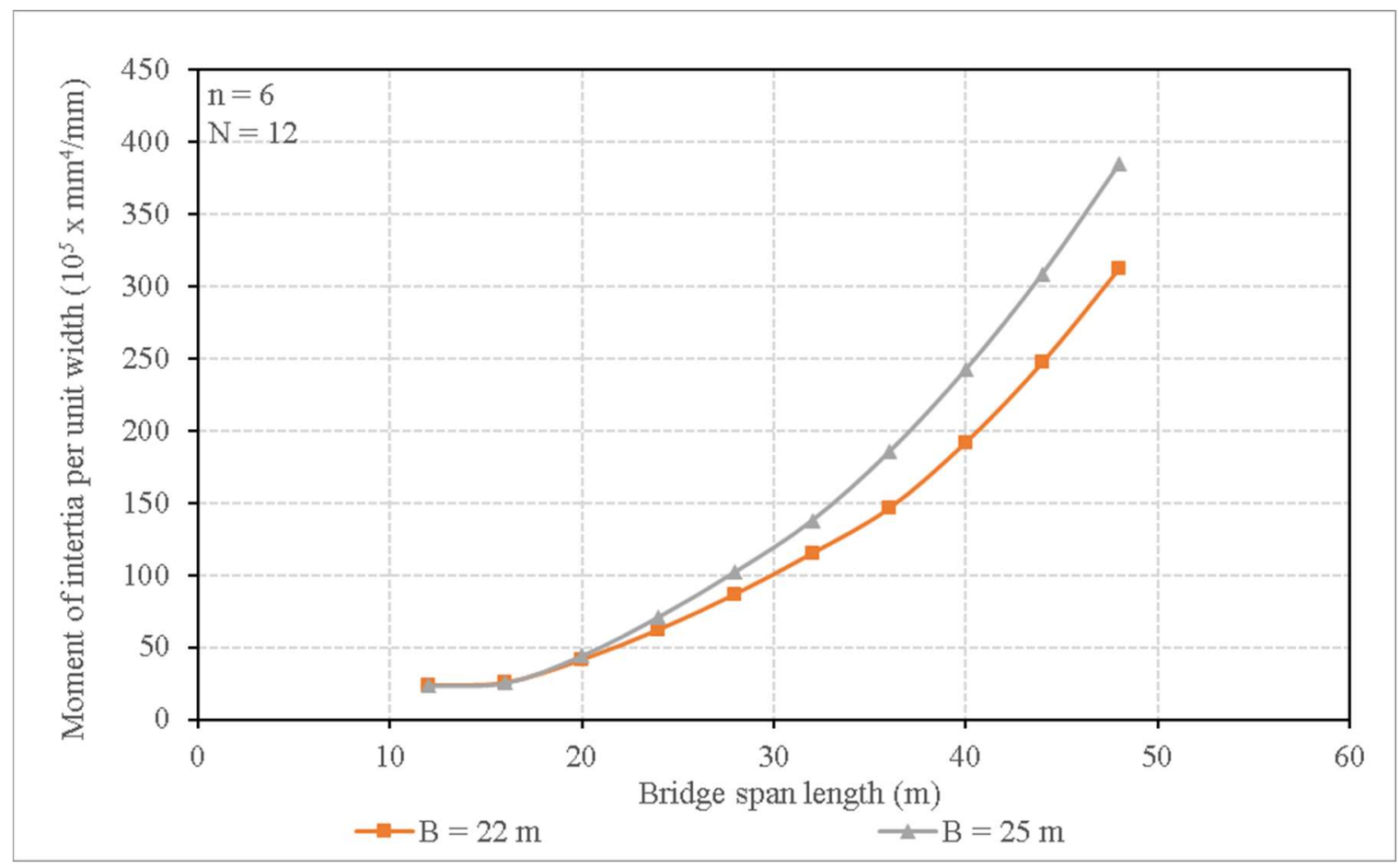

Figure 5.70: Moment of inertia of the composite concrete-steel section per unit width vs span length for a six-lane single span bridge under CL-625 truck loading with twelve girders

\subsection{Effect of number of design lanes on moment of inertia}

In order to study the effect of the number of design lanes (n) on the moment of inertia for the steel and the composite sections per unit width (Is/S \& Ics/S), multiple graphs were created for $n$ $=1$ through $\mathrm{n}=6$ for single span bridge configurations under CL-625 truck loading.

Furthermore, parametric equations were created to represent the values for moment of inertia for the steel and the composite sections per unit width for each design lane case.

In the case of one design lane shown in Figure 5.71, the moment of inertia per unit width can be seen to show a second degree polynomial relationship with the span length. This is true for both moment of inertia per unit width of the steel section and the moment of inertia per unit width of the composite section. The equations developed for single span bridge configurations can be seen below; 


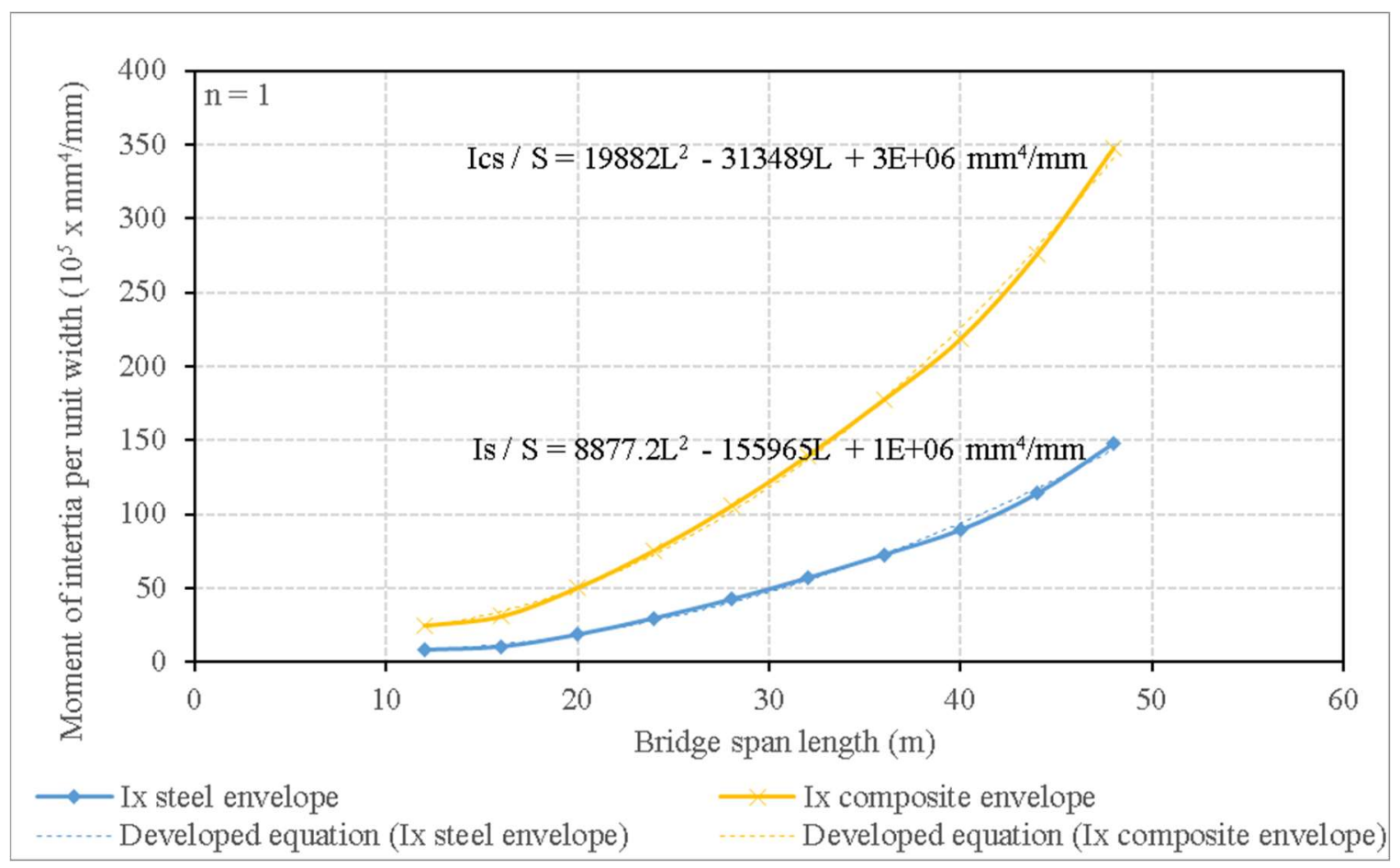

Figure 5.71: Envelopes for moment of inertia for the steel and the composite concrete-steel section per unit width vs span length for one-lane single span bridge under CL-625 truck loadings

$$
\begin{array}{ll}
\text { [5.1] Ics } / \mathrm{S}=19900\left(\mathrm{~L}^{2}\right)-314000(\mathrm{~L})+3 * 10^{6} \mathrm{~mm}^{4} / \mathrm{mm} & \mathrm{n}=1, \text { CL-625 truck loading } \\
{[5.2] \mathrm{Is} / \mathrm{S}=8900\left(\mathrm{~L}^{2}\right)-156000(\mathrm{~L})+1 * 10^{6} \mathrm{~mm}^{4} / \mathrm{mm}} & \mathrm{n}=1, \text { CL-625 truck loading }
\end{array}
$$

As for the case of two design lanes shown in Figure 5.72, the moment of inertia per unit width shows a very similar pattern to that of a single design lane. Second degree polynomial equations were created to represent the moment of inertia per unit width of the steel section and the moment of inertia per unit width of the composite section. The equations developed for single span bridge configurations can be seen below; 


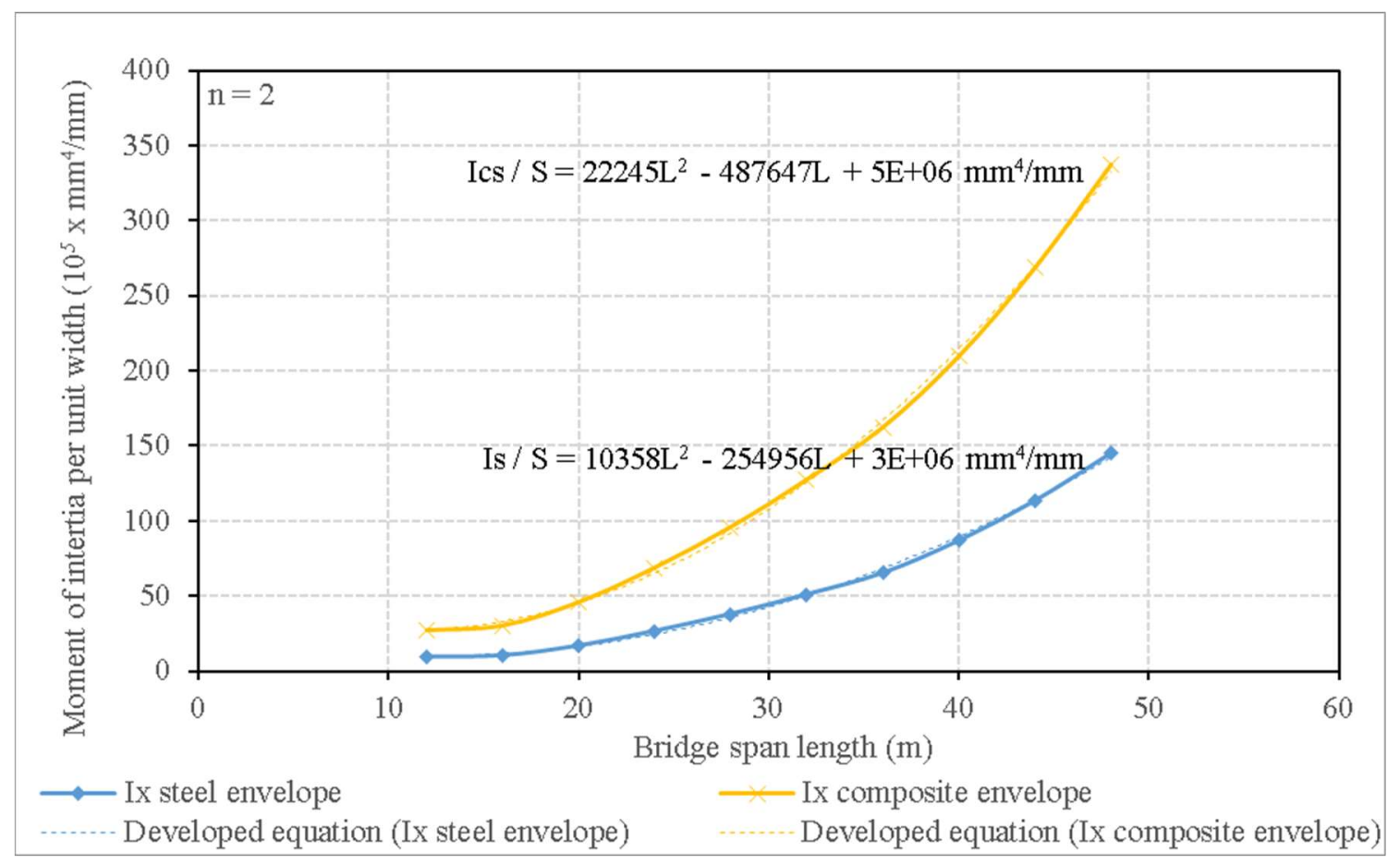

Figure 5.72: Envelopes for moment of inertia for the steel and the composite concrete-steel section per unit width vs span length for two-lane single span bridge under CL-625 truck loadings

$$
\begin{array}{ll}
\text { [5.3] Ics } / \mathrm{S}=22300\left(\mathrm{~L}^{2}\right)-488000(\mathrm{~L})+5 * 10^{6} \mathrm{~mm}^{4} / \mathrm{mm} & \mathrm{n}=2, \text { CL-625 truck loading } \\
{[5.4] \mathrm{Is} / \mathrm{S}=10000\left(\mathrm{~L}^{2}\right)-260000(\mathrm{~L})+3 * 10^{6} \mathrm{~mm}^{4} / \mathrm{mm}} & \mathrm{n}=2, \text { CL-625 truck loading }
\end{array}
$$

As for the case of three design lanes shown in Figure 5.73, the moment of inertia per unit width shows a very similar pattern to that of a one and two design lanes with the exception of moment of inertia at $12 \mathrm{~m}$ span length. This is due to some cases being overdesigned as the bridge dimensions are in some cases very small with too many girders thus being overdesigned. Second degree polynomial equations were created to represent the moment of inertia per unit width of the steel section and the moment of inertia per unit width of the composite section. The equations developed for single span bridge configurations can be seen below; 


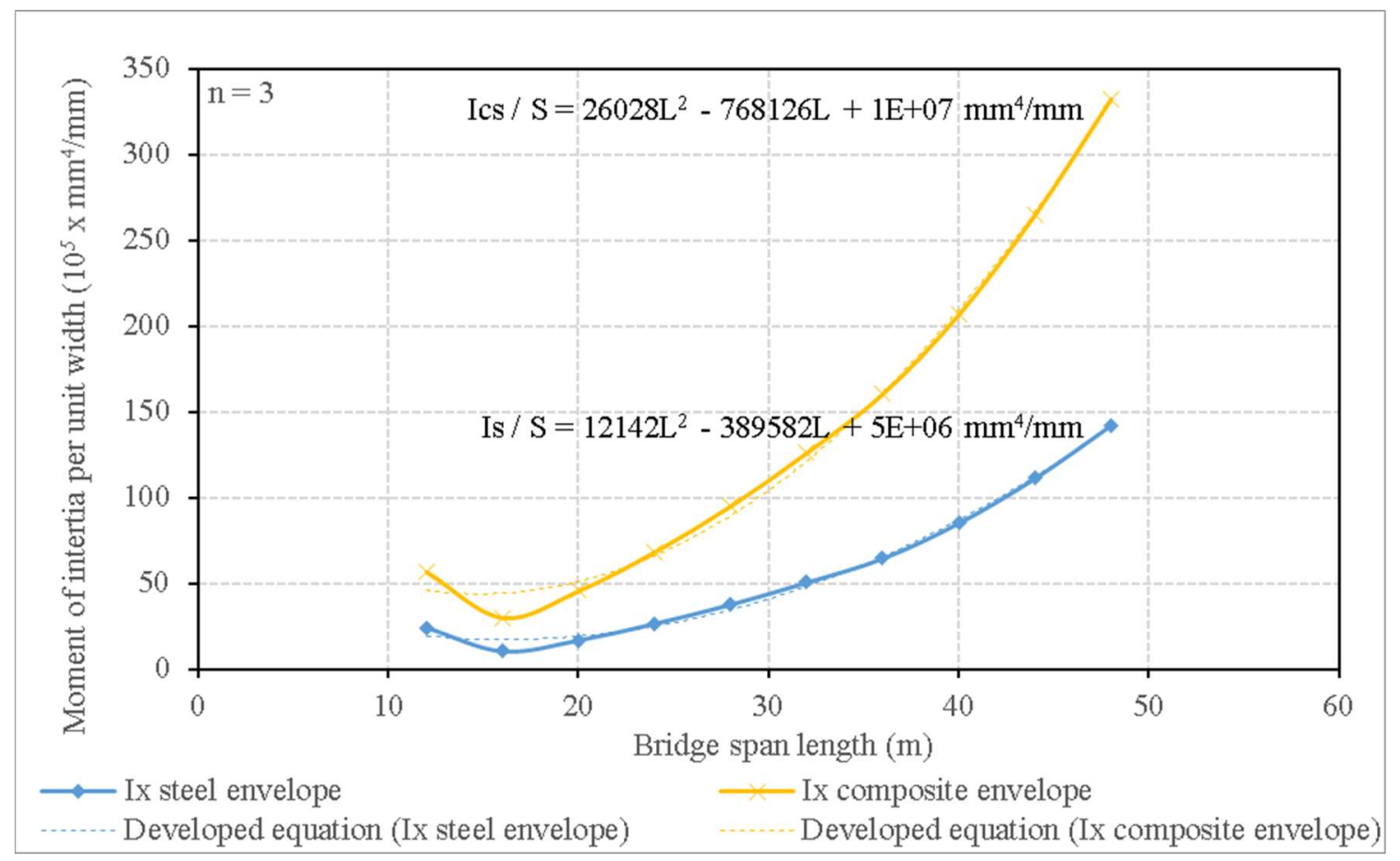

Figure 5.73: Envelopes for moment of inertia for the steel and the composite concrete-steel section per unit width vs span length for three-lane single span bridge under CL-625 truck loading

$$
\begin{array}{ll}
\text { [5.5] Ics } / \mathrm{S}=26000\left(\mathrm{~L}^{2}\right)-768000(\mathrm{~L})+1 * 10^{7} \mathrm{~mm}^{4} / \mathrm{mm} & \mathrm{n}=3, \text { CL-625 truck loading } \\
{[5.6] \mathrm{Is} / \mathrm{S}=12000\left(\mathrm{~L}^{2}\right)-390000(\mathrm{~L})+5 * 10^{6} \mathrm{~mm}^{4} / \mathrm{mm}} & \mathrm{n}=3, \text { CL-625 truck loading }
\end{array}
$$

As for the case of four design lanes shown in Figure 5.74, the moment of inertia per unit width shows a very similar pattern to that of three design lanes. Second degree polynomial equations were created to represent the moment of inertia per unit width of the steel section and the moment of inertia per unit width of the composite section. The equations developed for single span bridge configurations can be seen below; 


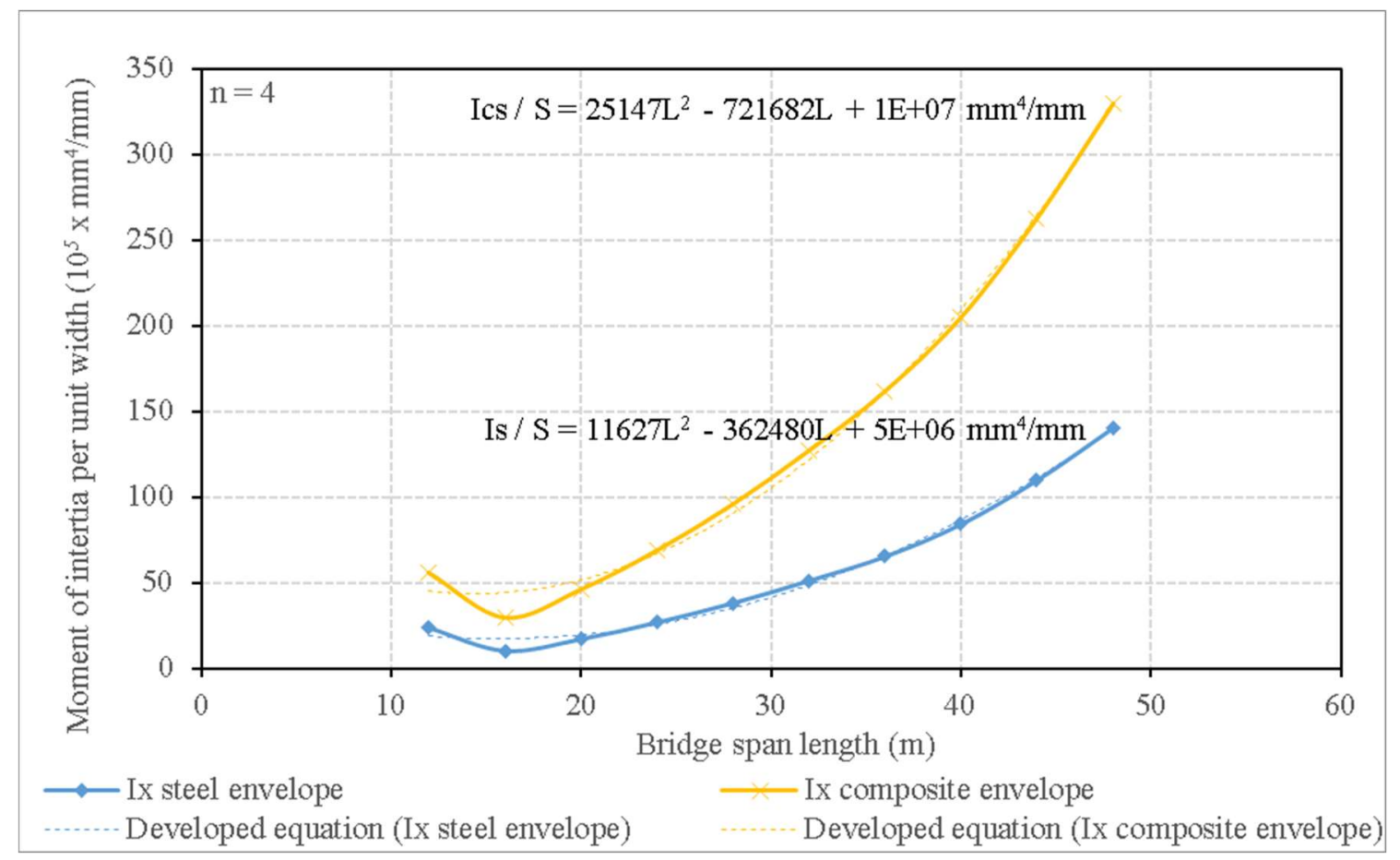

Figure 5.74: Envelopes for moment of inertia for the steel and the composite concrete-steel section per unit width vs span length for four-lane single span bridge under CL-625 truck loadings

$$
\begin{array}{ll}
\text { [5.7] Ics } / \mathrm{S}=26000\left(\mathrm{~L}^{2}\right)-720000(\mathrm{~L})+1 * 10^{7} \mathrm{~mm}^{4} / \mathrm{mm} & \mathrm{n}=4, \text { CL-625 truck loading } \\
{[5.8] \mathrm{Is} / \mathrm{S}=12000\left(\mathrm{~L}^{2}\right)-360000(\mathrm{~L})+5 * 10^{6} \mathrm{~mm}^{4} / \mathrm{mm}} & \mathrm{n}=4 \text {, CL-625 truck loading }
\end{array}
$$

As for the case of five design lanes shown in Figure 5.75, the moment of inertia per unit width shows a very similar pattern to that of three and four design lanes. Second degree polynomial equations were created to represent the moment of inertia per unit width of the steel section and the moment of inertia per unit width of the composite section. The equations developed for single span bridge configurations can be seen below; 


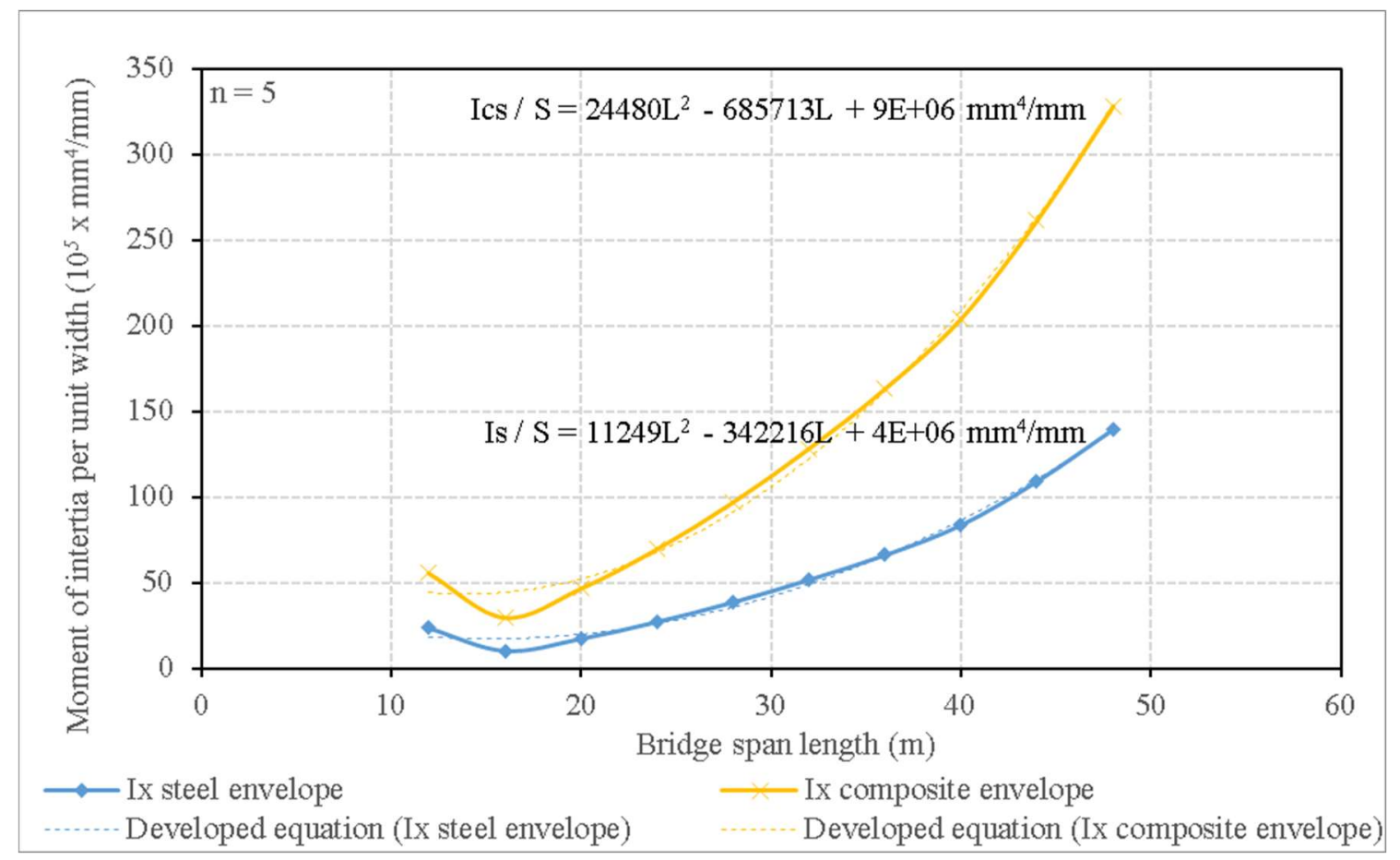

Figure 5.75: Envelopes for moment of inertia for the steel and the composite concrete-steel section per unit width vs span length for five-lane single span bridge under CL-625 truck loadings

$$
\begin{array}{ll}
\text { [5.9] Ics } / \mathrm{S}=25000\left(\mathrm{~L}^{2}\right)-680000(\mathrm{~L})+9 * 10^{6} \mathrm{~mm}^{4} / \mathrm{mm} & \mathrm{n}=5, \text { CL-625 truck loading } \\
{[5.10] \mathrm{Is} / \mathrm{S}=11000\left(\mathrm{~L}^{2}\right)-340000(\mathrm{~L})+4 * 10^{6} \mathrm{~mm}^{4} / \mathrm{mm}} & \mathrm{n}=5 \text {, CL-625 truck loading }
\end{array}
$$

Finally, in the case of five design lanes shown in Figure 5.75, the moment of inertia per unit width shows higher values than its previous counterparts. This is due to these values being governed by the case of $\mathrm{N}=12$ discussed in previous sections. This causes these values to heavily overestimate the required moment of inertia per unit width for the case of six design lanes. This being said, second degree polynomial equations were created to represent the moment of inertia per unit width of the steel section and the moment of inertia per unit width of the composite section. The equations developed for single span bridge configurations can be seen below; 


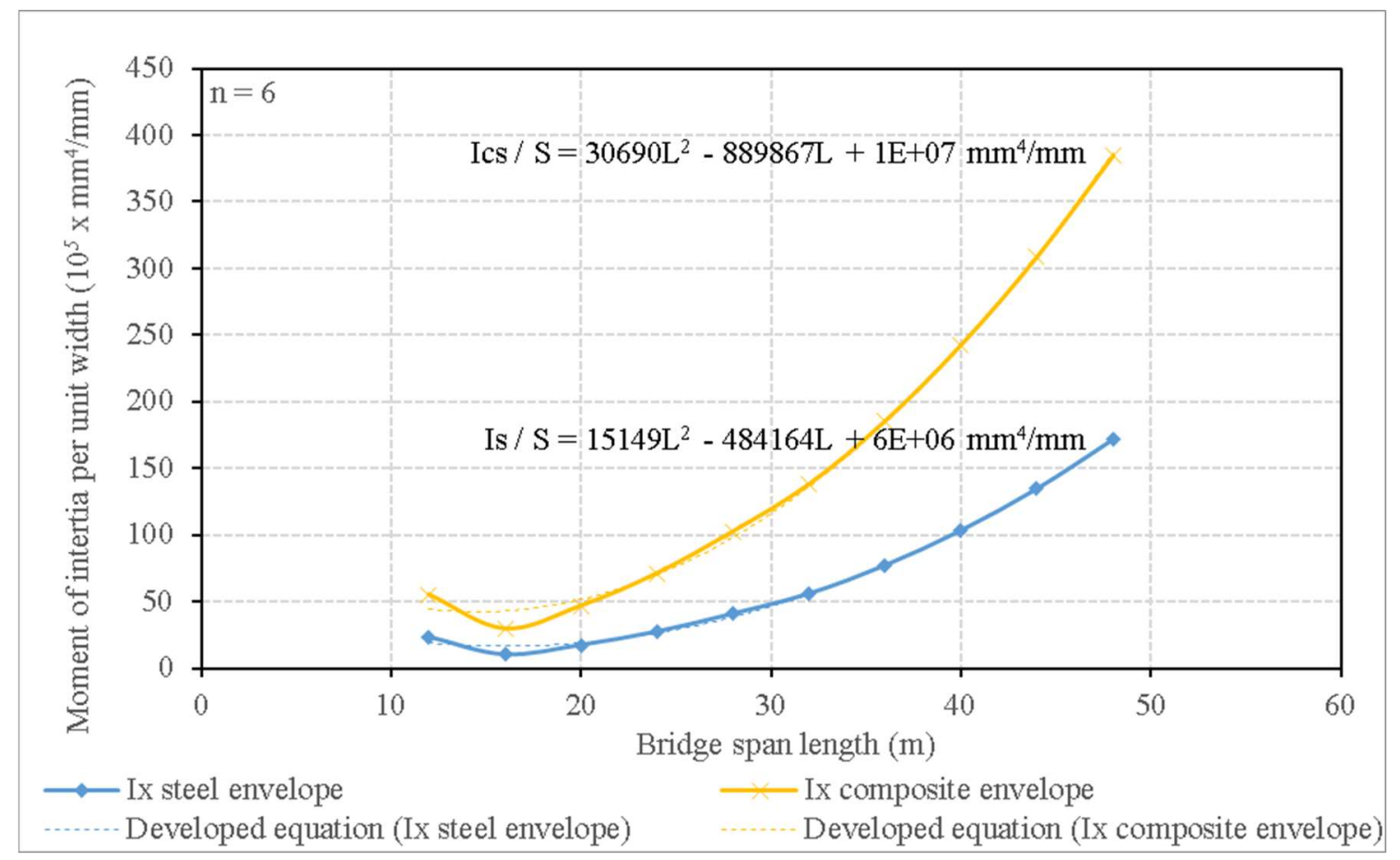

Figure 5.76: Envelopes for moment of inertia for the steel and the composite concrete-steel section per unit width vs span length for six-lane single span bridge under CL-625 truck loadings

$$
\begin{array}{ll}
{[5.11] \mathrm{Ics} / \mathrm{S}=31000\left(\mathrm{~L}^{2}\right)-890000(\mathrm{~L})+1 * 10^{7} \mathrm{~mm}^{4} / \mathrm{mm}} & \mathrm{n}=6, \text { CL-625 truck loading } \\
{[5.12] \mathrm{Is} / \mathrm{S}=15000\left(\mathrm{~L}^{2}\right)-480000(\mathrm{~L})+6 * 10^{6} \mathrm{~mm}^{4} / \mathrm{mm}} & \mathrm{n}=6, \text { CL-625 truck loading }
\end{array}
$$

To put the difference in values in perspective, Figures 5.77 and 5.78 show the difference in results between the cases of one to five design lanes and that of six design lanes which is governed by the $\mathrm{N}-12$ case. As can be seen, the values are very close between $16 \mathrm{~m}$ and $48 \mathrm{~m}$ for $\mathrm{n}=1$ through $\mathrm{n}=5$. The $\mathrm{n}=6$, being governed by the $\mathrm{N}=12$ case shows higher values when compared to the other five cases in both graphs. The difference shown is reduced in Figure 5.78. However, this is due to the slab contributing to the moment of inertia which reduces the percentage contributed by the I-girder to the moment of inertia per unit width. 


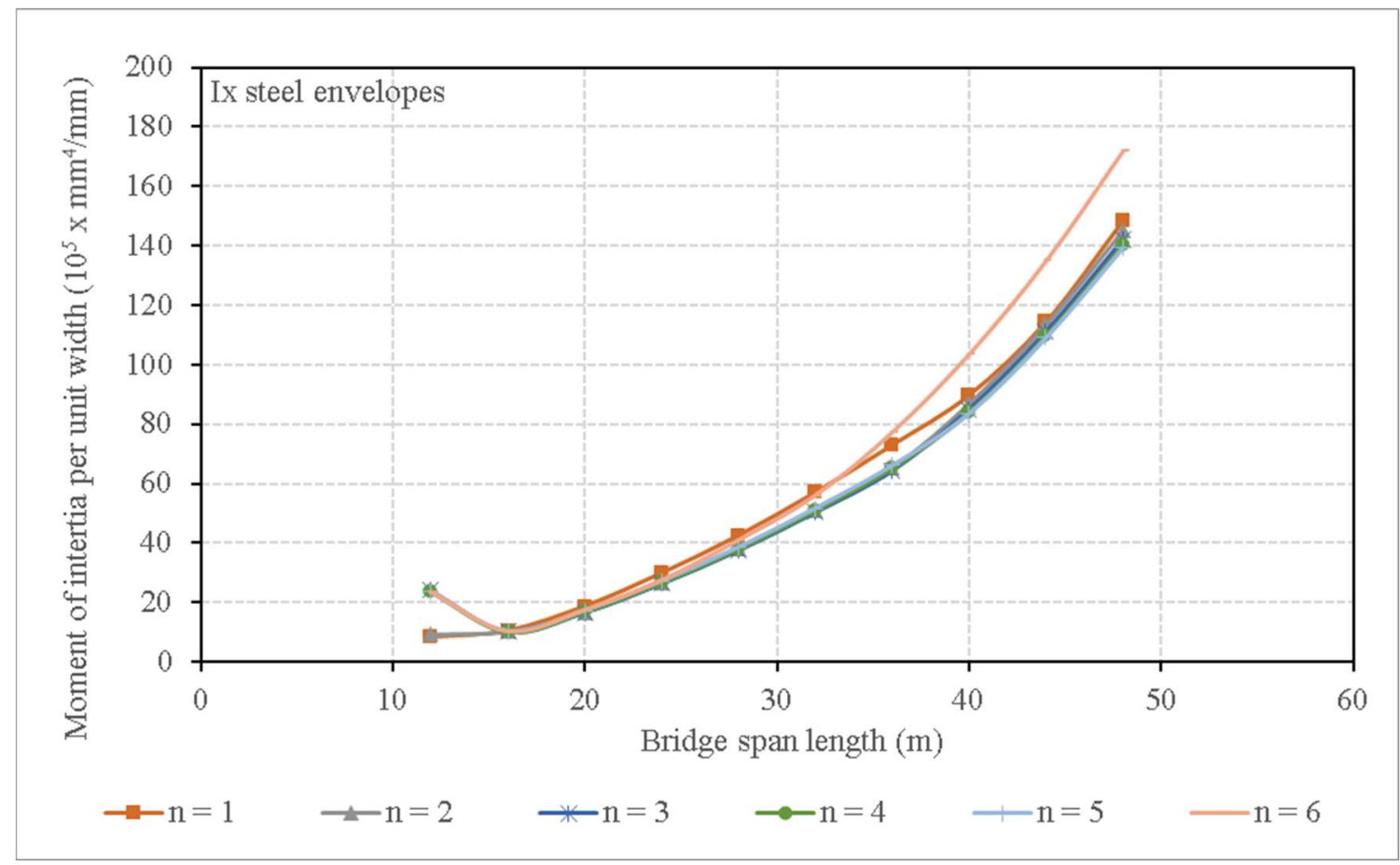

Figure 5.77: Combined envelopes for moment of inertia for the steel and the composite concretesteel section per unit width vs span length

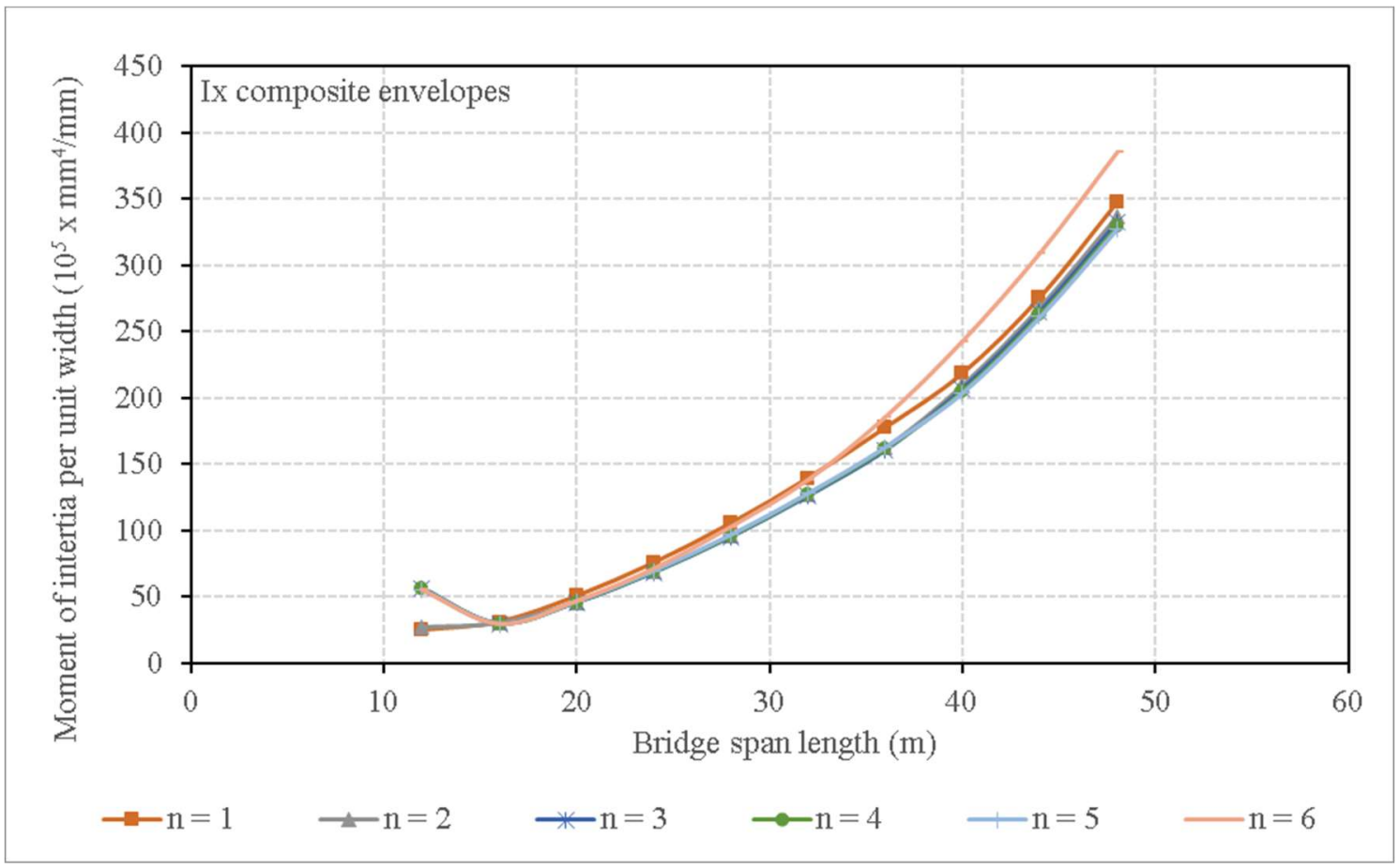

Figure 5.78: Combined envelopes for moment of inertia for the steel and the composite concretesteel section per unit width vs span length 


\subsection{Developed equations for single span bridge configurations}

\subsubsection{Bridge configurations under CL-625 truck loading}

Considering the results from the analysis conducted in sections 5.1 through 5.3 , the case of $\mathrm{N}=$ 12 was omitted when creating equations to represent the results obtained. Figure 5.79 shows the envelope of the results obtained for both Is and Ics. The equation representing the moment of inertia per unit width of the steel section and the moment of inertia per unit width of the composite section can be seen below;

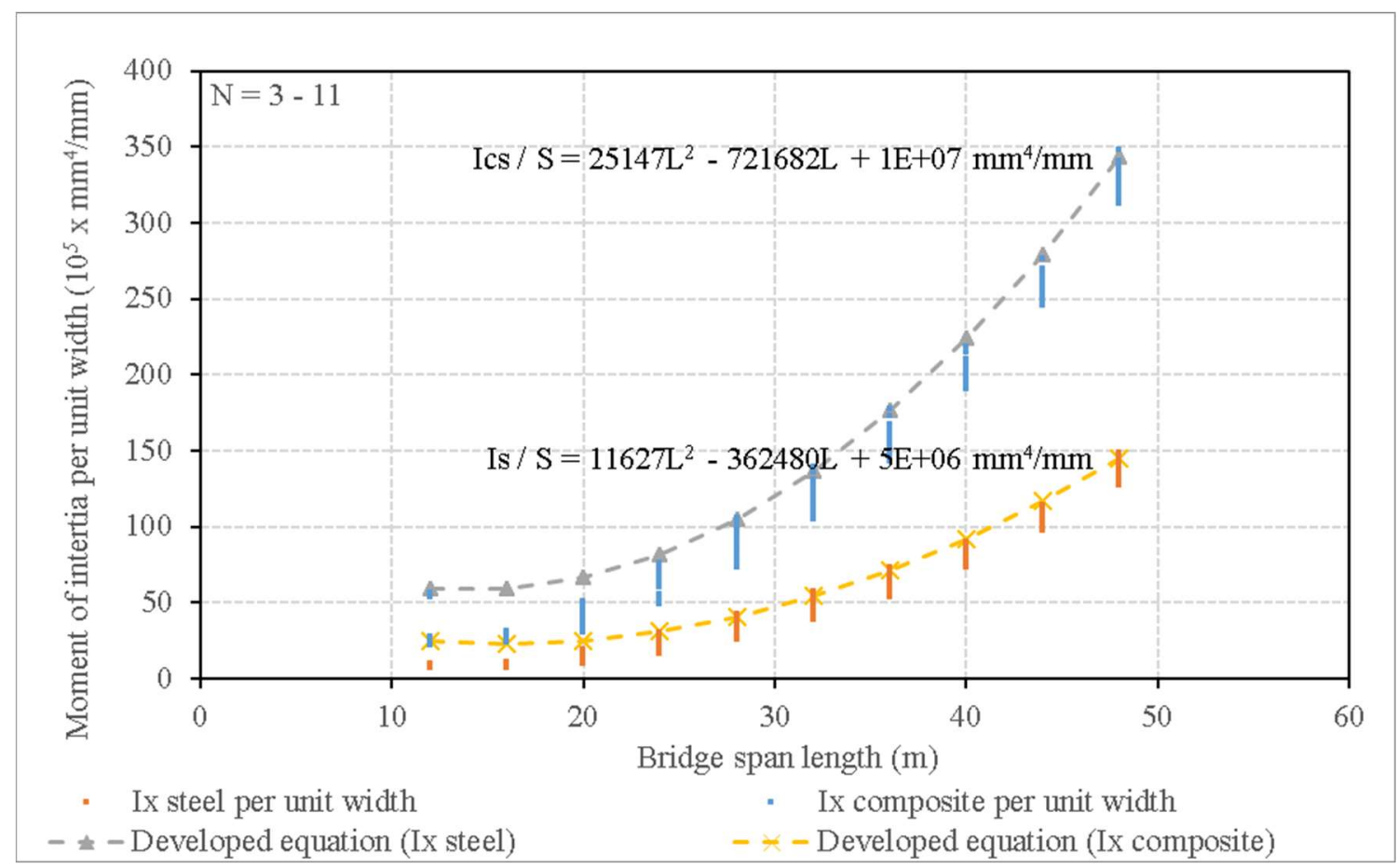

Figure 5.79: Combined envelope for moment of inertia for the steel and the composite concretesteel section per unit width vs span length for single span bridge under CL-625 truck loading between three and eleven girders

$$
\begin{aligned}
& {[5.13] \mathrm{Ics} / \mathrm{S}=25000\left(\mathrm{~L}^{2}\right)-720000(\mathrm{~L})+1 * 10^{7} \mathrm{~mm}^{4} / \mathrm{mm}} \\
& {[5.14] \mathrm{Is} / \mathrm{S}=12000\left(\mathrm{~L}^{2}\right)-360000(\mathrm{~L})+5 * 10^{6} \mathrm{~mm}^{4} / \mathrm{mm}}
\end{aligned}
$$

To study the effect of girder spacing on the area of the web per unit width (Aw/S), a graph showing Aw/S vs span length for different girder spacing values was created. Figure 5.80 shows the results for such analysis. It can be seen that with an increased girder spacing, the Aw/S value decreases. This was taken into account when creating the final equation to represent the area of 
the web. Furthermore, a similar graph was created to study the effect of the number of girders on the web area per unit width. Figure 5.81 shows the graph created. It can be seen that there are overlapping lines in contrast to Figure 5.80. This is due to some cases having different number of girders while having similar spacing. It was concluded from that study that the web area per unit width varies with the spacing regardless of the number of girders. A two-variable equation for the web area per unit width was created to represent that characteristic. The equation can be seen below;

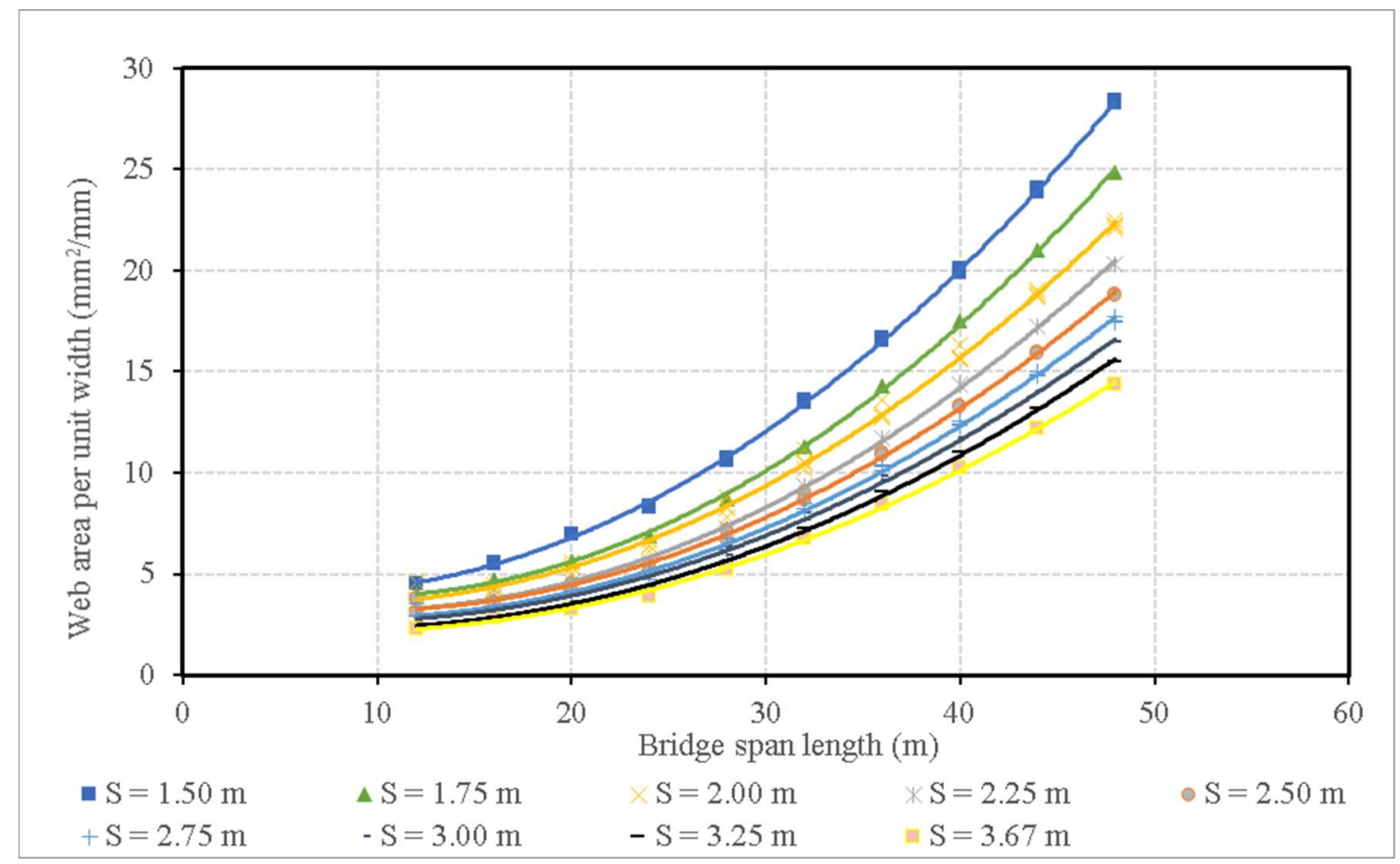

Figure 5.80: Web area per unit width vs span length for single span bridge under CL-625 truck loading with girder spacing ranging between $1.5 \mathrm{~m}$ and $3.67 \mathrm{~m}$ 


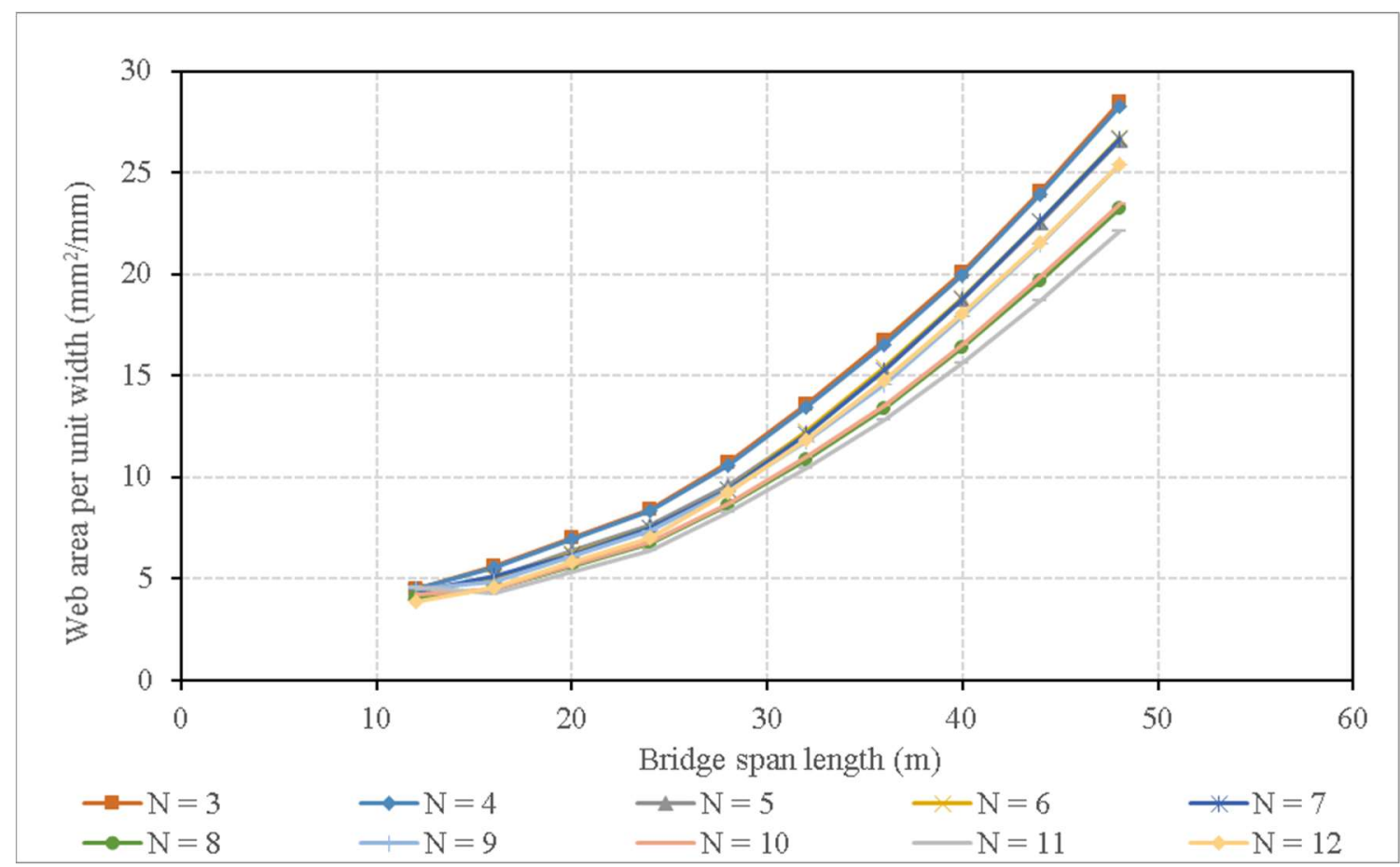

Figure 5.81: Web area per unit width vs span length for single span bridge configurations under CL-625 truck loading ranging between three to twelve girders

$[5.15] \mathrm{Aw} / \mathrm{S}=(0.018-0.029(\mathrm{~S}))\left(\mathrm{L}^{2}\right)-(1.19-0.22(\mathrm{~S}))(\mathrm{L})+5.85-0.91(\mathrm{~S}) \mathrm{mm}^{2} / \mathrm{mm}$

The performance of the equation when compared to the program results can be seen in Figure 5.82. The equation created shows excellent representation while always slightly overestimating the Aw/S required for any given section. 


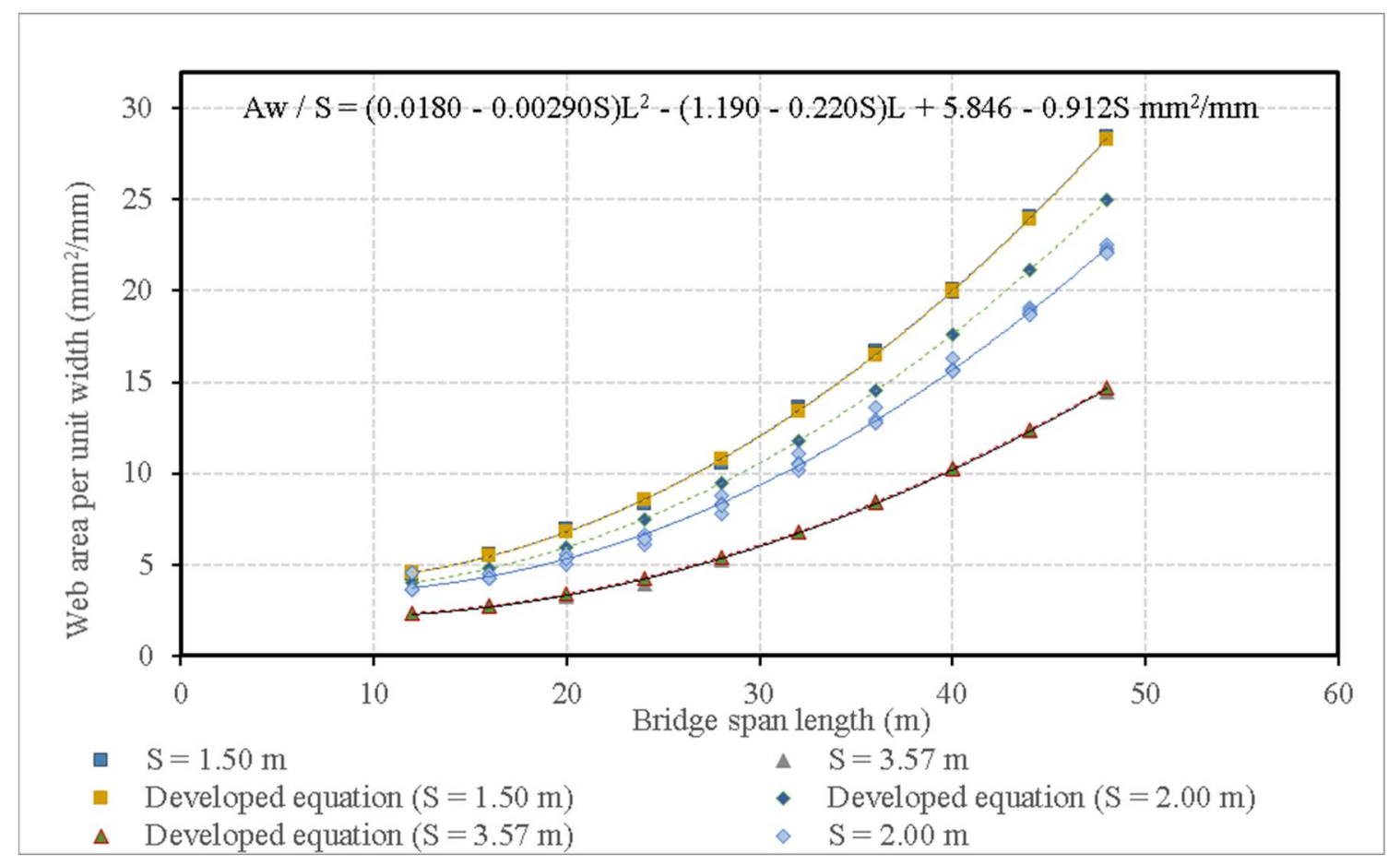

Figure 5.82: Comparison between program results and developed two-variable equation for web area per unit width vs span length for single span bridge under CL-625 truck loading with girder spacing ranging between $1.5 \mathrm{~m}$ and $3.67 \mathrm{~m}$

The difference between the results from a similar previous study conducted by Bakht $\mathrm{B}$. and the results from this study can be seen in Figure 5.83. The longitudinal flexural rigidity (Dx) results in this study show a tighter data distribution between the lower and upper bounds as well as a much lower upper bound and a slightly reduced lower bound for shorter spans (Bakht \& Moses, 1988). It is worth noting that the results from Bakht's study are for the CL-740 truck that was being used in the OHBDC of 1983 (MTO, 1983). Some information is not stated regarding the calculation of the longitudinal flexural rigidity in Bakht's work. However, it is assumed that the concrete used in the 1980s has a lower compressive strength $\left(\mathrm{f}_{\mathrm{c}}\right)$ and is not to the current standards. This might have an effect on the results produced for Dx. 


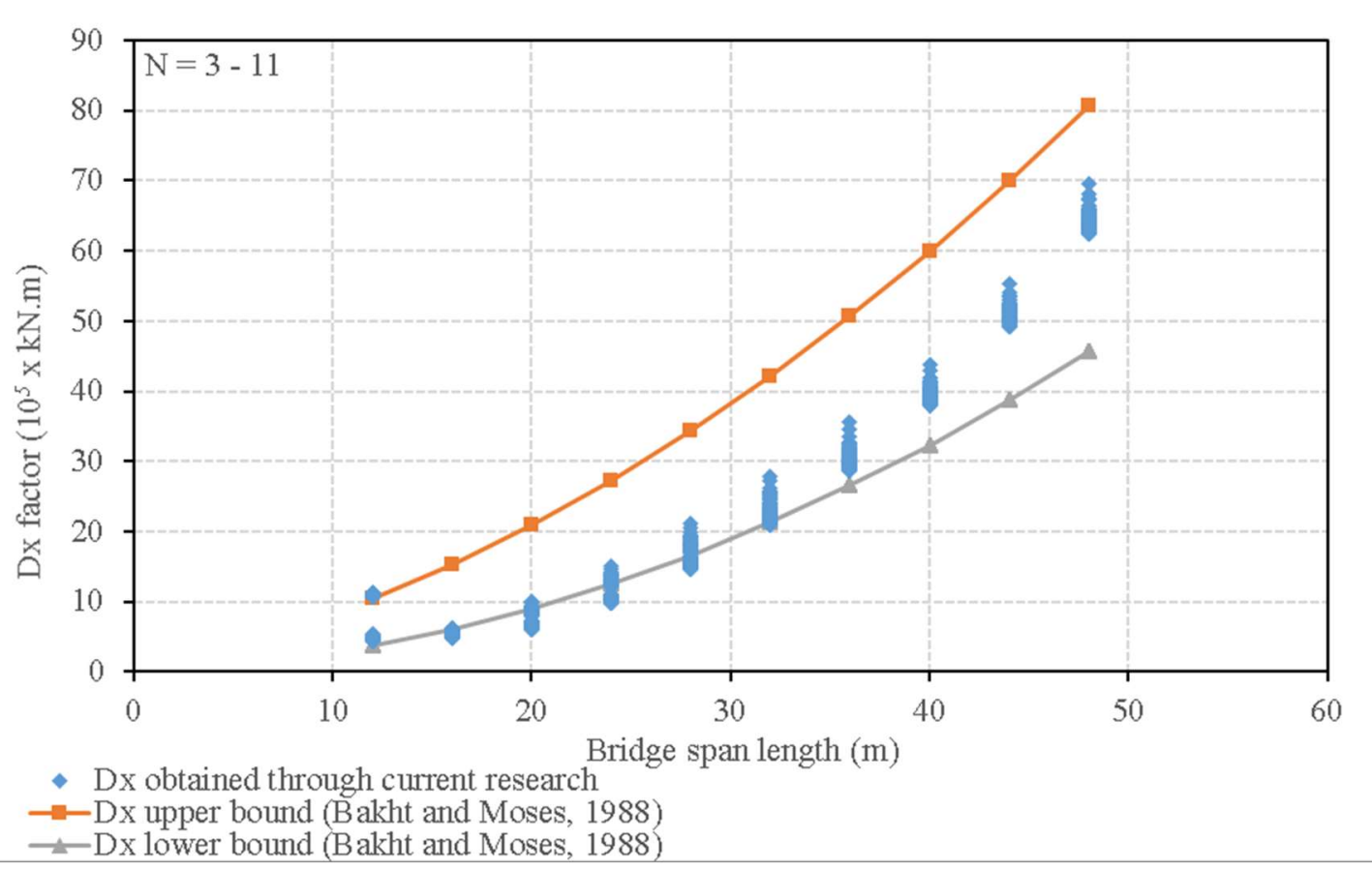

Figure 5.83: Comparison between Dx factor obtained in this research for single span bridge under CL-625 truck loading and the boundary values obtained by Bakht B., and Moses, F (Bakht \& Moses, 1988)

\subsubsection{Bridge configurations under CL-800 truck loading}

Similar to section 5.4 , the case of $\mathrm{N}=12$ was omitted when creating equations to represent the results obtained. Figure 5.84 shows the envelope of the results obtained for both Is and Ics per unit width. The equation representing the moment of inertia per unit width of the steel section and the moment of inertia per unit width of the composite section can be seen below; 


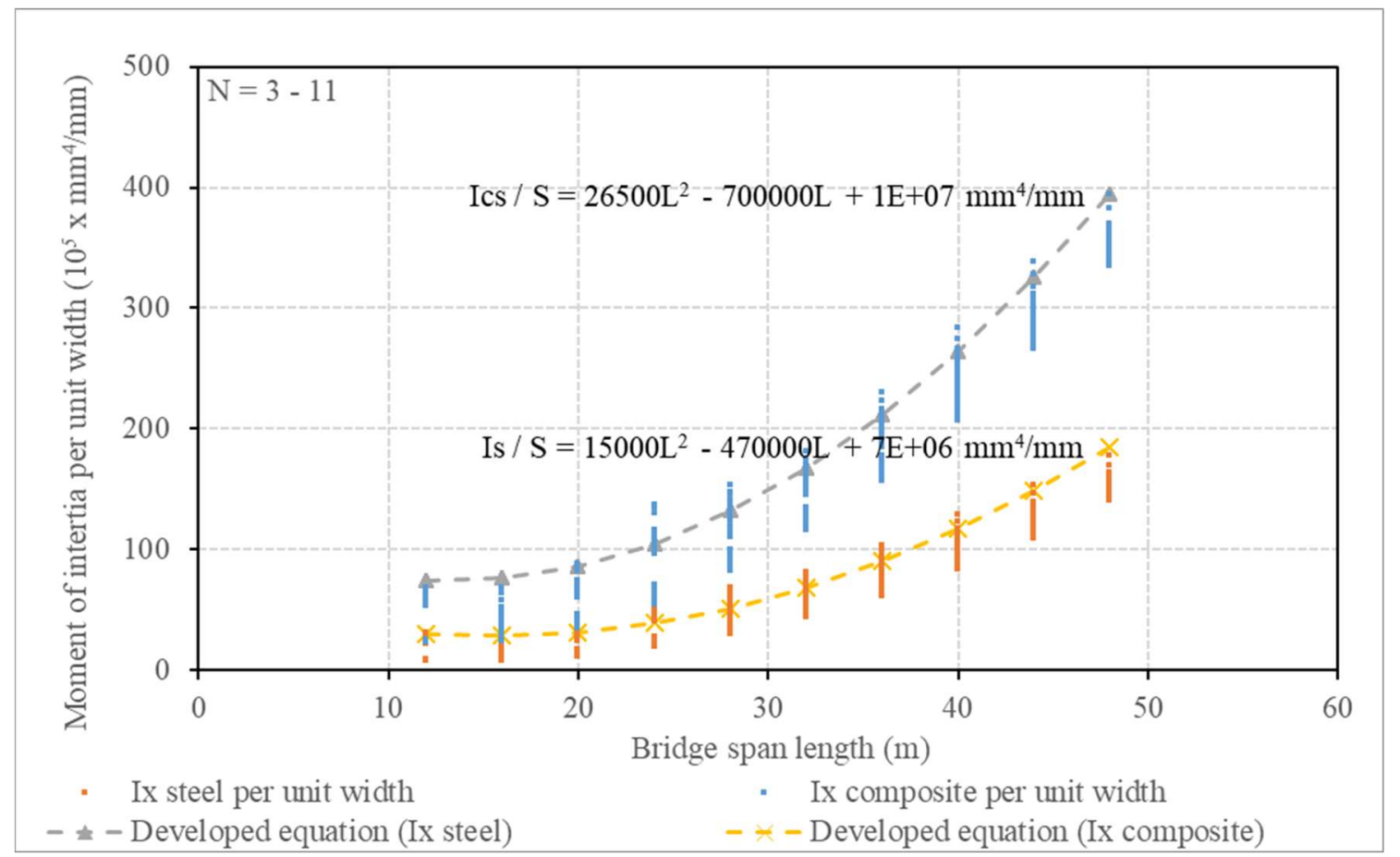

Figure 5.84: Combined envelope for moment of inertia for the steel and the composite concretesteel section per unit width vs span length for single span bridge under CL-800 truck loading between three and eleven girders

$$
\begin{aligned}
& {[5.16] \mathrm{Ics} / \mathrm{S}=26500\left(\mathrm{~L}^{2}\right)-700000(\mathrm{~L})+1 * 10^{7} \mathrm{~mm}^{4} / \mathrm{mm}} \\
& {[5.17] \mathrm{Is} / \mathrm{S}=15000\left(\mathrm{~L}^{2}\right)-470000(\mathrm{~L})+7 * 10^{6} \mathrm{~mm}^{4} / \mathrm{mm}}
\end{aligned}
$$

Based on the results of the study conducted in section 5.4, a graph showing Aw/S vs span length for different girder spacing values was created. Figure 5.85 shows the results for such analysis. A similar distribution to Figure 5.85 can be seen. This behavior was taken into account when creating the final equation to represent the area of the web for this section. A two-variable equation for the web area per unit width was created to represent that characteristic. The equation can be seen below; 


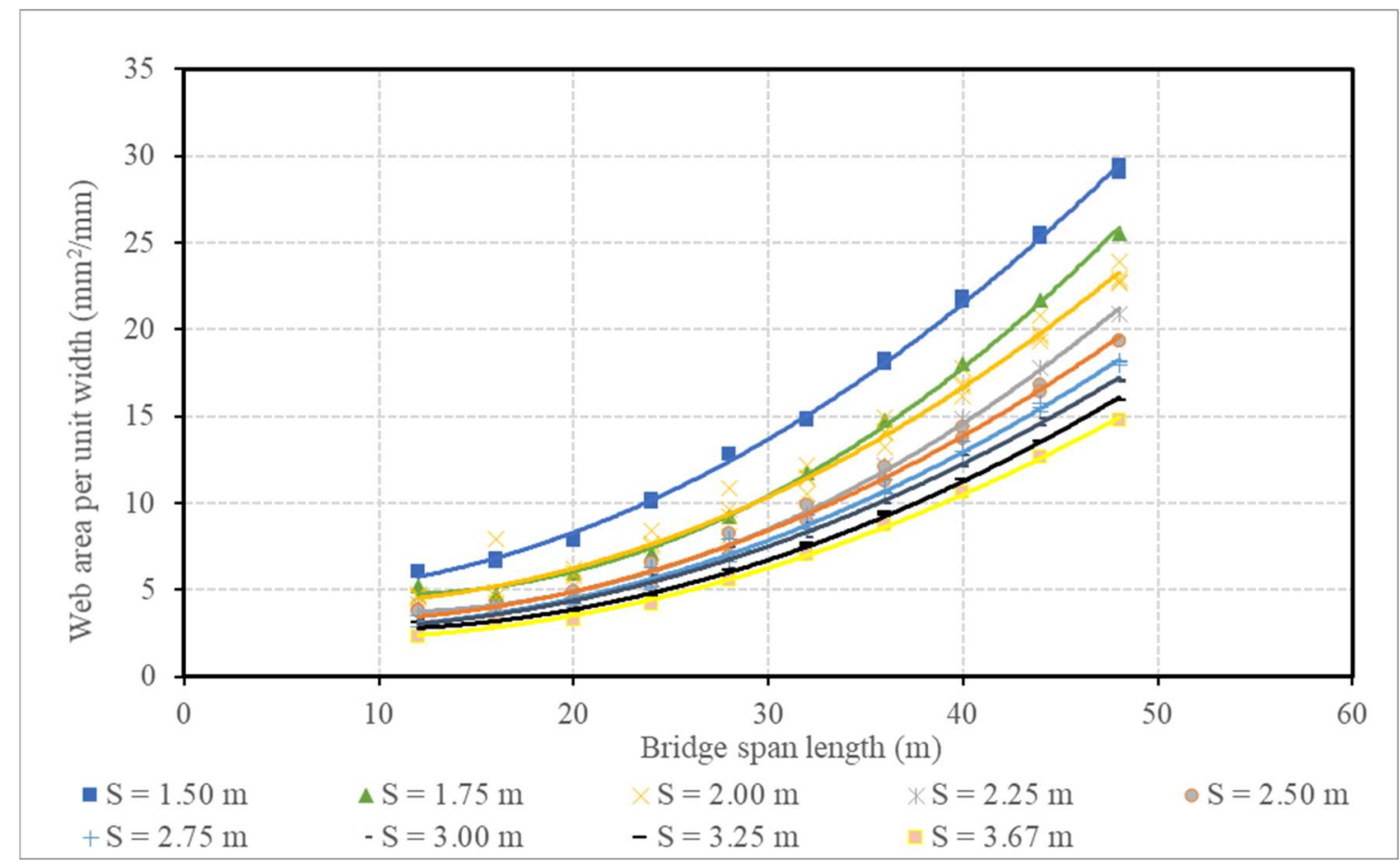

Figure 5.85: Web area per unit width vs span length for single span bridge under CL-800 truck loading with girder spacing ranging between $1.5 \mathrm{~m}$ and $3.67 \mathrm{~m}$

$[5.18] \mathrm{Aw} / \mathrm{S}=(0.0156-0.024(\mathrm{~S}))\left(\mathrm{L}^{2}\right)-(0.0495-0.0 .0126(\mathrm{~S}))(\mathrm{L})+5.00-$ $0.138(\mathrm{~S}) \mathrm{mm}^{2} / \mathrm{mm}$

The performance of the equation when compared to the program results can be seen in Figure 5.86. The equation created shows excellent representation while always slightly overestimating the Aw/S required for any given section. 


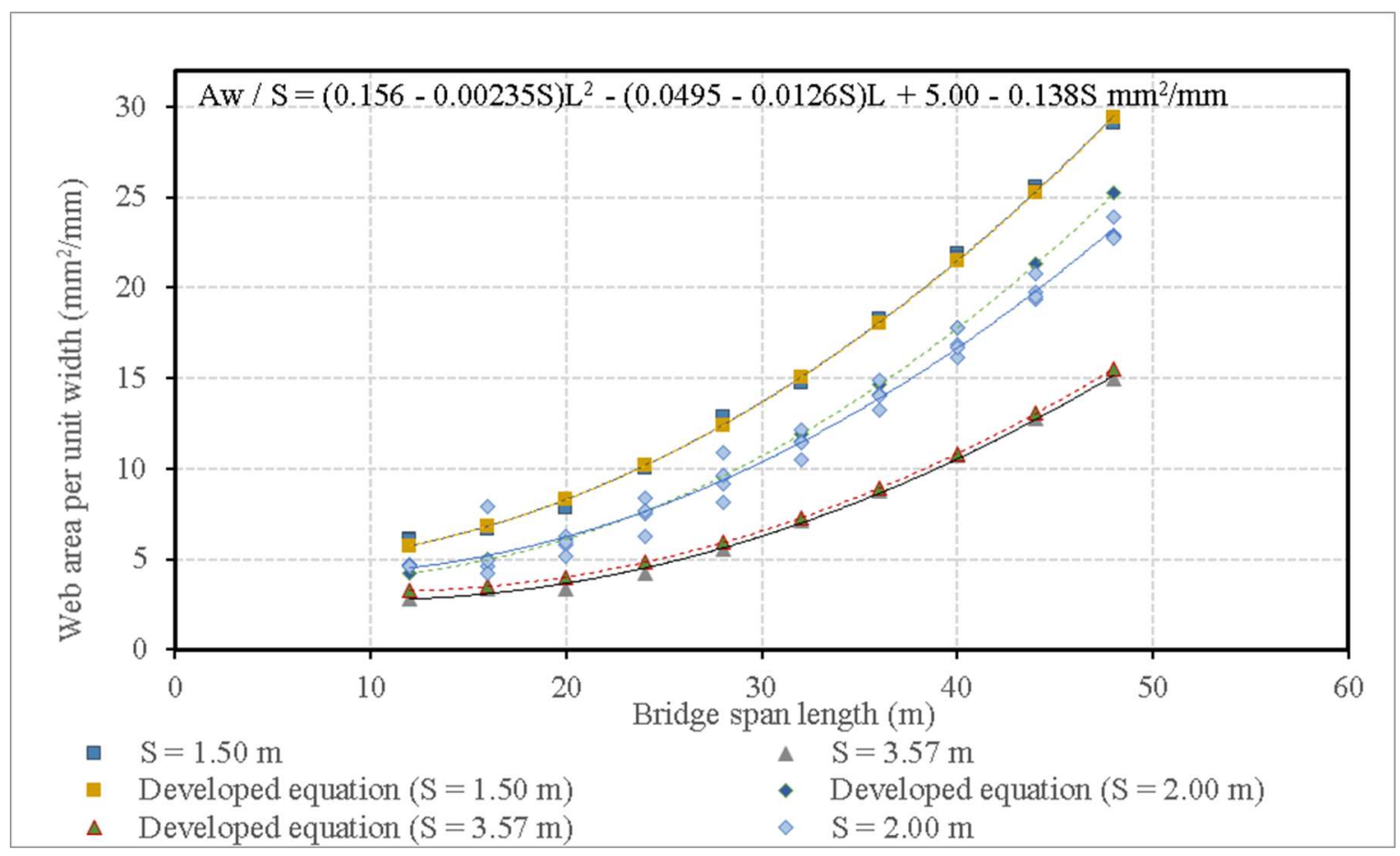

Figure 5.86: Comparison between program results and developed two-variable equation for web area per unit width vs span length for single span bridge under CL-800 truck loading with girder spacing ranging between $1.5 \mathrm{~m}$ and $3.67 \mathrm{~m}$

The difference between the results from a similar previous study conducted by Bakht B. and the results from this study can be seen in Figure 5.87. The longitudinal flexural rigidity (Dx) results in this study show a very similar data distribution between the lower and upper bounds to the results obtained in the previous study (Bakht \& Moses, 1988). It is worth noting that the results from Bakht's study are for the CL-740 truck loading that was being used in the OHBDC of 1983 which is very close in weight to the CL-800 truck loading (MTO, 1983). 


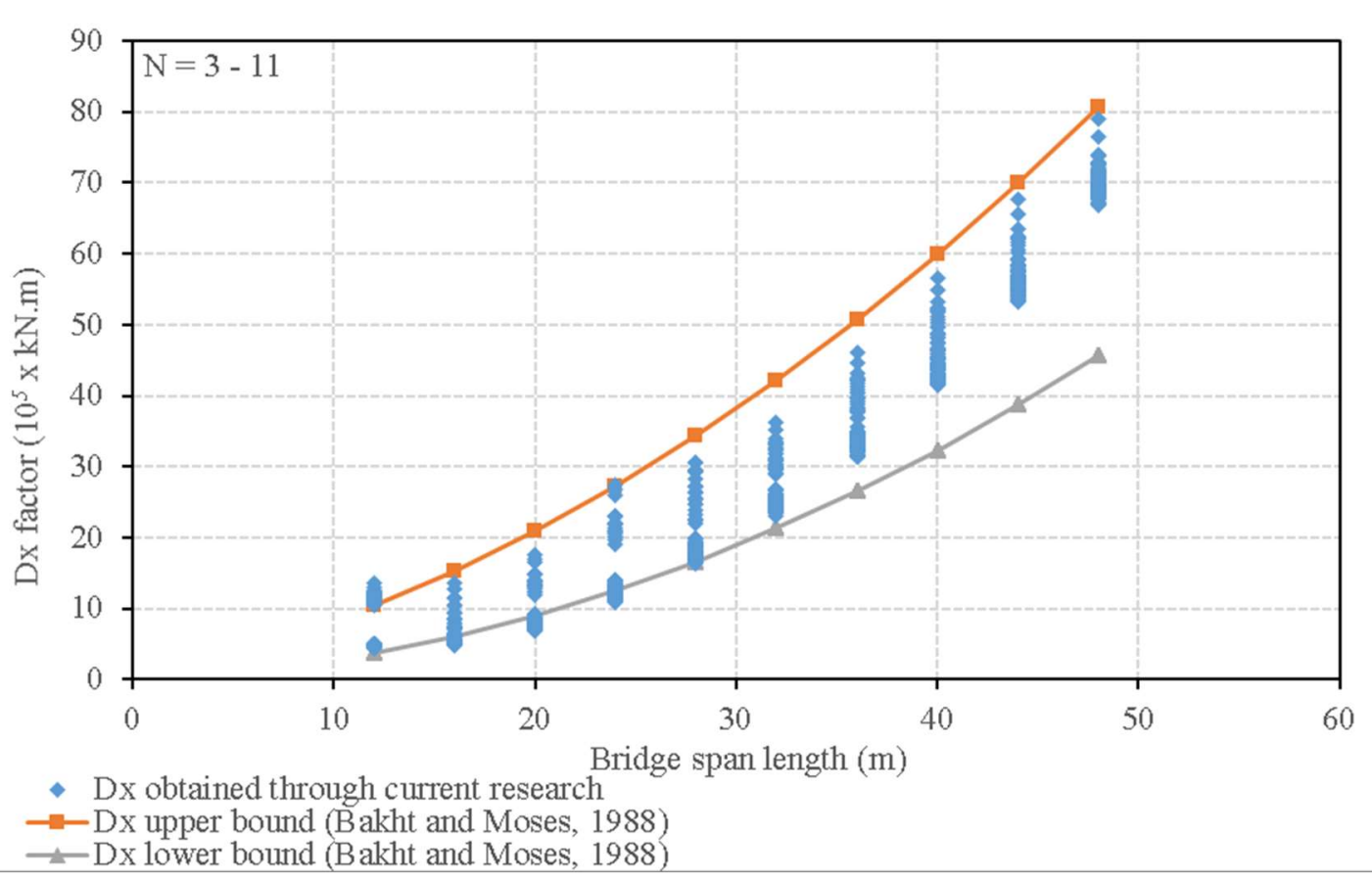

Figure 5.87: Comparison between Dx factor obtained in this research for single span bridge under CL-800 truck loading and the boundary values obtained by Bakht B., and Moses, F (Bakht \& Moses, 1988)

\subsection{Developed equations for two equal span bridge configurations}

\subsubsection{Bridge configurations under CL-625 truck loading}

Considering the results obtained for single span cases, similar results were produced for two equal span bridge configurations. Figure 5.88 shows the envelope of the results obtained for both Is and Ics at support location and Figure 5.89 shows the envelope of the results obtained for both Is and Ics at midspan location. The equations representing the moment of inertia per unit width of the steel section and the moment of inertia per unit width of the composite section can be seen below; 


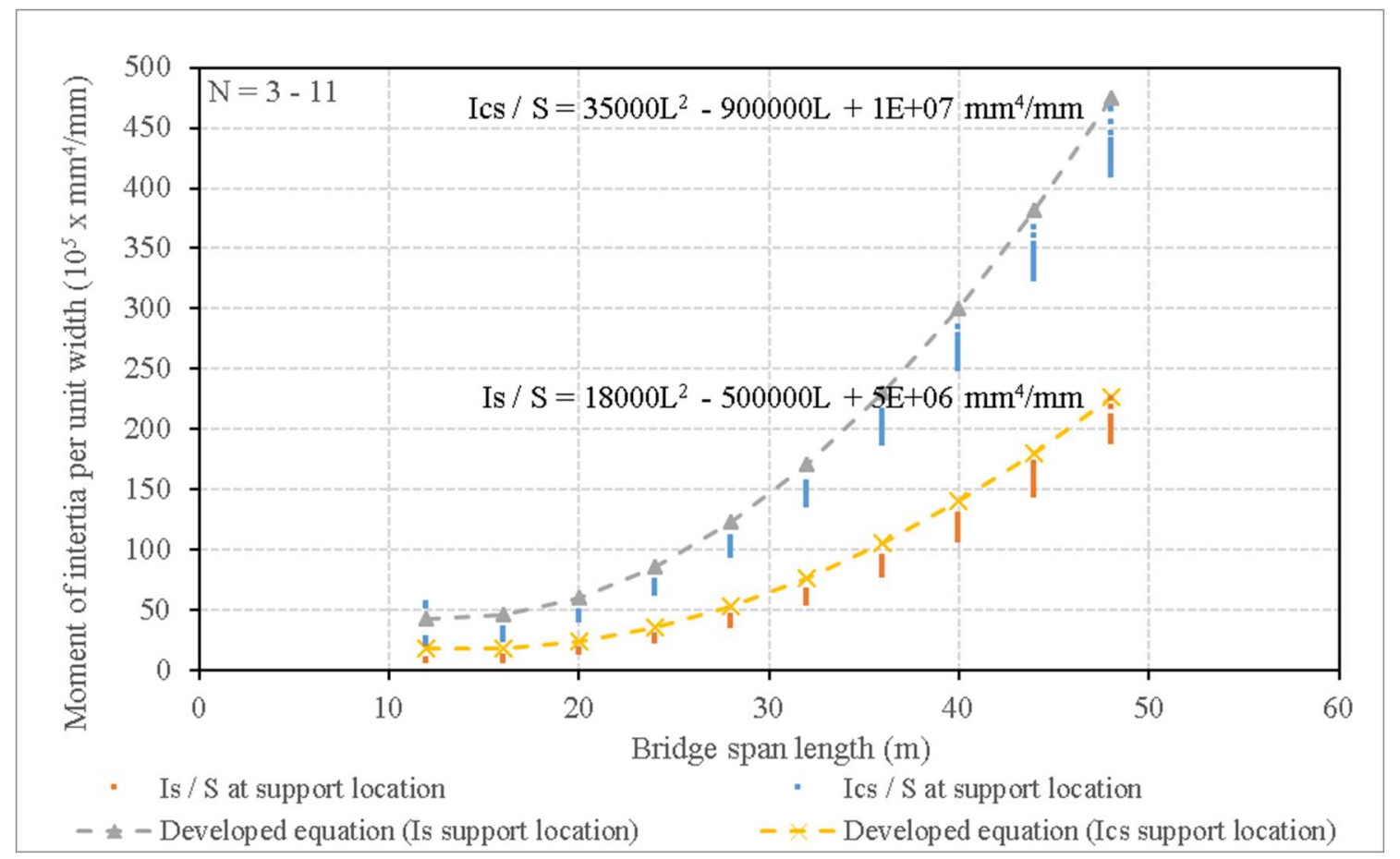

Figure 5.88: Combined envelope for moment of inertia for the steel and the composite concretesteel section per unit width vs span length at support location for two equal span bridge under CL-625 truck loading between three and eleven girders

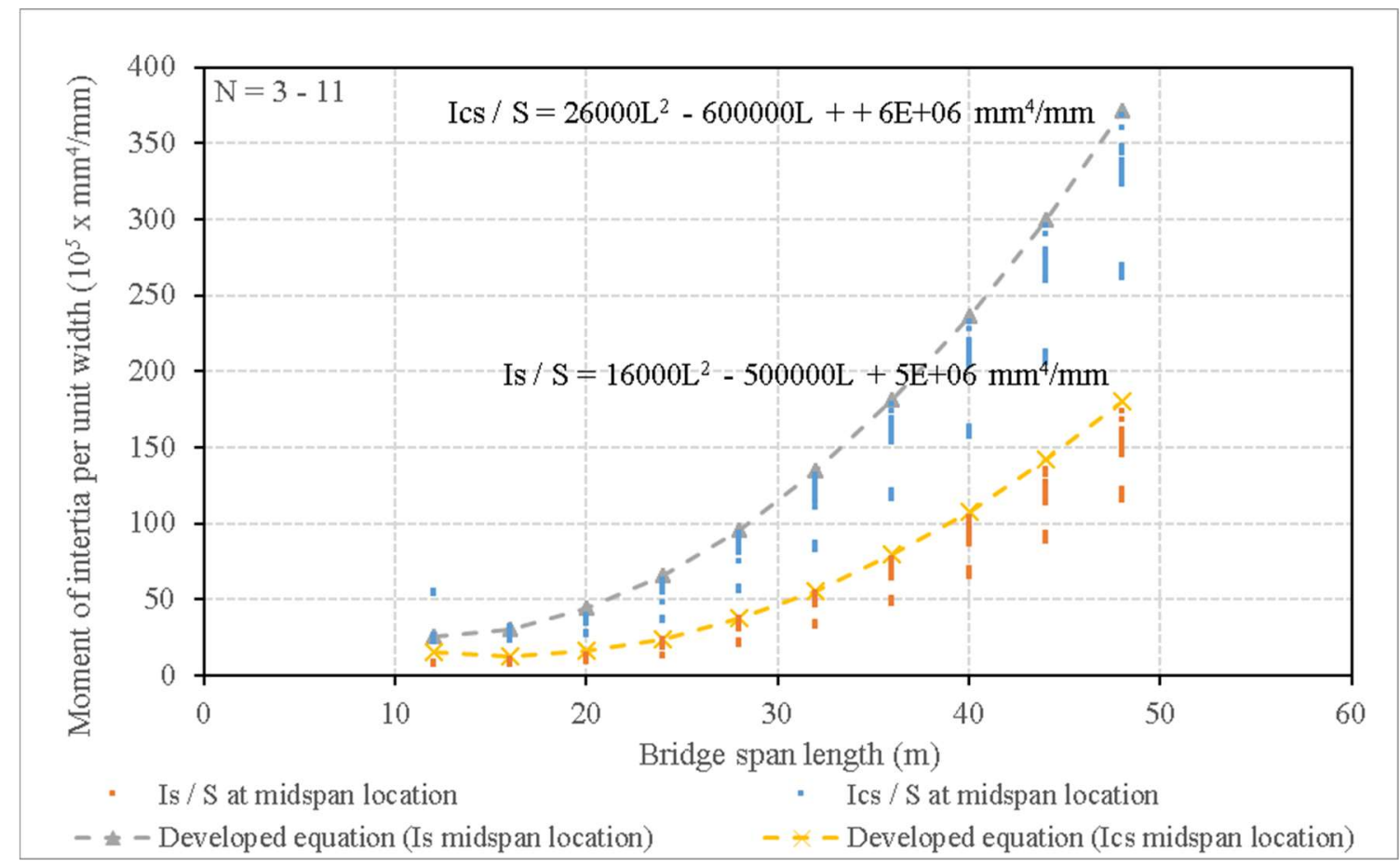

Figure 5.89: Combined envelope for moment of inertia for the steel and the composite concretesteel section per unit width vs span length at midspan location for two equal span bridge under CL-625 truck loading between three and eleven girders 
[5.19] Ics $/ \mathrm{S}=35000\left(\mathrm{~L}^{2}\right)-900000(\mathrm{~L})+1 * 10^{7} \mathrm{~mm}^{4} / \mathrm{mm}$

$[5.20] \mathrm{Is} / \mathrm{S}=18000\left(\mathrm{~L}^{2}\right)-500000(\mathrm{~L})+5 * 10^{6} \mathrm{~mm}^{4} / \mathrm{mm}$

$[5.21] \mathrm{Ics} / \mathrm{S}=26000\left(\mathrm{~L}^{2}\right)-600000(\mathrm{~L})+6 * 10^{6} \mathrm{~mm}^{4} / \mathrm{mm}$

[5.22] Is $/ \mathrm{S}=16000\left(\mathrm{~L}^{2}\right)-500000(\mathrm{~L})+5 * 10^{6} \mathrm{~mm}^{4} / \mathrm{mm}$ at support location at support location at midspan location at midspan location

Based on the results of the study conducted in section 5.4, a graph showing Aw/S vs span length for different girder spacing values was created. Figure 5.90 shows the results for such analysis. A similar distribution to Figure 5.85 can be seen. This behavior was taken into account when creating the final equation to represent the area of the web for this section. A similar twovariable equation for the web area per unit width was created to represent that characteristic. The equation can be seen below;

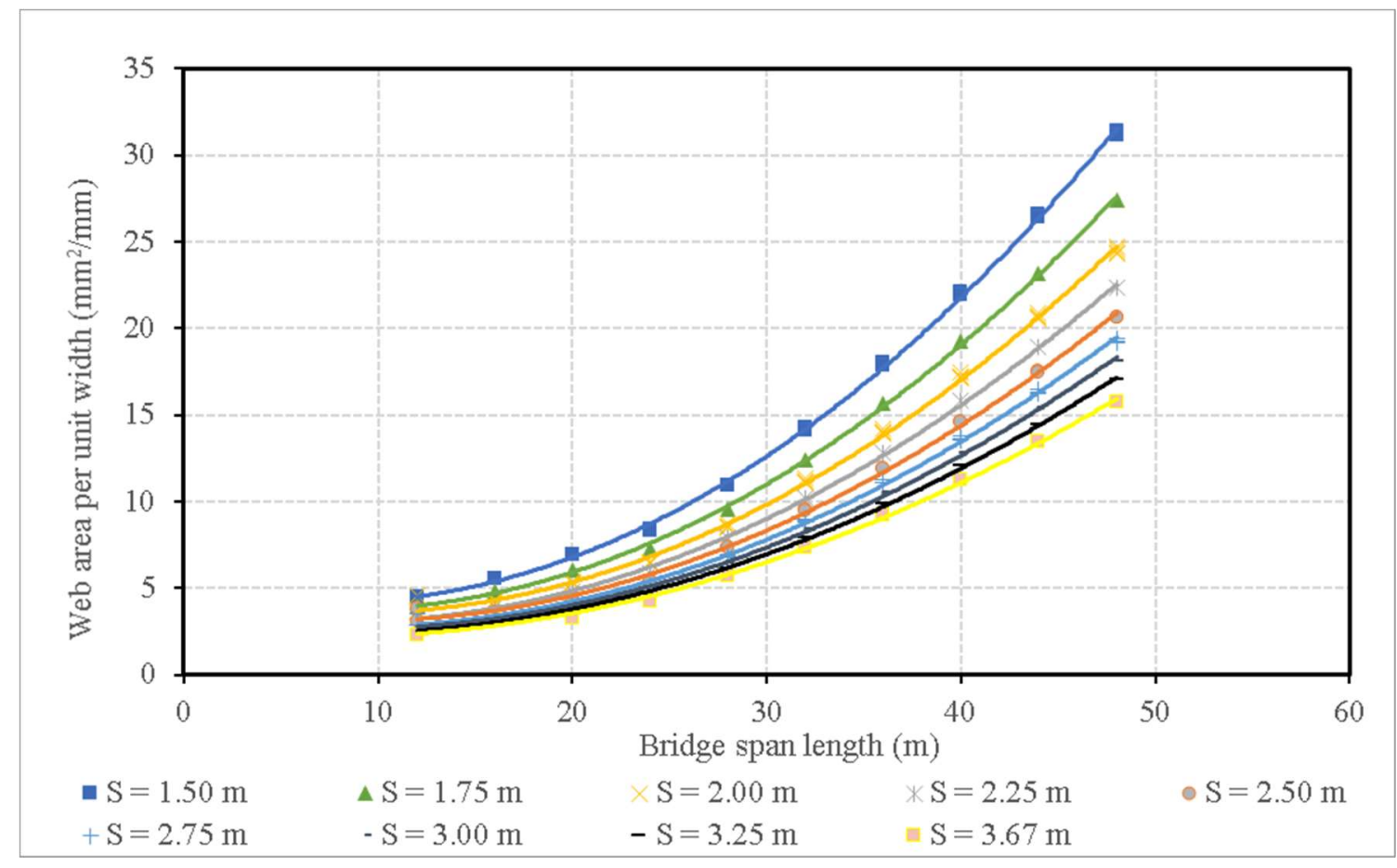

Figure 5.90: Web area per unit width vs span length for two equal span bridge under CL-625 truck loading with girder spacing ranging between $1.5 \mathrm{~m}$ and $3.67 \mathrm{~m}$

$[5.23] \mathrm{Aw} / \mathrm{S}=(0.021-0.029(\mathrm{~S}))\left(\mathrm{L}^{2}\right)-(0.32-0.046(\mathrm{~S}))(\mathrm{L})+7.00-1.25(\mathrm{~S}) \mathrm{mm}^{2} /$ $\mathrm{mm}$ 
The performance of the equation when compared to the program results can be seen in Figure 5.91. The equation created shows excellent representation while always slightly overestimating the Aw/S required for any given section.

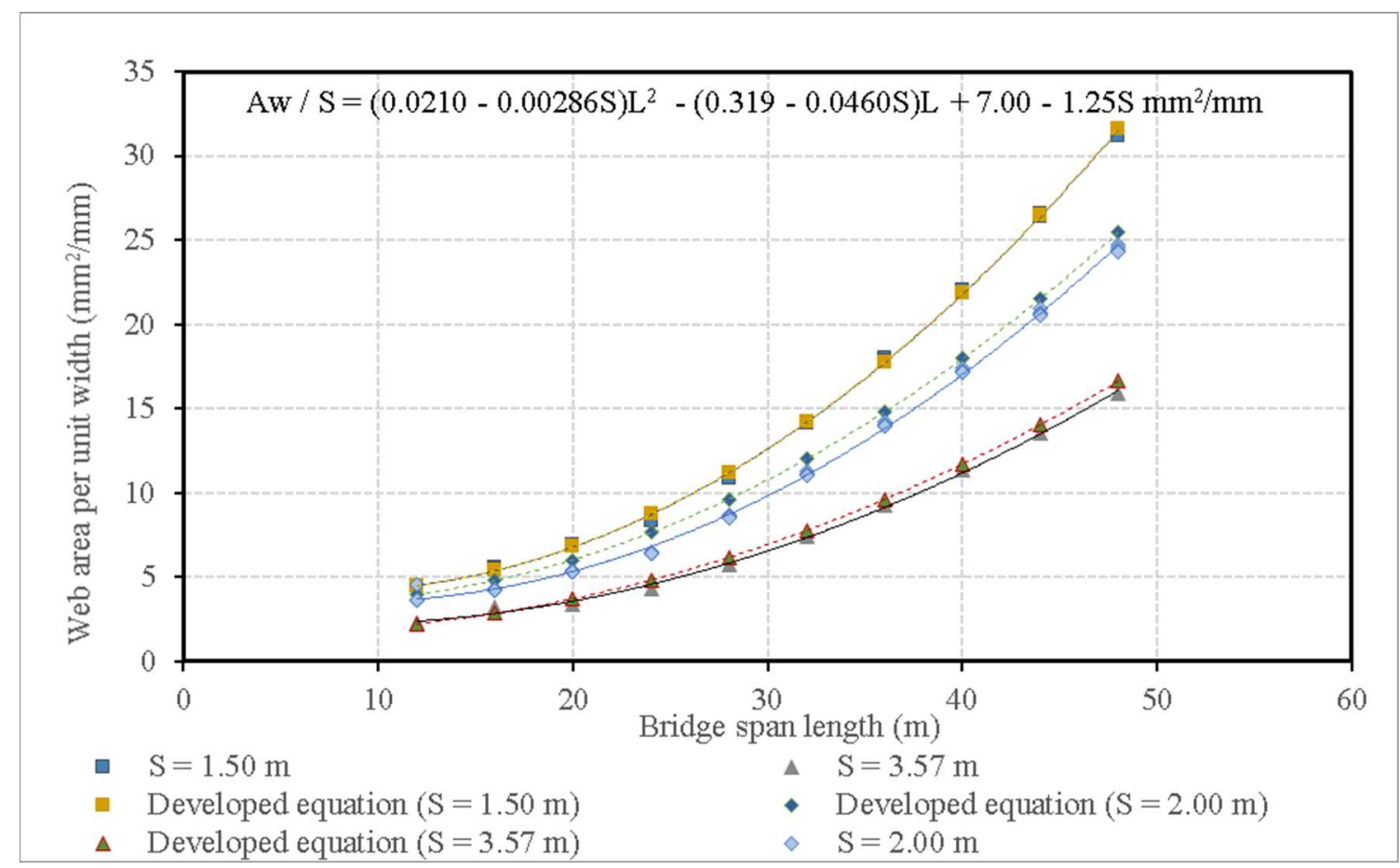

Figure 5.91: Comparison between program results and developed two-variable equation for web area per unit width vs span length for two equal span bridge under CL-625 truck loading with girder spacing ranging between $1.5 \mathrm{~m}$ and $3.67 \mathrm{~m}$

The difference between the results from a similar previous study conducted by Bakht B. and the results from this study can be seen in Figures 5.92 and 5.93 for support location and midspan location respectively. The longitudinal flexural rigidity (Dx) results in this study show a higher upper bound for support locations for longer spans due to these equations being developed by Bakht B. for midspan location for single span bridge configurations (Bakht \& Moses, 1988). However, the results produced for midspan show a much better distribution when compared to the values obtained in the previous study as expected. It is worth noting that the results from Bakht's study are for the CL-740 truck that was being used in the OHBDC of 1983 (MTO, 1983) while in this portion of the study the CL-625 is used. 


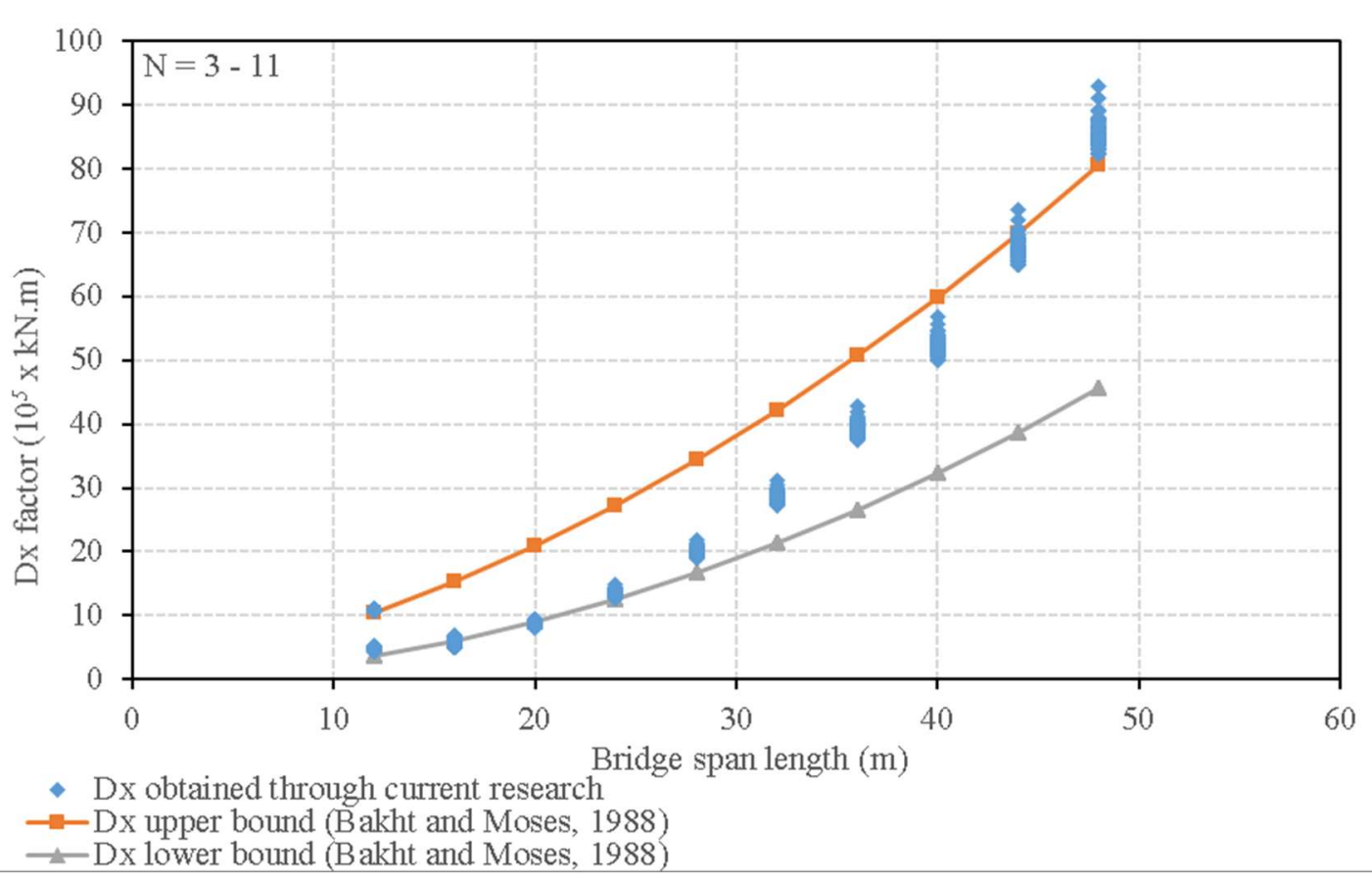

Figure 5.92: Comparison between Dx factor at support location obtained in this research for two equal span bridge under CL- 625 truck loading and the boundary values obtained by Bakht B., and Moses, F (Bakht \& Moses, 1988)

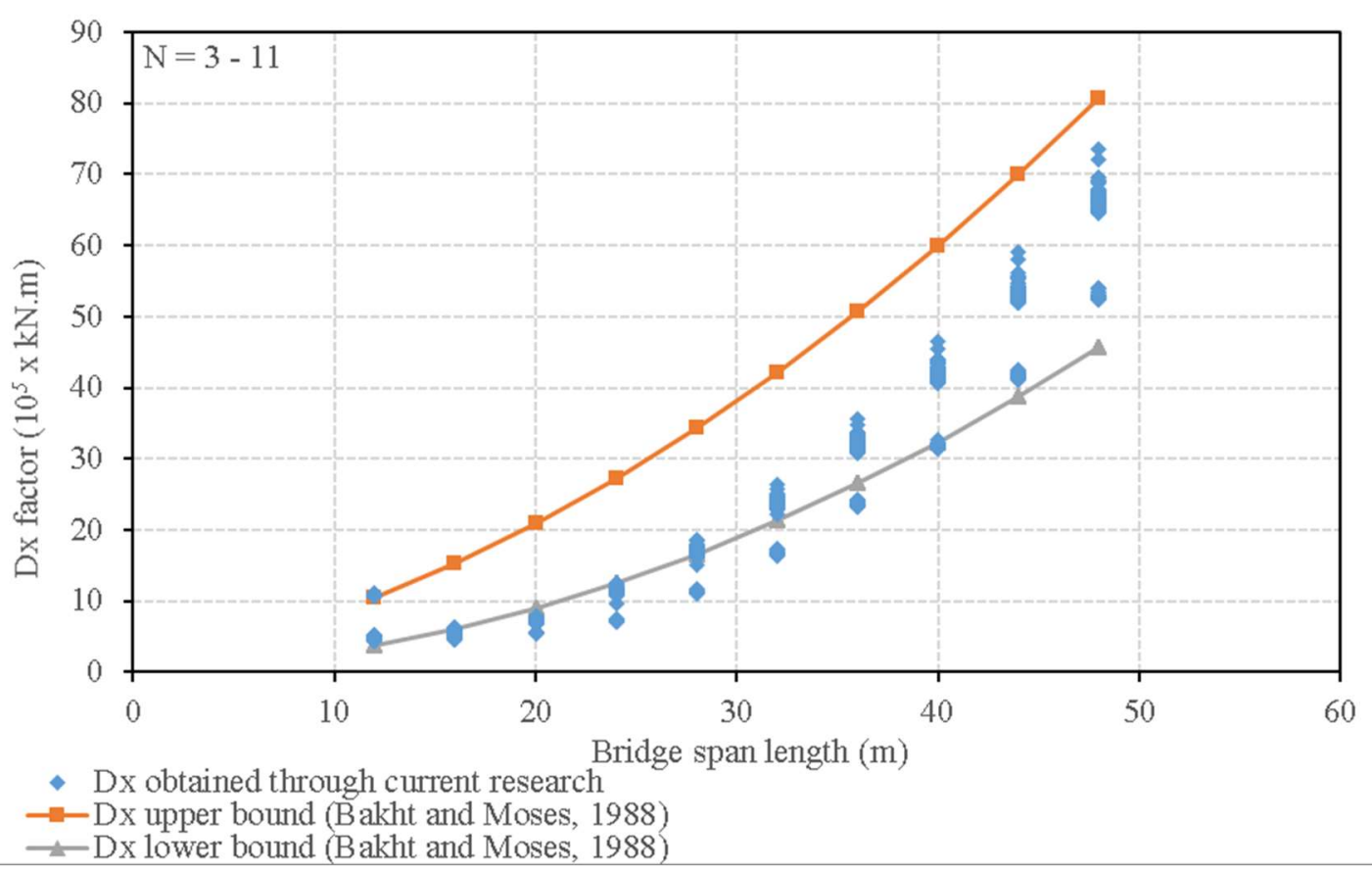

Figure 5.93: Comparison between Dx factor at midspan location obtained in this research for two equal span bridge under CL- 625 truck loading and the boundary values obtained by Bakht B., and Moses, F (Bakht \& Moses, 1988) 


\subsubsection{Bridge configurations under CL-800 truck loading}

Considering the results obtained for single span cases for the CL-625 truck, similar results were produced for two equal span bridge configurations. Figure 5.94 shows the envelope of the results obtained for both Is and Ics at support location and Figure 5.95 shows the envelope of the results obtained for both Is and Ics at midspan location. The equations representing the moment of inertia per unit width of the steel section and the moment of inertia per unit width of the composite section can be seen below;

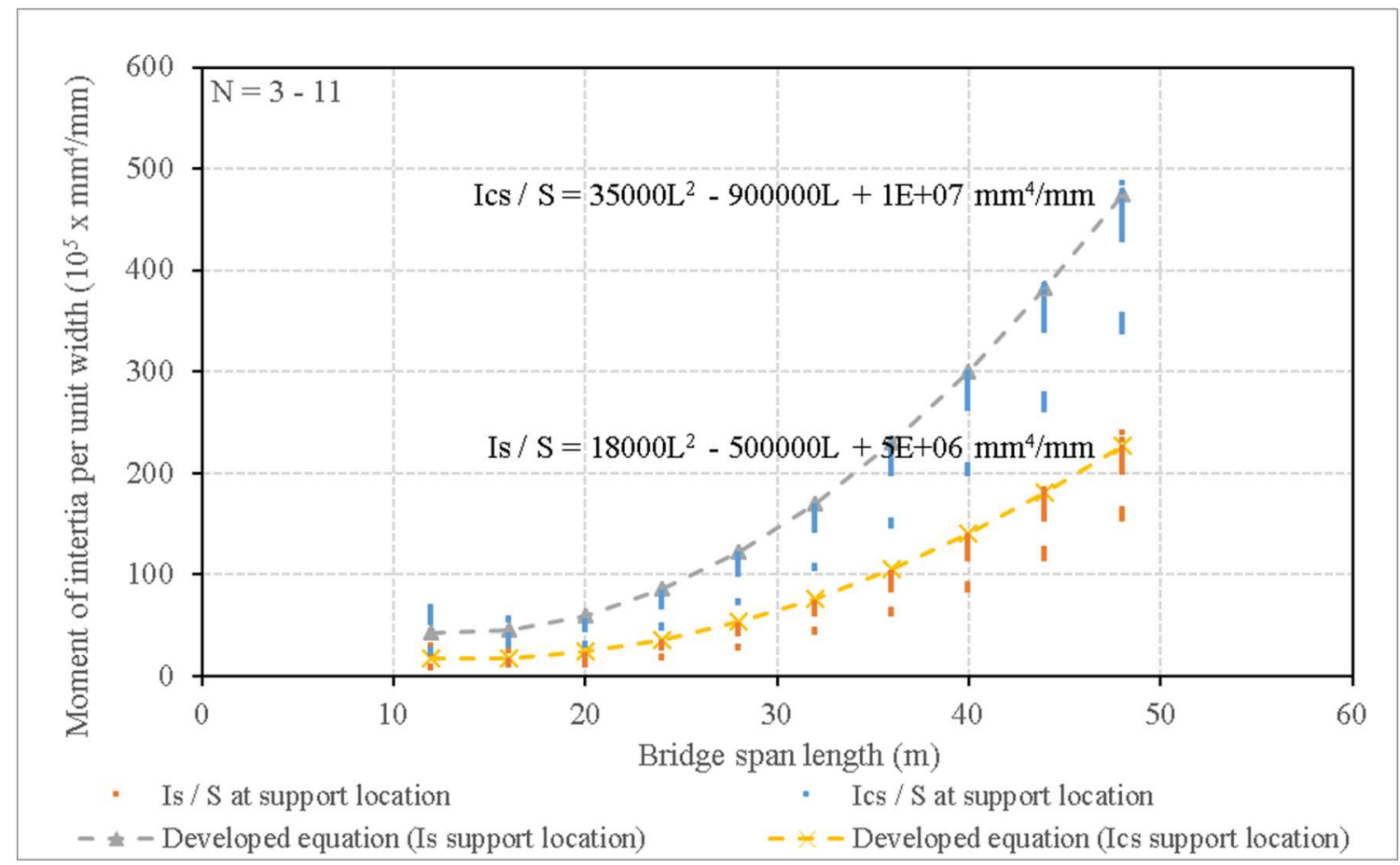

Figure 5.94: Combined envelope for moment of inertia for the steel and the composite concretesteel section per unit width vs span length at support location for two equal span bridge under CL-800 truck loading between three and eleven girders 


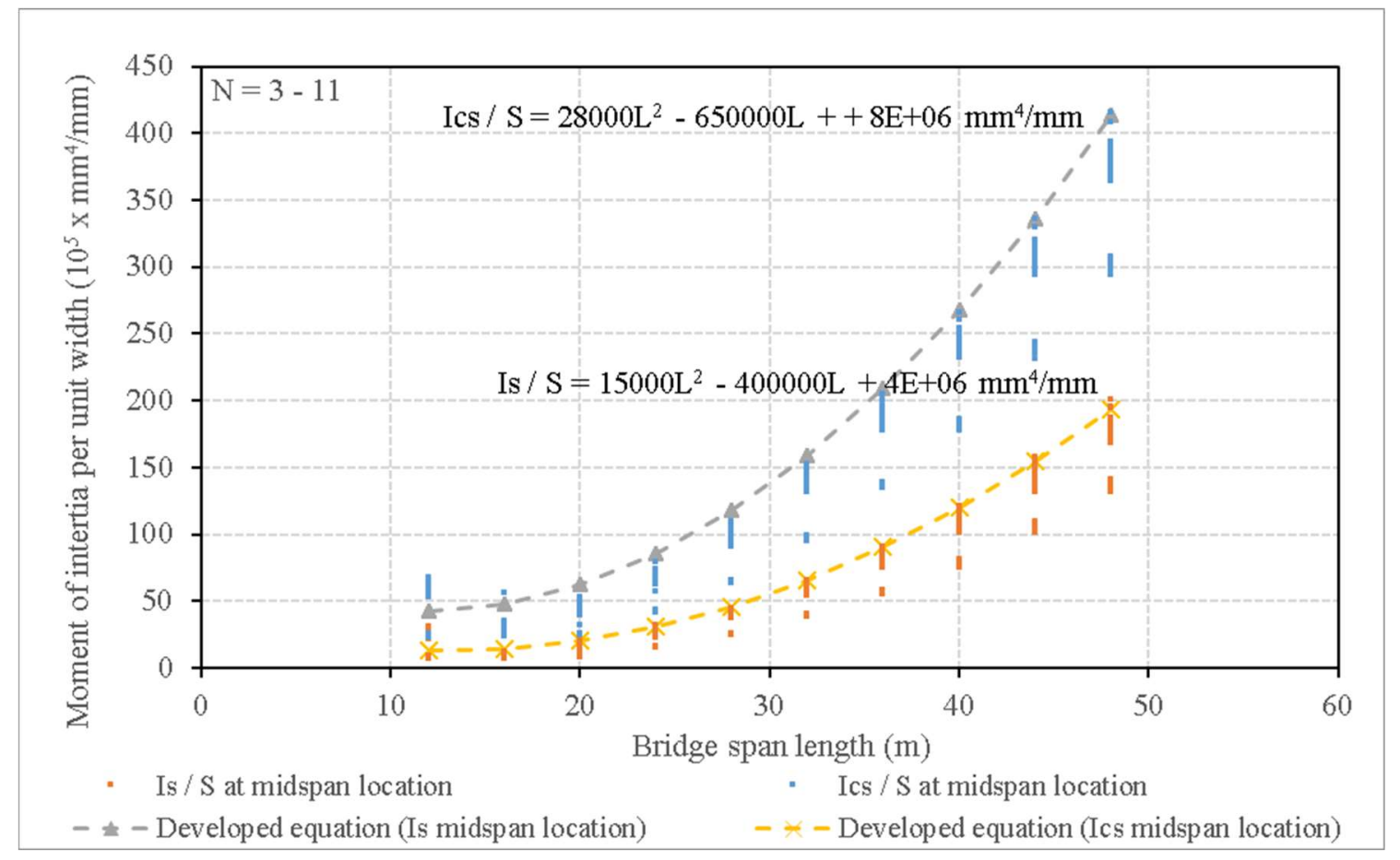

Figure 5.95: Combined envelope for moment of inertia for the steel and the composite concretesteel section per unit width vs span length at midspan location for two equal span bridge under CL-800 truck loading between three and eleven girders

$$
\begin{array}{ll}
{[5.24] \text { Ics } / \mathrm{S}=35000\left(\mathrm{~L}^{2}\right)-900000(\mathrm{~L})+1 * 10^{7} \mathrm{~mm}^{4} / \mathrm{mm}} & \text { at support location } \\
{[5.25] \mathrm{Is} / \mathrm{S}=18000\left(\mathrm{~L}^{2}\right)-500000(\mathrm{~L})+5 * 10^{6} \mathrm{~mm}^{4} / \mathrm{mm}} & \text { at support location } \\
{[5.26] \mathrm{Ics} / \mathrm{S}=28000\left(\mathrm{~L}^{2}\right)-650000(\mathrm{~L})+8 * 10^{6} \mathrm{~mm}^{4} / \mathrm{mm}} & \text { at midspan location } \\
{[5.27] \mathrm{Is} / \mathrm{S}=15000\left(\mathrm{~L}^{2}\right)-400000(\mathrm{~L})+4 * 10^{6} \mathrm{~mm}^{4} / \mathrm{mm}} & \text { at midspan location }
\end{array}
$$

Based on the results of the study conducted in section 5.4, a graph showing Aw/S vs span length for different girder spacing values was created. Figure 5.96 shows the results for such analysis. A similar distribution to Figure 5.85 can be seen. This behavior was taken into account when creating the final equation to represent the area of the web for this section. A similar twovariable equation for the web area per unit width was created to represent that characteristic. The equation can be seen below; 


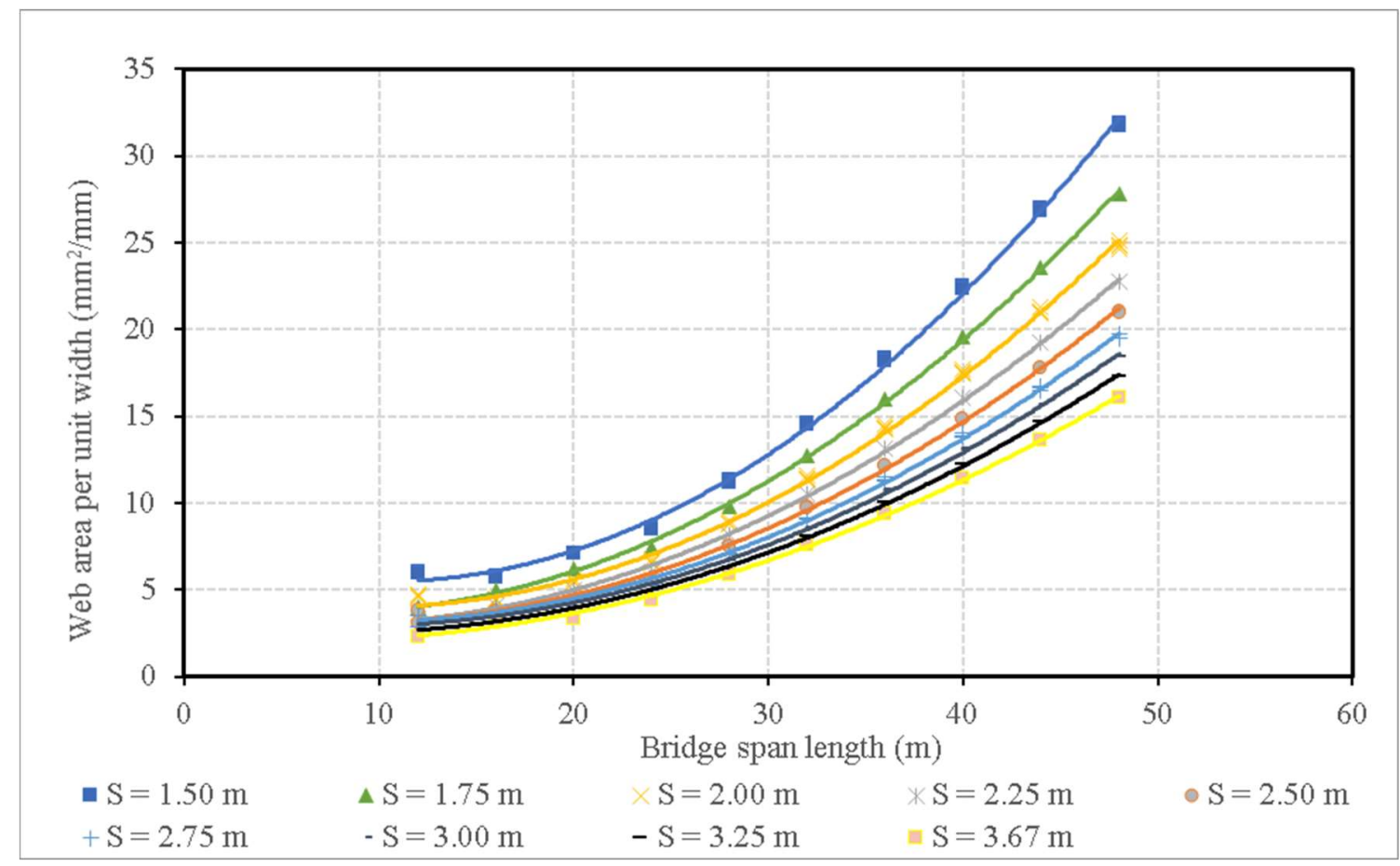

Figure 5.96: Web area per unit width vs span length for two equal span bridge under CL-800 truck loading with girder spacing ranging between $1.5 \mathrm{~m}$ and $3.67 \mathrm{~m}$

$[5.28] \mathrm{Aw} / \mathrm{S}=(0.024-0.036(\mathrm{~S}))\left(\mathrm{L}^{2}\right)-(0.51-0.085(\mathrm{~S}))(\mathrm{L})+9.83-1.59(\mathrm{~S}) \mathrm{mm}^{2} /$ $\mathrm{mm}$

The performance of the equation when compared to the program results can be seen in Figure 5.97. The equation created shows excellent representation while always slightly overestimating the Aw/S required for any given section. 


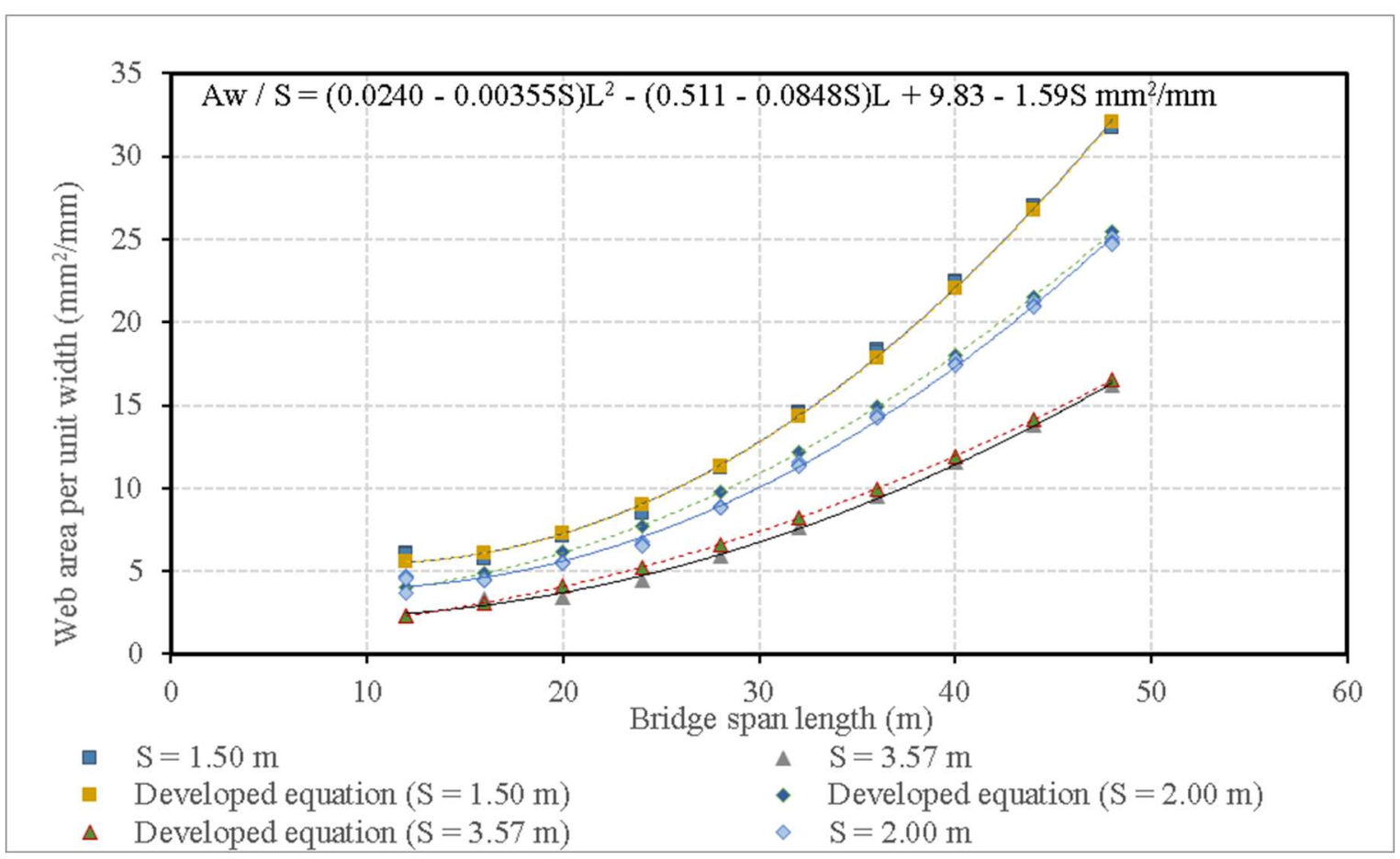

Figure 5.97: Comparison between program results and developed two-variable equation for web area per unit width vs span length for two equal span bridge under CL-800 truck loading with girder spacing ranging between $1.5 \mathrm{~m}$ and $3.67 \mathrm{~m}$

The difference between the results from a similar previous study conducted by Bakht B. and the results from this study can be seen in Figures 5.98 and 5.99 for support location and midspan location respectively. The longitudinal flexural rigidity (Dx) results in this study show a higher upper bound for support locations for longer spans due to these equations being developed by Bakht B. for midspan location for single span bridge configurations (Bakht \& Moses, 1988). However, the results produced for midspan show a much better distribution when compared to the values obtained in the previous study as expected. It is worth noting that the results from Bakht's study are for the CL-740 truck that was being used in the OHBDC of 1983 (MTO, 1983) while in this portion of the study the CL-800 is used which is very similar in weight to the CL740 truck loading. 


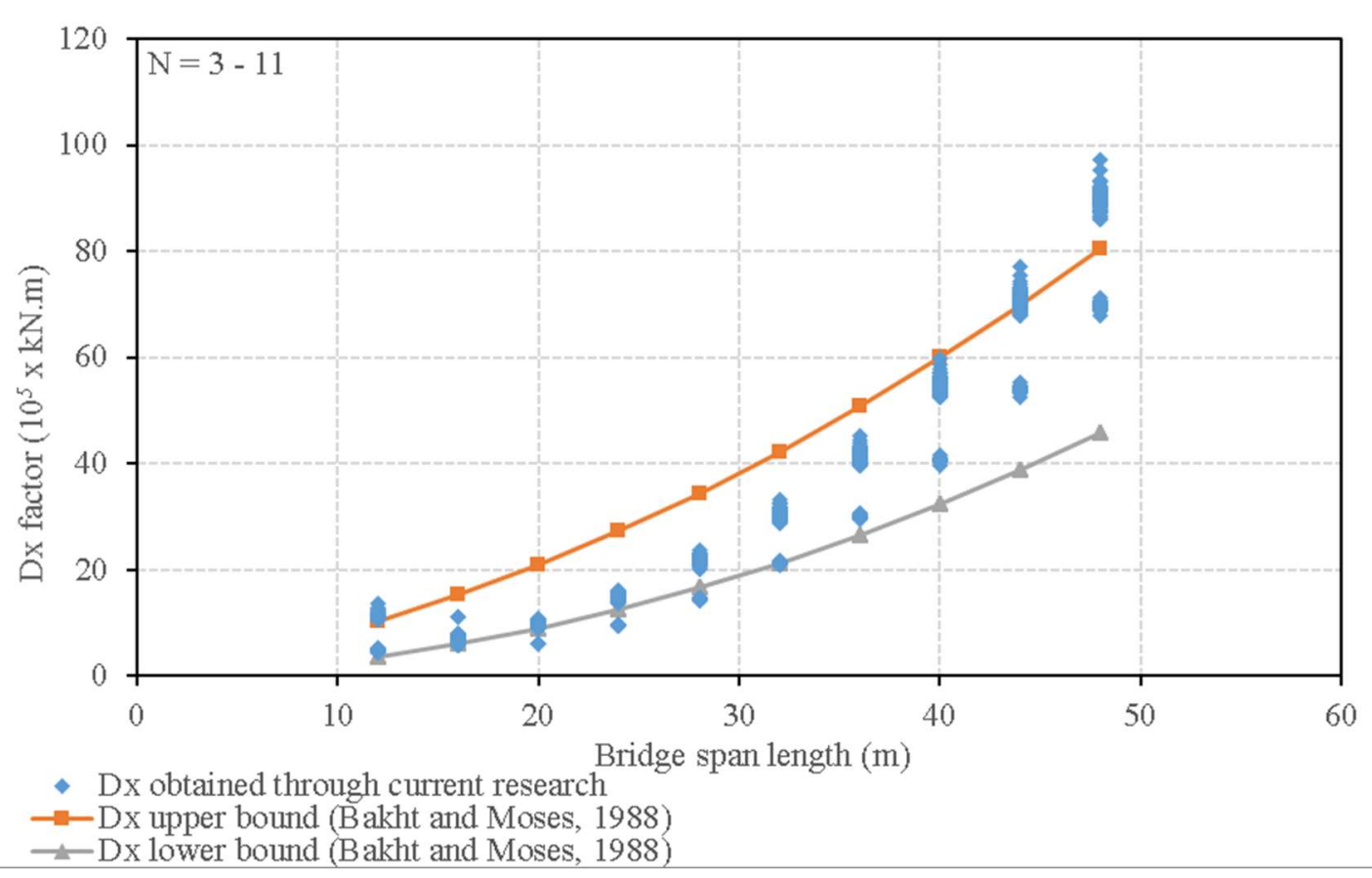

Figure 5.98: Comparison between Dx factor at support location obtained in this research for two equal span bridge under CL-800 truck loading and the boundary values obtained by Bakht B., and Moses, F (Bakht \& Moses, 1988)

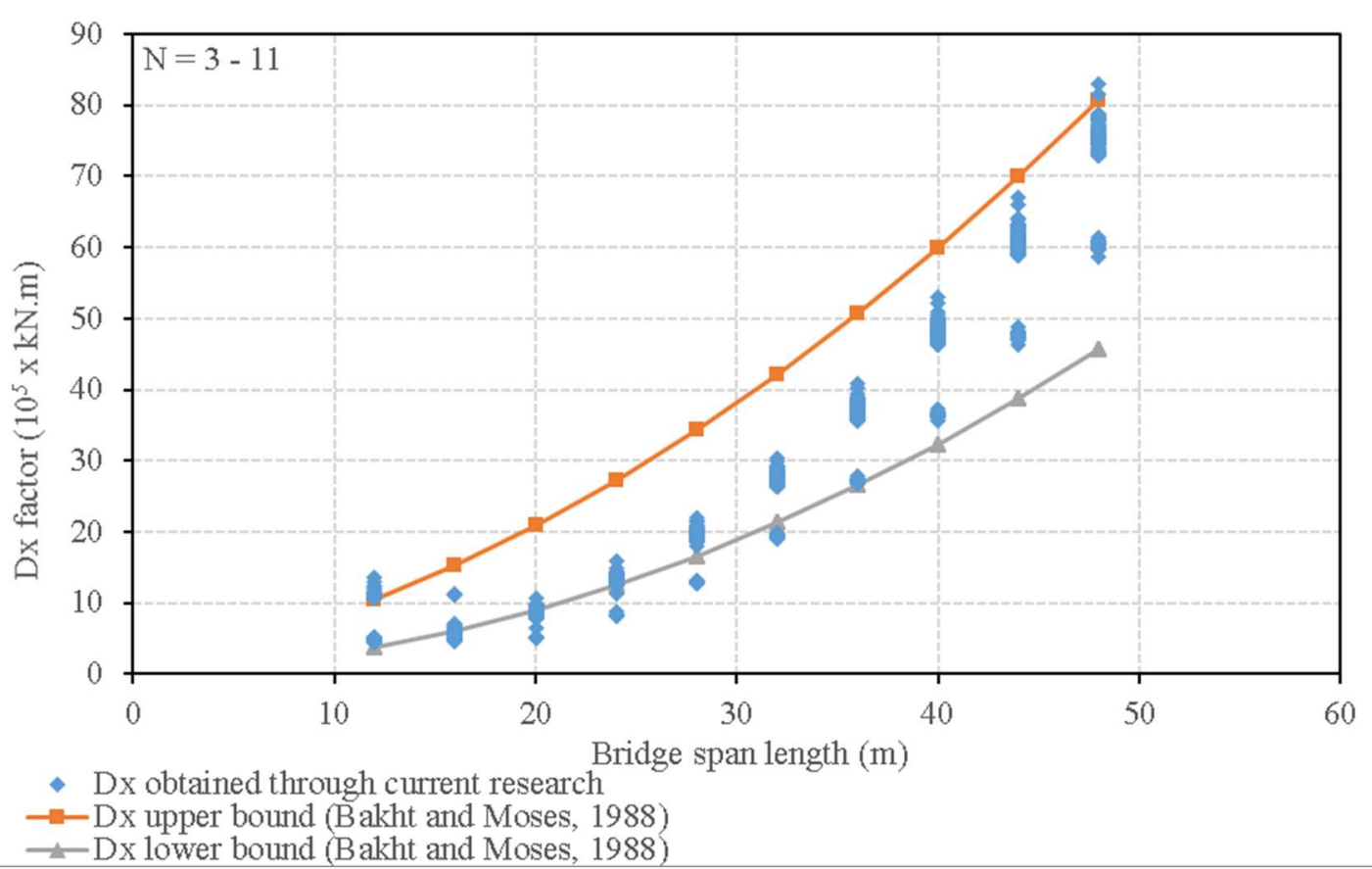

Figure 5.99: Comparison between Dx factor at midspan location obtained in this research for two equal span bridge under CL-800 truck loading and the boundary values obtained by Bakht B., and Moses, F (Bakht \& Moses, 1988) 


\subsection{Developed equations for three equal span bridge configurations}

\subsubsection{Bridge configurations under CL-625 truck loading}

Considering the results obtained for single span cases, similar results were produced for two equal span bridge configurations. Figure 5.100 shows the envelope of the results obtained for both Is and Ics at support location and Figure 5.101 shows the envelope of the results obtained for both Is and Ics at midspan location. The equations representing the moment of inertia per unit width of the steel section and the moment of inertia per unit width of the composite section can be seen below;

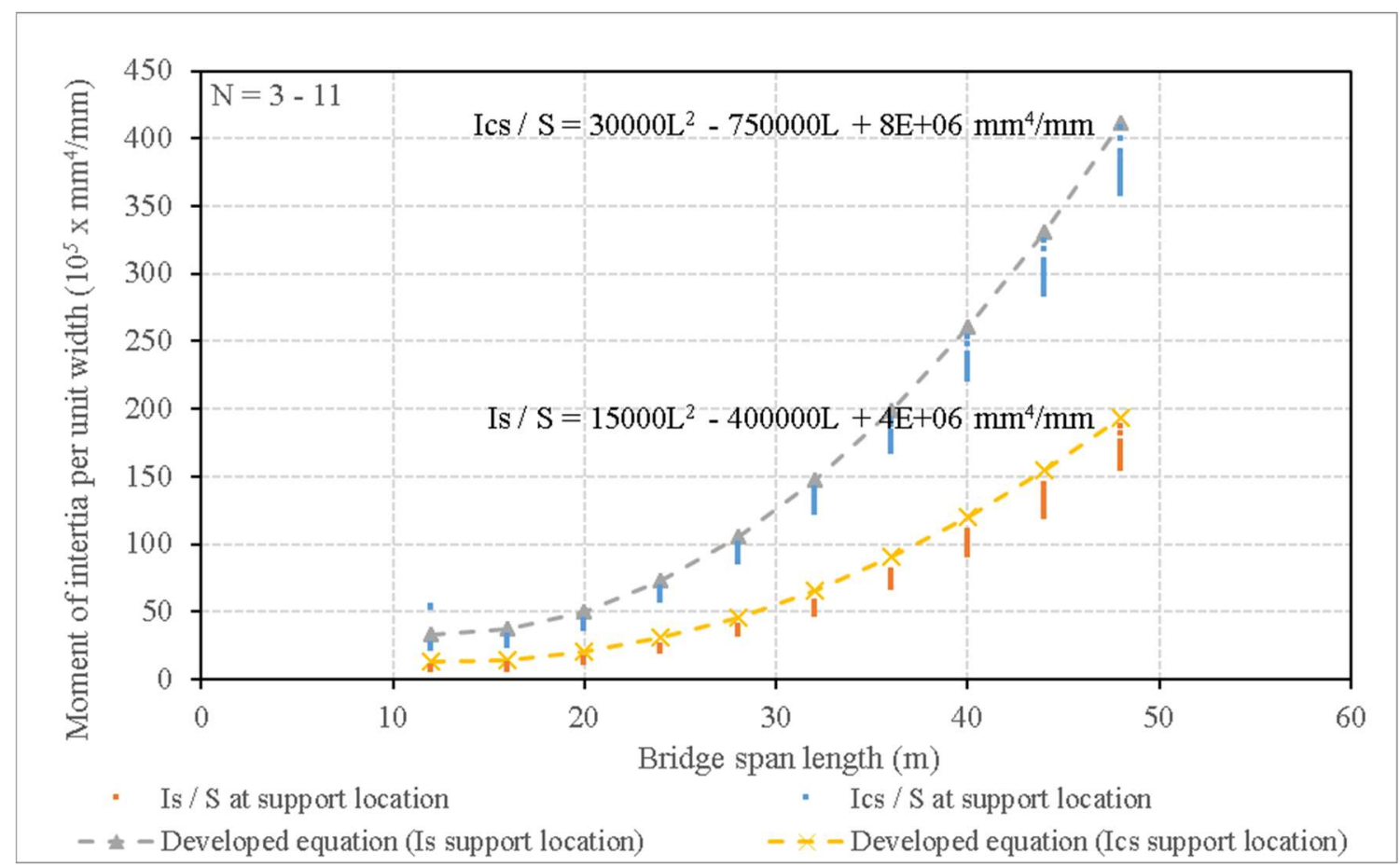

Figure 5.100: Combined envelope for moment of inertia for the steel and the composite concretesteel section per unit width vs span length at support location for three equal span bridge under CL-625 truck loading between three and eleven girders 


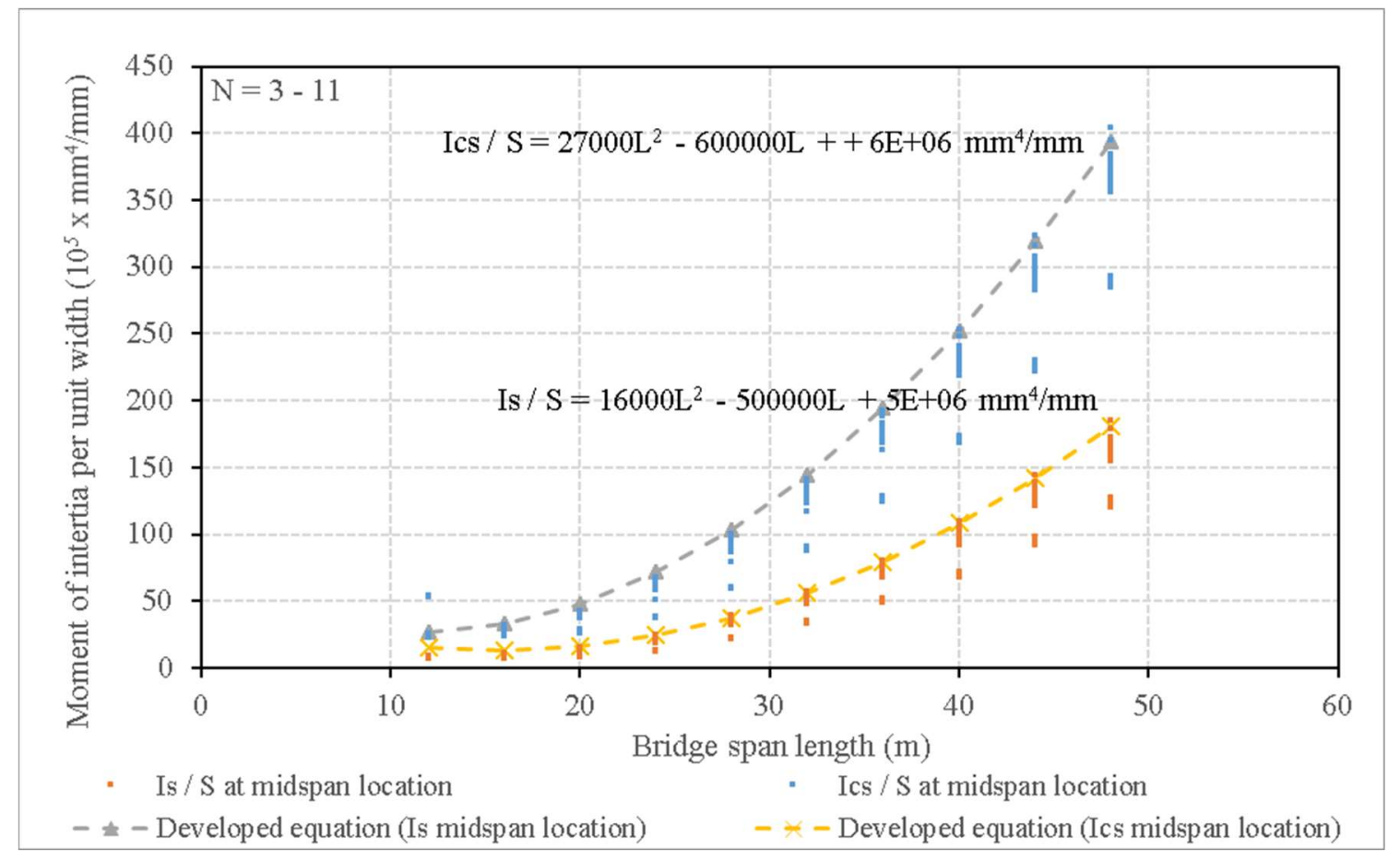

Figure 5.101: Combined envelope for moment of inertia for the steel and the composite concretesteel section per unit width vs span length at midspan location for three equal span bridge under CL-625 truck loading between three and eleven girders

$$
\begin{array}{ll}
{[5.29] \text { Ics } / \mathrm{S}=30000\left(\mathrm{~L}^{2}\right)-750000(\mathrm{~L})+8 * 10^{6} \mathrm{~mm}^{4} / \mathrm{mm}} & \text { at support location } \\
{[5.30] \mathrm{Is} / \mathrm{S}=15000\left(\mathrm{~L}^{2}\right)-400000(\mathrm{~L})+4 * 10^{6} \mathrm{~mm}^{4} / \mathrm{mm}} & \text { at support location } \\
{[5.31] \mathrm{Ics} / \mathrm{S}=27000\left(\mathrm{~L}^{2}\right)-600000(\mathrm{~L})+6 * 10^{6} \mathrm{~mm}^{4} / \mathrm{mm}} & \text { at midspan location } \\
{[5.32] \mathrm{Is} / \mathrm{S}=16000\left(\mathrm{~L}^{2}\right)-500000(\mathrm{~L})+5 * 10^{6} \mathrm{~mm}^{4} / \mathrm{mm}} & \text { at midspan location }
\end{array}
$$

Based on the results of the study conducted in section 5.4, a graph showing Aw/S vs span length for different girder spacing values was created. Figure 5.102 shows the results for such analysis. A similar distribution to Figure 5.85 can be seen. This behavior was taken into account when creating the final equation to represent the area of the web for this section. A similar twovariable equation for the web area per unit width was created to represent that characteristic. The equation can be seen below; 


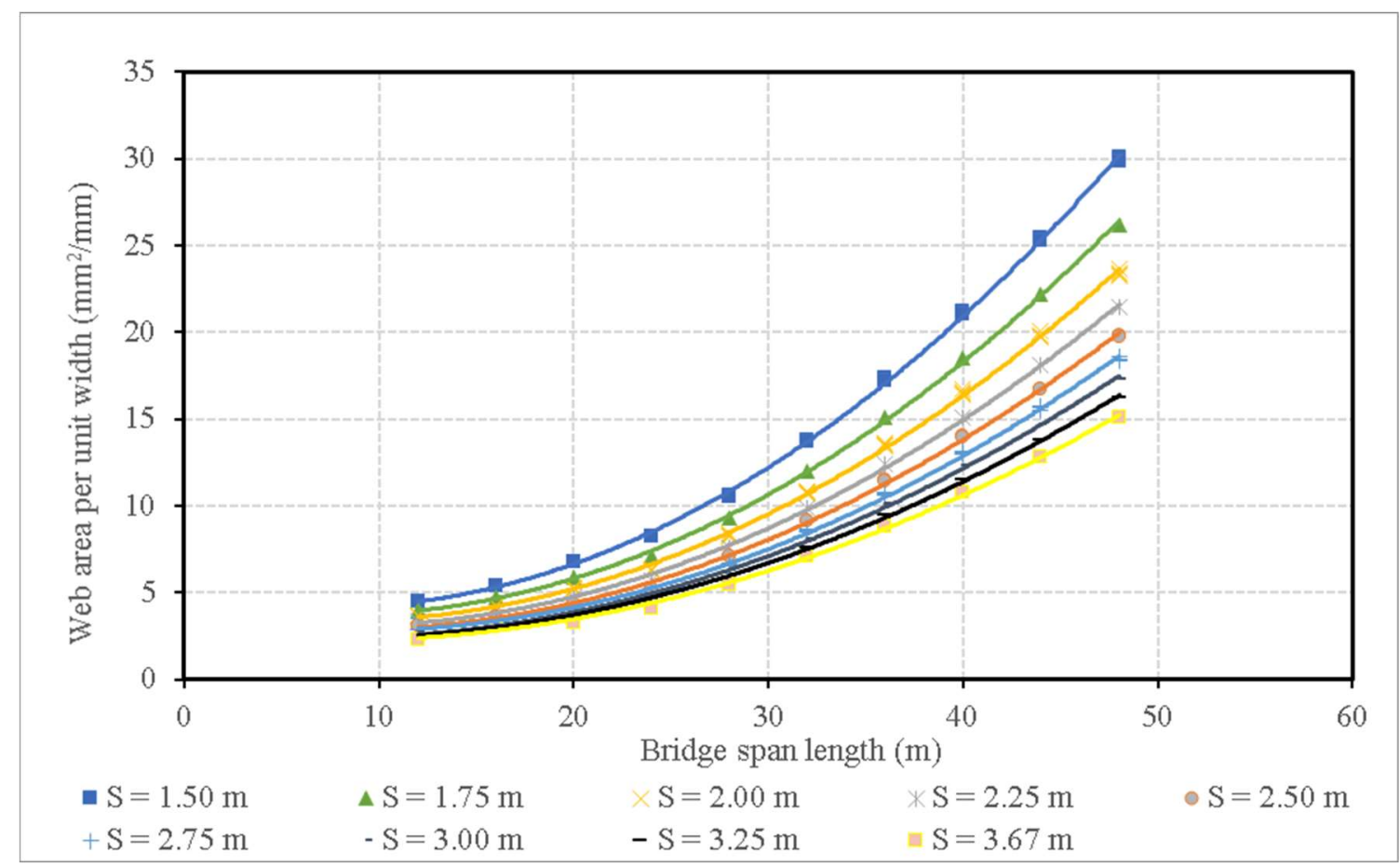

Figure 5.102: Web area per unit width vs span length for three equal span bridge under CL-625 truck loading with girder spacing ranging between $1.5 \mathrm{~m}$ and $3.67 \mathrm{~m}$

$[5.33] \mathrm{Aw} / \mathrm{S}=(0.021-0.029(\mathrm{~S}))\left(\mathrm{L}^{2}\right)-(0.32-0.046(\mathrm{~S}))(\mathrm{L})+7.00-1.25(\mathrm{~S}) \mathrm{mm}^{2} /$ $\mathrm{mm}$

The performance of the equation when compared to the program results can be seen in Figure 5.103. The equation created shows excellent representation while always slightly overestimating the Aw/S required for any given section. 


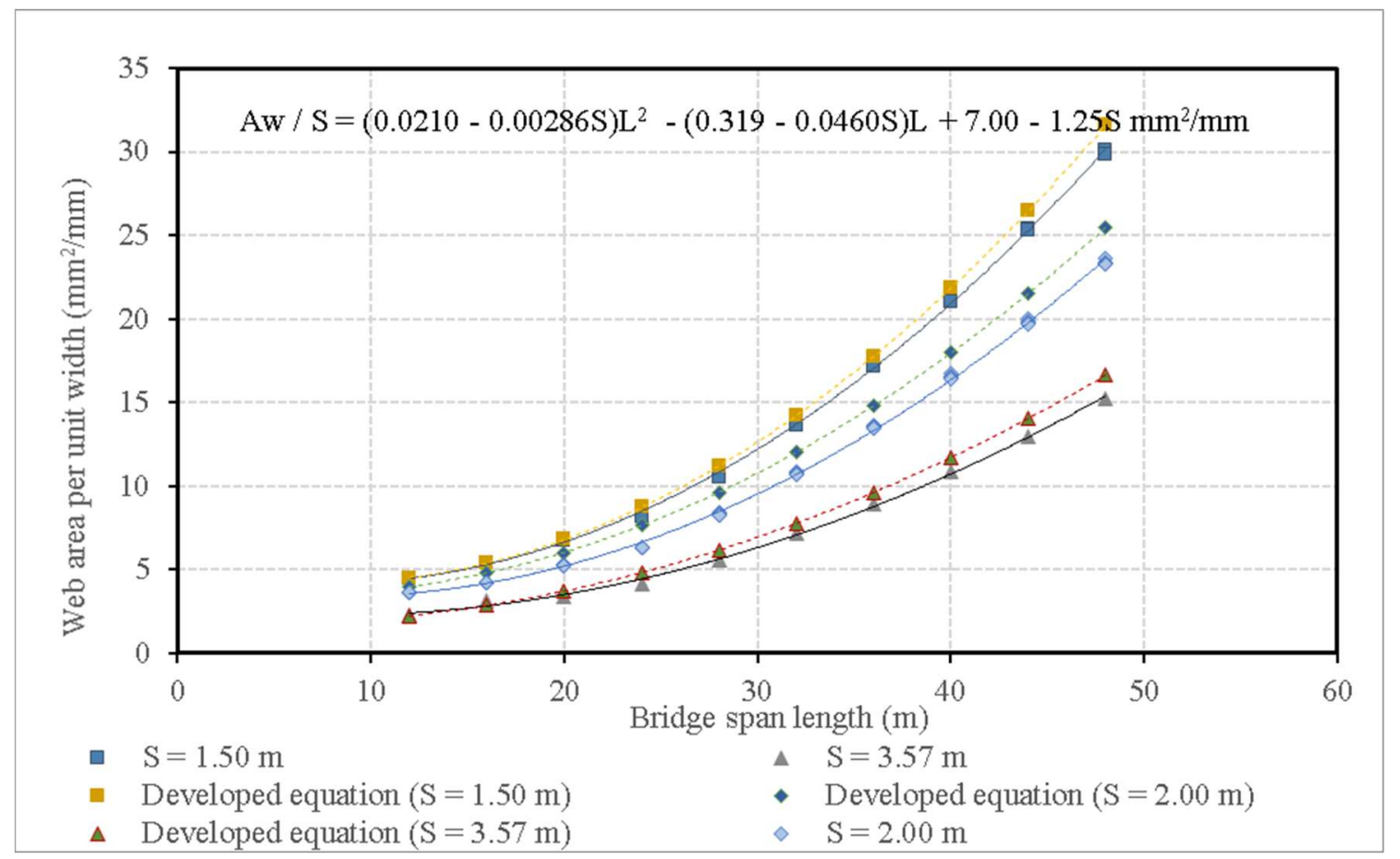

Figure 5.103: Comparison between program results and developed two-variable equation for web area per unit width vs span length for three equal span bridge under CL-625 truck loading with girder spacing ranging between $1.5 \mathrm{~m}$ and $3.67 \mathrm{~m}$

The difference between the results from a similar previous study conducted by Bakht $\mathrm{B}$. and the results from this study can be seen in Figures 5.104 and 5.105 for support location and midspan location respectively. The longitudinal flexural rigidity (Dx) results in this portion of the study show good results produced for midspan and support locations. It is worth noting that the results from Bakht's study are for the CL-740 truck that was being used in the OHBDC of 1983 (MTO, 1983) while in this portion of the study the CL-625 is used. 


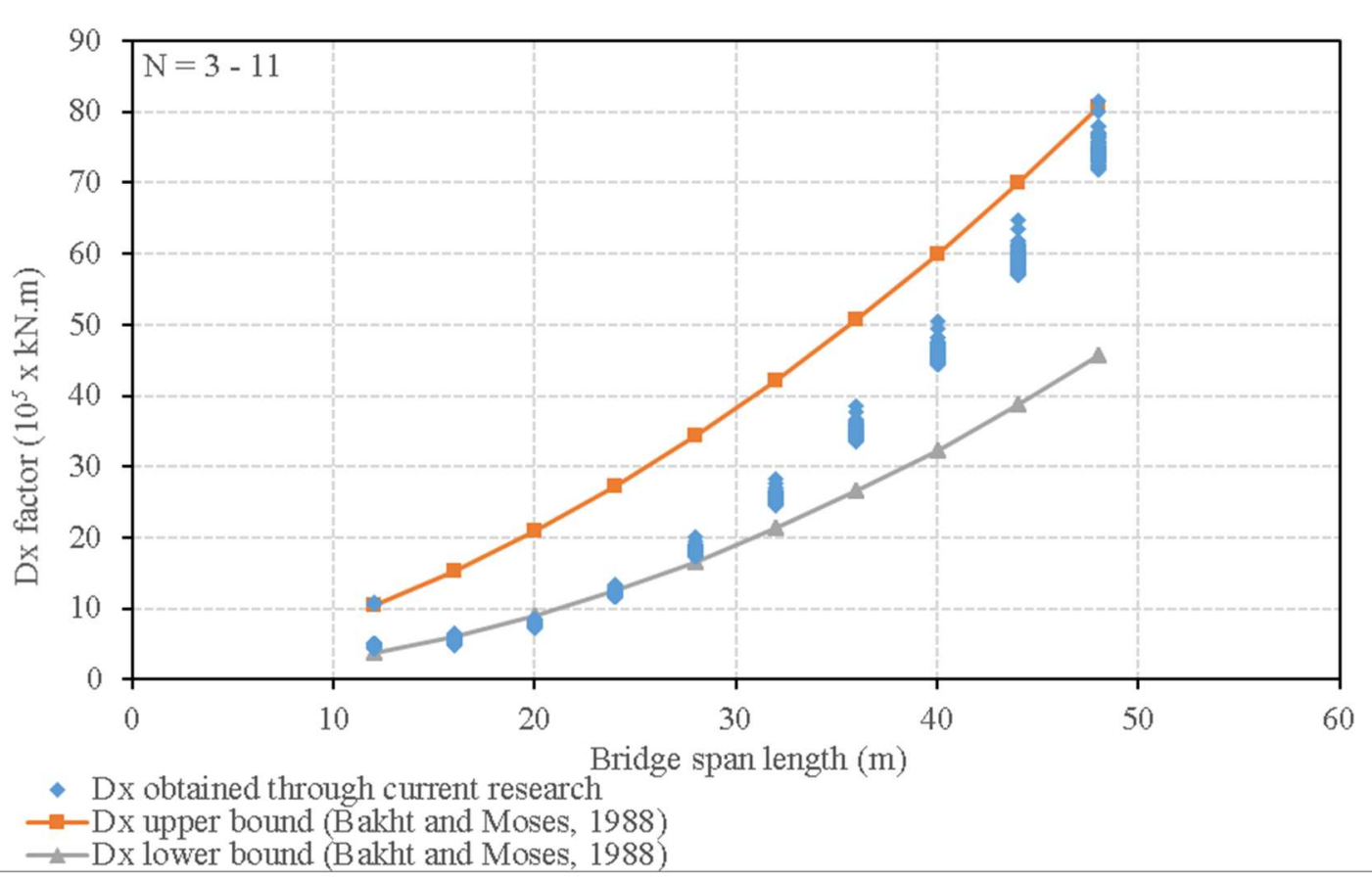

Figure 5.104: Comparison between Dx factor at support location obtained in this research for three equal span bridge under CL-625 truck loading and the boundary values obtained by Bakht B., and Moses, F (Bakht \& Moses, 1988)

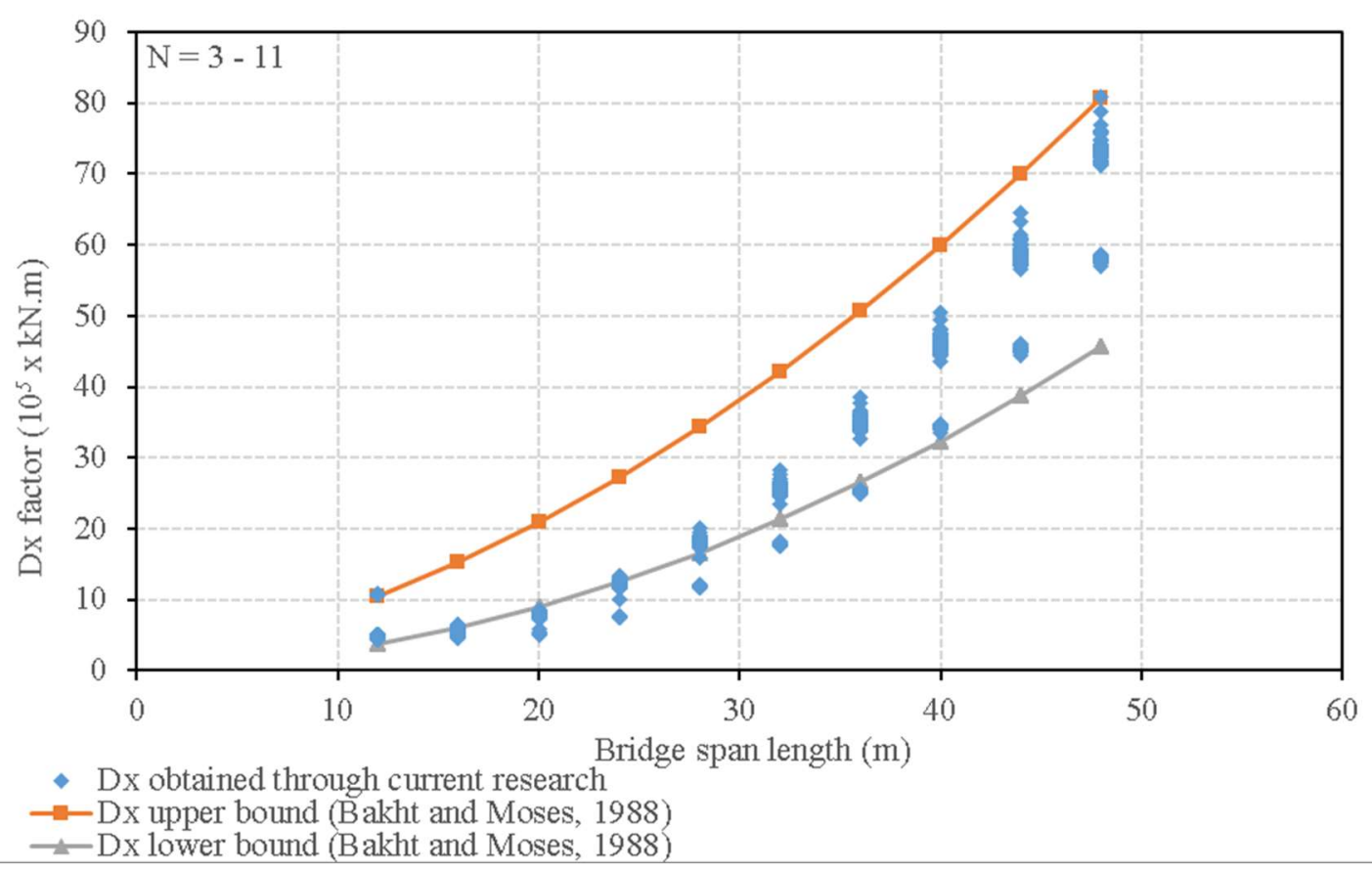

Figure 5.105: Comparison between Dx factor at midspan location obtained in this research for three equal span bridge under CL-625 truck loading and the boundary values obtained by Bakht B., and Moses, F (Bakht \& Moses, 1988) 


\subsubsection{Bridge configurations under CL-800 truck loading}

Considering the results obtained for single span cases for the CL-625 truck, similar results were produced for two equal span bridge configurations. Figure 5.106 shows the envelope of the results obtained for both Is and Ics at support location and Figure 5.107 shows the envelope of the results obtained for both Is and Ics at midspan location. The equations representing the moment of inertia per unit width of the steel section and the moment of inertia per unit width of the composite section can be seen below;

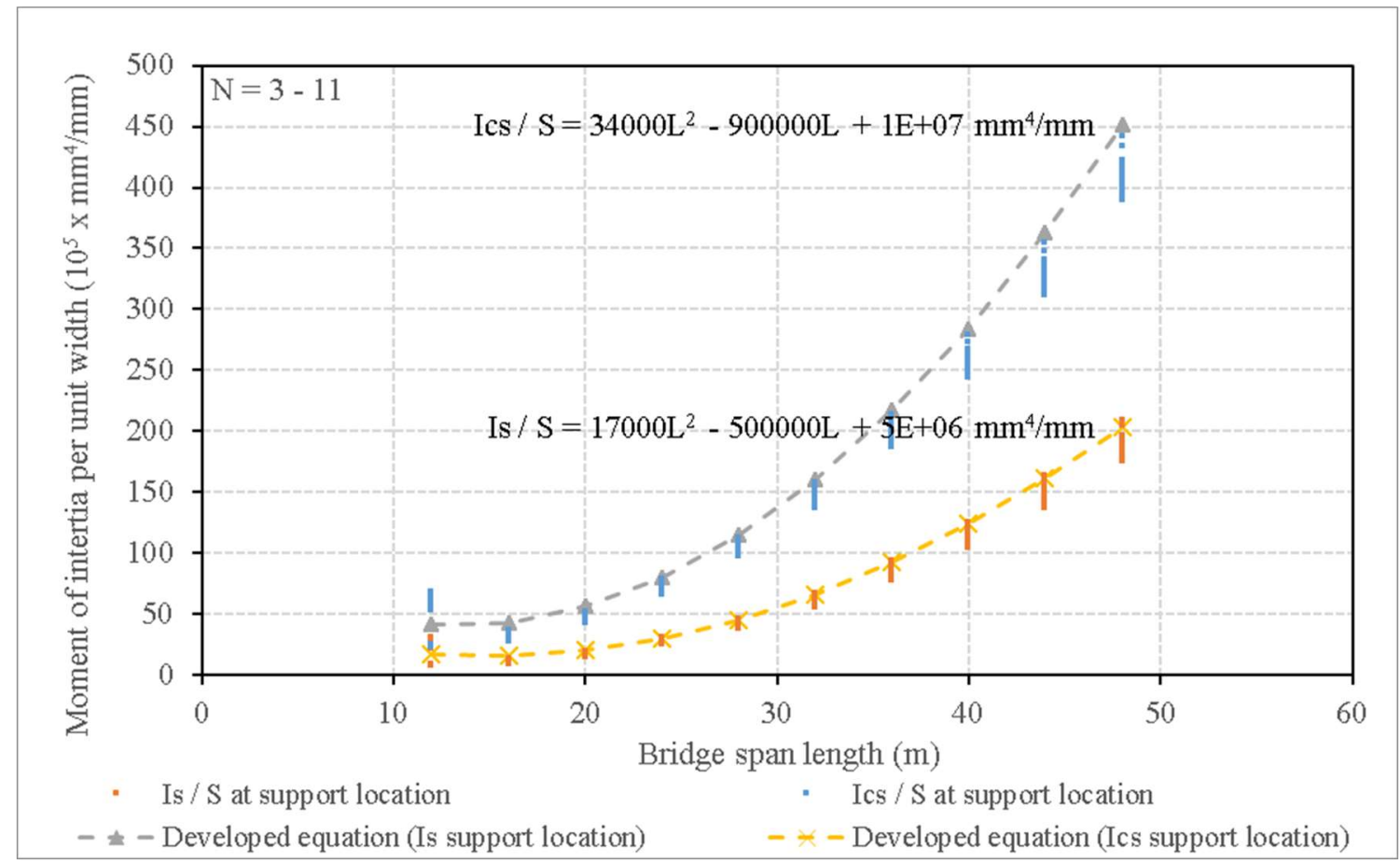

Figure 5.106: Combined envelope for moment of inertia for the steel and the composite concretesteel section per unit width vs span length at support location for three equal span bridge under CL-800 truck loading between three and eleven girders 


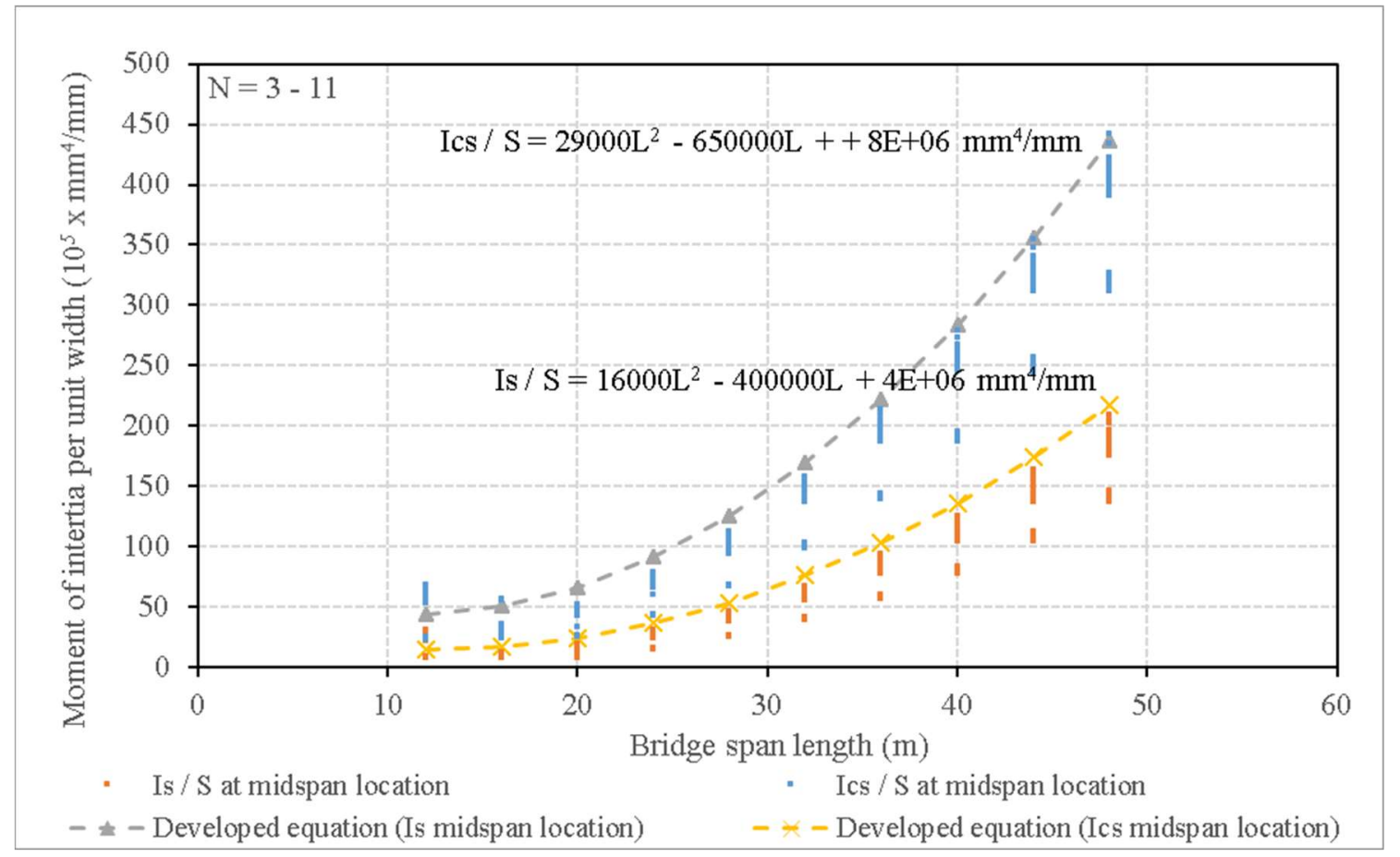

Figure 5.107: Combined envelope for moment of inertia for the steel and the composite concretesteel section per unit width vs span length at midspan location for three equal span bridge under CL-800 truck loading between three and eleven girders

$$
\begin{array}{ll}
{[5.34] \mathrm{Ics} / \mathrm{S}=34000\left(\mathrm{~L}^{2}\right)-900000(\mathrm{~L})+1 * 10^{7} \mathrm{~mm}^{4} / \mathrm{mm}} & \text { at support location } \\
{[5.35] \mathrm{Is} / \mathrm{S}=17000\left(\mathrm{~L}^{2}\right)-500000(\mathrm{~L})+5 * 10^{6} \mathrm{~mm}^{4} / \mathrm{mm}} & \text { at support location } \\
{[5.36] \mathrm{Ics} / \mathrm{S}=29000\left(\mathrm{~L}^{2}\right)-650000(\mathrm{~L})+8 * 10^{6} \mathrm{~mm}^{4} / \mathrm{mm}} & \text { at midspan location } \\
{[5.37] \mathrm{Is} / \mathrm{S}=16000\left(\mathrm{~L}^{2}\right)-400000(\mathrm{~L})+4 * 10^{6} \mathrm{~mm}^{4} / \mathrm{mm}} & \text { at midspan location }
\end{array}
$$

Based on the results of the study conducted in section 5.4, a graph showing Aw/S vs span length for different girder spacing values was created. Figure 5.108 shows the results for such analysis. A similar distribution to Figure 5.85 can be seen. This behavior was taken into account when creating the final equation to represent the area of the web for this section. A similar twovariable equation for the web area per unit width was created to represent that characteristic. The equation can be seen below; 


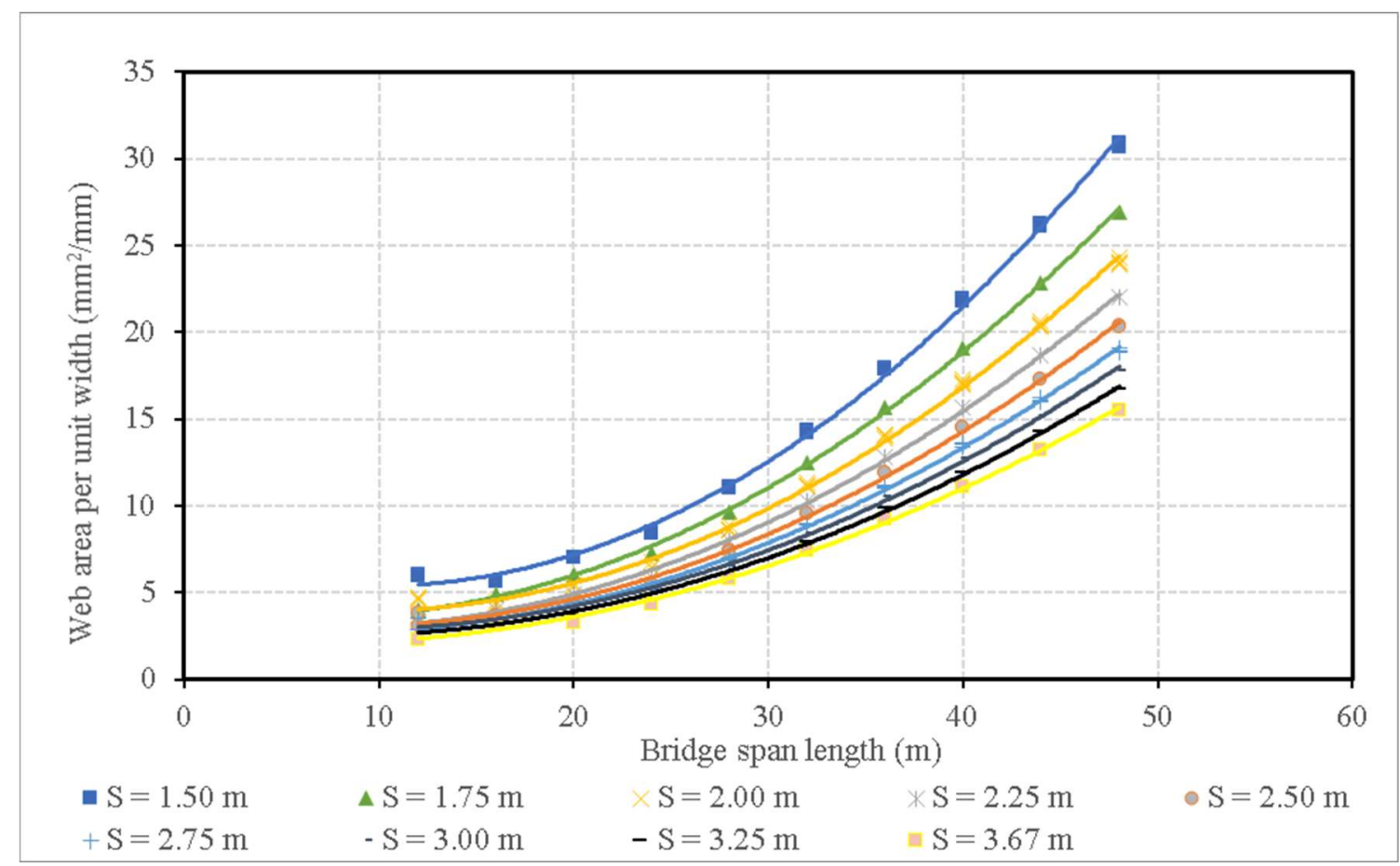

Figure 5.108: Web area per unit width vs span length for three equal span bridge under CL-800 truck loading with girder spacing ranging between $1.5 \mathrm{~m}$ and $3.67 \mathrm{~m}$

$[5.38] \mathrm{Aw} / \mathrm{S}=(0.024-0.036(\mathrm{~S}))\left(\mathrm{L}^{2}\right)-(0.51-0.085(\mathrm{~S}))(\mathrm{L})+9.83-1.59(\mathrm{~S}) \mathrm{mm}^{2} /$ $\mathrm{mm}$

The performance of the equation when compared to the program results can be seen in Figure 5.109. The equation created shows excellent representation while always slightly overestimating the Aw/S required for any given section. 


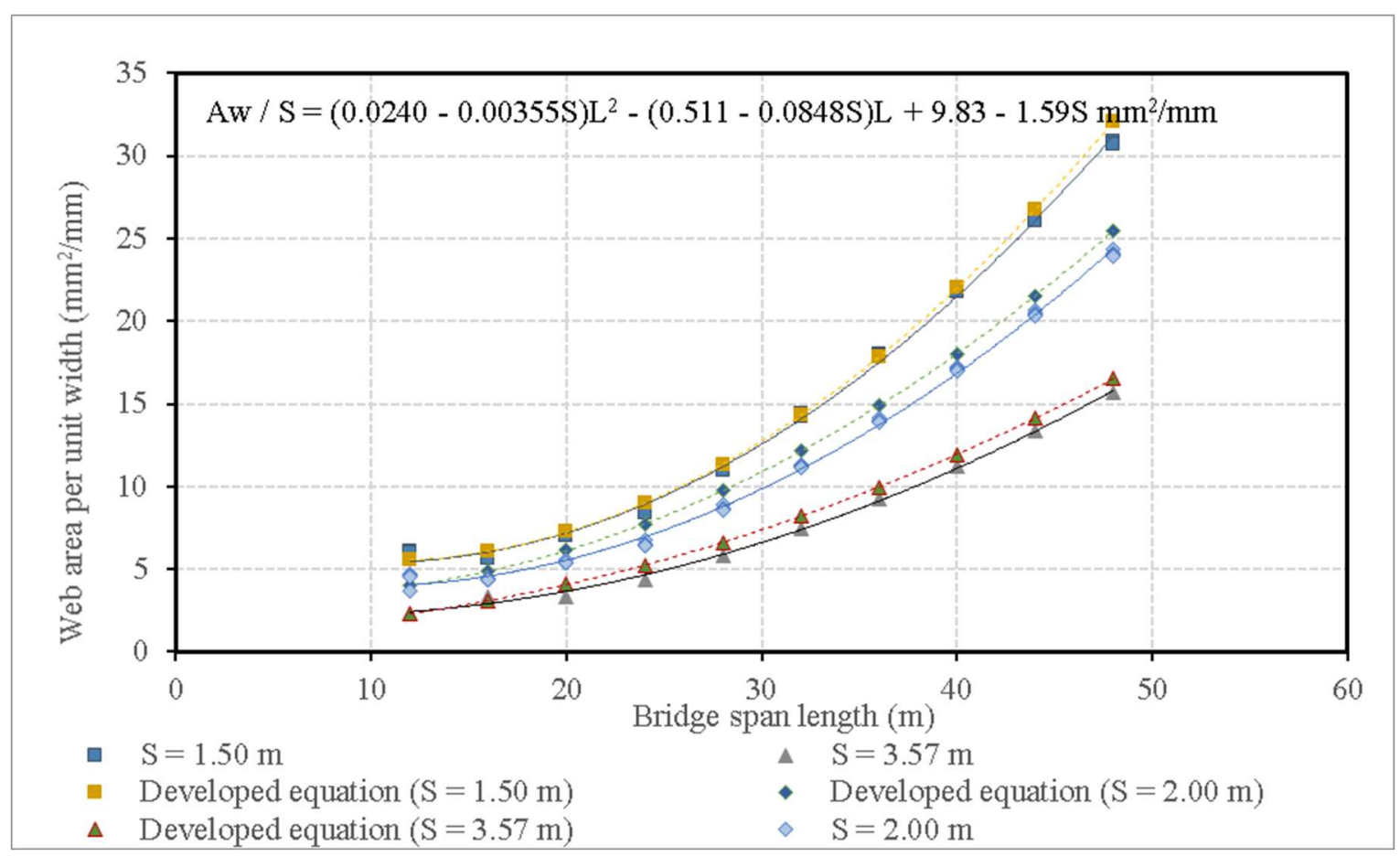

Figure 5.109: Comparison between program results and developed two-variable equation for web area per unit width vs span length for three equal span bridge under CL-800 truck loading with girder spacing ranging between $1.5 \mathrm{~m}$ and $3.67 \mathrm{~m}$

The difference between the results from a similar previous study conducted by Bakht B. and the results from this study can be seen in Figures 5.110 and 5.111 for support location and midspan location respectively. The longitudinal flexural rigidity (Dx) results in this study show a higher upper bound for support locations and midspan locations for longer spans due to these equations being developed by Bakht B. for CL-740 truck loading (Bakht \& Moses, 1988). 


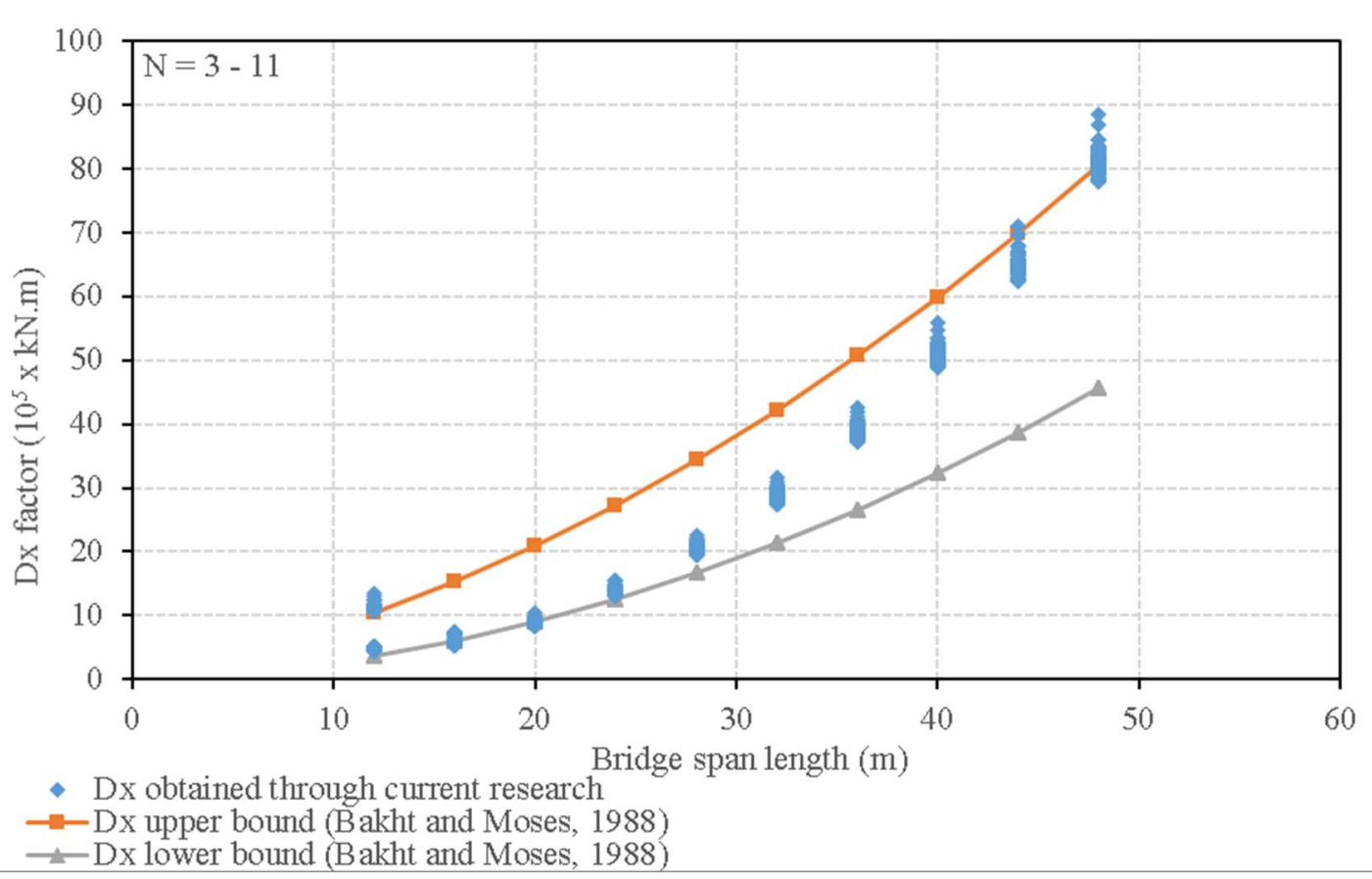

Figure 5.110: Comparison between Dx factor at support location obtained in this research for three equal span bridge under CL-800 truck loading and the boundary values obtained by Bakht B., and Moses, F (Bakht \& Moses, 1988)

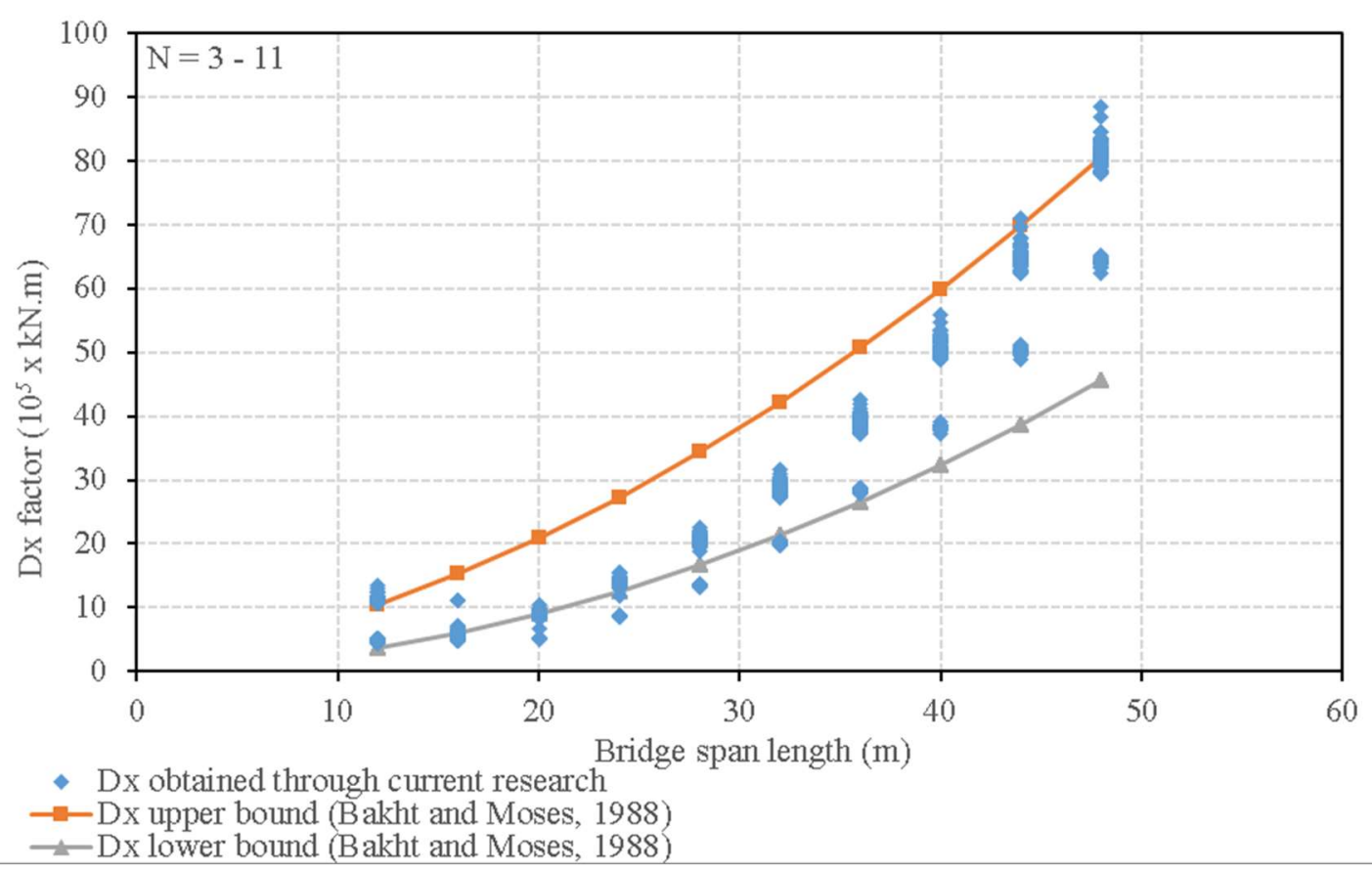

Figure 5.111: Comparison between Dx factor at midspan location obtained in this research for three equal span bridge under CL-800 truck loading and the boundary values obtained by Bakht B., and Moses, F (Bakht \& Moses, 1988) 


\subsection{Developed equations for four equal span bridge configurations}

\subsubsection{Bridge configurations under CL-625 truck loading}

Considering the results obtained for single span cases, similar results were produced for two equal span bridge configurations. Figure 5.112 shows the envelope of the results obtained for both Is and Ics at support location and Figure 5.113 shows the envelope of the results obtained for both Is and Ics at midspan location. The equations representing the moment of inertia per unit width of the steel section and the moment of inertia per unit width of the composite section can be seen below;

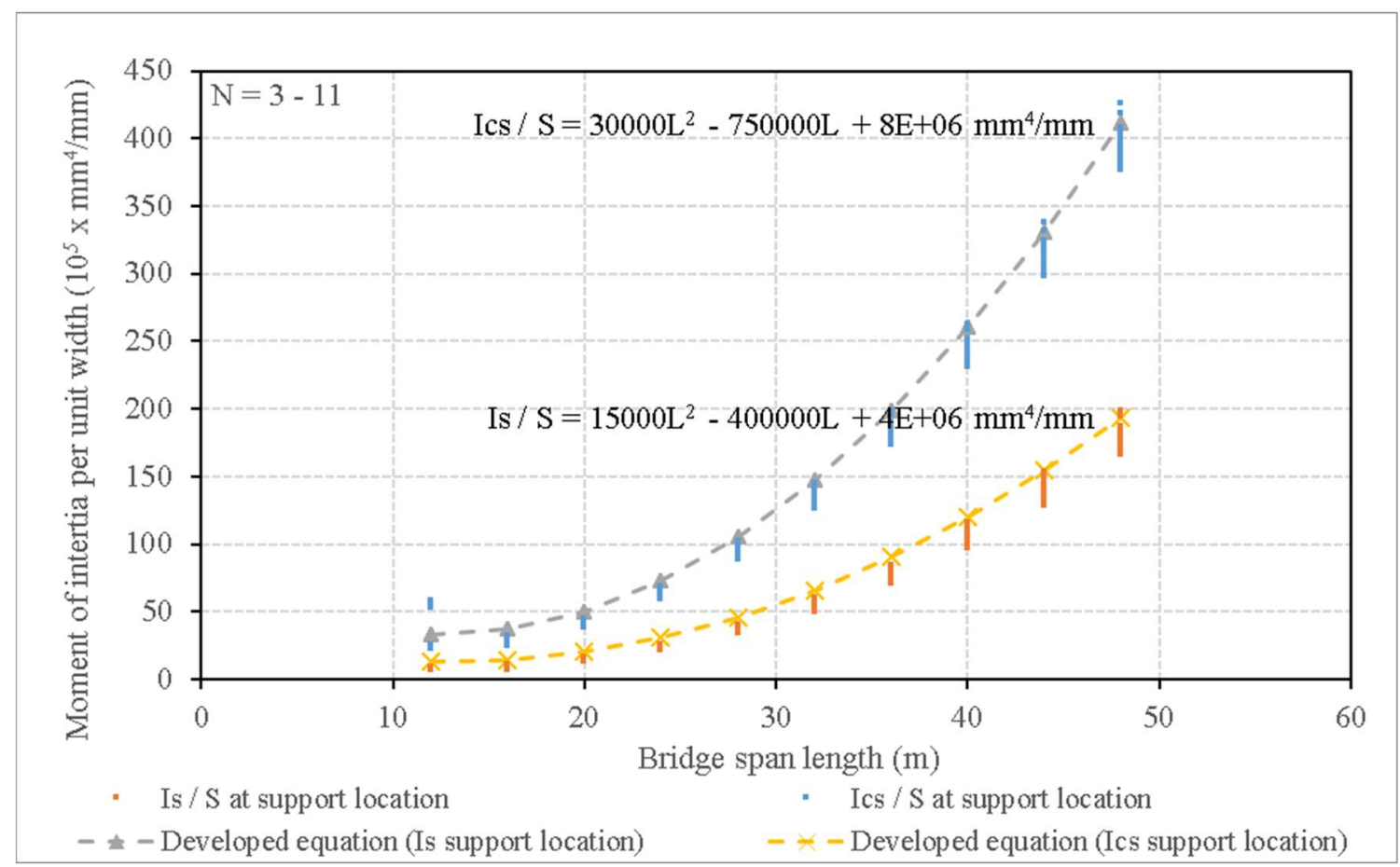

Figure 5.112: Combined envelope for moment of inertia for the steel and the composite concretesteel section per unit width vs span length at support location for four equal span bridge under CL-625 truck loading between three and eleven girders 


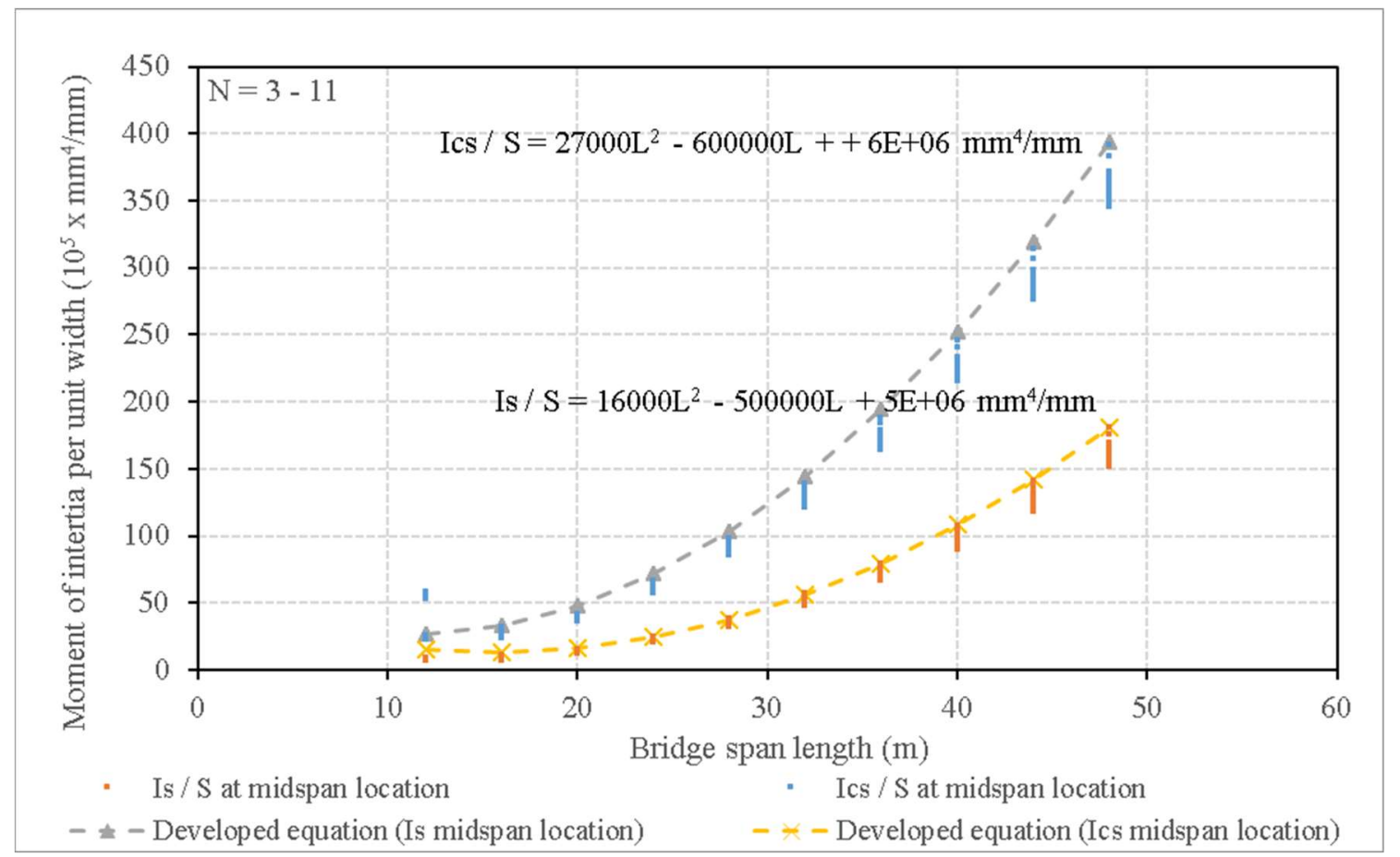

Figure 5.113: Combined envelope for moment of inertia for the steel and the composite concretesteel section per unit width vs span length at midspan location for four equal span bridge under CL-625 truck loading between three and eleven girders

[5.39] Ics $/ \mathrm{S}=30000\left(\mathrm{~L}^{2}\right)-750000(\mathrm{~L})+8 * 10^{6} \mathrm{~mm}^{4} / \mathrm{mm}$

at support location

$[5.40] \mathrm{Is} / \mathrm{S}=15000\left(\mathrm{~L}^{2}\right)-400000(\mathrm{~L})+4 * 10^{6} \mathrm{~mm}^{4} / \mathrm{mm}$ at support location

$[5.41] \mathrm{Ics} / \mathrm{S}=27000\left(\mathrm{~L}^{2}\right)-600000(\mathrm{~L})+6 * 10^{6} \mathrm{~mm}^{4} / \mathrm{mm}$ at midspan location Is $/ \mathrm{S}=16000\left(\mathrm{~L}^{2}\right)-500000(\mathrm{~L})+5 * 10^{6} \mathrm{~mm}^{4} / \mathrm{mm}$ at midspan location

Based on the results of the study conducted in section 5.4, a graph showing Aw/S vs span length for different girder spacing values was created. Figure 5.114 shows the results for such analysis. A similar distribution to Figure 5.85 can be seen. This behavior was taken into account when creating the final equation to represent the area of the web for this section. A similar twovariable equation for the web area per unit width was created to represent that characteristic. The equation can be seen below; 


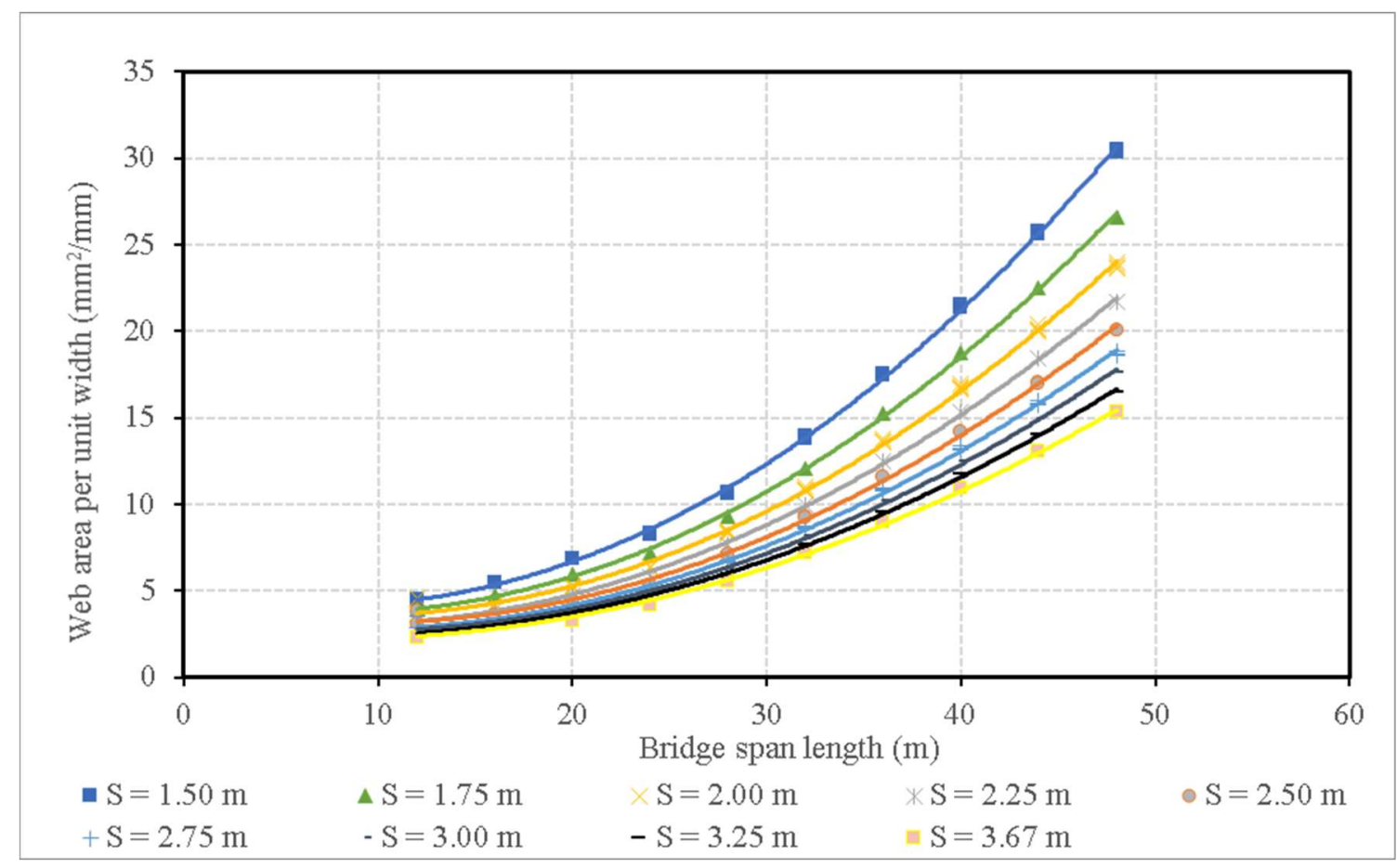

Figure 5.114: Web area per unit width vs span length for four equal span bridge under CL-625 truck loading with girder spacing ranging between $1.5 \mathrm{~m}$ and $3.67 \mathrm{~m}$

$[5.43] \mathrm{Aw} / \mathrm{S}=(0.021-0.029(\mathrm{~S}))\left(\mathrm{L}^{2}\right)-(0.32-0.046(\mathrm{~S}))(\mathrm{L})+7.00-1.25(\mathrm{~S}) \mathrm{mm}^{2} /$ $\mathrm{mm}$

The performance of the equation when compared to the program results can be seen in Figure 5.115. The equation created shows excellent representation while always slightly overestimating the Aw/S required for any given section. 


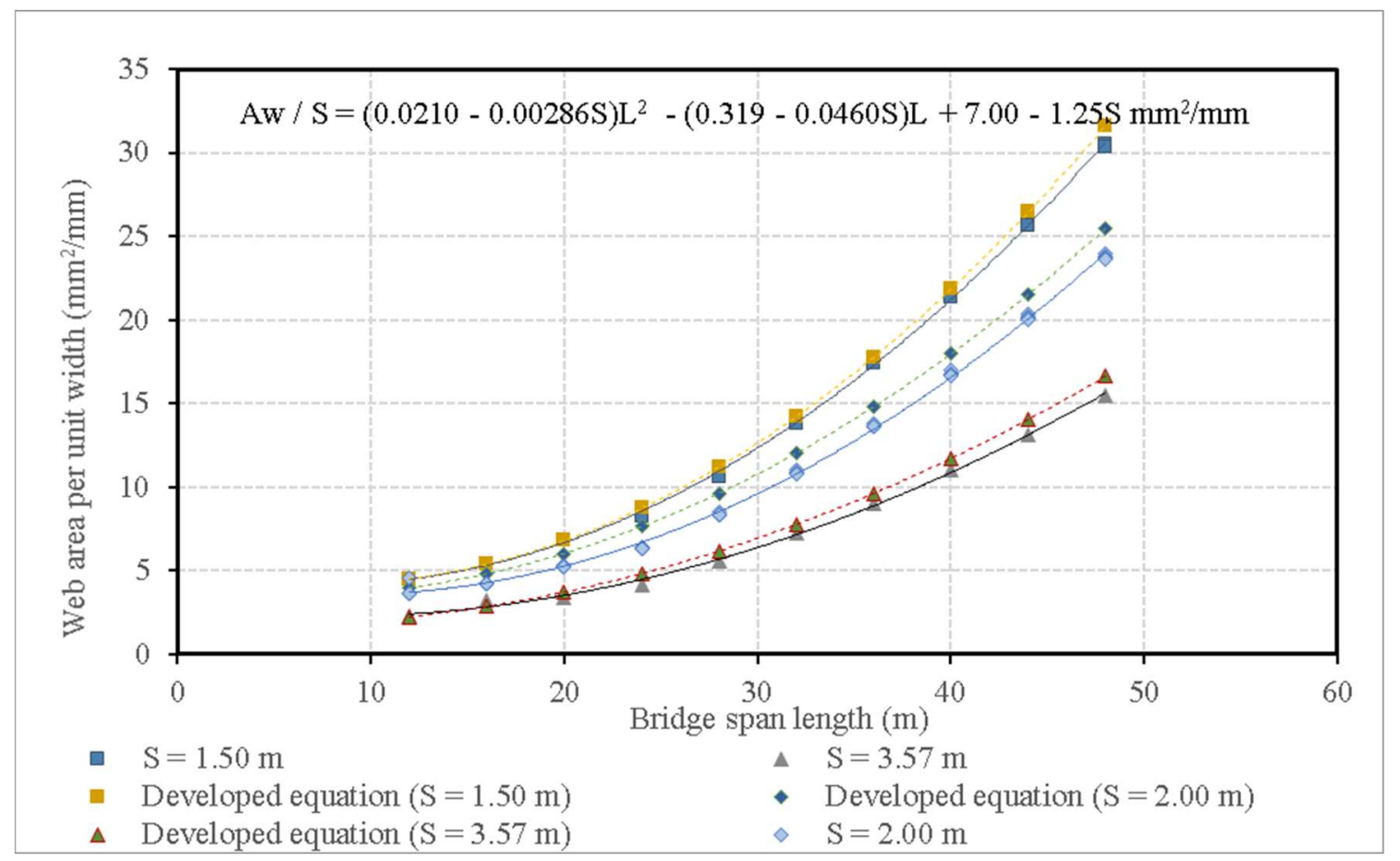

Figure 5.115: Comparison between program results and developed two-variable equation for web area per unit width vs span length for four equal span bridge under CL-625 truck loading with girder spacing ranging between $1.5 \mathrm{~m}$ and $3.67 \mathrm{~m}$

The difference between the results from a similar previous study conducted by Bakht $\mathrm{B}$. and the results from this study can be seen in Figures 5.116 and 5.117 for support location and midspan location respectively. The longitudinal flexural rigidity (Dx) results in this portion of the study show good results produced for midspan and support locations. It is worth noting that the results from Bakht's study are for the CL-740 truck that was being used in the OHBDC of 1983 (MTO, 1983) while in this portion of the study the CL-625 is used. 


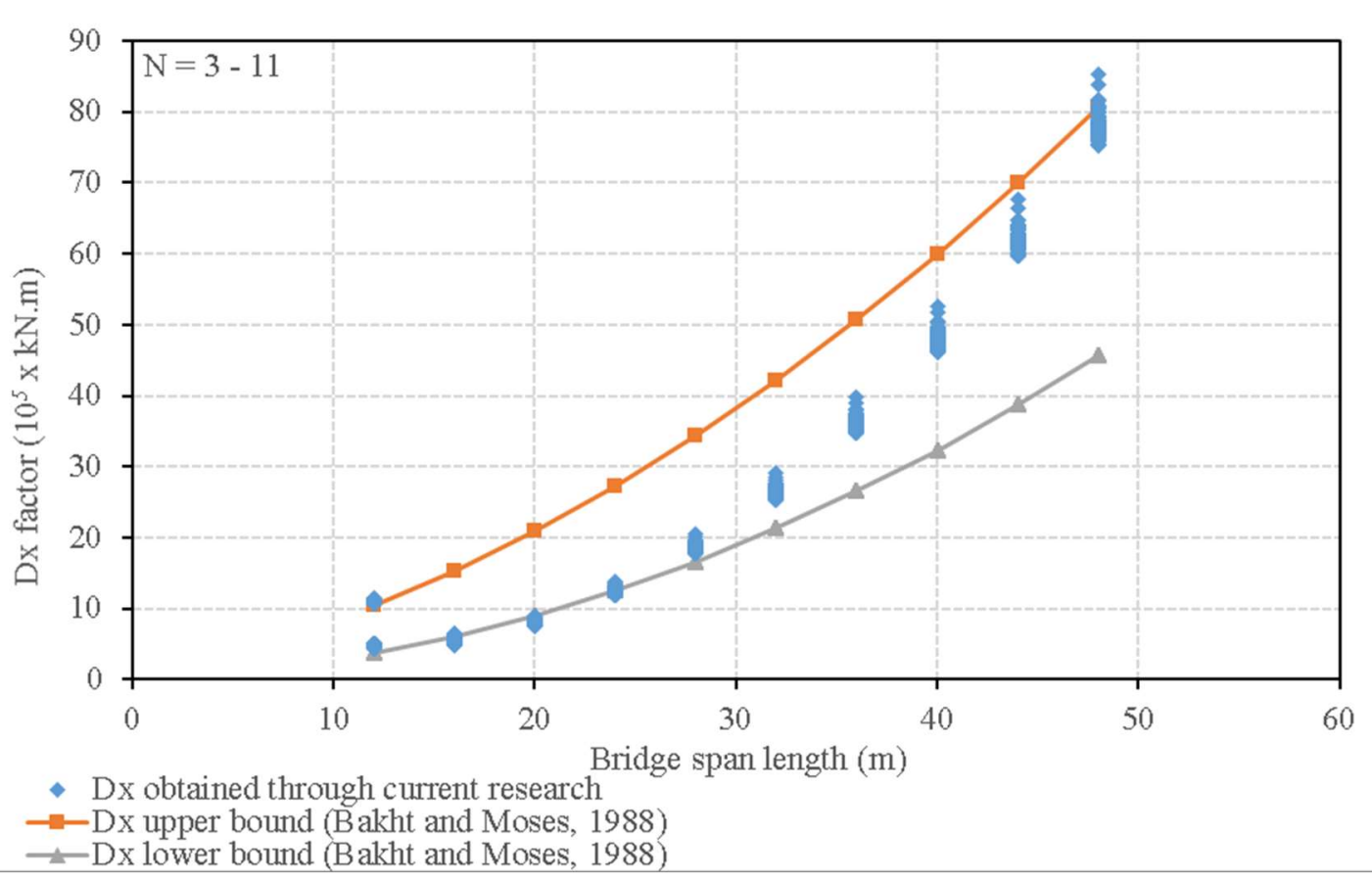

Figure 5.116: Comparison between Dx factor at support location obtained in this research for four equal span bridge under CL-625 truck loading and the boundary values obtained by Bakht B., and Moses, F (Bakht \& Moses, 1988)

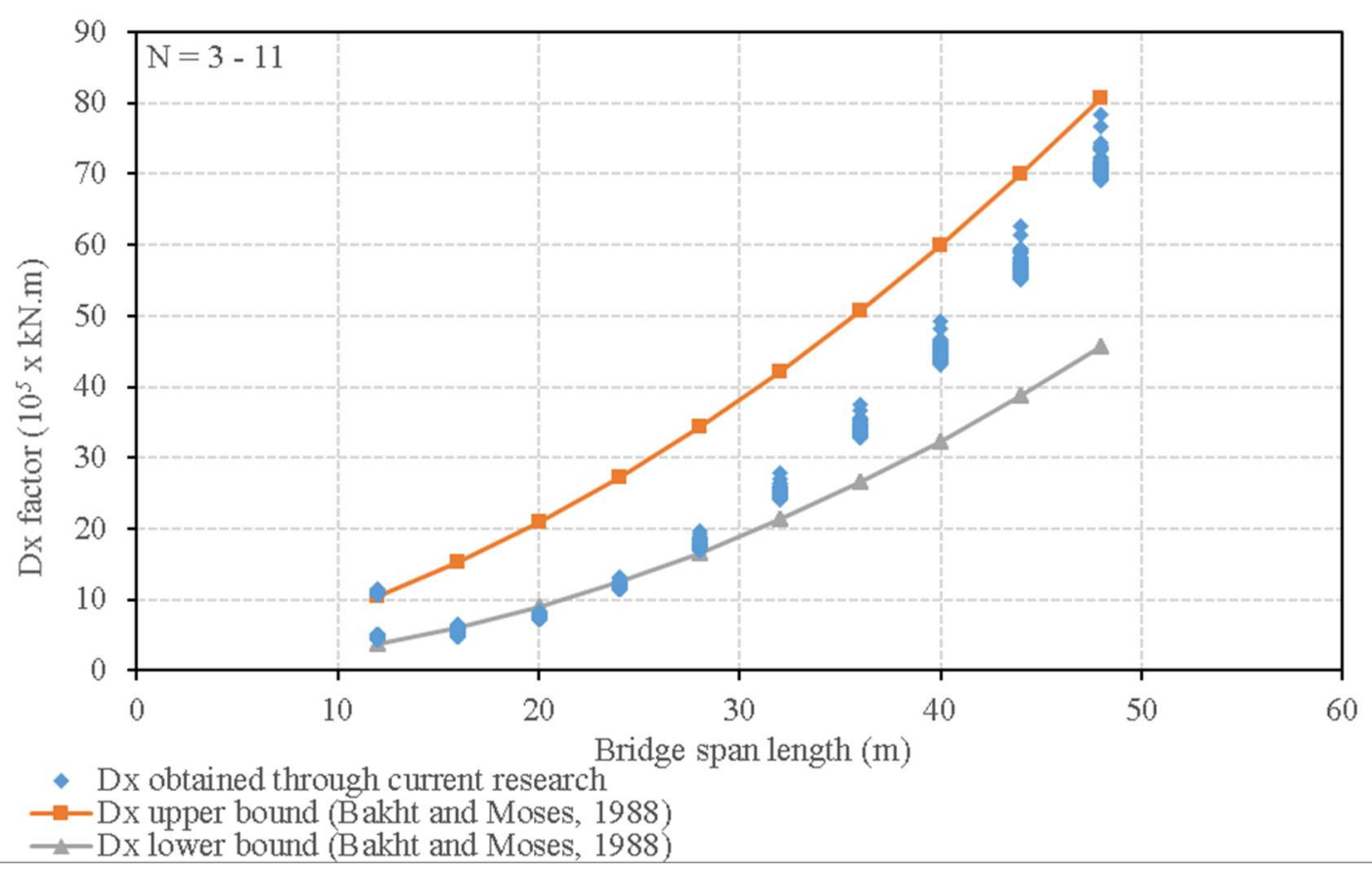

Figure 5.117: Comparison between Dx factor at midspan location obtained in this research for four equal span bridge under CL-625 truck loading and the boundary values obtained by Bakht B., and Moses, F (Bakht \& Moses, 1988) 


\subsubsection{Bridge configurations under CL-800 truck loading}

Considering the results obtained for single span cases for the CL-625 truck, similar results were produced for two equal span bridge configurations. Figure 5.118 shows the envelope of the results obtained for both Is and Ics at support location and Figure 5.119 shows the envelope of the results obtained for both Is and Ics at midspan location. The equations representing the moment of inertia per unit width of the steel section and the moment of inertia per unit width of the composite section can be seen below;

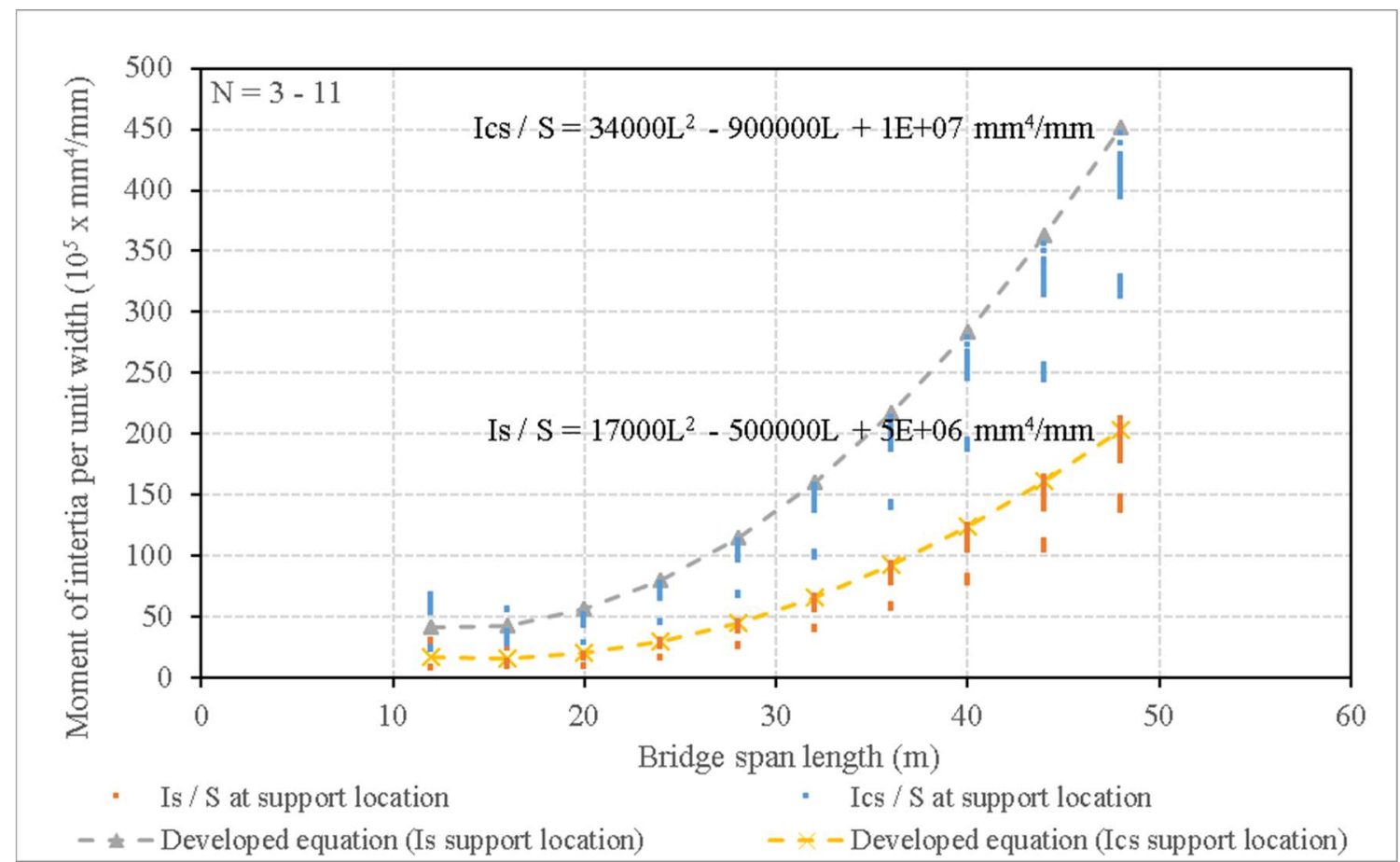

Figure 5.118: Combined envelope for moment of inertia for the steel and the composite concretesteel section per unit width vs span length at support location for four equal span bridge under CL-800 truck loading between three and eleven girders 


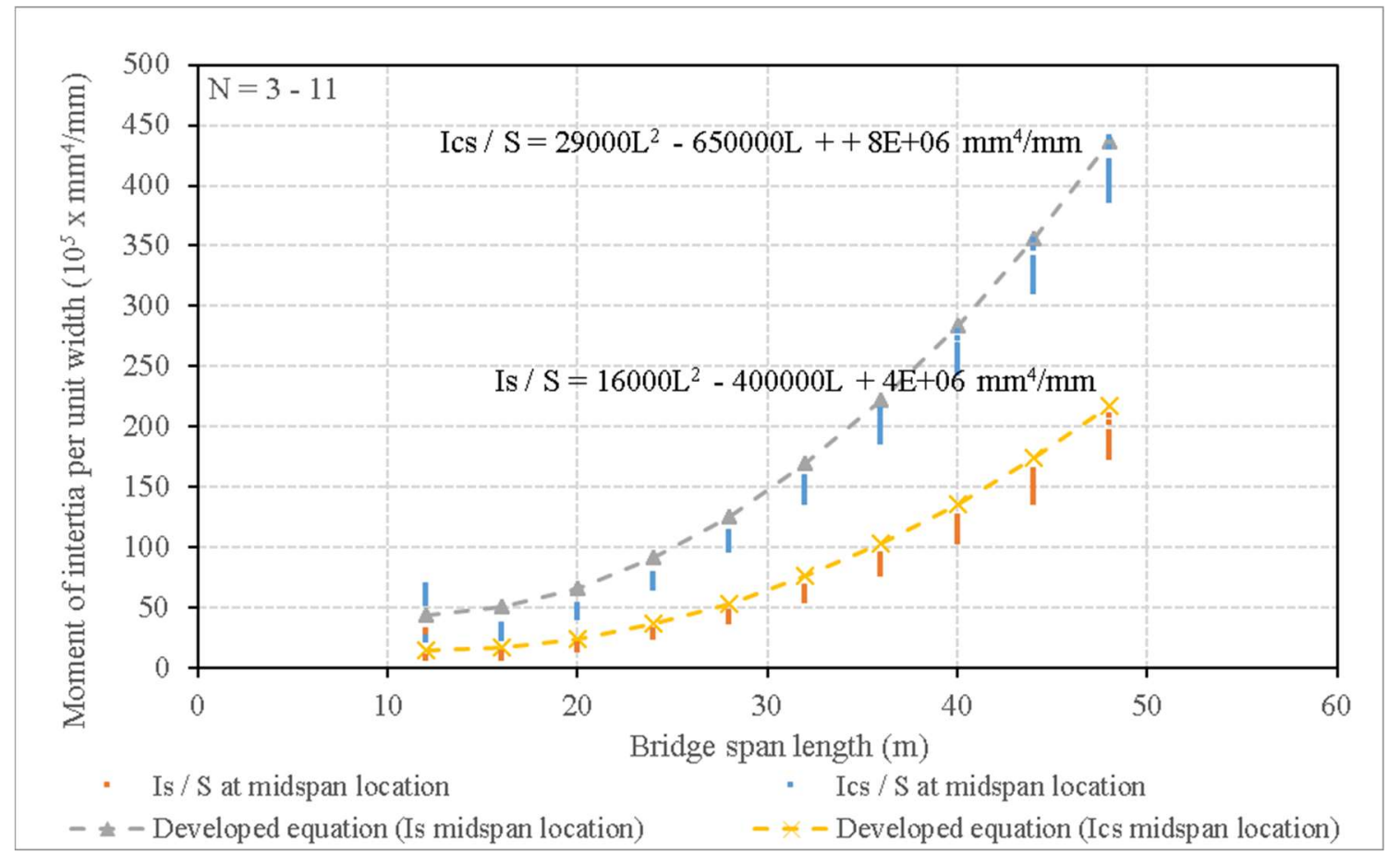

Figure 5.119: Combined envelope for moment of inertia for the steel and the composite concretesteel section per unit width vs span length at midspan location for four equal span bridge under CL-800 truck loading between three and eleven girders

$$
\begin{array}{ll}
{[5.44] \mathrm{Ics} / \mathrm{S}=34000\left(\mathrm{~L}^{2}\right)-900000(\mathrm{~L})+1 * 10^{7} \mathrm{~mm}^{4} / \mathrm{mm}} & \text { at support location } \\
{[5.45] \mathrm{Is} / \mathrm{S}=17000\left(\mathrm{~L}^{2}\right)-500000(\mathrm{~L})+5 * 10^{6} \mathrm{~mm}^{4} / \mathrm{mm}} & \text { at support location } \\
{[5.46] \mathrm{Ics} / \mathrm{S}=29000\left(\mathrm{~L}^{2}\right)-650000(\mathrm{~L})+8 * 10^{6} \mathrm{~mm}^{4} / \mathrm{mm}} & \text { at midspan location } \\
{[5.47] \mathrm{Is} / \mathrm{S}=16000\left(\mathrm{~L}^{2}\right)-400000(\mathrm{~L})+4 * 10^{6} \mathrm{~mm}^{4} / \mathrm{mm}} & \text { at midspan location }
\end{array}
$$

Based on the results of the study conducted in section 5.4, a graph showing Aw/S vs span length for different girder spacing values was created. Figure 5.120 shows the results for such analysis. A similar distribution to Figure 5.85 can be seen. This behavior was taken into account when creating the final equation to represent the area of the web for this section. A similar twovariable equation for the web area per unit width was created to represent that characteristic. The equation can be seen below; 


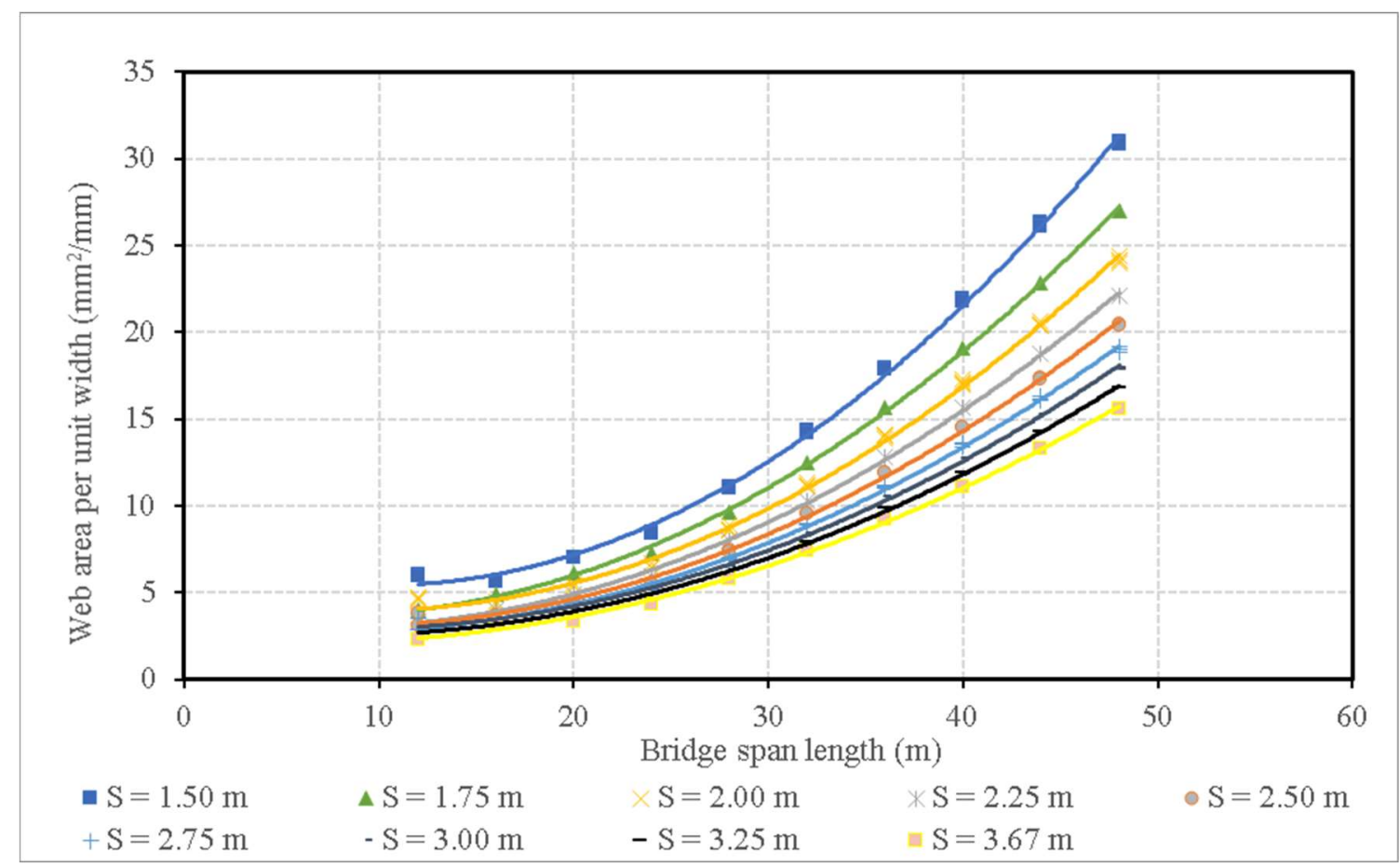

Figure 5.120: Web area per unit width vs span length for four equal span bridge under CL-800 truck loading with girder spacing ranging between $1.5 \mathrm{~m}$ and $3.67 \mathrm{~m}$

$[5.48] \mathrm{Aw} / \mathrm{S}=(0.024-0.036(\mathrm{~S}))\left(\mathrm{L}^{2}\right)-(0.51-0.085(\mathrm{~S}))(\mathrm{L})+9.83-1.59(\mathrm{~S}) \mathrm{mm}^{2} /$ $\mathrm{mm}$

The performance of the equation when compared to the program results can be seen in Figure 5.121. The equation created shows excellent representation while always slightly overestimating the Aw/S required for any given section. 


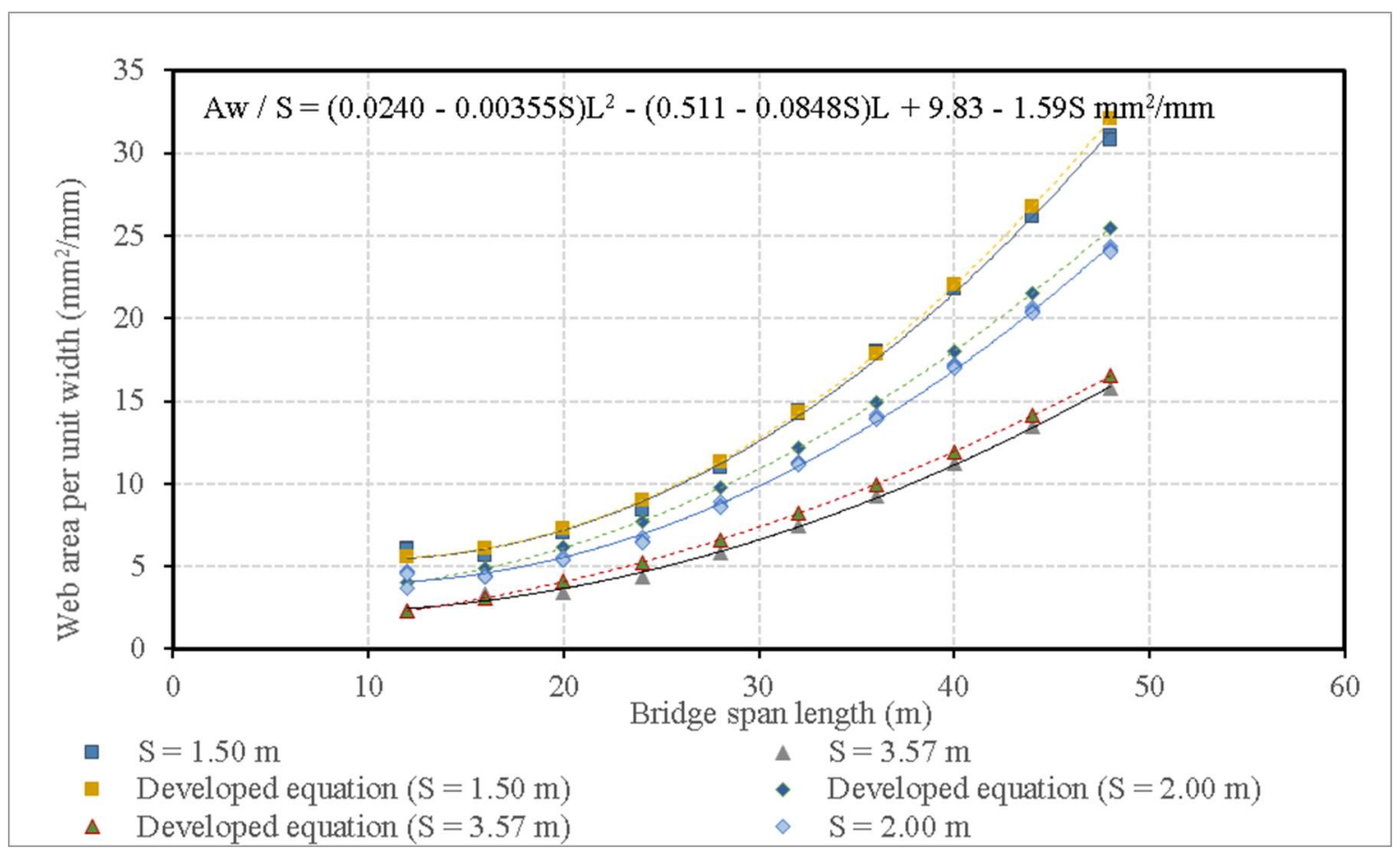

Figure 5.121: Comparison between program results and developed two-variable equation for web area per unit width vs span length for four equal span bridge under CL-800 truck loading with girder spacing ranging between $1.5 \mathrm{~m}$ and $3.67 \mathrm{~m}$

The difference between the results from a similar previous study conducted by Bakht B. and the results from this study can be seen in Figures 5.122 and 5.123 for support location and midspan location respectively. The longitudinal flexural rigidity (Dx) results in this study show a higher upper bound for support locations and midspan locations for longer spans due to these equations being developed by Bakht B. for CL-740 truck loading (Bakht \& Moses, 1988). 


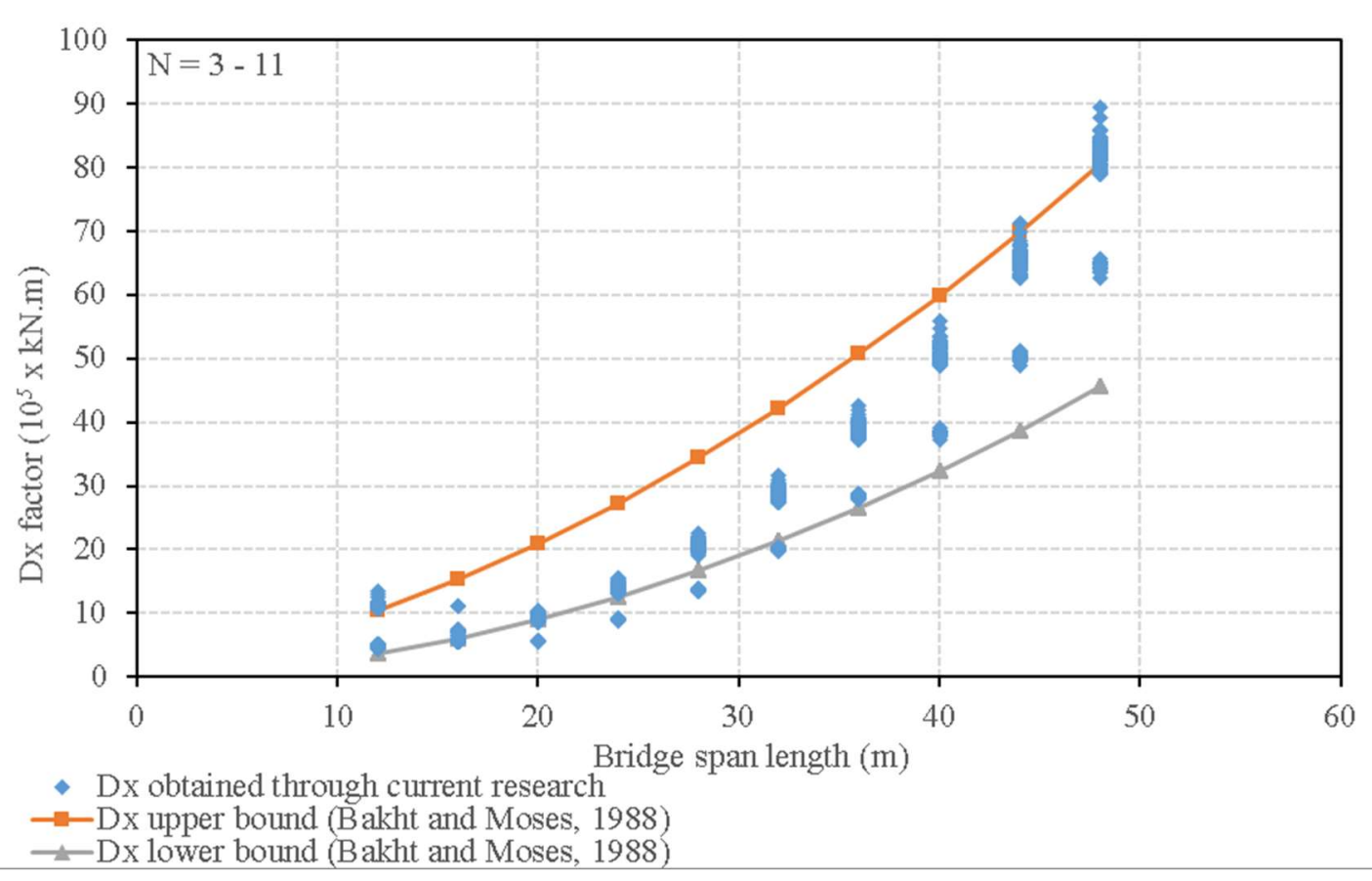

Figure 5.122: Comparison between Dx factor at support location obtained in this research for four equal span bridge under CL-800 truck loading and the boundary values obtained by Bakht B., and Moses, F (Bakht \& Moses, 1988)

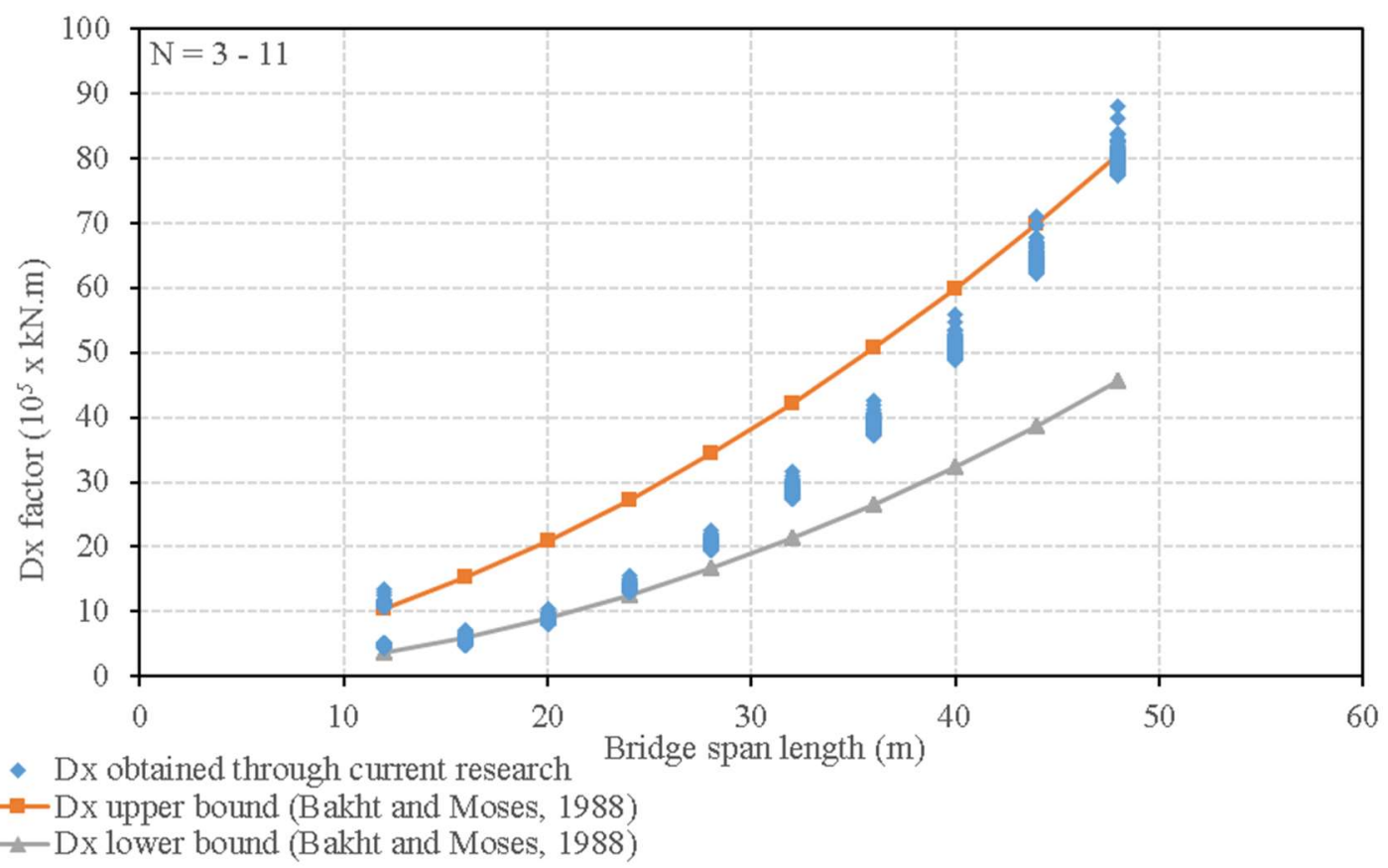

Figure 5.123: Comparison of Dx factor at midspan location obtained in this research for four equal span bridge under CL-800 truck loading and previous research (Bakht \& Moses, 1988) 


\section{Chapter VI}

\section{Conclusion and Recommendations for Future Research}

\subsection{Conclusions}

As the steel technology is falling behind the concrete industry in terms of ease of design and implementation, this research aimed to increase the efficiency and optimization of design in the early stages such as bidding and preliminary analysis. Firstly, ready-made equations were created to mimic the effect of truck loading on a single lane of bridge loading. The truck loadings considered in that portion of the research were the (i) CL-625 truck loading used in all Canada's Provinces except Ontario and Alberta, (ii) CL625-ONT truck loading used in Ontario, and (iii) CL-800 truck loading used in Alberta. Bridge configurations included single span bridges, twoequal-span bridges, three-equal-span bridges and, four-equal-span bridges between $12 \mathrm{~m}$ and 48 $\mathrm{m}$ in length. Third degree polynomial equations were produced for the maximum longitudinal moment generated by one lane of CL-W loading, $\mathrm{M}_{\mathrm{T}}$, the maximum longitudinal shear generated by one lane of CL-W loading, $\mathrm{V}_{\mathrm{T}}$, support reaction generated by one lane of CL-W loading, $\mathrm{R}_{\mathrm{T}}$, deflection generated by one lane of CL-W loading, $\Delta_{\mathrm{T}}$ and can be found in chapter 3 .

Furthermore, by utilizing the developed equations in addition to CHBDC code requirements, a VB.Net software was developed that is able to calculate live loads at all limit states, dead loads at all limit states, truck loading factor $\mathrm{F}_{\mathrm{T}}$ at all limit states for shear and moment and, maximum factored moment, shear, deflection and support reaction at all limit states. In addition to the load calculation capabilities, the program is able to assess girder sections as per CHBDC code requirements and produce an optimized girder section for the applied loadings as per the code limitations. The developed program was limited by the scope of work of the developed live load equations in chapter 3. Finally, by means of using the developed program, 6240 bridge configuration cases were studied in order to optimize an I-girder section size for super structure. The scope of work included bridges of span lengths $12 \mathrm{~m}$ to $48 \mathrm{~m}$, truck loadings of CL-625 and CL-800 and, single span to four-equal span bridge configurations. The results from this analysis were used to study the effect of number of girders on the moment of inertia of the optimized Igirder section size, the effect of bridge width on the moment of inertia of the optimized I-girder section size, the effect of girder number and girder spacing on the area of the web of inertia of the optimized I-girder section size. It was found that the moment of inertia $I_{x}$ per unit width had a 
strong correlation to the span length. Furthermore, the web area $\mathrm{A}_{\mathrm{w}}$ per unit width had a strong correlation with both the spacing and the span length. Second degree polynomial equations were developed for the moment of inertia per unit width within the scope of the research.

Additionally, two-variable equations were developed for the area of web per unit width in order to mimic the behavior of web area which depends on the girder spacing and span length. Finally, the flexural rigidity of data produced was compared to a previous study conducted by Bakht B. et al. (Bakht \& Moses, 1988). The data produced in this research showed tighter packing but similar distribution to the results produced in the previous research conducted by Bakht B. et al. Finally, upon studying the produced equations for Ix and Aw per unit width, it was also found that the equations produced for multi-span bridges are very similar to each other.

\subsection{Limitations of use}

In this research,

1- The end conditions of the girders were considered to be simply supported (conventional construction).

2- The effect of the construction method of the cantilever slab on the transverse capacity of the braced exterior girder is not included in this study. 


\subsection{Recommendations for future research}

Based on the research conducted in this publication, the author recommends future research be conducted on the following:

1- Study and produce empirical equations for live load for multi-span bridge configurations with unequal span lengths.

2- Produce similar ready-made equations to mimic the effect of dead load to replace the IL method.

3- Further study the effect of various aspects of the bridge configurations on the girder dimensions and modify the equations produced here accordingly.

4- Produce similar equations for different steel sections such as WWF sections, singly symmetrical W sections, box-girder sections etc. to further optimize a suitable design.

5- Conduct similar research for skewed and curved bridge configurations.

6- Study the effect of increasing the steel section depth at the interior support on the minimum section size to satisfy the SLS, ULS and, FLS requirements.

7- Extend the scope of work to include integral abutment bridges.

8- Study potential change in girder size due to the effects of construction of cantilever slab on the transverse capacity of braced exterior girders. 


\section{Appendix A: CL-625 truck loading optimization program results}

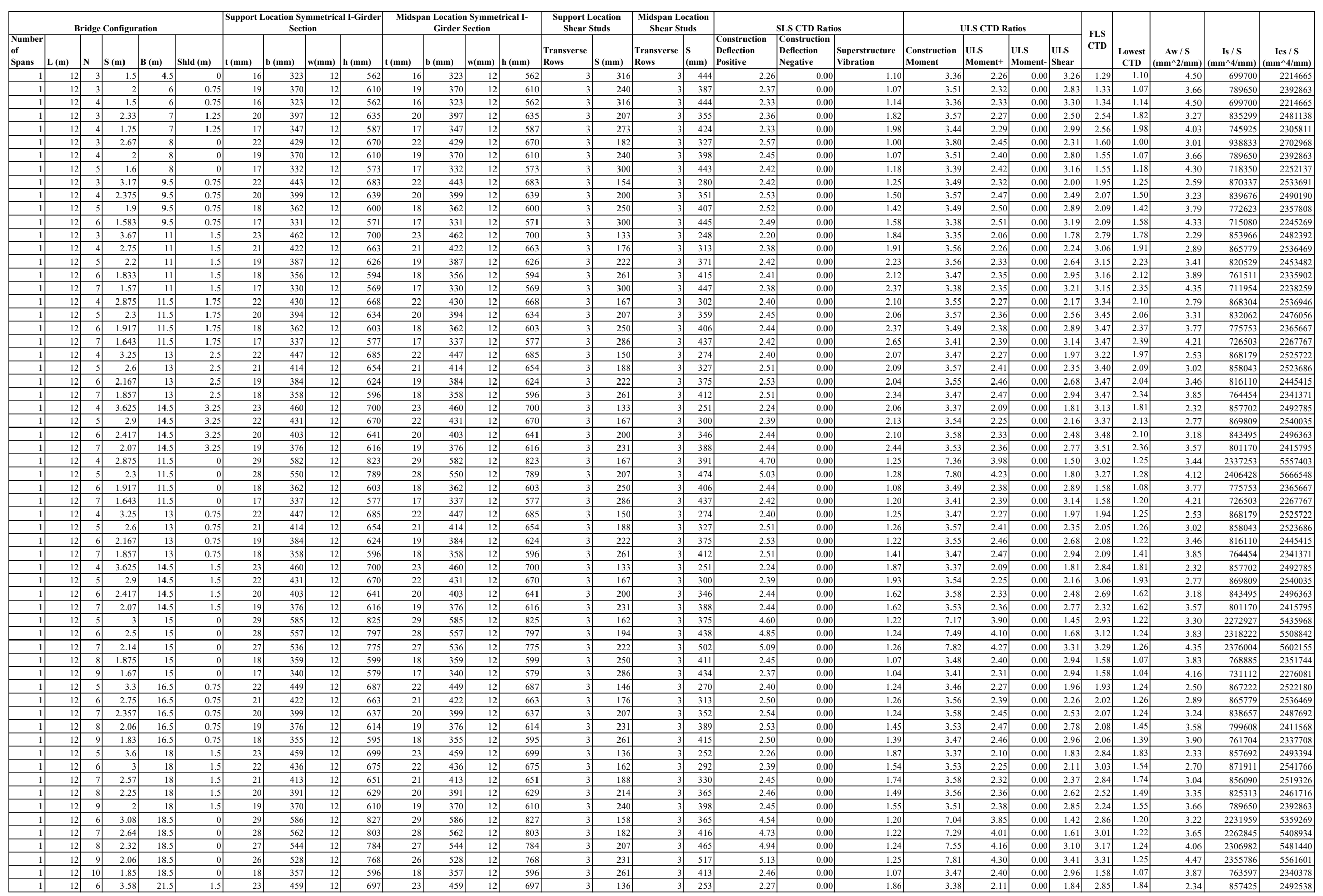




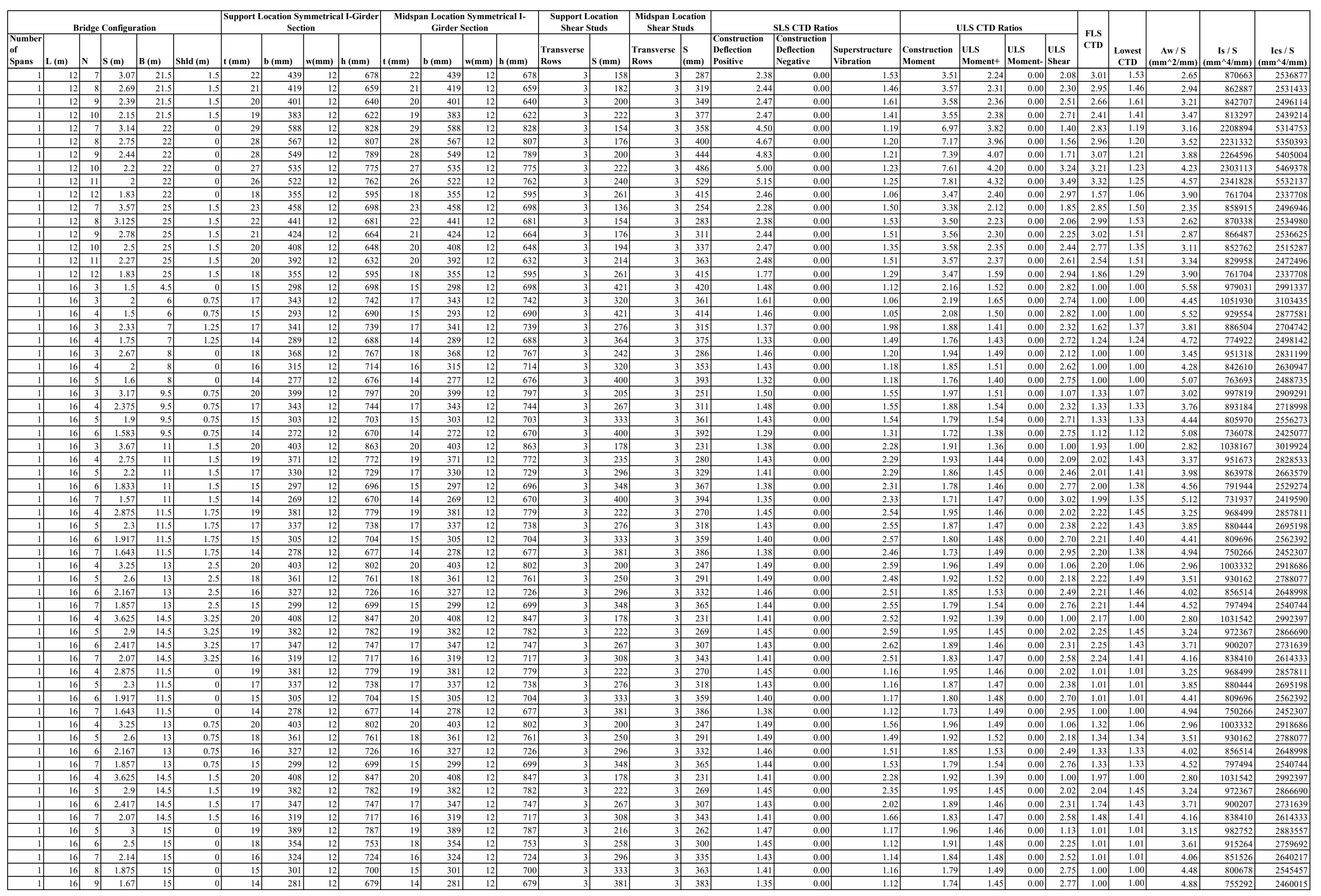




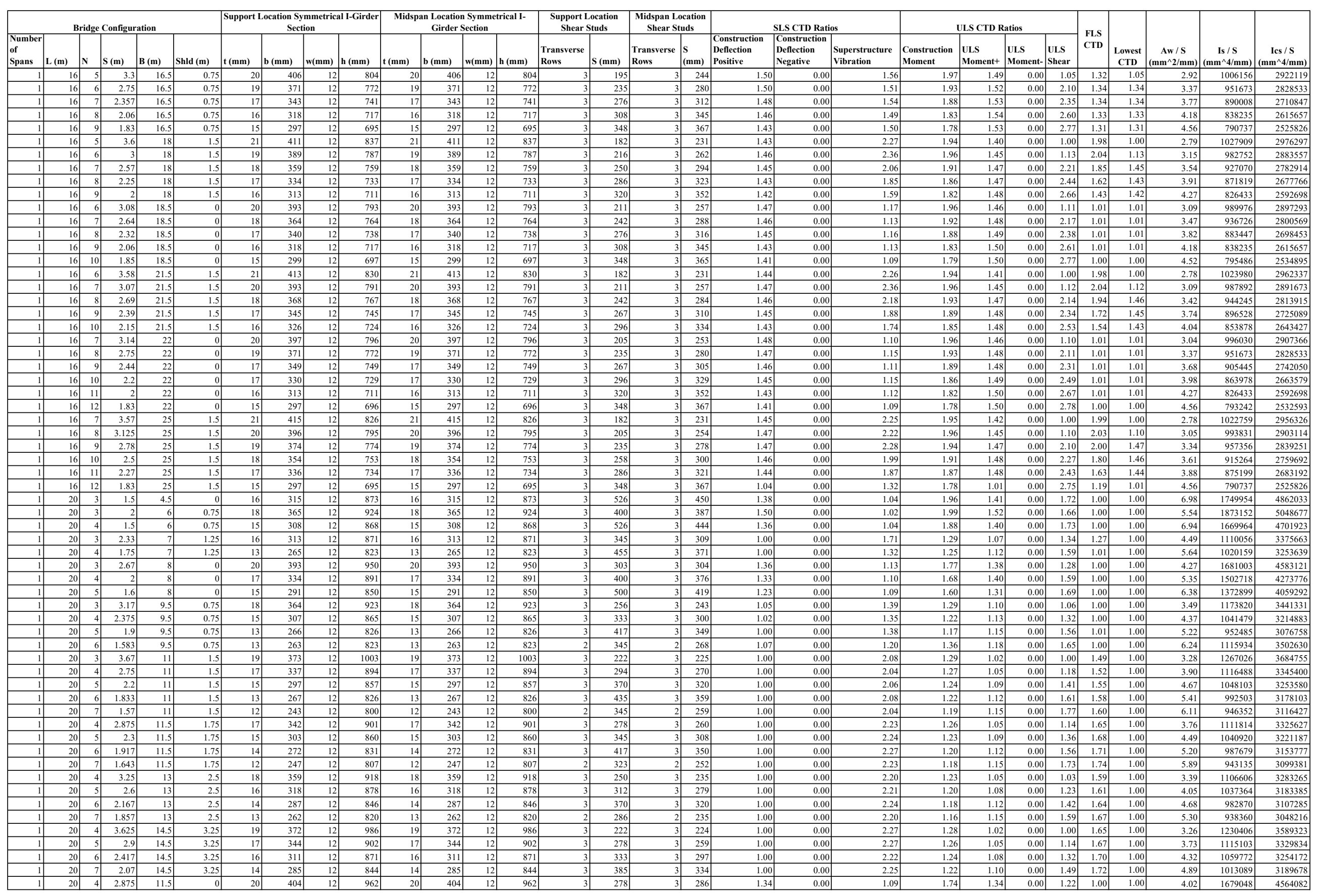




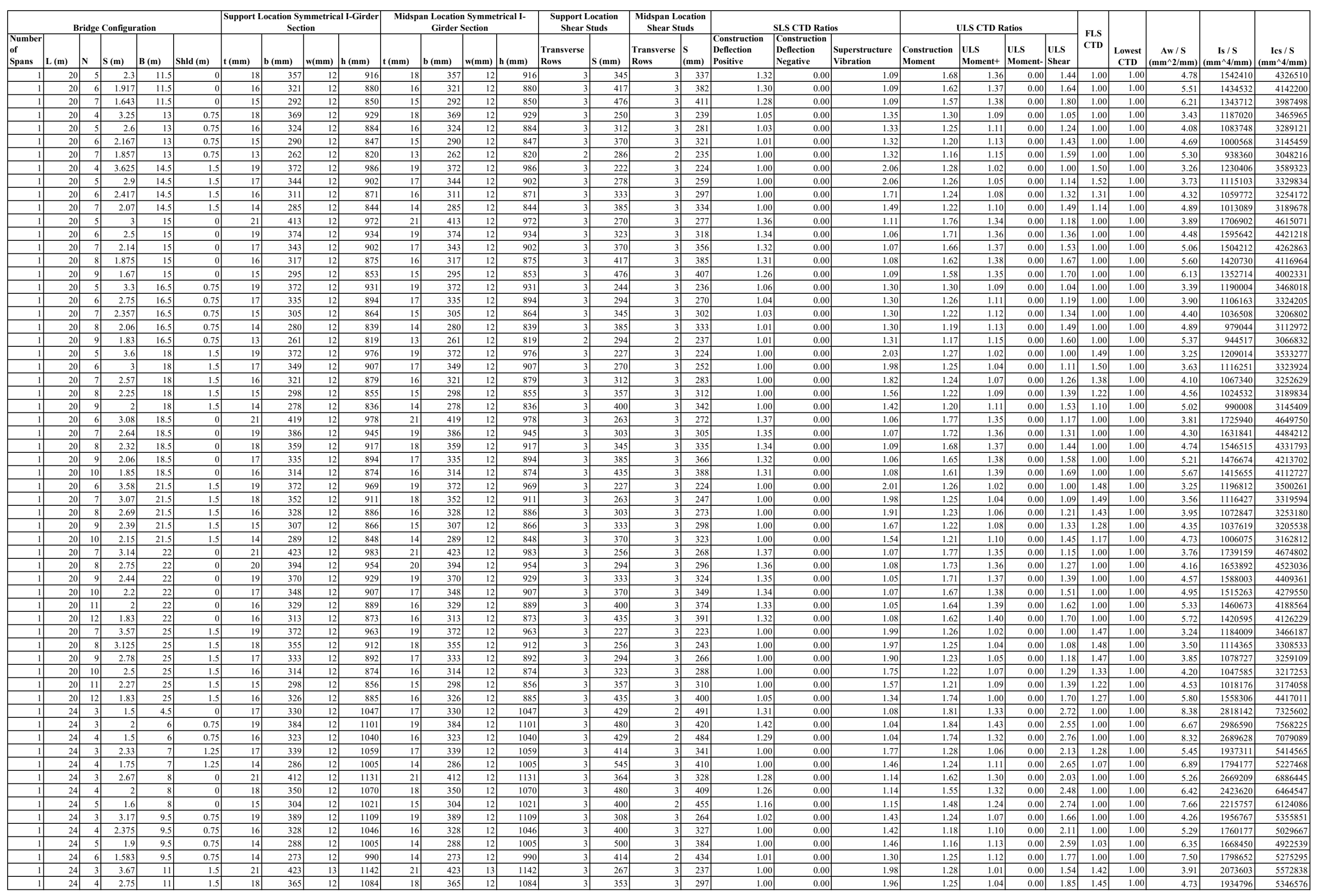




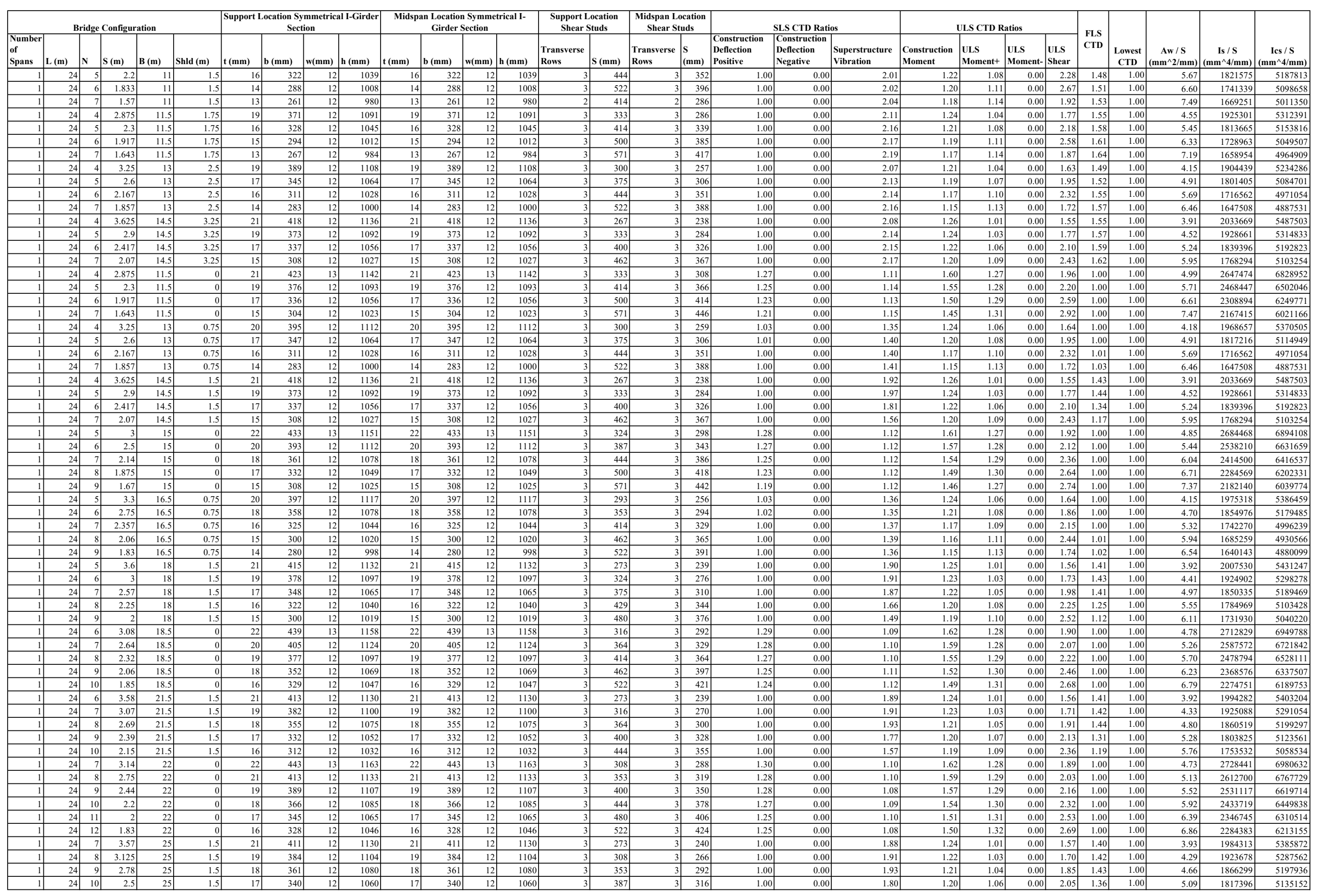




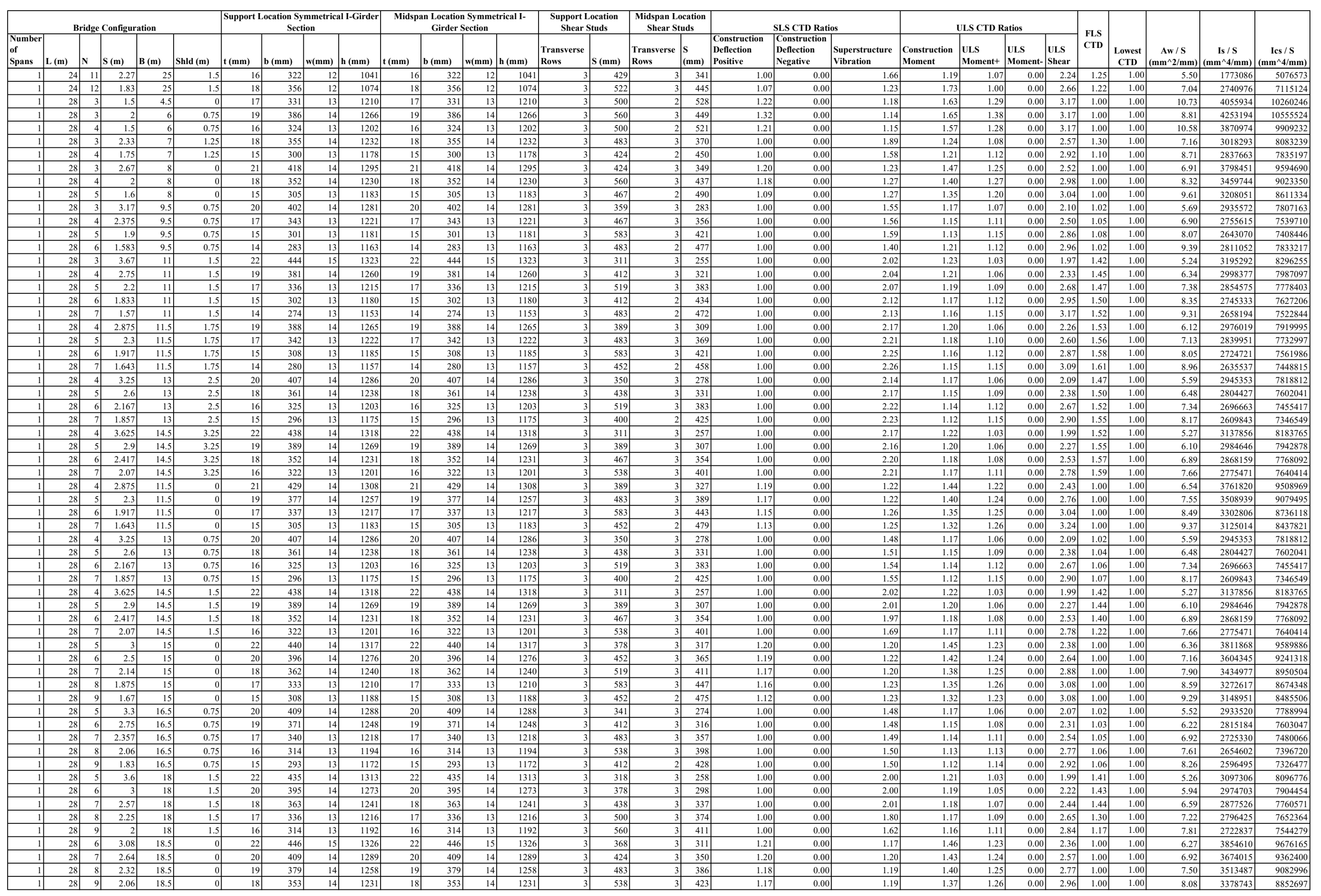




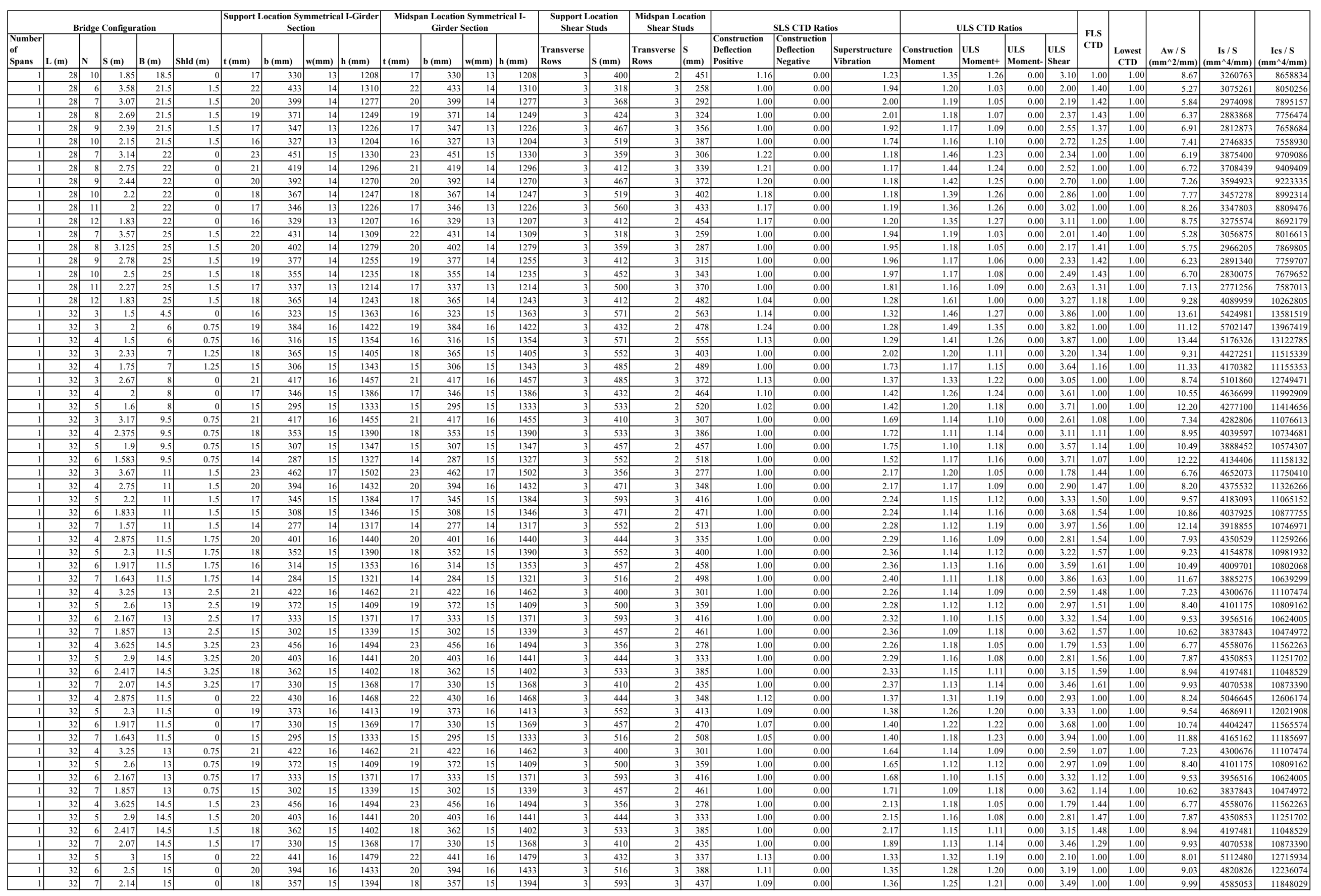




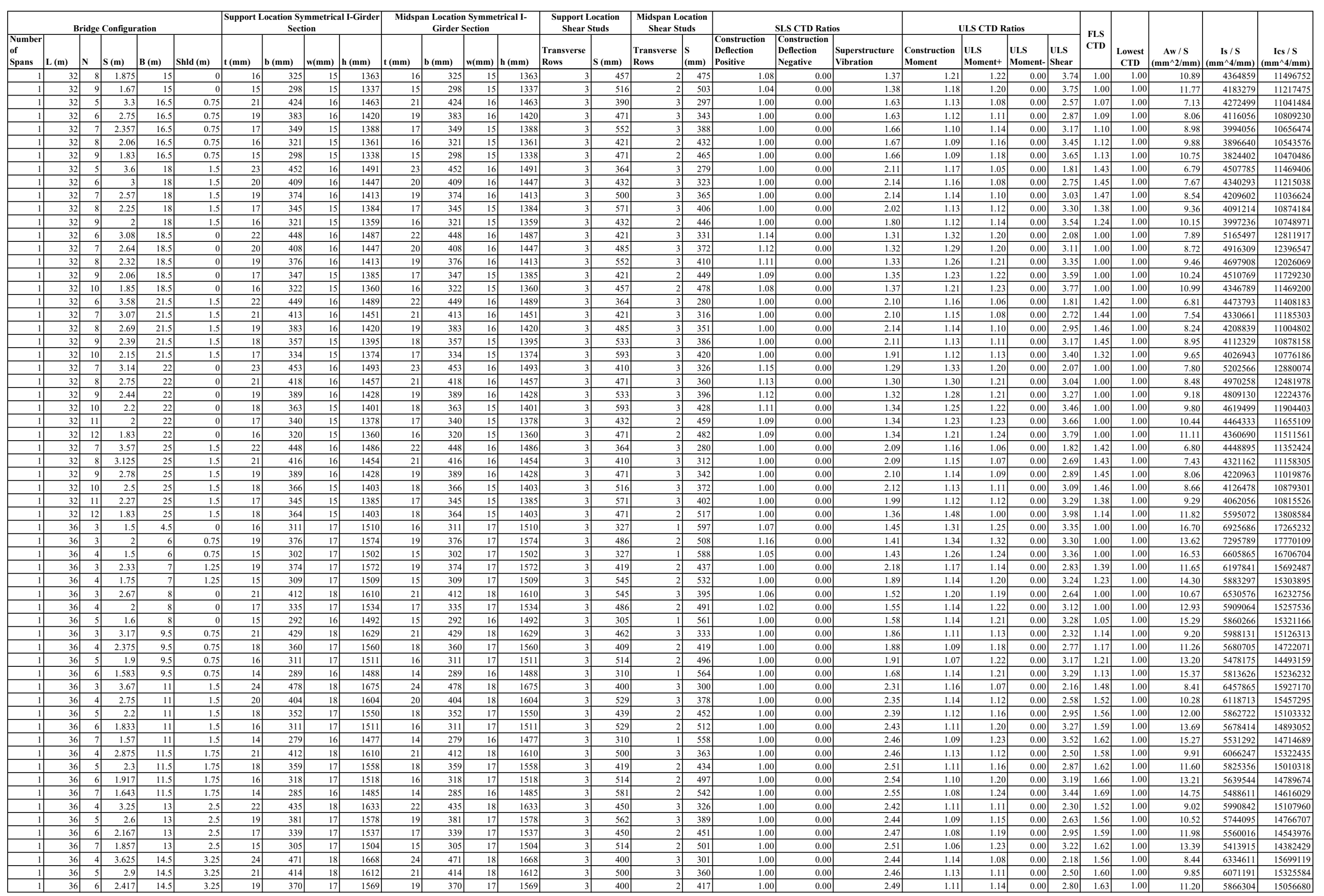




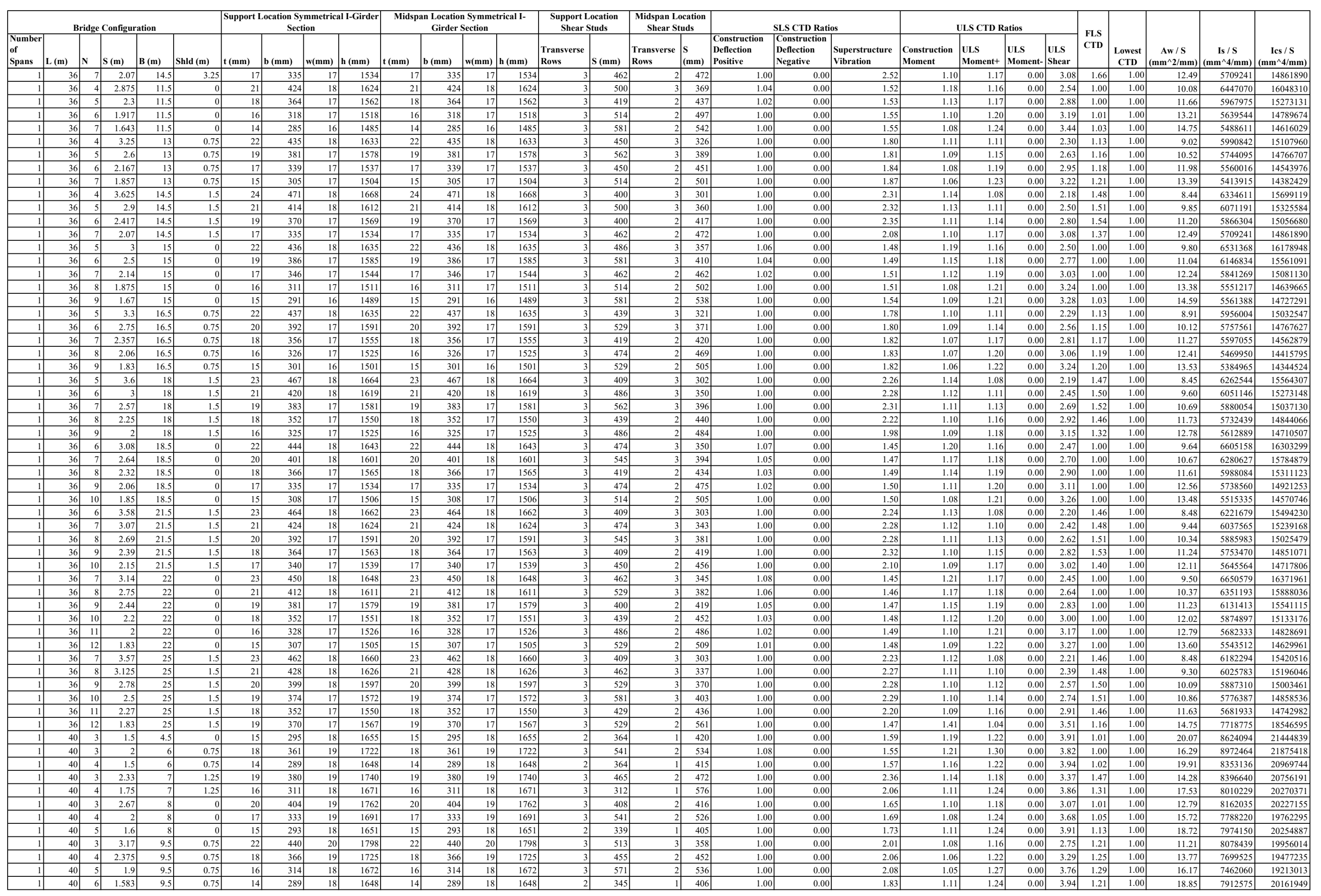




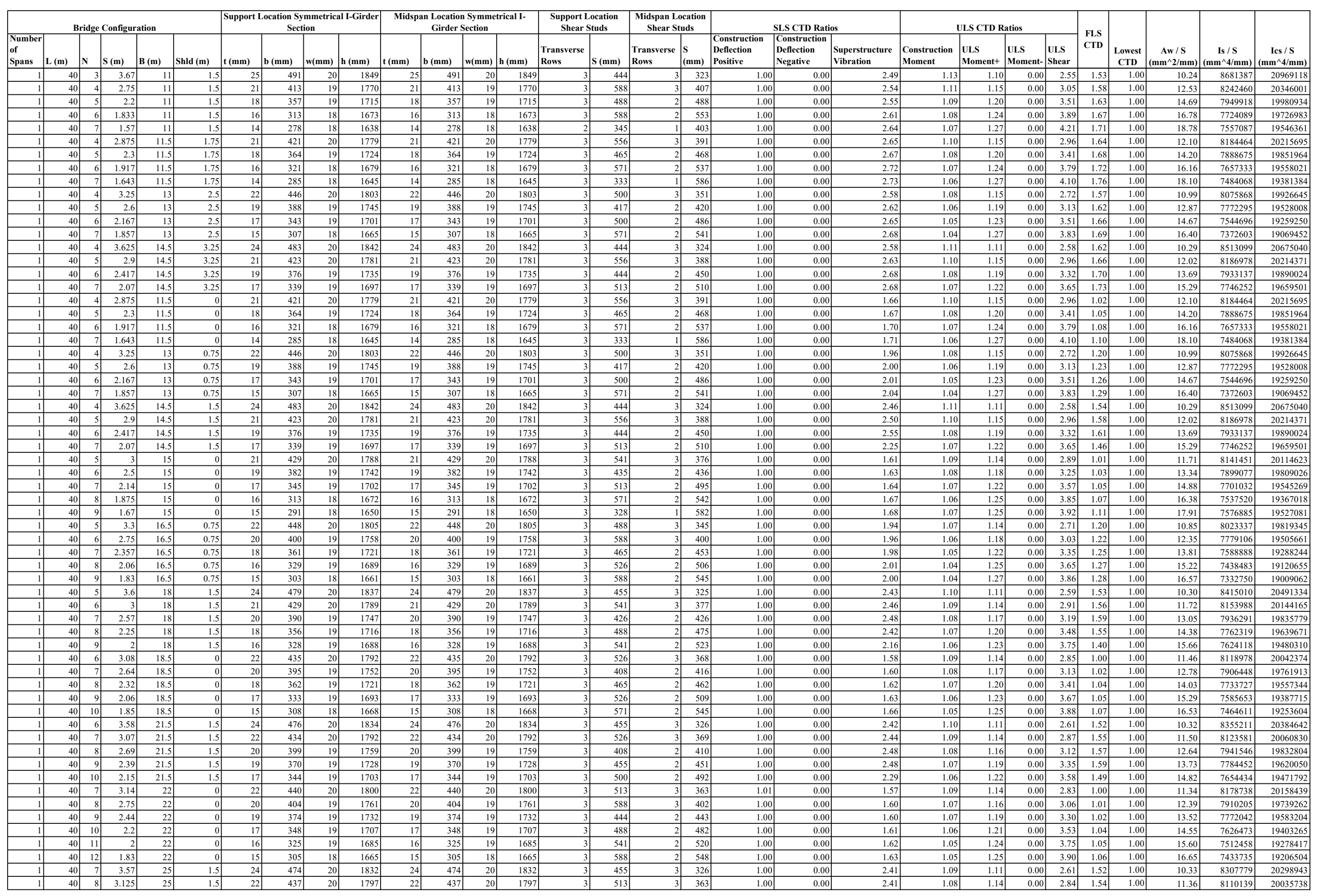




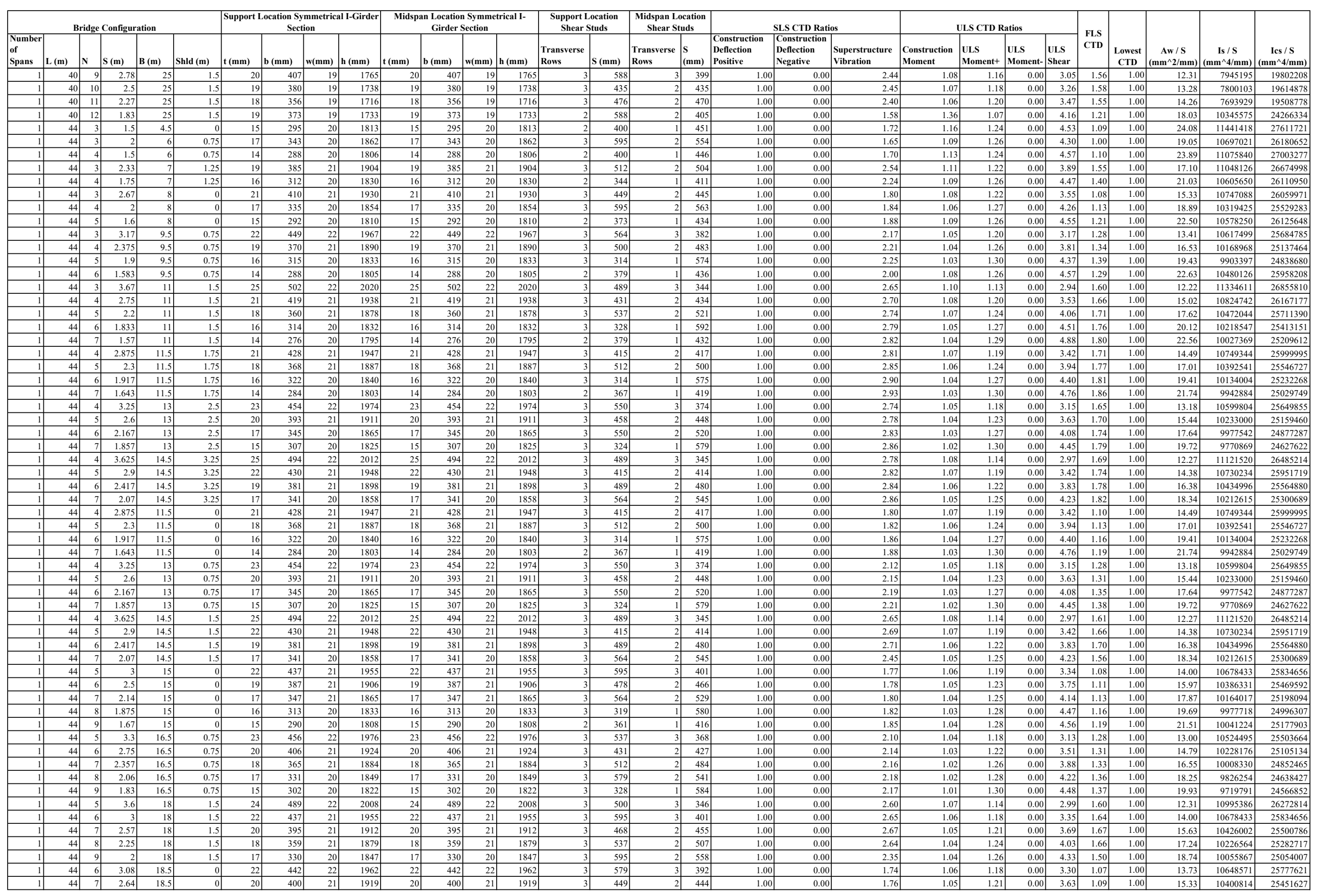




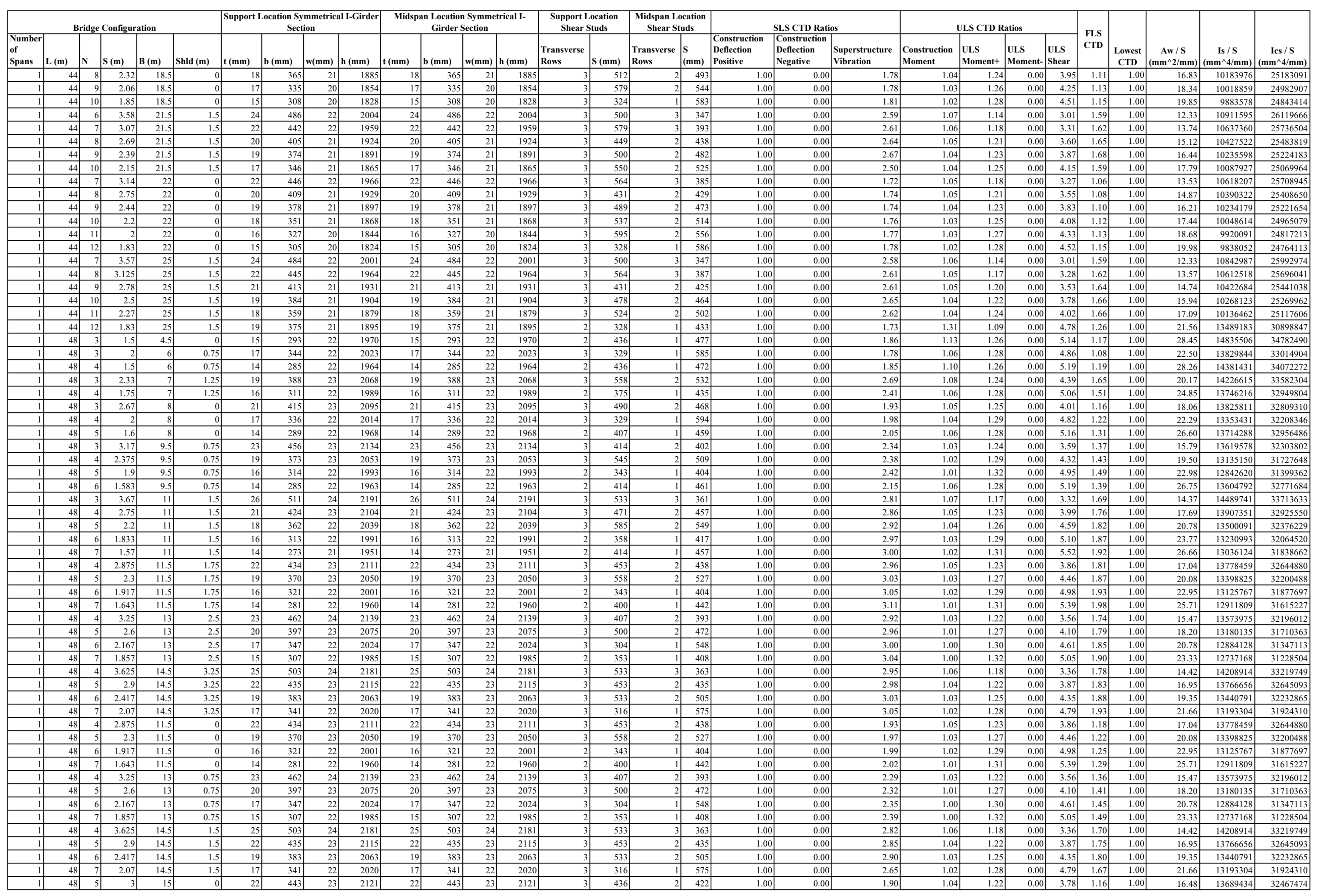




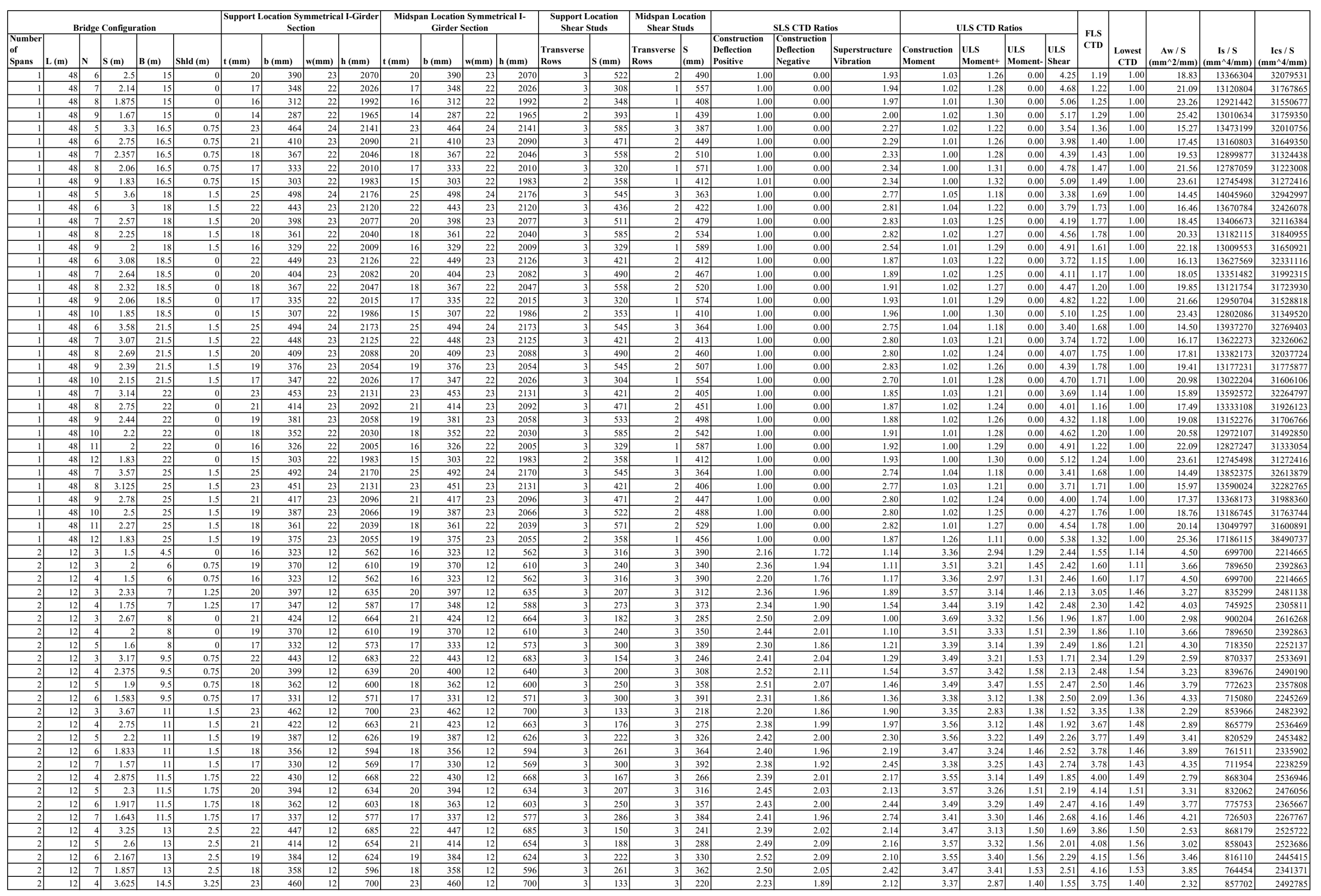




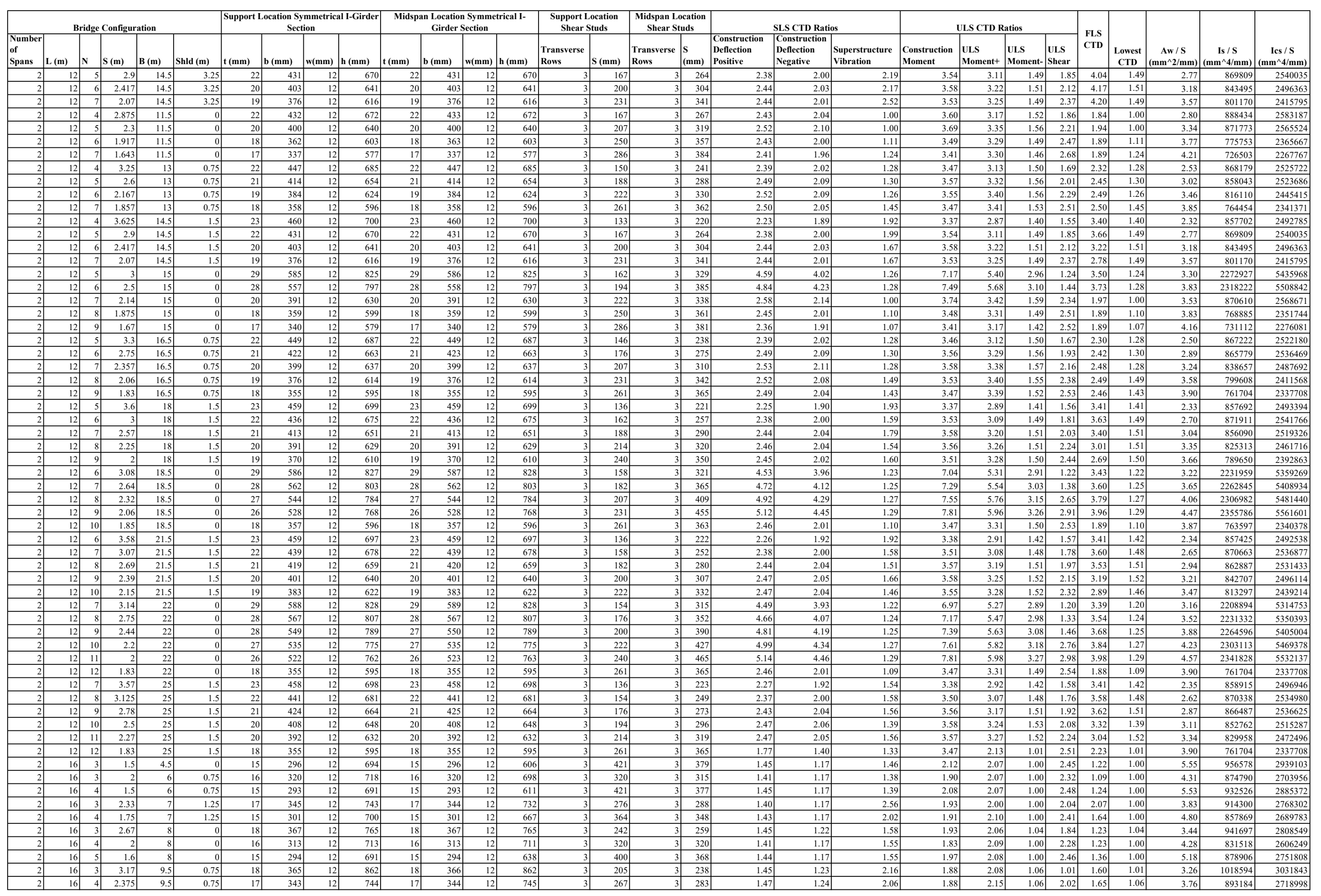




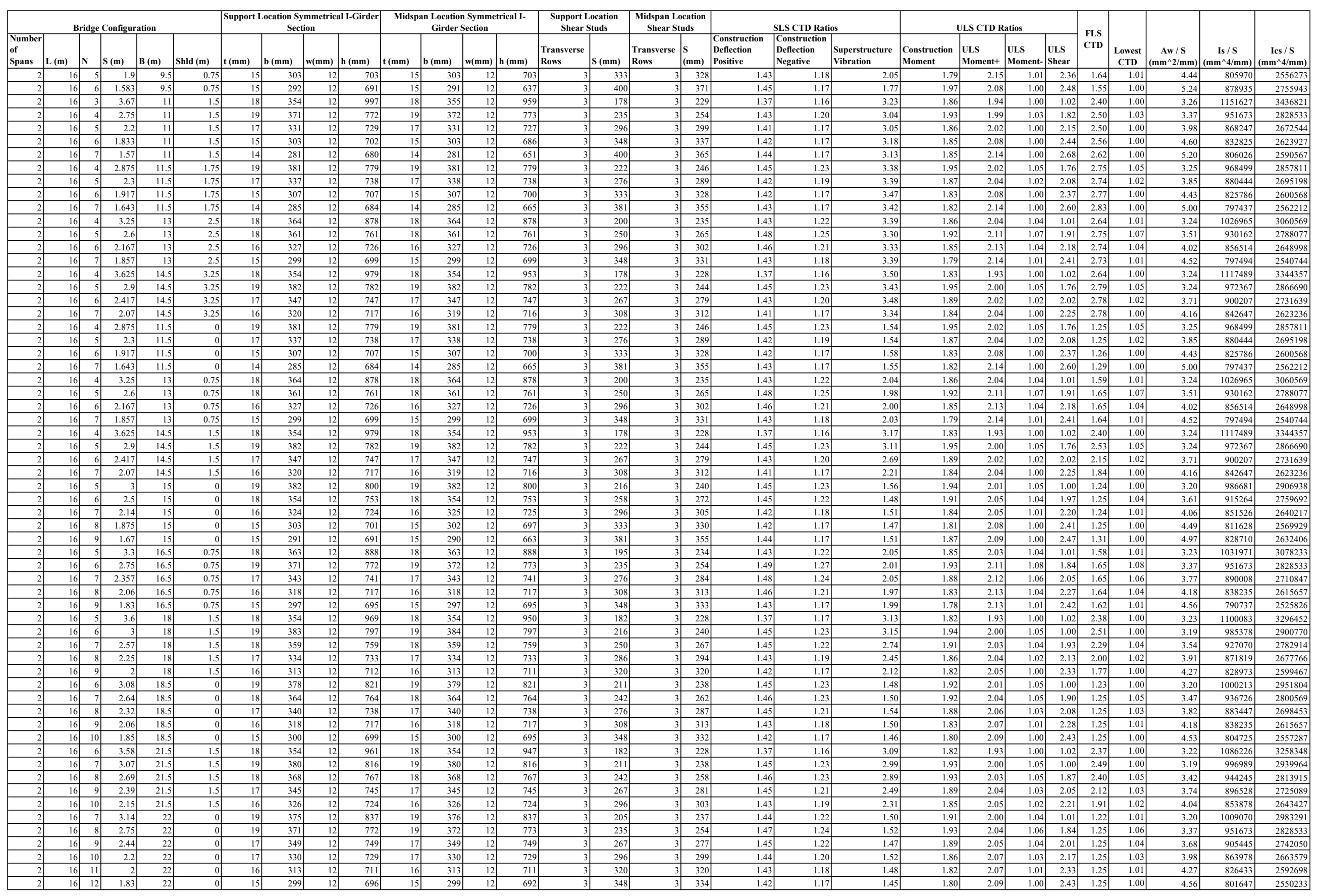




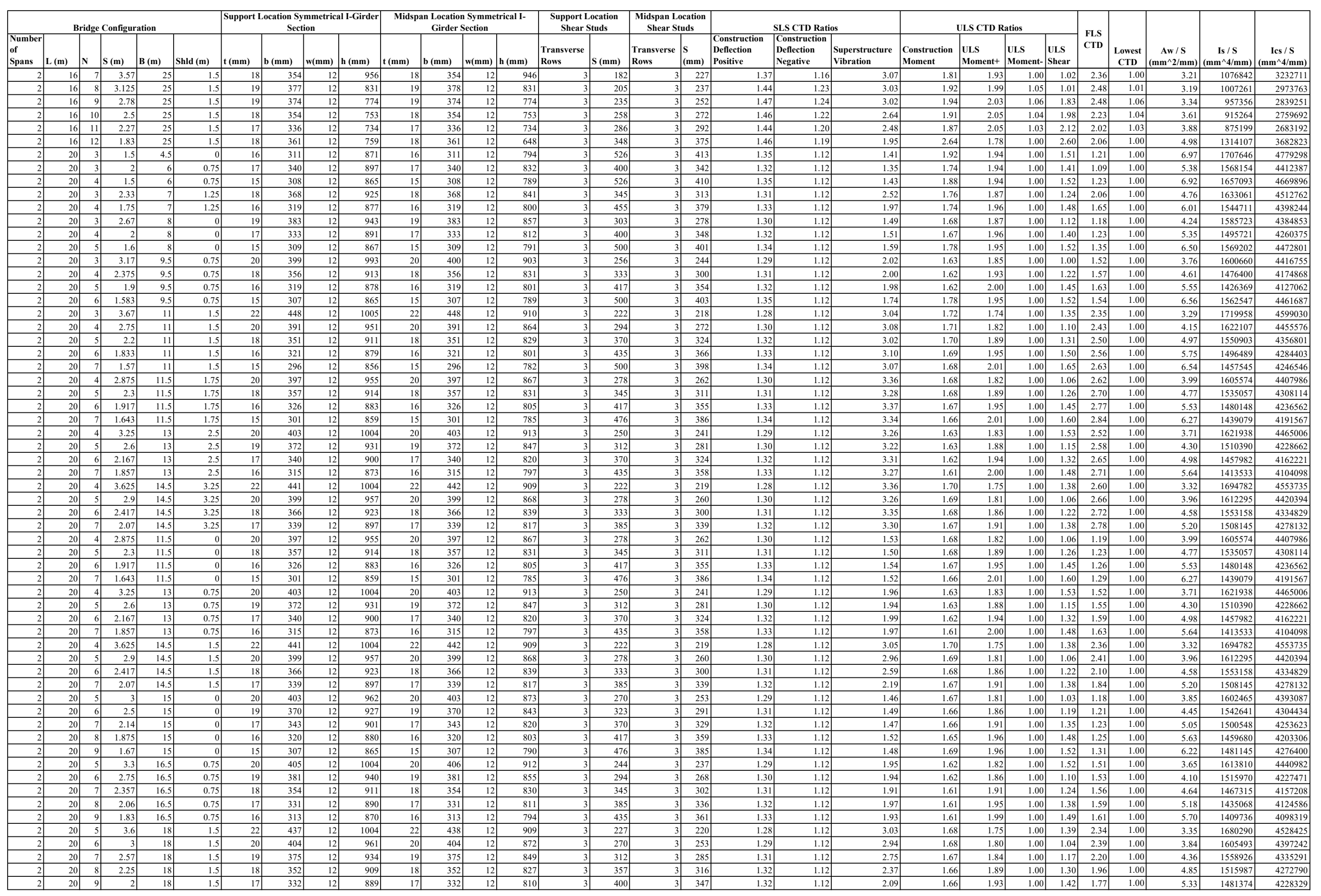




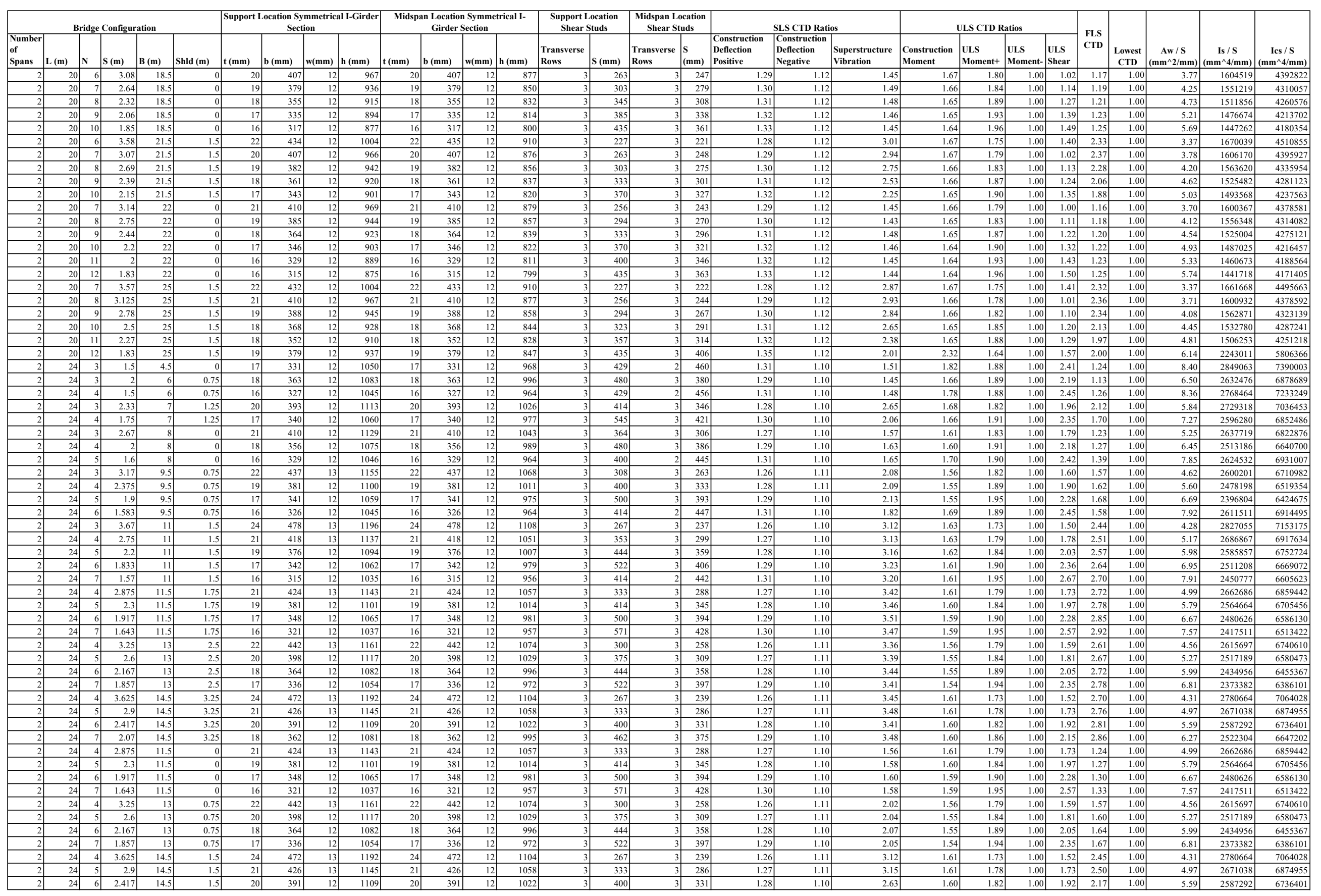




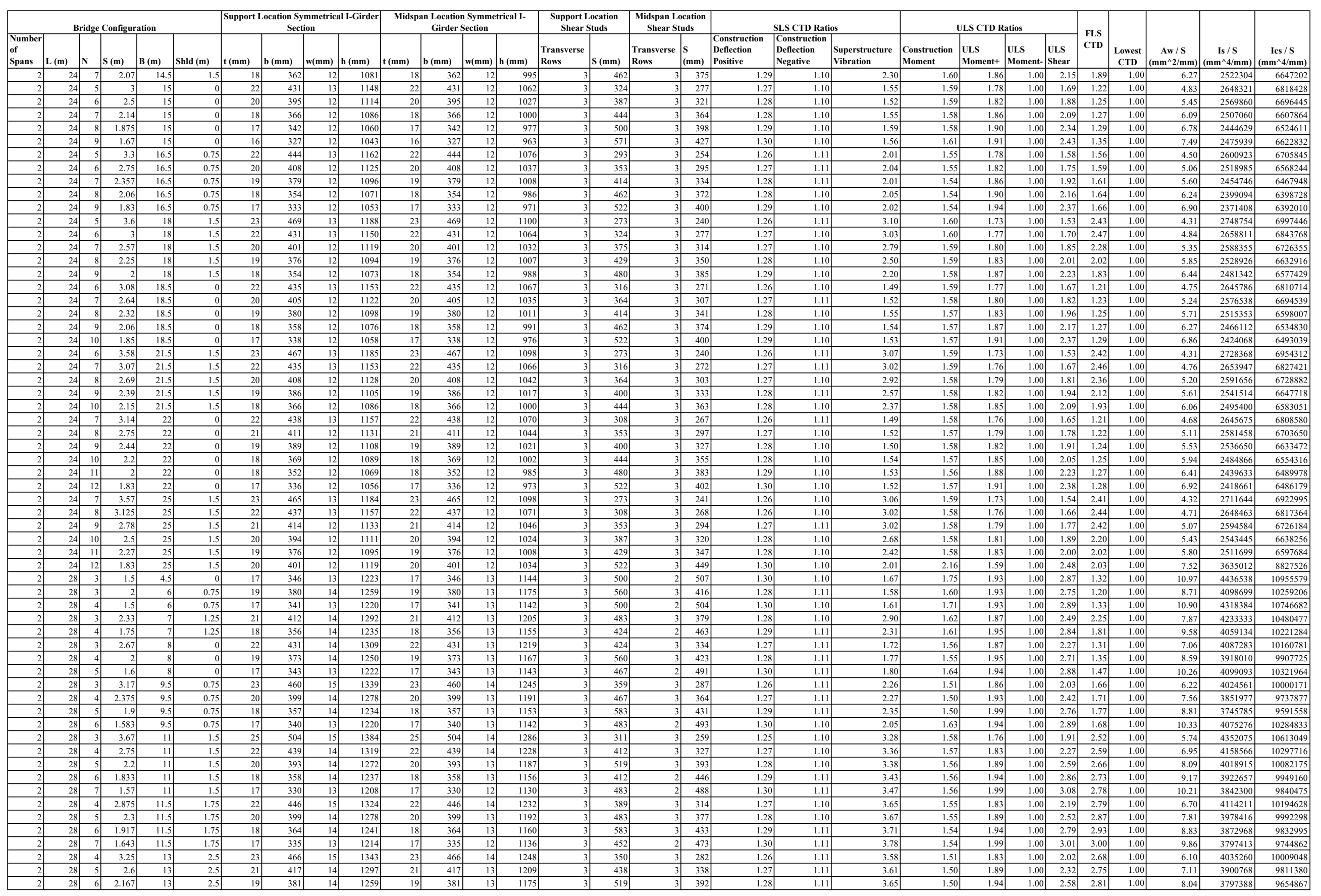




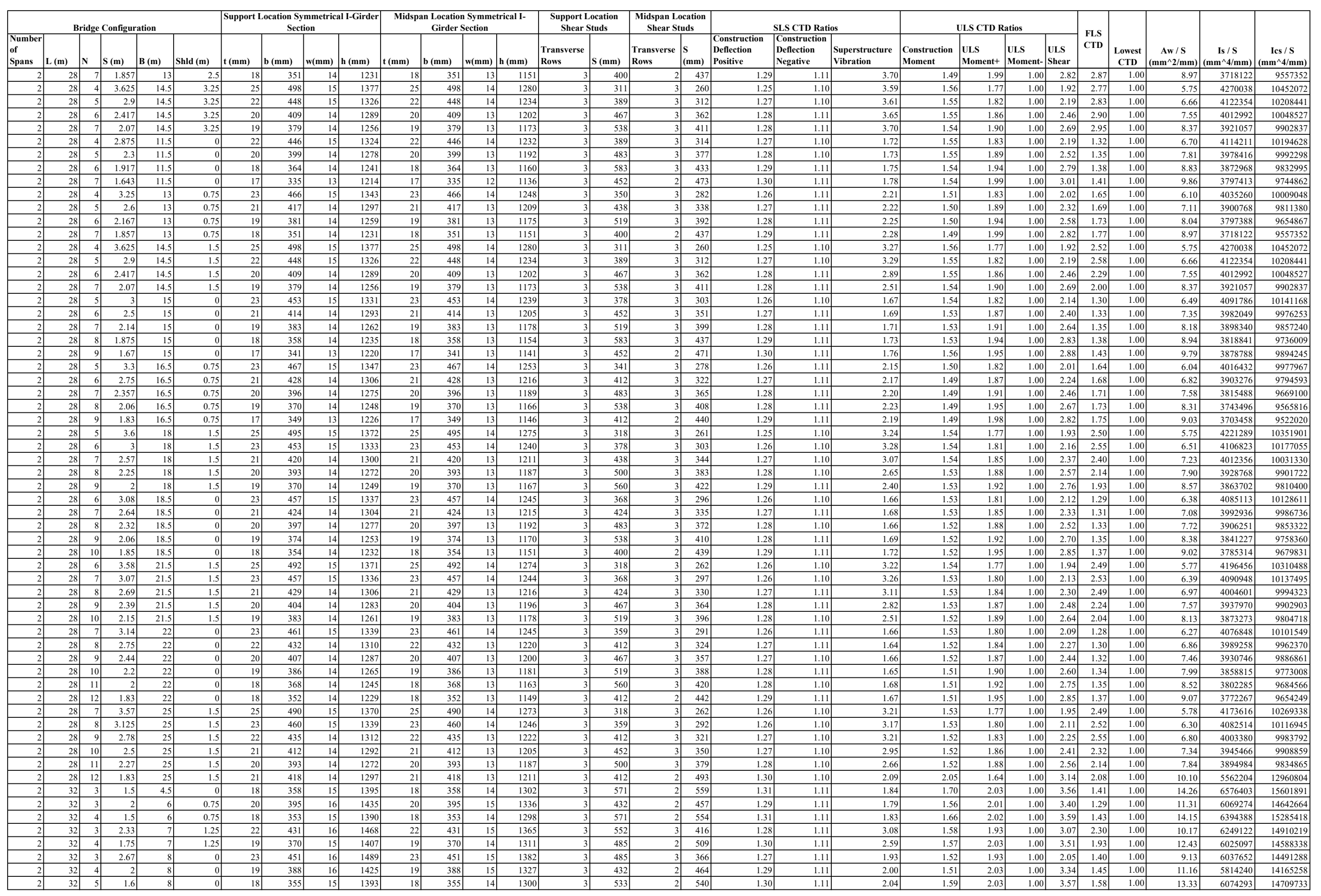




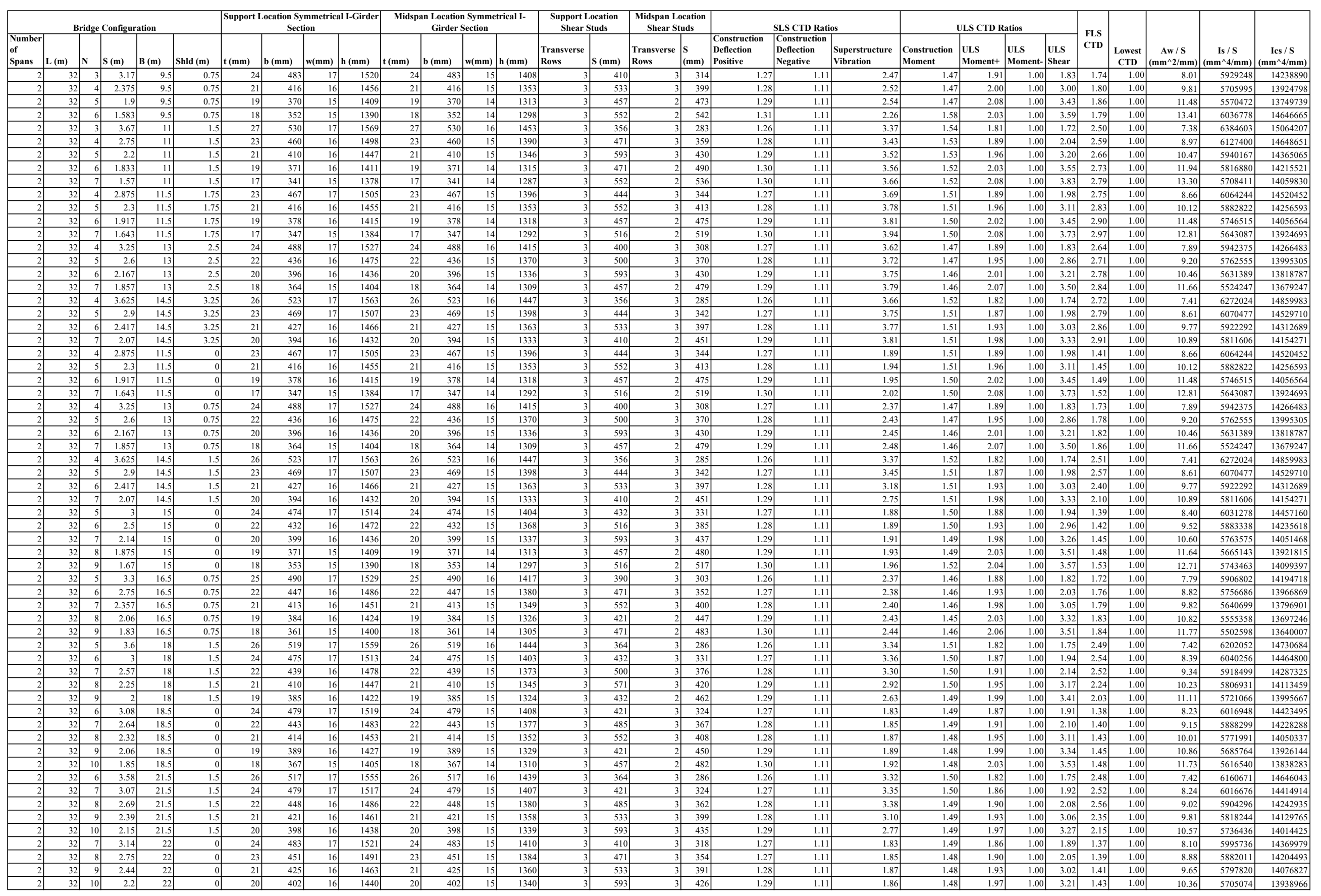




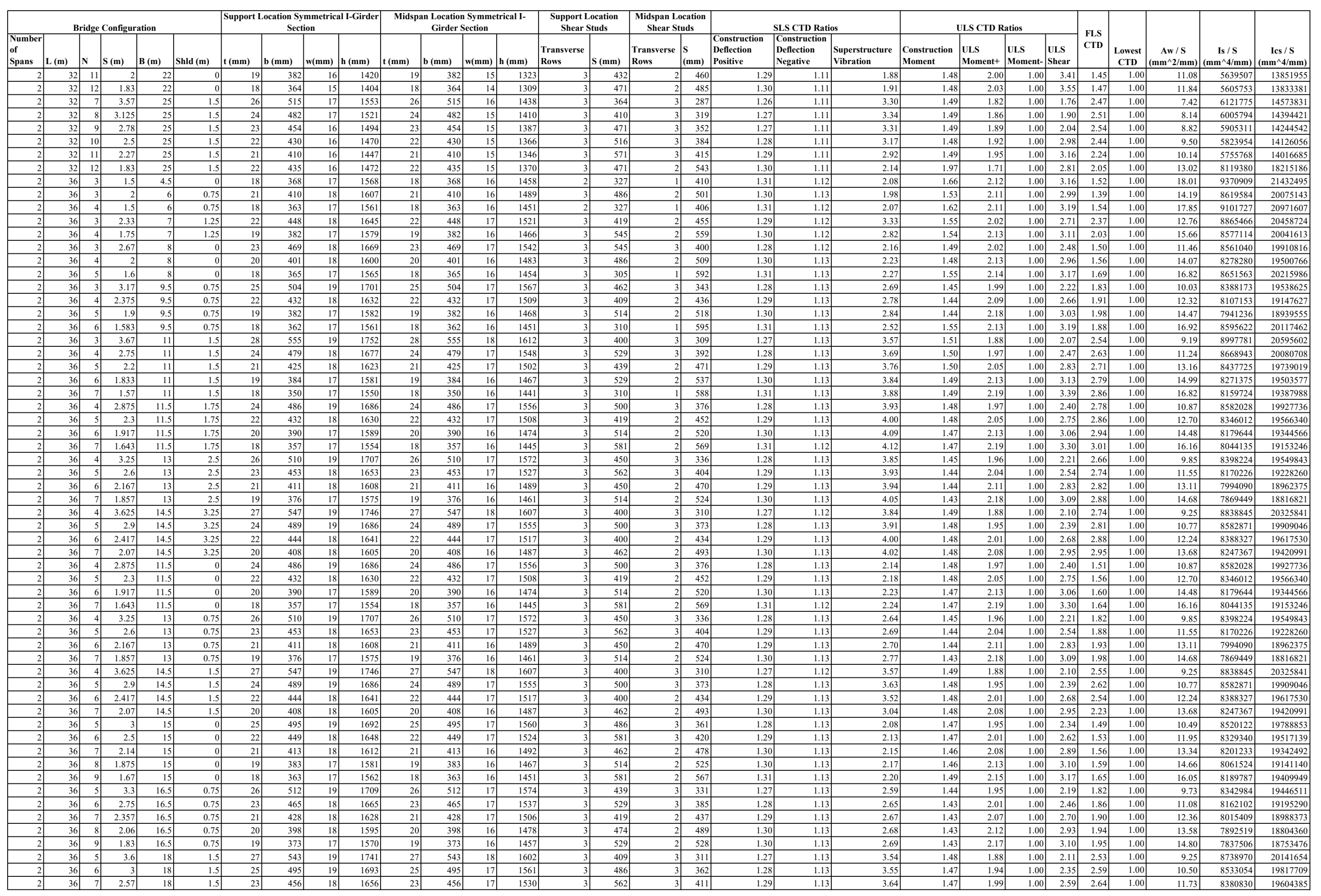




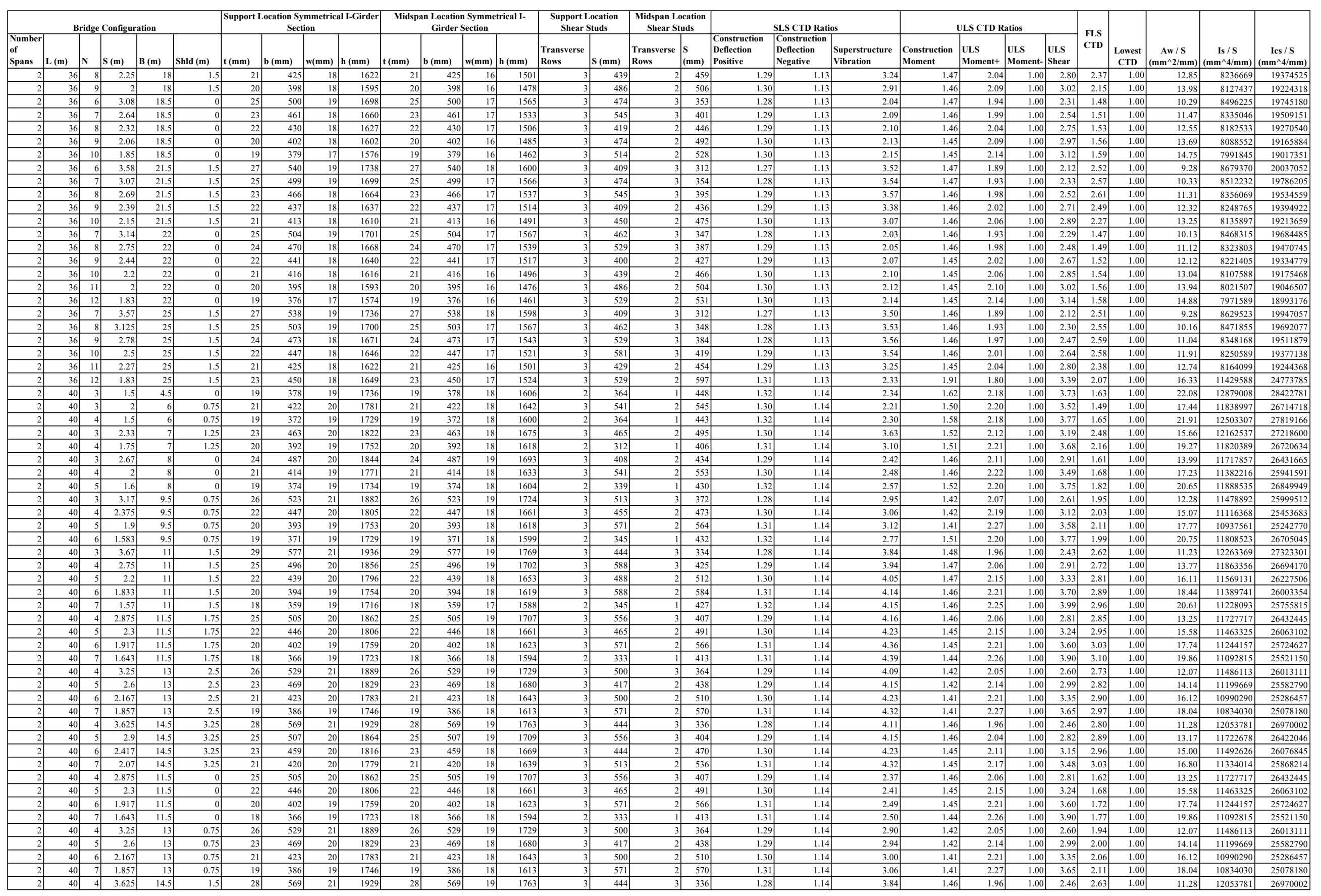




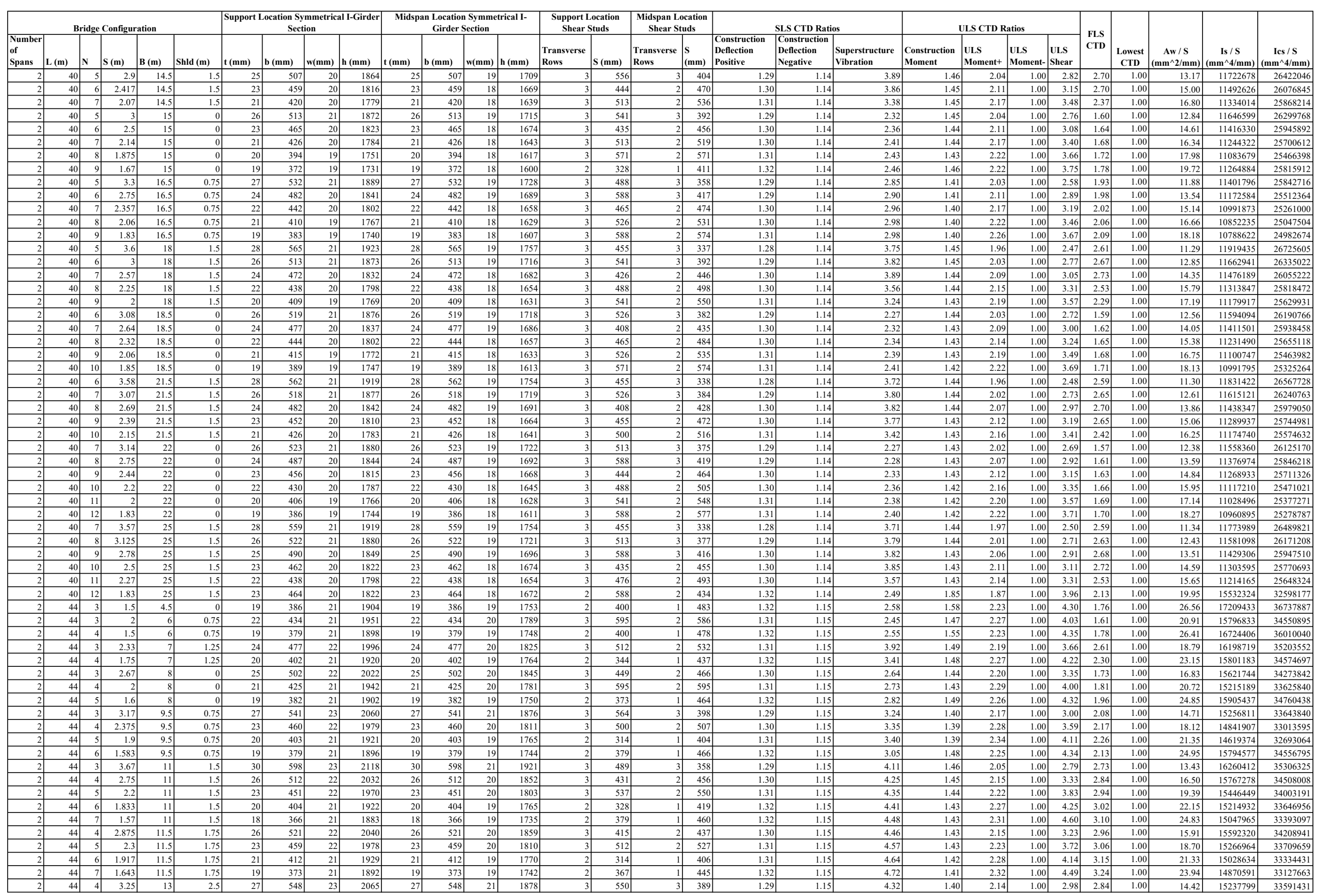




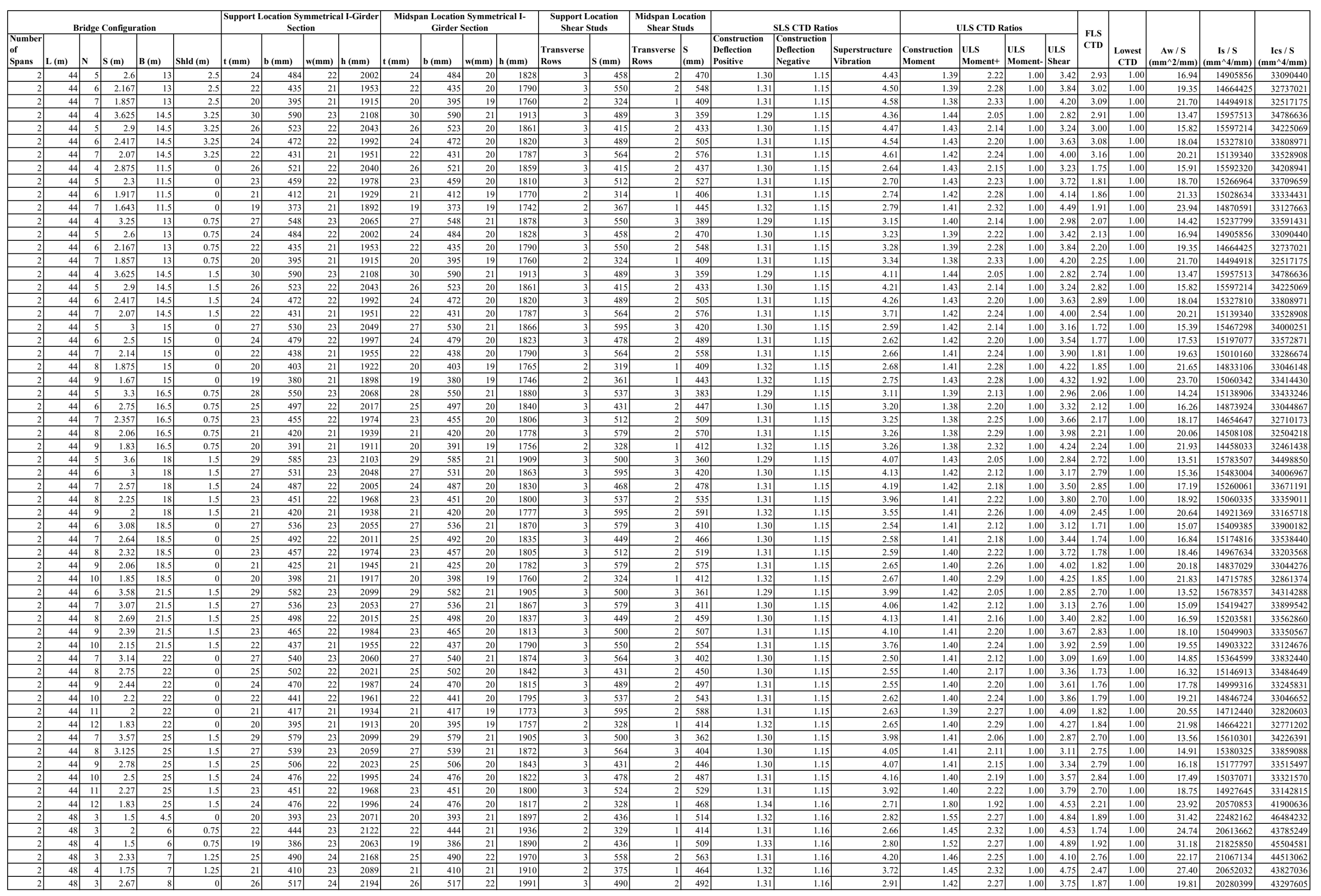




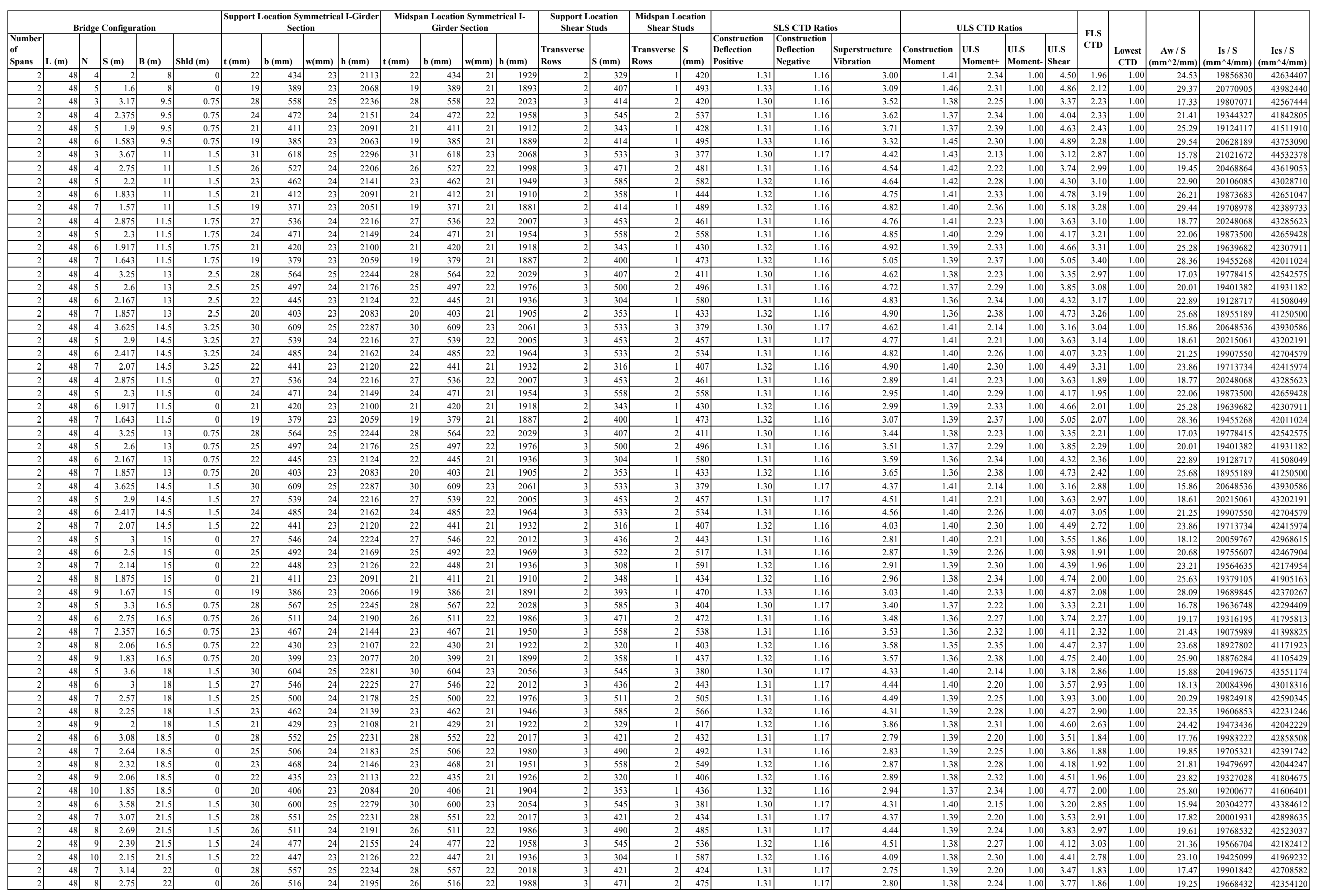




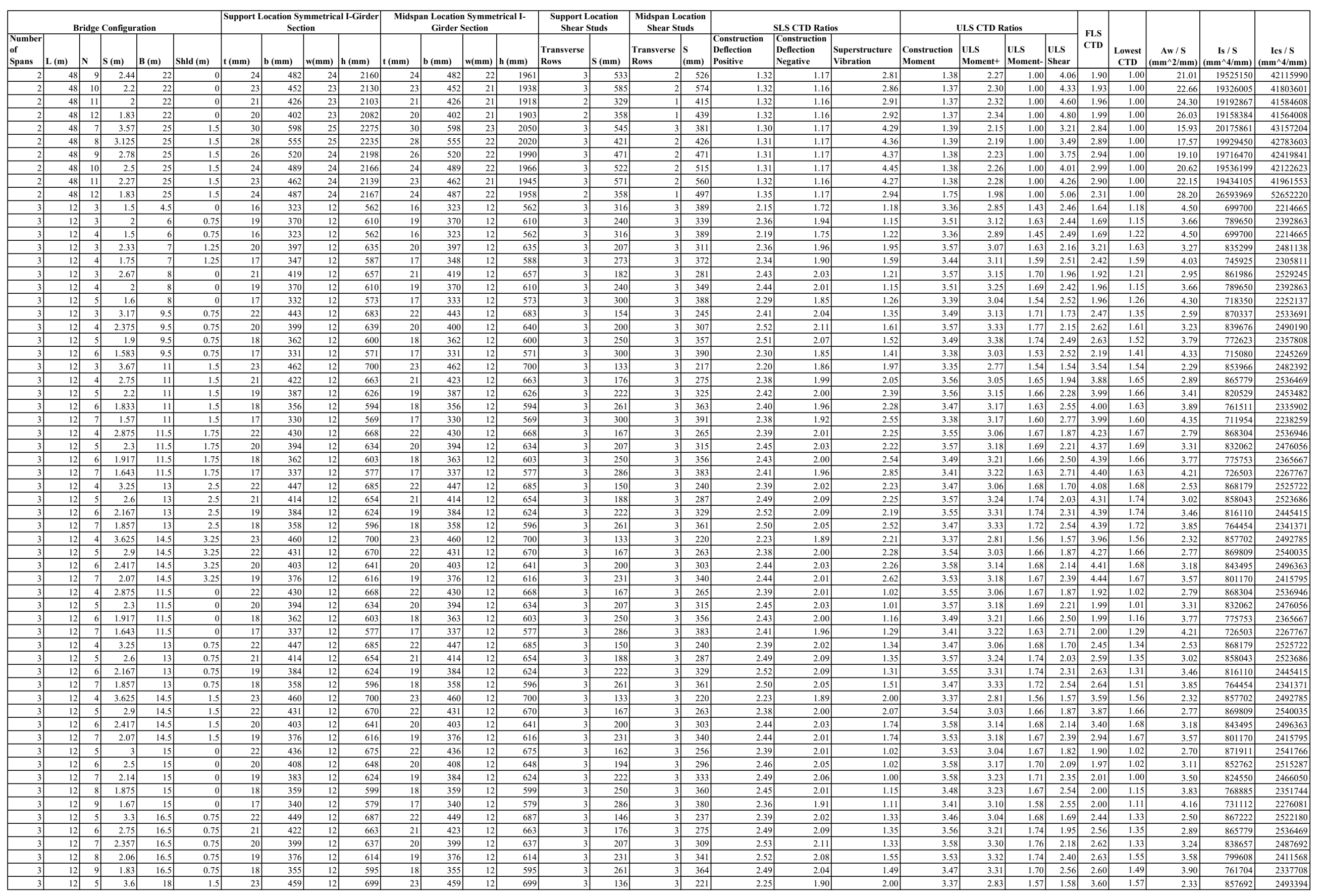




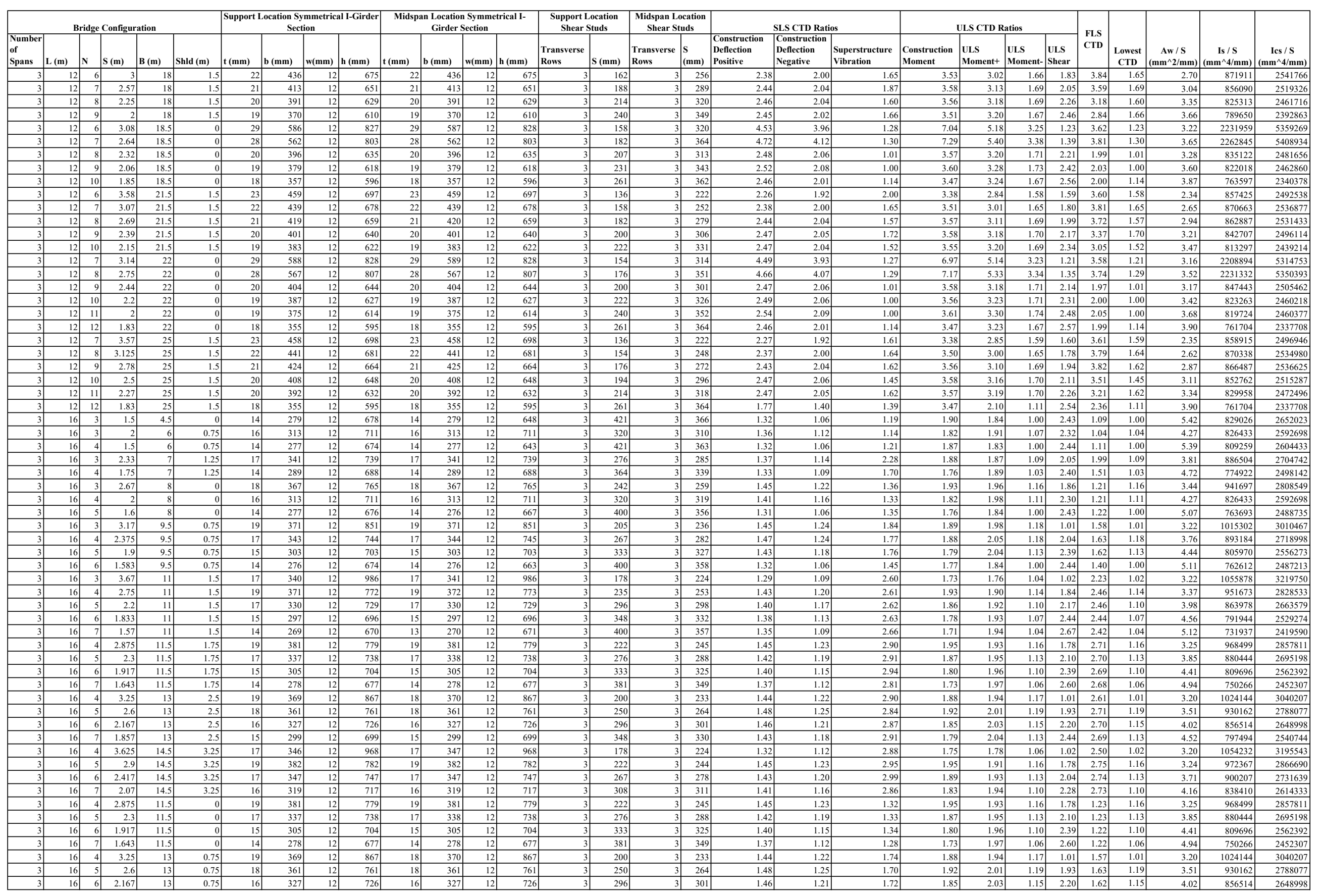




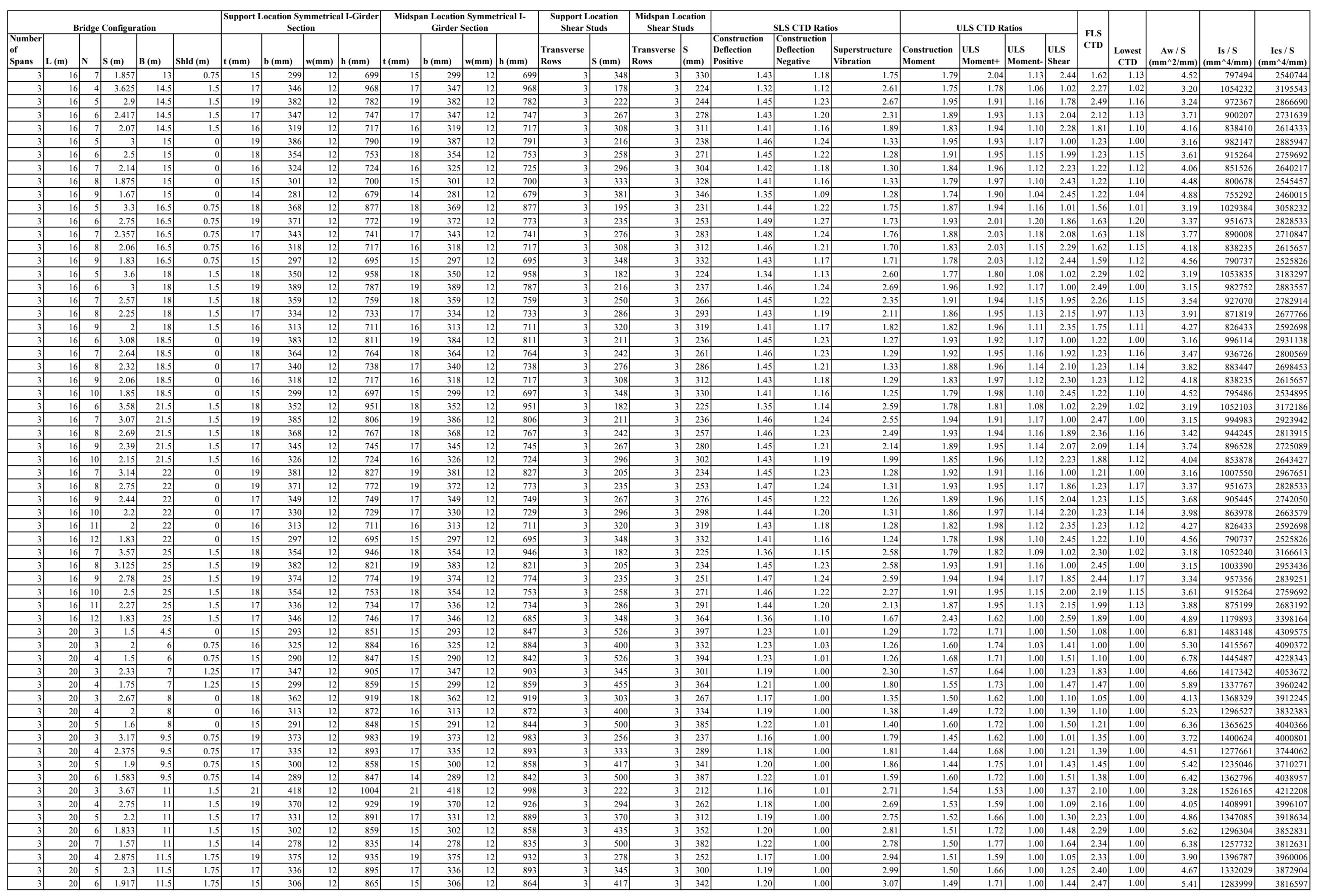




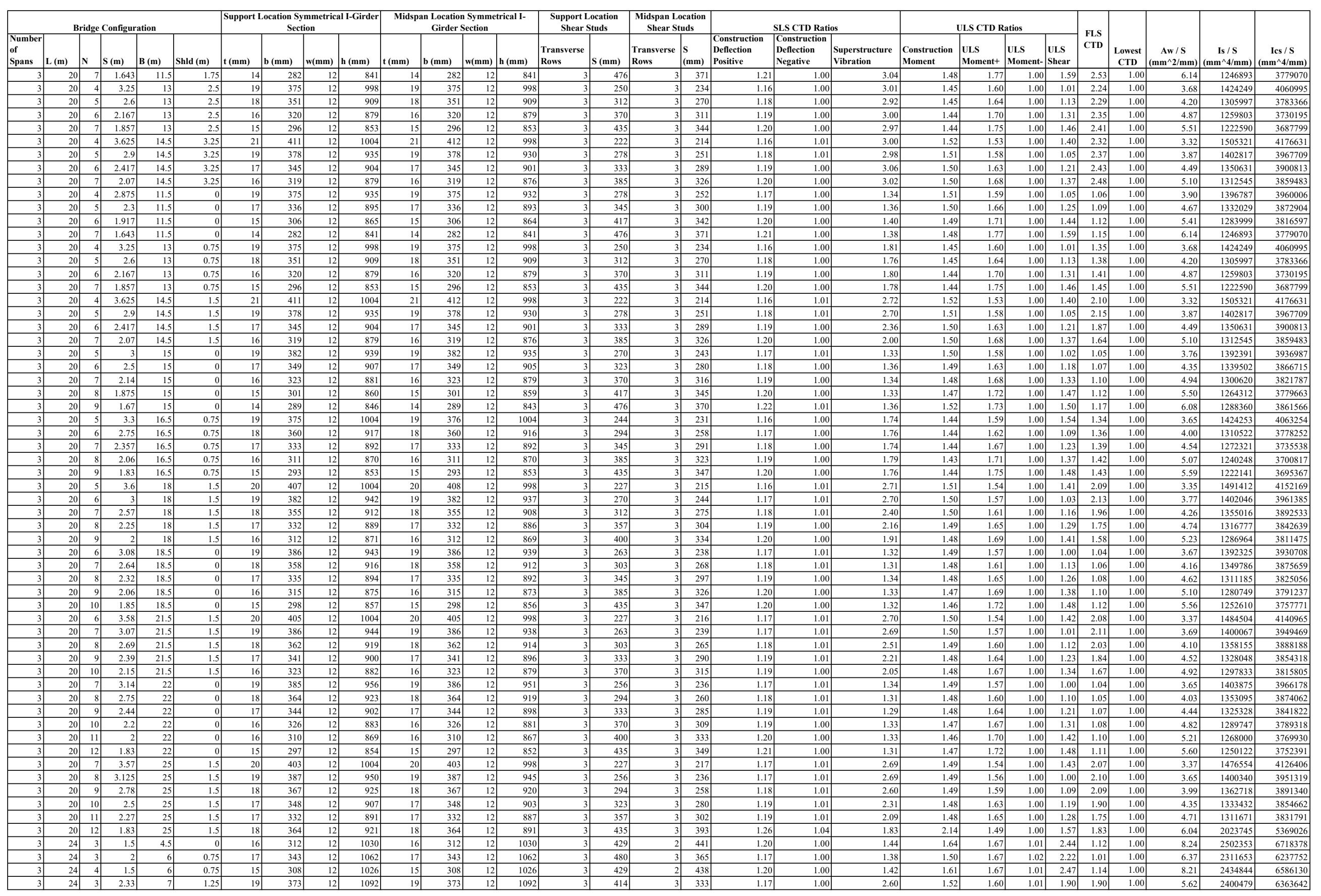




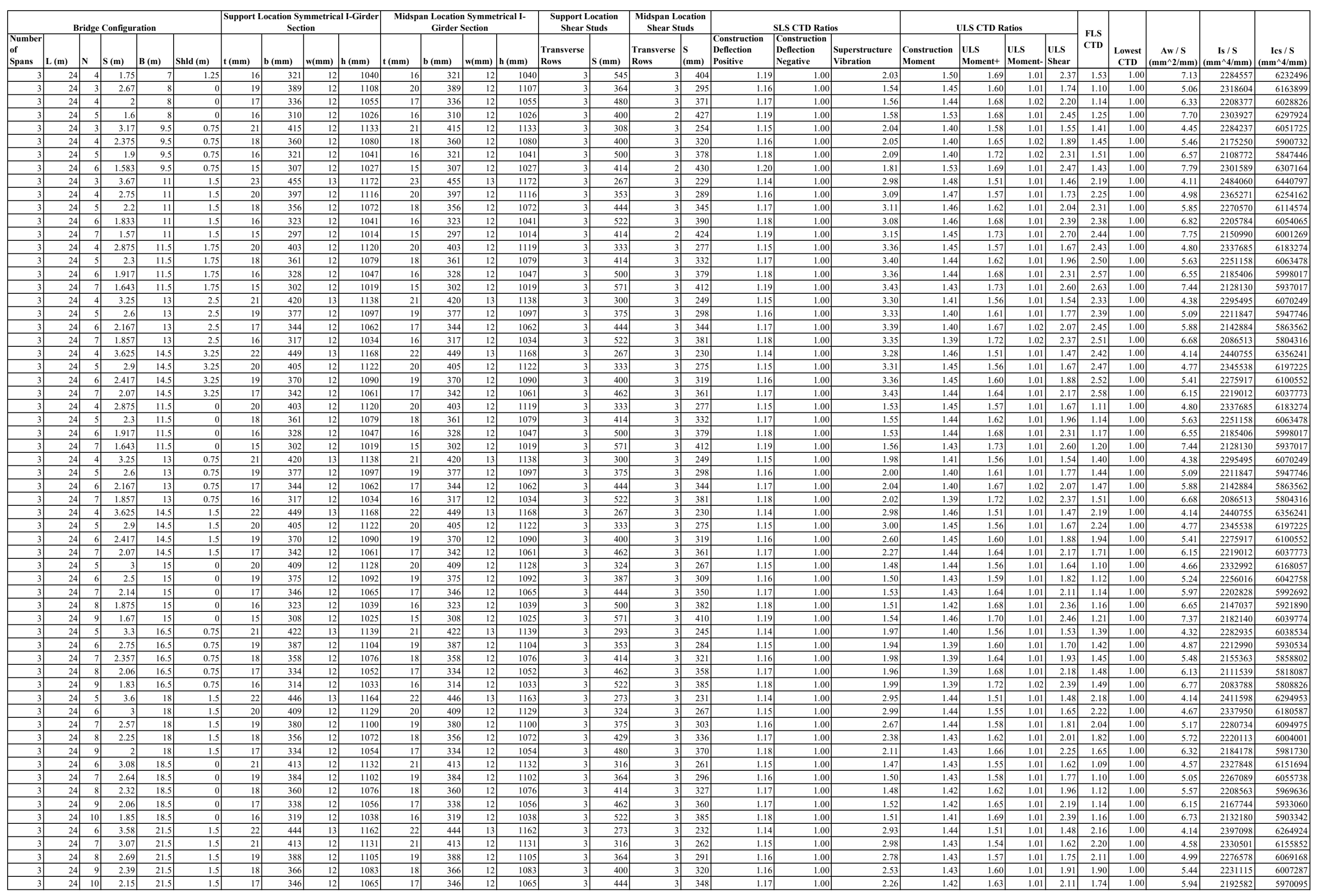




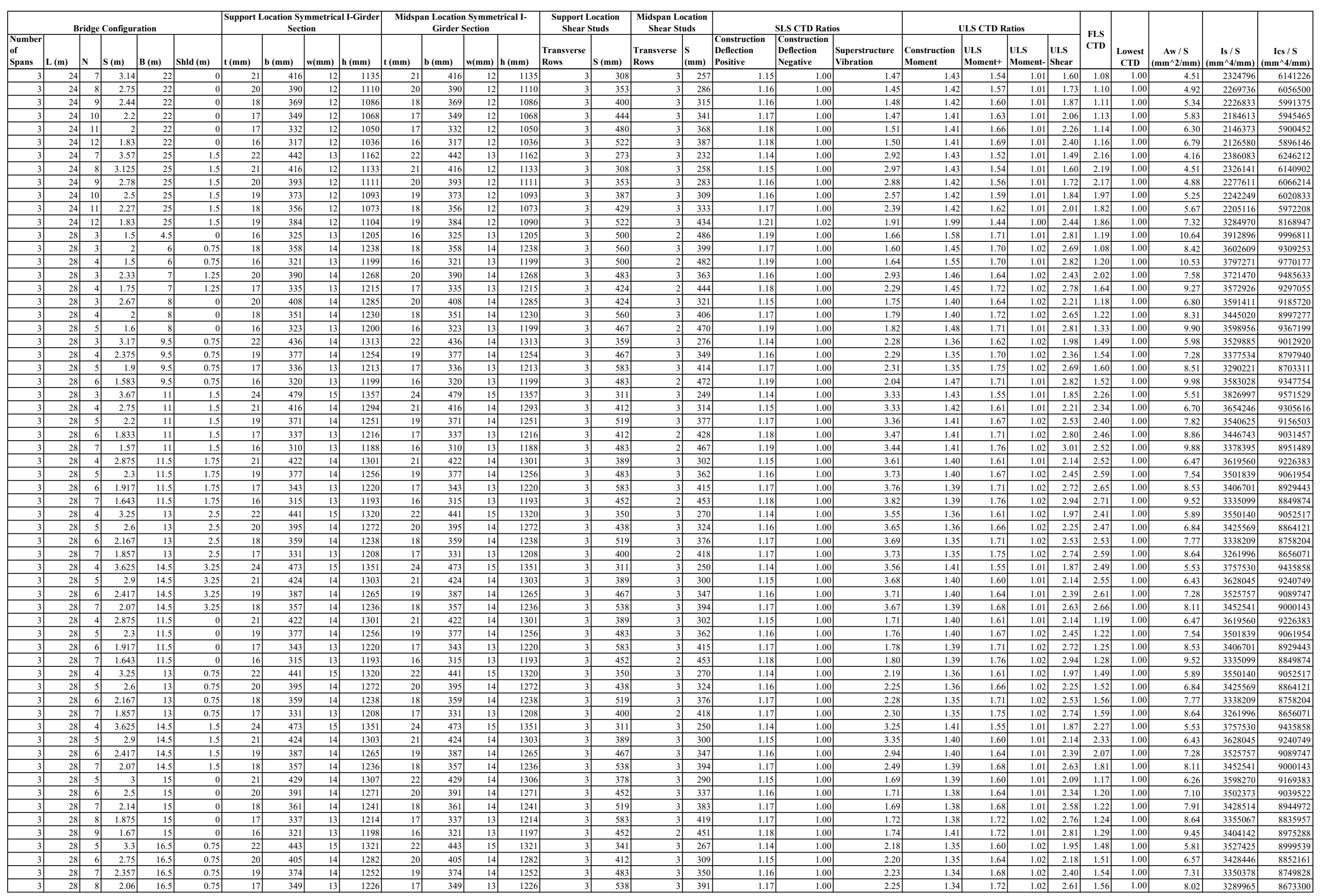




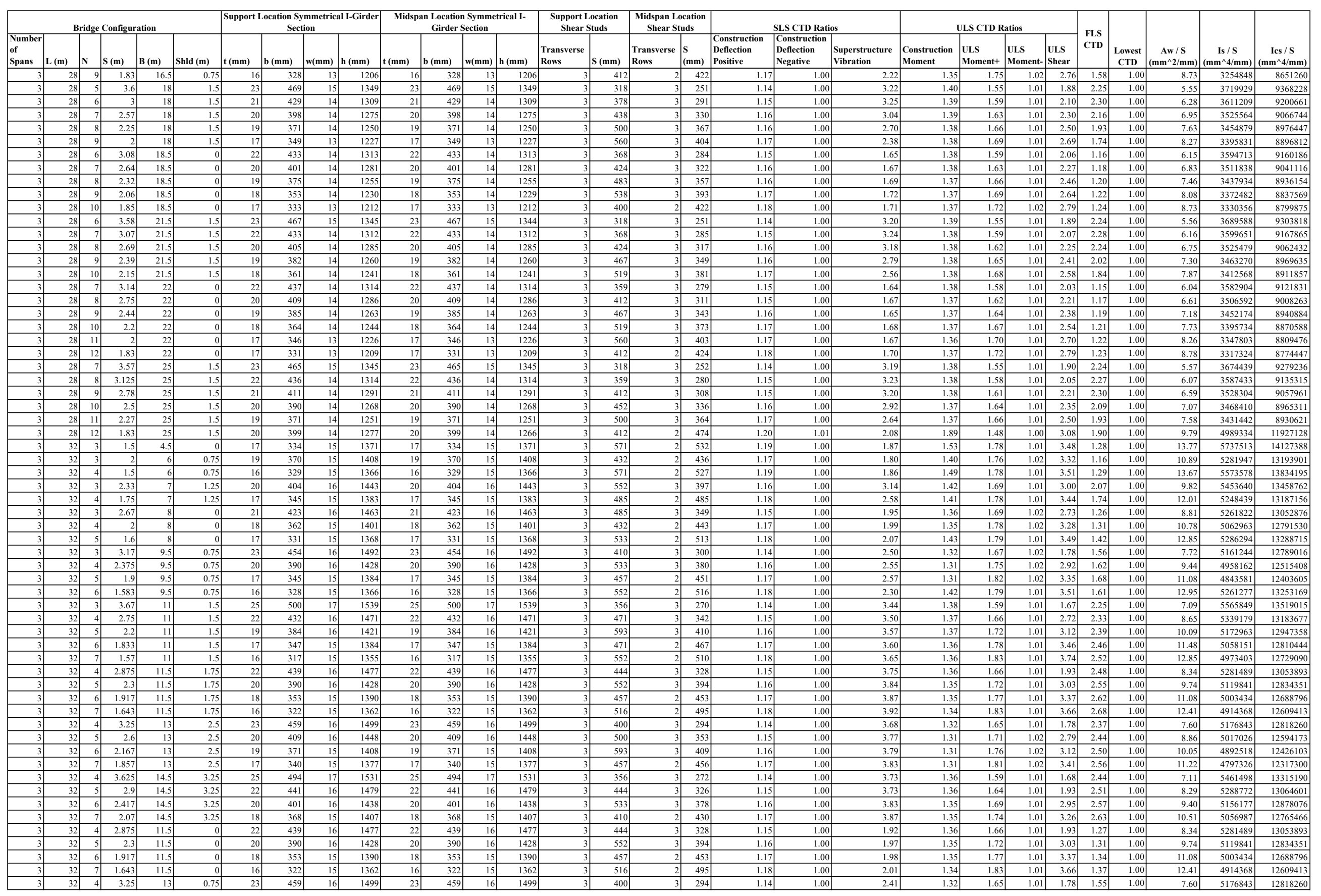




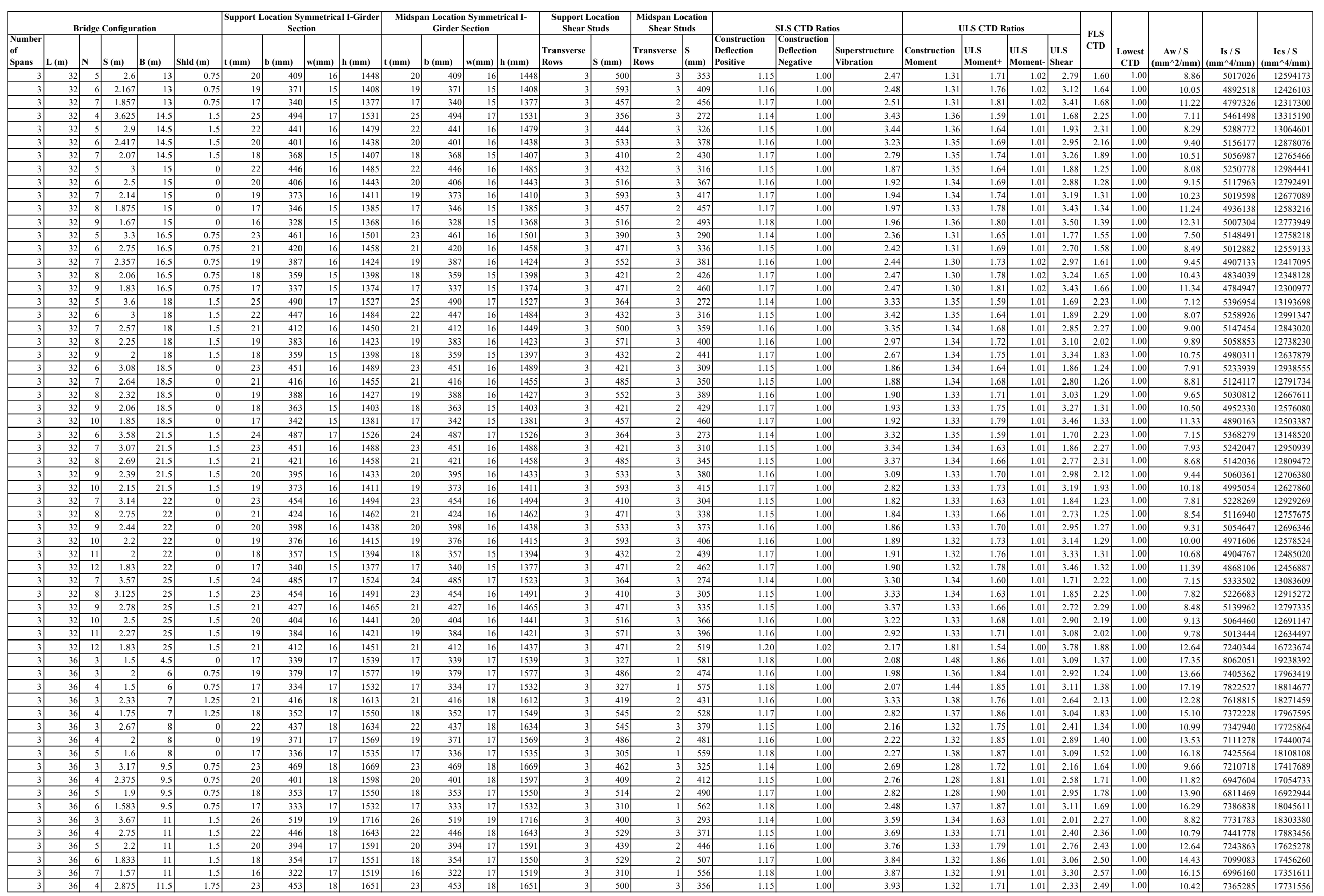




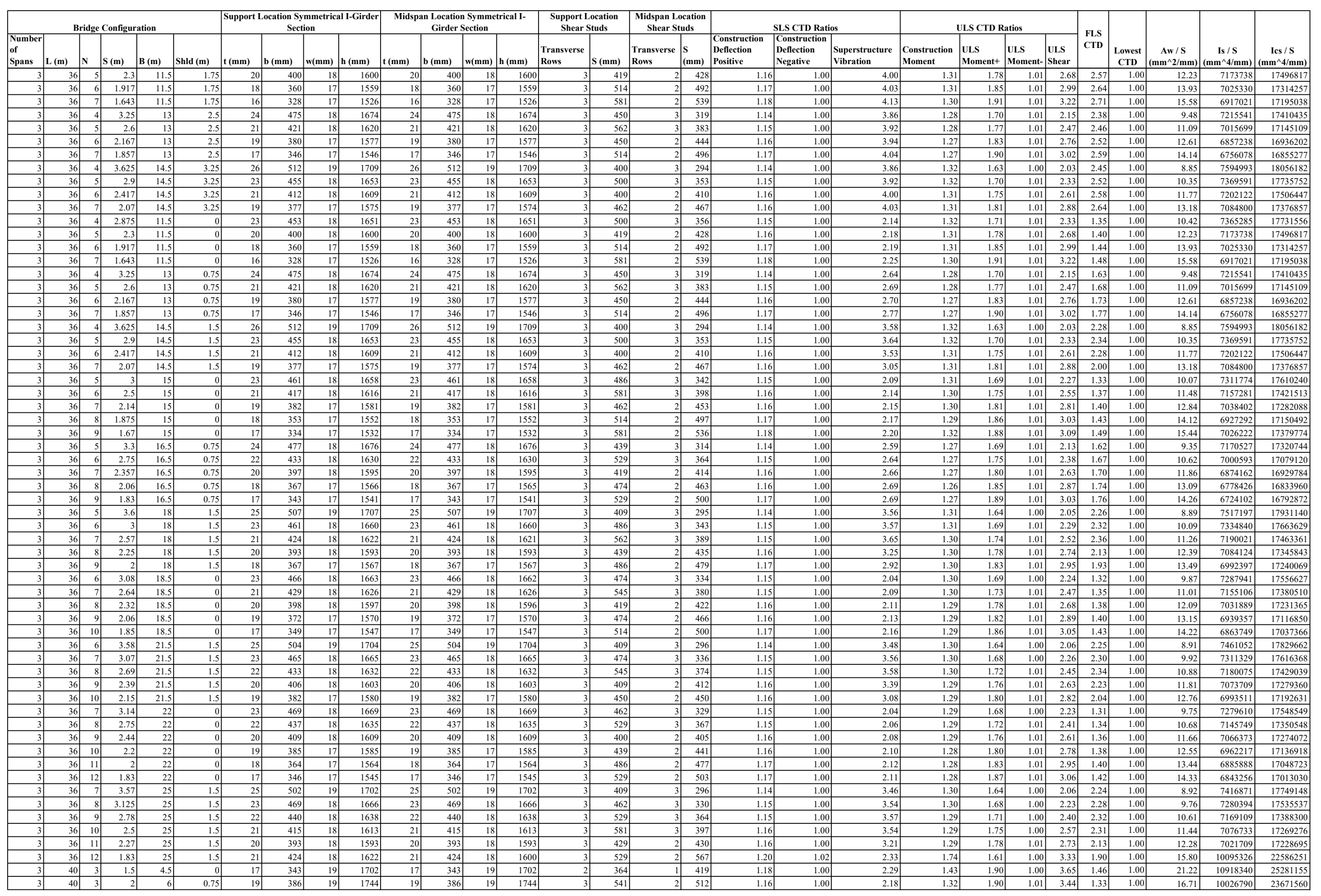




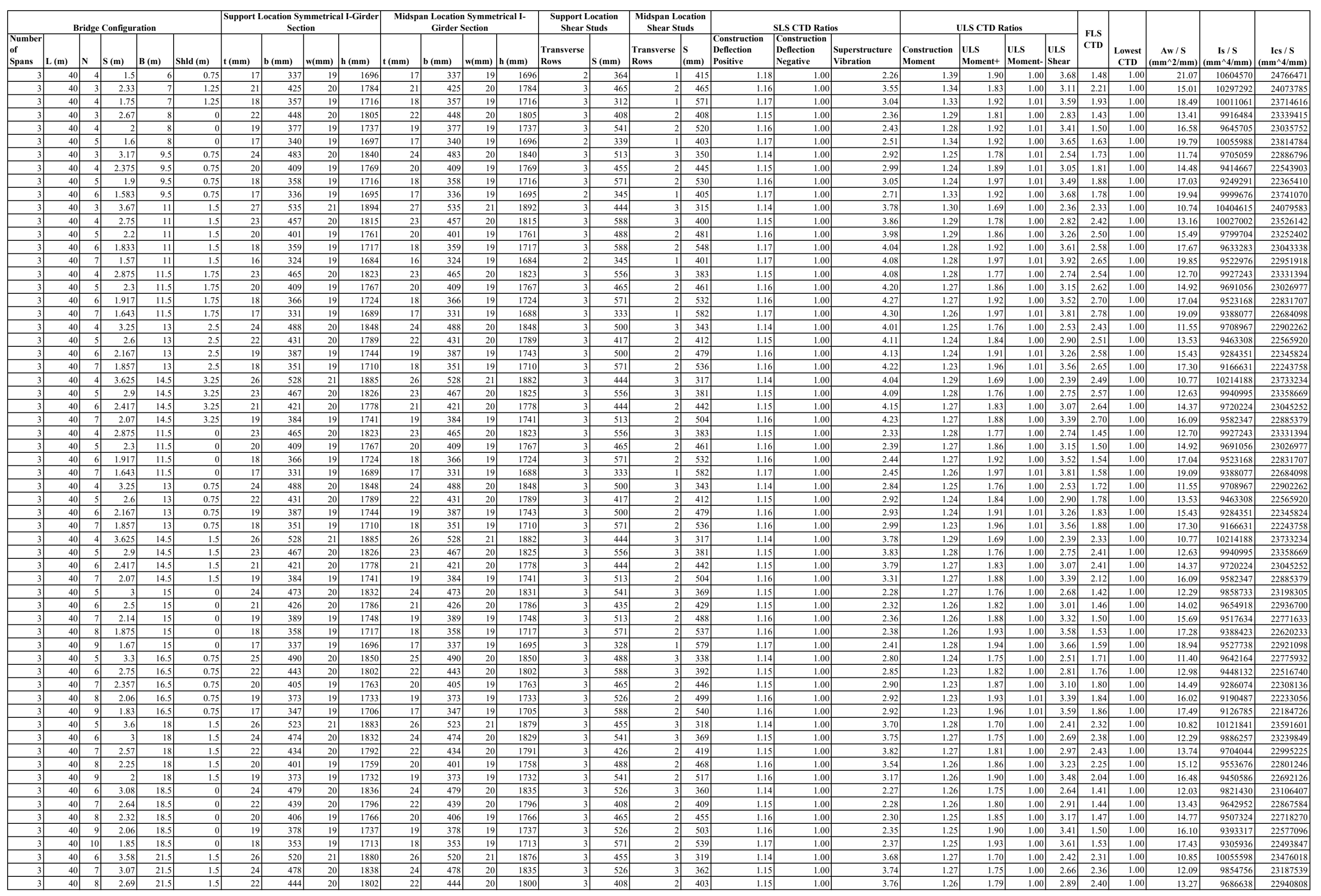




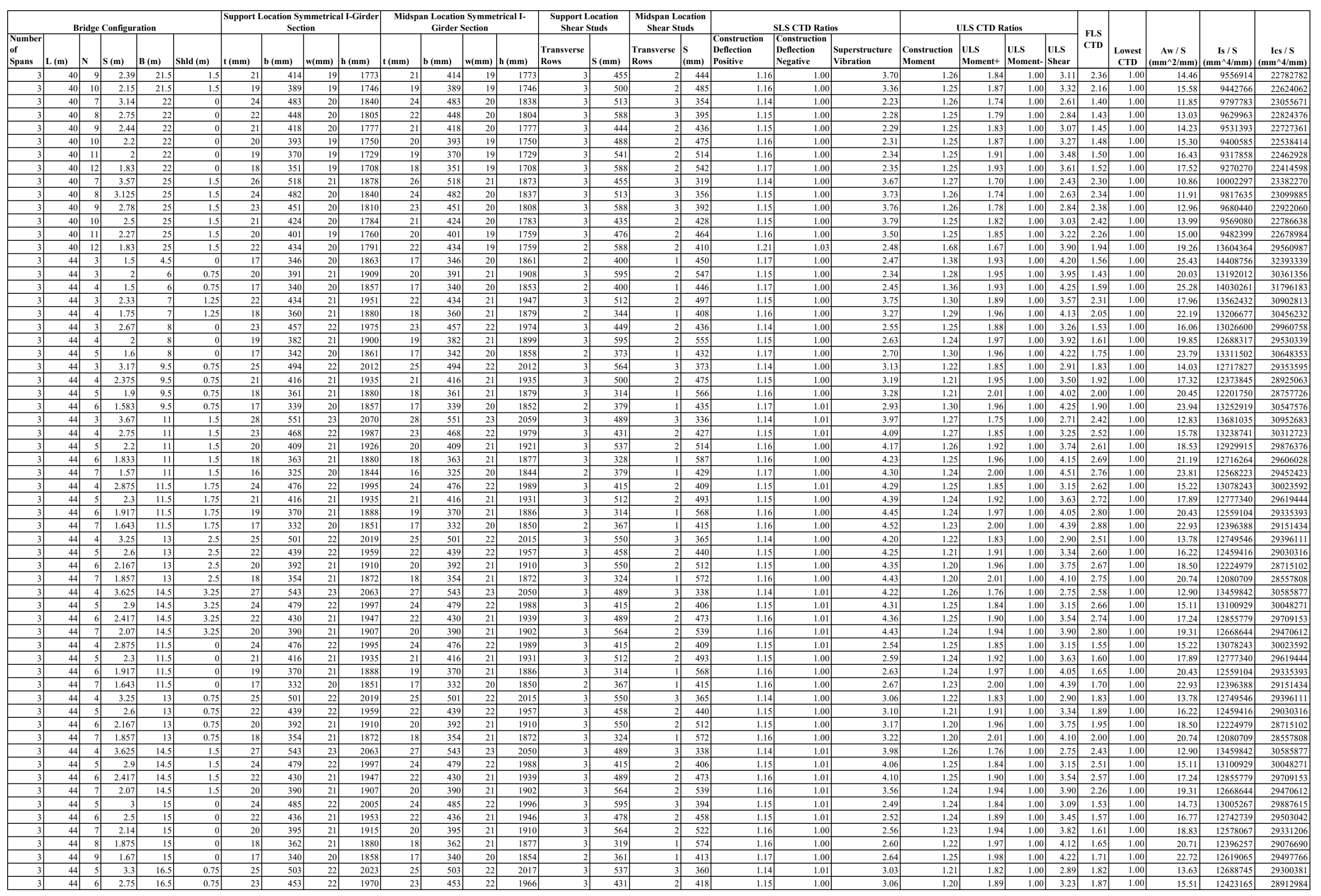




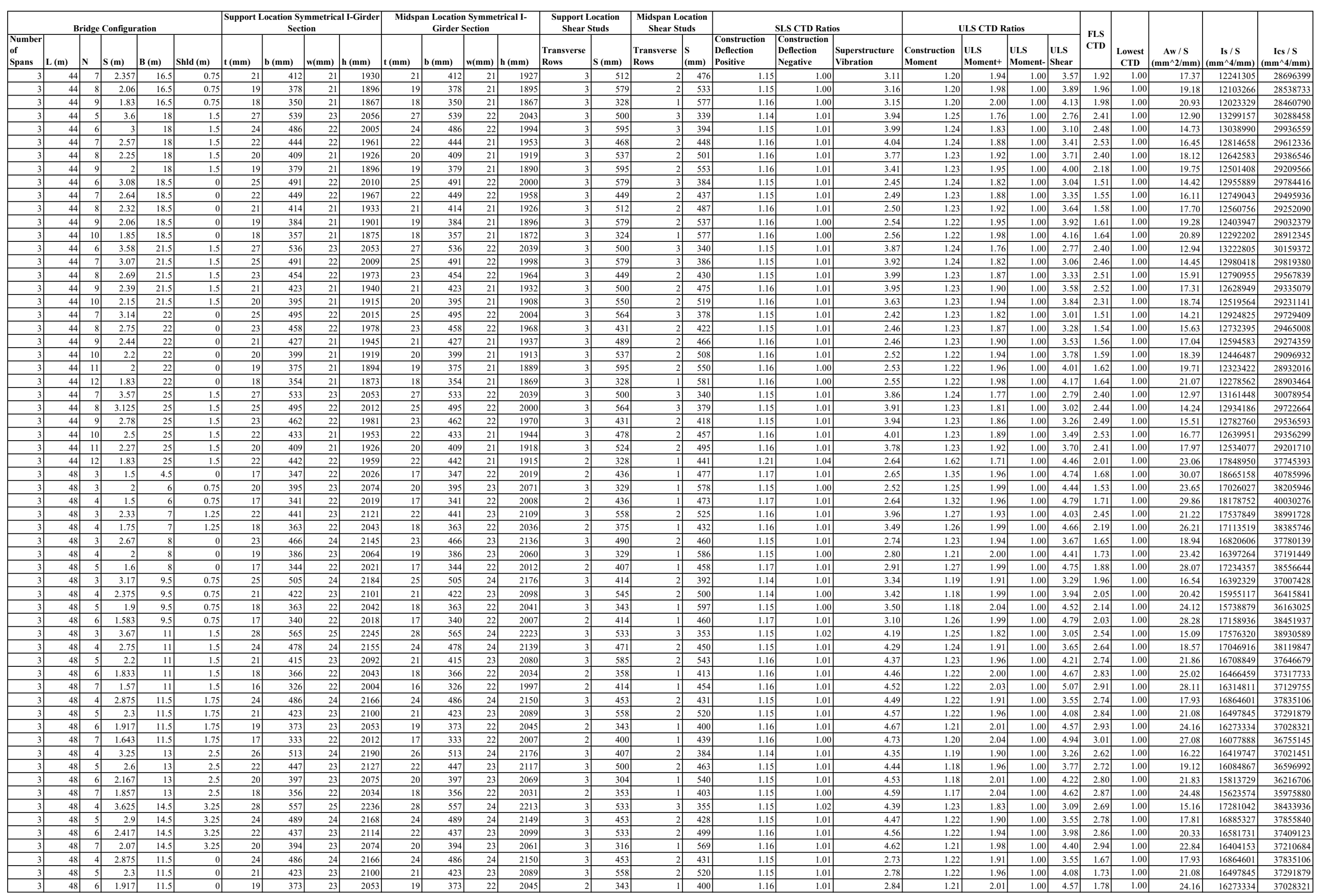




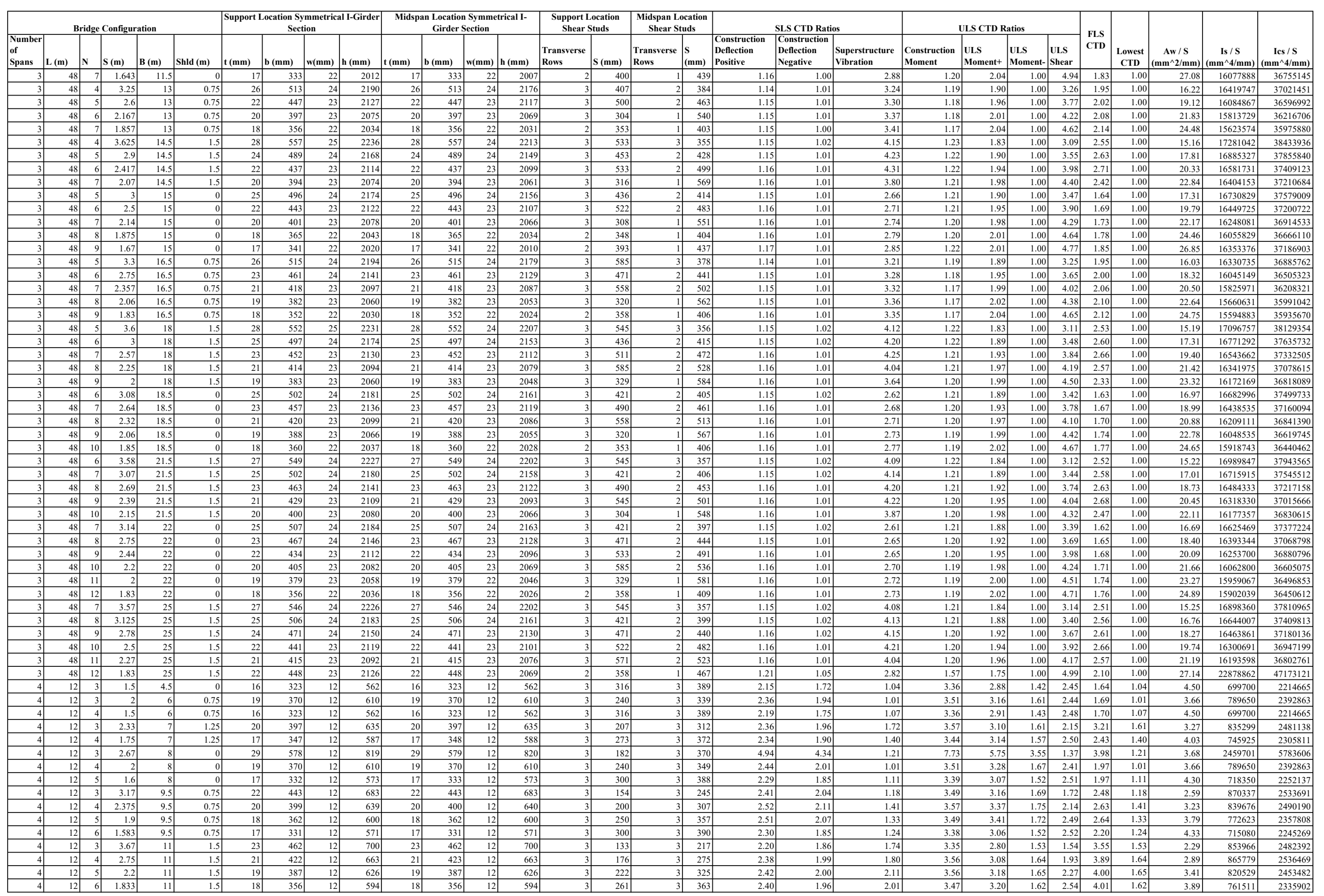




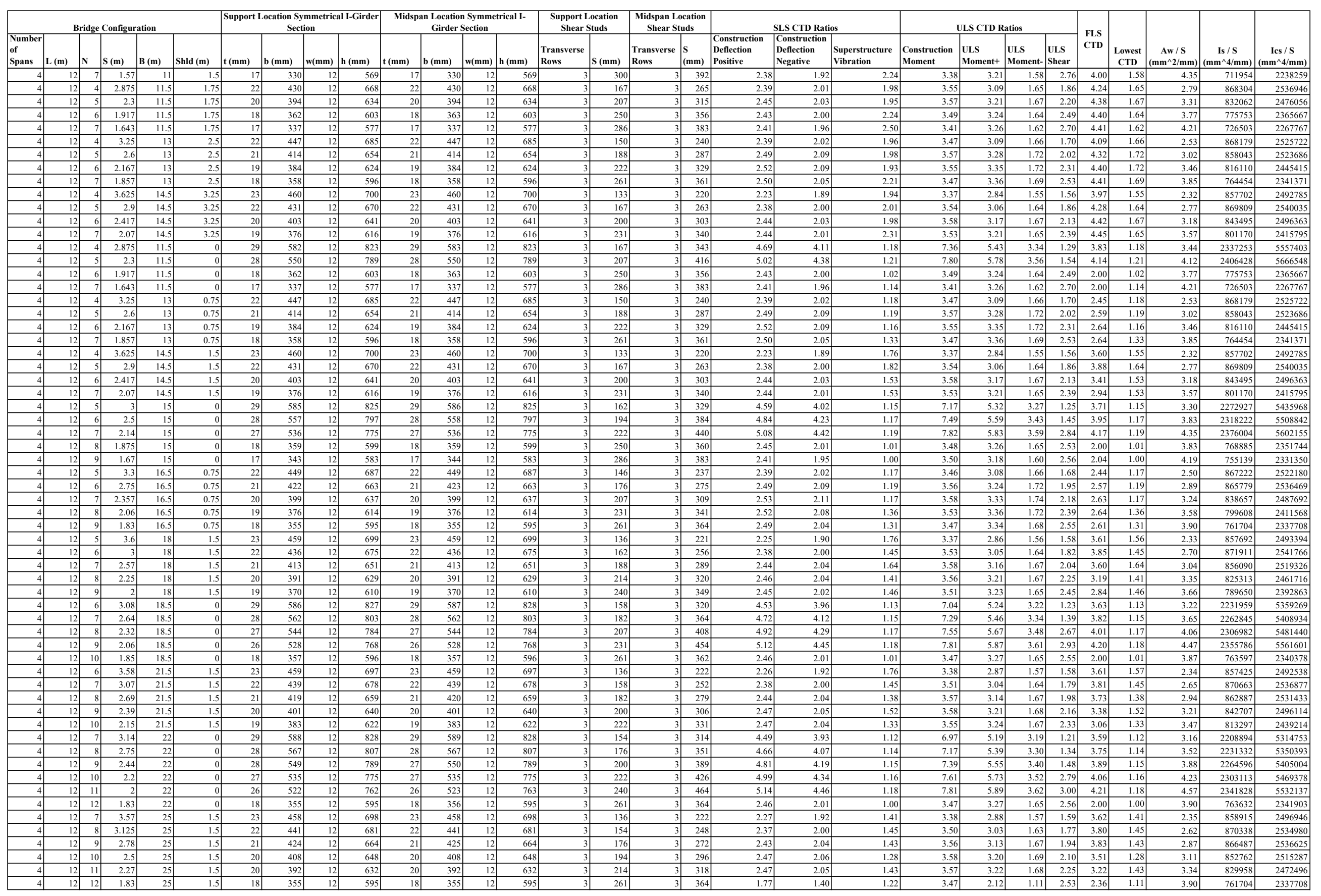




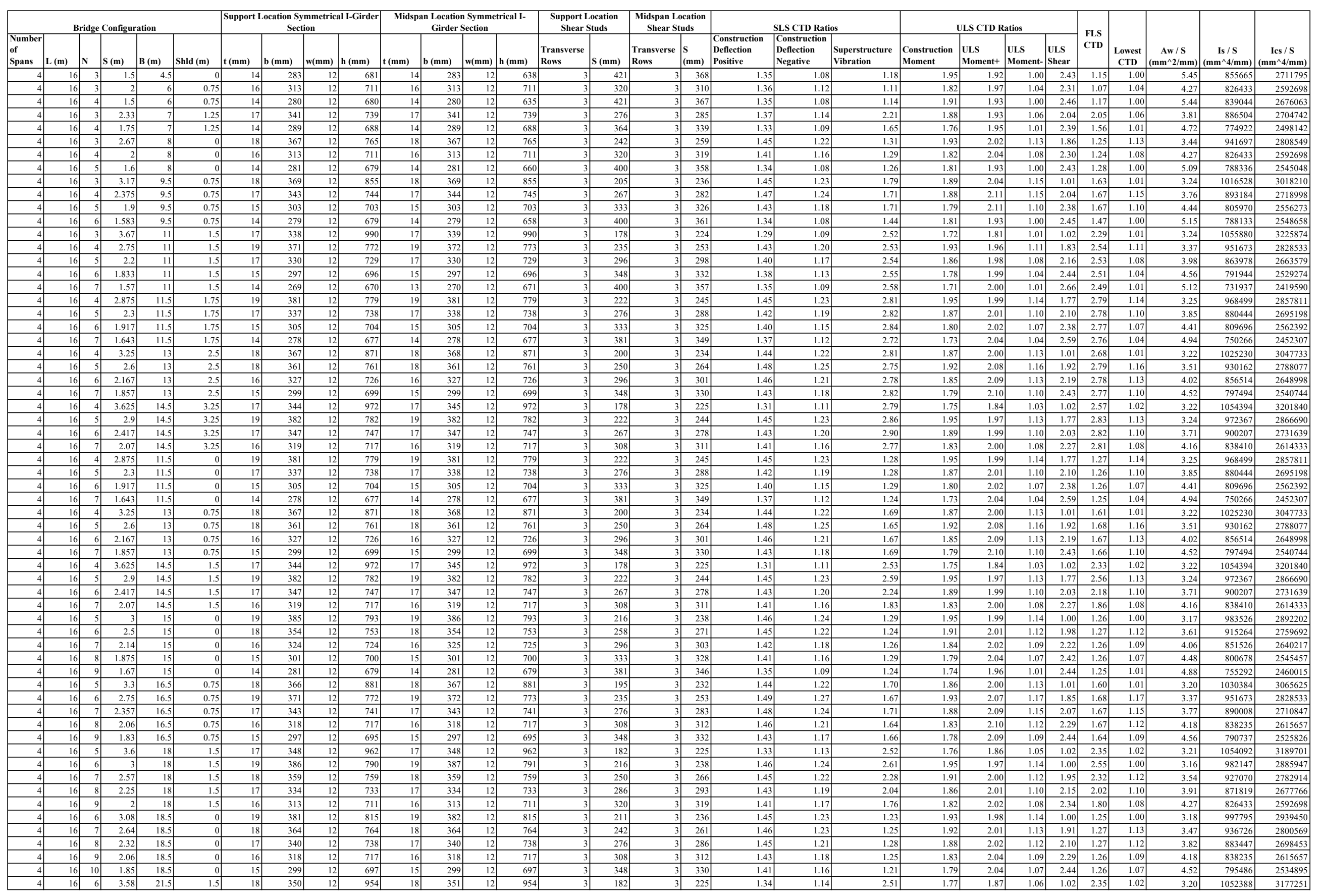




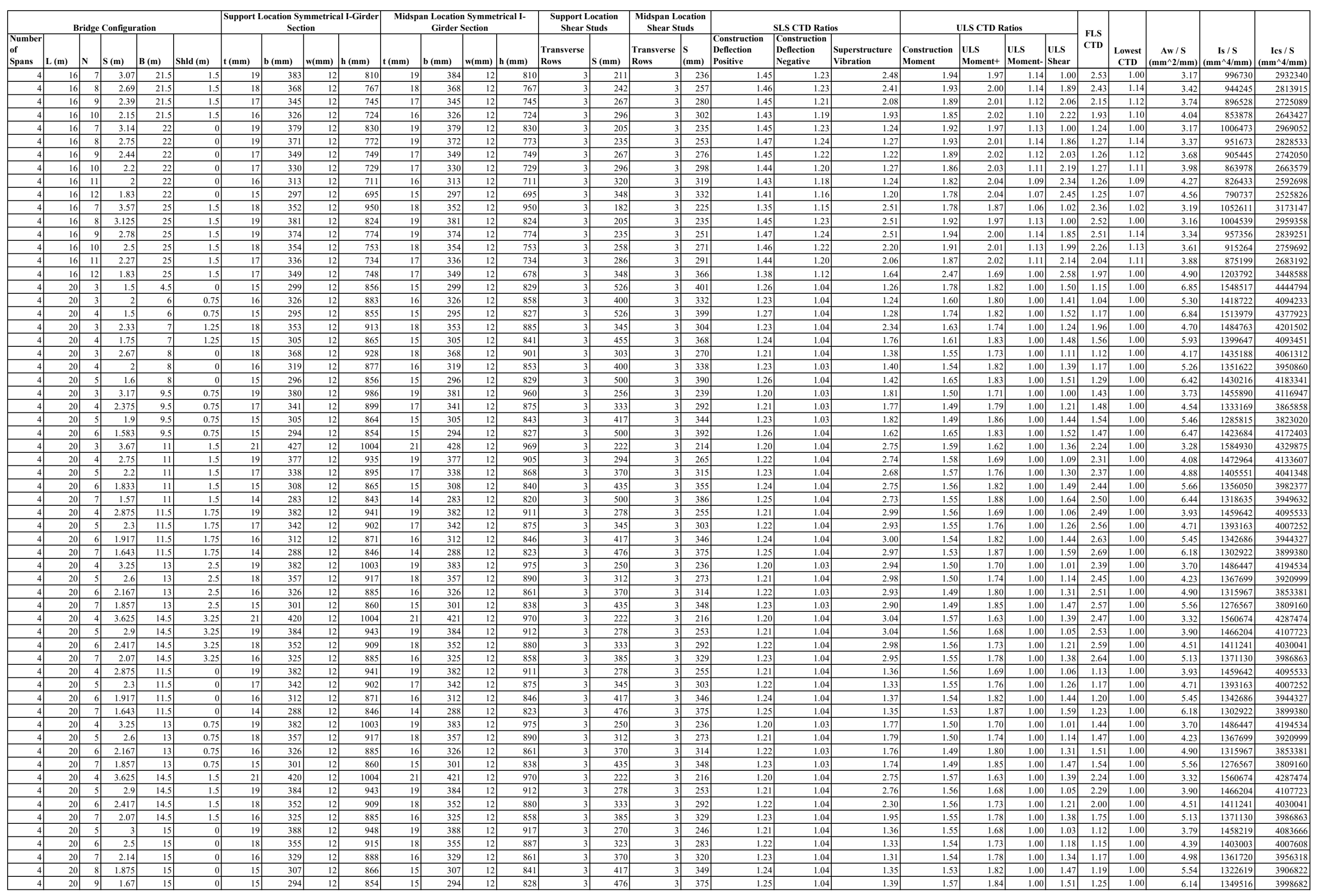




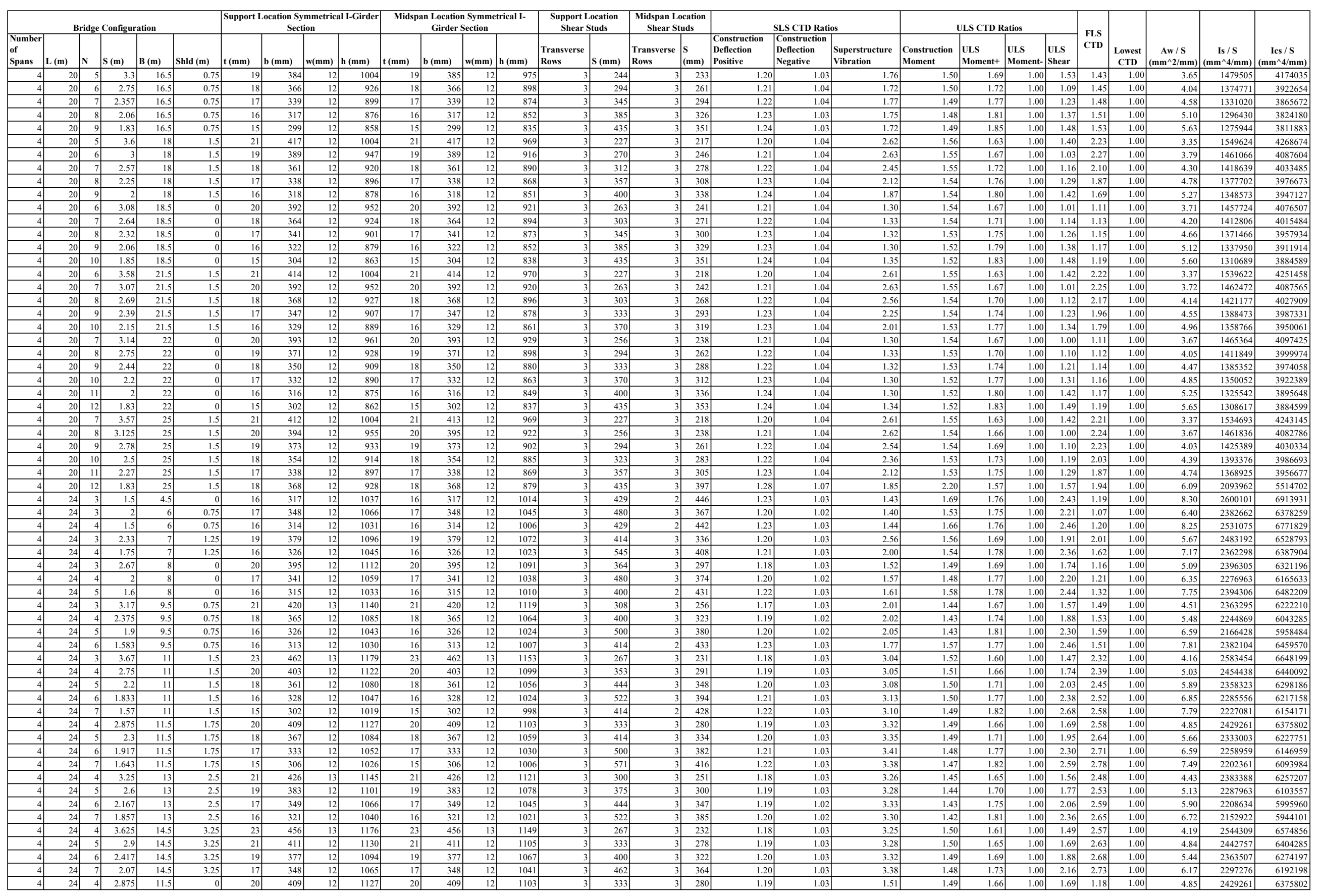




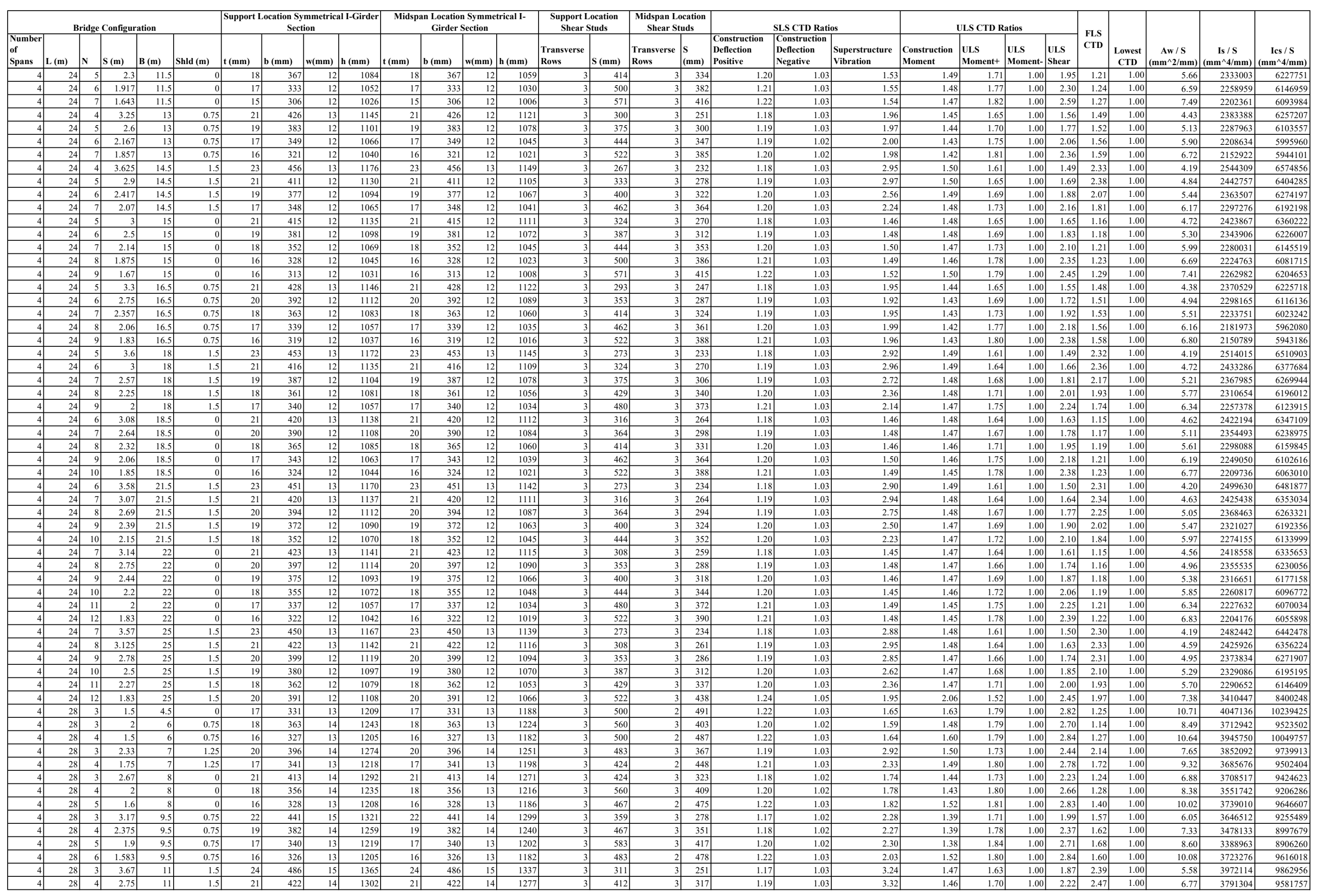




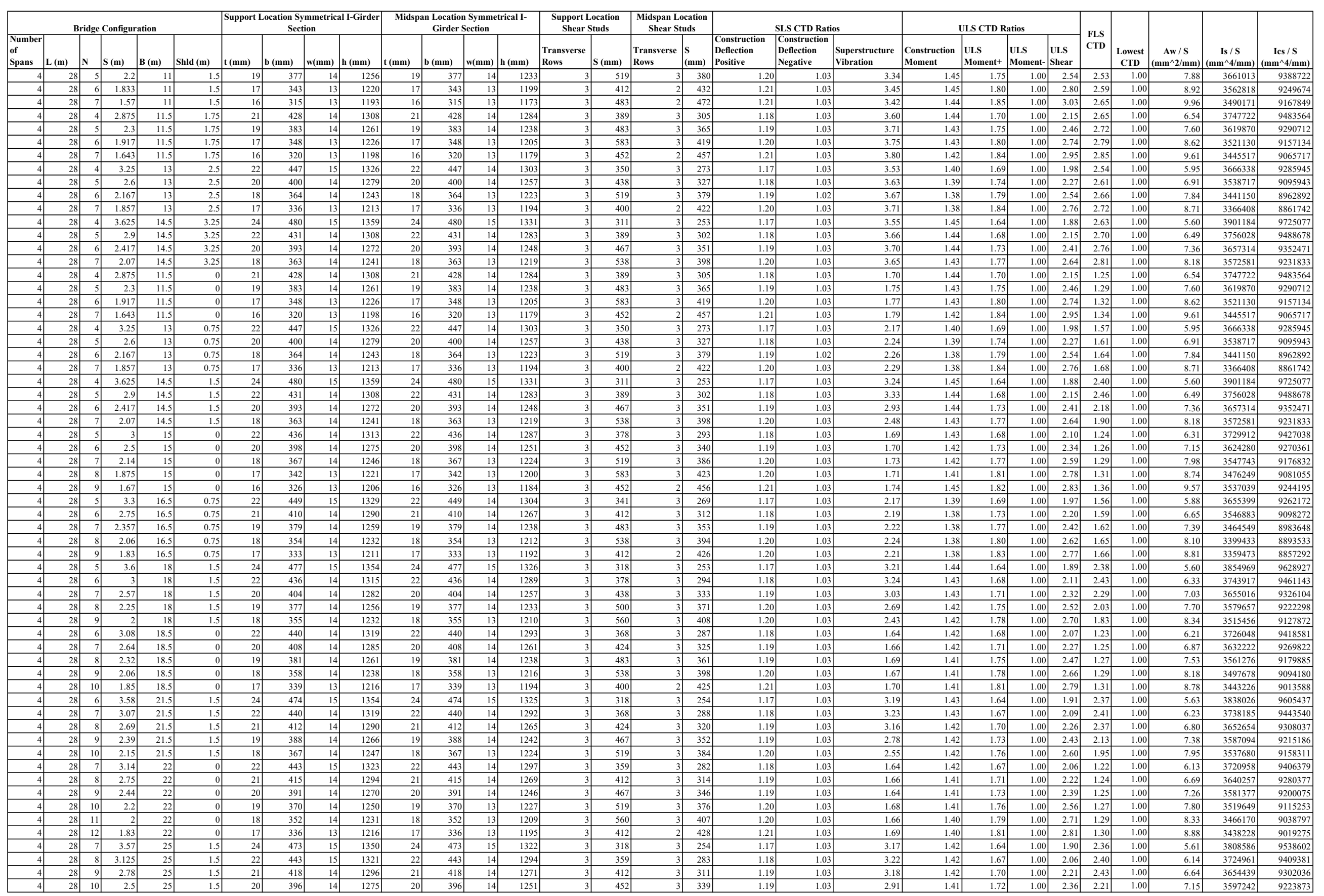




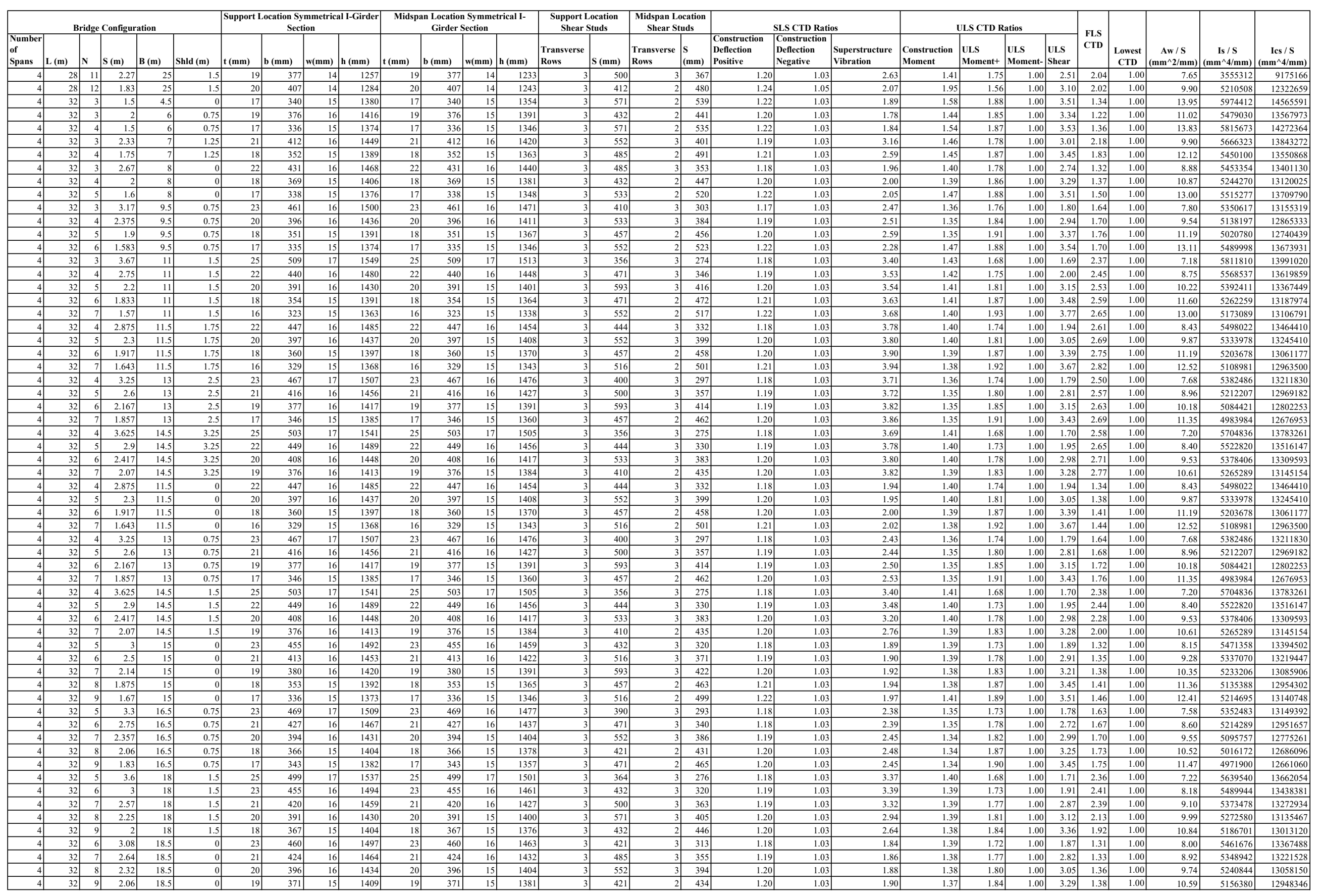




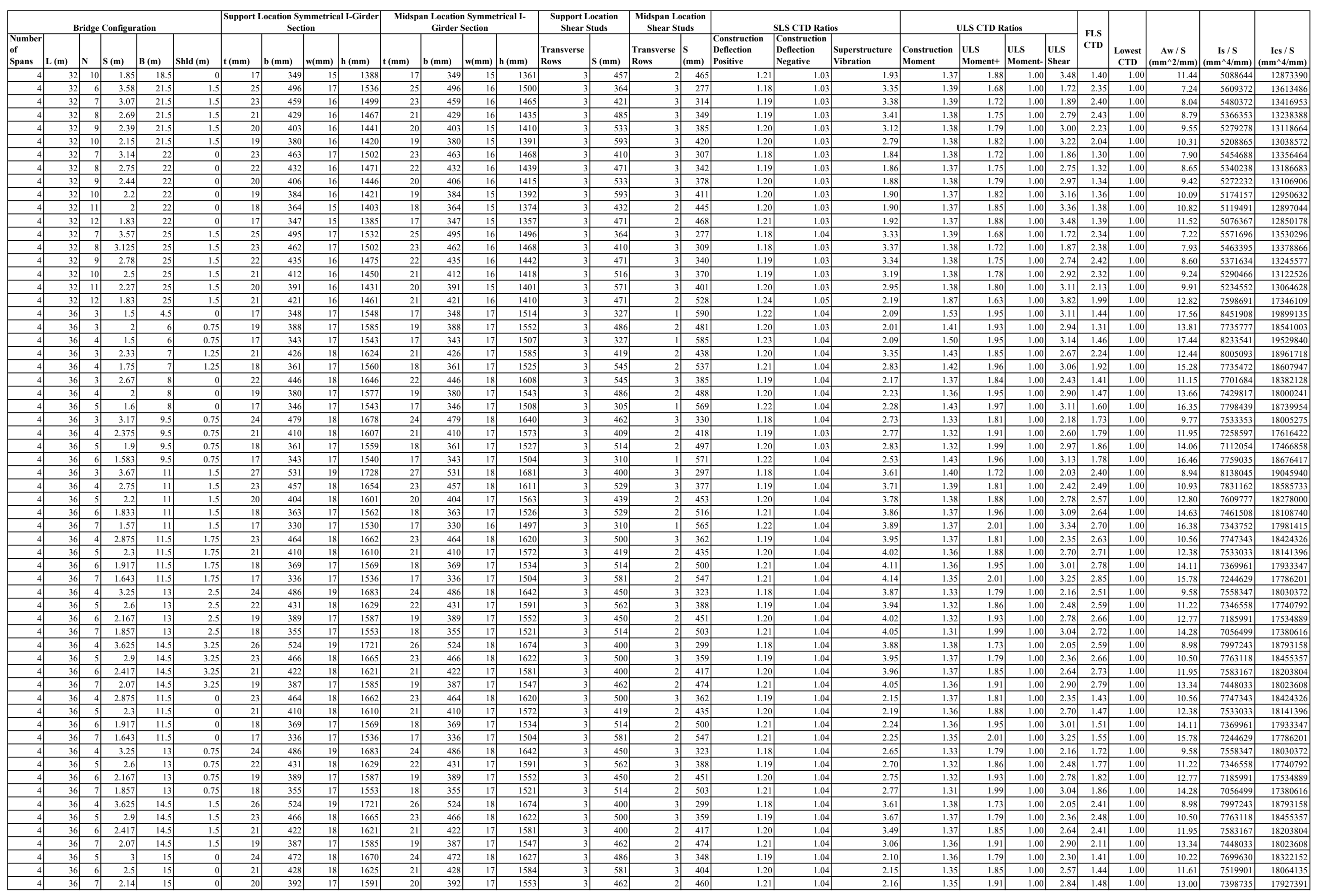




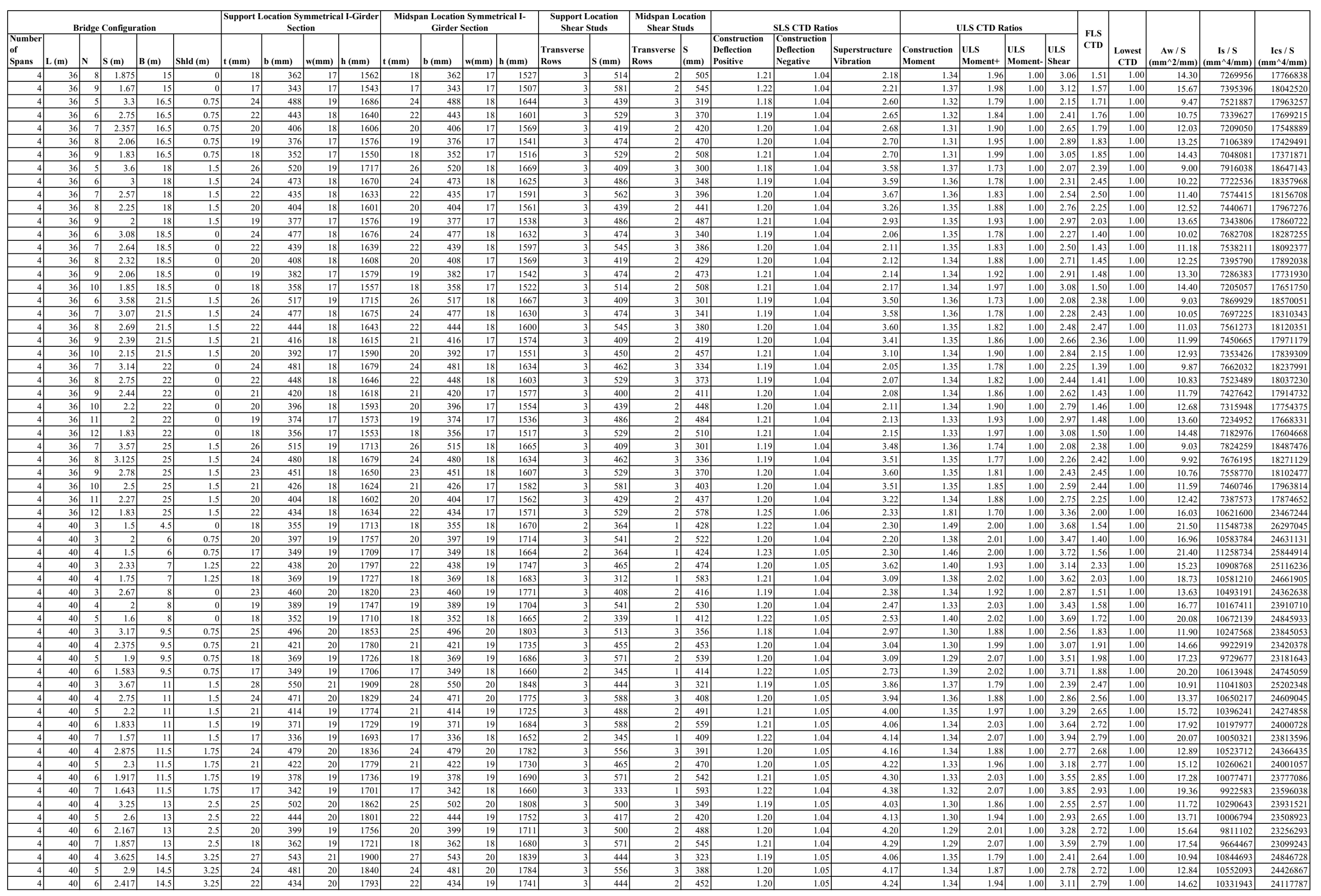




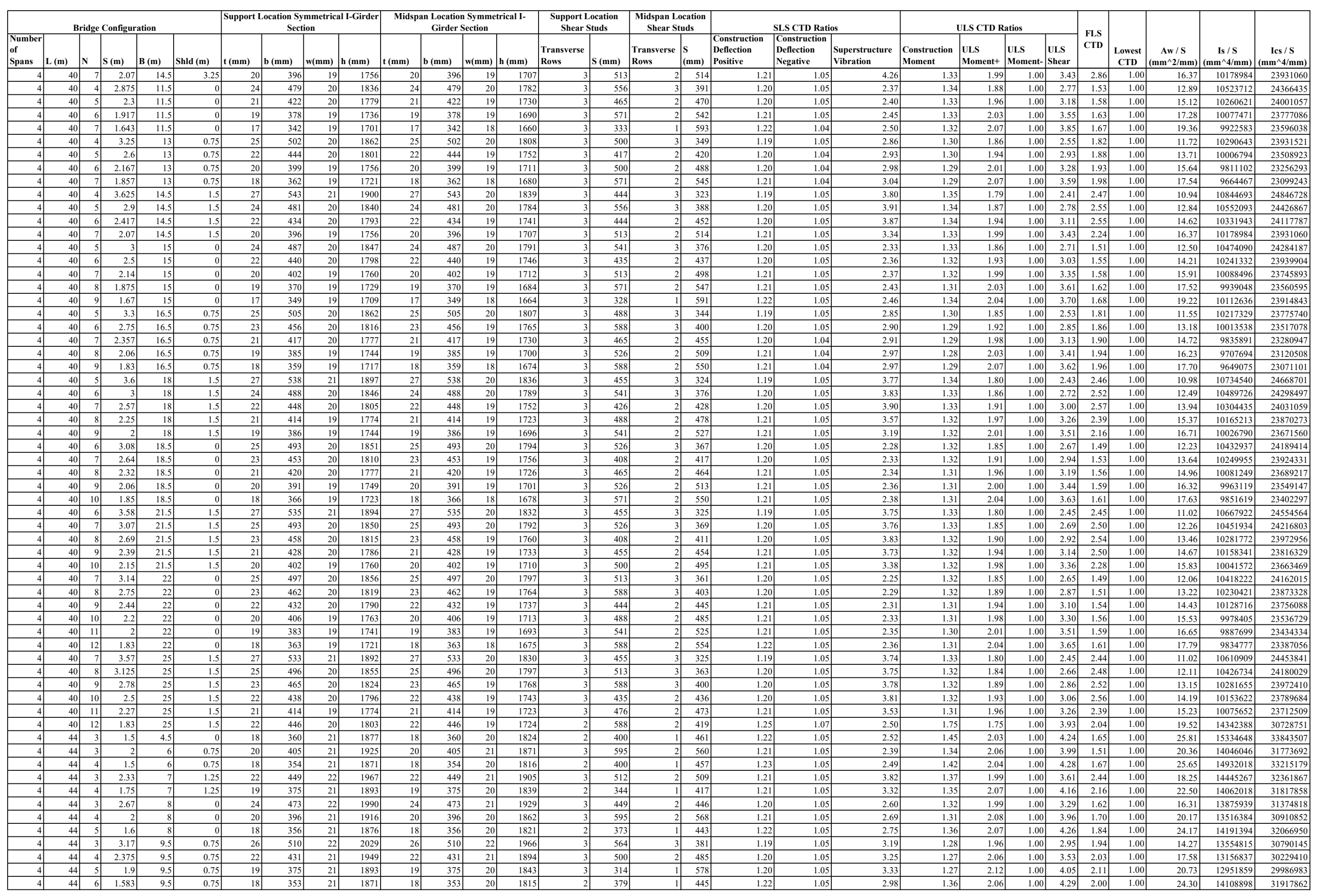




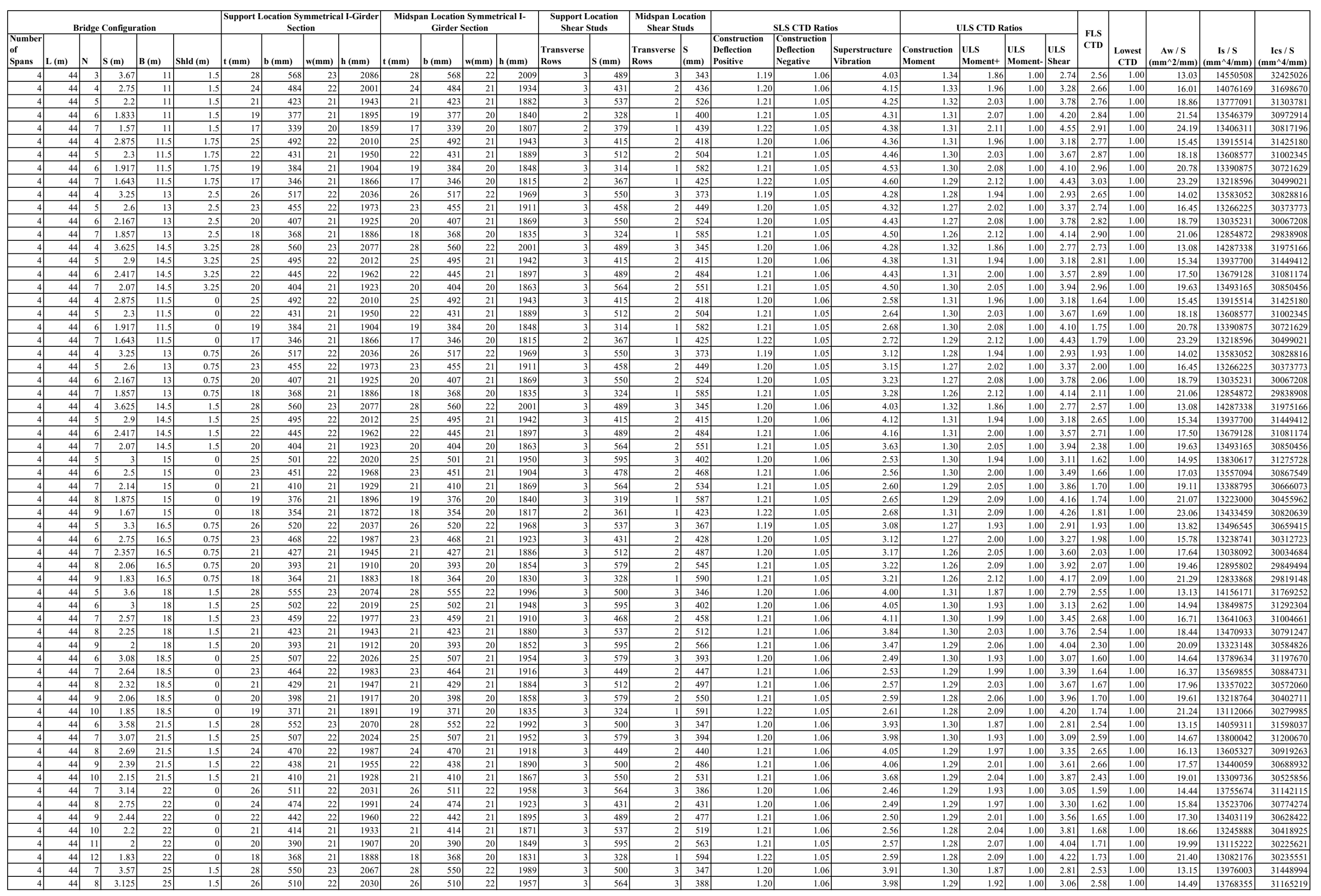




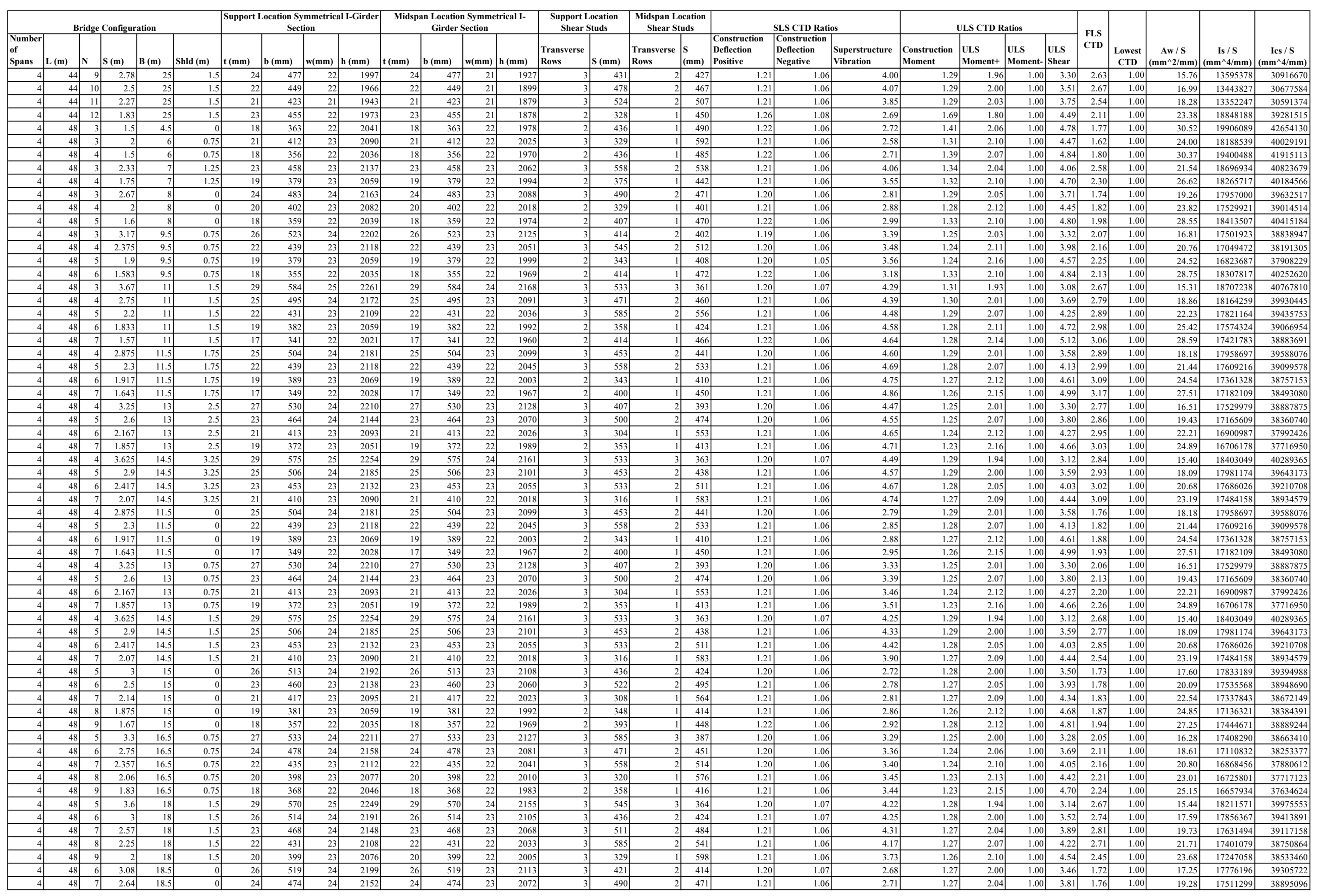




\begin{tabular}{|c|c|c|c|c|c|c|c|c|c|c|c|c|c|c|c|c|c|c|c|c|c|c|c|c|c|c|c|c|c|}
\hline \multicolumn{6}{|c|}{ Bridge Configuration } & \multicolumn{4}{|c|}{$\begin{array}{c}\text { Support Location Symmetrical I-Girder } \\
\text { Section }\end{array}$} & \multicolumn{4}{|c|}{\begin{tabular}{|c|}
$\begin{array}{c}\text { Midspan Location Symmetrical I- } \\
\text { Girder Section }\end{array}$ \\
\end{tabular}} & \multicolumn{2}{|c|}{\begin{tabular}{|l|}
$\begin{array}{l}\text { Support Location } \\
\text { Shear Studs }\end{array}$ \\
\end{tabular}} & \multicolumn{2}{|c|}{\begin{tabular}{c|c|}
$\begin{array}{c}\text { Midspan Location } \\
\text { Shear Studs }\end{array}$ \\
\end{tabular}} & \multicolumn{3}{|c|}{ SLS CTD Ratios } & \multicolumn{4}{|c|}{ ULS CTD Ratios } & \multirow{2}{*}{$\begin{array}{l}\text { FLS } \\
\text { CTD }\end{array}$} & \multirow[b]{2}{*}{$\begin{array}{c}\text { Lowest } \\
\text { CTD }\end{array}$} & \multirow[b]{2}{*}{$\begin{array}{c}\mathrm{Aw} / \mathrm{S} \\
\left(\mathrm{mm}^{\wedge} \mathbf{2} / \mathrm{mm}\right)\end{array}$} & \multirow[b]{2}{*}{$\begin{array}{c}\text { Is } / \mathrm{S} \\
\left(\mathrm{m}^{\wedge} 4 / \mathrm{mm}\right)\end{array}$} & \multirow[b]{2}{*}{$\begin{array}{c}\text { Iss } / \mathrm{S} \\
\left(\mathrm{mm}^{\wedge} 4 / \mathrm{mm}\right)\end{array}$} \\
\hline $\begin{array}{l}\text { Number } \\
\text { of } \\
\text { Spans }\end{array}$ & $L(m)$ & $\mathrm{N}$ & $\mathbf{S}(\mathrm{m})$ & B (m) & Shld (m) & $t(\mathrm{~mm})$ & b (mm) & $\mathbf{w}(\mathrm{mm})$ & h (mm) & $t(\mathrm{~mm})$ & b (mm) & $\mathbf{w}(\mathbf{m m})$ & $\mathrm{h}(\mathrm{mm})$ & \begin{tabular}{|l|}
$\begin{array}{l}\text { Transverse } \\
\text { Rows }\end{array}$ \\
\end{tabular} & $\mathbf{s}(\mathrm{mm})$ & \begin{tabular}{|l|}
$\begin{array}{l}\text { Transverse } \\
\text { Rows }\end{array}$ \\
\end{tabular} & $\left.\begin{array}{|l|l}\mathbf{S} & \\
(\mathbf{m m})\end{array}\right)$ & \begin{tabular}{|l|} 
Construction \\
Deflection \\
Positive
\end{tabular} & \begin{tabular}{|l|} 
Construction \\
Deflection \\
Negative
\end{tabular} & \begin{tabular}{l|l} 
Superstructure \\
Vibration
\end{tabular} & \begin{tabular}{|l|}
$\begin{array}{l}\text { Construction } \\
\text { Moment }\end{array}$ \\
\end{tabular} & \begin{tabular}{|l|} 
ULS \\
Moment+
\end{tabular} & \begin{tabular}{|l|} 
ULS \\
Moment-
\end{tabular} & \begin{tabular}{|l|} 
ULS \\
Shear
\end{tabular} & & & & & \\
\hline & 48 & 8 & 2.32 & \begin{tabular}{|l|}
18.5 \\
\end{tabular} & 0 & 22 & 437 & 23 & 2114 & 22 & 437 & 22 & \begin{tabular}{l|l|l|}
2039 \\
\end{tabular} & & 558 & & 525 & 1.21 & 1.06 & 2.75 & 1.26 & 2.07 & 1.00 & 4.13 & 1.79 & 1.00 & 21.18 & \begin{tabular}{|l|l|}
17275019 \\
\end{tabular} & \begin{tabular}{|l|l|}
38540940 \\
\end{tabular} \\
\hline & 48 & 9 & 2.06 & 18.5 & 0 & 20 & 404 & 23 & 2083 & 20 & 404 & 22 & 2012 & & 320 & & 581 & 1.21 & 1.06 & 2.80 & 1.25 & 2.10 & 1.00 & 4.46 & 1.83 & 1.00 & 23.15 & 17131014 & 38363689 \\
\hline & 48 & 10 & 1.85 & 18.5 & 0 & 19 & 376 & 23 & 2053 & 19 & 376 & 22 & 1986 & & 353 & & 416 & 1.21 & 1.06 & 2.84 & 1.25 & 2.13 & 1.00 & 4.72 & 1.86 & 1.00 & 25.04 & 16994205 & 38151794 \\
\hline 4 & 48 & 6 & \begin{tabular}{l|l}
3.58 \\
\end{tabular} & \begin{tabular}{l|l}
21.5 \\
\end{tabular} & 1.5 & 28 & \begin{tabular}{|l|}
567 \\
\end{tabular} & 25 & 2244 & 28 & \begin{tabular}{l|l|}
567 \\
\end{tabular} & 24 & 2150 & & 545 & & \begin{tabular}{l|l}
365 \\
\end{tabular} & 1.20 & 1.07 & 4.19 & 1.28 & 1.94 & 1.00 & 3.15 & 2.65 & 1.00 & 15.46 & 18079138 & 39739157 \\
\hline 4 & 48 & 7 & 3.07 & 21.5 & 1.5 & 26 & 519 & 24 & 2197 & 26 & 519 & 23 & 2110 & & 421 & & \begin{tabular}{l|l}
415 \\
\end{tabular} & 1.21 & \begin{tabular}{l|l|l|}
1.07 \\
\end{tabular} & 4.24 & 1.27 & 1.99 & 1.00 & 3.48 & 2.72 & 1.00 & 17.29 & 17792409 & 39314313 \\
\hline 4 & 48 & 8 & 2.69 & 21.5 & 1.5 & 24 & 480 & 24 & 2157 & 24 & 480 & 23 & 2075 & & 490 & & 464 & 1.21 & 1.07 & 4.30 & 1.27 & 2.03 & 1.00 & \begin{tabular}{|l|}
3.77 \\
\end{tabular} & 2.77 & 1.00 & 19.01 & 17555182 & 38950656 \\
\hline & 48 & 9 & 2.39 & 21.5 & 1.5 & 22 & 446 & 23 & 2124 & 22 & \begin{tabular}{l|l}
446 \\
\end{tabular} & 22 & 2046 & & 545 & & 513 & 1.21 & 1.06 & 4.32 & 1.26 & 2.06 & 1.00 & \begin{tabular}{|l|} 
\\
\end{tabular} & 2.83 & 1.00 & 20.74 & 17383614 & 38716373 \\
\hline & $\begin{array}{ll}40 \\
48\end{array}$ & 10 & 2.15 & 21.5 & 1.5 & $\frac{24}{21}$ & 417 & 23 & 2094 & 21 & 417 & 22 & 2020 & & 304 & & 561 & 1.21 & 1.06 & 3..52 & 1.26 & 2.09 & 1.00 & \begin{tabular}{|l|}
4.35 \\
\end{tabular} & 2.60 & 1.00 & 22.41 & 17232993 & 38492938 \\
\hline 4 & 48 & 7 & 3.14 & 22 & 0 & 26 & 524 & 24 & 2202 & 26 & 524 & 23 & 2114 & & 421 & & 407 & 1.20 & 1.07 & 2.67 & 1.27 & 1.99 & 1.00 & \begin{tabular}{|l|}
3.42 \\
\end{tabular} & 1.70 & 1.00 & 16.97 & 17711016 & 39174242 \\
\hline 4 & 48 & 8 & 2.75 & 22 & 0 & 24 & 484 & 24 & 2163 & 24 & 484 & 23 & 2080 & & 471 & & 455 & 1.21 & 1.07 & 2.71 & 1.26 & 2.03 & 1.00 & \begin{tabular}{|l|}
3.72 \\
\end{tabular} & 1.74 & 1.00 & 18.70 & 17477136 & 38838871 \\
\hline & 48 & 9 & 2.44 & 22 & 0 & 23 & \begin{tabular}{l|l}
450 \\
\end{tabular} & 23 & 2130 & 23 & 450 & 23 & \begin{tabular}{l|l|}
2052 & \\
\end{tabular} & & 533 & & \begin{tabular}{l|l|}
503 \\
\end{tabular} & 1.21 & 1.06 & 2.72 & 1.26 & 2.06 & 1.00 & \begin{tabular}{|l|} 
\\
\end{tabular} & 1.77 & 1.00 & \begin{tabular}{|l|}
20.43 \\
\end{tabular} & 17338540 & 38659409 \\
\hline & $\begin{array}{l}\frac{40}{48} \\
48\end{array}$ & 10 & 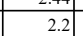 & 22 & & $\frac{23}{21}$ & 421 & 23 & 2099 & 21 & 421 & 22 & 2025 & & 585 & & 549 & 1.21 & 1.06 & 2.77 & 1.25 & 2.09 & 1.00 & \begin{tabular}{|l|}
4.028 \\
\end{tabular} & 1.80 & 1.00 & 22.01 & 17132777 & 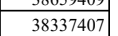 \\
\hline 4 & 48 & 11 & 2 & 22 & 0 & 20 & \begin{tabular}{l|l|}
395 \\
\end{tabular} & 23 & 2074 & 20 & 395 & 22 & \begin{tabular}{|l|l|}
2003 \\
\end{tabular} & & 329 & & \begin{tabular}{l|l|}
595 \\
\end{tabular} & 1.21 & 1.06 & 2.78 & 1.25 & 2.11 & 1.00 & 4.55 & 1.83 & 1.00 & 23.63 & 17021942 & 38198123 \\
\hline 4 & 48 & 12 & 1.83 & 22 & 0 & 19 & 372 & 23 & 2052 & 19 & 372 & 22 & 1984 & & 358 & & 419 & 1.22 & 1.06 & 2.80 & 1.25 & 2.13 & 1.00 & \begin{tabular}{|l|}
4.75 \\
\end{tabular} & 1.86 & 1.00 & 25 & $\frac{10977772}{169}$ & 38161969 \\
\hline & 48 & 7 & 3.57 & 25 & 1.5 & 28 & 564 & 25 & 2243 & 28 & 564 & 24 & 2150 & & 545 & & 365 & 1.20 & 1.07 & 4.13 & 1.27 & 1.95 & 1.00 & \begin{tabular}{|l|} 
\\
\end{tabular} & 2.65 & $\begin{array}{ll}1.00 \\
\end{array}$ & \begin{tabular}{l|l|}
15.49 \\
\end{tabular} & 17986747 & 39608289 \\
\hline & $\begin{array}{l}\frac{40}{48} \\
48\end{array}$ & 8 & 3.125 & 25 & 1.5 & 26 & 523 & 24 & 2201 & 26 & 523 & 23 & 2113 & & 421 & & 409 & 1.21 & $\begin{array}{l}1.07 \\
\end{array}$ & 4 & 1.27 & 1.99 & 1.00 & \begin{tabular}{|l|}
3.44 \\
\end{tabular} & 2.70 & 1.00 & 17.04 & \begin{tabular}{l|l|}
17731695 \\
\end{tabular} & 390209280 \\
\hline 4 & 48 & 9 & \begin{tabular}{l|l|}
2.78 \\
\end{tabular} & 25 & 1.5 & 24 & 488 & 24 & 2166 & 24 & 488 & 23 & \begin{tabular}{l|l|}
2082 \\
\end{tabular} & & 471 & & 451 & 1.21 & 1.07 & 4.25 & 1.26 & 2.02 & 1.00 & \begin{tabular}{|l|}
3.71 \\
\end{tabular} & 2.75 & 1.00 & 18.55 & 17529243 & 38911576 \\
\hline 4 & 48 & 10 & 2.5 & 25 & 1.5 & 23 & $\begin{array}{l}450 \\
457 \\
\end{array}$ & 23 & 2137 & 23 & $\begin{array}{l}457 \\
457 \\
\end{array}$ & 23 & 2057 & & 522 & & 493 & 1.21 & 1.06 & 4.27 & 1.26 & 2.05 & 1.00 & \begin{tabular}{|l|}
3.97 \\
\end{tabular} & 2.80 & 1.00 & 20 & 17382402 & 38723132 \\
\hline 4 & 48 & 11 & 2.27 & 25 & 1.5 & 22 & 431 & 23 & 2109 & 22 & 431 & 22 & \begin{tabular}{l|l|}
2032 \\
\end{tabular} & 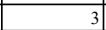 & 571 & & 535 & 1.21 & 1.06 & 4.14 & 1.26 & 2.07 & 1.00 & 4.21 & 2.71 & 1.00 & \begin{tabular}{|l|}
21.53 \\
\end{tabular} & 17267828 & 38544796 \\
\hline 4 & 48 & 12 & 1.83 & 25 & 1.5 & 23 & 462 & 24 & 2142 & 23 & 462 & 22 & 2030 & 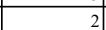 & 358 & & 478 & 1.26 & 1.09 & 2.86 & 1.63 & 1.83 & 1.00 & \begin{tabular}{|l|}
5.03 \\
\end{tabular} & 2.20 & 1.00 & 27.55 & 24203531 & 49159855 \\
\hline
\end{tabular}




\section{Appendix B: CL-800 truck loading optimization program results}

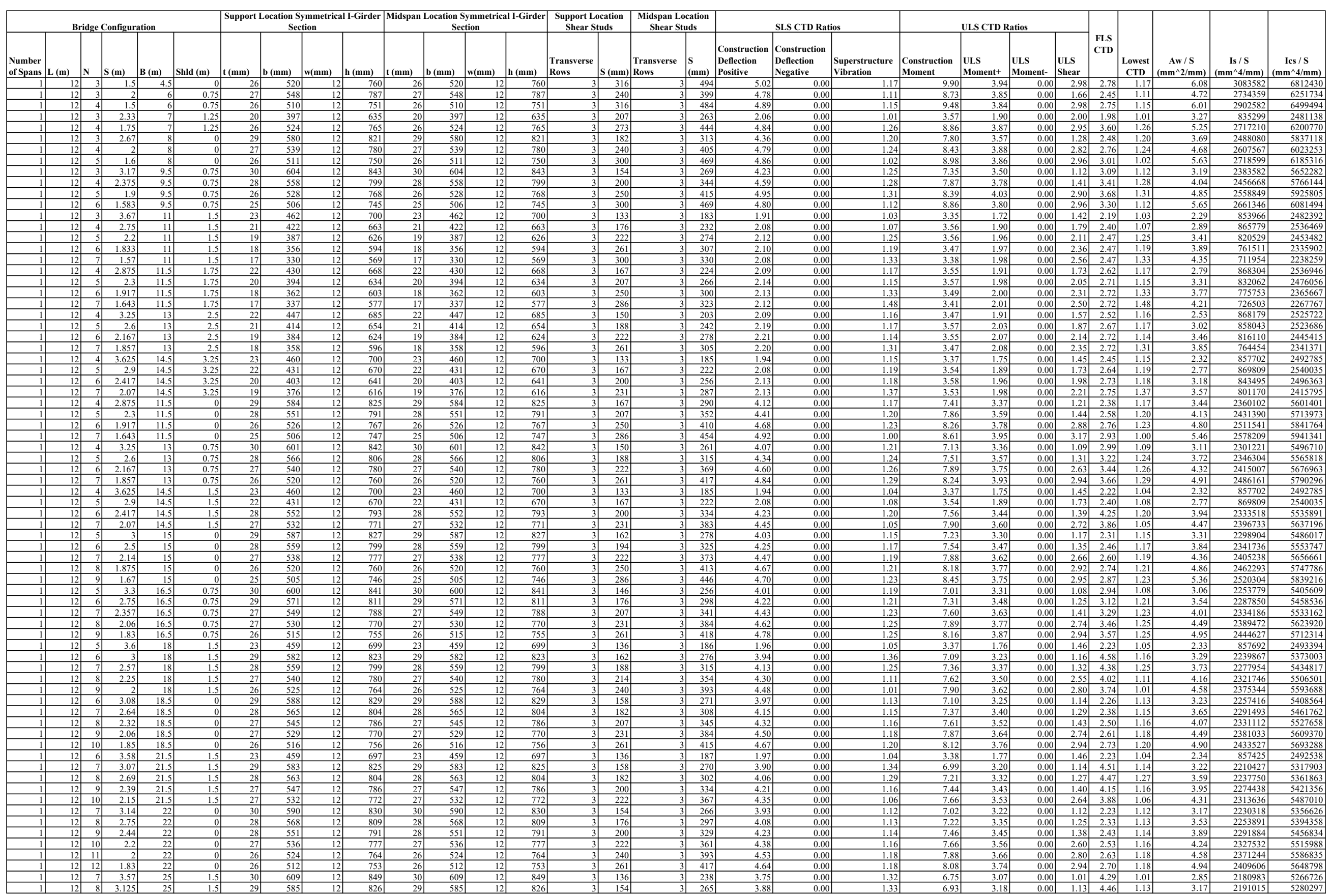




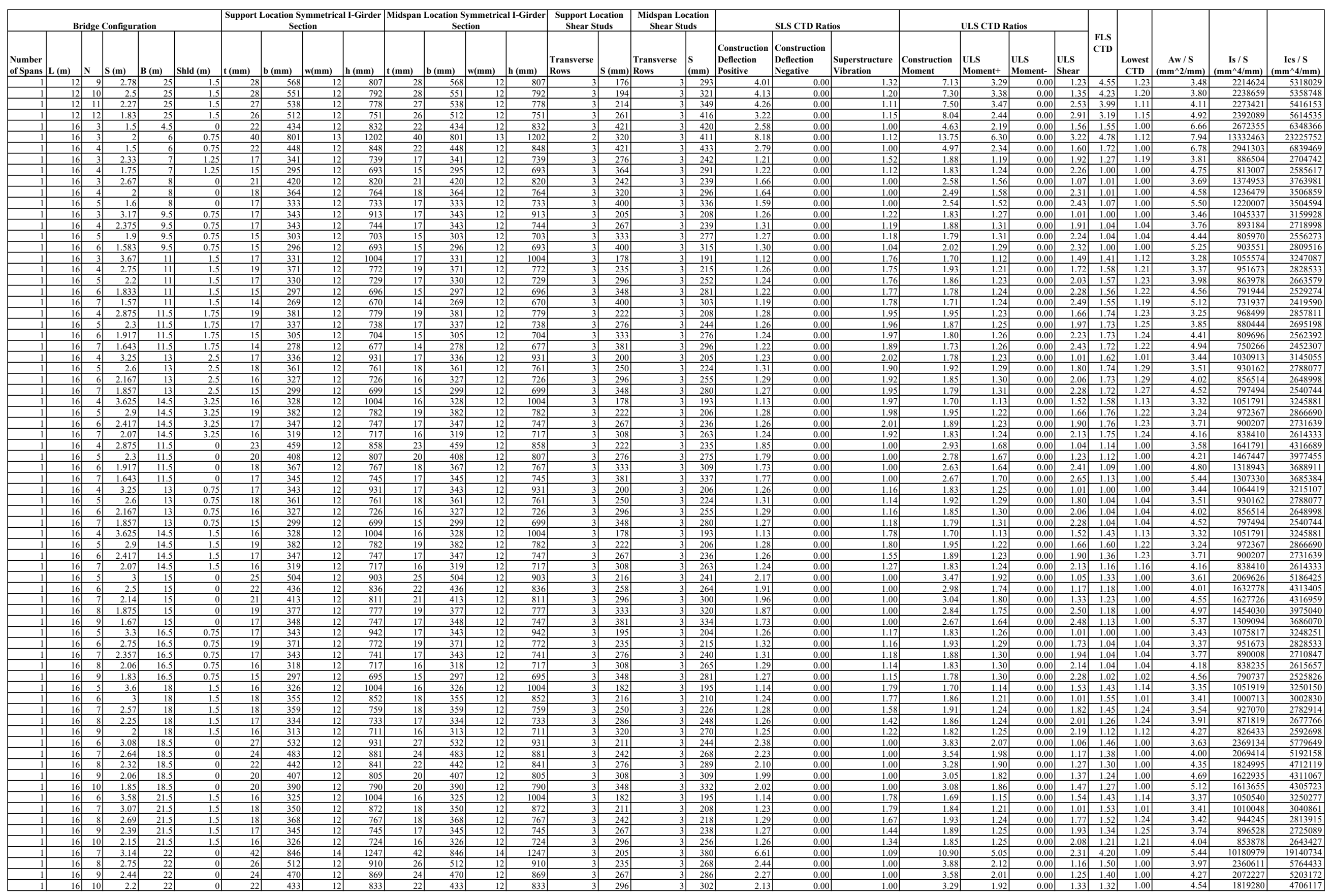




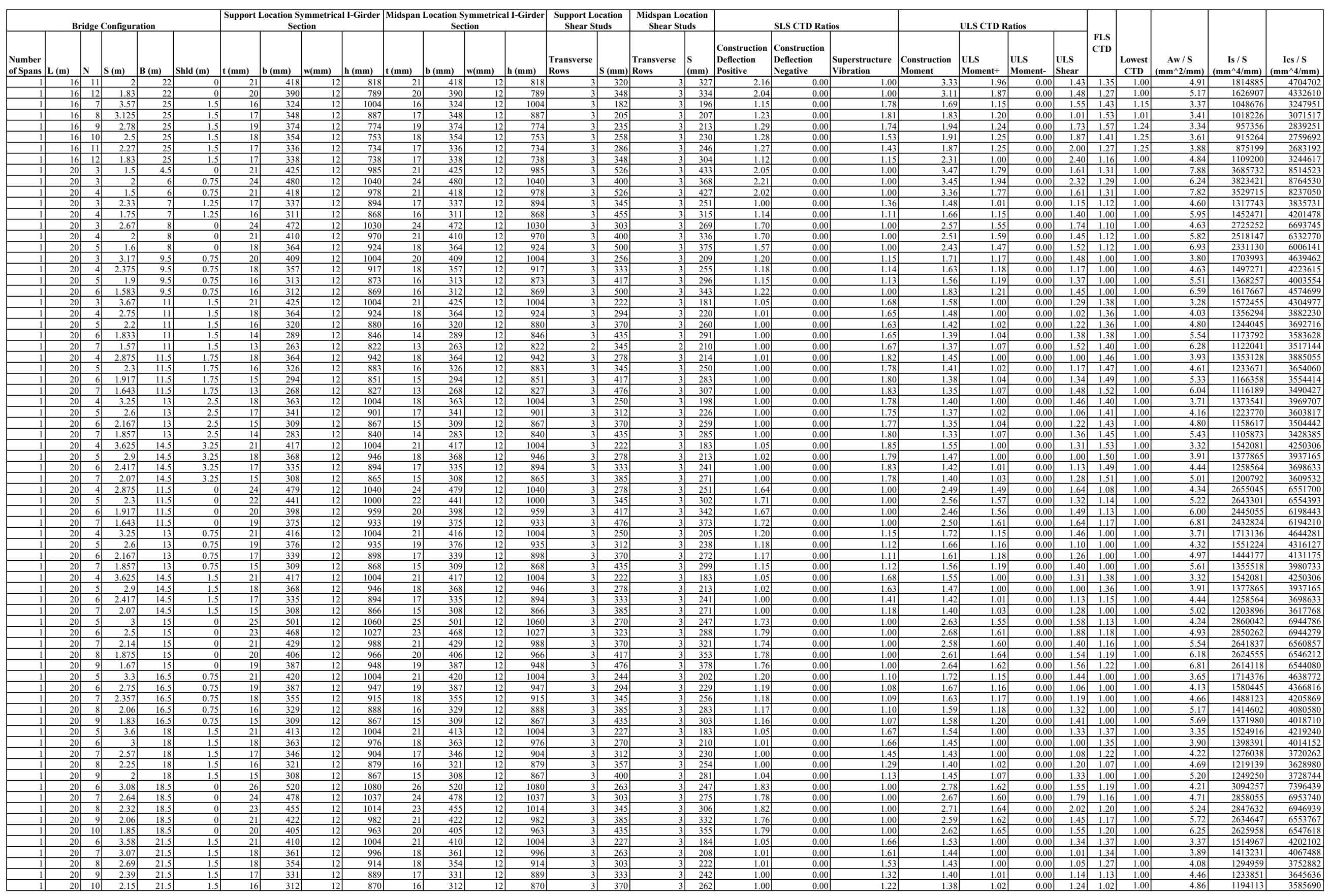




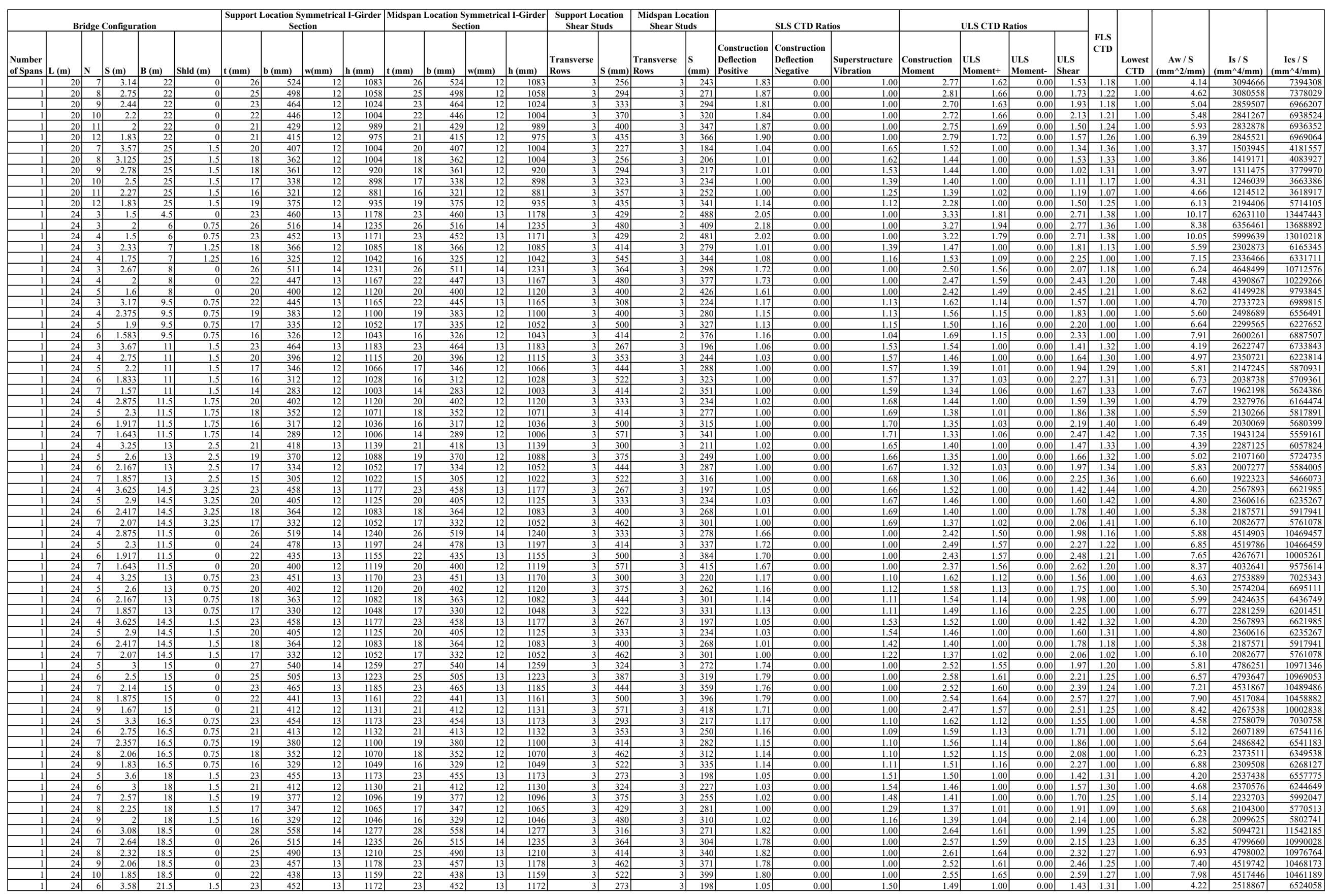




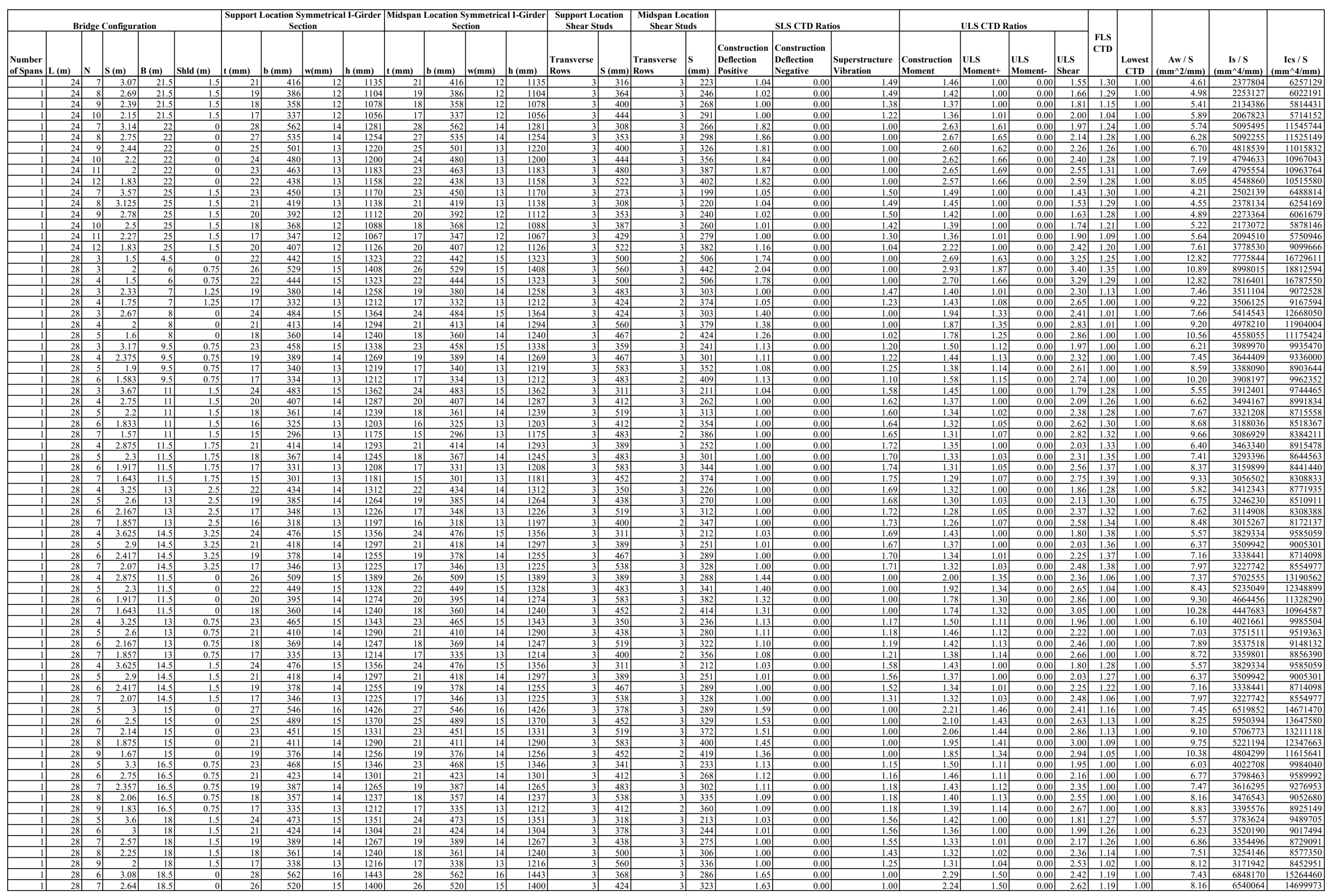




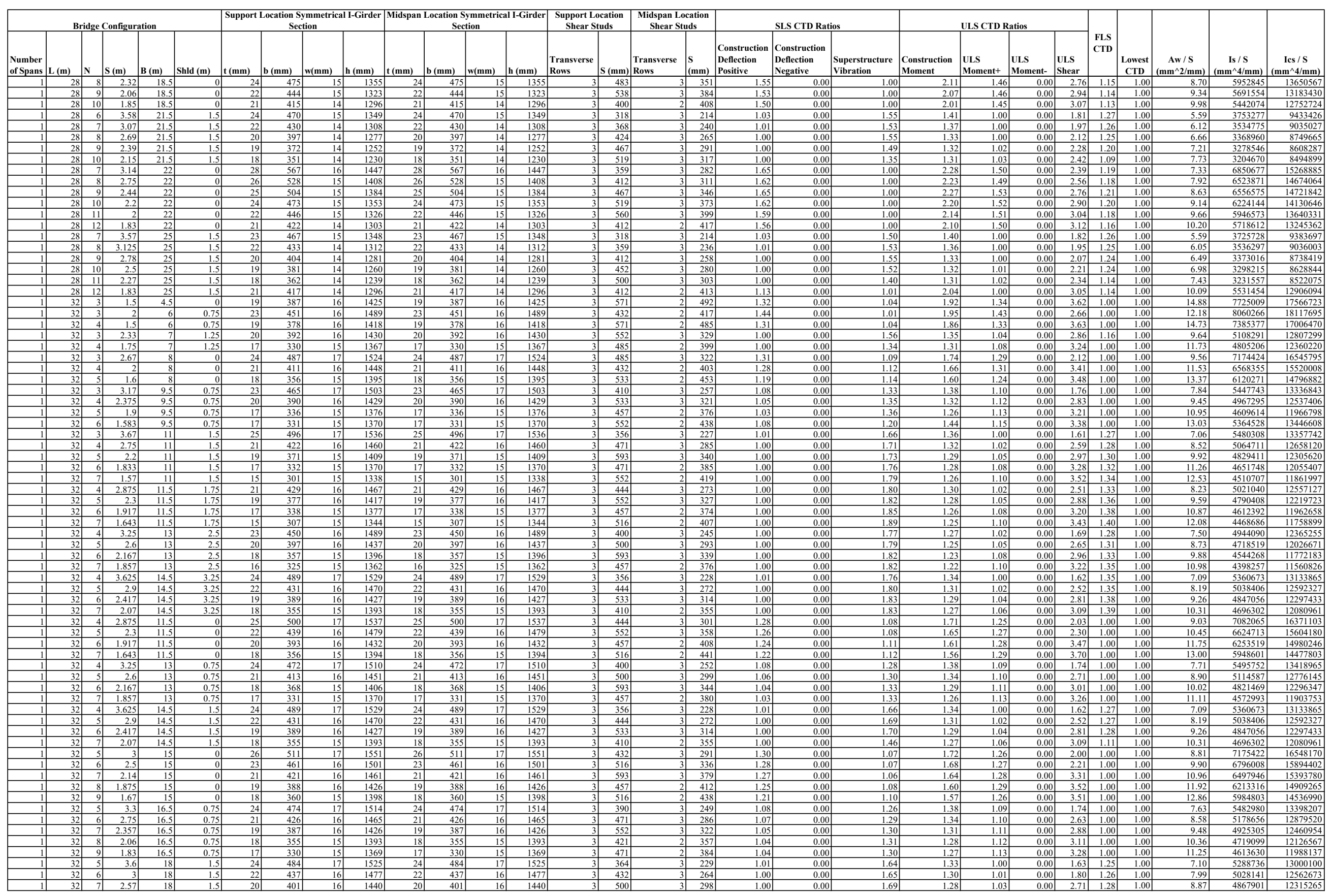




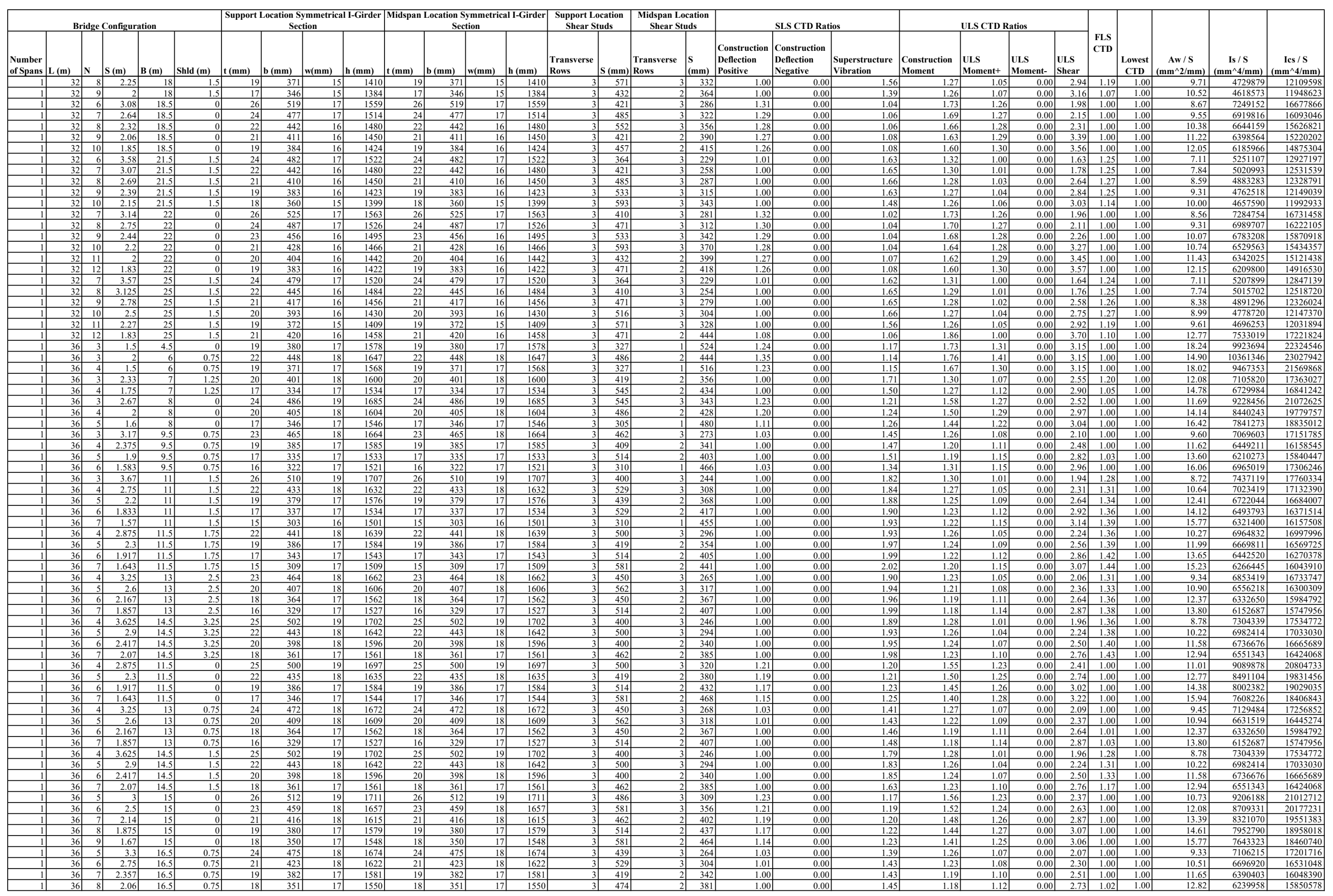




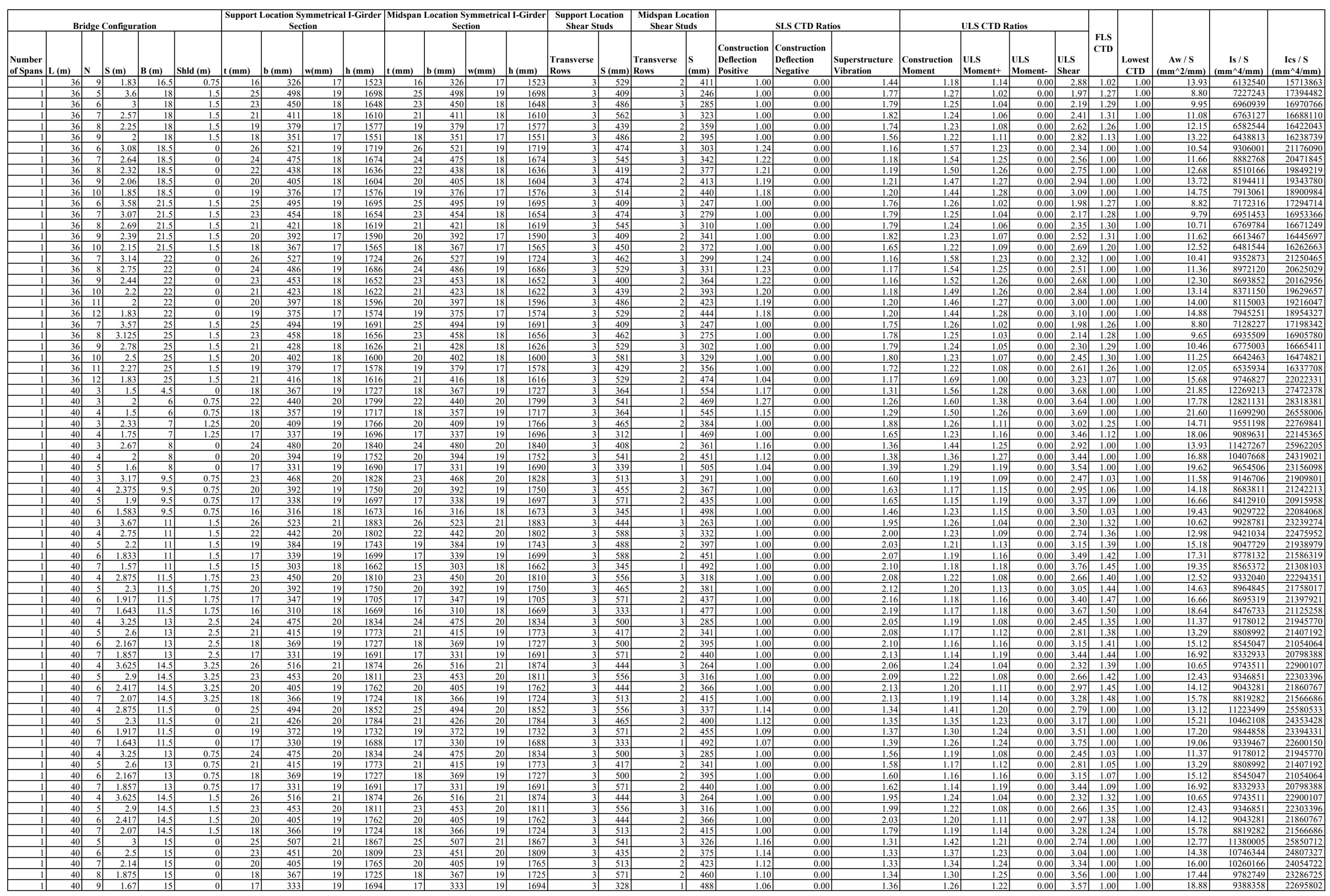




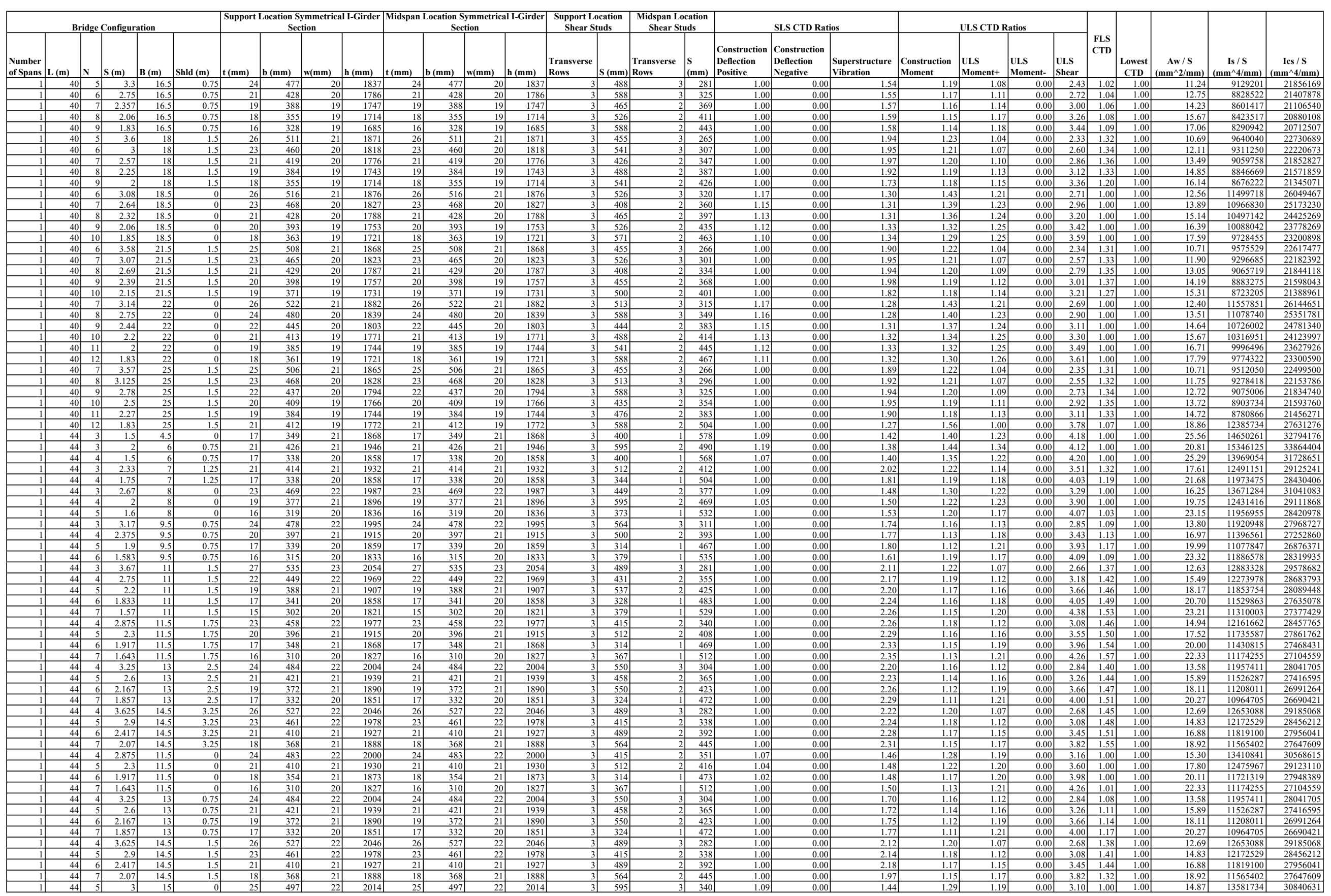




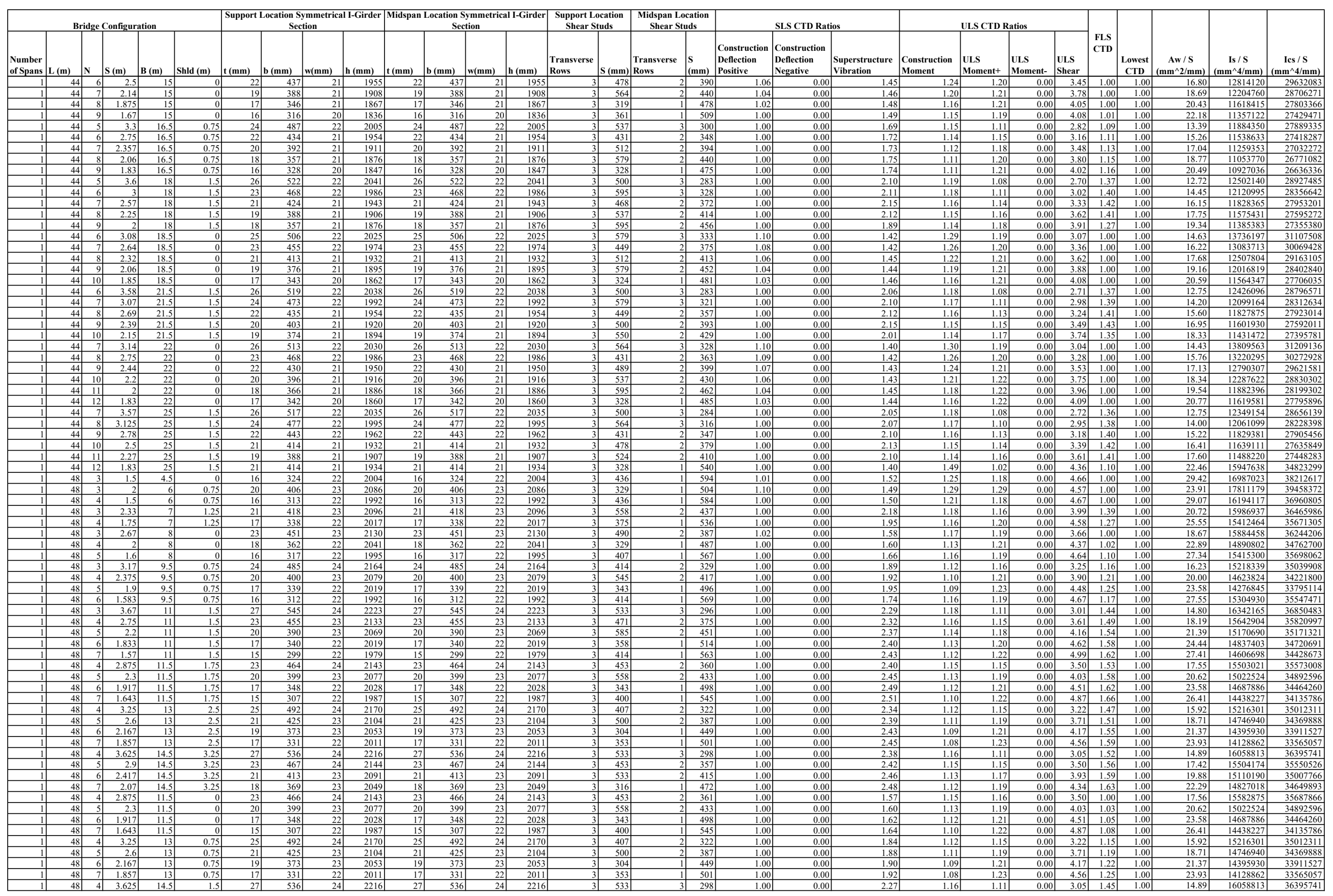




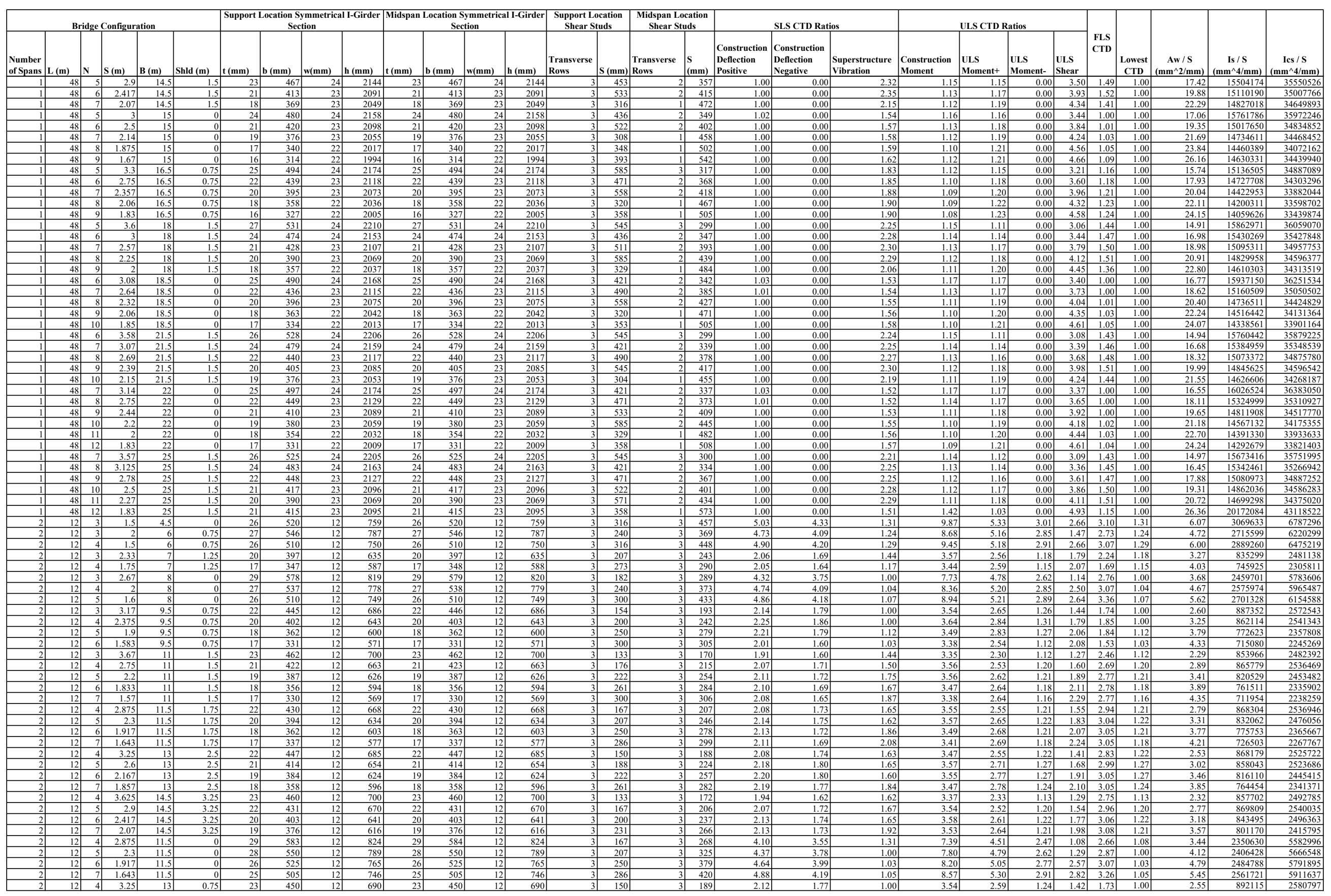




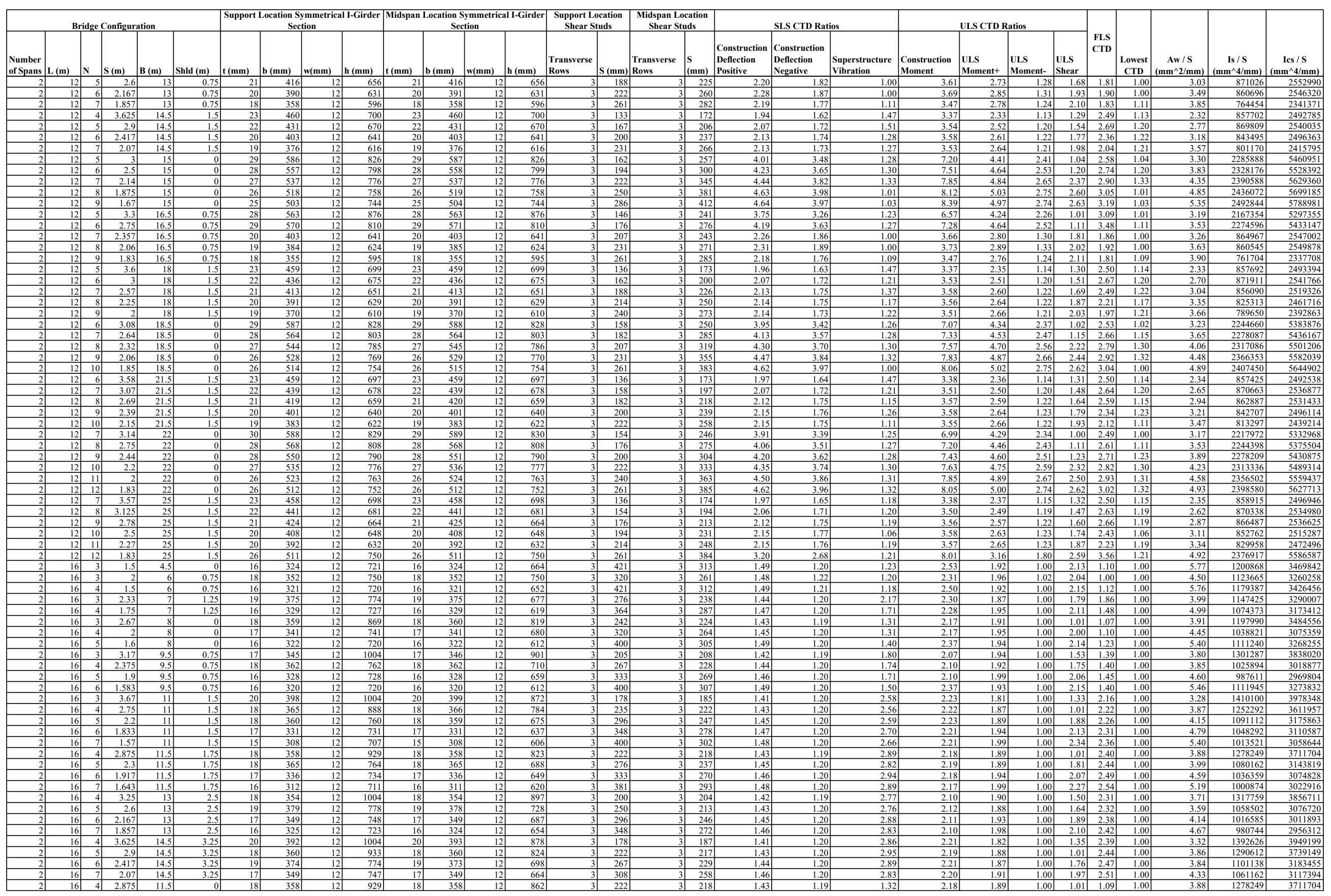




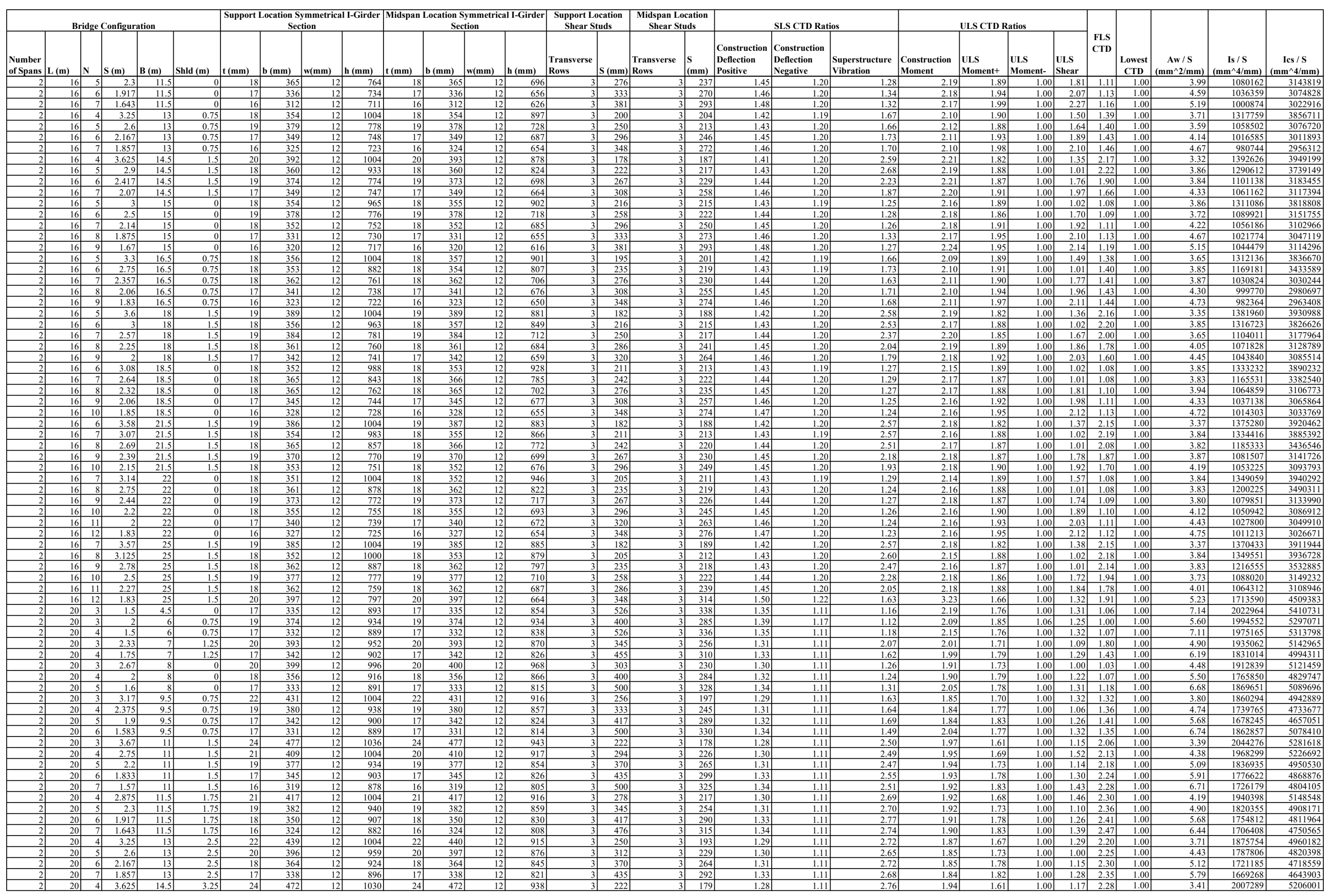




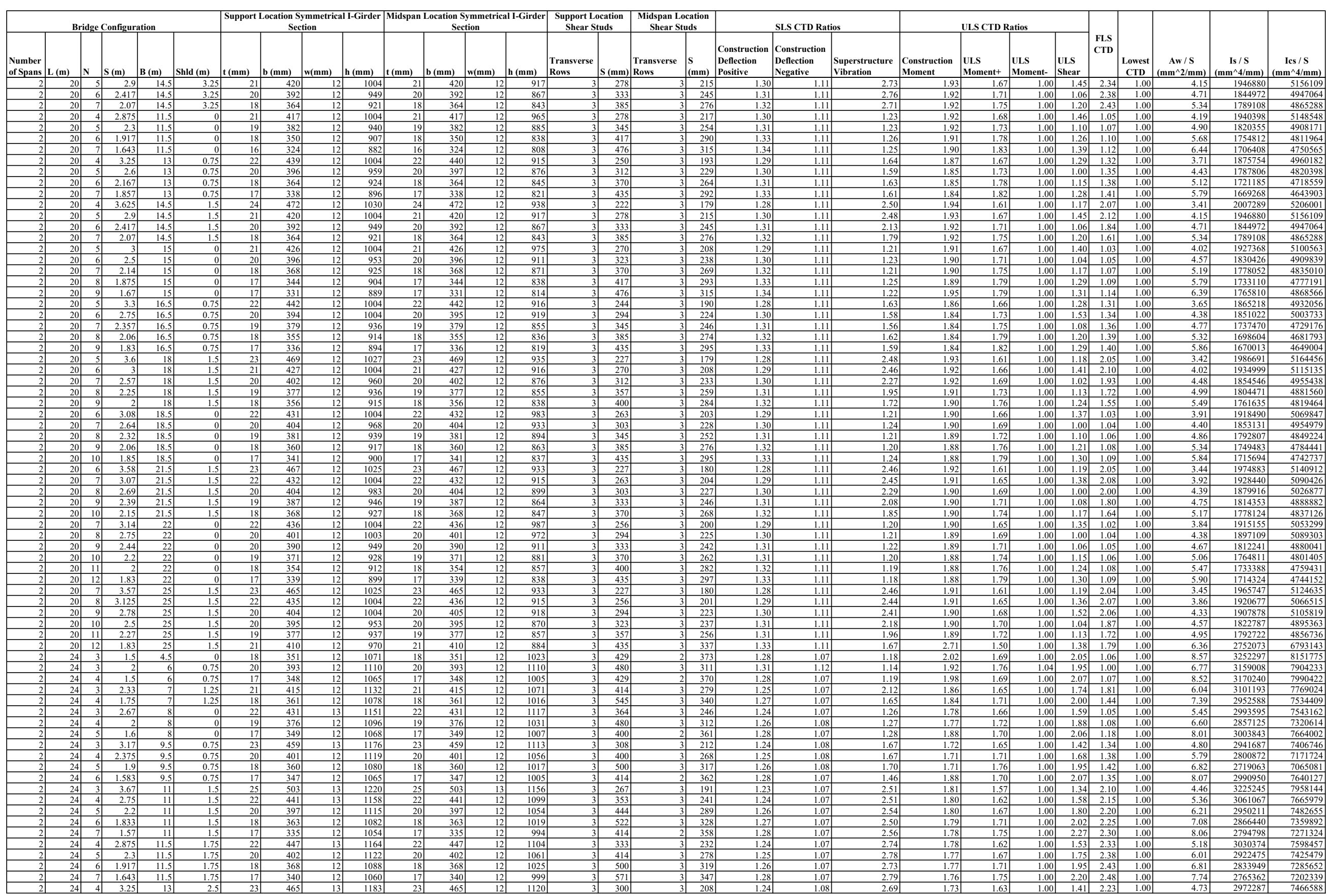




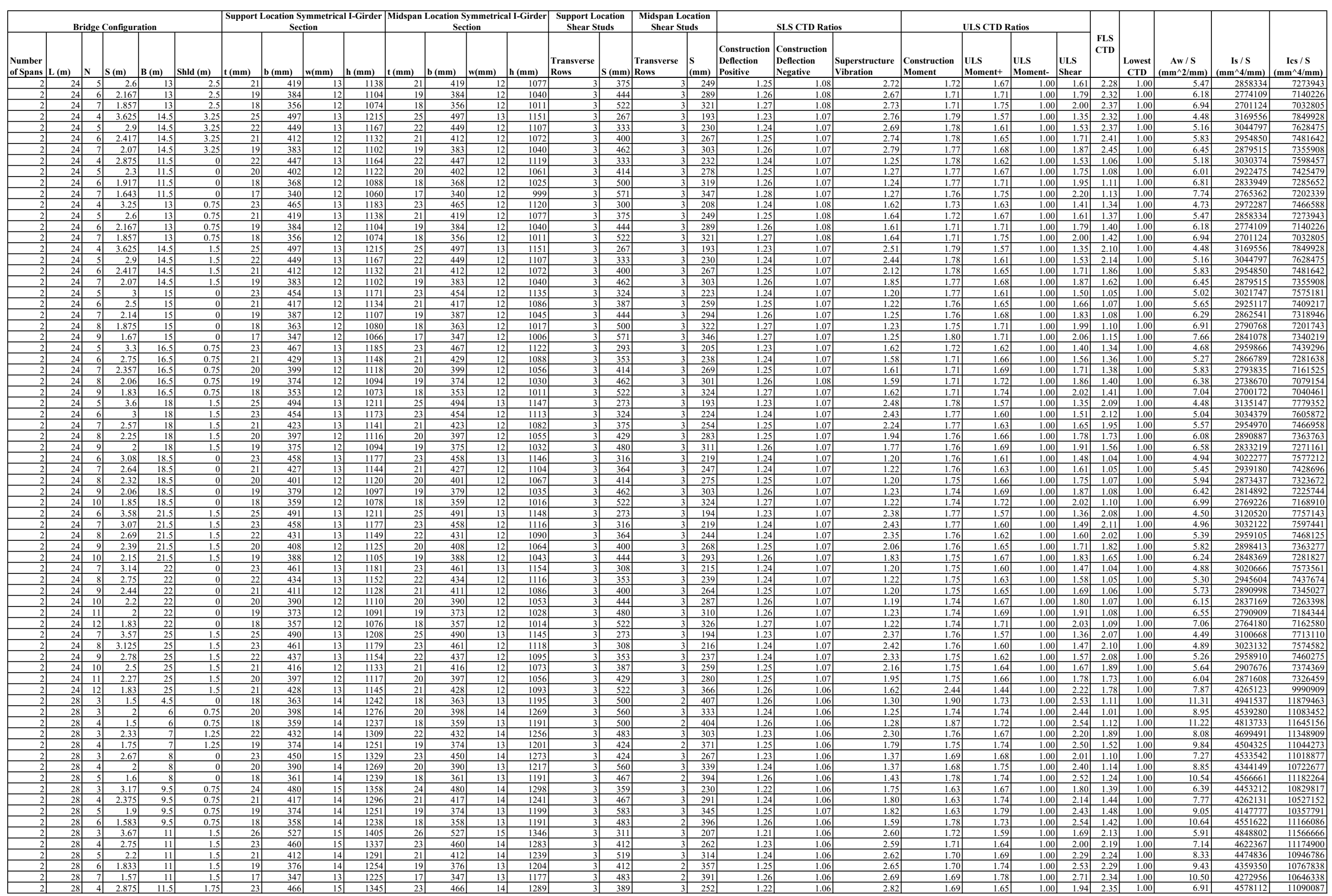




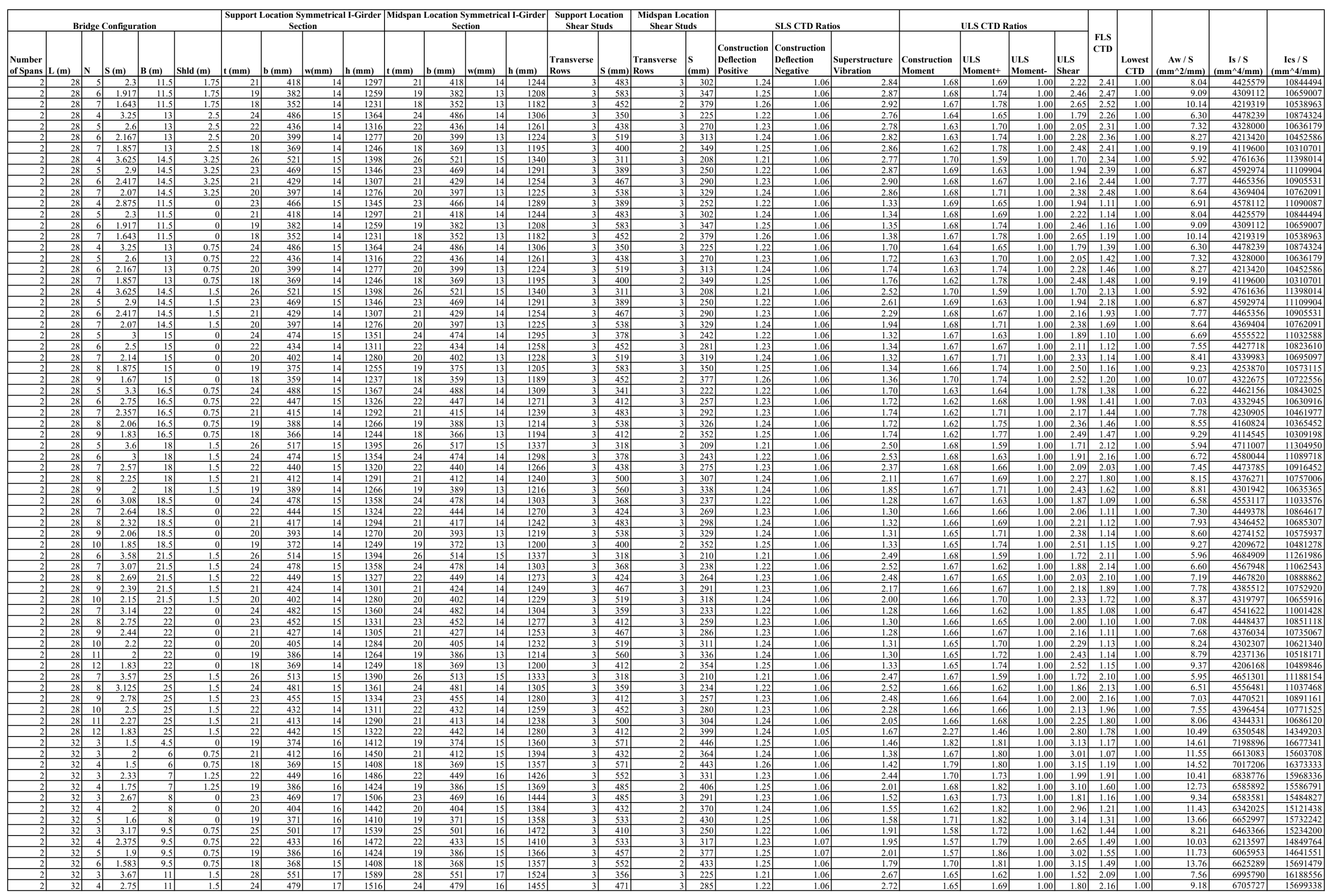




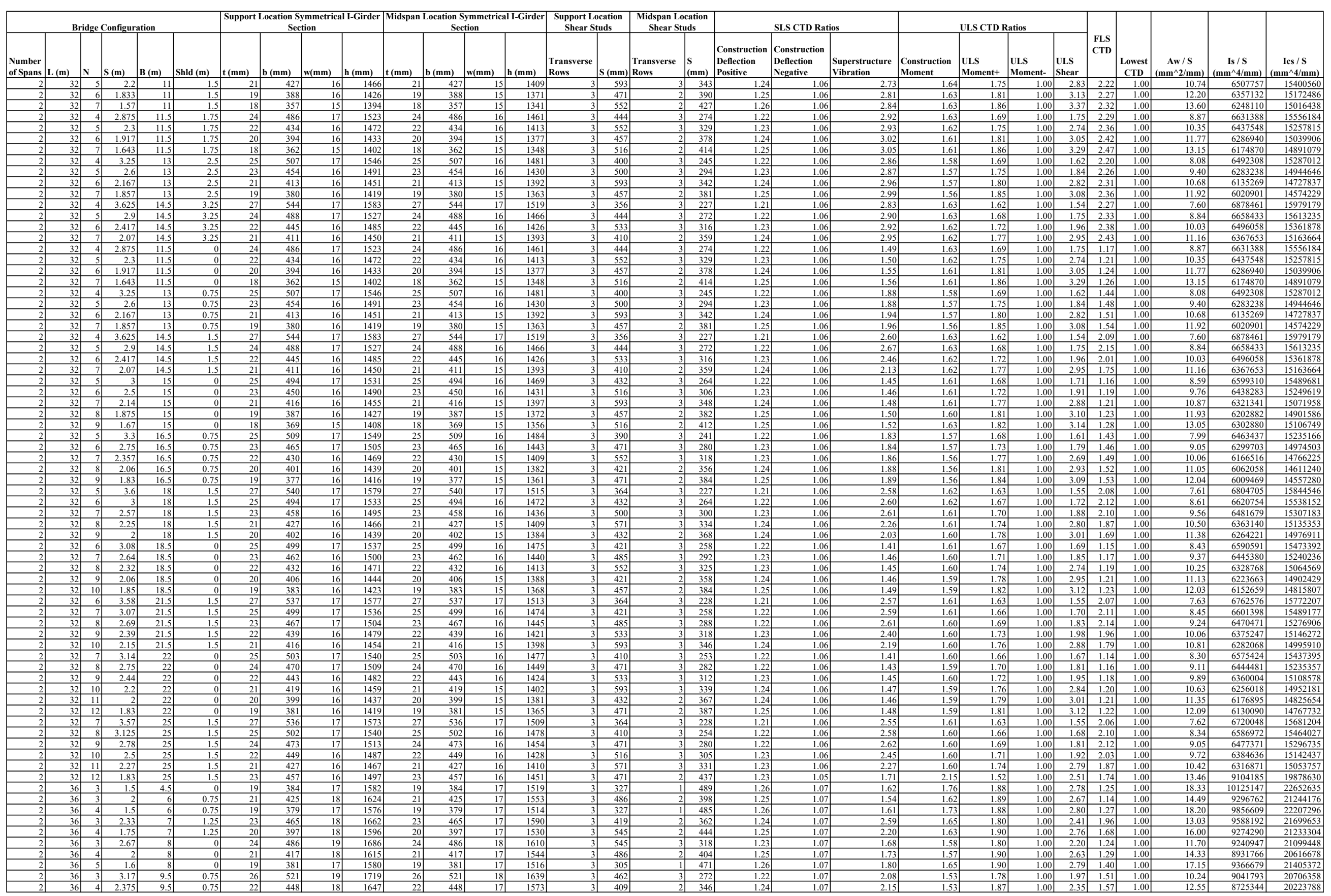




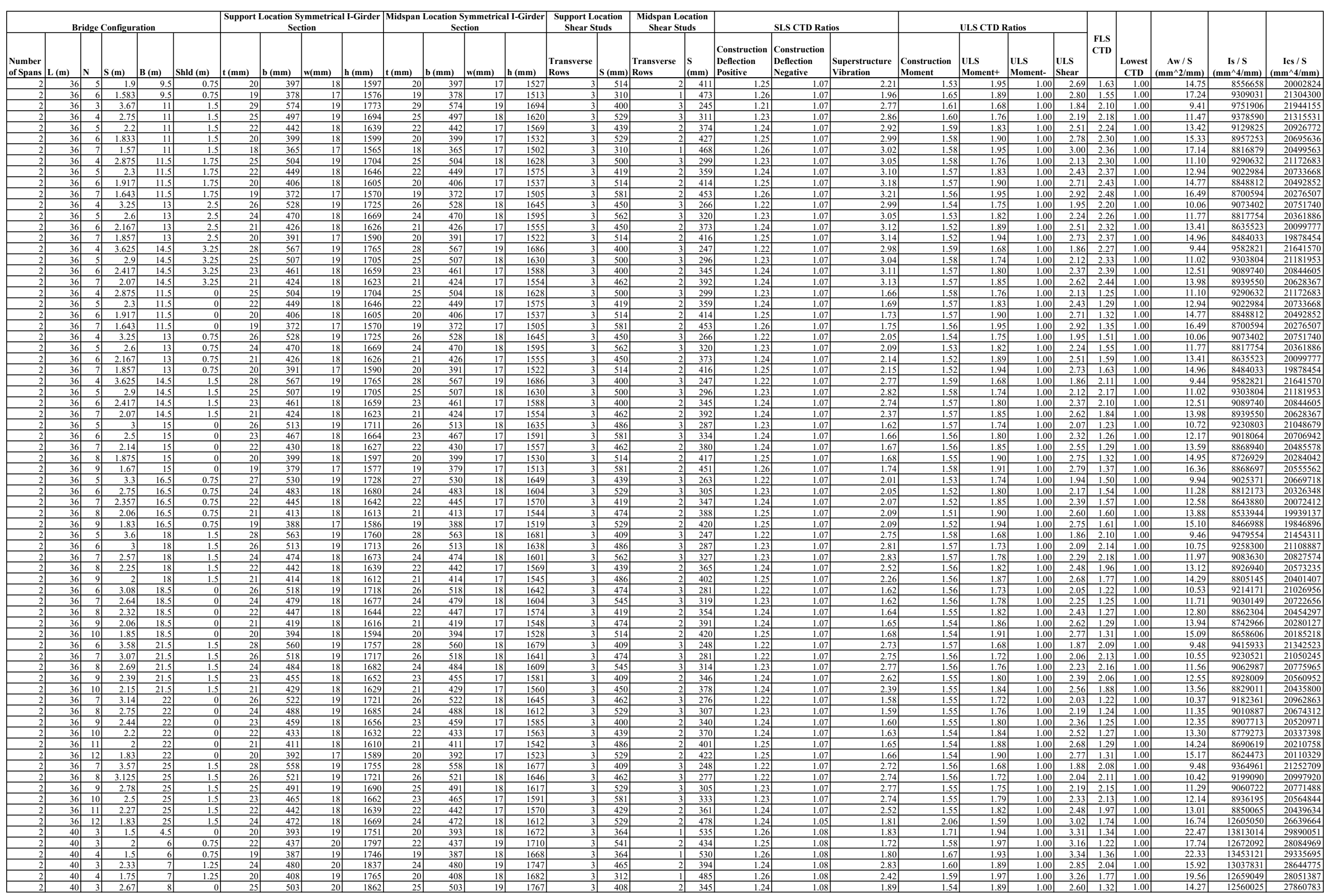




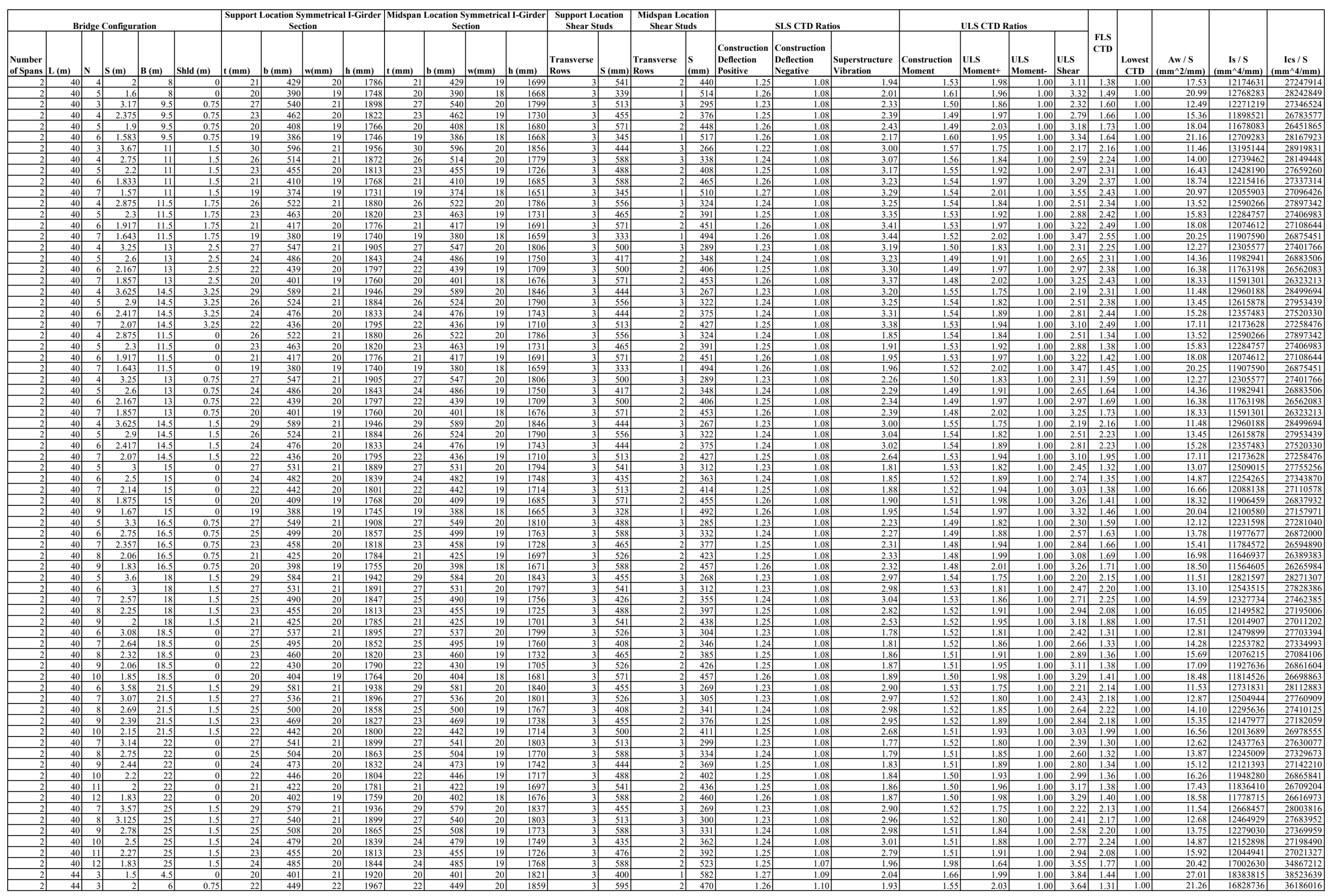




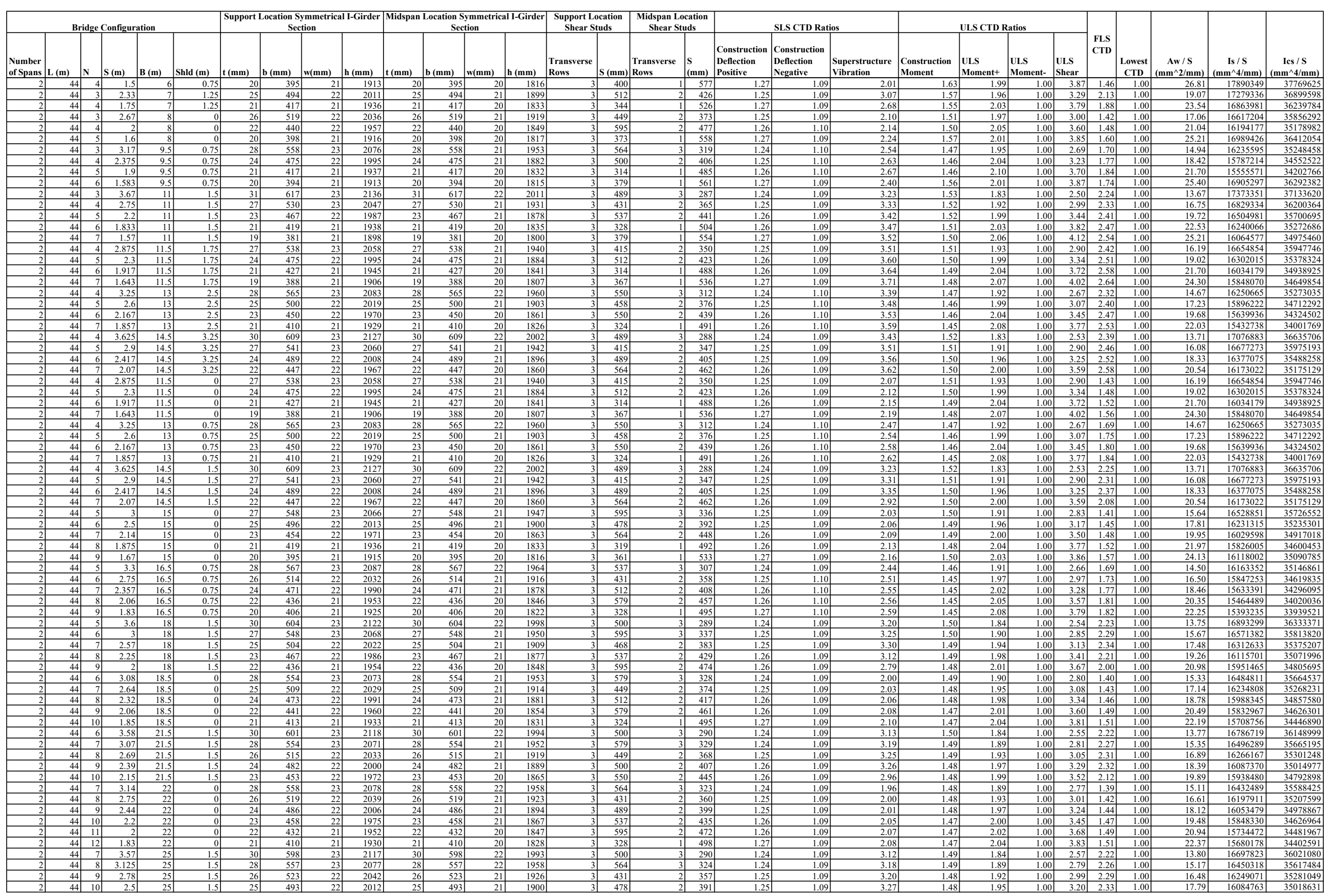




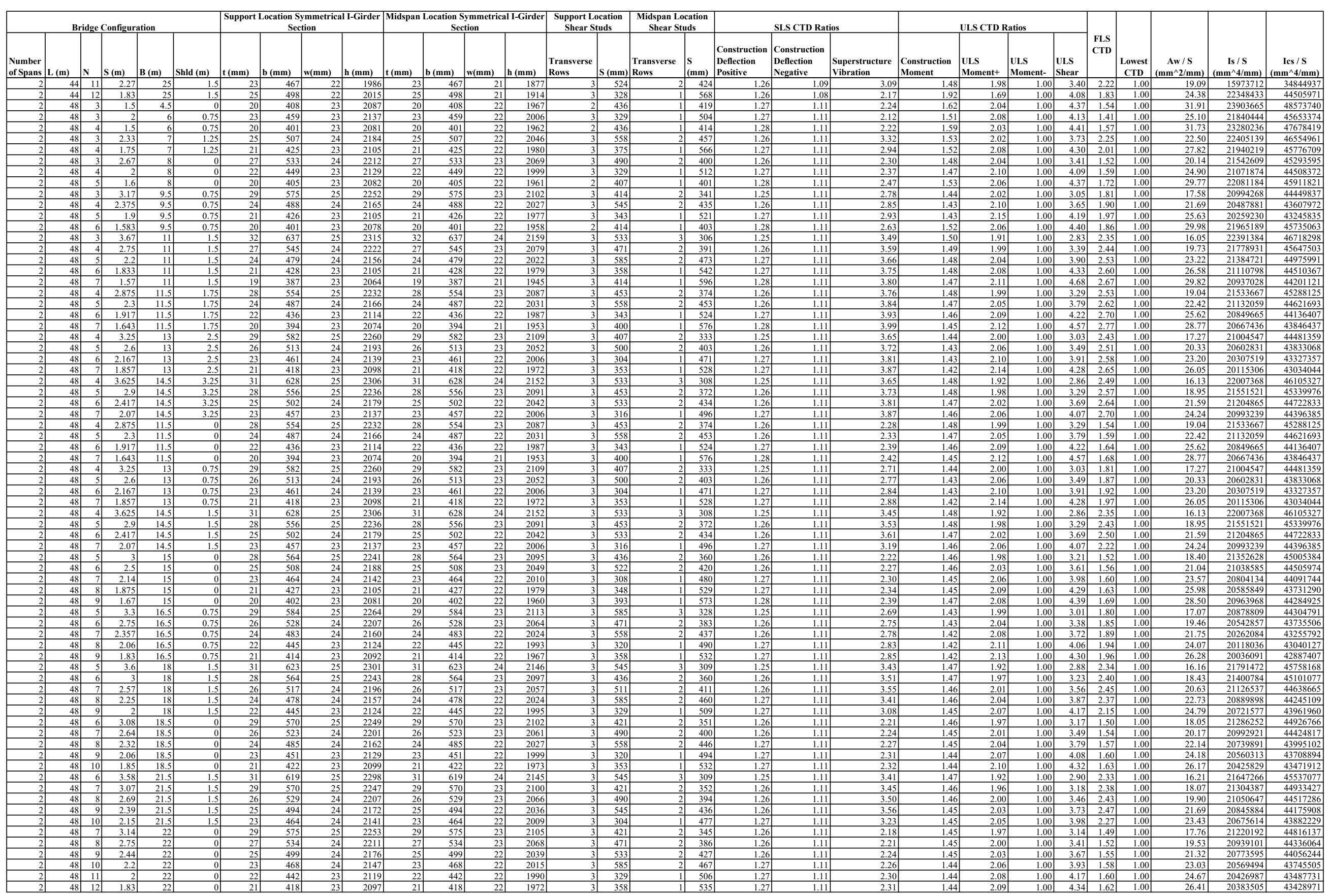




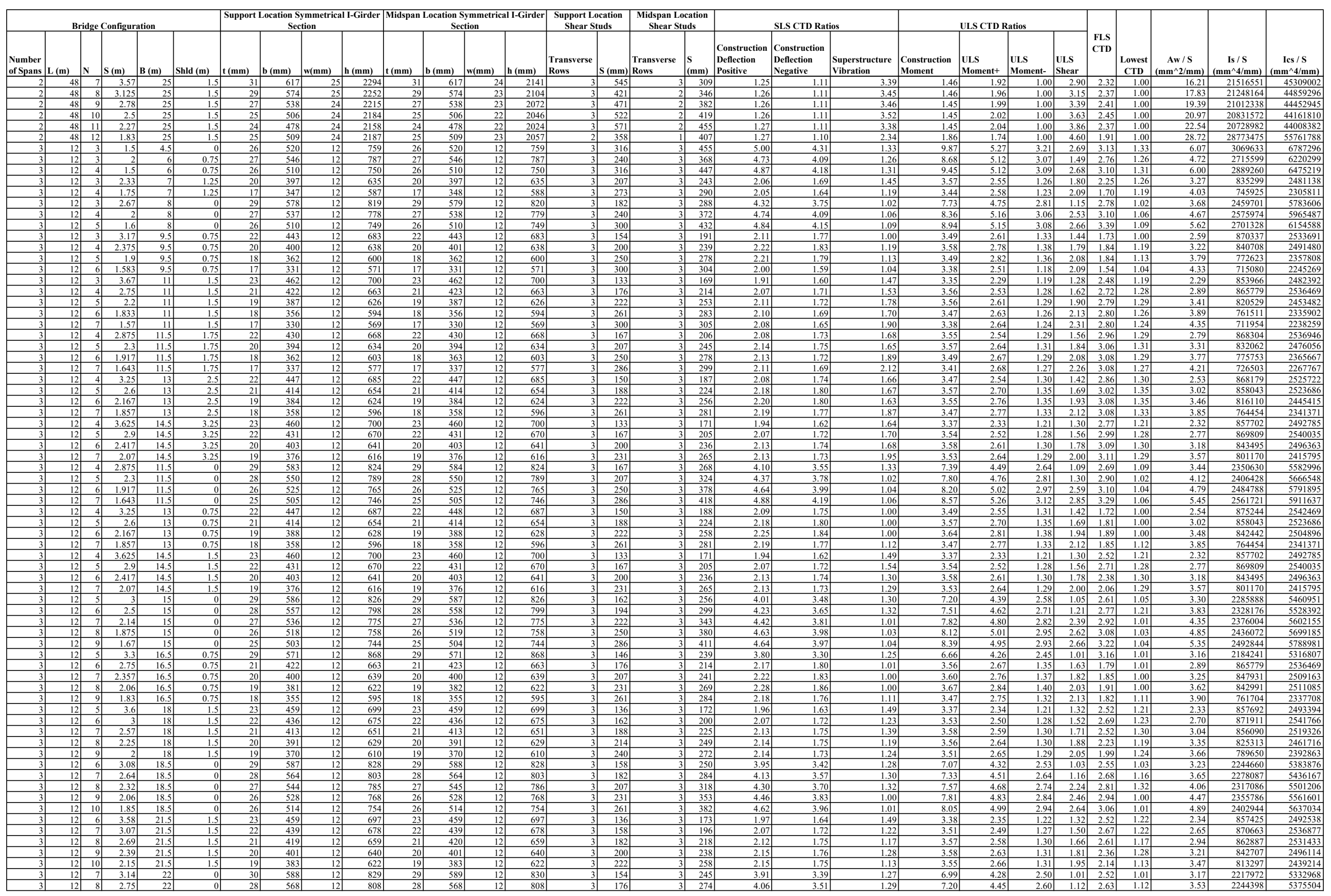




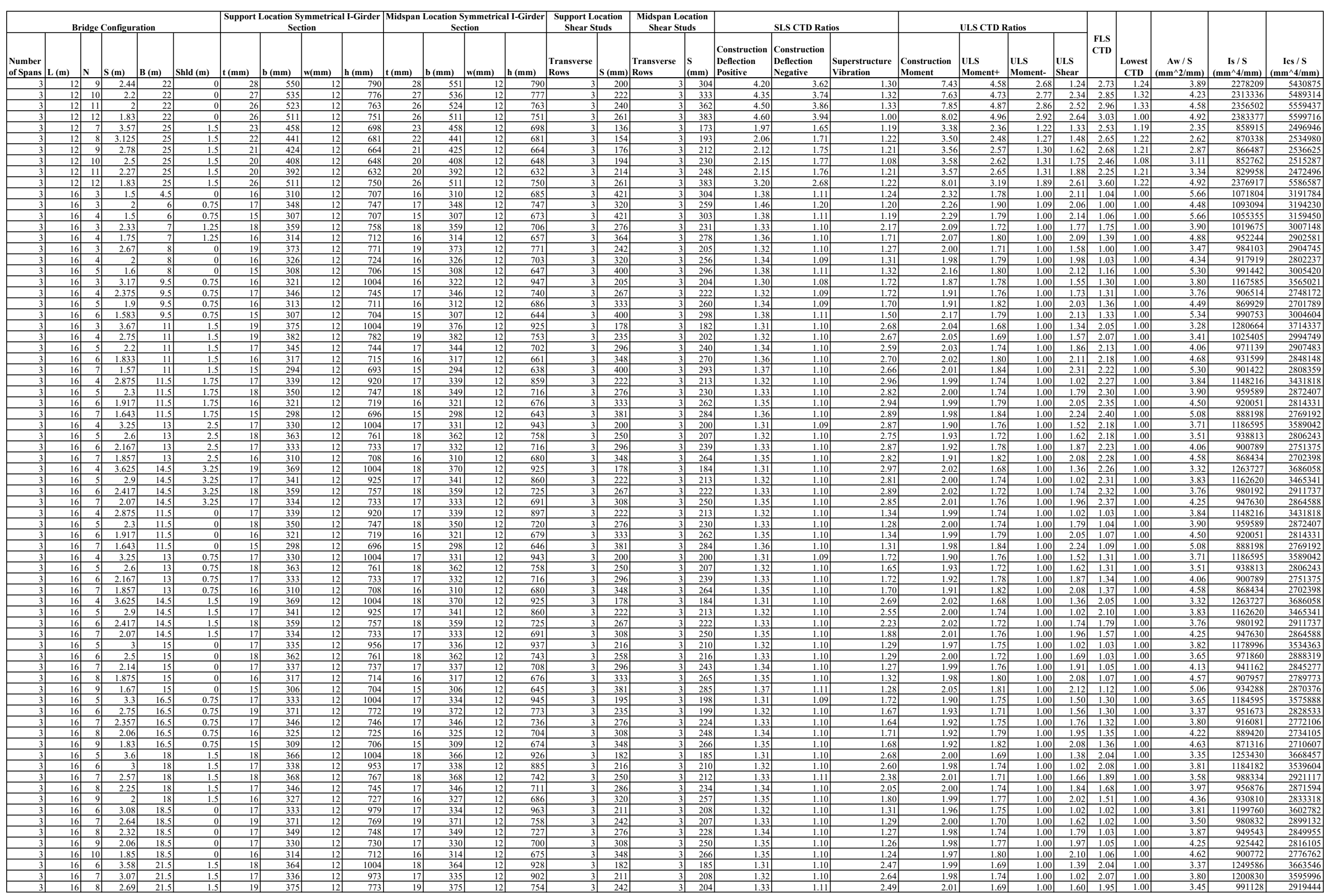




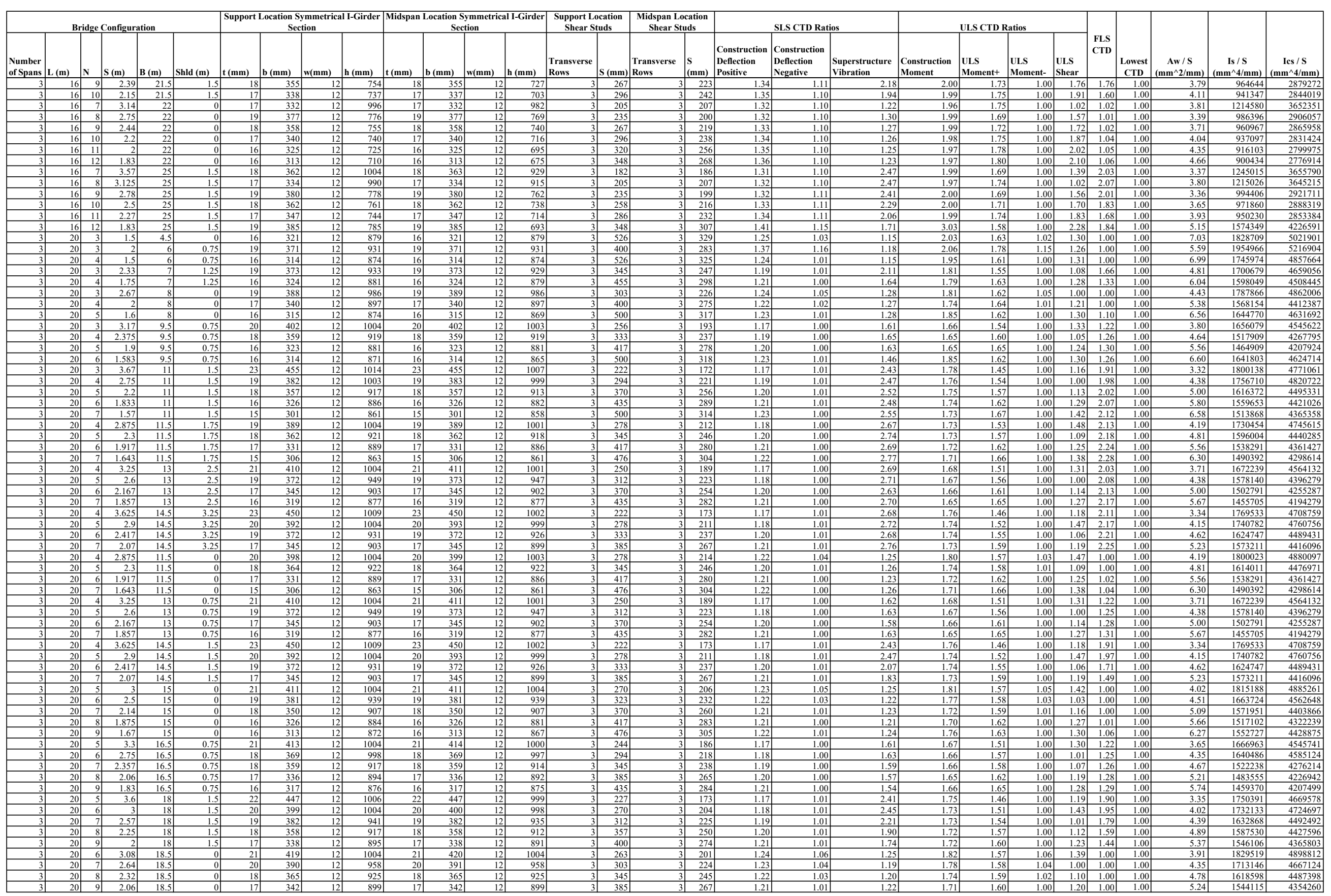




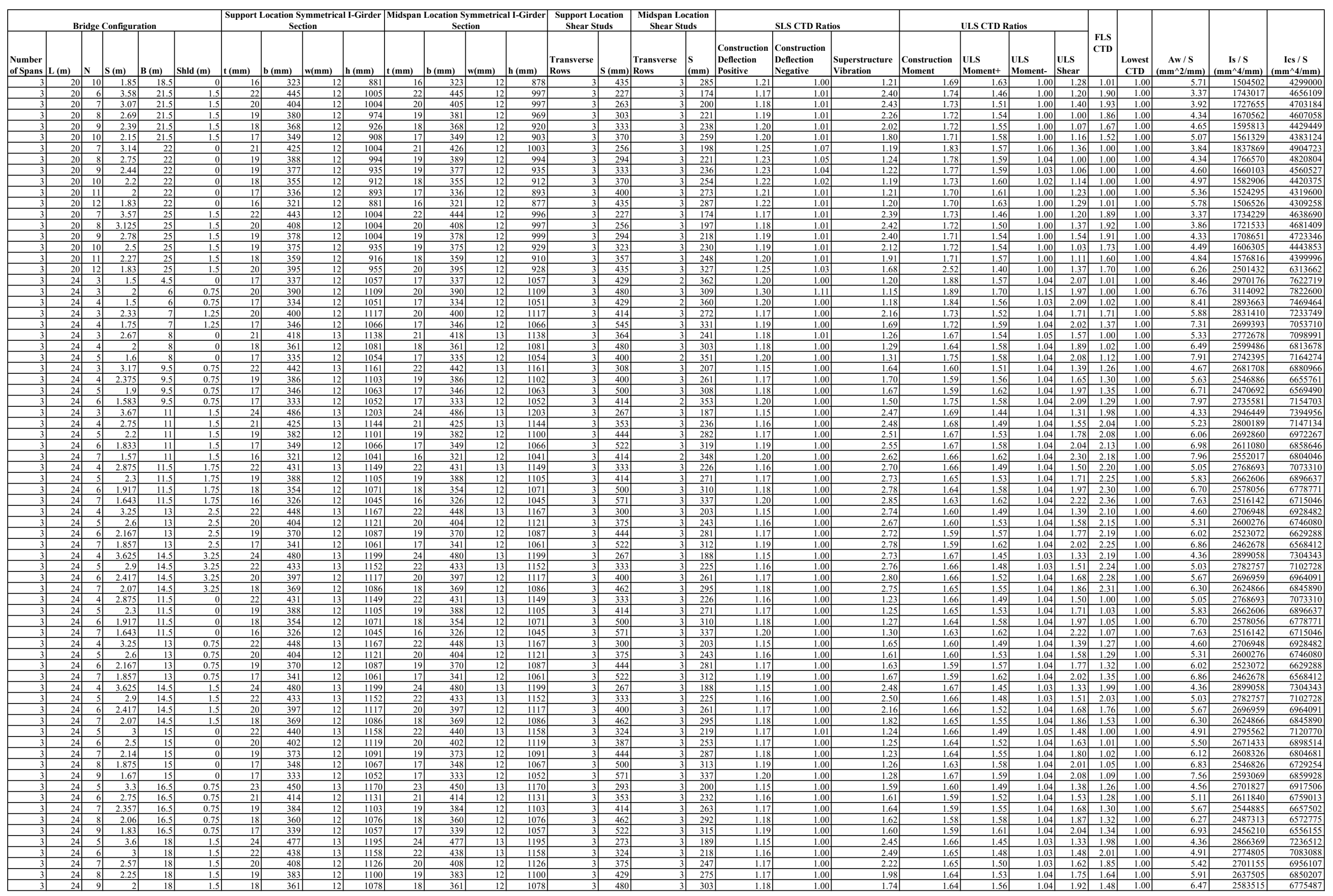




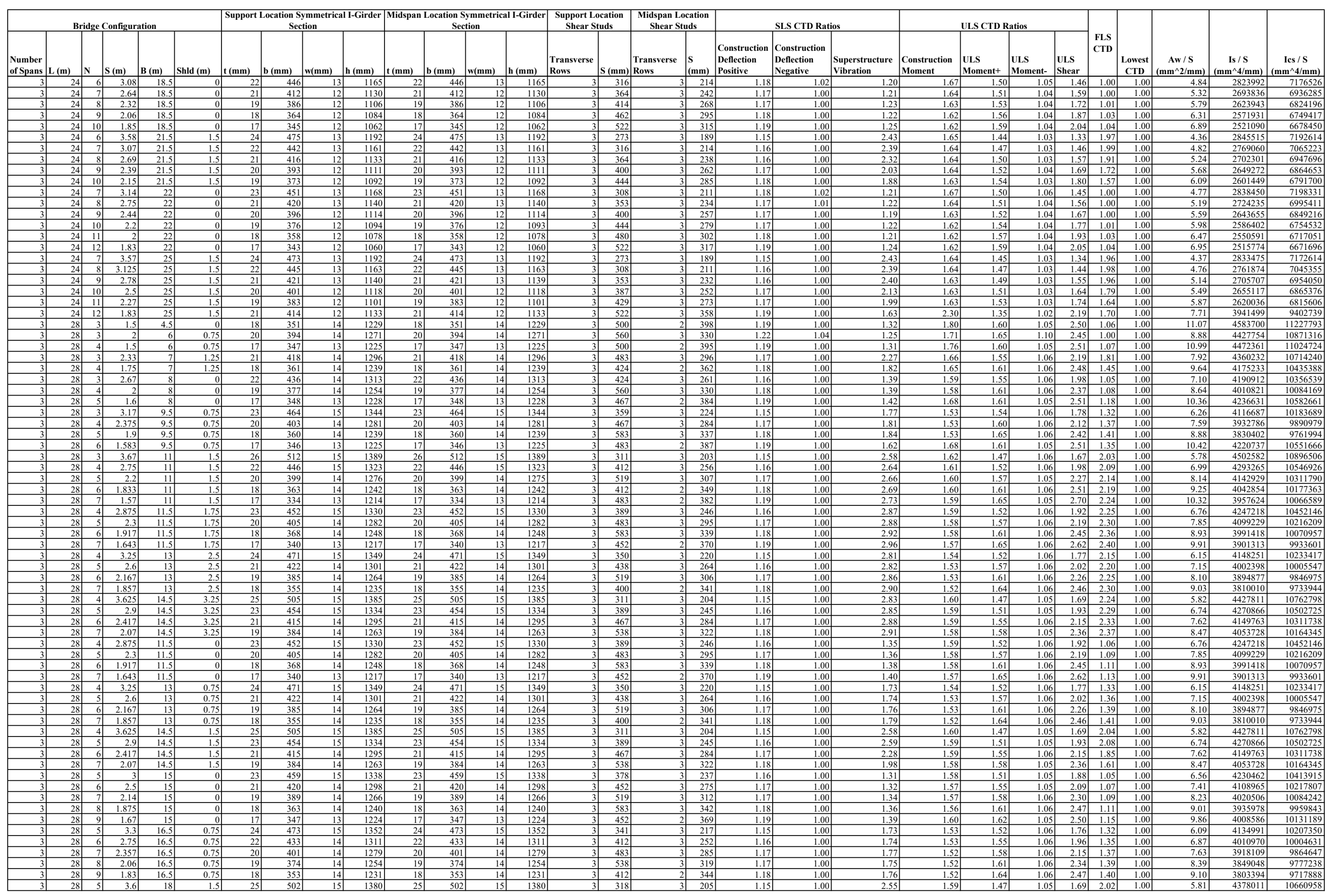




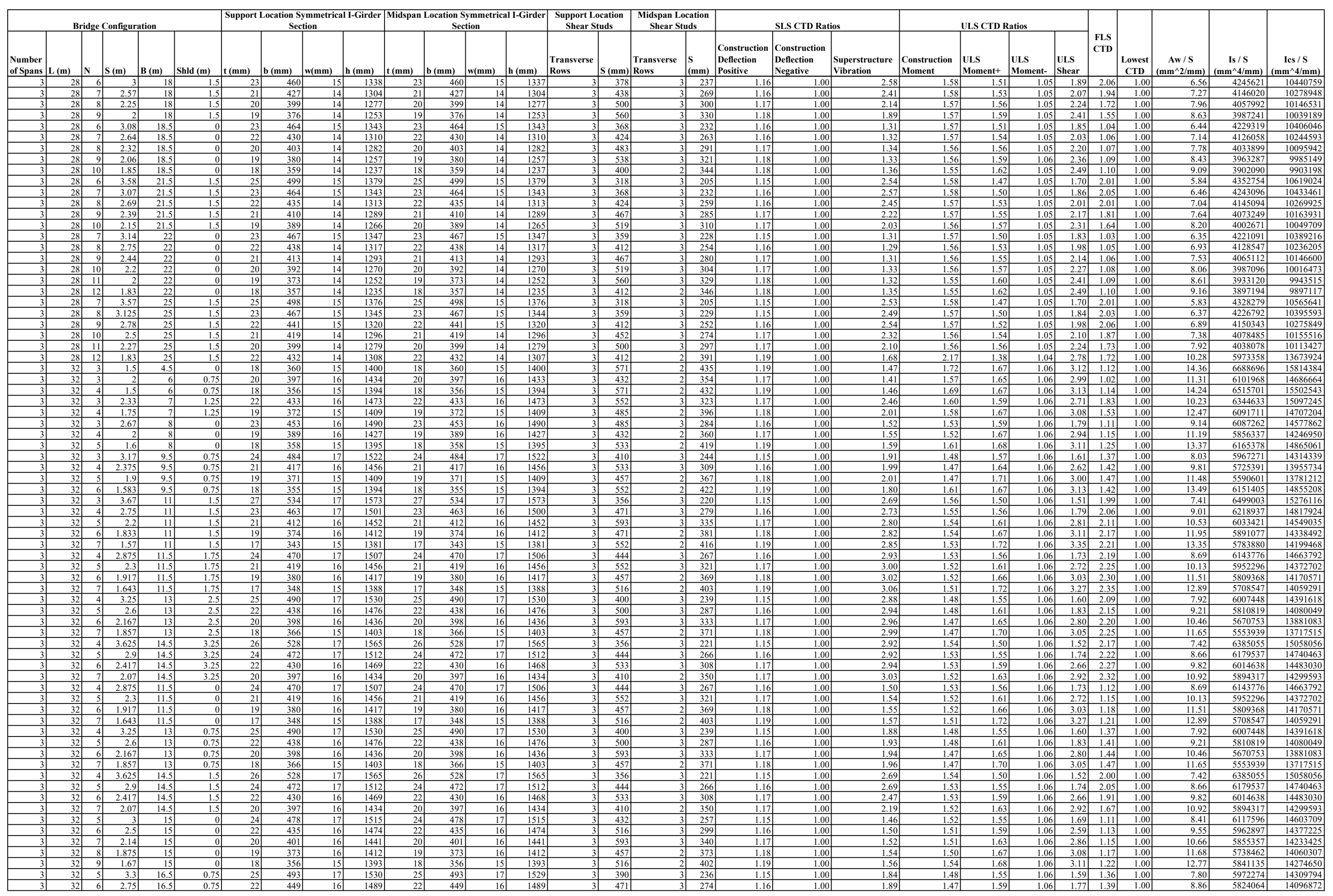




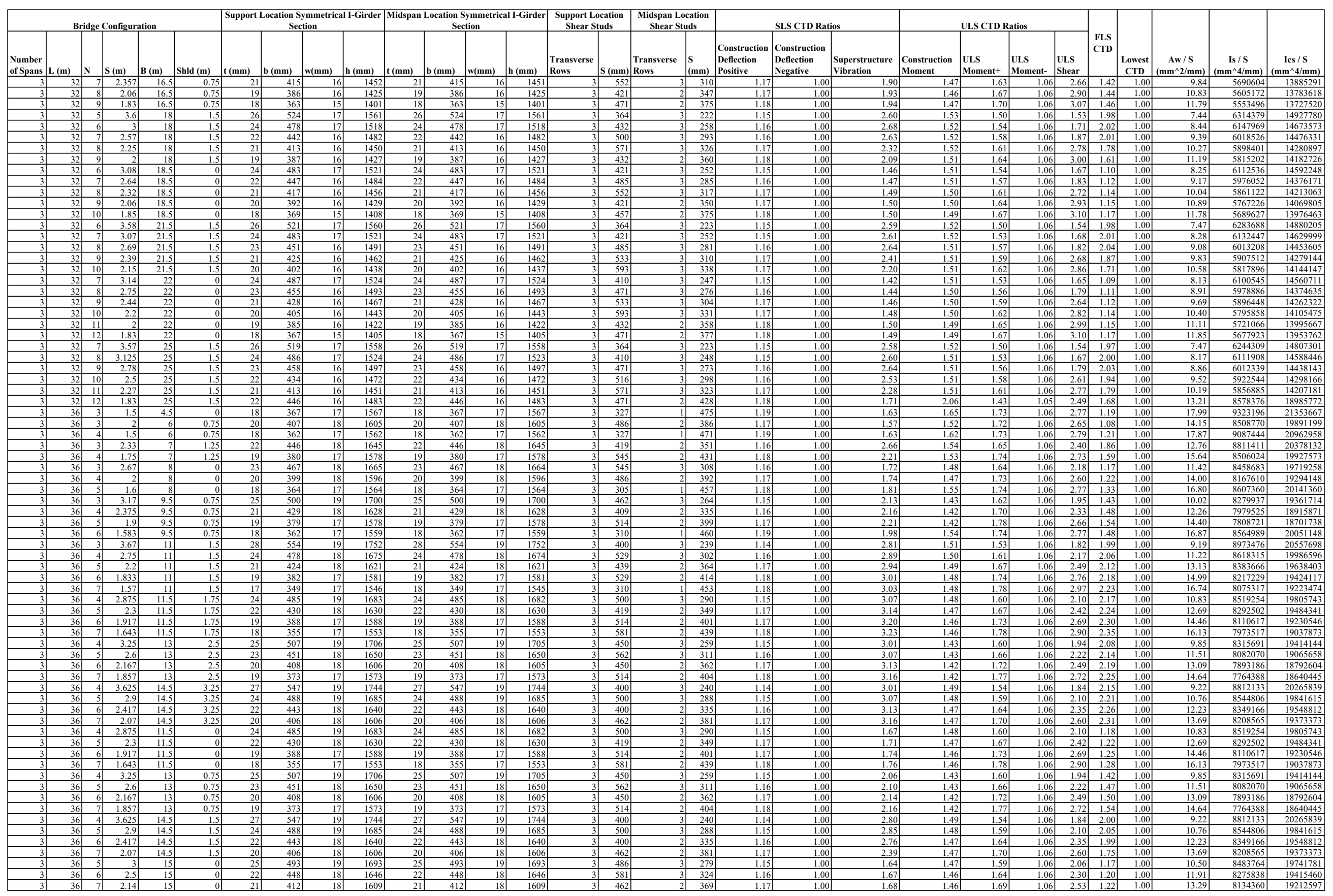




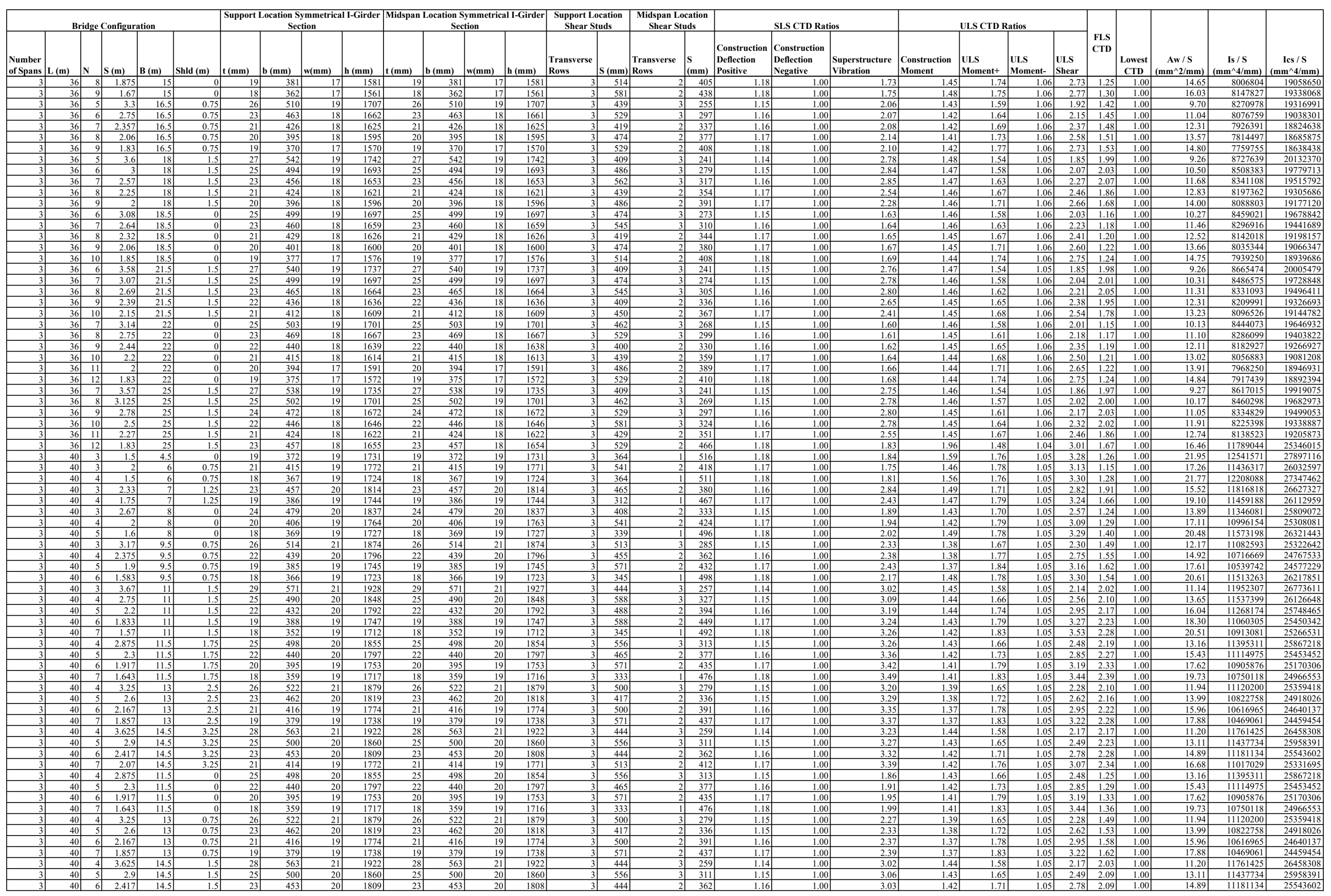




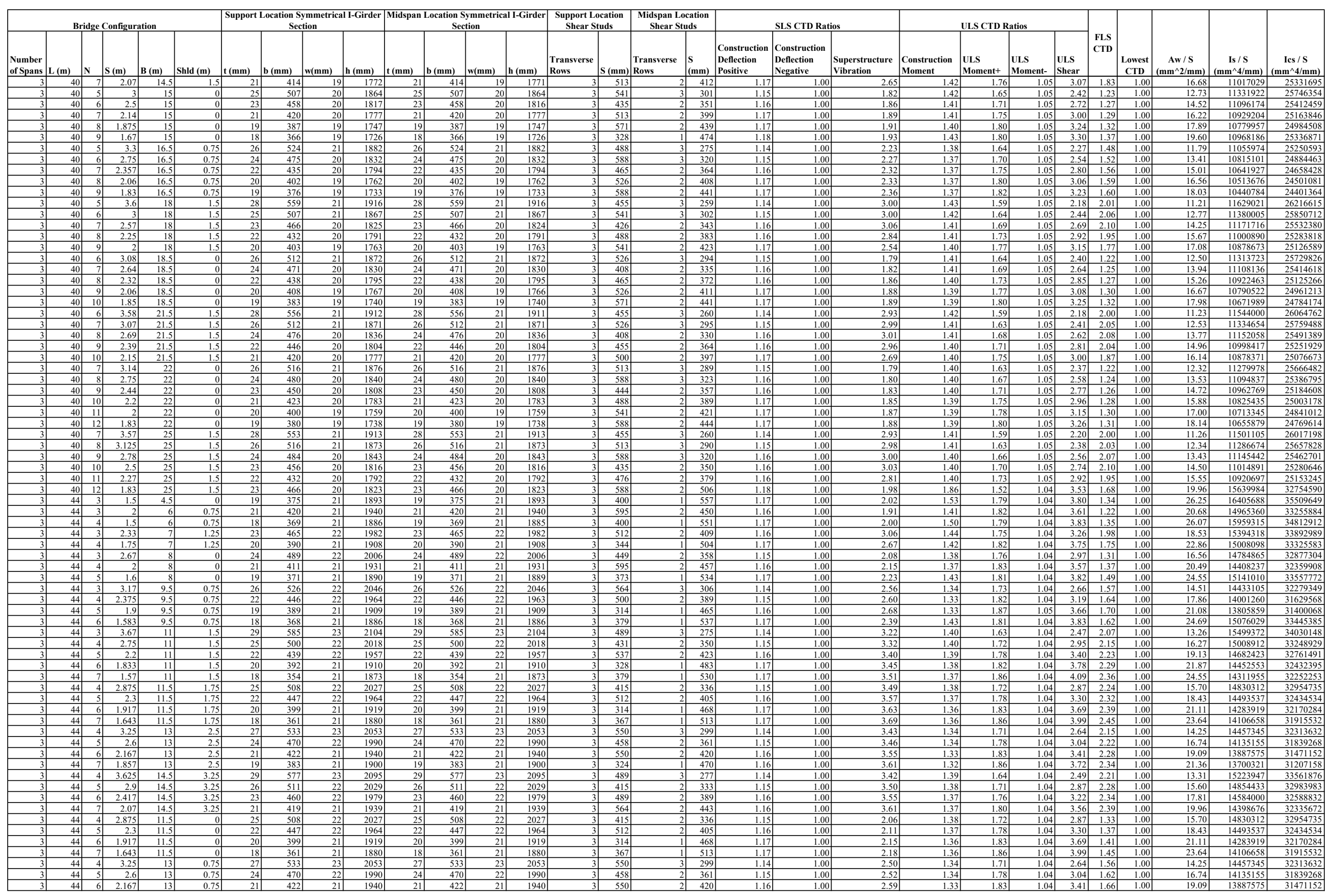




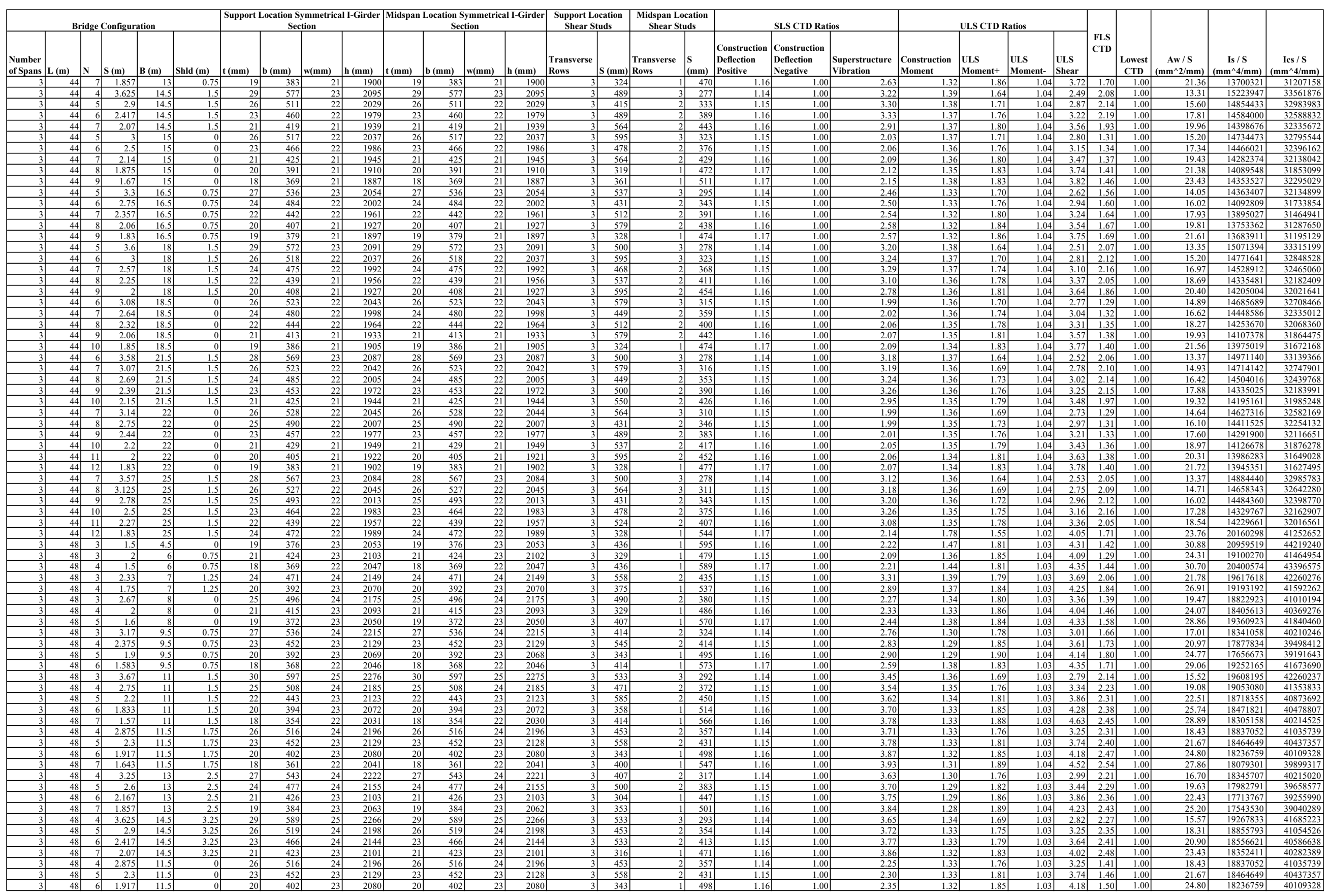




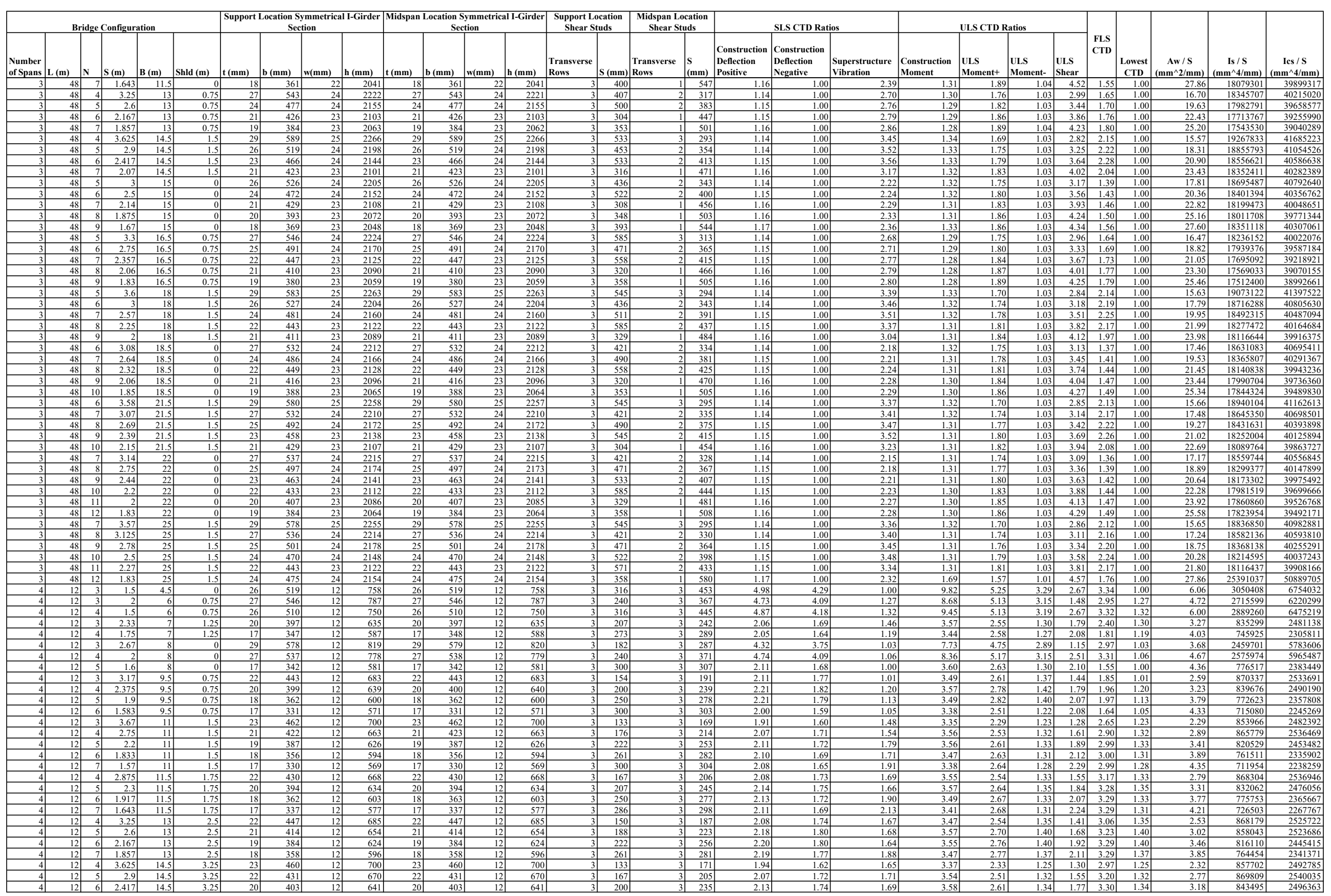




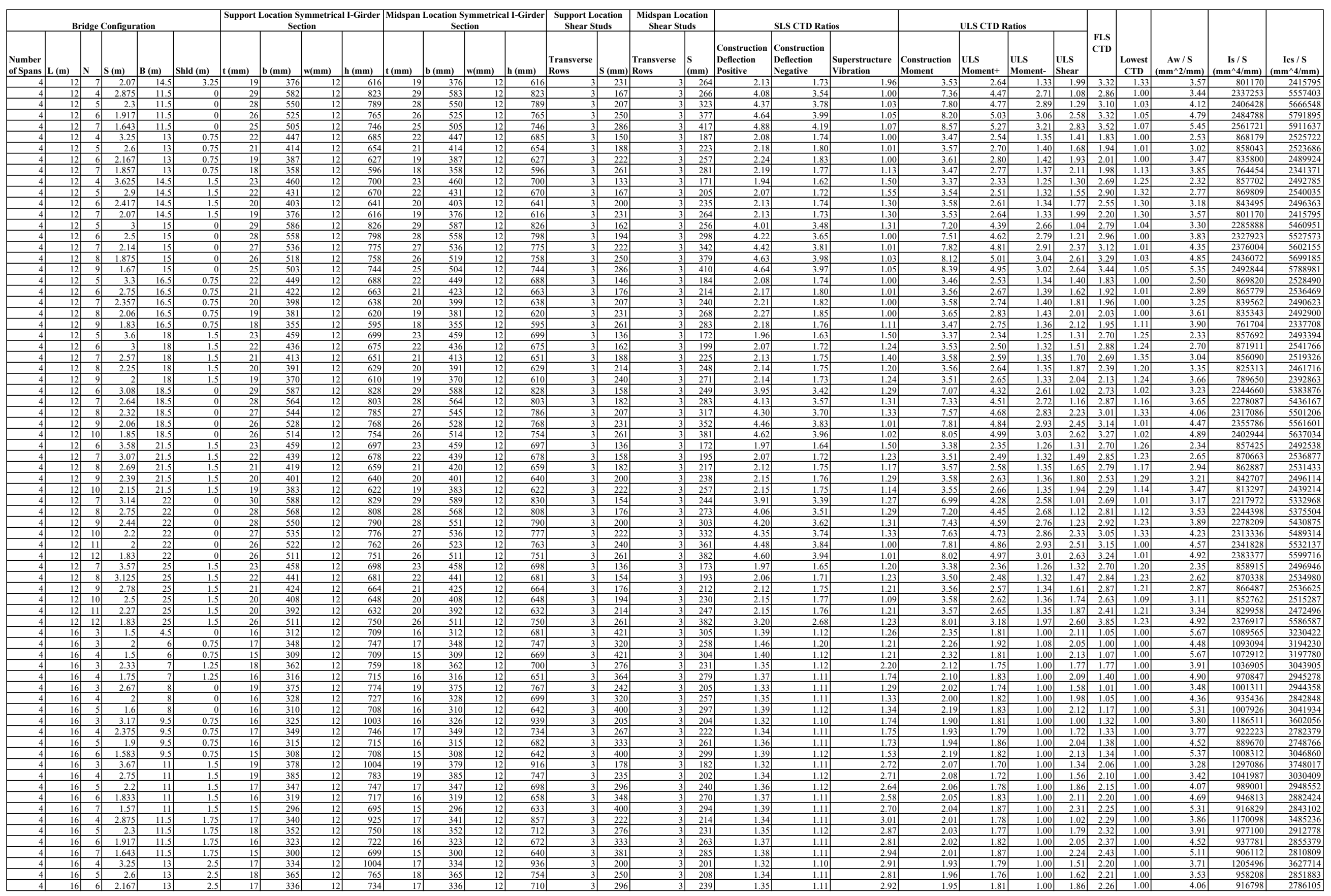




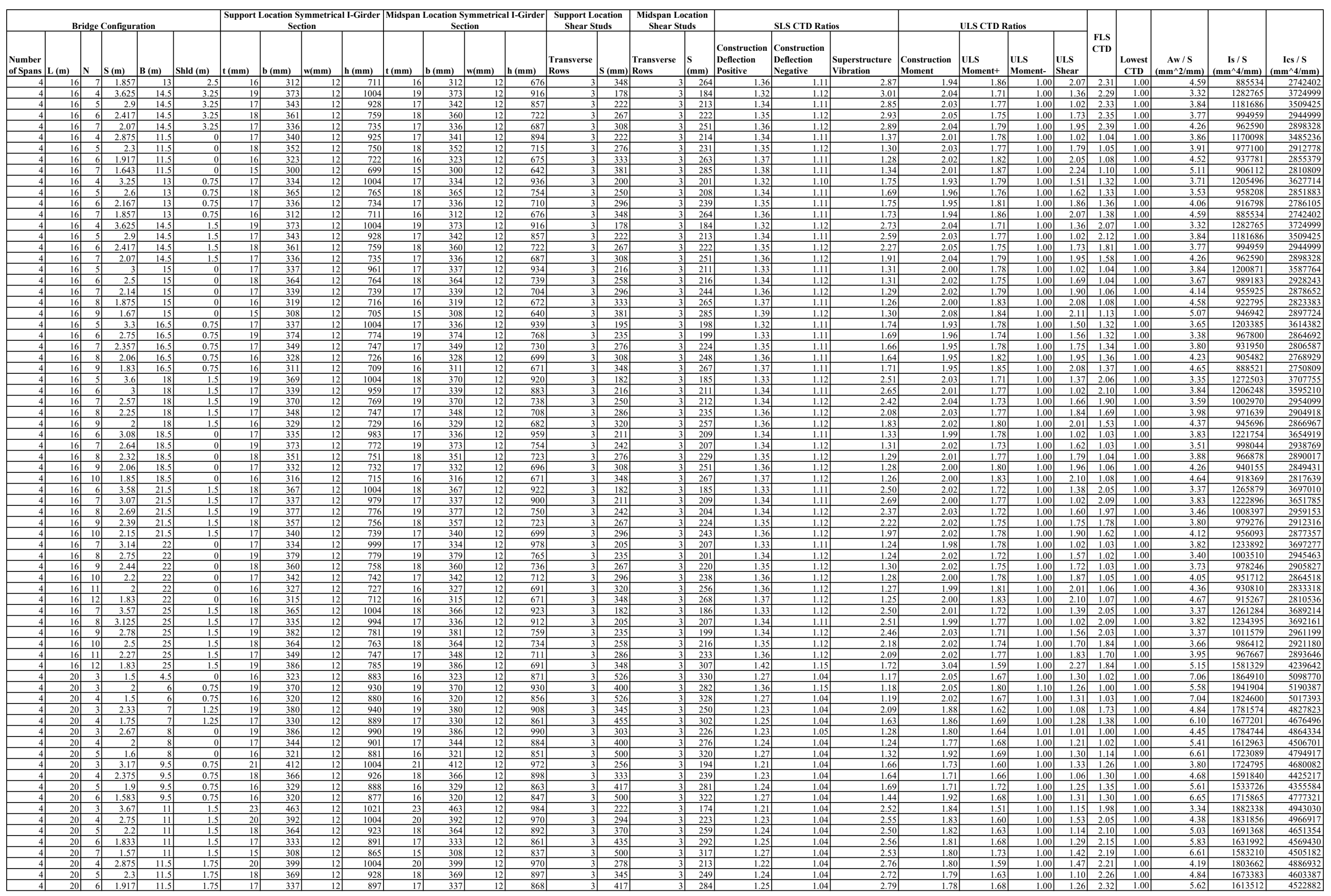




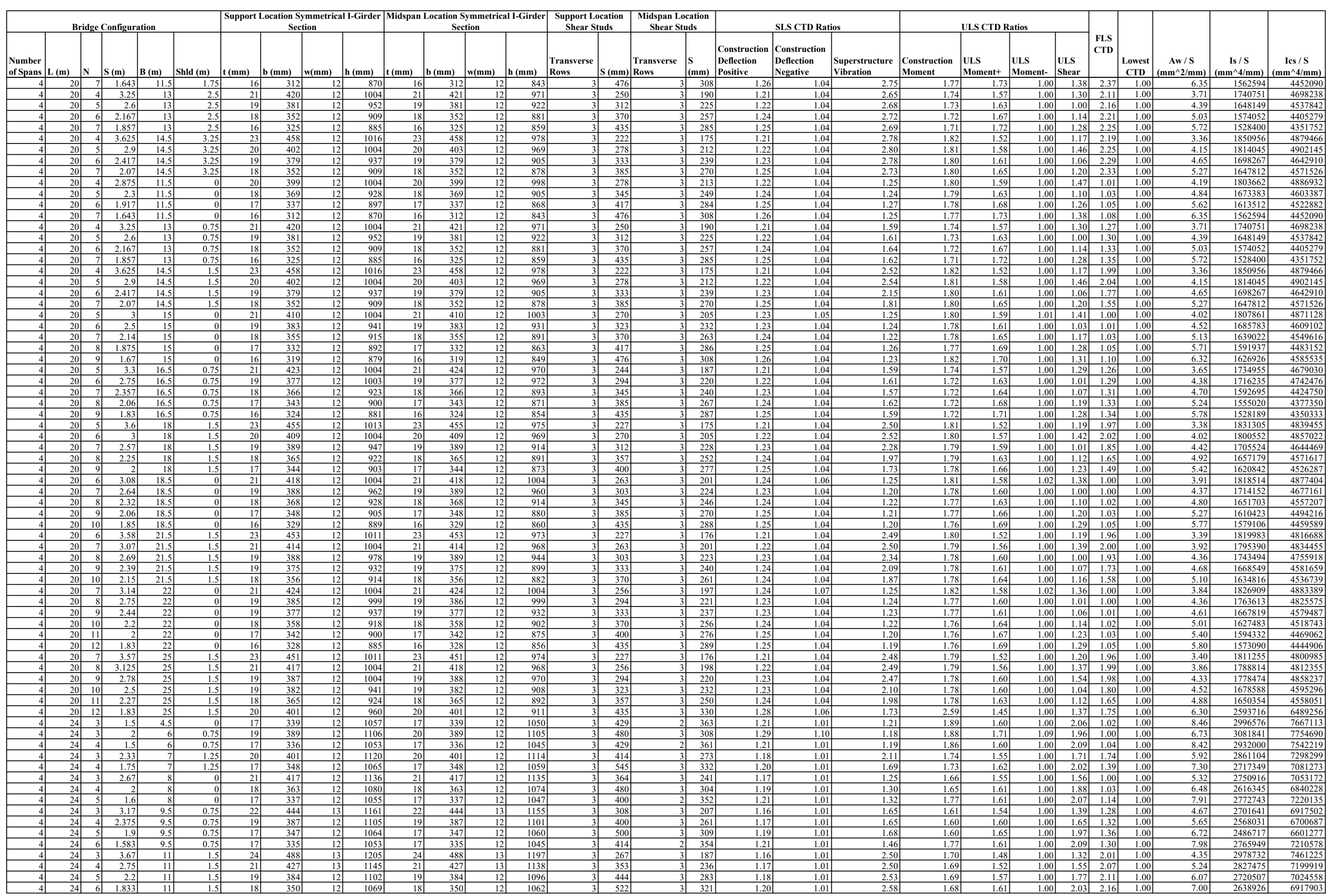




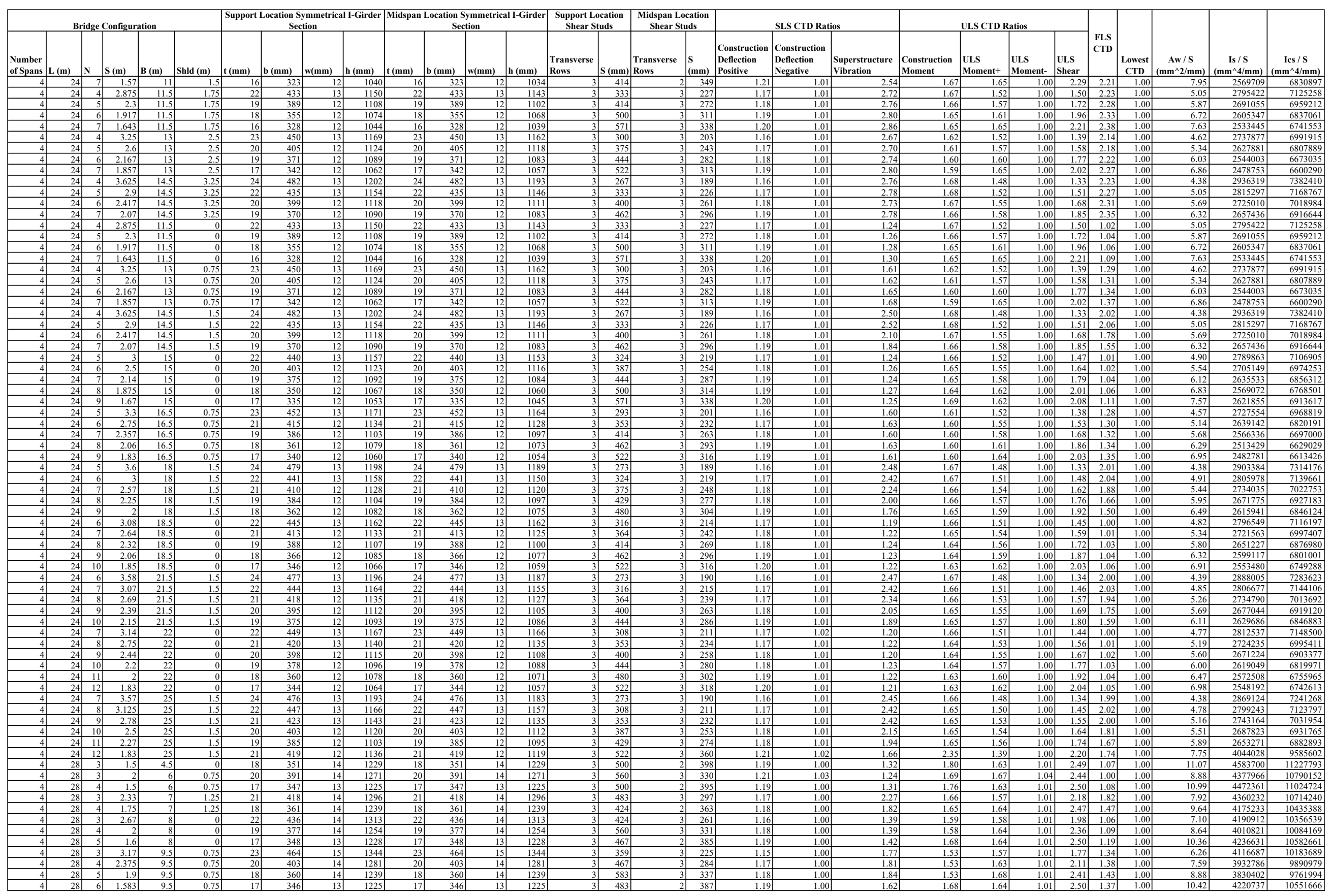




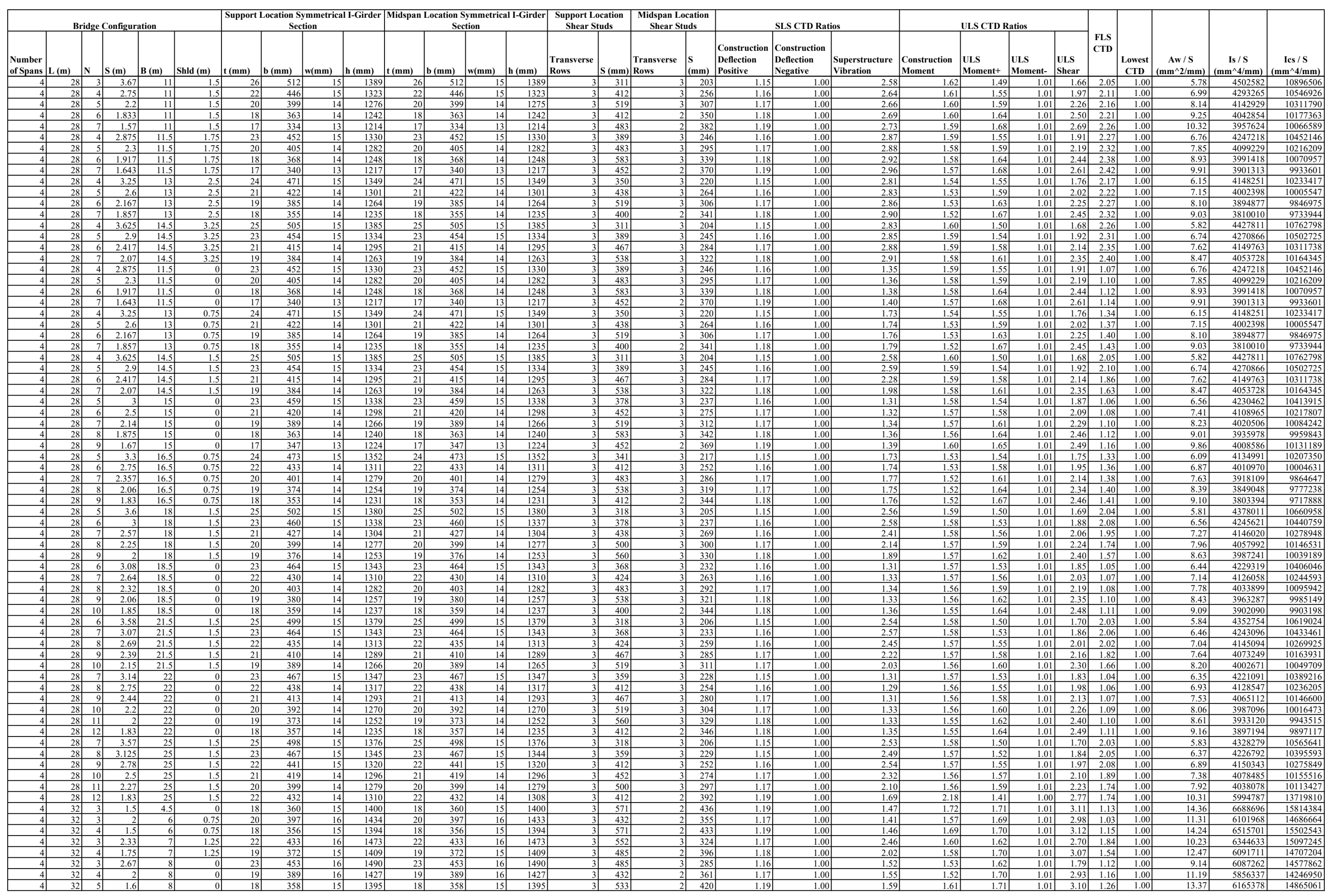




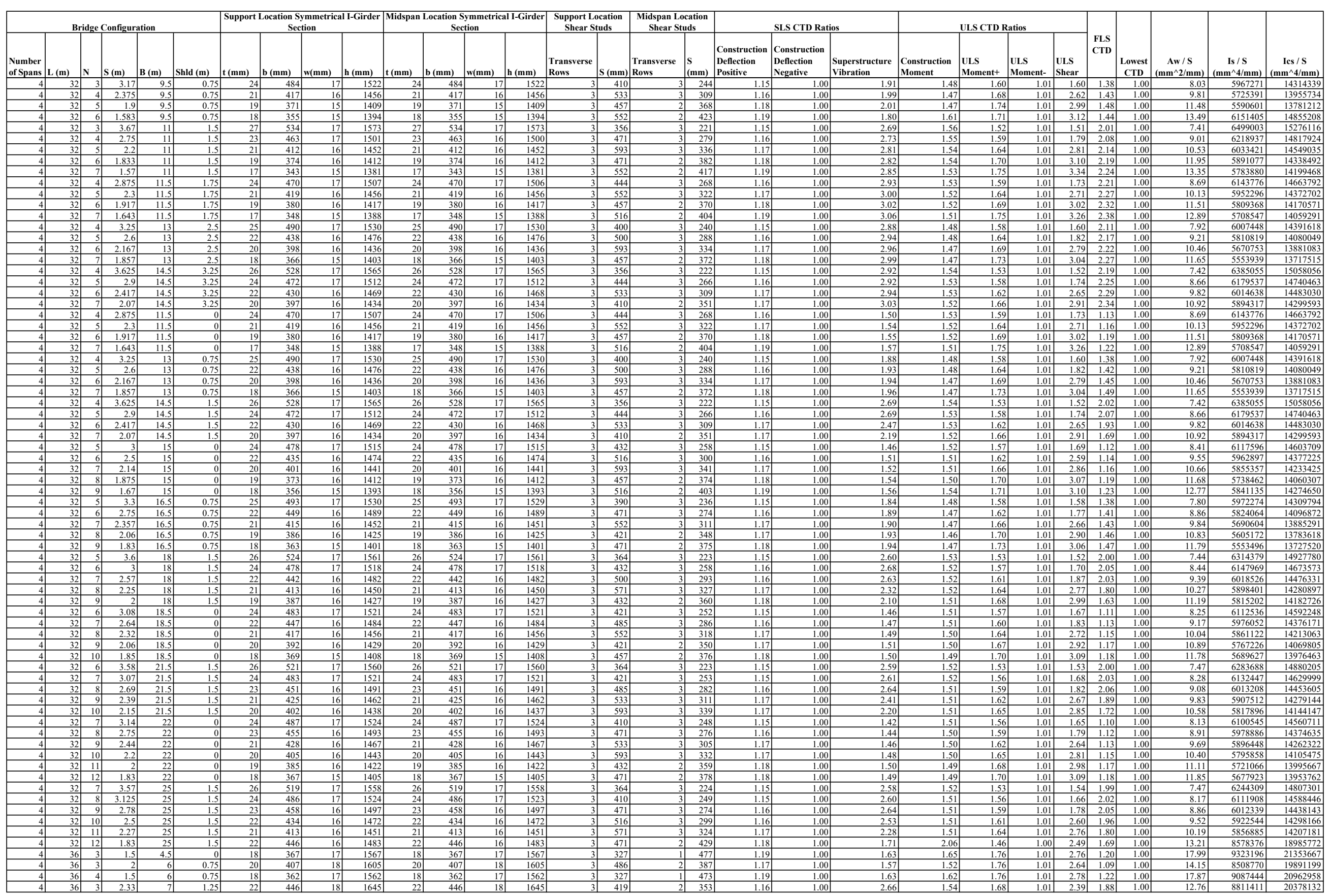




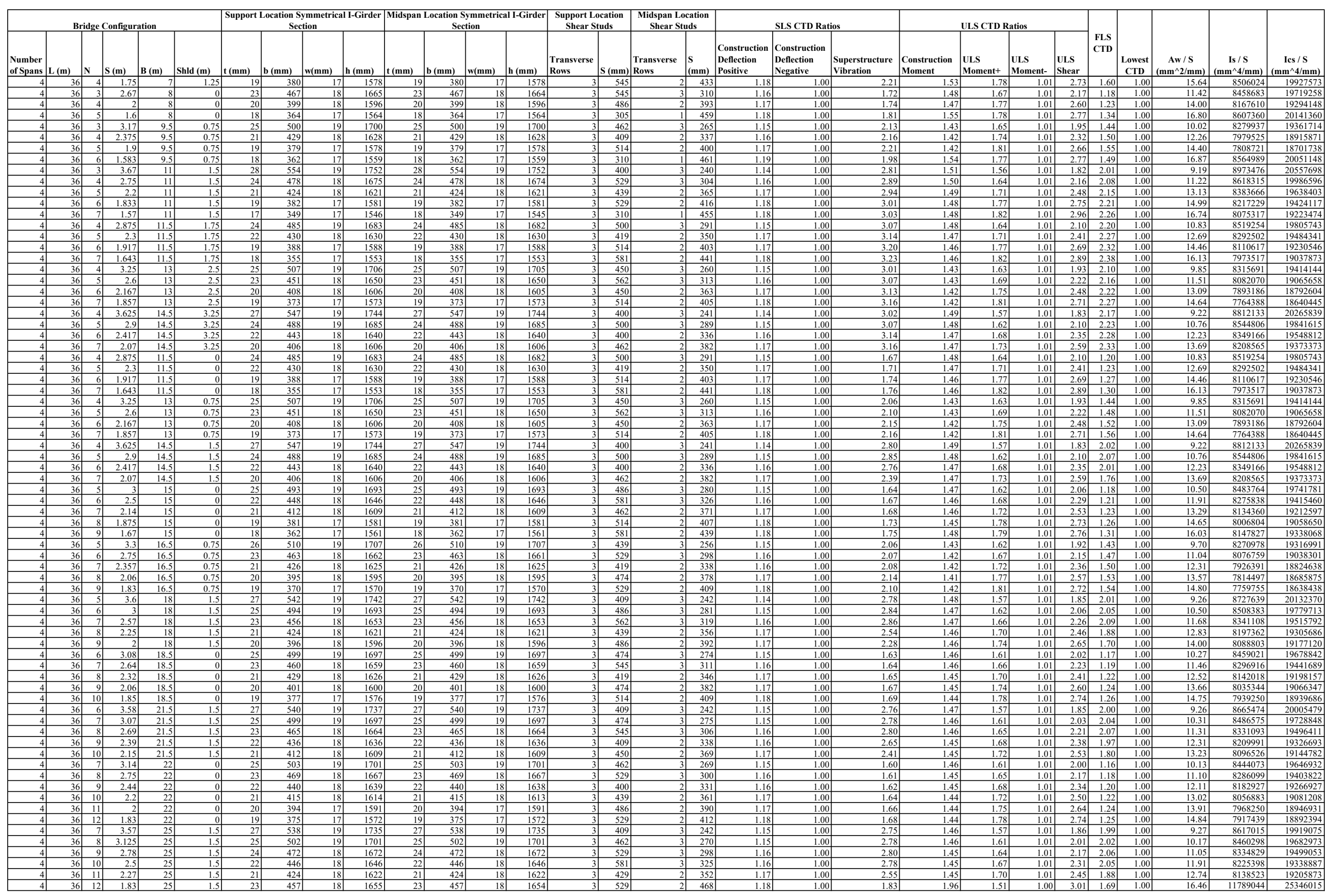




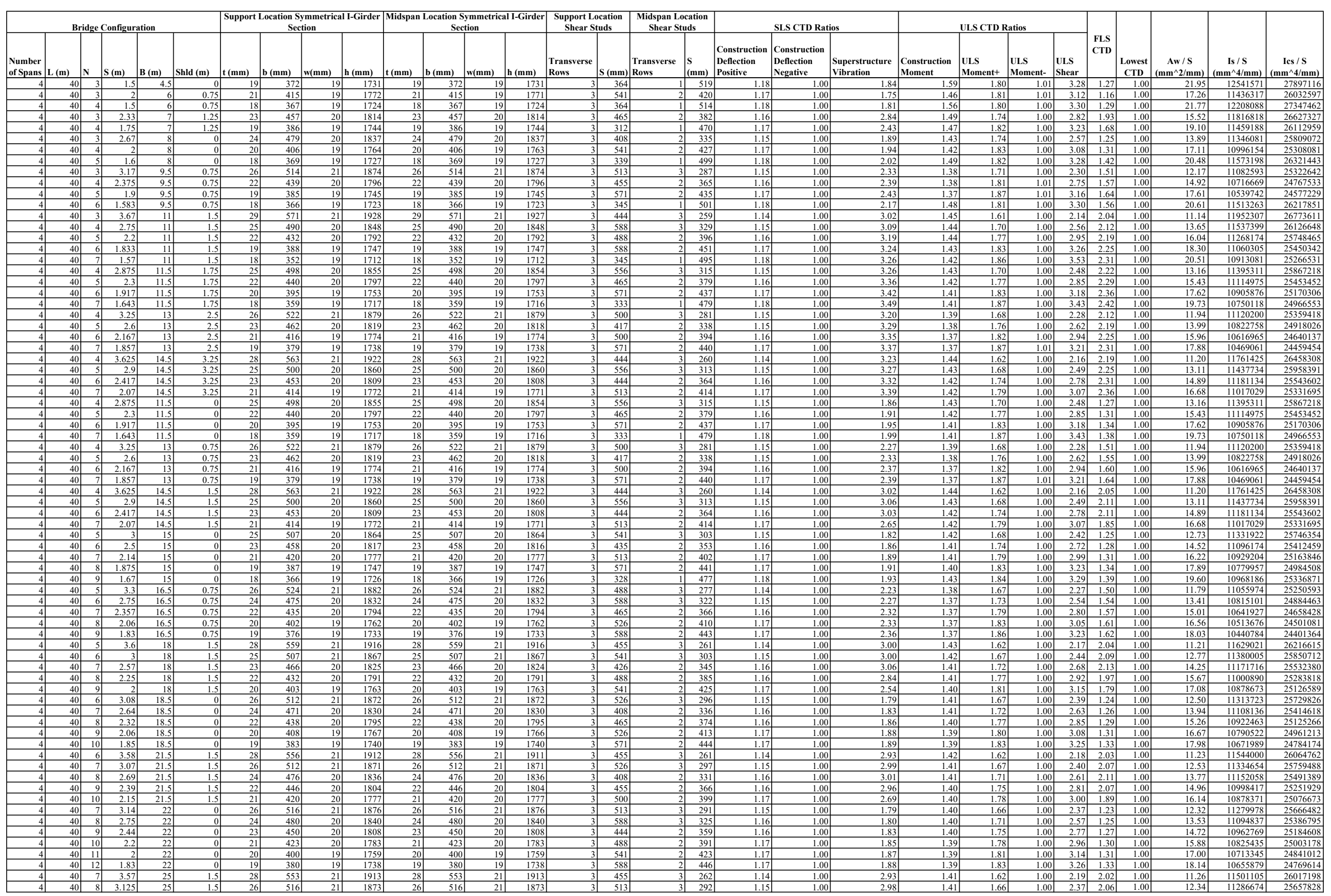




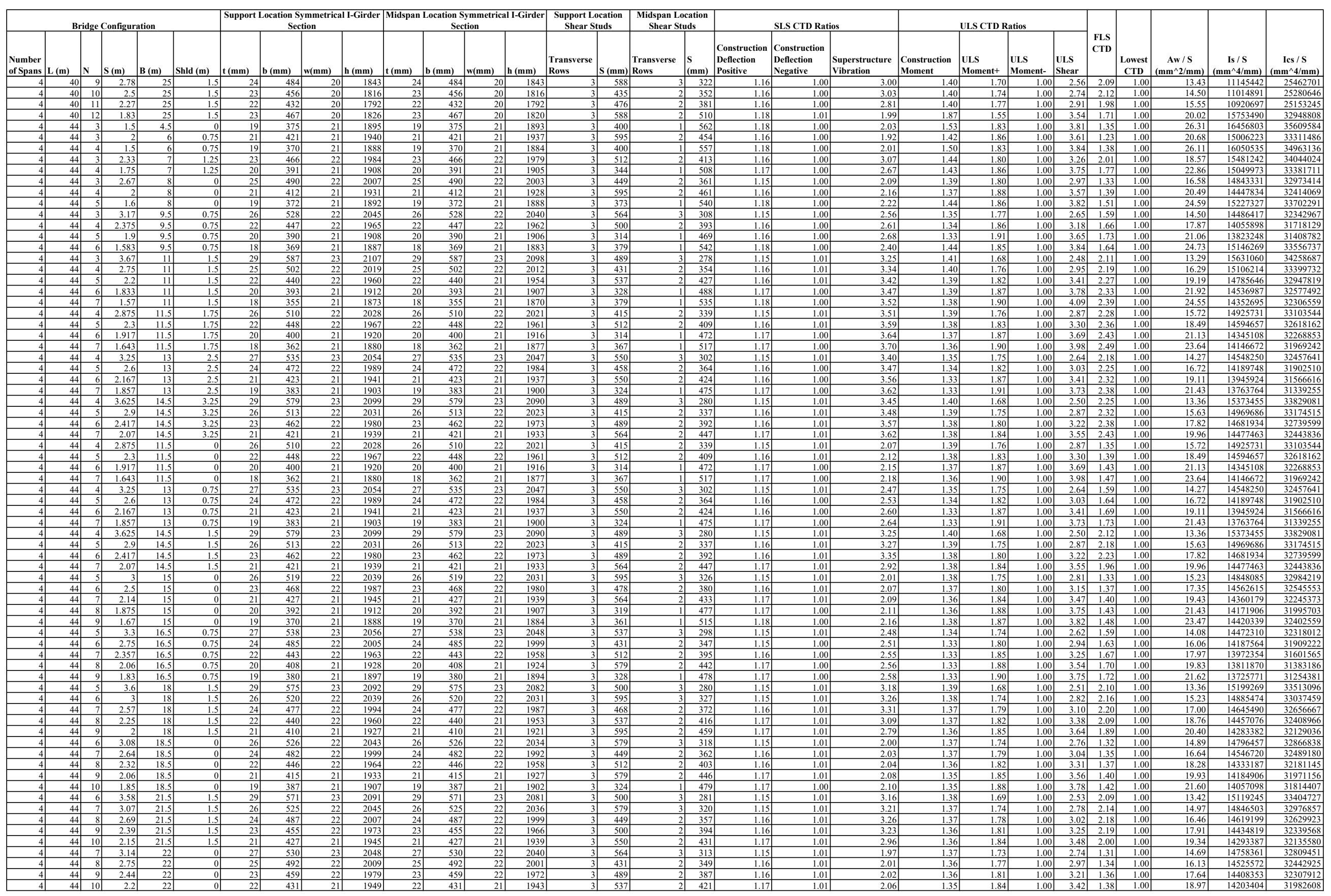




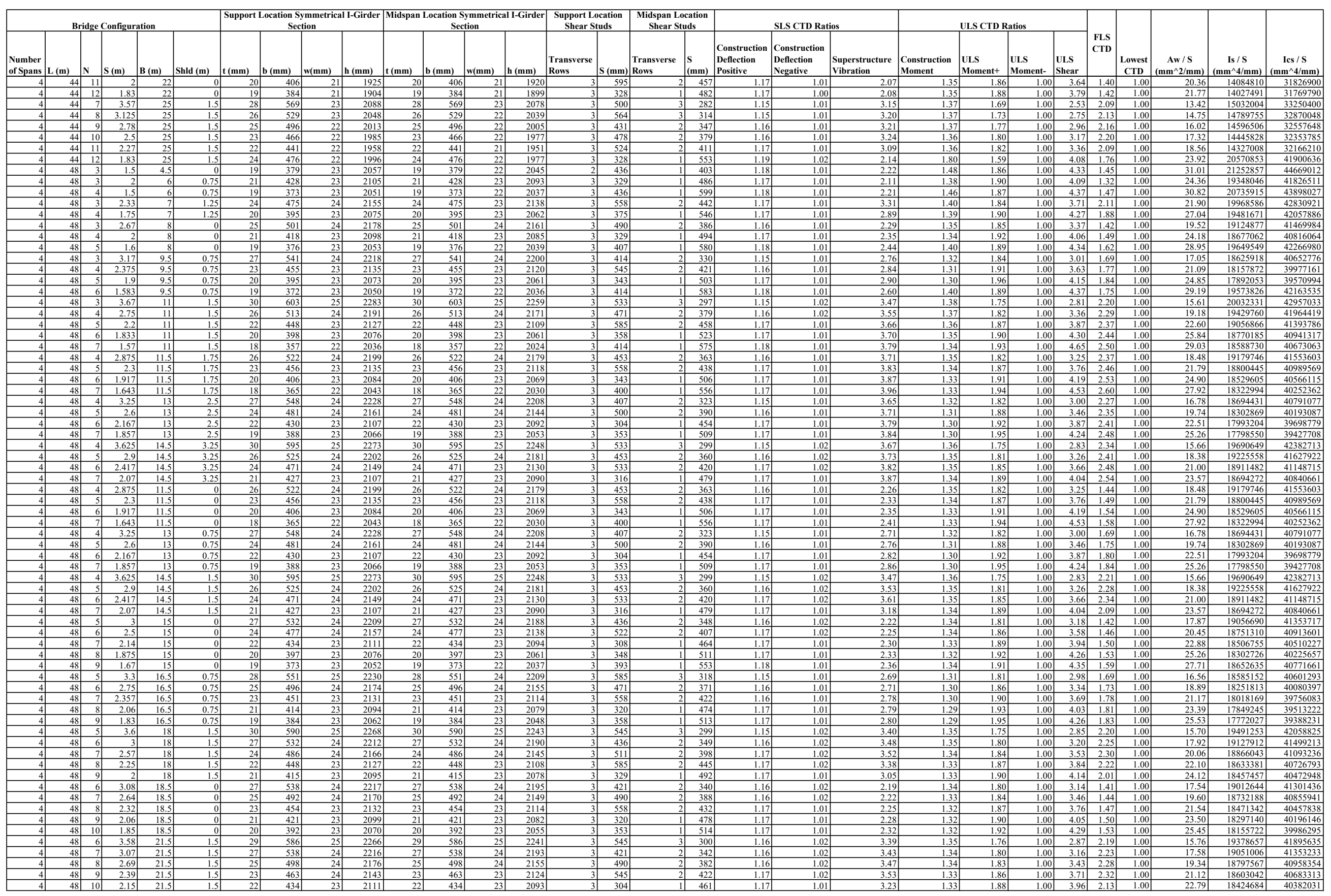




\begin{tabular}{|c|c|c|c|c|c|c|c|c|c|c|c|c|c|c|c|c|c|c|c|c|c|c|c|c|c|c|c|c|c|}
\hline \multicolumn{6}{|c|}{ Bridge Configuration } & \multicolumn{4}{|c|}{\begin{tabular}{|c|}
$\begin{array}{c}\text { Support Location Symmetrical I-Girder } \\
\text { Section }\end{array}$ \\
\end{tabular}} & \multicolumn{4}{|c|}{$\begin{array}{c}\text { Midspan Location Symmetrical I-Girder } \\
\text { Section }\end{array}$} & \multicolumn{2}{|c|}{\begin{tabular}{|c|} 
Support Location \\
Shear Studs \\
\end{tabular}} & \multicolumn{2}{|c|}{$\begin{array}{c}\begin{array}{c}\text { Midspan Location } \\
\text { Shear Studs }\end{array} \\
\end{array}$} & \multicolumn{3}{|c|}{ SLS CTD Ratios } & \multicolumn{4}{|c|}{ ULS CTD Ratios } & \multirow{2}{*}{$\begin{array}{l}\text { FLS } \\
\text { CTD }\end{array}$} & \multirow[b]{2}{*}{$\begin{array}{c}\text { Lowest } \\
\text { CTD }\end{array}$} & \multirow[b]{2}{*}{$\begin{array}{c}\mathrm{Aw} / \mathrm{S} \\
\left(\mathrm{mm}^{\wedge} \mathbf{2} / \mathrm{mm}\right)\end{array}$} & \multirow[b]{2}{*}{$\begin{array}{c}\mathrm{Is} / \mathrm{S} \\
\left(\mathrm{mm} \mathbf{m}^{\wedge} / \mathrm{mm}\right)\end{array}$} & \multirow[b]{2}{*}{$\begin{array}{c}\text { Ics } / \mathrm{S} \\
\left(\mathrm{mm}^{\wedge} 4 / \mathrm{mm}\right)\end{array}$} \\
\hline $\begin{array}{l}\text { Number } \\
\text { of Spans }\end{array}$ & (m) & & $\underline{S}(\mathbf{m})$ & B (m) & Shld $(\mathbf{m})$ & $t(\mathrm{~mm})$ & b (mm) & $\mathbf{w}(\mathbf{m m})$ & $\mathbf{h}(\mathbf{m m})$ & mm) & $\mathbf{b}(\mathrm{mm})$ & $\mathbf{w}(\mathrm{mm})$ & $\mathbf{h}(\mathrm{mm})$ & $\begin{array}{l}\text { Transverse } \\
\text { Rows }\end{array}$ & ; (mm) & $\begin{array}{l}\text { Transverse } \\
\text { Rows }\end{array}$ & $\begin{array}{l}\mathrm{s} \\
(\mathrm{mm})\end{array}$ & \begin{tabular}{|l}
$\begin{array}{l}\text { Construction } \\
\text { Deflection } \\
\text { Positive }\end{array}$ \\
\end{tabular} & $\begin{array}{l}\text { Construction } \\
\text { Deflection } \\
\text { Negative }\end{array}$ & $\begin{array}{l}\mid \begin{array}{l}\text { Superstructure } \\
\text { Vibration }\end{array} \\
\end{array}$ & \begin{tabular}{|l|}
$\begin{array}{l}\text { Construction } \\
\text { Moment }\end{array}$ \\
\end{tabular} & \begin{tabular}{|l|l} 
ULS \\
Moment +
\end{tabular} & \begin{tabular}{|l|l} 
ULS \\
Moment-
\end{tabular} & \begin{tabular}{|l} 
ULS \\
Shear
\end{tabular} & & & & & \\
\hline & & & \begin{tabular}{l|l}
7 & 3.14 \\
7 & 275
\end{tabular} & & & 27 & 543 & 24 & 2220 & & 543 & & 2197 & & 421 & & 334 & 1.16 & 1.02 & 2.16 & 1.33 & 1.80 & 1.00 & \begin{tabular}{l|l}
0 & 3.1 \\
\end{tabular} & 1.4 & & $\begin{array}{ll}17.26 \\
1.02\end{array}$ & 18941710 & 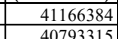 \\
\hline & & & $\frac{2.75}{2.44}$ & & & 253 & $\frac{502}{468}$ & $\frac{24}{24}$ & $\frac{2181}{2147}$ & $\frac{25}{23}$ & $\frac{502}{468}$ & $\frac{24}{23}$ & $\frac{2160}{2127}$ & & \begin{tabular}{|c|c|c|}
533 \\
\end{tabular} & & $\frac{374}{444}$ & $\frac{1.16}{1.17}$ & $\frac{1.02}{1.02}$ & $\frac{2.19}{2.22}$ & $\frac{1.33}{1.33}$ & $\frac{1.83}{1.86}$ & $\frac{1.00}{1.00}$ & \begin{tabular}{l|l}
0 & 3.3 \\
0 & 3.6
\end{tabular} & $\frac{1.4}{1.4}$ & $\frac{1.00}{1.00}$ & $\frac{19.02}{20.76}$ & $\frac{186884210}{18546265}$ & $\frac{\mid 407933315}{40579871}$ \\
\hline & & 10 & 2.2 & & & $\frac{25}{22}$ & 438 & 23 & $\frac{2147}{2117}$ & $\frac{25}{22}$ & 438 & 23 & 2099 & & 585 & & $\frac{451}{451}$ & $\frac{1.17}{1.17}$ & $\frac{1.02}{1.02}$ & $\frac{2.26}{2.26}$ & $\frac{1.33}{1.32}$ & $\frac{1.80}{1.88}$ & $\frac{1.00}{1.00}$ & \begin{tabular}{l|l}
0 & 3.0 \\
0 & 3.9 \\
\end{tabular} & $\frac{1.4}{1.4}$ & $\frac{1.00}{1.00}$ & 22.39 & 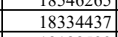 & 40257818 \\
\hline & 48 & 11 & 1 & 22 & 0 & 21 & 412 & 23 & 2090 & 21 & 412 & 23 & 2073 & & 329 & & 489 & 1.17 & 1.01 & 2.27 & 1.31 & 1.90 & 1.00 & 4.1 & 1.5 & 1.00 & 24.00 & 18188539 & 40029191 \\
\hline & 48 & 12 & 1.83 & 22 & & 19 & 389 & 23 & 2067 & 19 & 389 & 23 & & & 508 & & 517 & 1.18 & 1.01 & 2.28 & 1.31 & 1.92 & 1.00 & 4.3 & 1.5 & 1.00 & & 18134036 & 39953510 \\
\hline & 48 & 7 & $\begin{array}{l}7 \\
7.5 .57 \\
\end{array}$ & 25 & 1.5 & 29 & 584 & 25 & 2262 & 7 & 584 & 25 & 2237 & & 545 & & 300 & 16 & 1.02 & 3.37 & 1.34 & 1.76 & 1.00 & 2.8 & 2.1 & 1.00 & 15.76 & 19257028 & 41679537 \\
\hline & & $\frac{8}{9}$ & \begin{tabular}{l|l}
8 & 3.125 \\
9 & 2.78 \\
\end{tabular} & $\frac{25}{25}$ & $\frac{1.5}{1.5}$ & 27 & $\frac{542}{506}$ & $\frac{24}{24}$ & 2220 & $\frac{27}{25}$ & $\frac{542}{56}$ & $\frac{24}{24}$ & 2197 & & 421 & & \begin{tabular}{|c|}
3366 \\
371
\end{tabular} & 1.16 & 1.02 & $\frac{3.42}{3.47}-1913$ & $\frac{1.34}{1.33}$ & $\frac{1.79}{1.83}$ & $\frac{1.00}{1.00}$ & $\begin{array}{l}0.1 \\
0.3 \\
0\end{array}$ & 2.2 & $\frac{1.00}{100}$ & \begin{tabular}{|c|c|}
17.33 \\
18.89
\end{tabular} & $\frac{18985061}{18781275}$ & $\begin{array}{l}41245523 \\
4049922 \\
\end{array}$ \\
\hline & $\frac{48}{48}$ & \begin{tabular}{l|l}
8 & 9 \\
8 & 10 \\
\end{tabular} & $\frac{2.18}{2.5}$ & $\frac{25}{25}$ & $\frac{1.3}{1.5}$ & $\frac{25}{24}$ & $\frac{506}{475}$ & $\frac{24}{24}$ & $\frac{2186}{2154}$ & $\frac{25}{24}$ & $\frac{306}{475}$ & 23 & $\frac{2164}{2134}$ & & $\frac{4 / 1}{522}$ & & $\frac{311}{405}$ & $\frac{1.16}{1.17}$ & 1.02 & $\frac{3.47}{3.49}$ & $\begin{array}{l}\mid c .33 \\
1.33 \\
\end{array}$ & $\frac{1.83}{1.85}$ & $\frac{1.00}{1.00}$ & \begin{tabular}{c|c}
0.3 \\
0
\end{tabular} & \begin{tabular}{|l|l|}
2.2 \\
\end{tabular} & $\frac{1.00}{1.00}$ & $\frac{\mid c 8.89}{20.40}$ & $\frac{187881275}{18589900}$ & $\begin{array}{r}40949922 \\
40647639\end{array}$ \\
\hline & 48 & \begin{tabular}{l|l}
8 & 11 \\
\end{tabular} & $\begin{array}{ll}1 & 2.27 \\
\end{array}$ & 25 & 1.5 & 22 & 448 & 23 & 2127 & 22 & 448 & 23 & 2108 & & 571 & & 440 & 1.17 & 1.02 & 3.35 & 1.33 & 1.87 & 1.00 & $\begin{array}{l}0.8 \\
0\end{array}$ & 2.2 & 1.00 & 21.91 & $\begin{array}{l}18473092 \\
\end{array}$ & 40474220 \\
\hline & & $\begin{array}{l}8 \quad 12 \\
8\end{array}$ & 1.83 & 25 & 1.5 & 24 & 484 & & 2164 & 24 & 484 & 23 & 2129 & & 358 & & $\mid$\begin{tabular}{|l|l|}
$\mid$ & 594 \\
\end{tabular} & 1.20 & 1.03 & 2.35 & 1.74 & 1.63 & 1.00 & \begin{tabular}{l|l}
0 & 4.6 \\
\end{tabular} & 1.8 & 1.00 & 28.12 & 26297729 & 522226 \\
\hline
\end{tabular}




\section{References}

AASHTO. (2017). AASHTO LRFD Bridge Design Specifications. Washington, D.C.: American Association of State Highway and Transportation Officials.

Alberta Transportation. (2015). Bridge Load Evaluation Manual. Alberta, Canada: Technical Standard Branch.

Autodesk Civil Engineering. (2018). Structural Bridge Design software Manual. Autodesk Inc.

Bakht, B., \& Moses, F. (1988). Lateral distribution factors for highway bridges. Journal of Structural Division, vol. 114, no. 8, Pg. 1785-1803.

CISC. (2016). Steel Bridges Design, Fabrication, Construction Course Design Examples. Canada: CISC.

CISC. (2017). Handbook of Steel Construction, 11th Edition, 3rd Printing. Canada: CISC.

CSA. (2014). Canadian Highway Bridge Design Code, CAN/CSA-S6-14. Ontario, Canada:

Canadian Standards Association.

CSI. (2017). Introduction to CSIBridge. Computers and Structures Inc.

Diab, A., \& Sennah, K. (2018). Simplified Equations For Moment And Shear Values In Bridge Girders Resulting From Truck Loading. SMSB 2018. Quebec City, Quebec, Canada.

Duan, M., Perdikaris, P., \& Chen, W. (2000). Impact Effect of Moving Vehicles. Bridge Engineering Handbook. Boca Raton: CRC Press.

Hays, C. O., Sessions, L. M., \& Berry, A. J. (1987). Further Studies on Lateral Load Distribution using Finite Element Methods. Washington, D.C.: Transportation Research Board.

MIDAS Civil. (2014). MIDAS Civil User Guide. MIDAS Information Technology.

MTO. (1983). Ontario Highway Bridge Design Code. Downsview, Ontario: Ministry Of Transportation Ontario

MTO. (1991). Ontario Highway Bridge Design Code. Downsview, Ontario: Ministry Of Transportation Ontario

MTO. (2002). CANBAS GUI, Canadian Bridge Analysis System Graphical User Interface, User Guide. Downsview, Ontario: Ministry Of Transportation Ontario.

Nofal, M. (1988). Inelastic Load Distribution of Composite Concrete-Steel Slab-on-Girder Bridges: An analytical and Experimental Study. M.Sc. Thesis. Ottawa, Ontario, Canada: Civil Engineering Department, Carlton University. 
Pre-Con. (2004). Precast Prestressed Bridge Components Technical Brochure. Alberta, Canada: Precon Inc.

Prestressed Concrete Institute. (1978). PCI design handbook: Precast and Prestressed Concrete. Chicago: Prestressed Concrete Institute.

Razaqpur, A. G., \& Esfandiari, A. (2006). Redistribution of Longitudinal Moments in Straight, Continuous Concrete Slab - Steel Girder Composite Bridges. Canadian Journal of Civil Engineering, 33: 471-488.

SAP2000. (2017). Integrated Finite Element Analysis and Design of Structures. Berkley, CA, USA: SAP2000 Computer and Structure Inc.

Theodor, N., \& Al-Bazi, G. (1997). Manual of Standard Short-Span Steel Bridges. Ministry of Transportation Ontario, Structural Office.

Yang, Y.-B., \& Lin, B.-H. (1995). Vehicle-bridge interaction analysis by dynamic condensation method. ASCE Journal of Structural Engineering, 121: 1636-1643.

Yang, Y.-B., \& Yau, J.-D. (1997). Vehicle-bridge interaction element for dynamic analysis. ASCE Journal of Structural Engineering, 123: 1512-1518. 